


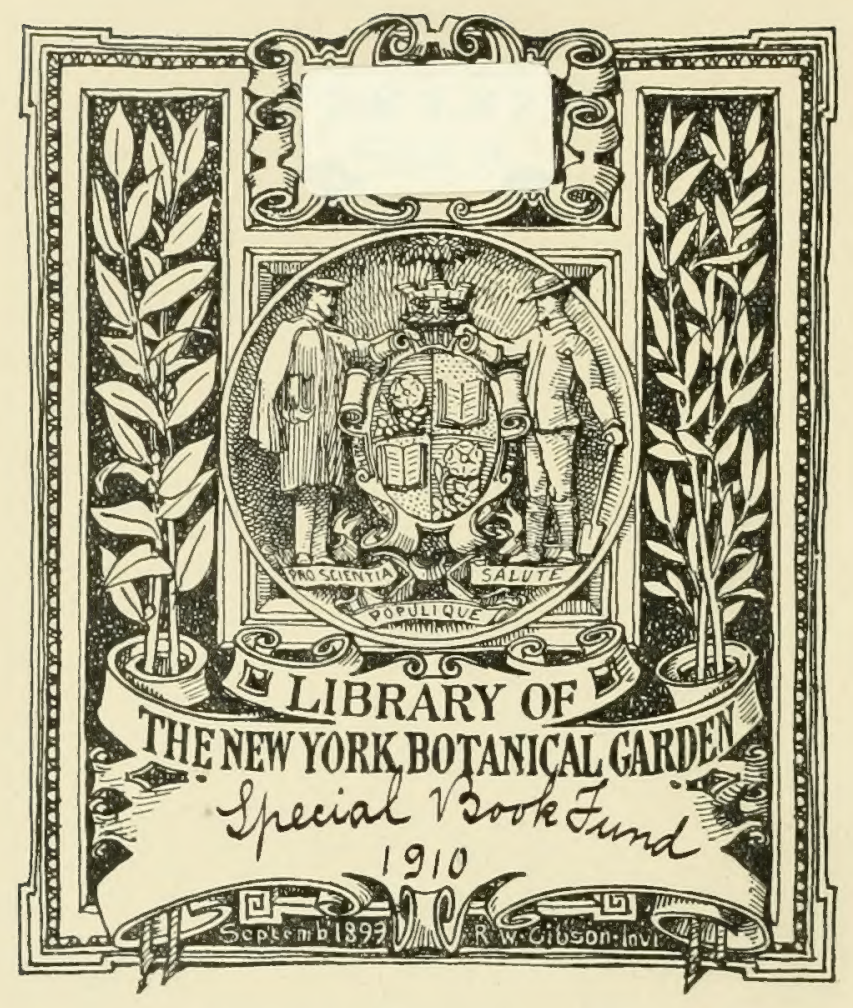








\section{Die Rosen}

\section{des südlichen und mittleren Frankenjura:}

ihr System und ihre phylogenetischen Beziehungen, erörtert mit Hinsicht auf die ganze Gattung Rosa und das allgemeine Deszendenzproblem.

Von

Dr. Joseph Schwertschlager,

Professor am Lyceum Eichstätt.

Mit 2 Tafeln. \&

München.

Isaria-Verlag.

1910. 



Die Rosen des südlichen und mittleren Frankenjura. 



\section{Die Rosen}

\section{des südlichen und mittleren}

\section{Frankenjura:}

ihr System und ihre phylogenetischen Beziehungen, erörtert mit Hinsicht auf die ganze Gattung Rosa und das allgemeine Deszendenzproblem.

Dr. Joseph Schwertschlager,

Professor am Lyceum Eichstätt.

S Mit 2 Tafeln. \& 
Druck der Kunst- und Verlaqsanstalt Schaar \& Dathe, Komm.Ges. a. Akt., Trier. 


\section{VORWORT.}

Seit dem Jahre 1892 hatte der Verfasser angefangen, den wildwachsenden

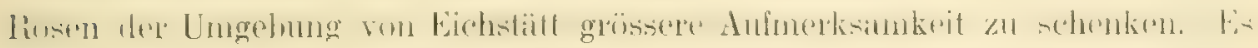

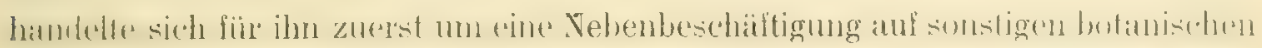

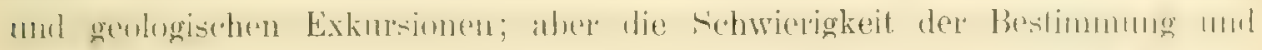

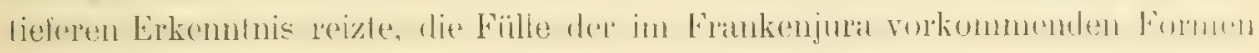
lockte an, und so wurde diese Nebenbeschäfligung allmählich zu einem bevorzugten Studium. Sehr bald hatte ich mich dabei der liebenswirdigen Unter-

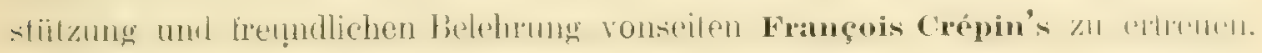

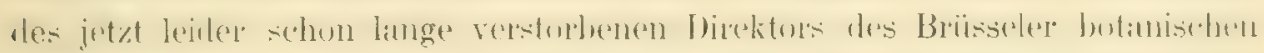

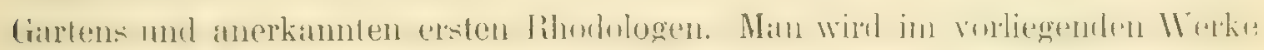

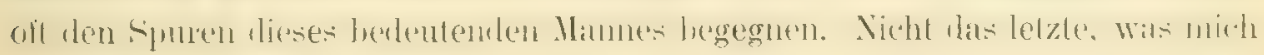

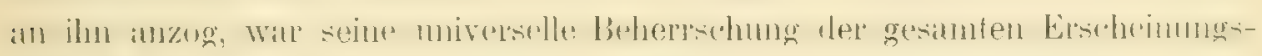

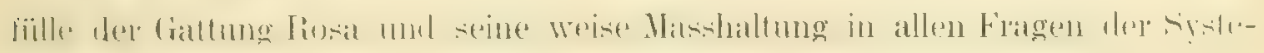
matik. Doch habe ich auch niemals gezögert, ans seinen Fusstaplen zu treten, wo ich anderer Ansicht war.

Neben meinen eigenen oftmaligen und ausgedehnten Sammelausflügen,

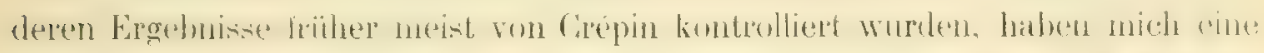

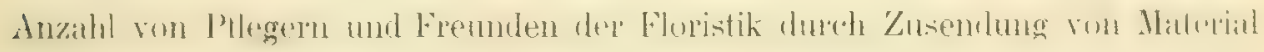
aus dem Gebiete erfreut odel sonst in dessen Durchforschung unterstiitzt. Es sind dies namentlich die Herren; G. Dore t, E. Erdner, F. Honig, Dr. $x$. Killermann. J. Kräinzle, J. Lutz †े F. Nïgele, O. Prechtelsbaner, chr.

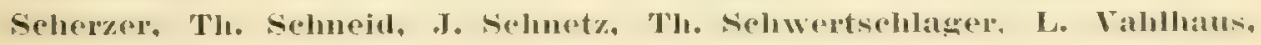
J. Zinsmeister. Ihnen Allen sei herzlicher Dank gezollt. Ich habe im systematischen 'Teile nicht verfehlt, an der geeigneten Stelle ihren Anteil hervor-

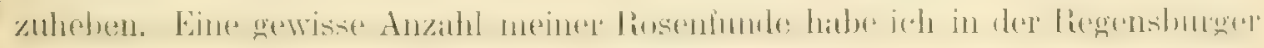

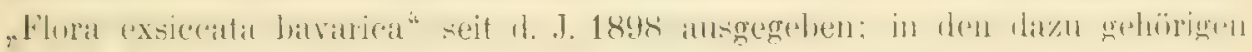

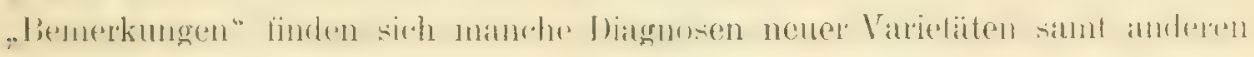

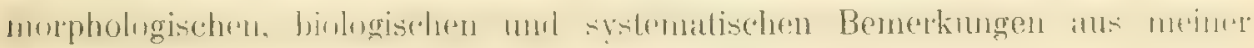

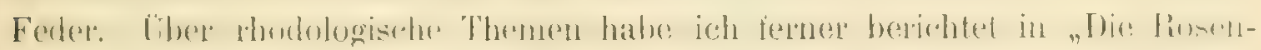

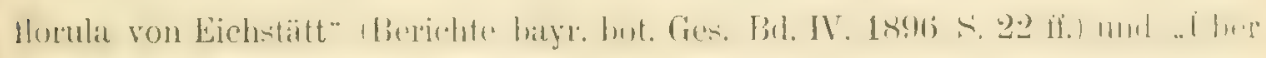

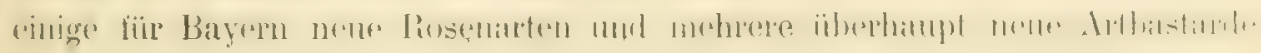
von Rosen" (Ebd. Bd. XI. 1907 S. 170 ff.). 
Bei der Beslimumng del von mir gesammelten oder wenigstens revidierten

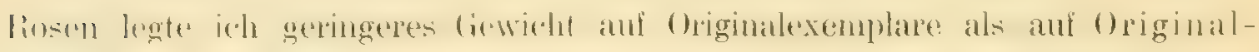

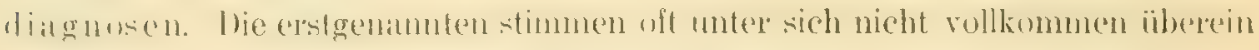

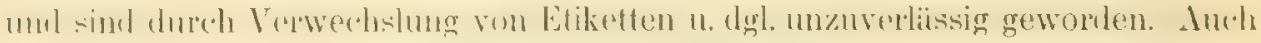
fribt es eine gewisse Entwicklung in der Auffassung des Autors einer Rosen-

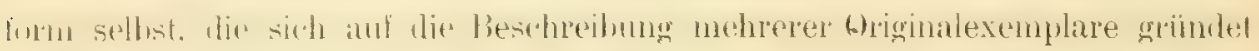

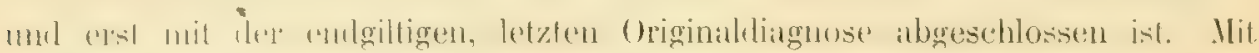
vershmommencu beschreihmgen nemer formen kam uan freilich nicht zurechtkommen; noch weniger ist es möglich, die Masse aller in Zeilschriften, Floren,

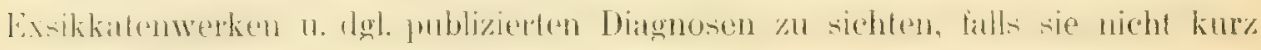
und prïzis gehalten sind. Ich habe mich deswegen bemiiht, sowohl meine

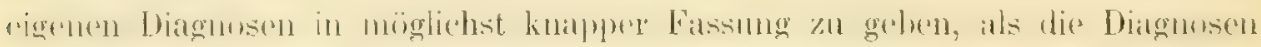
oder Beschreibungen anderer Autoren auf den-kürzesten Ausdruck zuriickzutïhren. Wenn ich hier zuweilen das Richtige nicht traf oder die erlaubten

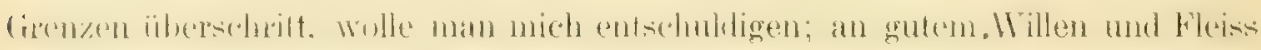
hat es mir nicht gefehlt. Ohne Zweifel sind im Laufe der Zeit viele Varietiten rer Gathung Rosa mehmals beschrieben worden, ohne dass die Synonymie rrkannt wurde. Das gilt besonders für die aus verschiedenen Läudern stam-

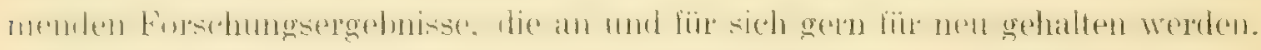
Anch ich werde gelegentlich in diesen Hehler gefallen sein. Etwas anders hat man die Handlungsweise von Floristen zu beurteilen, die nene Diagnosen und

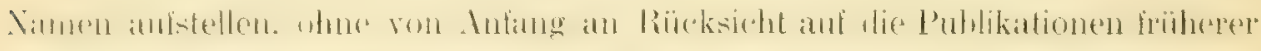
Rhodologen nelmen zu wollen. Nomina sunt odiosa. Es war.im Gegensatz dazu mein ständiges Bestreben, Anschluss an die Forschungen der klassischen Autoren zu finden, die insbesondere in llitleleuropa gearbeitet laben, ich nenne hier besonders Crépin, Christ, R. Keller, H. Braun, E. Sagorski und M. Schulze. Insbesondere wïnschte ich die vortreffliche Bearbeitung, welche die Gattung Rosa in der "Synopsis der mitteleur. Flora" durch R. Keller erfahren hat, auf mein spezielles Gebiet anzuwenden, ohne die Lrgebnisse zu vernachlässigen. die in der von H. Braun beeinflussten Schwarz'schen "Flora von NürnbergElangen" enthalten sind. Ein steter Vergleich mit dem nahen Thüringen war reboten schon deswegen, weil mich Crépin mehrfach auf die Mhulichkeit der Rosenflora des Frankenjura mit der dortigen aufmerksam machte.

Die Nomenklaturfragen haben mir grössere Nïhe bereitet, als ich an-

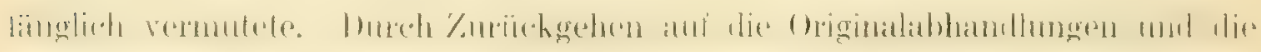

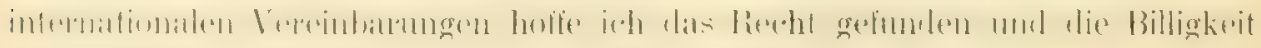
nicht verletzt zu haben. Eine Exkursionsflora für den praktischen Gebrauch zu schaffen, hatle ich nicht im Sinne. Doch richtete ich durch das Anhïngen zweich "Bestimnungsschlïssel" die Sache so ein, dass man auch diesen 


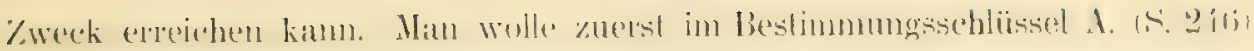
(lie Gruppe, dann in B. (S. 2.4 f.) die Art erkennen, zu der eine vorliegende Rose gehört. Hierauf schlage man im Teil II. das Verzeichnis und die Dia-

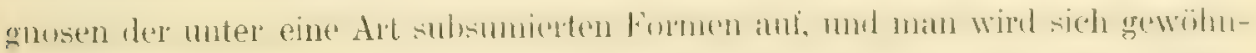

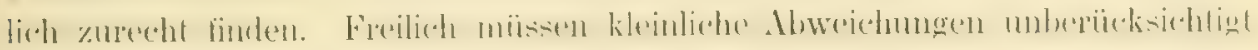
hleiben; und ein jeder, der in grösserem Umfange sammelt, wird von Zeit zu \%eit auf noch unbeschriebene Formen stossen. Auch mir ist das öfter vor-

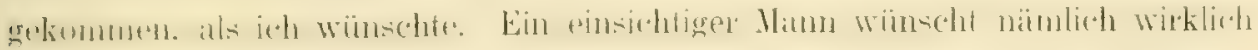
nicht, das Gestrüppe der schon beschriebenen "kleinen Arten" noch zu vergrössern, wenn er sich selbst schon in diesem Geisleslabyrinth abgemüht hatte. Wo jedoch eine Form in der Entwicklungsreihe eine deulliche Lïcke ausfïllt, muss sie festgelegt werden. Dass noch weitere systematische Ergebnisse der Losenforschung in. Bayern z. B. zu erwarten sind, lehrt mich meine bisherige Untersuchung dieses Landes. Bei der Nenge der schon vorhandenen Formen und der noch in Aussicht stehenden halle ich die Konstruierumg von dichotonischen Bestimmungsschliisseln, welche simbliche Formen berïchsichtigen sollen, für ein verfehites Unternehmen.

Ubrigens gestehe ich offen: hätte ich nicht die begrïndele Ilofinung in meinem Busen gehegt, iiber die blosse morphologische Beschreibung nenel Losenformen und ihre systematische Verwertung hinauszukommen, so hälte ich schon lange meine Exkursionen auggegeben und niemals die feder zur Ablissung dieses Werkes in die Hand genommen. Es ist viel Richtiges an dent, was Graf H. zu Solms-Laubach einmal schreibt: „Im ïbrigen möchte Referenł

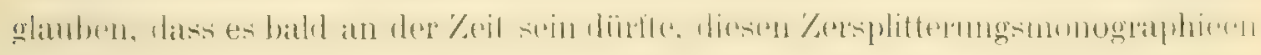
ein Ziel zu setzen, nachdem sie jetzt ihren Dienst geleistet und der Uberzengung von der Vielförnigkeit fast aller unserer Arten bei den Systematikern zum Durchbruch verholfen haben. Denn es kann wirklich nicht in Interesse der Wissenschaft liegen, überall Zustïnde zu schaffen, wie sie für Ilieraciun, Rosa, Potentilla II. a. bereits bestehen. Bei seinen Studien ïber Fragaria hat sich lief. iiberzeugt, dass die Jordan'schen Formen, die man nie wieder erkennen kann, - und ähnlich werden sich die Dahlstedt'schen und Almquist'schen auch verhalten - nur dazu dienen können, dis Volum und den Preis der Supplemente zım Index Kewensis zu erhöhen" (Bot. Zeitung 1907 II. Abt. Nr. 22. S. 359). Noch prïgnanter drückt sich Wesenberor in einem Artikel über die PlanktonOrganismen (Biol. Centralbl. Bd. XX. 1900. S. 650) aus: "Nichts kann der exakten

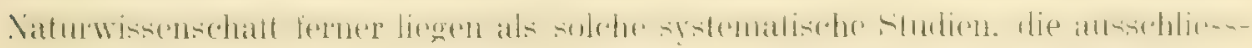

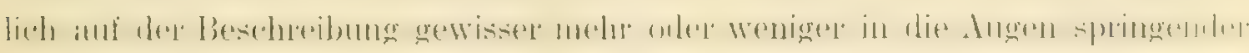

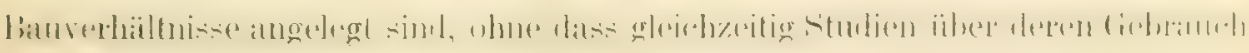
und die Faktoren, die sie hervorgerufen, angelegt werden; die Systeme, die ans 
solchen Studien hervorgehen, sincl nu leere Phantasien, und schwerlich hat

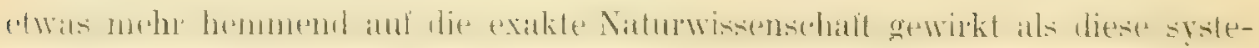

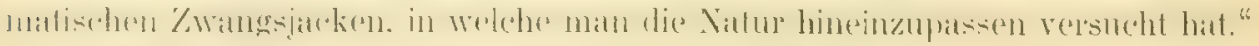
Ich habe deswegen gleichzeitig Studien über den Gebrauch der Organe bei den hosen gemacht und über die Faktoren, vou denen sie hervorgerufen werden; ich habe den Versuch gewagt, die morphologischen Eigenschaften der liosen kausal zu erkläiren, indem ich ihre Entstehung auf gewisse natirliche Ursachen zurilckführte. Als solche erkannte ich die Anpassung und die Nutation, ungefüh in dem Sinne, in welchen H. Driesch sagt: „Es greifen real in Einzelfall nach unserer Ansicht Mutation und Adaption in einander, die lelztere wahrscheinlich verbunden mit einer "Vererbung" des "Erworbenen". Die Mutation schafft den Typus und die Organisationshöhe der Formen, die

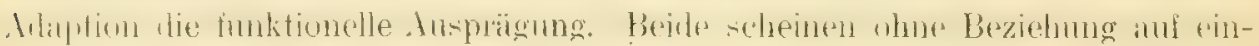
ander zu arbeiten, beide unterliegen gewissen Beschränkungen, daher kann es atcel geschehen, dass die eine, die Mutation, der andern, der Adaption, ent-

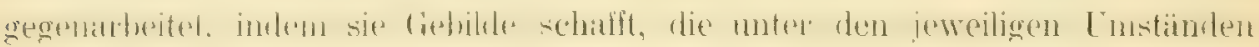

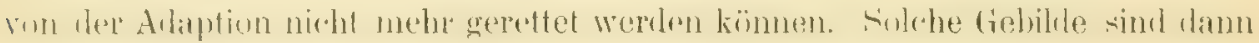
existenzunfähig, sie werden eliminiert" (Aufsatz "Kritisches und Polemisches" in Biol. Centralbl. 1902. Bd. XXII. S. 189). Leider bin ich mir wohl bewusst.

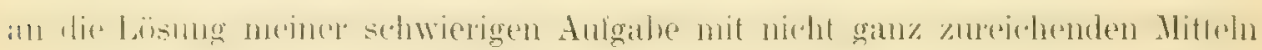
herangetreten zu sein. Ich habe das auch im Context meines Werkes öftel betont. An Beobachtung in der freien Natur liess ich es nicht fehlen; in meinem engeren Gebiet habe ich seit einem Jahrzehnt das Blühen, Wachsen, Leben und Vergehen der Rosen mit eindringender Aumerksamkeit verlolgt. Aber

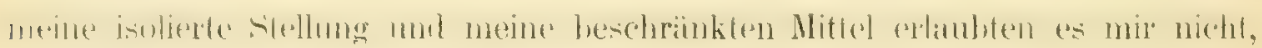

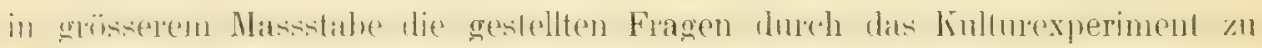
beantworlen und meinen Gedanken einen sichern Abschluss zu verleihen. Hier bleibt noch sehr viel zu tun, und kamn jeder Nachfolger reiche Früchte der Forschung pfliicken.

Wenn ich so dem kausalen Zusammenhang der Rosenformen nachspürte.

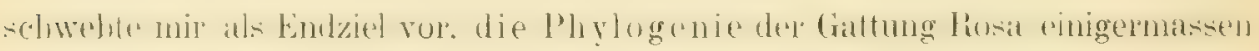
aulzuklären und meine Arbeit durch die Aufstellung eines obgleich unvollständigen doch plausiblen Stammbaums der Rosen zu krönen. '/u diesem Behuie und um äberhaupt allgeneine Resultate zu gewinnen, bin ich besonders im III. 'Teil über den engeren Bereich des Frankenjura hinausgegangen. Ein grosser T'eil der gesamten bayrisehen Rosenflora ist mir bereils von Autopsie

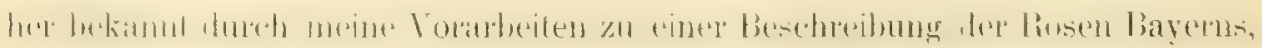
welche ich für die Zwecke der bavi: botanischen Gesellschaft unternommen

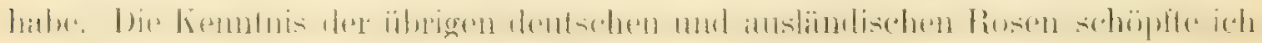


ans Herbarien und Literatur. Und so hoffe ich anch bei dieser Vergrösselung

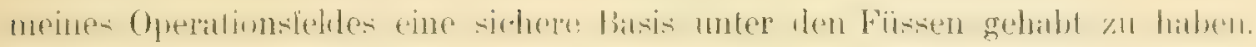
Hätte ich meinen Arbeitsplan nicht etwas erweitert, so wäre ich kaum zu einem

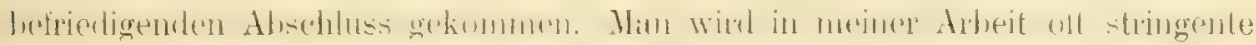
Beweise vermissen und Wahrscheinlichkeiten an ihrer Stelle sehen; anch an Ilypothesen herrseht in ihr kein llangel und manche detinitive Erklärung, z. B. iler Reizerscheinungen, konnte und wollte ich nicht geben. Allein das lässt sich in einer so schwierigen und vichleicht immer dunklen Sache nicht vermeiden.

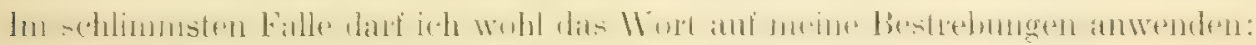
In magnis et roluisse sat est.

Eichstiut, im Novenber 1909.

Joseph Schwertschlager. 



\section{Inhalts-Übersicht.}

\section{Einleitung}

Die Begrenzung des Gebieles. . . . . . . . . . . . . . 1

Der geologische und geographisclie Charakter dessellen. . . . . . . . .

Seine ḱlimaverhältnisse . . . . . . . . . . . . . . . . .

I. Teil: Methodologische und morphologische Vorbemerkungen... . -

Erster Abschnitt: Methodologisches . . . . . . . . . . . . . is

Die anzuwendenden Allgemeinbegrife. . . . . . . . . . . in is

Die Zitierung der Antoren von Rosennamen . . . . . . . . . . . 111

Die Abkürzung der Diagnosen, Unterschied der Beschreibungen . . 11

Die Übergänge zwischen den Kategorien. . . . . . . . . . 1르

Zweiter Abschnitt: Morphologisches .......... . . . . .

Die Organe der hosen ....... . . I:

Der Stamm und die Achsen....... 1 it

Die Trichome .......... . . . .

Die Blätter . . . . . . . . 16

Der Blitenstand . . . . . . . . . 1s

Die einzelnen Blittenteile ... . . . . . .

Die Scheinfriichte ..............

Die Korrelation der Eigenschatien. . . . . . . . . .

Die parallelen Variationen. . . . . . . . . . . . . .

Die Baslarde ... . . . . . . . . . . . .

11. Teil: System der im Gebiet wild oder verwildert wachsenden Rosen nach morphologischen Gesichtspunkten geordnet

¿bersicht der Sektionen der Rosen im allgemeinen und der im Gebiet vertretenen im besondern

Sectio 1: Synstylae DC.

Rosa arrensis Hurls. . . . ... . . 31

Sectio II: Gallicanae DC.

Suljsctio 1: Gallicanae verae Borh. . . . . . . . . . . . . . :3:

liosa gallica L. . . . . . . . . . . . . . . . . . . .;:

Sulusectio 2: Jundzillianae Crep. . . . . . . . . . 3i

Rosa Jundzillii Bess. . . . . . . . . . . . . . . . . . . .

Sectio III: Vestitae Chr. . . . . . . . . . . . . . 3!l

Rosa pomifera Herm. . . . . . . . . . . . . . . . . i.

Rosa tomentosn sm. . . . . . . . . . . i.

Sectio IV: Rubiginosae DC. . . . . . . . . . . i!

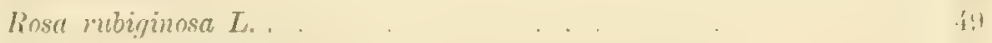

Rose micrantha Sim. . . . . . . . . . . . . . . . .

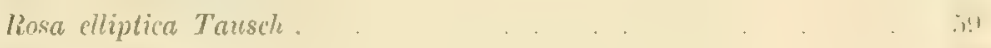

liosa agrestis sari. . . . . . . . lii 
Sectio V: Caninae D C.

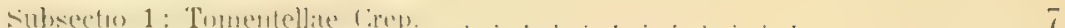

Rosa tomentella Lem. ................... 71

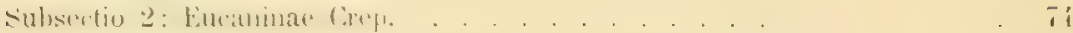

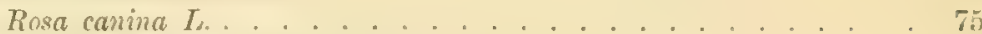

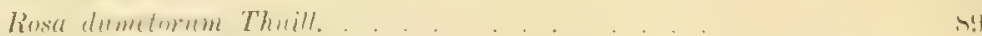

Rosa glauca Vill. .................... 97

Rosa corifolia Er. .................... 105

Sectio VI: Cinnamomeae DC.............................. 107

Subsectio 1: Cinnamomene rerae Schwerlscl. . . . . . . . . . . 107

lima immamomice $L$. . . . . . . . . . . . 111,

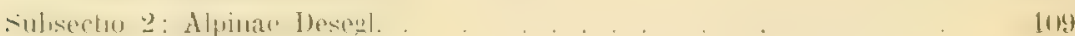

liosa blanda lit. ................... [1t!

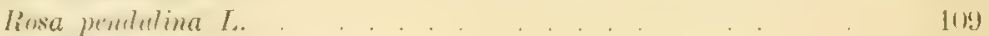

Sectio VII: Spinosissimae Bak. . . . . . . . . . . . . . . 111

Subsetu 1: I'mmpinellitoliac 1)6. . . . . . . . . . 111

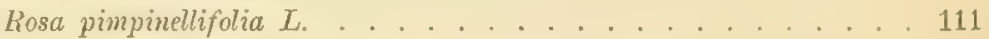

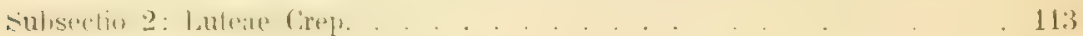

lírst linter Mill. . . . . . . . . . . . . . . 113

Die Bastarde: . . . . . . . . . . . . . . . 114

Seclio Gallicanae DC. . . . . . . . . . . . . 115

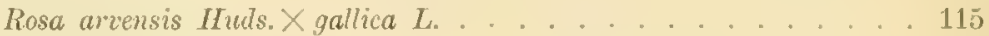

Sectio Vestitae Chr. . . . . . . . . . . . . . . . . . . 119

Rosa gallica L. $\mathrm{x}$ tomentosa Sm. . . . . . . . . . . . . 119

Sectio Rubiginosa UC. . . . . . . . . . . . . . . 120

Rosa micrantha Sm. Xrubiginosa L. . . . . . . . . . . 120

Rosa agrestis Savi X elliptica Tausch ............... 121

Sectio Caninae DC. . . . . . . . . . . . . 123

Rosa avensis Huds. X canina L. . . . . . . . . . . . . . . 122

lísa canina L. gallica I.. 1.2.

Rosa canina L. X. Jundzillii Bess. . . . . . . . . . . . . . . . 126

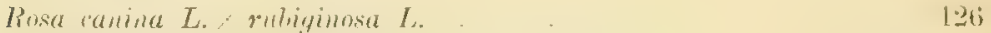

Rosa dumetorum Thuill. X gallica L. . . . . . . . . . . . . 127

Rosa dumetorim Thuill. X.Jumdzillii Bess. . . . . . . . . . . 130

Rosa dumetorm Thuill. X tomentosa Sm. . . . . . . . . . . 131

Rosa dumetorum Thuill. X micrantha Sm. . . . . . . . . 132

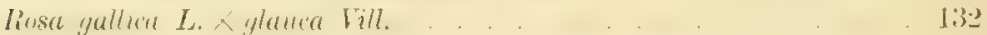

Rosa glauca Till.X Jundzillii Bess. . . . . . . . . . . . . 133

Rosa glanca Till. X tomentosa Sm. ............... 133

Rosa corifolia $\mathrm{Fr}$. $\mathrm{X}$ dumetorum Thaill. . . . . . . . . . 134

Sectio Cinnamomeae DC. . . . . . . . . . . . . . 135

Rosa cimamomea L. . gallica $L$. . . . . . . . . . . . 135

\section{I. Teil: Die Phylogenie der Rosen und die Vorbedingungen für die Erkenntnis ihres natürlichen Zusammenhanges}

Erster Abschnitt: Anpassung der Eigenschaften von Rosen an iussere Verhältnisse iokulowe del Rusent

1. Kapitel: Das IVasser . . . . . . . . . . 138

Hydrophytische Eigenschaften der Rosen . . . . . . . . . . . . 138

Xerophytische Eigenschaften der Rosen . . . . . . . . . . . . 142

Benetzlarkeit der Blälter . . . . . . . . . . . . . . . 143 
2. Kapite1: Die Wäme (Temperatur).

Phänologische Beobachtungen: an Blüten

Folgerungen dariaus

Sonstiges

3. Kapitel: Das Licht............ L L

Wirkungen des Lichles auf Bläter und Achsen. 1.j)

Wirkungen des Lichtmangels . . 1ij

Wie Hare dil

Das Anthocyan. 1. . . 152

†. Kapitel: Die Lult. . . . . . . Dis

ler Wind list

Der Luftdruck . . . . . . . . . . . . . . . . . . . . . . . . . . . . .

ber Wuchs der Gebirgsrosen . . . . . . . . . . . . . . 15!)

Die Beschafienheit der Kelchbecher und Griffel bei den Gebirgsrosen 160

5. Kapitel: Der Bodell . . . . . . . . . L

Von fremden Faktoren bestimmte Einwirkungen . . . . . . . . Lif

Die physikalische aud chemische Beschaffenheit des Bodens, die ,Kalkliebe" der Roselı. . . . . . . . . . . . . Jli.)

6. Kapitel: Das Zusammenleben mit andorn Organismen. Ititi

Einfluss der Uflanzen..... . L liti

Positive Einwirkungen der Tiere llit; Die Bestäubungr . . . . . lini

Die Verbreitung der Früchte . . . 11;

Vorwiegend negative Ampassungen gegen Tiere lit; Die Stacheln 16i:l

Die Drüsen . . . . . . . . . $17 i$

Einwirkungen von seite des Menschen . . . . . . . . . . 177

F Kapitel: Art und Weise wie bei den Rosen die Anpassungen crfolgen . . . . . 17!

Begrilisbestmmumen . 179

Wirkungsweise des Wassers 1kil

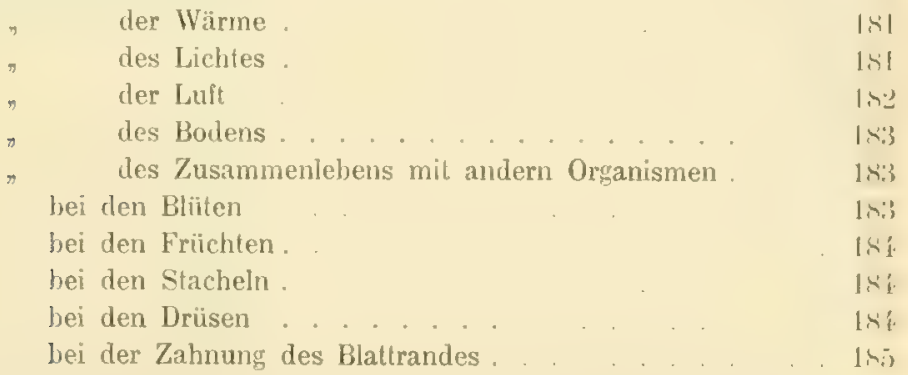

Zwoiter Abschnitt: Untersuchung der im Gebiet konstatierten Arten, Varietäten und Formen auf den Unterschied zwischen Anpassungs- und Organisationsmerkmalen; Korrekturen am üblichen System.

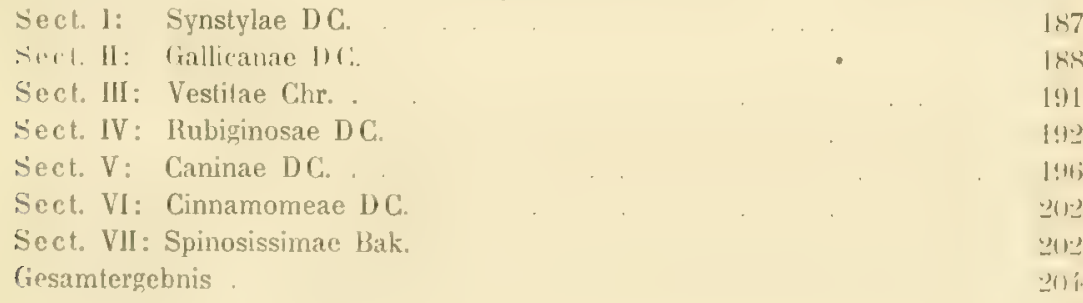


Dritter Abschnitt: Die Deszendenz der europäischen liosenarlen . . . . . . . 205

L. Kapitel: Die Organisationsmerkmale . . . . . . . 206

Die Achsen . . . . . . . . . . . . . . 207 207

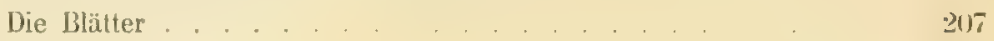

Die sexuellen Organe . . . . . . . . . . . . . . 20y

Die Hautorgane. . . . . . . . . . . 209

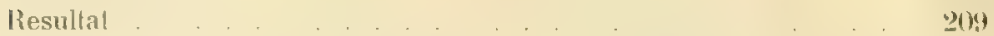

2. Kapitel: Die jetzige geographische Verbreitung der europäischen Arten im \%usammenhalt mit ihrer jährlichen Vegetationsperiode; Entwurf eines Stammbames der Rosen . . Jlu

A. Sectio Cinnamomeae mit IR. pimpinellifolia . . . . . 2ง।

B. Sectio Synstylae . . . . . . 21't

C. Seclio Gallicanae. . . . . . . . . . . . .

D. Sectio Caninae. . . . . . . . . . . . . . .

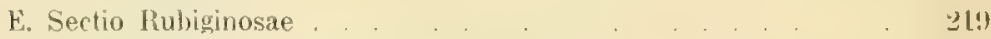

I. Sectio Vestitae . . . . . . . . . . . . . . . . . 2.2.)

Urheimat und Zugstrassen der Kosen, bes. der europäisclicn . . . . 2.2:3

Wege und Zeit des Einzugs der Rosen in das rechtsrheinische Bayern und spez. den Frankenjura, mit Tabelle ............ . . . i i

Die Deszendenz der europäischen Rosen und der ganzen Gattung graphisch dargestellt . . . . . . . . . . . . . 2.20

3. Kapitel: Ausblicke auf das allgemeine Deszendenzproblem . 2a!

Unterscheidung von Anpassungs- und Organisationsmerkmalen . . 22!)

Die Erblichkeit der Anpassungen . . . . . . . . . . . . . . . . . . . . .

Die Anpassungsbreite . . . . . . . . . . . . . . . . . 2:32

Bedeutung und Ursprung der Organisationsmerkmale . . . . . . . 2.3.

Die Variation (Mutation) der Organisationsmerkmale . . . . . . . 23:3

Die Berechtigung der kollektiven im Gegensatz zur elementaren Art 235

Prognose für die fernere Entwicklung der Sippe Irosa . . . . . . .3.

Literaturverzeichnis . . . . . . . . . . . . . . . . . . . . . . . . . . . . . . .

Verzeichnis der in Teil II behandelten Rosenformen . . . . . . . 2i.?

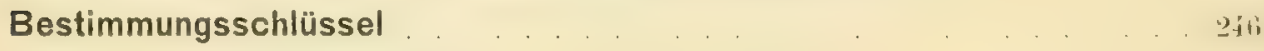

Tafel I und II mit Erklärung. 


\section{EINLEITUNG.}

\section{Das Gebiet: sein floristischer, geographischer, geologischer und klimatischer Charakter.}

Das Gebiet, welches sich der Verfasser für seine vorliegenden Rosenstudien ansgewählt hat, umfasst den südlichen mol mitleren Teil des havrischen duazuges: Seine Grenzen bilden: im Süden die Donau zwischen Donauwörth und

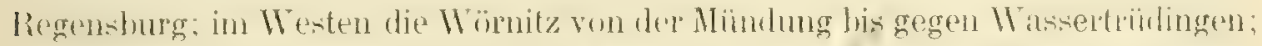
in Norden wird die ungelahre Grenze gegeben durch die Linie Wastertridingen-

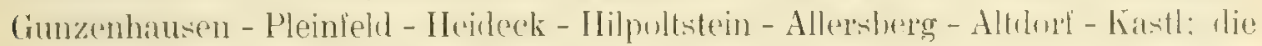
Ostgrenze liuft der Lautrach entlang von Kastl nach Schmidtmühlen, von da

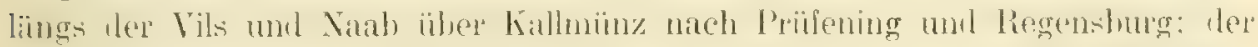

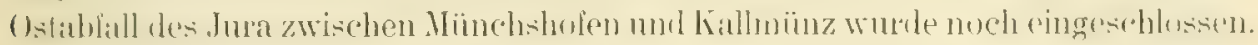

Zu dieser Auswahl veranlasste den Verfasser zunächst ein persönlicher Grund. Wer die Rosen nur in Herbarien studiert, kommt auf Abwege. Er wird vorzüghlich die Differenzen sthen und seinen Teil zur unseligen Furmen-

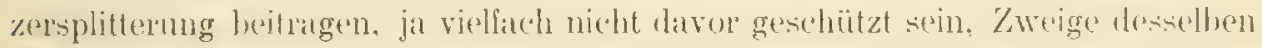
Strauches zu eigenen Varietiaten zu exheben. Klinatische Einflïsse, die II irkung

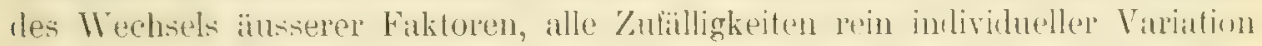
werden seinem Blicke entgehen. Darum Studium der Natur! Ein solches ist aber bei der Gattung Rosa, deren Formen sowohl zur Blïte- als Fruchtzeit in verschiedenen Jahren charakterisiert werten mïssen, lediglich damn möglich, wenn man sich in der Lage befindet, von seinem Wohn- und Aufenthaltsorte aus einen gewissen Bezirk bequem und wiederholt absuchen zu können. Fiir

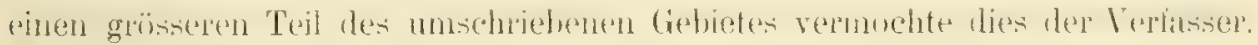

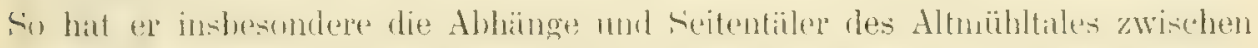
Treuchtlingen und helleim, volah die nihere L'mgebung von Eichstiatt, geman

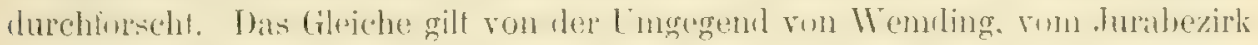
zwischen Neumarkt i. O. und Altdorf b. N., der Velburger Gegend und anderen.

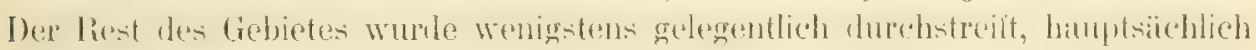
zur Fruchtzeit im Herbste. Jene Herren, welche mich mit Beiträgen unterstützten - ich habe ihre Funde stets eingesehen und meist bestimmt - wurden von mir in der Vorrede genannt. Doch stammt das bei weitem reichste Naterial aus meinen eigenen Exkursionen. Am meisten Lücken weist die Kenntnis des Ostens unseres Bezirkes aul.

Das von mir ausgewahlte Gebiet empfiehlt sich aber auch aus sachlichen Grüuden. Von Jura Wiintembergs mel Bayerns gilt das Gleiche, was Chuist vom Schweizer Jura bemerkt: „Die übrige Schweiz steht hinter dem Jura an Resichum und Entwickelung der Losen weit zuräks." 1, Der Jum ist anch in

1) H. Christ: "Die Rosen der Schweiz." Basel 1873. S. 3 bis S. 7 nennt Chr. den Schweizer Jura sogar , den privilegierten Rosengarten Europas". 
Bayem vorwiegemel rin halkguhirgé. I)je Rosen gehö̈en aber nach allgemeiner Anschaumg zu den kitkliehemben H'tanzen. Ferner sind sie - ehenfalls nach Christ - ..turehschnittich Hïgel- und Bergpflanzen und bedïrfen der Nïhe des Waldes und nahrungserehor. befeuchteler standorte. Daher beginnen die meisten Arten orst mit der Hügelzone: sie lieben starke Insolation, aber ohne Austrocknung des linlens." ${ }^{1}$, Golche Stindorte bieten ihnen die Abhänge des Frankenina in rejehen Misse: die trockensten stellen freilich erweisen sich vorwiegend ron den an Wassernangel angepassten Arten der Rubiginosa-Gruppe. besetzt. Lediglich die Ilochebene selber zeigt eine verhältnismïssige Armut an Losen. denn wo sie nicht (ictreide trägt, ist sie mit grossen Hochwïldern bestockt. Man kimn wohl rom Frankenjura kaum behaupten, was Christ rom Schweizerjura vermutet, dass er nümlich der Bildumgsherd mehrerer Arten sei. $\left.{ }^{2}\right)$ Dafür steht er in reicher Wechselbeziehung zum mitteldeutschen Hiigellande, zur rauhen Alb und zul' sehwibisch-baylischen Hochebene. Seit dem Ende de's Mesozoikums Festland geworten hat er der Enwicklung der Planzenwelt und des Genus Rosa stets eine gïnstige Linterlage geboten. Wenn man sieht, wieviele Hecken, auch Rosenhecken, fiihnlich durch den Inverstand der Grundbesizer und durch die Zerstorungsilust ron Linberulenen jeder Alt mit Fener und Eisen verwïstet werden, möchle num glauben, es könne kein nennenswerter Bestand von Rosenformen mehr vorhanden sein, oder doch, das Jahr sei nahe, in dem die letzle wilde Rose blüht. Zum Glïck besitzen Rosen ein ïusserst zähes individuelfes Lehen, überdauern meist den Brand und werden bloss durch Ausgraben endgiltig ausgerottet. Ausserdem bergen die Abhinge des Jura soviele felsige und sonst schwer zugängliche Zufluchtsstcllen, dass, wie andere Kinder Floras, so auch die lichlichen Rosen noch lange eine bevorzigte Heimstatte in unserem Frankenjura haben werten. Wir wählten also gewiss keine ungïnstige Region zum Sludium der Gattung Rusa.

Da ungelïh bei der Riessenke der geologisch-paliontolugische Charakter des schwibischen dter rauhen Alb) in denjenigen des Franken- und (oberpfilzer Jura ïbergeht, wird der liern unseres Gebietes ron der Weissjura-Hochplatte des letzteren gebildet. Diese zeigh im allgemeinen eine Neignung gegen riaden und Usten: ihre bedeutenderen Erhebungen liegen also an der Westgrenze und im nördlichen Bezirk, die tieksten Senkungen in der Donaulinie besonders zwischen Kethein und Regensburg. Keine Höhe erretelst $700 \mathrm{~m}$. Abgeschen rom Häselberg $\left.\left(690, f^{\prime} m\right)^{3}\right)$ an der Westgrenze seien an Jurahöhen im Westen und Norden unsteres liebietes genannt: Der Diirenherg an Hahnenkanm bei Heidenheim

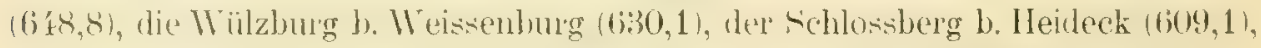

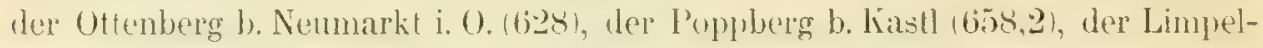

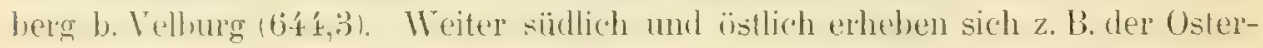
herg zwischen Langenaltheim und folnhoten blosis mehr bis $24597,6 \mathrm{~m}$, die

1) „D. Ros. d. Schw。" S. 14.

2) Ebd. S. 11.

3) Sämtliche Höhenangaben wurden dem bayrischen topographischen Atlas, Massstab 1:50000, entnommen. Sil beziehen sich auf Xormalpewel des mittellindischen Meeres und sind um rund $2 \mathrm{~m}$, genauer 1,78, höher als diejenigen, welche auf dem in Deutschland offiziellen Pegel der Nordsee basieren, z. B. in der deutschen Reichsharte 1:100000. 


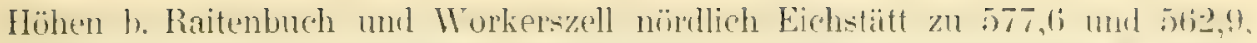

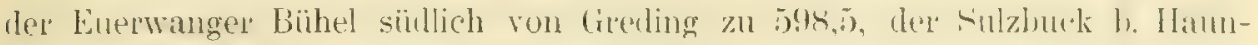

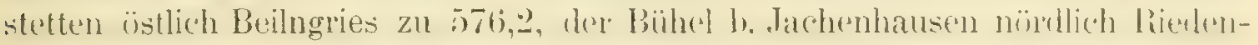
burg zu 555,8, der Eichelberg b. Painten nördlich Kelheim zu $546 \mathrm{~m}$. Als

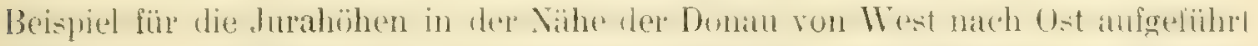

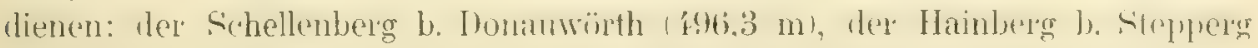

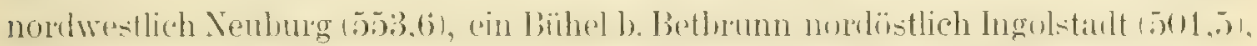

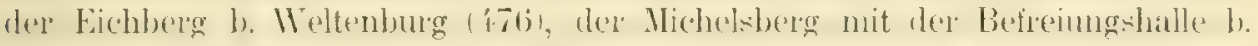

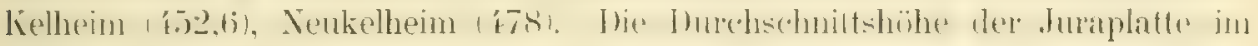

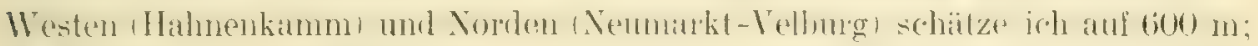

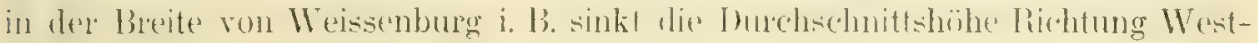
Ost von etwa 580 auf $550 \mathrm{~m}$, in der Breite von Eichstäit von 550 auf 520 , am Rande gegen die Donau von 500 auf $450 \mathrm{~m}$.

In Gogensatze zn diesen Höhen kommen den wichtigsten Talungen unseres

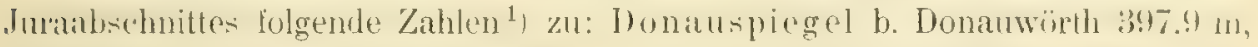

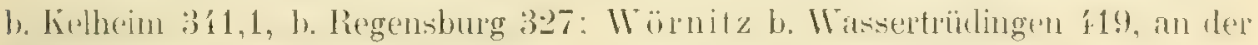

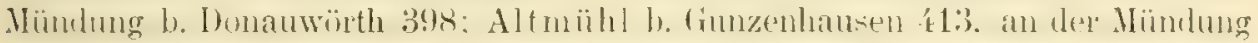

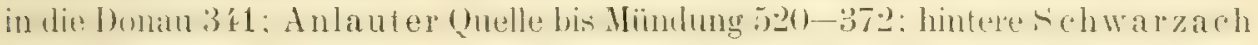
desgleichen 418-371,5; Sulz ca. 140-366; Lauterach 480-355; Vils von

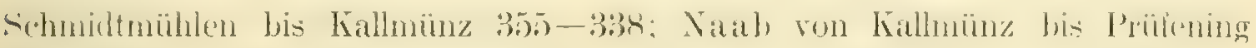

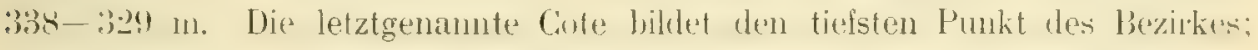
die Flusstilter der Rezat und der Fioth gehen, soweit sie den Bezirk beribren, nicht tiefer als $380-365 \mathrm{~m}$. Die bei weitem meisten Talstrecken innerhalb des Gebietes laufen zwischen 440 und $340 \mathrm{~m}$ und werden in den höchsten

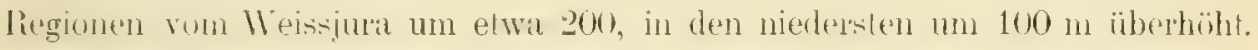

Die Jurahochebene gehört dem Weissjura (Malm) an. Sïdlich von der Linie Solnhofen - Ruppertsbuch - Kipfenberg - Jachenhausen - Painten ïberwiegtn auf der Oberfläche die Plattenkalke und deren lehmige Ehuvialgethilde; nördlich sind es ältere Stufen des Malm, die zutage treten: Quaderkalk $(\delta)$ bes. in der Facies der Schwammkalke und zuletzt anch Dolomit $(\varepsilon)$. Weite Strecken der Alb zeigen aus dem Tertiär (?) stammende Lehm- und in geringerem Mass anch Sandiiberdeckung. Tertïre Siisswasserkalke und diluviale Lehme sind im Ries unl an der Böschung des Juar gegen dits I)nmutal zwischen Neuburg und Pföring in grossartigen Massstabe algelagert. The Talhänge gehören bast stets dem Malmkalken an: das Altmïhltal zeigl von Doulhstein ab slarke Dolomitlelsentwicklung. die von Riedenlumg lis Kedhein den Felsenkalke Plalz macht. Nur an wengen , Gellen des südlichen Frankenjura schureden die Tailer bis in den Dogger (Braunjura) oder gar in den Lias (Schwarzjura) ein. Sandsteine

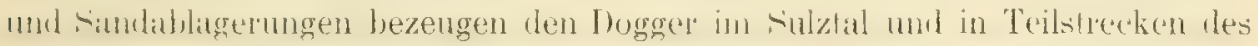
Anlanter- mol Schwazachtales; hei leeilngries trill Dogger auch in Altmïhtale aut. An Nordwestabfall des Jura dagegen, hei Gunzenhausen. Weissenlurgr, Heideck, Nennarkt, wird der Eisensanlstein des Dogger und der dunkle Kalk-

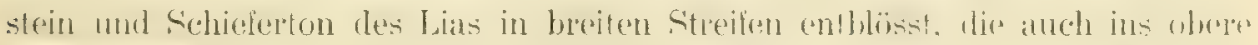

1) Teilweise aus dem topographischen Atlas genommen und teilweise aus W. Gätz: Geographisch-histor. Handbuch v. Bayern. München, 2 Bde. 1895 u. 1898. 
Altmiihltal und seine dortigen Nebentiilen heromeichen. Duch ist hier äherall

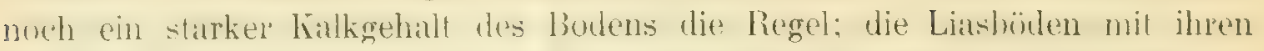
schweren lethnen gehören zu den liduhbarsten Anen unseres Viaterhandes. Ich Jin selbstverstandlich da, wo dere hetper in unseren Bezirk herein- veler an ihn heranpeicht, auf some sunten mol sandhedeckten Terrainwedlen hinabgestiegen und habe so insbesondere die Pleinfelder Gegend untersucht.

Im Gebiete der Malmablagerungen hersscht Trockenheit und zuweilen

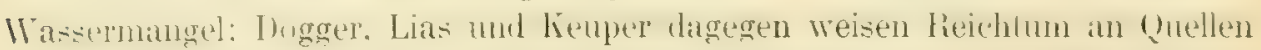

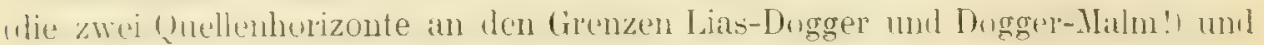
an gextuntem Wasser auf. Das Gileiche gilt vom Ries und rom Donautal, überhaupt allun Talalluvionen. An fruchlbarsten sind dieste Xieldrungen: ihnen folgen an Fruchtbarkeit jene Teile der Hochebene, welehe tielgriandigen Lehmhoden besitzen. Aber gerade solde P’artieen zeigen sich arm an liosen, weil sie allzu sorghiltig kultiviert und lieine Odungen gertuldet werten; anch waren

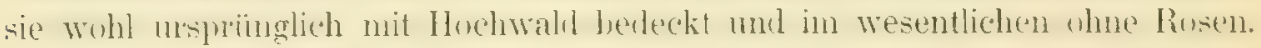
Die besten stamlylitze fïr liosen sind in unserem Gebiet stets die siidhänge de' Tälex, besonder's des Altmïhltales, falls sie werler bewahlet, noch gamz mi!

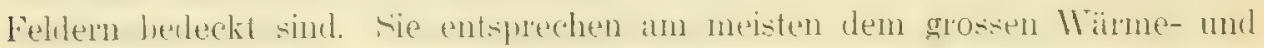

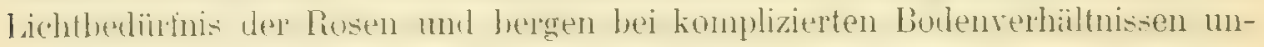
berührte und ursprüngliche Zufluchtsstïtten der Pilanzenwelt.

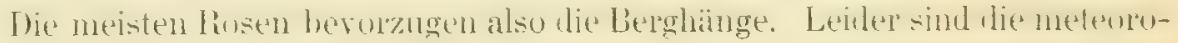

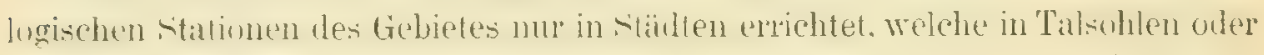
auf Talehenen liegen. Die entsprechuden meteurulugischen Beubachtungen

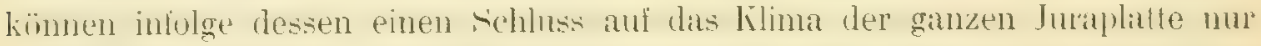
mil heserve zulassen. Cler die Temperaturverhailtnisse liegen mir Angaben ans

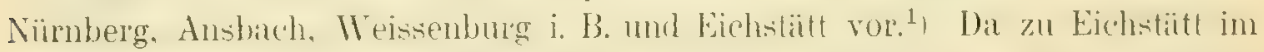
Zusammenhang bluss von 1890- Ls95 beobachtet wude und späler eint Pause eintrat - jetzt wird wieder observiert - , wurden die Angaben aus den übrigen milkelthinkischen Stationen ebenfalls aul diese Zeil bezogen. Damach belrug das Temperaturmittel dieser 6 Jahre:

$\begin{array}{ll}\text { in Nürnberg } & 8,4^{\circ} \text { C. } \\ \text { in Ansbach } & 7,7^{\circ} \\ \text { in Weissenburg } & 7,8^{\circ} \\ \text { in Eichstätt } & 7,8^{\circ}\end{array}$

Aufallend erscheint beim Vergleich ron Ansbach und Eichstïtt, dass hier das miltlere Ninimm des August mo $0 . \hat{t}^{0}$ tiefer liegl: auch der Januar ist in Eichstiitt stets hetrïhtlich kïlter. Dagegen sind in Eichstaitt relatir hoch die Tomperaturen des September und ()ktuber. Die meteorologischen V'erhälnisse ron Eichititt lagen nicht den Chamkter der mittelfrinkischen Ebene, sumdern

1) Das Folgende ist ein kurzer Auszug aus einer mir von Herrn k. Reallehrer Ḱn̈irzer

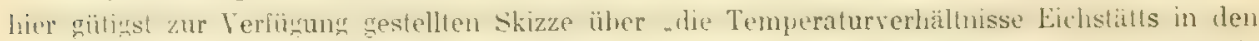
Jahren 1890-1895" (vgl. auch dessen "Die Temperaturmiltel Würzburgs von 1850-1903", Eichstätt, 190h). Für die Berechnung der Mittel wurde die Formel angewandt: $\frac{1}{4}\left(7 \mathrm{~h} \mathbf{a}+2^{\mathrm{h}} \mathrm{p}+\right.$ $2 \times 9 \mathrm{~h} p)$. Diese wie sonstige notwendige Korrekluren und Reduktionen erklären es, wenn die im Texl milneleilten Jahresmiltel der Temperatur für Nürnberg und Weissenbur hüher ausfielen, als sie gewöhnlich angegeben werden. 


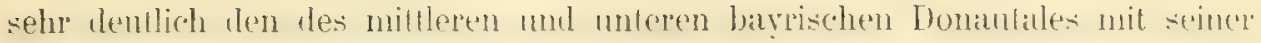
unverkenubaren kontinentalen Ausprägung.

Phänologische Beobachtungen wuden ron mir in Eichstatt i'Tal mol 'Tal-

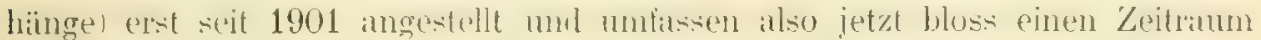
von acht Jahren. Fiir einige dter berbatchteten Pilanzen gebe ich in folgenten den achtjährgen Durchschnitt und zwar im Vergleich mil den Litten des zehnjährigen Durchschnitts kle gleichen Pilanzen ans den Nürnberger Benbachtungen, die A. Schwarz in der Flora von Nürnberg anführt. ${ }^{1}$ ) Nach ihren Existenzbedingungen (IVitme. Licht, Iruchthater Linden) habe ich die Eichstitter Stand-

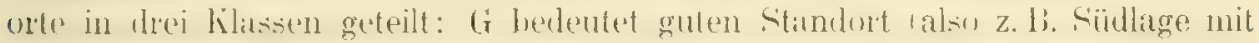
Kiilteschutz und vollem Lichtgenuss), $M$ einen Standort mit mittleren Verhällnissen lalse z. B. zwar geschützte Lage und guten Bulten, aluer keine volle Besonnung), $\mathrm{S}$ einen schlechten Standort. $\left.{ }^{2}\right)$
Beobachtete Pflanze
Datum Eichstätt
Lage
Datum Nürnberg

Erste Blattoherfläche sichtbar:

$\begin{array}{llll}\text { Aesculus Hippocastanum, Rosskastanie } & 22 . \text { IV } & \text { II } & \text { 15. IV } \\ \text { Fagus silvatica, Buche . . . . } & \text { 24. IV } & \text { G } & 28 \text {. IV }\end{array}$

Volle Belaubung:

Fagus silvatica, Buchenwald . . $\quad 3 . \mathrm{V}$ M $4 . \mathrm{V}$

Stäuben der Antheren:

Corylus Avellana, Haselstrauch . . . 9. III $\quad$ M $\quad$ 6. III

Erste Blïte offen:

\begin{tabular}{|c|c|c|c|}
\hline Ribes rubrum, Johannisbeere & & 25. IV & 16. IV * \\
\hline Prunus spinosa, Schlehe . . & . & $20.1 \mathrm{~V}$ & 21. IV * \\
\hline avium, Kirsche . . . & . & 25. IV & 23. IV * \\
\hline Cerasus, Weichsel. . & . & 26. IV & 26. IV * \\
\hline Padus, Ahlkirsche. . & . & 1. V & 26. IV * \\
\hline Pirus communis, Früh-Birnbaum & . & 27. IV & 26. IV * \\
\hline Malus, Früh-Apfelbaum & . & 4. V & 1. $V *$ \\
\hline Syringa vulgaris, Flieder . . & . & 9. V & 6. $V *$ \\
\hline Aesculus Hippocastanum, Rosska & & 10. V & 6. $V *$ \\
\hline Sorbus aucuparia, Vogelbeere . & . & 18. V & 13. $\mathrm{V} *$ \\
\hline Crataegus oxyacantha, Weissdorn & . & 19. V & 13. $\mathrm{V} *$ \\
\hline Cytisus Laburnum, Goldregen . & . & 22. V & 16. $\mathrm{V} *$ \\
\hline Secale cereale, Winterroggen & . & 27. V & 25. V \\
\hline Ligustrum vulgare, Rainweide & . & 14. VI & 13. VI \\
\hline Lilium candidum, weisse Lilie & . & 30. VI & 30. VI \\
\hline
\end{tabular}

Erste Frucht reif:

\begin{tabular}{|c|c|c|c|c|}
\hline Ribes rubrum, Johannisbeere & . . & 27. VI & G & 22. VI \\
\hline Secale cereale, (Ernteanfang). & . & 12. VIl & G & 9. VIJ \\
\hline Sorbus aucuparia, Vogelbeere & . & 28. VII & $M$ & 3. VIII \\
\hline Ligustrum vulgare, Rainweide & . & 6. IX & G & 10. IX \\
\hline
\end{tabular}

Allgemeine Laubverfärbung:

Fagus silvatica, Buchenwald . . 10. X 15 $15 . \mathrm{X}$

I) Teil I S. 171 ff, - Für die mit* bezeichneten Daten war mir Quelle der 22 jährige Durchschnit, den E. Ihne in , Phänolorische Karte des Friildingseinzuss in Mitleleurnpa" Pelermanns Mitteilungen 1905) nach F. Schultheiss wiedergibt.

*) Ich halte dafür, dass phänologische Angaben ohne solche oder ähnliche differentielle Standurtshezeichmunr einen noch viel geringeren Wert haben als man iluen jelzt überhaupt 
Wie zu erwarten war, entwickelt sich im allgemeinen die Vegetation in

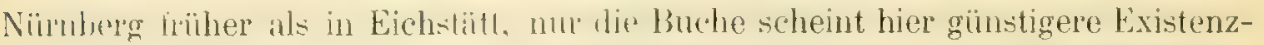
berlingungen zu tinden. Anlexe unerwatete Ausnahmen rühren entweder vou Meinungsverschiedenheiten bei der Beobachtung her (beurleilung des lieifezustandes von Früchten!) uler wumeln in Eigentümlichkeiten des speziellen Standortes einer b'lanze, die eben in der phinolngischen Zahl nicht korrekt zum Ausilnuth kummen. Insolem stehen also die meteorologischen und die phinologischen bubachtungen in Einklang. Eine speziellere Benteilung der vorgetiilnten Erebuisse halte ich ats den in der Anmerkung erörterten Grinden fiir anssichtslos, Gegenïber den Stitndorten in Tale wiirden diejenigen auf der Jurahochebene b. Eichstätt mindestens um 3 bis 4 Tage inbezug aul die gleichen P’lanzen zurïckstehen. Denn wenn wir für den Frankenjura die glciche Wiameabnahme annehmen, wie IIann und R. Gradmann sie fïr die schwähische Alb

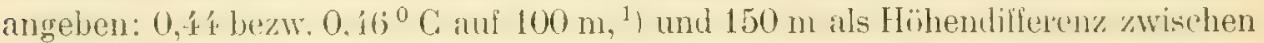
Eichstiitt und den umliegrnten Matenus zugrunde legen, su wiinde das Lílima auf mserer Hochehene un ctwa $0,66^{\circ}$ in der besseren Jahreszeit kïhler sein wie im Tikle. Das entspricht fast der Differenz zwischen Station Eichstït und Station Nibuberg und muss sich in einer entsprechenden phinologischen Anderung kundgeben. ${ }^{2}$ )

zuzuschreiben geneigt ist. Selbst in ebener Lage geniessen Gartenpflanzen durch den Schutz der Nauer u. dgl. einen wesentlichen Vorteil vor Individuen der gleichen Art und Varietät, welche im Freien den Kampf ums Dasein zu kämpfen haben. So habe ich gefunden, dass Apfelbäume in einem gut gelegenen Garten am Spalier nach vierjährigem Durchschnitt 7 Tage vor Apfelhochstimnen desselben Gartens blïhten iSpalierbäune und Hochstïmme gehörten dem Früholsst anı; die Hochstïmme blïhten aber ihrerseils wieder 5 Tage vor Holzapfelläumen in ziemlich guter Umgebung, doch $100 \mathrm{~m}$ höher gelegen. Rosen der gleichen Varietät können an einem nach Süden gerichteten Abhang um 1 bis 2 Wochen früher blühen als solche an einem Nordabhang. Die Pflanzen, welche man zur Erzielung phänologischer Daten an den verschiedenen Stationen benutzt, werden also nach der gewöhnlichen Methode voraussichtlich ausser der individuellen Variation, die auch auf Entwicklunsszeit Finfluss ausïbt, unter so verschiedenen äusseren Bedingungen stehen, dass von genauen Vergleichswerten keine Rede sein kann. Da Eichstätt in einem relativ engen Tale liegt, werden die untersuchten Pilanzen, auch wenn man sich nicht auf die nahe Jurahochebene begibt, wegen der unvermeillichen Abhänge selır wechselnden Wachstumseinflüssen unterliegen. Alle zu untersuchenden Pflanzen können unmöglich an einem gleichartigen Standorte aufgefunden werden.

3) R. Gradmann: „Das Pflanzenleben der schwäb. Alb". 2. Aufl. Tübingen, 1900. I. Teil, ¿. 15. - Entsprechende Beohachlunsen aus unserem Frankenjura sind mir nicht bekannt.

2) E. Thne führt Kipfenberg, im Altmühltale bei $394 \mathrm{~m}$, aber an der Schaltenseite, und Denkendorf, auf der Hochebene bei ungefähr $522 \mathrm{~m}$ gelegen, als Orte auf mit einem Frühlingsanfang vom 13. his 19. Mai ( Phänologische Karte des Frühlingseinzuges in Mitleleuropa"). Wenn ich für Gydonia vulgaris, die von mir nicht beobachtet wurde, als wahrscheinlichen Mittelwert 20. V einführe, so geben meine Eichstätter Auizeichnungen als Mittelwert der 13 Typusblütenzeiten die Pflanzen nit *, dazu Cyrlonia vulgaris, und damit als achtjähriges Mittel des Frühlingseinzuges in Eichstätt den 4. V. Da Nürnberg mit 2.V eingesetzt ist, steht Eichstätt-Tal-Sonnenseite ihm nach, aber nur um 2 Tage, und gehört zur selben Abteilung: Frühlingsanfang 29. IV bis 5. Y. hipfenterg und Denkendurf scheinen unter besonders ungünstigen Verhältnissen beobachlet zu hahen. heweisen aber jedenfalls die urossen klimabweichungen bei benachbarten Orten auch eines Mittelgebirges. 


\section{TEIL:}

\section{Methodologische und morphologische Vorbemerkungen.}

Unsere eigentliche Aufgabe soll gelöst werden im II. und III. T'eile. Im II. Teile werden die im Gebiet aufgefuntenen Rusenfurmen möglichst kurz und klar beschrieben und in systematischer ()rdnung vorgetührt. Hier gehe ich ganz von morpholugischen desicht:punken ans: der Aufbau meines systems dere knnstatierten Pusen ist auf die morphologische Beschreibung und dis Tatsiachenmaterial gegrïndet, das niemand emstlich jestreiten kann. Doch mïssen wir uns zuror klar werden über die Bedentung der einzelnen morpholugischen Charaktere: sie sind von sehr verschiedener Wirchtigkeit: anch werden wir uns davon überzeugen, dass sie keineswegs schun ille genügende Darstellung gefunden haben, so oft auch Rhowlologen anl sie zu sprechen gekmmmen sind. Ähnliches gilt von den rein formalen uder lugischen Lirwägungen und Voraussetzungen, welche bein Auban eines Systems mitspielen. Nanche bediuten einer Korrektur, einer Abschwiichung wher stirkeren betonung. [has alles erledigen wir zweckmässig in diesen I. Teile. Tieferen wirsenschattlichen Bedürf-

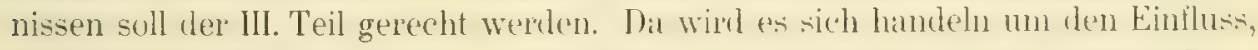
welchen äussere und innere Faktoren auf die Entwicklung der Gattung Ruma ansgeübt haben und ansüben: un die Auffindung von $\mathrm{Ab}$ ):tammung.linien, von geographischen und klimatischen Firmengruppen: kurz un einen Versuch, dem wahnhatl natürlichen System der Rusen und den Lrsachen seiner Entstehung näher zu kommen. 


\section{Erster Abschnitt: Methodologisches.}

Was die in systematischen Teil anzuwendenten Allgemeinbegrilie anlangt, so befinde ich mich grossenteils in thereinstimmung nit den Herantigebern der

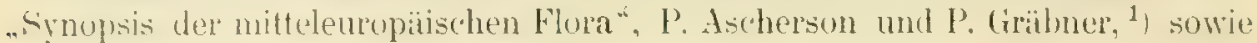
dem Bearbeiter der (iattung Rosa in dieser symosis, R. lieller. ${ }^{2}$ ) Ich gebranche ber der genatueren Gliedermm unserer Gattung die Kategorien Sektion, Lnterselition isulsectio), Gesantart, Art, Lnterart (subspecies), Varictä, Form, Formenkreis, Unterform (subforma).

Bezüglich der Fassung des Artbegriffes hielt ich mich wie R. Keller in der Mitle zwischen der Zersplitterung zu kleinsten Arten, die ihre gegenseitige Verwandtsehalt und rie systematische Verknïpfung allzusehr vermissen vder doch allzu undentlich hervortreten lassen, $\left.{ }^{3}\right)$ und einer verschwommenen, inhaltslemen V'rhindung zu vieler Formen. Auf dieser Linie des juste milieu hewegte sich ïhrigens schum del Altmeister der Rhodologir, H. Christ, $\left.{ }^{4}\right)$ und nicht minder der umlassembte Kenuer, Fi. Crepin, wenigstens was die späteren Jahre seiner Forschung betrilft. ${ }^{5}$ i Natïrlich wird es stets dem personlichen Ermessen anheingergehen sein, welche und wieviele norphologische Einheiten in sinne von Ihogu de Vries ${ }^{6}$ ) in dem Begriffe einer Art zusammengefasst werden. Für jetzt ist es nämlich selbst einem Anhänger der Theorie des genannten Forschers rein unmïglich, mit strengen Beweisen und in einigermassen grïsserem Imange das Genus Rosa in elementure Arten atufulüsen, d. h. in solche, die durch ein einziges, wem auch verschierlene Organe beeinflussendes Merkmal ausgezeichnet und von andern verschieden sind. Die Arten, von welchen in unserer Arbeit die Rede ist, sind also keine elementaren, aber auch gewöhnlich keine Linneschen, sondern in der Mitte zwischen heiden stehende massvoll kollektive oder dureh Gruppen elementarel Arten gebildete. Zu ihrer Aufitellung gehört, wie II. de Vries mit Recht bemerkt, „systematischer Takt"; zur Aufstellung der elementaren ist das physiolngische Experiment nötig $\left.{ }^{\top}\right)$ und zwar in einem Lmfange und bei den langsam wachsenden Rosen unter solchen Schwierigkeiten, dass der Gedanke daran allein in Schrecken versetzt.

1) Syn. d. mitteleuropäischen Flora, Leipzig 1896 ff., Bd, I S. 7 ff.

2) Ebd. Bd. VI S. 32-384.

3) Wie es leider viele französische und österreichische Autoren belieben.

4) H. Christ: Die Rosen der Schweiz, Basel 1873, und andere Verölfentlichungen.

5) Dass Crépin's Prodrome de la monographie des roses, dessen Erscheinen für 1895 er mir auch persünlich (in lit.) mitgeteilt hatte, das Licht der Öffentlichkeit nicht erblickte, bleibt tief bedauerlich. Eine su grossartige Vertiefun» in die Erkenntnis einer der schwierigsten Pflanzengattungen und jedenfalls der häufigst beschriebenen hat nun keinen Abschluss gefunden und die ganze Arbeit muss von einem andern wieder geleistet werden.

6) Hugo de Vries: Die Mutationstheorie, Leipzig 1901 und 1903, z. B. Bd. I S. IV. S. 41 ff.

i) Die Mutationstheorie I S. 43. 
Unter der Bezeichnung Gesamtart verstehen wir Gruppen sehr nahe verwandter Arten. Ihr jeweiliger Name wird entweder von der sog. "Leitart" - der verbreitetsten und bekanntesten der Gruppe - entlehnt oder nach Umständen neu gebildet. - Unterart ist eine systematische Gruppe, "die von

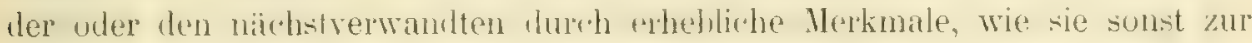
Lnterscheidnng von Arten verwendet werten, abweicht, mit densellen aber durch unverkennbare (nicht hybride) Zwischenformen verbunden wird." ${ }^{1}$ )

Jede Art gliedere ich erst in Varietãten und hernach in Formen.

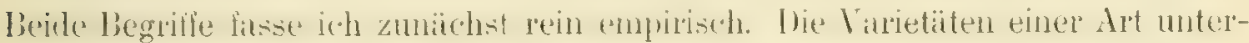
scheiden sich rom einander lluch Merkmale, dit weniger wichtig sind als diejenigen der Art und wichtiger als diejenigen der Formen. Eine Form kann durch eine einzige unbedentunle Eigentimlichkeit charakterisient sein. I) ats gilt jedenfalls von der Unterform, die zudem zum Ausdruck öfter vorkommender Nuanzirungen der Eigenschalten hemutat whi, \%. B. Aes Abblassens von bliiten, des Antrotens einzelner Härchen 1 . dgl. Bei den Formen werten auch die l'nterabarten, die Spielanten mul Munstrosititen untergebracht, die letzten beiden jedoch als solche gekennzeichnet (durch l und m, bez. lus. und monstr.). Bei den Varietiiten finclen sich meist auch die Rasien, d. h. jene Rusen, deren eigentiünliche gengraphisehe Verhreitung auf bestimmte klimatische oler phylugenetische Ein-

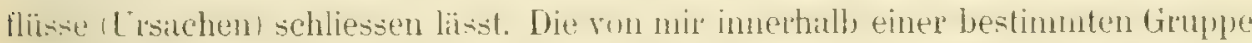

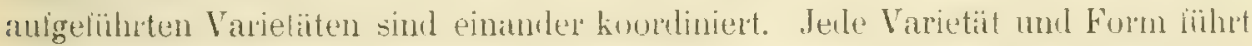
cinen Xamen, den die Auturbezeichnung angehingt ist. Einer anfgestellen Fom stets einen Namen geben zu müssen hat manche Lnzutrïglichkeit in Gefolge, hesumlers wenn es sich un stets wiederkehrende Moditikationen gewisser Eigenschatten himlelt. Dorh kitnn man sich diesem Gebrach mu der Verstindlichkeit willen zur Zeit kaum schon entziehen. Auch in der Synopsis von Asch. u. Gr. wurle wenigstens für die lirsen llotz einer komplizierten Einteilung nach Vorzeichen daran festgehalten. ${ }^{2}$ )

1) Asch. u. Gr. Synopsis I S. VII.

Vielleicht ist es von Interesse, die Delinitionen kennen zu lernen, welche Crépin von Arı und Unterart gibt. Die Art bezeichnet er als eine Summe von Individuen, die eine gewisse Zahl von Merkmalen semeinsan haben, welche Ifrkmale cunbeschadet der tunahne einer allowemeinen Deszendenz) fixiert, unter sich mehr oder minder unabhängig und ohne Übergänge zu denen anderer Arten sind (Les variations parallèlles, Sep. aus Bull. soc. bot. Belg. tom. 36, p. 206 (4), Bruxelles 1897). - Jede Art kann nach Crépin weiter in Gruppen, die Unterarten, zerfallen, die von einander durch Mlerkmale eines niedrigeren systematischen Wertes als die spezifischen sich unterscheiden und geradezu als die Anfänge, die Zündsätze neuer Arten, die sich erst aus den alten entwickeln, aufgefasst werden müssen. Die Unterarten zerfallen dann wieder in Varietäten mit Merkmalen noch geringeren Wertes. - Mit der Definition der ${ }_{\text {Art }}{ }^{\star}$ durch Crépin können wir einverstanden sein, aber nicht ganz mit jener der „Unterart*. Wenn Crépin hier die landläufige formulierung sich zu eigen macht, so vereitelt er sich selbst den Ausweg, die Unterarten als Sammelbehälter für beginnende Arten auszunützen. Ulisere Definition dagegen ist, wie wir später erkennen werden, sehr geeignet, die Zwischenglieder und Anfänge von Arten aufzunehmen, da sie ihren Merkmalen höheren $=$ Artenwert zuschreibt. Die "Unterarten" Crépins decken sich grösstenteils mit unsern "Varietäten".

2) In bezug auf das Verhältnis zwischen Varietät und Form habe ich mich dem herrschenden Gebrauche anbequemt, die Varietät zugleich als typische Form aufzufassen und die ihr subordinierten mit eigenen Namen gekennzeichneten Formen ihr folgen zu lassen. Eigentlich 
Ëinen schwierigen (iegenstand bildet unter Lmstänlen die richlige Zitierung

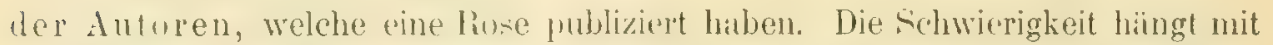
dem ITechsel der Anschaumgen über den engeren oder weiteren Begriff der "Art" bei der Gattung liksil, sowie mit dem ungemeinen Formenreichtum dieses Geschlechles zusimmen, der unler den verschiedensten Gesichtspunkten geordnet werden kamn. Crepin bechräinkt sich anch noch im Tablean andytique darauf, allen bei rine Apt erwihnten und anch von ihm dazu gestellten Formen die allgenepine Bezeichnung liusa zu geben und als Autormamen den elsten anzufiigen, lex dio Form beschrieben hat, z. B. erwïhnt er Losa subglobosa sim. als Varietät der R. tomentosa $\mathrm{Sm}_{*}{ }^{1}$ ) J. B. v. Keller zitiert gewöhnlich den ältesten Antur, einerlei ob dieser die betr. Rose als Form, Varietit oder Art eingeführt hat, und welche stellung lieller selbst in der Frage eimnimmt.2) Iteinrich Braun macht es ïhnlich, bemerkt jedoch stels, wenn der Autor die Rose in Gegensatz zu ihm als Art beschrieben hat. ${ }^{3}$ ) Burnat und Gremlit) (lagegen enlsprechen den Nonenklaturegeln, wie sie rom intemationalen bolanischen liongress zu Wien 1905, Sekt. 5) Alt. 43 Ḧxient worden sind. Hiedureh wird eine von 0. Kuntze mul den "Berliner Nomenklituregeh" ") empfohlene P'lixis von den höheren Gruppen auf die unter der Giattung stehemlen ausgedehnt hezw. auszudehnen gestattet. Diesem Verlahren schliesse ich mich an. Ich werde demzufolge, wo man genötigt ist, die Dignital einer Gruppe zu veründern, z. B. Varieliten zur Art zu erheben oder, wie älter, Arten zu Varietiten und Formen zu erniedrigen, den Autor, welcher die Verïnderung bewerkstelligte, zitieren, aber auch den ursprünglichen Urheber des Namens in Kilanmer beisetzen, also z. B. Rosa tomentosa Sim. var. subghlobsa (sin.) Carion. Formen und Varietiten werden hier nicht weiter berücksichtigt, d. h. Autorbenennungen werden nicht geändert,

müsste die Definition der Varietät so weit sein, dass sie auf alle Formen passt. Man müsste dann aber stets noch eine Form (mit dem Kennzeichen der gewöhnlichen Varietät) herausheben und durch einen separaten Namen kennzeichnen, also das Heer von Namen noch weiter vergrössern. Als Beispiel diene die var. syntrichostyla (Rip.) H. Br. mit ihren Formen f, dilucida (Desgl. et $\mathrm{Oz}_{\text {. }}$ H. Br. und lasiostylis Borb. Diese Formen unterscheiden sich von der Varjetät teils durch die Gestalt der Scheinfrüchte, teils durch andere geringfügige Abweichungen. Wollte man ganz korrekt verfahren, so dürften in die Diagnose der Varietät keine Eigenschaften aufgenommen werden, die nicht auf sämtliche Formen, also hier f. dilucida und lasiostylis passten, z. B. die abweichende eiförmige Gestalt der Scheinírüchte bei var. syntrichostyla. Um aber die Aufstellung eines neuen Namens zu vermeiden, ist in die Definition der var. syntrichostyla diese bestimmte Fruchtgestalt aufgenommen und so die var. syntrichostyla zugleich als f. typica erklärt.

1) Fr. Crépin: Tableau analytique des roses européennes, Sep. aus Bull. soc. roy. bot. Belg. tom. 31 (1892) p. 78 (13).

2) Siche die von J. B. v. Kíoller bearbeitete Beschreibung der Rosen in Nachträge zur Flora v. Niederỏsterreich" von E. Halícsy und H. Braun, Wien 188:.

3) Vgl. die Bearbeitung der Gattung Rosa in "Flora v. Niederösterreich von G. Beck v. Mannagetta" (Wien 1890-1893), welche von H. B1aun herrührt.

4) B. et Gr.: Les roses des alpes maritimes, Genève et Bâle 1879.

5) Vgl. \& $5 \mathrm{~g}) \mathrm{h}_{1}$ ) und i) in 0 . Kuntze: Nomenclaturae botanicae codex brevis maturus, Stuttgart 1903, und: Regel Nr. 7 der ${ }_{n}$ Nomenklaturegeln f. d. Beamten d. k. bot. Gartens zu Berlin". (Notizblatt d. k. bot. G., Leipzig 1897.) - Die „Internationale Regeln der botan. Nomenklatur, angenommen v. intern. bot. Kongress zu Wien $1905^{*}$ zitiere ich nach der Ausgabe von G. Fischer in Jena, 1906. 
wenn eine Rose ihre Stellung, ob Form oder Varielät, wechselt. ${ }^{1}$ ) - In sinngemässer Chereinstimmung mit dem letzten Alincia der "Emptehlung" XXY der internat. Regeln 1905 werten in 11180um systematischen Teil die Namen der

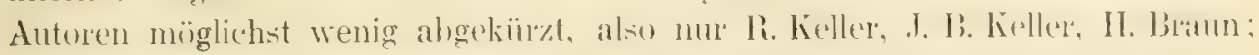
die äbliche volle Abkïpzung wenden wil bediglich an bes allgemein grelkamben

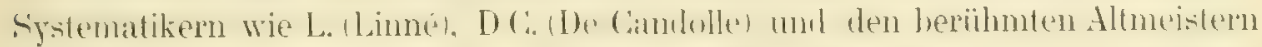

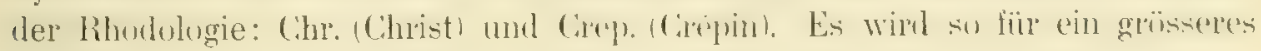
Publikum die wünschenswerte Deutlichkeit gewahrt.

Der Ausdruck Formenkreis", den ich oft anwenden werde, hat meist rein diagnostische, aber keine systematiseh wimligembe Bedtutumg. '/at einem

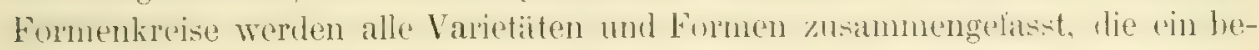
stimmtes, leicht fassliches äusseres lemmeichen an sich tragen, ïhre drisen morphologischen oder physiologischen Wert kein Lrteil gefiallt wirk. [hoch kium dieses hennzeichen auch systematisch wichtig soin mol es schlicsist dam die Glieder dieses Formenkreises zu einer Unterart oder ähnlichen Kategorie zusammen. Auch ermöglicht die Lnterseheidung von Formenkreisen oft imberhalb, einte Art eine morphologische Gliederung nach der auf- und absteigemlen Entwicklung des fraglichen Merkmals.

Ausserst hinderlich für das Studium der Rosen und für die Auffindung eines gestigen Fadens in der gewaltigen fluristischen Literatur ist die ibhiche Weitschwejigkeit in den Diagnosen neben der mangelulen Genangkeit in der Mahl der morphologischen Kunstausdrüicke. Tor allem nïisstes man streng unterscheiden zwischen der eigentlichen Diagnose, Definition drer Gattung, Art. Varielial usw.) und der Beschreibung. In der letztgenamnten mag man sich ergehen, individuelle Ziige in den Gontext verwehen mol durch Aufnahme von Merkmalen aus den ïhergerertneten Gruppen, die dort schon aufgeführt wurleu, verstïndich aber weitschweifig werden. Die Diagnuse dagegen muss möghichst kurz und möglichst präzis gefasst werden. Es darf nichts aus der Diagnose höherer Kategurien bereits Bekanntes in sio aufgenommen werlen, urch weniger vielleicht bloss am vorliegenden Strauch sich findende, als allgentein für clie beschriebene Gruppe geltend noch merwiesene Eigenschalten. Mit Recht fordern die .internat. Regeln" für neue Diagnusen exakte lateinische Wiedergabe. In̈ilt man sich nicht an die vorgetragene Distinktion von Diagnose und Beschreibung (letztere kamn ja der Diagnose nachfolgen) - und man hat sich meist nicht daran gehalten -, so weiss schliessilich der Leser nicht mehr, wis ein Antor

1) R. Keller führt in der "Synopsis ${ }^{*}$ Bd. VI den ersten Autor eines Namens in Klammer nicht an, wenn er, wie es oft geschieht, eine (kleine) Art des betr. Autors zur Varietät erniedrigt, sondern verweist ihn einfach unter die Synonymen. Das scheint mir in unserem Falle, wo die Ansichten über den Umfang der Art sich so entgegenstehen, und die kleine Art als elementare in der Gegenwart eher wieder grössere Bedeutung gewinnt, als unbillig. - Gegen die Nomenklaturregeln dürite es, wenigstens dem Sinne nach, verstossen, wenn bei Anderung eines Artnamens (z. B. R. alpina in pendulina) die Autoren der Varietäten ebenfalls durch den Autor verdringt werden, welcher den Artnamen verindert und nicht eimmal sachliche Veriulerungen vorgenommen hat. Im übrigen stellt die Synopsis dadurch, dass sie alle Synonymen und die wichtigsten Autoren in chronolorischer Reihenfolge antht, eine wahre Fundgrube dar fïr Erledigung von Prioritätsiragen. 


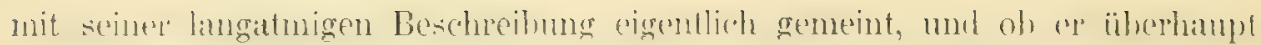

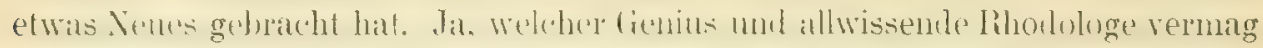
das riesige und jährlich noch zmehmende Lager von neuen Variethten und Formen zu überschauen, zu sichten und kritisch zu verarbeiten, wenn es sich um die Darstellung grösserer Gebiete handelt? Daran verzweilelte auch ein Crépin. ${ }^{1}$ ) Wir sahen uns, um zur Klarheit zu kommen, genötigt - zuweilen

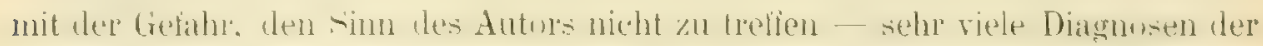

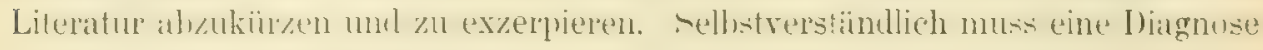
um so kürzer sein, je tiefer man im System herabsteigt, also am kürzesten bei „Formen" und „Unterformen“. - In del sehr lesenswerten Einleilung zur Beschreibung der Rubi in der "Synopsis" von Asch. u. Gr. Bd. VI warnt Focke anch mit liecht vor der benutzung allzu geringhïgiger Luterseheihngsmerkmale

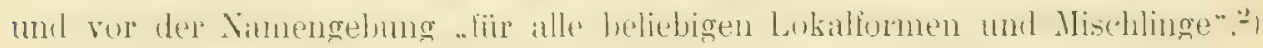

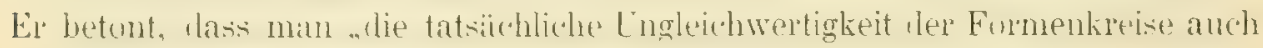
in der Systematik anerkennen und zum Ausdruck bringen" müsse. Ich habe mich bemüht, in meinem systematischen II. Teile diesen Grundsatz durchzu-

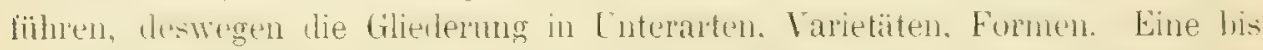
ins hlomste durchgefïnte dichotomischo Einteilung halte ich nicht bloss bei den Rubi, sondern auch schon bei den Rosen für unangebracht. Denn man muss sich in trster Linie Jemiihen, die Texwandtschalt der Formen andzulecken und anzuterement erst in zweiter linit ihre morphologische I)ifferenzienung, um den Ausdruck der phylogenetischen Entwicklung zu finden. Die Unterschiede müssen übrigens ebenso gut nach ihrem systematischen Werte abgestuft werden wie die Ähnlichkeiten und Gleichheiten.

Bei den Autoren existiert eine Kontroverse darüber, ob man zwischen den Arten Chergänge annehmen diurfe. Cirpin bestreitet das. $\left.{ }^{3}\right)$ mal anch die Vorrede zur Synopsis von Asch. u. Gr, scheint dieser Ansicht zu sein. R. Keller dagegren herut sich in seiner bearbeitung der Gattung hosa fïr die gleiche Symunsis and Namen wie Burnat, Christ. Gremli. Schulze. die wie er dureh das

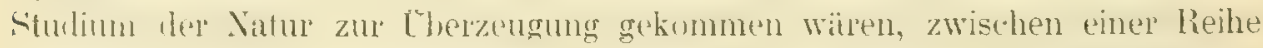

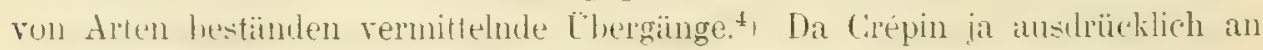
der zitierten fitelle und sonst iffer lïr die allgeneine Deszendenz eintritt und

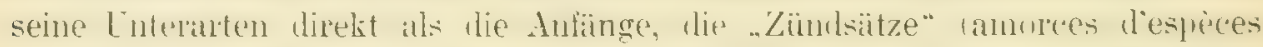

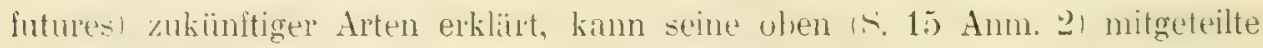
Definition von "Art" bloss formale Bedeutung haben. Real nimmt er selbst Übergänge an: „Die Charaktere der Art sind nur scheinbar für unsere Zeit fixiert": in Wirklichkeit anheitet die Evolution beständig aber mit grörster Lang-

1) Deshalb bin ich mit Focke, wenigstens für dic Rosen, nicht einverstanden, wenn er S. 418 Bd. VI der Syn. v. Asch. u. Gr. schreibt: ,Wegen der in Einzelnheiten vielfach schwankenden Merkmale sind zur Erkennung der Arten ausfïhrliche Beschreibungen unerlässlich. “ - Uber das "Schwanken" der Merkmale oder besser der Definitionen werde ich mich sofort im Texte verbreiten.

3) Syn. VI. S. 448

3) Les variat. parallèles p. 206. (Bull. soc. bot. Belg. tom. 36, Bruxell. 1897) u. sonst.

4) Les variat. parall. p. (6). 


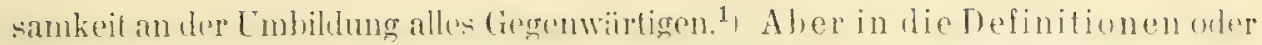
Diagnosen der Art, Varietät und Form dïrfen diese Ubergänge nicht aufgenommen werden. Man findet häufig in der naturwissenschaftlichen

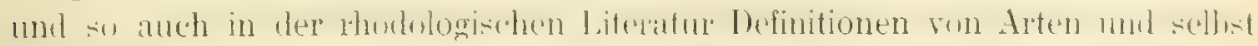

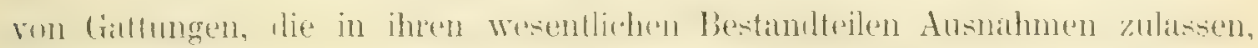

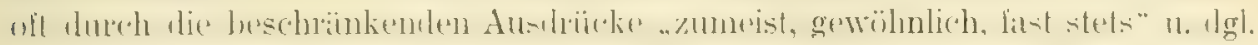
maskiert. Dieses Verfahren ist sicher logisch unzulïsig, da sämtliche in einer

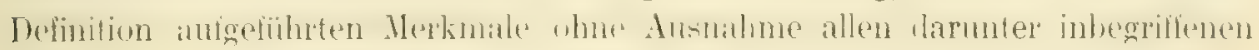
Individuen zugeschrieben werden müssen. Es lässt sich auch vermeiden. Ein-

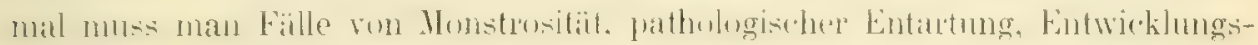
hemmung von der Diagnose ausschliessen und nur anmerkungsweise anfïgen.

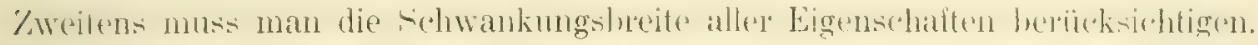

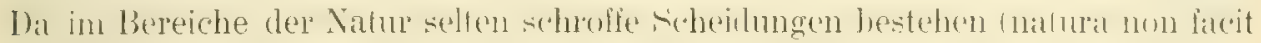

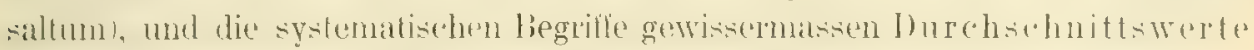

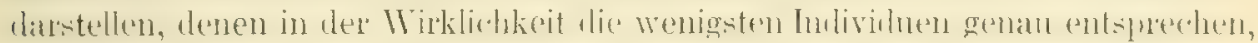
während die meisten ein wenig unter oder über den Durchschnitt fallen, so miissen die Termini tiner butinition entsprecheod weit gehalten und als Mittelwerte verstanden werden. Handelt es sich aber drittens wirklich um Zwischen-

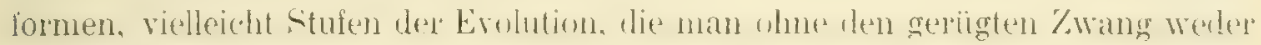

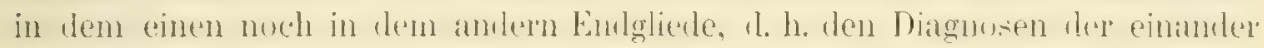

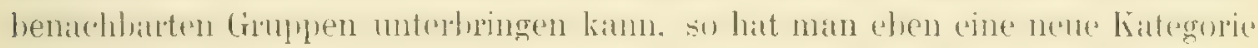
aufzustellen. Dazu eignet sich in den meisten Fällen der von uns oben nach

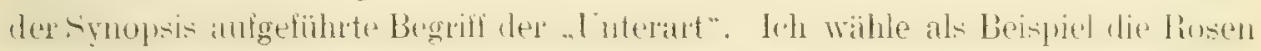
von der Formenreihe der var. subcnnina Chr. Es sind das Rosen, welche von den wichtigsten Merkmalen der R. glanca Vill. in dem einen oder andern Punkte (Kürze der Blïtenstiele, wolliges Griffelköpfchen, an der Frucht aufgerichtete Kelchblätter) abweichen und gegen die R. canina L. himneigen. Aus

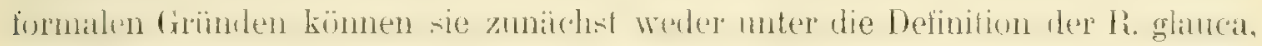

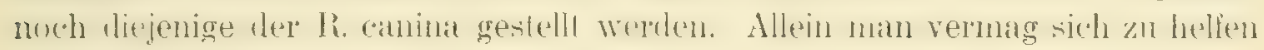

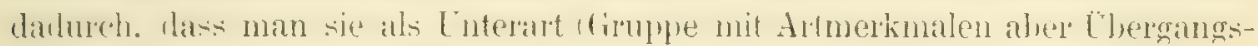
formen) der $R$. glauca, ev. der R. canina beigesellt. Sollte trotz allem in einer Diagnose ein Ausdruck wie "meist" u. dgl. vorkommen, so müsste er entweder

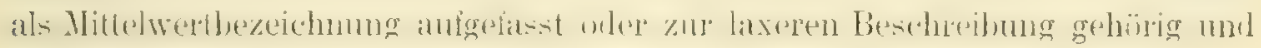
in die Diagnose eingeschmuggelt betrachtet werden.

1) Ebd. p. 206 (4) Anm. 2. - Klarer trilt das Verhältnis zwischen der relativen Fixation der Arten und der beständig umbildenden Einwirkung der Evolution in der Delinition hervor, welche G. Klebs von der Art gibt: ${ }_{7} Z u$ einer Spezies gehören alle Individuen, die, vegetativ oder durch Selbstbefruchtung vermehrt, unter gleichen äusseren Bedingungen viele Generationen hindurch übereinstimmende Merkmale zeigen." (G. Klebs: „Uber Variationen der Blüten $^{2}$, Rel. in Bot. Z. 1906 II. S. 50 ff.) Allerdings nimmt Klebs als Lamarckist eben nur die ausseren Bedingungen als bewirkenden Faktor der Deszendenz an. 


\section{Zweiter Abschnitt: Morphologisches.}

Wir besprechen zuerst die Organe der Rosen im einzelnen und erörtern sodann einge allgemeinere Fagen. Welche die Organe hetrefien und für die Beschreibung von Bedeutung sind.

\section{Der Stamm.}

Dieser Teil wird bei den Autoren am stiefmütterlichsten behandelt. Nach meinen Lntersuchungen gilt Folgendes. Alle Rosen hakm die Eigentümlichkeit,

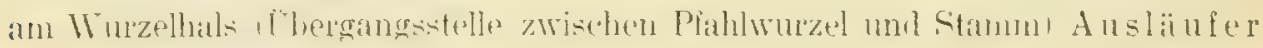
zul treiben: Ausläufer- und Rhizumbilılung kommt ührigens bei vielen hosaceen vor, z. 13. Fragaria, Potentilla. Rubus, Comarum, Filipenulula. ${ }^{1}$ ) Diese Auslüufer hleihen zuwrilen ganz oberirdisch. indem sie sich durch eine Krimmung solort in rinen orthotropen Siross remandeln. Meist aber dringen sie mehr oder minder tiel in den Boden ein, wo sie eine ver'schieden linge trecke annïhernul wagerecht zurücklegen. Jie plagiotrope Giplelknospe des Ausliufers stirht dann ab, und die ihr zunïchst befindlichen, also jüngsten Achselknospen entlalten sich gewöhnlich ebenfalls plagiotrop und bewirken dadurch eine oft schr ausgetehnte Verzweighung des Ansliulersystems. Altere Achselknospen und manche wait zuriek an den verholzten Rhizonen durehbrechende Adrentivkmospen theben sich damm als orthotrope Sprosse zum Licht und erzeugen cin neute Rosenstämmchen. Da. wo sie aus den Auslïufer - noch im Boden hervobrechen, bilden sig gewöhnlich einen Büschel Nebenwurzeln, ohne dass der Zusammenhang mit dem Ansliufer getrennt wird: ihre untersten Blättchen sind schuppentrtige Niederbliatter; erst an Licht entwickeln sich zuerst ganz cinfiche, nehenblattartige, spaiter typische Laubblitler. Lass es sich bei der unlerirdischen Verzweigung der Rosen nicht um Wrurzelbut handelt, ergibt sich ans der anatonischen vtruktur auch ler ätesten, am stamme entspringenten unterirdischen Achsen, sowie darans, lass sie mu ventral inserierte wenig verïslelte Nehenwurzeln zeigen: jüngere im Boden befindliche Achien tragen stets dentliche Ninlenblätter. - Auch hei der R. gallica dürte kein eigentlicher unter-

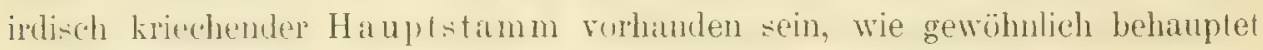
wirl. Bei ihı laufen nur die plagiotrupen Achsen am weitesten und rerzweigen

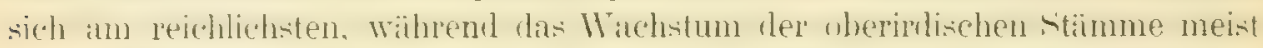
ein beschränktes hleibt. Chrigens wind die enorne unterindische Verdoreitung

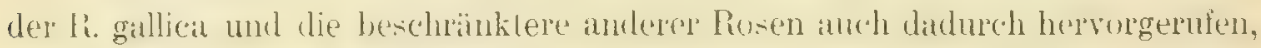
dass sie an ihren eigentlichen standoten. an Graspanen, in lileceickern und Wiesen. sehr regehnäsigg ahgemäht wird. Wo das nicht geschieht, ïberdeckt sie ähnlich der h. arvensis beschäinkte oherirdische Butenstrecken mit einem dichten Gewirr zienlich langer Stianme und Aste. I) Intensität der Ausläufer-

1) Einige entwickeln auch Wurzelbrut, z. B. Spiraea, Prunus domestica. 
bildung richtet sich also nicht bloss nach der Natur der Art, sundern ist auch äkolugisch berlingt. Sie ist stirlier in loxkerem Buden; wird reichlicher, wenn die orthotropen stämmchen ahsterben oder gewaltson zersört werlen. Bei besonder's ïppigen Wachstum der oberirdischen Achsen, z. B. bei schünen limsenbïmmchen, entstehen un so weniger unterirdische Sprossen. Es verhält sich dant geradero wie mit dem Ausherhen von Wassershossen (Adventivknuspen) bei Laubbåumen. Die Heckensysteme der Rosen werden um so dichter, je

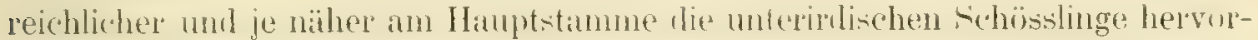
brechen. Bekanntlich treiben die liosen dimoben in ersten Jahre sterile lang-

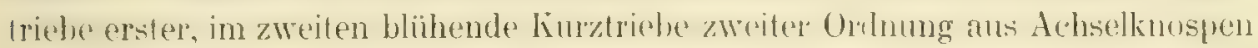
des Hauptsiammes. Wollten wir die widhtigsten einheinischen Arlen und Gruplen der Rusen nach dem Grade ihrer unterirdichen Verzweigung ordnen, so wiurde die absteigende Reihe etwa so aussehen: R. gallica L., R. pimpinellifolia L., R. cimnamomea L., R. pendulina I., R. Jundzillii Bess., Sektion Rubiginosae Crepp. (Leitart IR. rubiginosa L.), Sektion Veslitae Chr. (Leitart R. Lomentosa Sim.), Sektion Caninae D C. (Leitart R. canina L.), R. arvensis Huds. ${ }^{1}$ )

Ein anderes wichtiges Lnterscheidmugsmerkmal hetrifft die oberirlische Achse. Die Aste und Zweige smwie deren Internodien sind bei verschiedenen Arten verschieden lang und infolge dessen verschieden start bez. schlaff. Dits lïngsten und schlalfsten Zweige besitzt die R. arvensis; nuch ein wenig in dieser Pichtung weiler, und es entstehen liletterusen wio die auslindischen R. multiflura Thunb., seligera Rich., Bankside Ri. Br. Aber anch die R. arvensis und die nahe verwandte sempervirens L. vermögen schon elwas zu klettern. Oit unterscheiden sich systemalisch sehr nahe verwamlte Arten, ja Glieder einer Gesamtart wie R. rubiginosa L. und micrantha Sun, oder R. elliptica Tutuch und agrestis savi, durch die Furn des Wuchses: die "rsten Glinder dieser Gegensïze hahen einen komuakten Wuchs bei kurzen und kriitigen Zweigen, die zweiten einen flattrigen. Der untersetzte Wuchs wird hier nicht bloss von der Kürze und Startheit der Aste, sondern anch vom Reichtum der Verzweigung bedingt, der damn bis auf den Blütenstand übergreift.

\section{Die Trichome.}

Alle Trichome, d. h. Slieldrïsen, Hatre, stachehn, sind Gebilde der Epidermis; bloss bei den stacheln wirkt Grundgewehe (Rindeuparenchym) mit. Stacheln stehen nur an oberirdischen Achsenorganen: stïmmen, Zweigen, Blibten- und Blattstielen, Blittmitteherv, hier C̈hergang zu Drüsen. Stieldrïsen unt Haare kommen an allen Organen des Rousenspurses vor. Die Blälter tragen Drüsen

1) Der R. arvensis kommt eine besondere Eigentümlichkeit zu. Sie bildet zwar ebenfalls, wie ich oft konstatieren konnte, kurze unterirdische Ausläufer, besonders gerne im Mulm des Buchenwaldes. Diese verwandeln sich jedoch bald in mehr oder minder oberirdische, lang über den Boden hinkriechende Ranken, die sogar zuweilen gleich den Ausläufern einer Potentilla durch Nebenwurzeln sich auf dem Boden fixieren. Darnach ist die Angabe bei H. Dingler

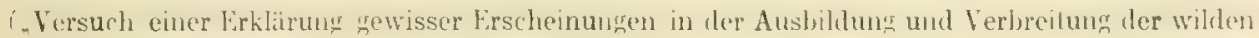
Rosen", Aschafienburg 1907, S. 18) zu ergänzen und zu berichtigen. Zur dort entwickelten Theorie stimmt m. E. nicht, dass die R. gallica, welche abfällige Kelchzipfel besitzt, die meisten und längsten Auslïufer bildet. 


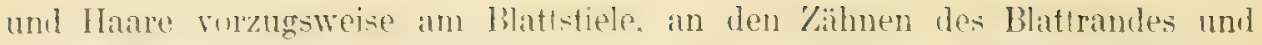

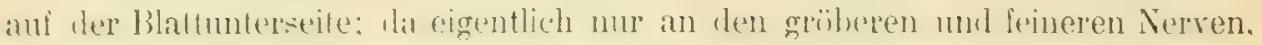

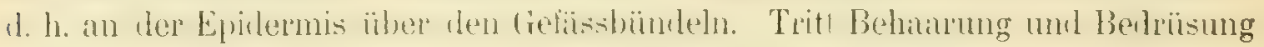
zurück, so sieht man bloss noch die gröberen Blattnerven und zuletat den Mitleherv der Unterseite mit diesen Trichomen versehen. Die Behaarung ist

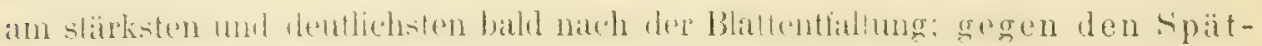
sommer und Herbst verkahlen alle Blättchen mehr oder minder, was man bei der Aufstellung von Formen wohl berïcksichtigen muss. Die Drüsen

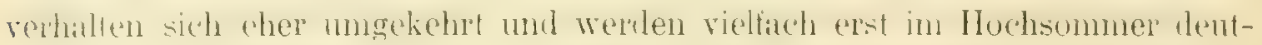
licher. Stacheln gibt es dünne und derbe; der Gestalt nach gekrümmte, oft hakenfömige, und gerade. Die letzlern tragen zuweilen Dribenköplehen und

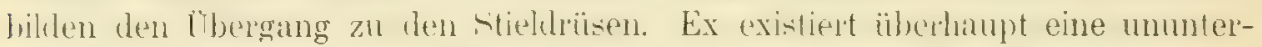

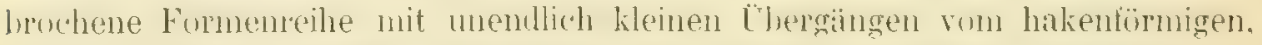
meist grosigen und derben Siachel bis zum keineren, geraldn, schliesslich zur gestielten Drüse. Für die Systematik empliehlt as sich jedoch, mit Gremli ${ }^{1}$ ? die Rosen nach ihrer bestahelung in homöakanthe wie shacheln am gleichen

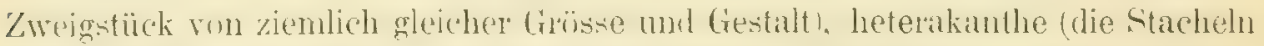
teils grosis und gektimmt, teils klein mol gerate) und subheterakanthe zu unter-

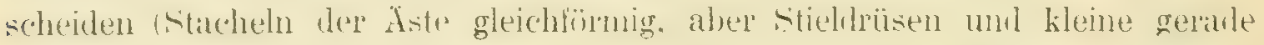

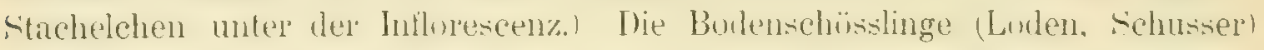
neigen zur Bildung gerader uml burstlicher Stacheh. anch wenn die erwachsenen Aste und Zweige andere besitzen. Das betont auch J. B. v. Keller: „Die Loden fïhren häulig lladeltörnige und burstliche stachehn." $\left.{ }^{2}\right)$ Diese geraden Stacheln

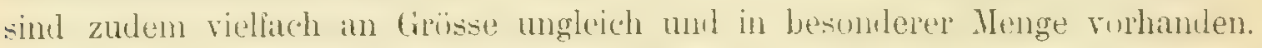
$\mathbb{M}^{\top}$ enn sie an Ilu alten Stïmmen persistieren, tritt win aulallenler Gegensatz gegen die Bestachelung dex Aste mul Zweige ein. Man darl auf diesen Punkt beim Bestinmen nicht allzuriel Gewicht legen und nicht gloch zur Aubtellung neuer Funnen schreiten. Besumlers wit sah ich die geschihlerte Erscheinung an Rosen der Gruppen Caninae und Rubiginosae.

\section{Die Blätter.}

An den Blïttern kommen, ahgesehen ron der schon erwihnten Bekleidung nit Trichomen in Butrach: Zahl der Fiederblittehen, Grïsse, Form, Zahnung de's Blattrander, Dicke und sonstige Beschaffenheit der Blattlïiche, Farbe der () )er- und Lnterseite, spaltioffnungen. ${ }^{3}$ ) Alle eurnpäischen Rosen tragen FiederJlittchen, eine einzige Exute hat ungetierlerte Blitter: die Zahl der Fielerpare bez. der Fiederchen, da stets ein unpaares an der Spitze steht, ist für die

1) Exkursionsflora für die Schweiz, Aarau. 8. Aufl. 1896. S. 155.

2) Nachtr. z. Flora v. N.-Österreich. 1882. S. 180.

3) Fiir die Bestimmung der meisten Blatteigenschaften leisten die Abbildungen der Fiederblättchen recht gute Dienste, welche E. Sagorski seiner Ablandlung „Die Rosen der Flora von Naumburg" (Naumburg 1885) beigegeben hat. Auch die Abbildungen - Photogramme im Anhang von II. Waldner: Uber europäische Rosentypen, Zahern 185ว̆, bieten Manches.

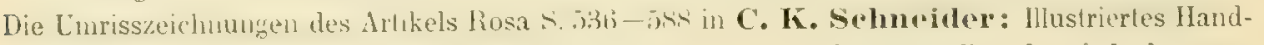
buch der Laubholzkunde, Jena, Bd. I, 1906, sind im ganzen sehr wertvoll, geben jedoch wegen des kleinen Massstabes die Zahnung des Blattrandes ungenügend wieder. 
gräseren Abteilungen ron diagnustischer Bedentung, duch muss die Region am Stamme unterschieden und bei den vielen zufalligen Abweichungen ein Durchschnitt berechnet werden. Ihre Grösse hält meist die von der R. canina bekannte

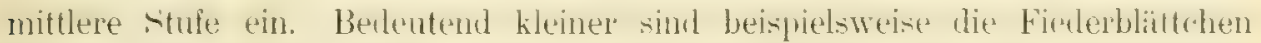
der R. pimpinellifolia. Man muss aher wohl beuchten, diss die unfrurhtbaren Langtriche des oberirdischen Sumsies stets weit grössere Blattchen entwickeln, wie die fertilen Kurztriebe. Die Blättchen der aus dem Boden kommenden

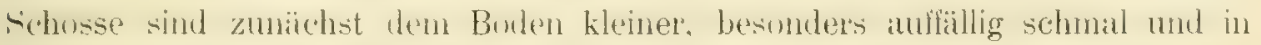
anderen Beziehungen reduziert, gimz unten nur schuppenlömig: ${ }^{1}$ ) bei der weiteren

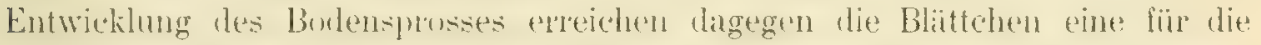
betreffende Form geraltezu maximale Grössts. Sehr vernathlissigh bei den meisten

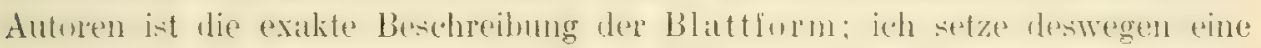

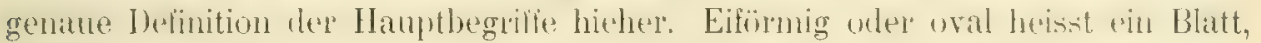
welches im Umriss die Gestalt eines Eies hat mit dem breiteren Teil am Blatt-

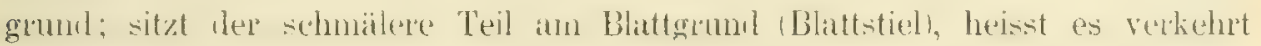
eiförmig. Elliptisch odel länglich muss sin Blatt genamut werlen, welches die

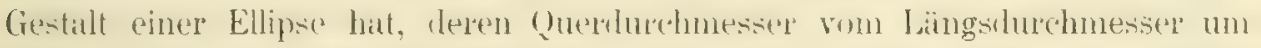
das Doppelte bis Vierlache ïbertroflen wird. Das lanzellömige Blatt hat die gleiche Lïnge und Breite (oder ist noch linger), ist aber an beiden Enden nicht abgerundel, smolem schart zugespitzt. - Ein ansgezedohnetes Mtrkmal ist die Zahnung des Blittchenrandes bei Rusen. Es gilut Bliittchen mit eintacher, mit zusammengestater mul mit mregelmitsiger bald einfacher, bald duppelter

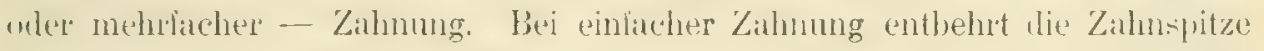
häulig der Drïse; lie sekmnlären und tertiären Einschattungen der primären

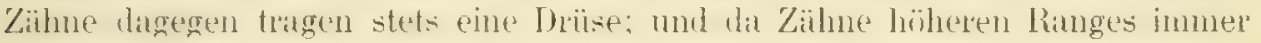
kleinere Ënschatungen des Blattander verurachen, gewaht nan schliesslich

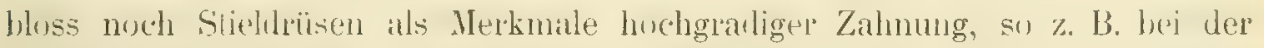
Gruppe der Rubiginnate. Stiaker gezahnle Blittchen zeigen nicht nar an liaude, sundern auch an den blattstielen usw. redohliche Drïsenbekleidung. - Meist mubleutende Differenzen, Welche die Blattspreite betreffen, sind: verschiedene Dicke, Runzehng der Obedläche (R. rugusa), stakes Ifervortreten der Nerven der Luterwite (R. Jundzillii, tomentella). Fultumg nuch (lem Mitteluerv. Die Farbe weicht ab: Blitter von schattenpilanzen (Mangel an Wachsausscheidungen!),

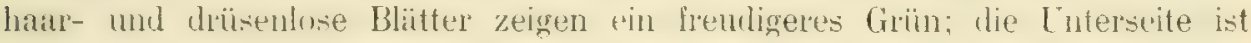
wegen des chlorophỵlarmen Schwamngewehes stets matter gefärbt, bei manchen

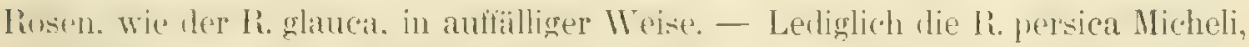

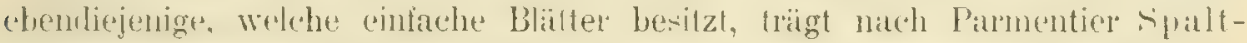
äfnungen anch aul der blattuberseile; alle ïbrigen mo and der Unterseite in den Winkeln del Nerven und lïngs derselben. ${ }^{2}$ )

Die Nebenblattehen (stipulae) sind meist flach, an den Blütenzweigen etwas breiter. and gewöhnlich fast ihner ganzen Lïnge nach an Hamptstiel

1) Es handelt sich in diesem Falle um eine Art zweckmässiger Etiolierung; eine entwickelte Spreite wäre zweckloser Materialverbrauch.

2) P. Pamentier: Recherches anatom. et taxinomiques sur le genre rosier (Annal. sc. nat. Bruxelles 1898), p. 6. 
rechts und links angewachsen. Das feine Spitzchen, Öhrchen, zeigt gewisse

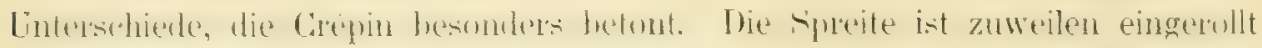

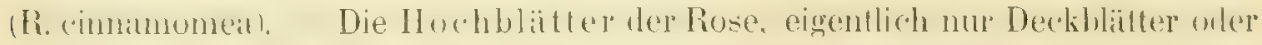

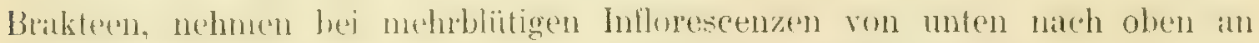
Grösse und Anshildung bestindig ab, gohen also vollkommen analog den mon-

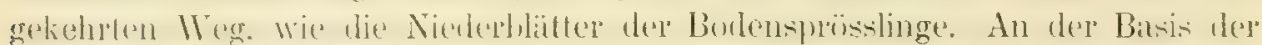

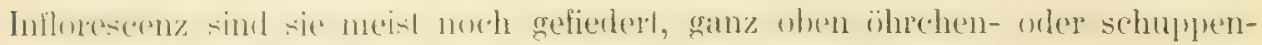
förmig. Näheres über sie im folgenden.

\section{Die Blüten und Früchte.}

Wir beginnen mit der Besprechung des Blütenstandes. Bei den mehrbliitigen Rosen stellt er eine cymöse Doldenrispe dar von wechselnd starker

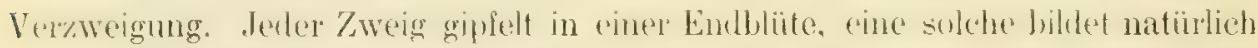

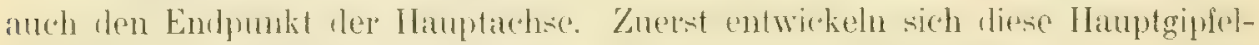

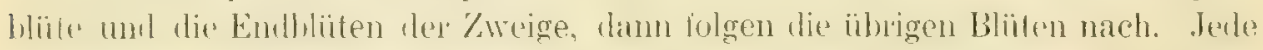

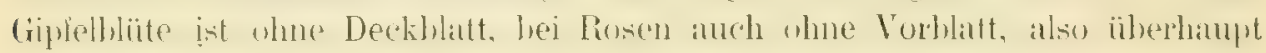

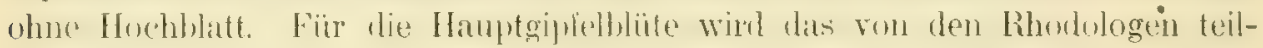
weise schon zugestanden durch den Satz: streng einblütige Rosen, wie R. pimpinellifolia, haben keine Hochblätter. Doch werden von den Autoren einige Ausmahmen zugedatsen und im übrigen nur zerstrate, mzusammenhängende

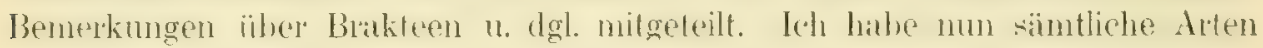
und die wichtigsten Vartibilon des Gebiefes, dazu verschiedene Gartenformen, in frischem Zustand - meist an der Hecke - studiert und analysicrt und bin zu folgemblen liesultat gekonmen. Die Roseninflorescenz zeigt lusser wie die irgend einer anderen P'llume, dass sie nur ein zusammengedräingtes Stäck des Sprosses mit nexamorphoserten Teihn darstellt. Jeder dst bei tiner stark entwickelten Inllurescenz, z. B. derjenigen der R. elliptica Tauseh var. typucia Cihr., und jeder

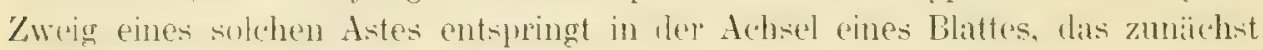
noch durchaus den Chasater cines typhishen Laublattes hat, also etwa noch 5 oder 7 Fiederblättchen mit Nebenblättchen besizt. Nit dem Fortschreiten nar.lr oben (imnen) werden dep Fierlerden wenger, und schlissich kann der letzte Zweig dep Inflorescenz bloss noch ron einem einfachen, zungenförmigen, doch grösseren Traghlatt (Deckblatt) gestïtzt sein, das den blaltitiele des urspringlichen kidederblattes entspricht; dem die Reduktion heginnt bei den Fiendern bez. don Blatspreiten. Thrigens ist gar nicht solten besonlers bei der hubiginusit-Gruppe anch moch das letzte Deckblatt eines Zweiges zwar klein aber gelieflert und somst typisch. Sogenamnte Vorblätter von zungen- oder schuppen-

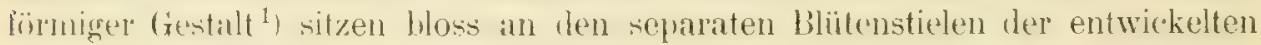

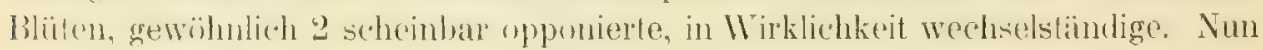
stelle ich die Thesis auf: keine einzige entwickelte Blüte trägt ein Vor-

1) Aber selbst diese tragen zuweilen leichte Fiederung, wie ich an einzelnen Exemplaren von R. glauca, rubiginosa, agrestis und besonders elliptica beobachtet habe. - Vgl. hiezu die allgeneinen Erörterunen über Horhblitter hei K. Gbbel: Organosraphic der P'flanzen, Jena 1901, S. 578 ff. Hier werden die allmähligen Abstufungen zwischen Laubblättern und Hoch-

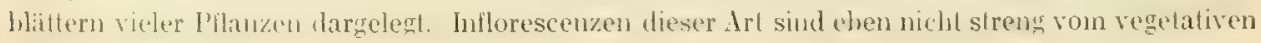
Spross geschieden. 


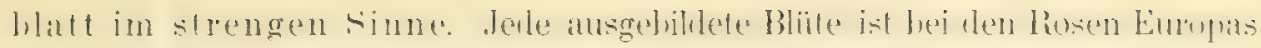

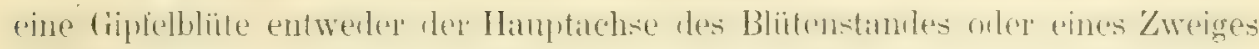
derselben und entbehrt der Braktee. Die scheinbar zu ihr gehörigen und an

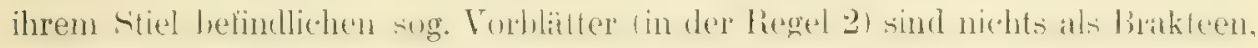
in deren Achseln rudimentäre unter sich und mit der Gipfelblüte spiralig wechselständige Blütenknospen sitzen. Mit dem blossen Auge, besser mit der Lupe, kann man diese bis zu versehiedenen Stadien der Ent-

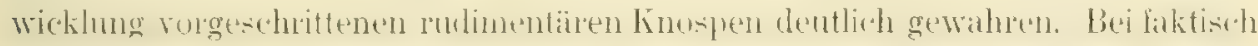

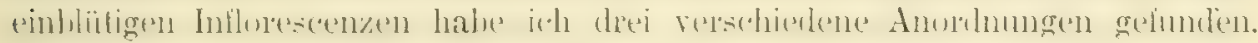
Prinzip ist die Einblütigkeit bei der R. pimpinellifolia; hier trägt die Blüte an

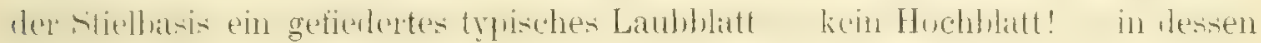
Achsel man eine zwar auch rudimentäre, aber grössere Knospe erblickt: das

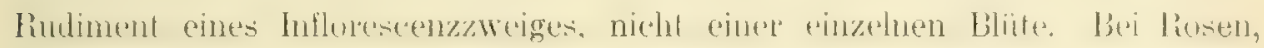

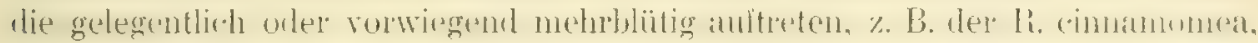

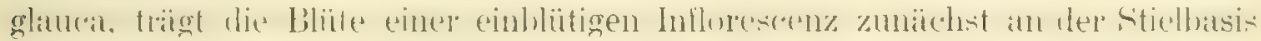

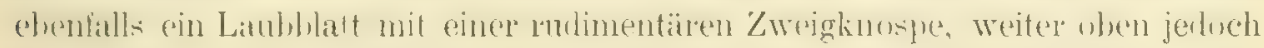

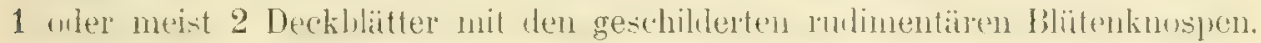
Am besten lassen sich diese verwickelten Verhältnisse aus den Zeichnungen ersehen, die sich auf Taf. I des Anhanges befinden. Sie stellen die wichtigsten Typen aler Infloresenz diat. Die Glieder dex rerschiedrnen Blïtenstïnle sind nach lestimnten in der Nitur nir vorgelegenen lowenindividuen in wesentlichen

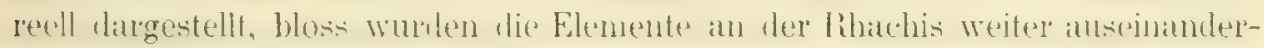
gerückt und in ihren Umrissen schematisch gehalten.

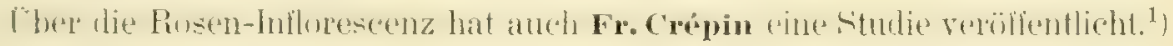
Er konstatiert zunächst, dass die Autoren Form und Zusammensetzung der

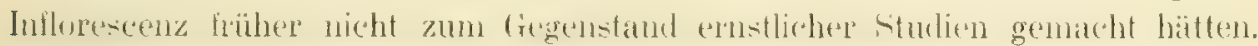
Aber auch er selbst geht nicht auf eine genaue Analyse der Inflorescenz ein, sondern macht nur einige allgenteine Benetkungen übro das Fehlen von Braktexn

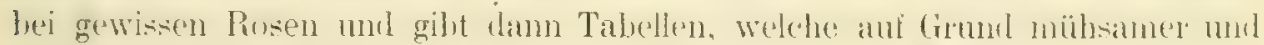
sehr ansoglehnter Zählungen, also nach der statistischen Methule, im einzelnen und im Durch-chnitt die Zahl der Bläten bestimmen, welche den Intenescenzen der verschiedensten Arten und Vinrietiaten von Rosal zukumnt. Diese Zïhlungen, welche auch R. Keller in der sympois gelegentlich vermerkt, simel mun. wie sich Cirepin trilweise selbst cingesteht, mit solchen fehlerguellen behafted, dass sie

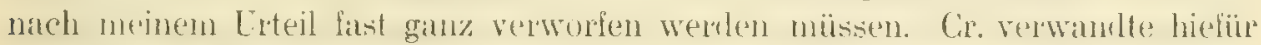

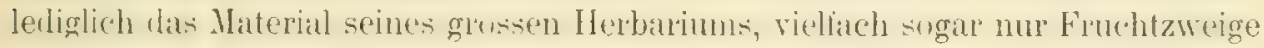

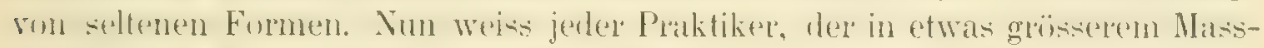

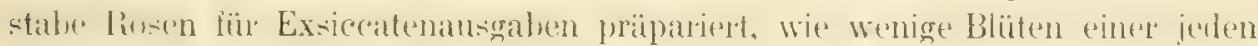

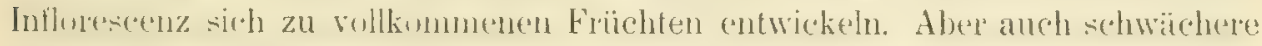

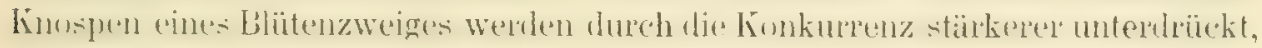
uml weitere fallen ab, woil sio durch die Angriffer von Insekten verletzt wumdent. Man kann also die Individuenzahl eines Blätenstandes absolut nicht an Ilorbanexemplaren erkennen, die bei dex nachträgliche'n Entwicklong viel zu siche zu

1) Remarques sur l'inflorescence des Rosa, Brüssel 1895 (Bull, soc. bot. Belg. t. 3!. 2. prt. pp. $32-53)$. 
gunsten einer scheinbaren Einblïtigkeit und Schwachblütigkeit verïmlert wurden. Lediglich Studien an lehembun Materdial führen zu richtigen Schlüssen. Dazu kommt entsprechend den rorhergehenden Erörterungen, dass Cir, offenbar den

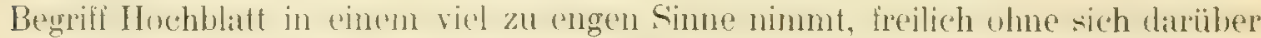
deullich anszusprechen. Wie es scheint, hält er fïr Hochblitter bhss die spreitelusen Blaltschupren, dit sich bei verschedenen Rosen in verschiedenter Zahl und Stellung am Blïtenstand befinden, und nur jene Blüten als zu einer Inflorescenz gehörig, die sulche tragen. Diesen Standpunkt dart man aber bei Rosen su wenig einnchmen, wie bei so vielen anderen Pflanzen, bei denen eben auch die typischen Laubhläter von der stelle an, wo die Blïten beginnen, ganz allmählich kleiner und einfacher werken, bis sie an der Spitze des Blütenstandes die einfachste Form erreicht haben. Ich erinnere an die Blütenstände verschiedener Arten der Gattungen Galium, Asperula, Aptemisia, Chrysuthemum, Hypericum, Campanula, Polygomm, Orchis latifolia!), Saxifraga (Aizon, Cotyledon), Sedum, Nonnea usw. Jeder Morphologe spricht hier von Cymen und Rispen, whwhl sich an den betr. Blïtenstimden Hochblitter befinden, die nur kleinere Laubhläter darstellen und ron unten nach oben eine lückenlose Reihe vom typischen Laubblatt zum ausgepräigten Hochblatt bihlen. Schliesslich geht ja die Metamorphose nuch weiter bis zum Kelch- und Kronblatt, Staubblatl, Fruchtblatt. Man muss hier einfich das blïtentragende Ende einer Achse als Influrescenz bezeichnen, wïhrend man den Begrilf Hochblatt in weiterem sinne interpretiert - oder man sieht sich genötigt, allen diesen Ptlanzen Einzelnblïten zuzuschreiben und ron jeder Gliederung und Würligung der Blütenverteilung Abstand zu nehmen. Der ITnterschied zwischen Lauh- und Huchblint ist eben in der Natur nicht so scharf, wie in mánchem Lehrbuch.

Plichtet man der von uns entwickelten Anschauung bei, so ist evident, dass es mit Ansnahme der prinzipiell einblütigen Rusen (R. pinpinellifolia) bei den übrigen Arten nur sehr wenige rimblïtige Inflorescenzen gibt, und, zieht man auch die pudimentiren Blïtenknuspen in Betracht, gar nicht geben kann. Aber selhst in dem Falle, dass man die Inchblïtter enger deliniere, erweisen sich wegen der wben arörterten Fehlerquellen die Zühlungen Crépins als irrig. Ich habe sehr viele, wenn auch nicht so systematische, Zïhlungen am lebemlen Strauche rorgenommen und gefumlen, enge Definition vom Ituchblatt im Simne Cirepins vorausgesetzt, wie schon bei der R. gallica an günstigem tiandorte die Zahl der ein- und mehrhlütigen Inflorescenzen sich die Wage hält, während bei allen einheinischen Arten der Soktionen Vestitar, Rubiginosae und Ganinae die mehrblütigen Inflorescenzen ïberwegen, sehr erheblich sugar bei R. glauca, rubrifulia, rubiginosi, elliptiea, agrestis. Nu das kimn man der Crépinschen Zählung zugestehen, dass sie, aber nicht in absuluten Zahlen, ein gewisses Stulenverhïlnis im Blïtencehtum der verschiedenen losen andeutet. W'vitere exakte Berechnungen wïren hier erwänscht, setzen aber die Arbeit an lebendem Material und die Einigung ïlex den Begriff des Hochblattes bei den Rosen vorans.

Die Blütenstiele mủssen bei den Rosen gewürdigt werden nach ihrer absoluton und relativen (zu den Brakteen, dem lielchberher, der Frncht) Länge und nach ihrer Bekleidung mit 'Trichomen. 
Der Blütenboden, das Receptaculum, ist bei den Rosen bekannter-

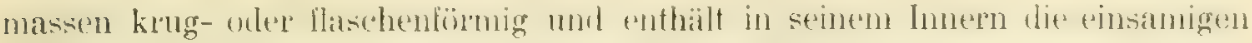

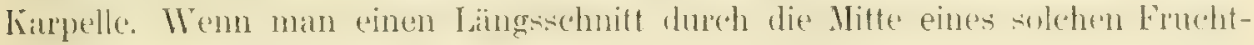
bechers, etwa der R. canina, macht, deren Kronblitter vor kurzem abgefallen

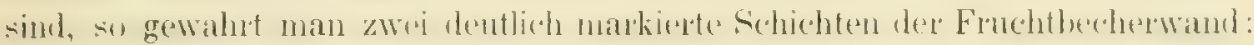
die eine äussere grüne, die Rindenschicht, zieht vom Stiel gegen den Hals

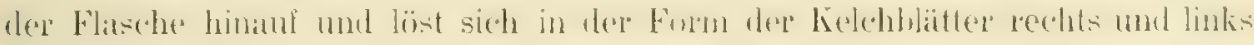
von der Markschicht ab, die später zum eigentlichen Fruchtfleisch sich ent-

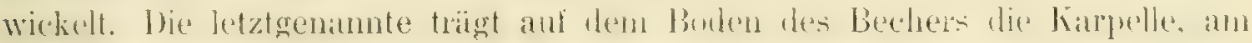

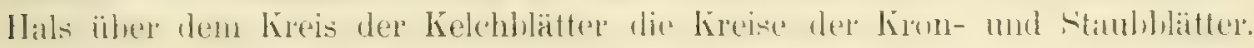
Nach oben schliesst sie - in der Totalansicht betrachtet - ab mit einem rrhöhten Wulst, dem Diskus, der alle morphuhgrischen Eigunichaften eines Nektargewebes besitzt, aher bei den allermeisten Rosen keinen solchon absundert. Dieser Wulst, der Diskus, ist bei der $R$. canina breit und ziemlich stark über die Insertion der lielchbläter erhöht, lïst aber in seiner Mitte bloss eines sthnales

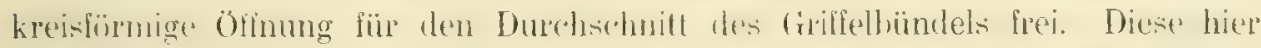

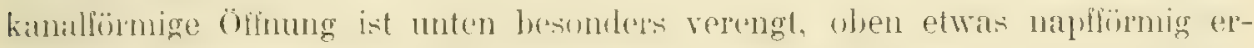
Weitert. Ein ganz anderes Bild bietet uns die R. pomilera oder pimpinellifulia. Die zwei Fruchthecherschichten sind vorhamben, die Markschicht zeight sich aher bedentend schwitcher, und insbesondere der Diskus ist ganz schmal und kium ïber die Insertion der Kelchblätter chöht: dagegen die zentrale öffunng sehr weit, seicht und nicht kanalfömnig. Sïntliche lassen verhalten sich num in bezng

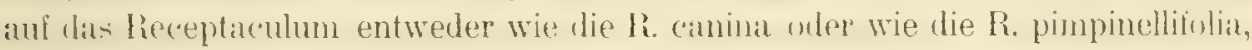
oder sie stehen zwischen beiden in der Mitte, wobei sie sich dem einen oder andern Typus anähern können. Von welcher Wichtigkeit dieser L'ntershied sei, werden wir im III. Teile sehen, wo noch weiteres ïber die Fruchthecher folgen wirt.

Von den fünf Blättern des Kelches sind bei den Rosen der Verwandtschaft von R. canina zwei ungefiedert, zwei getientert, eins halbgetiedert. Der Lntersehied rührt ron der teilweisen gegenseitigen tberlurkung in der hinospenlage her. Mehrere Arten: pimpinellifulia, arvensis, cinnanumea, haben einfuche lielchzipfel. Weitere Linterschiede ergeben sich alls dem Cilade der Fiederung, aus dem Crade und der Art der Bedrüsung der Kélchblitter aud dem Rïcken und an den Seiten, hez. Fistern. Besondere Wichtigkeit kmmmt der Lehenstlauer der Kelchblitter zu:

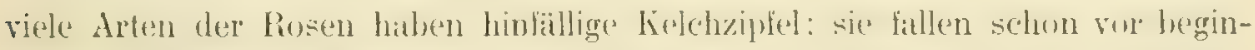
nender Rötung der Frucht al, nathem sie sich vorher gegen den Fruchtstiel zurürokgeschlagen haben. Anclere Kelohblïtler hoissen persistent: site lichlen sirch ïber den Einging des Fruchthechers anf und bleiben an der Frucht bis zum Sohlusie ihrer Existenz. Dazwischen stehen die Rusen mit subperistenten helehbläter'n: diese richten sich zwal aul und hleiben ziemlich lange an der Foucht,

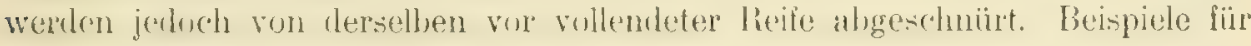
die drei Fälle sind: R. canina, pomifera, glauca.

Bei der Krone kommt vorzüglich die Farbe in Betracht. Zu bemerken ist,

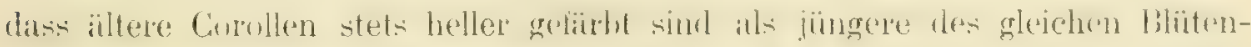

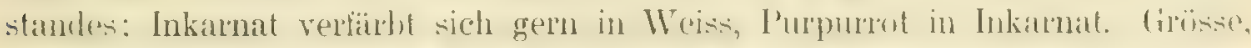

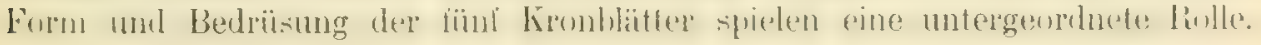


Vielleicht ist die Bemerkung nicht unerwinscht, dass die homblitter sehr leicht alfallen, wenn dire Bestäuhmug vollzugen worlen ist. Bei Sommensehein wird dies

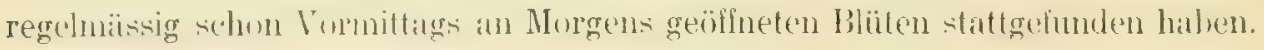
Wé also Rusen an Vachmiltag sammelt, muss nit dieser Eventualität rechnen.

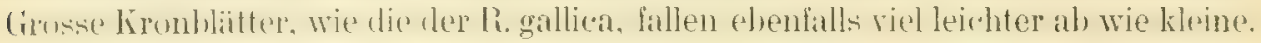

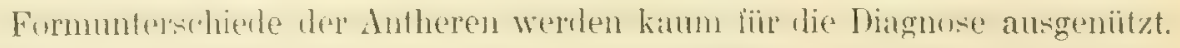
Ditgegen wind grossts frewicht atul dic beschaffenheit der stets zahlreichen Griffel der Rosenblïte gelegt. Ihre Lïnge wechselt in hohem Grade: die im Verhibluis zu den Antheren längsten Griffel besitzt die R. arvensis: die kürzesten

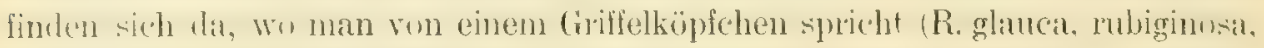

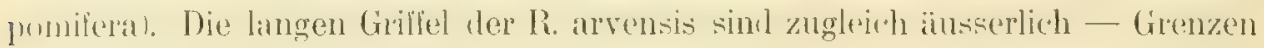
der einzelnen Griffel noch erkenntlich — zu einer Säule verwachsen, die an der Spitze die Narben vorstreckt; bei der $R$. stylosa ist die Griffelsäule von mehr lockerer Bindung. Ahnlich wie hier ragen die Ciriffel bei vielen Cinninem mehr durch Zufall hervor, hesunders wenn die Stauhgelïse schom früher ron Insekten abgefressen woplen waren. Die Beharang der Giffel geht durch alle Grade hindurds: die? Wulligste Behnarung zeigh sich an gewissen Griffelköptehen (R. glanca, corififulia, punilera). Aurh variert dir behatrung an den verschiedenen Teilen der Griffel.

Die Rosenf li roh te (Ilagebutten) gehören zur Abteilung ler Scheinfrüchte: es sind Sammelinichte, deren Einzelnfrüchtchen durch den kinglörmigen und fleischig sich mblildenden blïlenbulen zosammengehalten werlen. Die nuss-

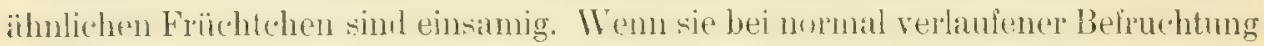
in grösterer Zahl sich ausbiliten mul dis Höhlung der Hagebute dichtgedräingt

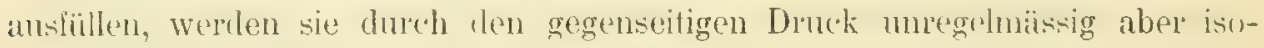
dianetrisch pulygumal. Entwickeh sie sich hloss in der Einzahl wer in geringer Zahl, wie bei Bastarden, so werden sie grösser und bleiben kugelig bis ellipsuidisch. Die scheinfüchte der Rosen zeigen Verschiedenheiten nach Grisse. Gestalt, Bedrïsung, Farde und Geschmack des reifen Fruchltleisches. Die Gristalt ansgewichsener Frïhte schwankt zwischen der reinen hugelgestalt (R. pimpinellifolia) und der einer langgestreckten Flasche (H. pendulina). Stehen mehrere Scheinfrüchte ron eikugeliger Gestalt in einer eng(n) Trugdolde zusanmen, so) wid die miltlere aus mechanischen Grïnden meist birnfömig. Diese Eigrntïmlichkeit lïsst sich sellstverstiumllich nicht zur Diagnose der Virintiat verwenden, wie s's gest geschieht. Alle Scheinfrüchte verändern sich bei allmählicher Revile wegen des Anschwellens der Nüsschen von der eï̈rmigen gegen die kugelige Gestalt hin uder von der flaschenfömigen gegen die wrale. Nur in wenigen Fïllen ermöglicht die Farbe der reilen Scheinlrüchte eine scharfe Unterscheidung gegenüber anderen Arten oder gar Varietäten.

Wie wirhtig liir die Enterscheidung der Arten und Sippen bei den Rosen es sei, die Zeit ihres Aulblühens und überhaupt der Entwicklung ihrer Infloreszenz zu bestimmen, davon werden wir uns in Teil III dieses Werkes überzeugen.

\section{Die Korrelation der Eigenschaften.}

Von den in den vorhergehenten Absitzen besprochenen Organeigenschaften der Rosen stehen manche in merkwïrdiger horrelition mit einander: "Es findet 
eine Werhelwirkung zwischen Teilen des Planzenkërpers staft; drinse mul Aus-

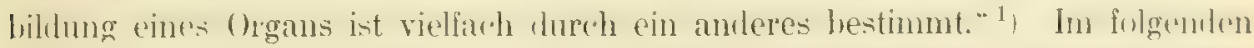
notiene ieh kurz die whohtigsten hier einschligigen Tatsachen. 11 Jente liosen,

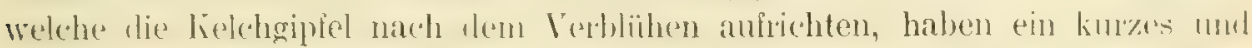

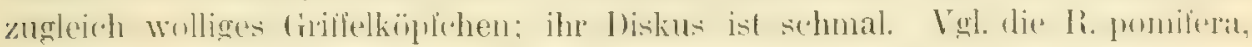

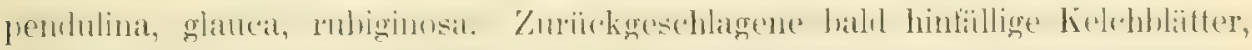
laingere meist nut harige Gilfel und cin hreiter Diskus charakterisiteren atudere

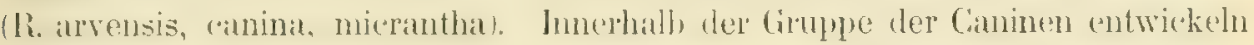

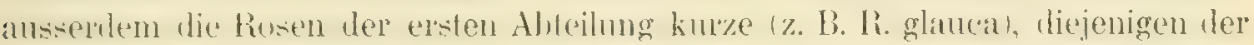

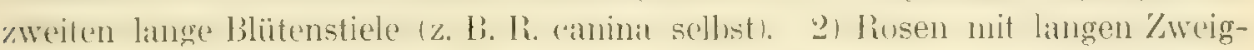
intemolien und infolge dessen flattrigem Wuchs zeigen germe lange bliitenstiele

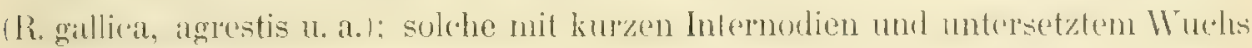
kurze (R. glauca, elliptica u. a.). 3) Je reicher die Zahnung des Blattrandes

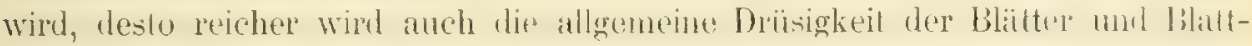
stiele. Dieses Gesetz gilt sowohl für den Unterschied der Arten als der Varietäten innerhalb einer Art. 4) Die Unterseite der Blätter trägt stets sowohl mehr Hare als mehr Drüsen wie die Oberseite.

Von der im Vorstehenden erwähnten Korrelation als einer "positiven",

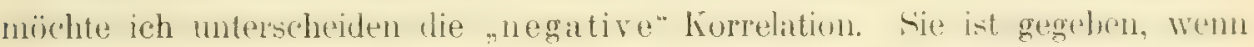
bein Auftreten einer Eigenschat onler eines (Irgans eine andere muterbleibt oder verschwindet, so dass die beiden Glieder der Korrelation sich einander ausschliessen. So entwickeh jene linsenblittchen, welche genïgend bohat sind, kein Anthocyan und umgekehrt.

\section{Die parallelen Variationen.}

Nahe stehende Arten und auch die Unterarten — nach unserem Sprachgebrauch die grösseren Varietäten - indern nach Crépin in gleichsinniger Weise ab: les variations parallibes. ${ }^{2}$ ) Diese Abanderungen billen hetten von unrndlich vielen nur minimal und duch ein geringstes Mrob-Minder verschiedenen viliedern. Man muss sich hïten, soleho Abinderungen zur Charakterisierung hïherer liategorien, selbst noch der drien und Lnterarten, zu benützen. Dahin gehören nach Cr.: 1) Vorhandonsein bun Iatren und brisen an blïtern, Arhsen,

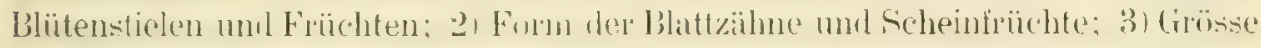

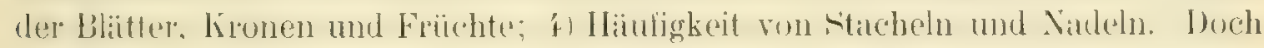

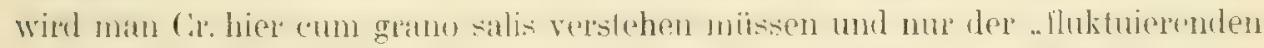
Variation" in Sinne von de Vriess so geringen Wort beilegen. Die Merkmale der Arten, Interaten unl grossen Variefiten besitzen eine gewisse sohwankmugbreite, innerhall, deren die kleinen Varationen unhestimmt hin und her pendeln.

1) So S. Gibbel S. 177 des I. Teiles der „Organographie der Pflanzen" (Jena, 1898). - E. Burnat und A. Gremli nennen das "de variations parallèles (in "Les roses des alpes maritimes", Genève 1879, p. 31). Fr. Crépin gebraucht aber diesen letzteren Terminus in einem ganz andern Sinne, vgl. "Les variations parallèles": Bull: soc. r. Belg. tom. 36, 1. part., 1897. Er dürfte damit Recht haben, umsomehr als schon vorher Christ mit „Parallelismus der Bildungen" (Ros. d. Schw. S. 26 ff.) untefähr das Gleiche meinte. Der Begriff der „Korrelation der Eigenschaften ${ }^{*}$ steht ohnehin in der neueren Morphologie im angegebenen Sinne fest.

?) Siehe obige Anm, 1) 
und die Idee Cr. von den parallelen Variationen zutrifit. Die Merkmale selbst künnen sich in bestimmter. Weist von einander abheben und liategoriemunterschiede begründen, anth wenn sie dem Gebiet der Hatare, Drüsen und Grüssenunterschiede angehören.

\section{Die Bastarde.}

In bezug auf die Anerkennung von Bastarden im allgemeinen, soweit die Benbachtung in der Natur massgebent ist, herscht bei den Systematikern ziemliche (iesetzhsigkeit, bez die Mode. Bei Anus, Salix und Rubus erklïrt man die Kwischenformen sehr gorn als Bastarde und will sugar Tripel- und Quatrupelbistarle noch erkennen. Bei livia ist man nïchterner, nimmt meist echte Nittelformen an unl verlangt Beweise fïr die Anerkemming von Hybriden. Besonders Cirepin war schwierig, wenn man ron Bastarden redete. Ohne Zweilel repmag nur das wistensehafliche Experiment, der hulturversuch, die Frage, uh) Mittelform dureh Variation z. B. Mutation - oler Bastardierung, eindentig zo lösen. Bastarle wïrden sich im Verlauf lortgesetzler kiulur in den meisten Fïllen nach den Mtendel'schen Regeln oder sonstwie in ihre homponenten auflïsen. Allein bei ansdamemden und spätblühenden Gewächsen wie Rosa und Salix wäre dazı eine schier unendliche Summe von Zeit und Arbeitskraft erforderlich, die jedenfalls ein Einzelne' nicht leisten kann. Ausserdem kann der Kulturversuch bloss mit genügend fruchtbaren Bastarden operieren und nuss deswegen von basturden höhtrex Ordumg gewrihnlich absehen. Man muss sich also anderweitig behelfen. Vor allem ist zu unterscheiden zwischen Artbastarten, IVybriden, und zwischen Varielätsmischlingen, Blendlingen. ${ }^{1}$ ) Wenn es sich un die z̈hlichen Kollektivirten handelt, lehrt die Erlahrung, dass die Diskrepanz der beiderseitigen lieschlechtszellen oder anderer massgebender Zellanlagen so gross ist, dass entweder gar keine Hybride erzielt wird, oder ein etwaiger Surösing durch moh oder minter grosse Sterilitit sligmatisiert ist, also selbst fieschlechtizullen von mangelhafter Aubildung besitzt. Selbstrerstïndlich werden die Pollenkïmer we die Eichen ron der Sterilitït betrolfen. Altein zur Begrtindung von mntrighlichen Kennzeichen der Bastardierung sind die ersteren wengstens bei den Rusen kaum geeignet. Fichon (hrist und Cirepin²) konstitieren, dass der Pullen bei unhezweifelt nicht hybriden hosenarten oft schlecht und atrophisch entwickelt sei, wie bei bastarden. I'armentier bemenk r. $23^{3}$ ) das (ileriche, sowie dass die Verschiedenhroiten des Pollens an firöse und fiestalt zur L'mlerscheidung von Rusenarlen nichl brauchbar seien. Nach Parmentier haben schlechten, vielfach atrophischen Pollen die Mehrzahl der Arten aus der Gruppe Caninar lunsere sect. Vestitae. Rubiginusa und Caninae), während die R. comamonea, pimpinellifolia, pendulina, gallica, arensis, sempervirens leinen Pollen besitzen. Nach den I'nterinchungen ron Parm. ist der Pollen nicht rimmal bei der sleichen Art bestindig, so nicht bei R. pisocarpa,

1) Siehe „Internat. Reg. d. bot. Nomenklatur" 1906 Art. 14.

2) Crépin handelt über den Pollen der Rosen in Recherches sur l'état de dévellopement des grains de pollen dans diverses espèces du genre Rose (Bull. soc. roy. bot. Belg. t. 28 2. part. 1889 p. 114 sqq.).

3) Recherch. anatom, et taxinom. s. J. g. Rosier. 
blanrla, rugusa, multifluna, muschata, gallica, micuphyplla. El glaubt, dasc ... le

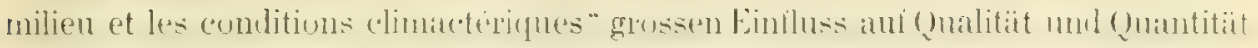
des Pollens ansiuben. Schlexhte Pollenkinder in beträchllicher Anzahl konnen nach Tisehler ${ }^{1}$, ̈̈brigens anch bei anderen fiatlungern und Artern vor, die dureh-

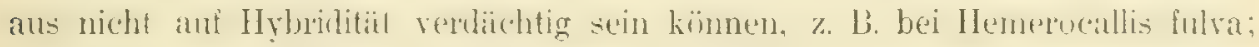
hier sind sie ebenfalls plasmaarm wie bei den Rosen.

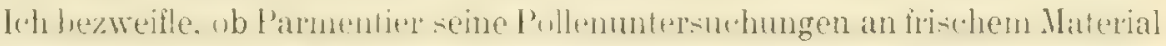

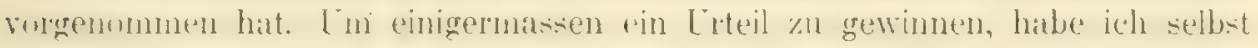
an einer Reihe einheimischer Rosenarten den frischen Pollen untersucht mit folgendem Resultat: ${ }^{2}$ )

R. arrensis var. bibracteata Ser. pimpinelifolia var. typica Chr. cinnamomea L.

gallica L. var. pumila Jacq. tomentosa Sm. subsp. scabriuscula var. vera $\mathrm{m}$. tomentosa var. subglobosa Car. dumetorum Thrill. var. comata $\mathrm{m}$. canina L. Formenkreis Transitoriae glauca Vill. verschiedene Var. rubiginosa $L$. elliptica Tausch var. hispida Schultze lutea Mill. canina $X$ gallica

\begin{tabular}{|c|c|c|}
\hline gute & Körner & $90-95 \%$ \\
\hline , & , & $90-95 \%$ \\
\hline . & $n$ & $75-80 \%$ \\
\hline$\Rightarrow$ & 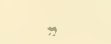 & ca. $65 \%$ \\
\hline , & 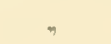 & $50-55 \%$ \\
\hline » & $\pi$ & ca. $50 \%$ \\
\hline " & , & ca. $60 \%$ \\
\hline & $n$ & ca. $50 \%$ \\
\hline & $n$ & $40-50 \%$ \\
\hline n & $\#$ & ca. $50 \%$ \\
\hline , & » & ca. $40 \%$ \\
\hline$n$ & , & ca. $5 \%$ \\
\hline$\pi$ & , & $10-15 \%$ \\
\hline
\end{tabular}

Ich bin also ungefähr zum selben Resultat gekommen wie Parmentier. Aufallend ist die geringe Fruchtharkeit der Canina-Verwandten fiect. Caninae, Vetitite mul Rubiginusal. die zu $50^{0}$ " schlechten Pullen besitzen. Nuch schlimmer steht es mit R. lutea, die sogar hinter einem sicheren Bastard zurückbleibt. Man wird sich der Ansicht nicht verschliessen können, dass die Zahl unausgebildeter Pullenkinner bei sirher legitimen Rusen allzu bedeutend ist, als dass man rin rollkommen zuverlüssiges Lrteil ïher Hỵhiditit anf die Buschatlenheit des Pollens gründen könnte.

1) G. Tischler: Über die Entwickelung des Pollens und der Tapetenzellen bei Ribeshybriden (Jahrb. f. w. Bot. 1906 Bd. 42 S. $545-578$ ).

2) Für die Untersuchung wählte ich Blüten aus, die gerade am Aulbrechen waren und

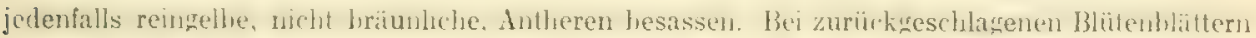
stiess ich die staujgefisse etwas aul das (objektglas auf, his menus Blütenstaul, auf demselhen lag, und untersuchte dann bei einer Vergrösserung von 200-250 zuerst trocken olne Deckglas, dann im Wassertropfen mit Deckglas. Die intakten Pollenkörner zählte ich dann mehrmals im

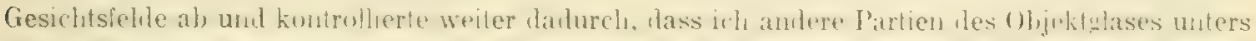

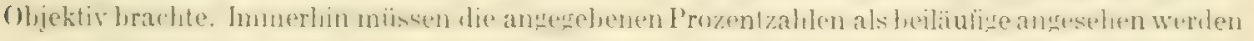

3) Die R. lutea, welche ich untersuchte, ist eine Verwilderung am Kugelberg b. E. und trügt ungefïllte Blüten, niemals Frïchte. Yon den Pollenkörnern waren wie angegeben nur $5 \%$ nach Form und Grösse ganz normal; weitere $10 \%$ hatten normale Gestalt, aber allzu geringe Grösse; der Rest war winzig und unregelmässig geformt. Crépin gibt als Resultat seiner Untersuchungen von R. lutea aus Turkestan: kaum ein Fünfzehntel der Körner waren ausagebildet. Im Gegensalz dazu behauptet Focke, einmal zwei Drittel guter Körner gefunden zu haben. Crépin bestreitet das mit Recht und wirft die Frage auf, ol nicht etwa R. lutea, an der fast nie

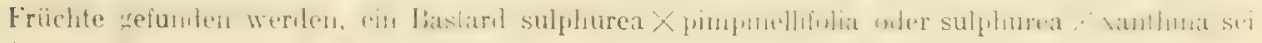
(Les roses récoltées par M. P. Sintenis: Bull. soc. r. bot. Belg. t. 29 p. 6 sq(\%). 
Wir sind also auf das andere Kriterium angewiesen, die Beschafienheit

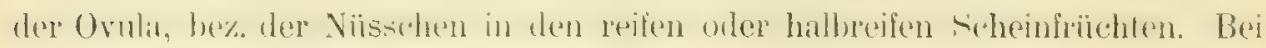

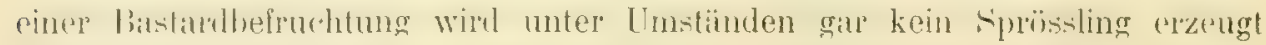

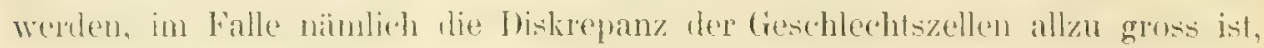
ähnlich wie man noch keinen Bastard Hund $X$ Katze beobachtet hat. Wird ein

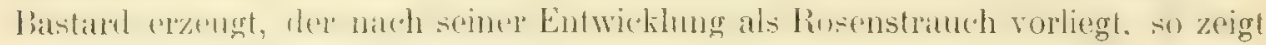

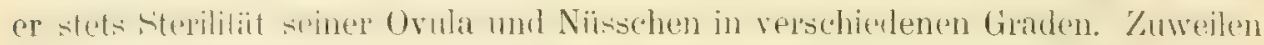

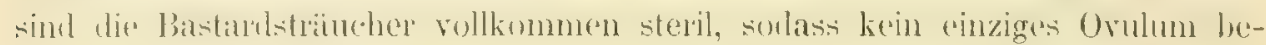
fruchtel Werden limn, unt deswegen alle Scheinfüichte noch in grïnem Zustande vertrudinen umb ablallen. Andere Bastardereilen eine gevisse Zablu von ficheinfrïchten vollkommen aus: diese enthalten damn 1, 2, 3-8, alsu eine beschä̈nkle

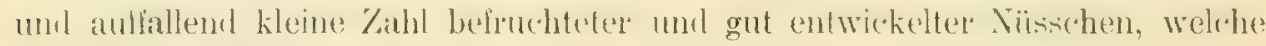

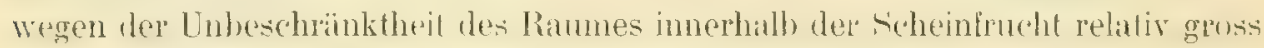
und ron eikugeliger Gestalt, nicht polygonal abgeplatted sind. Bei der Diengmese von Artbastarden liess ich mich immer zunïchst von der Beobachtung des

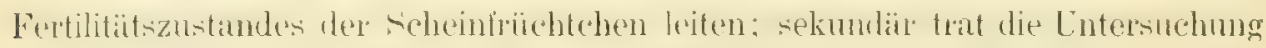
de: Pollens blühender P'llanzen dazu. Zuweilen füht aul die Shur eines Bastards anch die uffenkundige Mischung der Morknale zworer weit ansemander liegenuler Arten. Täuschungen sind selbstverständlich möglich. Manche Rosen setzen teils Wexen ungiuntigen, Standurtes (R. arvensis im Waldschatten) oder des Wittrungscharakter's in laufenden Jahre vele wergen mangelnder Aupassung an den jefaggen Standont (R. cinnanomea b). Eichstiit) verhältnismässig wenig Scheinfrüchte an. Verwilderte Exoten (R. huta) erkent man gerulezu an der seltenheit der Frühte umd der Befmehtumg ïberhauph. Man muss side hiilen, hier stets an Bastardierung zu denken. Ioh halte üherhaupl mit Grópin und Burnat-Gremli ${ }^{1}$ dafïr, dass man nicht allzu leicht Arten-Bastardierumg bei liusen annehmen soll. Sie kommt beim Genus Rosa wohl nicht so hämlig vor, als man bei den Gattungen Rubus, Cirsium, Hieracium, Salix hehauptet. Diejenigen Arten, welche am häufigsten

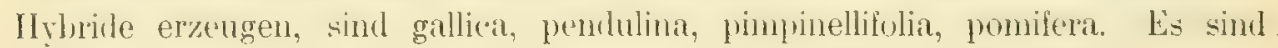
hier wohl zum grössten Teil äussere Umstände, warum diese Arten öfter als andere illegitine Eltern werden, hesonders Giösse, Farbe und Dult (pimpinellifulia!) des Sichauaphates, wodurch befruchtenle Insekten reichlicher angelockt werden.

Wie will man aber mangels physiologischer Lulturversuche entscheiden, (1) Varietiatenmischlinge oder echle Variationsmittelformen vorliegen? Je nïher sich Formen im Systeme und in der Phylogenie stehen, um so leichter werlen sie sich unhegrenzl fruchbar vermischen. Davom, diss man den Pollen ron solchen Blendlingen an mangelnder Ausbildung erkenne, ist keine Rede. ${ }^{2}$ ) Nangelnte Fruchtbatkeit des Gynäceums hat auch noch niemals ein Rhodologe auf eine andere als Arthybridisation zuräckgefïhrl. Man verläht also mit einer

1) Les roses d. alpes maritimes p. 34 .

2) Ich glaube auch nicht, was Focke S. 4 48 Bd. 6 der Synopsis v, A. u. Gr. bezüglich der eigentlichen Brombeeren, der Moriferi, schreibt: "Nicht allein die gut umgrenzten Arten, sondern auch viele (bergangsformen sind vollkommen fruchibar und samenbestindir, aber, nit wenigen Ausnahmen, enthalten alle in ihrem Blütenstaube eine mehr oder minder beträchtliche Anzahl verkümmerter oder missgebildeter Kürner. Diese Eigenschait deutet auf Kireuzungen unter den Vorfahren vieler heutiger Arten hin." 
notgedrungenen Wilkïr, wenn man leei den Rosen immer nur von Zwischentformen und nie ron Varietatenmishlingen spreht. In Wirklichleit kann der Formenreichtum wie hei Rubus su bei fhosa zu einen guten Teil auf Varietitfonmischumg beruhen. Wrir kimnen es nur zur Zeit nicht entscheilen und machen deswegen die einfachere und jedentals hed diommliche Annahme der Variatum in allen fraglichen Füllen. Es ist ja sugar möglich, dass Form, fröise, Farbe num Berlribung ler Früchte eines Sthanches mil den Jihren und mit den einzelnen Zweigen mal Blïten etwats rarieren, weil dit betreftenden Blïten mit Pollen

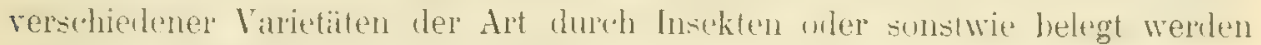
(Xenien!). Erfahren nämlich die: Nïsschen eine difterentielle Ausbihlung, so wird auch ein Einfluss auf die Scheinfrüchte selbst ausgeübt werden. 


\section{TEIL.}

\section{System der im Gebiet wild oder verwildert wachsenden Rosen (nach morphologischen Gesichtspunkten geordnet).}

Ich schicke vorans eine Ubersicht der Sektionen, in welche man das Genus Rosa gliedern kann, wenn man dessen Verbreitung auf der ganzen Erde ins Auge fasst. Rosen fimlen sich lediglich aul der nördlichen Halbkugel in Europa, Asien, Amerika und dirika. zunähst in den gemïssiglen und subtropischen Regionen, damn in den Citbirgen der heissen Zont. Die lulgenle Thersicht int mit wonigen meist die Nomenklatur betrefienten Anderungen entlehnt ans J. G. Baker : A revised classification of Roses. ${ }^{1}$ )

Blitter einfach, ohne Nebenblätter. . . . . I. Simplicifoliae Baker ${ }^{2}$ )

" gefiedert, mit Nebenblättern

Griffel zu einer Säule vereinigt, die sich über den

Diskus erhebt

II. Synstylae $\left.D C^{3}\right)$

Griffel frei, nicht auffallend über den D. erhaben

Nebenblätter frei, bald abliillig .....

1II. Banksianae Lindley ${ }^{4}$ )

mit dem Blattstiel verwachsen

Diacanthae: Stacheln oft gepaart

Früchte dauernd haarig, Brakteen gehäuft und tief eingeschnitten ....... IV. Bracteatae Thory

Frichte kahl

Hagebutte grün, mit dicker Schale. V V.Microphyllae Crep. rot, mit diinner Schale - VI. Cimnamomeae $D C^{5}{ }^{5}$ )

1) Im Journal Linn. soc. vol. 37, 1905, p. 70 sqq. - Crépin hat die Rosen der Untergattung Eurosa Focke (alle mit Ausnahme der Simplicifoliae Baker = Untergattung Hulthemia Focke) in 15 Sektionen eingeteilt. C. K. Schneider gründet in seinem „Illustriert. Handbuch der Laub-

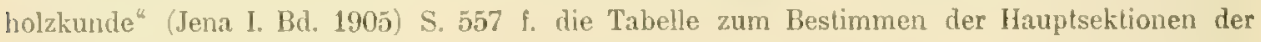
Gattung Rosa auf diese Einteilung Crépins; nur kassiert er mit R. Keller die Sektion Stylosae.

2) Bei Focke u. a. Untergattung Hulthemia.

3) Baker bringt hier auch die Crépin'sche sectio Stylosae, vertreten durch die einzige Art $R$. stylosa Desvaux unter. Ich rechne sie mit R. Keller und C. K. Schneider zu den Caninae, wo sie eine Untersektion bilden mag.

4) Dabei die Laevigatae Thory.

5) Dabei die Carolinae Crep. und Sericene Crep. 
Heteracan thae: Stacheln zerstreut, sehr ungleich

Die grösseren St. lang, schlank, gerade .

VII. Spinosissimae Baker ${ }^{1}$ )

"gekrümmt, stark . .

VII. Gallicanae $D C$.

Homoeacanthae: Stacheln zerstreut, überwiegend gleichförmig

Blätter kahl bis mässig haarig . . . .

, sehr haarig .........

IX. Caninae $D C 0^{2}$ )

, unten sehr drüsig .....

X. Testitae $\mathrm{Clm}^{3}{ }^{3}$ )

XI. Rubiginosae Crep.

Da es in der Absicht dieses Werkes nicht liegt, eine Nonographie der ganzen Rusengattumg zu lieferu. Wurde die Chersicht nach bakel hauptsäthlich

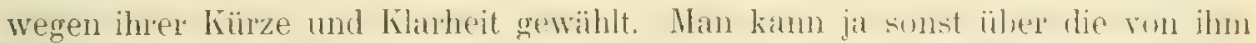

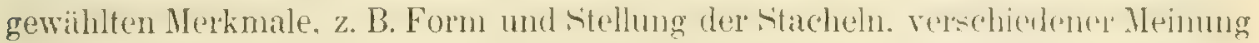
sein mul anch finden, dass er die charakteristischen Lnterschiede del bläter zu wenig bericksichtigt hat. Jetentalls aber erscheinen die von ihm alufgestellen Gruppen natürlich. Ich verchliesse mich den Grïnden nicht. Welche dir Vestitae und Rubiginosae in ein sehr nahes Verhälnis zu den Caminae bringen. Weil jeduch ihr Habitus etwas su Prägnantes audweist. und auch aus putstischen Grïnden, unn den hreis des sect. Caninae nicht allzusehr zu rergriorern. bin ich Baker gelolgt.

In Gehiete sind folgende Sektionen und Lutersektionen vertretron, welche ich im Anschluss an die Reihenfolge bei R. Keller (Synopsis) anfïhre:

Sectio I: Synstylae $D C$.

Sectio II: Gallicance $D C$.

Subsectio 1: Gallicanae verae Borbas.

2: Jundzillianae Crep.

Sectio III: Vestitne $C h$.

Sectio IV: Rubiginosae $D C$.

Sectio $\mathrm{V}$ : Caninne $D C$.

Subsectio 1: Tomentellae Crep.

2: Eucaninae Crep.

Sectio VI: Cinnamomeae $D C$.

Subsectio 1: Cimamomeae verae miti.

2: Alpinae Déséglise.

Sectio VII: Spinosissimae Balier.

Subsectio 1: Pimpinellifotiae $D C$.

2: Luteae Crep.

Bei der Sect. Caninae würden als subs. 2 die Rubrifoliae Crep. und als

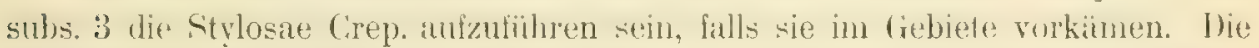
Eucaninae wïrden damn als subs. i folgen. Da die R. tomentella mit ihron Verwanden zwischen den echten Caninen und len liubiginusen vernittelt, aber mehr bigenschaften mit den Caninen gemein hat, liess ich sie nit Christ als

1) Dabei die Luteae Crep. und Minutiloliae Crep.

2) Dabei die Indicae Thory.

3) Die Priorität des Namens scheint hier Christ zu gebühren. Die Villosae Crep. haben einen anderen, beschränkteren Umlang. 


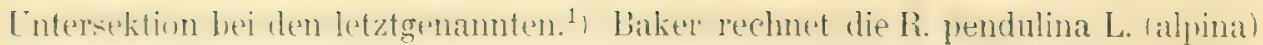

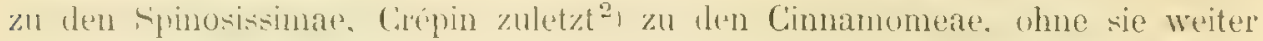
an:zuzerchnen. Sie verdient aber wohl eine höhere stellung, die ihr anch Crepin friihel gegehen hatle (sectio Alpinat. (hrist hat die Pendulina als stabs. Alpinae

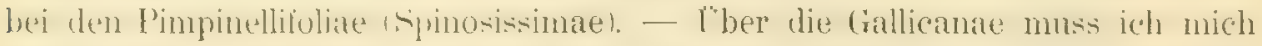
etwas weiter repheiten. ['nhestreitlua sind die Bezichnngen der R. Jumbillii und ihrer oft als Arten beschriebenen Varietäten sowohl zu den Caninae als den Crillicante, dere R. gallica. Mit den Caminen hat die R. J. gemeinsam die Zathl der Fienlerblältchen. nit der R. gallical den Wnchs, die meist schwächere und oft heterakanthe Bestachelmug. das vorspringende Alernetz der Blittchen und riele Eigrentünlichktiten der blüte. Christ und nach ihm R. Keller fassen die R. I. (resp. trachp̧pylla) anl als tinen alten bastard canina $X$ gallica, der durch Lebentiahigkeit und Fruchtharkeit sich bis zum Range einer sellsstindigen Ar! entwickelt habe. Doch lässt sich das schwerlich beweisen, und wemn man dieste hose einfach als drt der liegenwart registriert, scheint sie doch mehl Eigenschatten mit der R. gallica zu teilen. Ich halte es ans diesem Grumb mit Borlats fïr zweckmaissig, eine subsectio Jundzillianne neben die subs. Gallicanae verae zu stellen. Ich brauche wohl nicht eigens zu bemerken, dass die von mir angenommenen sektionen und Intersektionen bei den duturen der Namen nicht inmer gitnz den gleichen Lnfang und Rang besitzen. Das ensend. habe ich als zu schleppend weggelassen.

1) H. Christ: D. Ros. d. Schw. 1873 S. $40 \mathrm{ff}$.

2) Tabl. analyt. 1892 p. 27. 


\section{Sectio I: Synstylae DC.}

Griffel zu einer Säule verwachsen, welche die Länge der inneren Staubbätter erreicht und sich weit iiber den Diskus erheht: ${ }^{1}$, Stamm kletternd oder kriechend.

\section{Hosu "rrensis Hudson.2)}

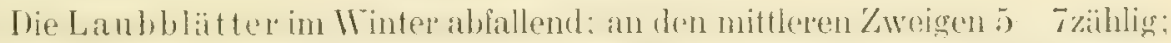

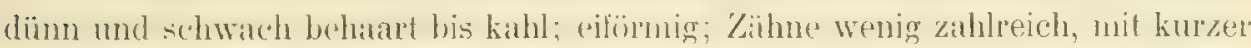
aufgesetzter Spitzes divergicuend. Hochbliilter klein. lanzetlich, aufecht, lange:

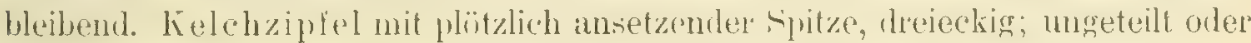
die 3 äussuen schwath fiederspaltig: abliblig. Kronblattcr weiss. Blatenstiele sehr lang. Scheinfrüchte um die ovale Form variierend, kahl.

Ubersicht der im Gebiet konstatierten Formen:

a) Stamm und Aste schlaff, niederliegend oder kletternd:

var. typica $R$. Keller
1. ovata (Lejeune) Desvaux
P. repens (Scopoli) Borbas

var. biserrata Crep.

b) Stamm niederliegend; Aste straff, mehr oder minder aufrecht:

var. bibractenta Séringe

f. umbellatr Godet

f. sublibractenta $H$. Braun.

\section{Diagnosen:}

1. Var. typice: Stachehn gleichartig. Zahmung der Blittrhen sehr vorwiegend einfach. Blïtenstand arm. Blittenstiele mit kurz gesticlen, fast sitzenden [rüsen.

2. F. ovata: Blüten gross. Kelchbecher und Scheinfrüchte oval.

3. F. repens: Kelchbecher und Scheinfrichte kugelig bis birnförmig.

4. Var. biservata: Zahnung der Blättchen vorwiegend doppelt.

5. Var. bibractenta: $\left.{ }^{3}\right)$ Blïttchen ziemlich gross. Blïtenstiel stieldriisigg. Scheinfrichte oval.

6. F. umbellata: Blïtenstand mehr- bis reichblütig.

7. F. sublibrecteate: $\left.{ }^{4}\right)$ Bliblensland armblitig. Aste und mittlere \%weige nur z. T. aufgerichtet.

1) Ich berücksichtige in den Definitionen der Sektionen und Arten solche Ausnahmen nicht, welche sich deutlich als Hemmungsbildungen, Monstrositäten u. dgl. verraten. Ferner sei ein für allemal bemerkt, dass die Charaktere der Sektion, weil sie auch für die darunter fallenden Arten gelten, bei diesen nicht weiter aufgefïhrt werden, und so mut. mut. immer rücksichtlich der Diagnosen höherer Gruppen im Verhältnis zu denen der nächst niederen.

2) Hudson gebührt die Priorität des Namens den Angaben R. Kellers in der Syn. zufolge, auf die ich mich in den meisten Fällen beziehe.

3) Nach Christ (Ros. d. Schw. S. 196) ist nicht etwa der Stamm selbst bei der var. bibr. aufrecht: ${ }_{7}$ Zweige sehr stark, aus niederliegendem Stamme 1/2 Meter gerade aufgerichtet."

4) Die f. subbibr. H. Braun ist eine Zwischenform zw. d. var. bibr. und typica. 


\section{Standorte:}

Ad 1. Zwischen Thaldorf und W'eltenburg (Kaufmann!). 1)

Un Monheim verbreitet. ${ }^{2}$ )

Ad 2. Waldschlucht des Frauenbergs b. E. ${ }^{3}$ ) (Kalkschieferboden $\left.500 \mathrm{~m}\right)^{4}$ )

Abhang ob Wasserzell b. E. (Kalkschieferboden $510 \mathrm{~m}$ )

Zw. Parkhaus u. Hirschgrund b. E. (Kalksehieferboden $500 \mathrm{~m}$ )

Rechter Waldrand des Trockentales zw. Ried u. Wielandshöle (Alluvialboden $450 \mathrm{~m}$ )

Am Waldweg zw. Feldmiihle und Biesenhardt (Kalkschieferboden $510 \mathrm{~m}$ ) Am Häselberg (Fl. v. Nbg.) ${ }^{5}$ )

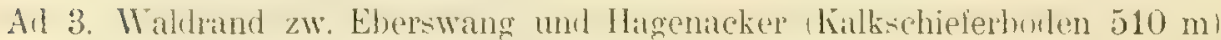

Waldrand b. Einsfeld (Kalkschieferboden $520 \mathrm{~m}$ )

Am Vühlberg b. Pappenheim (Fl. v. Nbg.)

Bei Treuchtlingen und Weiboldshausen (Fl. v. Nbg.)

Bei der Ruine Stauf (Fl. r. Nbg.)

Ad 4. Laubwald an Sperlesberg b. Velburg (Prechtelsbauer!)

Ad 6. (ieluitsch der rechten reite des Buchtals b. E. (Dulomitboden $490 \mathrm{~m}$ )

Wald zw. Eberswang und Hagenacker (Dolomitboden $490 \mathrm{~m}$ )

Ad 7. Wald zw. Pappenheim und Dietfurt (Prechtelsbauer!)

Stauferberg b. Greding (Schultheiss!)

Ausserdem stehen unbenannte Zwischenformen zw. 1. und 4. mit ziemlich viel doppelter Zahmung hinterm Hirschparkhaus b. E.; solche zwischen 2.., 5. und var. latevipes Gremli aul der Jurbhochebene sïdl. Eberswang starke, meist mehblütige P’lanzen mil wenig Drïsen an Blïtenstiel). - Ohne Ausscheidung der Formen ist mir die R. arvensis weiter hekannt rom Waldrand b. Landersholen a. A. Altmiihl, rom Waldrand les Schutlertales za. IV ellheim und Foldmühle. Die R. arv. fult in lichten Lanbwald und in Rindgeboisch des Malm wohl nirgendwo hiersulande gäinzlich. Die rar. bibmeteata berorzugt tiefgriindigeren, nahrhaften Boden mit ausgiebiger Bewaisserung.

1) Der Name in Klammer gehört dem Finder der Rose an. Ein! bedeutet, dass ich die Rose frisch oder im Herbar eingesehen und bestimmt habe. In allen Fällen - weitaus den meisten -, in welchen gar nichts bemerkt ist, habe ich selber die Pflanze aufgelunden.

2) Was die Reihenfolve der Fundorte betrifit, so gehe ich immer von der nächsten Umgebung von Eichstätt aus; dann reihe ich successive diejenigen des Altmühltales abwärts, dann diejenigen altmühlaufwärts an; es folgt die Gegend von Neumarkt i. Obpf. und das Donaugebiet unterhalb Kelheim. Die Seitentäler (Anlauter, Sulz) sowie die Plätze der Hochebene werden an die betreffende Partie des Altmühl- oder Donau- bez. Naabtales angeschlossen.

3) E. ist stets Eichstätt.

4) Wo die Bestimmung mit Hilfe des topographischen Atlasses von Bayern (1:50000)

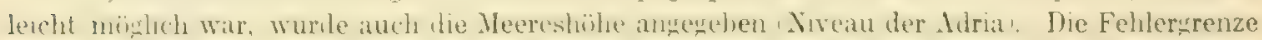
beträgt etwa $\pm 10 \mathrm{~m}$. - Freilich wird man sich aus der Vergleichung der Meereshöhen überzeugen, dass es in unserem Gebiet aul die Differenzen der Höhe wenig ankommt.

5) "Flora v. Nürnberg-Erlangen. "Heransg. v. A Schwarz, Nürnberg 1897-1901, 5 Teile. - Ich

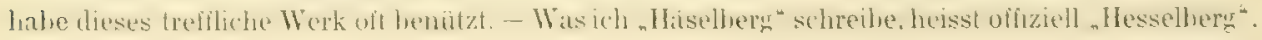




\section{Sectio II: Gallicanae D C.}

Oberirdische Achsen aufrecht, niedrig. - Zweierlei Stacheln am Stamme: stirkere mehr ofer minler hakige und kleine dritsige Borstenstacheln. Die eifömigen Blättchen gूuss, lederig. mit dutlich hervortretendem Adernet\%. Blïtenstiele lang. Die äusseren helehblitter stark gefieclert. abfällig. Kónbläter gross, lebhait gefärbt.

\section{Subsectio 1: Gallicanae verae Borbas.}

Mittlere Laubblätler der Bliatenzweige durehschnittich 5-. selten 3 zählig.

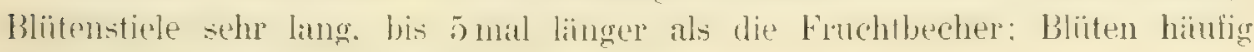
einzeln; ${ }^{1}$ ) die grossen Kronblätter purpurn.

\section{Liosa gallica $L$.}

Strauch mit zahlreichen unterirdischen, ursprünglich aus Auslïufern ent-

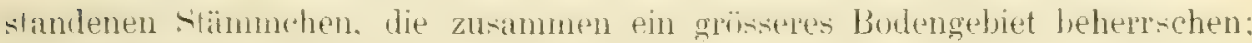

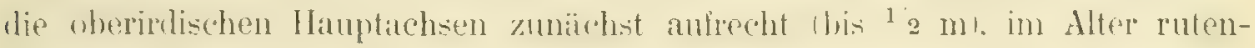

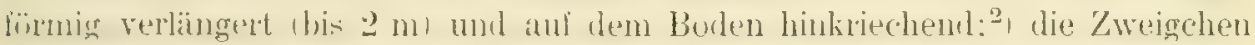
antrecht, starr. Die starkeren stachelu gekrimmt, whe aus lureitem Crunde zu entspringen, relativ schlank: dir sehwioheren oft driisigen Borsten hesonders an den Blïtenzweigen dicht stehemul. Laubblätchen mit abgerundeter Basis; Zahnung breit. stmmpl, rothandene Vebenzähnchen im Verhälnis sehr seicht: Nebenblïtchen schmal. drïsig gewimput. Blütenstiale dicht drisign. Sicheinfrïchte annähernd birnförmig, reif bräunlich, lederig.

1) Geschonte, in guter Lage befindliche Gallica-Sträucher haben viel häufiger mehrblütige Inflorescenz, als man gewöhnlich behauptet. Die R. g. ist offenbar keine prinzipiell einblütige Rose; das ergibt sich auch aus der verwickelten Art und Weise, wie die Brakleen auftreten.

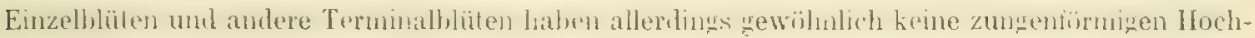
blätter (sog. Vorblätter), aber ausnahmsweise kommen trotzdem solche, und zwar mit rudimentären Achselknospen, vor. Seitenblüten tragen stets eine oder zwei solche Brakteen. Die absteigende Reihenfolge der Blütenstandsentwickelung heisst also bei der R. g.: a. Gipfel- und Seitenblüten besitzen Vorblälter (richtiger Deckblätter) mit rudimentären Achselknospen; b. die Gipfelblüten - scheinbaren Einzelblüten - besitzen Decklblätter mit rudim. Achselknospen, Seitenblüten fehlen; c. Die Gipfelblüten sind ohne Brakteen und rudim. Achselknospen, also wahre Einzelblïten.

2) Man trifft selten ganz unberührte Vegetationen der R. g., weil sie auf Rainen, Weiden und in Feldern gewöhnlich abgefressen, abgeschnitten und abgebrannt werden. Wo ich sie aber durch mehrere Jahrzehnte hindurch unberührt angetroflen habe und zwar in fruchtbarer und sonst günstiger Lage, zeigten die oberirdischen Achsen das in der Beschreibung gekennzeichnete Wachstum. Die var. flaccida J. B. Keller könnte hierher gehören und würde dann als blosse Standortsmodifikation zu kassieren sein. 
Ubersicht der i. G. k. Formen:

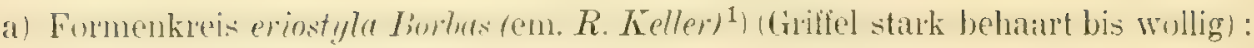
var. austriaca (Crantz) H. Braun

1. haplodonta Borbas

var. pumita (Jacquin) H. Braun

f. muscipula (Boullu) R. Keller ${ }^{2}$ )

var. officinalis Thory

b) Formenkreis liostyla Borluts (em. Gelmi ${ }^{3}$ ) (Griffel schwach behaurt bis kahll): var. elata Chr.

\section{Diagnosen:}

1. Varr. austriace: Blättehen vorwiegend breit. Pundlich elliptisch, an der Basis abgerundet; Zahnung einfach, aber durch die Randdrüsen beginnend doppelt. ${ }^{3}$ )

2. F. hephlodonte: Blättehen elliptisch bis rundlich elliptisch: Zahunng einfach und auch vorwiegend ohne Drüsen.

3. Var. pumila: Blïttchen nur mittelgross; elliptisch bis länglich elliptisch; längs des Mittelnerven oft zusammengelegt; Rand scharf doppelt gesägt und reich druisig.

4. F. muscipula: Bliitentragende'Zweige mit Drüsenborsten dicht bekleidet. Blättchen uberseits zerstrent, untersoits auf dem Mitteherv dicht, sonst zelstreut behatart.

1) R. Keller (bez, Gelmi) haben an tłer Bezeichnung von Borbas nur formelle Korrektionen vorgenommen uml gel, ührt Borbas die volle Prioritit. Vyl. V. Borbas: Primitiae monographiae rosarum imperii Hungarici, Budapest 1850, S. 357 und 359, 367 und 373.

2) Die R. muscipula gelört als Form zur var. pumila (siehe die folgende Diagnose), da die mir bekannten Stïcke stets mehrlache Zahnung des Blattrandes zeigen, aber stärkere Bedrüsung und stärkere Zahnung bei den Rosen parallel gehen.

3) Wenn ich die var. austriaca und pumila unterscheide, so folge ich dem Beispiele von

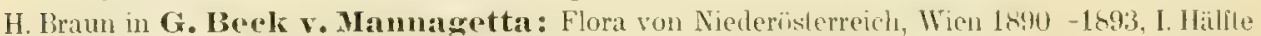
S. 779); nur die Unterschiede der Zahnung habe ich etwas anders gefasst. R. Keller macht in der Synopsis gar keinen Unterschied, desulejchen $\mathbf{A}$. Déséglise (Catalogue raisomé ou énumération métlıodique des espèces du genre rosier, S. 243 im Bull. soc. roy. bot. Belg. t. 15, 1876, Brüssel); Crépin scheint einen Unterschied zuzulassen (siehe Tabl, analyt. p. 8). Borbas u. a. nehmen hierher noch eine var. typica oder die R. gallica L. Ich habe clie Originaldiagnosen von Crantz (H. J. N. Crantz: Stirpium austriacarum ed. alt. ps. I, Viennae 1769 p. 86) und Jacquin (N. J. Jacquim: Florat austracae icones, vol. II, Viemnae 177f p. 59 eingesehen und allerdings selber die Uberzeugung gewonnen, dass beide die $\mathrm{R}$, austriaca und pumila sämtlicher Autoren für identisch hielten (die Namen finden sich annähernd schon bei Clusius, Bauhin, Parker und Zwinger). Trotzdem erlauben, ja fordern bei Crantz wie Jacquin die Beschreibungen, welche sie von den Blittern der nach ihnen benannten $\mathrm{R}$. gallica entwerfen, dass man die Unterschiede mache, die wir oben ausgedrückt haben. Die Blättchen der R. pumila sind nach Jacquin ,eiförmig, ölter umgekehrt eiförmig, hie und da mehr rundlich", meist "convenientia et reclinata" (was doch wohl heissen soll: "zusammengefaltet" und zurückgebogen), „scharf doppelt gezahnt". Crantz sagt von den Blättchen seiner $R$. austriaca lediglich: sie sind , am Stiel abgestumpft, zurïckgebogen, gezahnt, von der Rinne (dem Mittelnerv) aus verebnet (also nicht gefaltet), rundlich oder spitzförmig". - Um der Klarheit willen dürfte es also geraten sein, die von uns formulierten Diagnosen gut zu heissen. Ich leugne nicht, dass zwischen beiden Varietäten kein scharfer Unterschied besteht, insbesondere gehen die beiden Blattformen viel ineinander über, und ist die einfachere Zahnung nicht stets an die breiteren Blättehen gebunden. Solche Ubbergänge verwirren das System aber bei fast allen Rosenarten. 
5. Var. officinalis: Krone sehr gross, schwarz purpurn samtig.

6. Var. elata: Schlafler, bis $1 \mathrm{~m}$ hoher, etwas kletternder Strauch. Grössere Stacheln fehlen. Blättchen lïnglich oval, spitz.

\section{Standorte:}

Ad 1. Südsaum des Waldes zw. Ziegelhof b. E. und Buchenhüill (Schneid!) Rain nördl. von Buchenhuill

Links d. Altmuihl b. d. Briicke Arnsberg (Schneid!)

Mehrfach am Doosweiher b. Wending (Schneid!)

Waldrïnder b. Laaber (Killermann!)

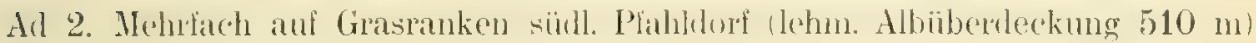
Buckschlagäcker b. Bertoldsheim (Herbar Dumoulin!)

Ad 3. Rosental b. E. (Dolomitboden $450 \mathrm{~m}$ )

Mehrfach in der Umgebung von Walting a. A.

Massenhaft in einem Erdfall südl. Pahldorf (lehm. Albüberd. $510 \mathrm{~m}$ )

Grosse Heckenreihe an Rinken siidwestl. Plahldorf (Jehm. Alhïherd. $520 \mathrm{~m}$ )

Südabhang des Kernbergs b. Gungolding (Alluvium $420 \mathrm{~m}$ )

An Feldweg westl. Gelbelsee b. Kipfenberg (Schneid!)

An Feldweg östl. Schelldorf (Schneid!)

Nehrfach b. Monheim (Herbar Lang!)

Igstetten b. Neuburg (Erdner!)

Ad i. Mehrfach an Grastanken Ostabhang des Kernbergs b. Gunguding (Dolonitboden $450 \mathrm{~m}$ )

Erdfall südl. Plahldorf (lehm. Albüberd. $510 \mathrm{~m}$ )

Ad 5. Ranken b. Riedelshof, Kipfenberg (Schneid!) ${ }^{1}$ )

Ad 6. Jurahochebene an Wahlraml siill. Lherswang (Kitkschiefer $530 \mathrm{~m}$ ).

Unbenannte Zwischenformen: Zwischen 1. und 2., viele Blättchen mit einfachen drïsenlosen Zïhnen, steht eine Roses aul den Dolomitielsen oberhalb) der Brunnmïhle b. Walting a. A.; desgleichen an Fahrweg Wending-Mathesmühle (Schneid!). Zw. 1. und var. cordata (Cariot) R. Keller ein Exemplar am

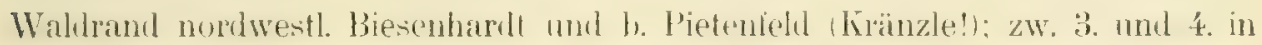
einem Erollikll aul der Hochebene sïdl. Plahldurf; zw. 1. und 3. mil ganz genischter Blattform am Waldrand b. Hieting.

Die $R$. centifolia $L$, welche nach der übereinstimmenden Ansicht der neneren Autoren bloss eine gedialle Aball dere R. Gallica darstellt wahrscheinlich aus dem Orient stammend, wärdst verwilder in einer halbgefïllten form aul Kalkgeröll des Kungelbergs b. E. $(460 \mathrm{~m})$. $^{2}$ )

Ohne Ausscheidung von Formen ist die R. gall. ferner bezeugt von: Landersholen h. E. (Ph. Hoffuann) ${ }^{3}$, haine der Pielenfelder IJöhe (Ph. Holmann), Feld-

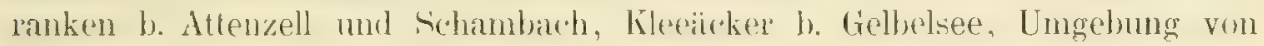

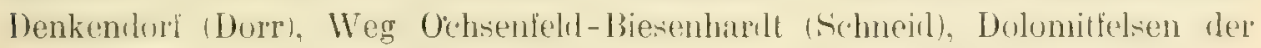

1) Diese Rose wird wegen ihrer aufallenden Farbe und ihres Wohlgeruchs von den Leuten der Umgegend zu Sträussen geholt. Die Blüte ist ungefüllt. Ich glaube nicht, dass es sich um eine Verwilderung handelt.

2) Von Crépin eingesehen.

3) „Exkursionsflora für die Flussmebiete der Altmühl" usw., Eichstätt 1879. 
Altenhiil'g b. Aieha im Wellheimer T'al, Donauanen b. Gerolfing (Ph. IIoffmamm), Waldweg Wolferstall-Gundelshem (Ph. Hoffmann), b. Lnterau närhst Kelheim.

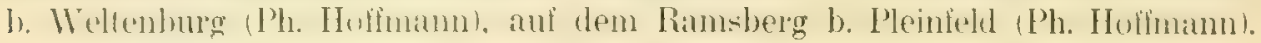

Dits Verbertungsgebict der R. g. im Bezirke umfasst also den sïdlichen Ted

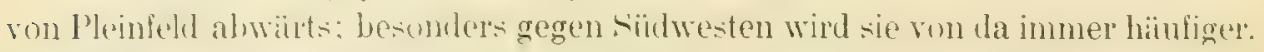
sie herorzugt ilen Kilkhoden, ohne andere Budenarten ganz auszuschliesien. In Eichstiitter Jura bewohnt sie noch die hïchsten Regionen, aber damm gerne geschützte Plätze, besonders mit südlicher Exposition.

\section{Subsectio 2: Jundzillianae Crépin.}

Mitlere Laubblïtter der Blätenzweige gewöhnlich Tzählig. Der Blïlenstand prinzipiell zusammengesetzt; die Kronen lobhaft rosa. Heterakanthie der Achsen wenig ausgeprägt.

\section{Rost Jundrillii' Resser.}

Strauch mit vielen unterirdischen Ausläufern; Wuchs der oberirdischen Achsen ziemlich stralf, in Alter clwas ïherhängend, niedrigg (meist zwischen

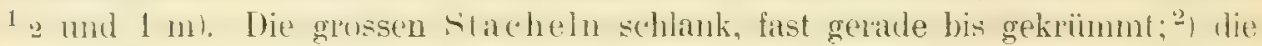
nakdlörmigen häufiger bluss unter der Influrescenz auftretend. Bläflehen auf der Interseite tmit Dräsen bescetzt; die Blattzithe nicht oflen wie bei R. gall., sondern etwats zusimmenneigend: Vebenblättchen breit. Kelchblät ter lang, die änsseren

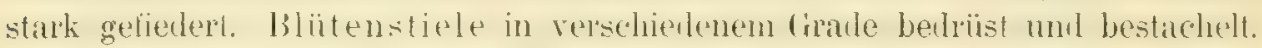
Griffelköpf(hen wollig lehart. Scheinfrïchte kugelig bis linglich oval, rut, fleischig.

Ubersicht der i. G. k. Formen:

a) Formenkreis der var. Pugetii (Boreau) Crep). (Blättchen breil oval, auf der

Unterseite behaart und bedrüst):

var. Pugetii (Boreau) Crep.

f. typica Chr.

f. latifolia $C h$.

f. serrata mihi ${ }^{3}$ )

b) Formenkreis der var. trachyphyllu (Rou) Crep). (Blittchen schmäler und spitzer. unterseits kahl oder fast kahl):

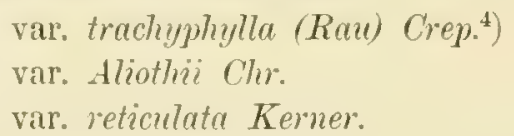

Die von mir gewïhlten beiden Formenkreise entsprechen den Ansichten von Christ und Creipin. Lnsere jetzige Art R. Jundzillii ist zusammengeschweisst

1) Der Name hat vor R. trachyphylla Rau u. a. die Priorität. Nach den Nomenklatur-

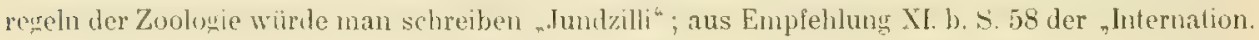
Regeln der botan. Nomenklatur" 1905 geht jedoch hervor, dass wir abweichend von obigem Gebrauche "Jundzillii" zu schreiben haben.

2) Crépin teilt der R. J. ggerade oder fast gerade" Staeheln zu (Tabl. anal. p. 15), wie er auch privatim dieses Merkmal stets betonte. Hierin war er einseitig, denn die meisten deutschen Varietäten besitzen gekrümmte Stacheln.

3) Serratus, sägeförmig gezackt.

4) Die R. trachyphylla Rau zählt Crépin im Tabl. anal. unter den Varietäten der R. Jundzillii Besser aul, nur gibt er ihr nicht formell den Namen „var. als definitiver Autor anzusehen ist, nicht etwa K. Keller. 
aus den $R$. Jundzilliana Besser und $R$. trachyphylla Rau, wie sie noch Christ

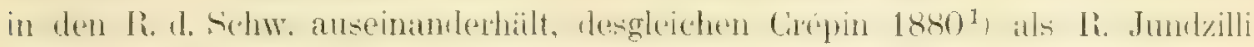
besser und li. trach. Rau. Der letztgentunte behandelt bibrigens bede liosen

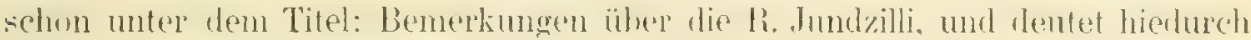

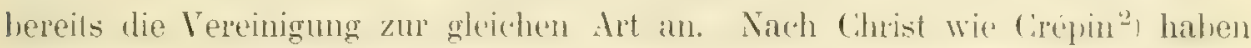
wir in der $R$. Pugetii Boreau den Typus für die R. Jundzilliana, also unsern

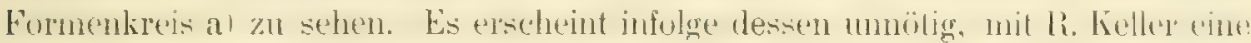

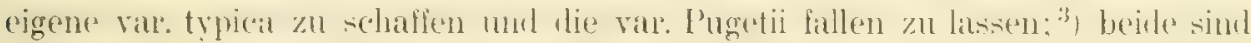

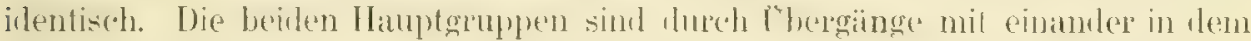
Grade verkniipft, dass auch nach dem Zeugnis von E. Sagorski eine strikte

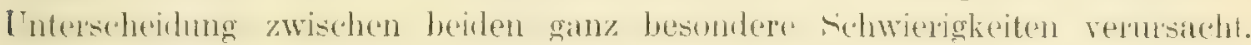
Ich fasse die var. reticulata Kerner als eine derartige, besonders weit verbreitete I'bergangsvarietat. Originalexemplare ans logatn tragen durchans diesen cha-

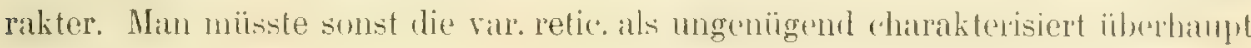
fallen lassen.

\section{Diagnosen:}

1. Var. Pugetii: Stacheln nur gebogen, öfter mit geraden Borsten vermischt. Blättchen gross, breitoval und breitelliptisch bis rundlich; Zähne breit, ihre spitzen getn narh anssen absthend, nit drisigen sekmbithzähnchen; Blattstiele und wenigstens die Hauptnerven flaumig bis behaart; Stieldrüsen mindestens aul dem Mittelnerv vorhanden, sonst ganz unregelmässig. Brakteen klein. Scheinfrichte kugelig oder eikugelig.

2. F. typica: Wuchs gedrungener. Noch breitblättriger, spärlicher behaart und ämer an Subfoliardrïsen als die var. Pug.

3. F. latifulat: Wuchs niedrig. Betachthong anden oberen Teilen des stranches fast fehlend. Blättchen denen der R. gall. var. austriaca sehr ähnlich: gross,

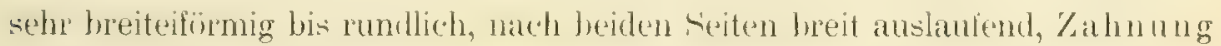
auffillig stumpf.

4. F. serrata: Die älteren Stacheln gekrümmt. Blättchen ähnlich denen der 1. latif., aber die etwas unregelmässige Zahnung spitz und sehr tief.)

5. Var. trachyphylla: Stacheln kräftig und ziemlich stark gekrümmt. Blättchen verlängert eiförmig und elliptisch, oft mit fast parallelen Rädern: vorwiegend schatf uml lang zugespilzt: Zïhne schmal unl mehr nach vorn gerichtet, Serratur sehr drüsig; Adernetz sehr auffallend hervortretend: Blattstiel haarig, blattunterseite kahl; Subfoliandrïsen wite bed var. Pug. Brakteen breit und lang, öfter blattartig. Blütenstiele stark stieldrüsig und stachelig. Scheinfrüchte fast kugelig. $\left.{ }^{\circ}\right)$

1) Primitiae monographiae rosarum-Nateriaux pour servir à l'histoire des roses. 5. fasc. p. $36 \pm$ sqq. (Bull. soc. roy. bot. Belg. Bruxelles et Gand).

2) Crépin: Materiaux etc. 5. fasc. p. 366; Christ: Ros. d. Schw. S. 141. - Christ glaubt allerdings, dass seine f. typica am besten dem Begriff der R. Jundzilliana bei Besser selbst entspreche, zitiert aber seinen Vorgänger Chavin, der R. Pugetii und R. Jundzilliana identifiziert.

3) Synopsis Bd.6. 1. S. 54 .

*) Lat. Diagnose: Aculei vetustiores incurvi. Foliola magna, latissima, subrotunda, ad apicem retusa atque margine irregulari quodam modo acutissime et altissime dentata.

5) Wenn Christ in den R. d. Schw. S. 146 versichert, seine f. typica der R. trachyphylla Rau stimme vollkommen mit der Beschreibung Rau's selbst, die dieser von seiner R. trachy- 
6. Vur, Aliothii: Zwergstruch mil weng rerzweigten Asten; dagegen kriechen die unterirdischen Achsen weit umher. Altre Teile fast stachellos, die Stacheln diinn und gemule. Blältchen hörhstens mittelgross, schmal und spitz. lielchbecher schmal eiförmig. Scheinfrüchte eiförmig oder länglich eiförmig.

7. Var. roticulatu: (iruse Blättchon mit unent-hiedener, zwischen Formenkreis a) und b) schwankemer Form und Zahnumg. Feheinfritchte kugelig bis rikugelig. Im allgemeinen mehr vom Aussehen der var. trachyphylla.

$$
\text { Standorte: }
$$

Ad 1. Zw. Habsberg und Utzenhofen (Fl. v. Nbg.)

Sinzing b. Regensburg (Killermann!)

Ad 2. Bei Walting a. A. (Dorr!)

Mehrfach am Kernberg b. Gungolding (Dolomitboden)

Bei Hieting (Herbar Dumoulin!)

Hessellohe b. Neuburg a. D. (Erdner!)

Ad 3. Am neuen Weg b. E. (Dolomitboden $460 \mathrm{~m}$ )

Ad 4. Dolomitfelsen über der Brunnmühle b. Walting a. A. (Dorr!)

Waldrand b. d. Attenbrunner Mühle nächst Breitenfurt $(435 \mathrm{~m})$

Ad 5. Mehrmals b. Walting a. A. (Dorr!)

Ad (i. Bein lireuz an Beginn des Fussweges Berg b. Nemmakt-liadenzhofen (Doggerlehm $425 \mathrm{~m}$ )

Waldrand des ,schwaren Iolze; b. Berg-Neumarkt (Doggerlehm ito m)

Ad 7. Bei Walting a. A.

Ann Kirnberg in d. Nïhe des Fussweges Gungolding-Arnsberg (Alluviallehm $420 \mathrm{~m}$ ).

Der R. Jundzillii eignet fast wie der R. gallica ein grosses Licht- und Wärmebediirlnis. Sie besiedelt gerne nach, Sïl und West neigende Cimshöschungen, Waldänder und den humuseicheren Fuss schützonder Felsabhänge. Morkwïrdig ist ihre Verbreitung, wenn man sie mit derjenigen der R. gallica vergleicht. Diese fehlt in Norden und besonders in Nordosten des Ciebietes wie Bayerns überhaupt, ist dingegen häutfig in sïden und überschreited anch die Donau. Die R. Jundzillii disgegen felhlt last vollstindig aul der jenseitigen schwibisch-bayrischen Hochebue, steht aber nicht selten im nördlichen Mittelfanken und der nördlichen Oberpfalz; in Lnterfranken epecht sie das Maximum ilner Häuligkeit. Dort zeigen anch die Varietüten beider Formenkreise einen viel grösseren Reichtum an Driisen, auch Subloliardrisen, wie etwa in der Lmgegend ron Eichstitt.

phylla gibt, überein, so ist das nicht ganz richtig. A. Rau schreibt (Enumeratio rosarum circa Wirceburgum et pagos adjacentes sponte nascentium; Norimbergae 1816, p. 124 sq.): die Kelchröhre ist eiförmig. die Frucht aber nsubglobosus", annähernd kugelig. So habe ich auch zahlreiche Exemplare aus der Umgebung von Würzburg gefunden, die alle hieher gehören. Die Form der reifen Frucht weicht von der Kugelgestalt lediglich durch einen ganz leichten Vorsprung gegen Stiel und Diskus ab. Die Frucht geht bei der Reife durch das Anschwellen der vielen Nüsschen von der Ei- in die ungefähre Kugelgestalt über. Jedenfalls kann man die Form der Früchte von var. trachyphylla nicht in Gegensatz stellen zu der von var. Pugetii (= typica R. Keller). Unter den Blättchen von var. trach. finden sich allerdings manche mit breiterer Form mul alueschwichler Spitze. Dies auch zur Würdigung der Bemerkungen H. Bramn's in: "Beitrïge zur Kenntnis.... der Gattung Rosa", Wien 1885. S. 13. 


\section{Sectio III: Vestitae Christ.}

Grosse, aufrechle Slräucher. Stacheln in der liegel einerlei und von Ciestalt geraule bis grebugen. nich stark gekrïmmt. Die nitteren Blätter an Bliitenzweigen durehsehnittlich 7 zählig: beiderseits weichfilzig behaat. besonders auf der Lnterseite. Blïtchen wie Bliitenteile, zunäichst die blïtensticle, ron'wiegend druisig. Inflorescenz mehrbluitig. Die relativ kleinen Corollen lebhaft rosa.

Die Unterschiede zwischen den Arten der Sektion Vestitae, die in Mittel-

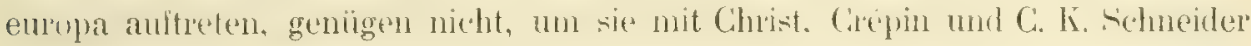
in die zwei Untersektionen der Villosae und Tomentosae zu gliederu. Diese Auturen nehmen z. B. getate und zickzadklomige Adhen als einem wichtigen Unterschied zwischen ihren beiden Untersektionen an. Das lässt sich bei vorurteilsfreiex Prüfung nicht anderdht emalten. Das (ileiche gilt von der angeblichen Verschidenheit der Nebenbläler und ihrer Önchen. Die bejilen unterschiedenen

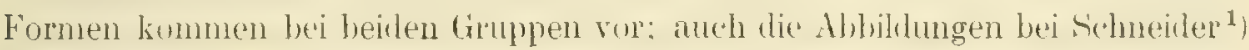

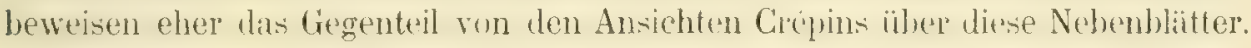
Mit genïgender fichärte lissen sich allgenein giltige I)ingnosen lexliglich antstellen für 2 Arten: Die R. pomifera Herrmam und die R. tomentosa Smith. Verwendhat sind hietiir: Die (iestalt der stateheln, die Lïnge der libitenstiple mit lem kurrelaten Medkmal dex Tragblatentwicklung, die Persistenz der helchblättel mit dem Merkmal her Griltelbehatmug: in zweiter Linie die Nuance der Blïtenfarbe. In Fulgenden stelle ich diese diagnostischen Merkmale lediler fusen einander gegenïber:

\section{R. pomifera}

Sehr vorwiegend ganz gerade Stacheln: -2) Kelchzipfel aulnecht und persistent: Blütenstiele kı\%, in den grossen Brakteen verborgen; Griffel wollig. Blüten lebhaft rosa.

\section{R. tomentosa}

Geneigte bis stark gebogene

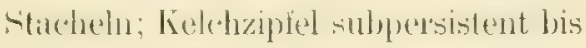
ablïllig; Bliitenstiele lang, Brakteen schwach; Griffel wollig bis haarig; Bliiten blässer rosa.

Rosen, welche Merkmale beider Gruppen in sich vereinigen, müssen als Zwischenformen aufgetast werten. IIteriber herscht unter den Autoren eine enorme Unklarheit und Verwirrung. Ich will nur dieses anführen. Die thüringischen Rhudulngen it. Sagorski uml M. Schulzel fassen lie meisten Clbergings-

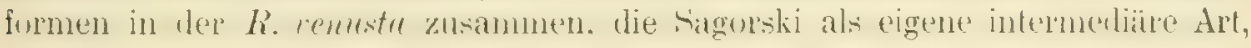

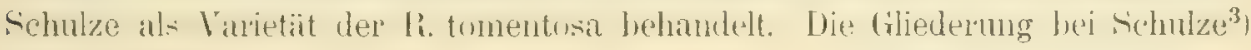

1) Handbuch d. Laubholzkunde I. S. 552.

2) Einzelne Stacheln - zuweilen die ganzer Zweige - sind auch bei der pomifera geneigt bis schwach gebogen; der Stachelgrund ist hie und da etwas verbreitert. Davon überzeugte ich mich oft an typischen Exemplaren des Nikolaitales im Oberwallis und auch an mir von Crépin zugesandten Stücken aus dem Dauphiné. Jena 1887),

3) M. Schulze: ${ }_{\pi} J e n a ' s$ wilde Rosen", S. 5 ff. (Mitteilungen geogr. Ges. zu Jena. 5. Bd. 


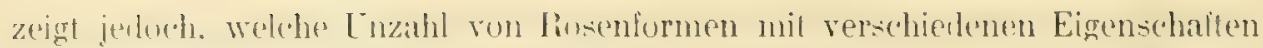

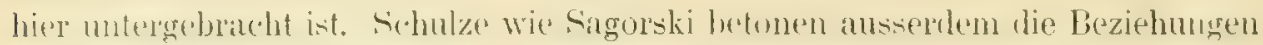
der R. venusta zu R. mollis und pomifera. Varietïten, die Christ und R. Keller bei li. mollis und omissa tuschieben, stehen bei den thïringischen Autoren leils bei renusta (z. B. R. Andrejomskii Besser) teils bei tomenlosil. Christ crkennt Weiter an, dass die gewähnlich bei tomentusa bechriebent var. subvillosia die

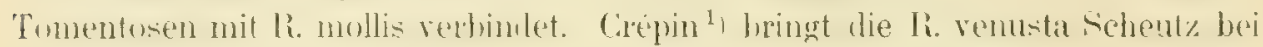
der R. tomentosa zur Sprache; R. Keller identifiziert die R. ven. der Thiuringer mit seiner var. Schulzei und stellt sie als ein Verbindungsglied zur R. omissa.

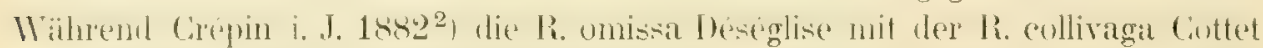

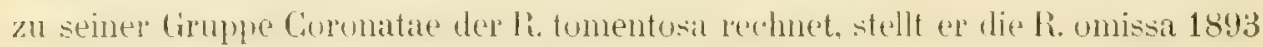
in 'Tabl. anal. wedere als eigene Art zwischen R. jumitera und tomentusa. Mit lebhalten IVorten lekhigt el sich" ïber stine und inderer Autoren Cinsicherheil in Bezug auf diese Zwischenformen zw. den Villosae und echten 'Tomentosae.

Ich versuche mich aus dem Chaos in folgender Weise zu retten. Die $R$. mollis weist gar keine Unterschiede auf, die uns berechtigten, sie von der punilera spezifisch zu tremnen. Sie unterscheider sich von der letztgenannten nach h. Keller ${ }^{*}$ und Crepin houptsächlich durch die „gewöhnlich" kleineren

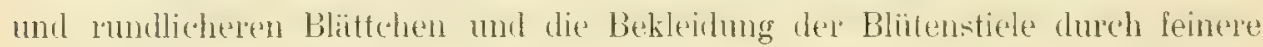
und spärlichere Drüsen. Das genügt höchstens, um sie als eine vorwiegend nördliche Rasse der pomifera zu erklären, aber nicht, um sie als selbstündige Art etwa mit der pomifera zu einer Gesamtart zusammenzufassen. Auch darf man nicht Rosenformen wie die var. Andrzejowskii (Besser) R. Keller zu ihr rechnen, $\left.{ }^{6}\right)$ die lange Blitenstiele haben. Auch Burnat und Gremli ${ }^{7}$ ) betonen die „sthr kurzen" Blittenstiele lex R. mollis. Doch schliesse ich hicmit die Diskussion über diese Rose, da sie im Gebiete nicht vorkommt. - Mit der spezifischen Unterscheidung der $R$. omissa steht es aber auch nicht sehr günstig. Von den vorhin dex Ri. pomifera zuguschriebenen Hanphnerkmalen besitzt sie drei und untrischeilet sich wesentlich nnl durch die meist geneigten bis gelwgenen Stacheln. Dass die Gestall der Nebenblittchen nicht milentscheideml sei. wie Crépin will, haben wir oben bereits betont. Auch der Grad der Persistenz der lielchblatter unterscheidet onissa kaun von promifera. Crepin schreibt von der omissa: „Sepales couronnant le réceplacle jusqu'à l'extrème maturité, à des

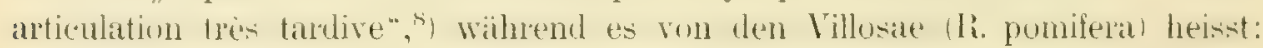

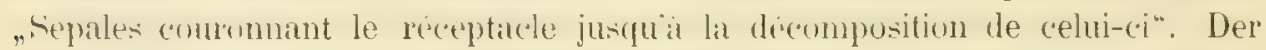
hier angedentefe l'nterschich zwishen einem höhsten Cral der Subpersistenz und der eigentlichen Persistenz ist so fein, dass ich ihn für einen Ausweg der Verlegenheil halte, un das eimmal angenommene P'rinzip zu rellen. (H) Jemand,

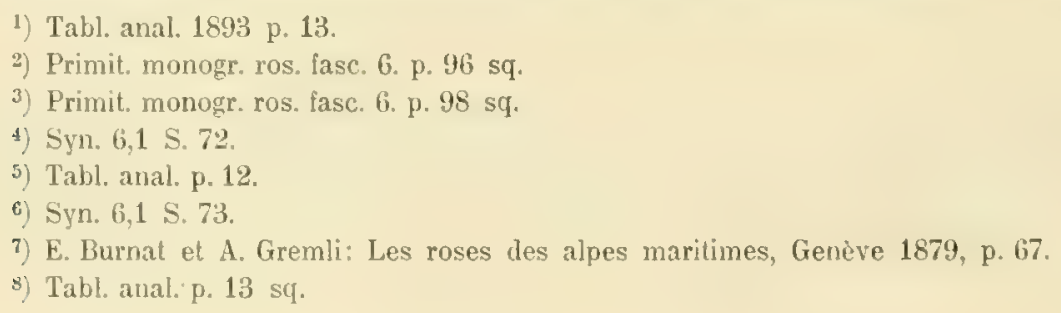


anch der beste Rhoulologe, su etwas in der Natur unterscheiden kann, weiss, ja glaube ich nicht und nehme deshalb attch keine Riucksicht darauf. ${ }^{1}$ Ich erworite

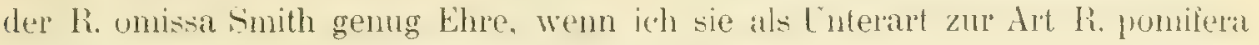
(nicht tomentosa, wie Crépin früher tat) stelle, mit welcher sie durch Formen mit mehr geraden Stacheln in unlösbarer Verbindung steht.

Nun gewahrt man im Gebiet noch eine Kklasse von Ubergangsformen.

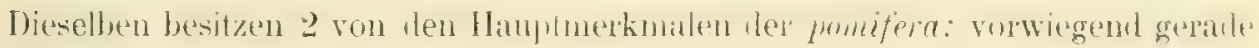
Stacheln, ausdauernde Kelchzipfel, und 1-2 von denen der tomentosa: lange

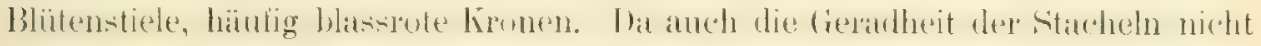
so entschieden ausgeprägt ist wie bei der pomif., so stellt man diese Klasse wohl am besten als Unterart zur toment. Sie erfiillt den Begriff der Unterart sehr gut: mulerscheilet sich durch Artmerkmale von der Hamptart, hängt aber durch "brgänge - Formen mit geneigten, jat sugat gebogenen stathetn und dgl. - mit ihr zusammen. ${ }^{2}$ ) H. Braun hat diese Rosen in seiner $R$. scabriuscula Smith vereinigt. Hieher wird wohl Vieles gehören, was Andere bei R. venusta, mollis und cmissa untergebracht haben. Che die Berechtignng, den Namen und Typus der li. scahriuscula Smith hieher zu ziehen, werde ich mich später äuserm.

\section{Liosa pomifere Hermun.}

Wuchs gedrungen, kurzästig. Stacheln sehr vorwiegend ganz gerade, schlank. Mittlepe Latubblatter gewöhnlich 5 Tzählig: Blittchen miltclguss

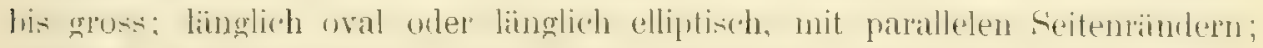
Zahmugg zusanmengesetzt, die Subzen der knrzen Zähne last rechtwinklig ab-

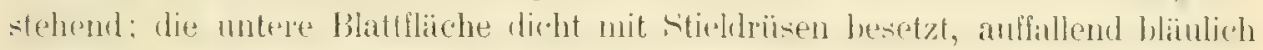
grün. Blütenstiele kurz $(1 / 2-2 \times$ so lang als die Kelchbecher), dicht mit Stieldrüsen und Nadelstacheln besełzt; Brakteen stark entwickelt. Corollen lebhaft rosa. Kielchblätter persistent, $d$. h. nach dem Verblühen aufgerichtet und bis zmm Zerfallen der reifen Frncht bleibend. Griffel ein grossten, wolliges Köplehen bitent. Scheinfrüchte vorwegend kugelig und weichstachelig;

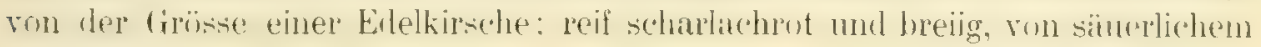
Geschmack. ${ }^{3}$ )

1) Crépin nimmt sogar bei der R. tomenlosa solche Formen an, welche die Kelchblaltstellung der Villosae simulieren, ,simuler" (sic! Tabl. anal. p. 13).

2) Eigentlich müsste ich, wenn ich an die gewöhnlichen Formen einer Rosenart eine Unterart anhänge, wie hier die subspec. scabriuscula an die ganze Art tomentosa, zu dieser Unterart die vorher besprochenen Formen ebenfalls als eine oder melirere Unterarten in Gegensatz stellen, also z. B. einteilen: R. tomentosa a. subspec. tomentosa genuina, b. subspec. scabriuscula. Ich möchte jedoch meine Unterarten, die ich am Schlusse der Formenübersicht bringe, gerne hervorheben als Abweichungen und häufig als Ubergangsglieder zu folgenden Arten. Für diesen Zweck erscheint es mir passender, an die Formenkreise der normalen Art die Unterart als letzten Formenkreis anzugliedern und nicht die ganze Art in Unterarten aufzuteilen.

3) Zur Definition der R. pomifera habe ich in weiterer Ausführung eines schon früher angenommenen Prinzips zu bemerken: Eigentümlichkeiten einzelner Kosenexemplare, von denen aus triftigen Gründen angenommen werden muss, dass sie A b normitäten darstellen, die durch

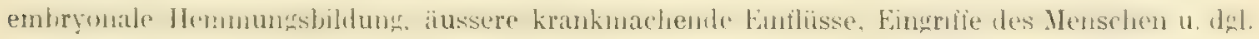
hervorgerufen wurden, berücksichtige ich in der Diagnose der Art oder höheren Kategorie überhaupt nicht. Dahin gehört beispielsweise Mangel an Drüsen bei sonst ganz reichdriisigen Arten, Mangel an Behaarung bei stark behaarten Sippen, abweichender Zwergwuchs. Man vermeidet 
Im Bezirke nur folgende Varietait:

Var. recondita (Puget) C $\%$ r.

Diagnose: Blättchen oberseits dicht, unterseits filzig behaart und reich bedrüst. Scheinfrüchte kugelig, dicht weichstachelig.

Diese Varietait wächst in einer etwas kahleren Form (Blättchen oberseits angedrickt, unterseits dicht h(haat; Kronblitter gewimpert) an mehreren stellen der rechtrn Suite des ()hsenkellertales h. E. (Lehm mit Kalkgeröll. 120 m). Ohne Zweilel handelt es sich dabei um eine Verwildetrung. demn del Standort ist zu niedrig und sonnig, ganz isoliert; Äcker und Häuser sind in der Nähe. Subspecies: omissa (Déséglise) Parmentier. ${ }^{1}$ )

Sitrauch gedrungen. Grosse Stachelu leicht bis stiuker gebogen, Borstenstacheln zuweilen vurhanden. Blätchen miltelgruss bis klein; wal bis linglich oral: Zahmung zusammengetetzt, Zïhnchen kurz, aber spitz: Subtuliardrüsen stels vorhanden. Bliitenstiele kïrzer als die Tragblitler, mgelahr so lang als die Kelchbecher: mit kurzen stieddriben hesetzt. Die aulgerichteten lielchblätter persistent. Krone lebhaft rosa. Griffel stark behaart bis wollig. Scheinfrüchte kugelig bis eikugelig.

Im Gebiete nur:

Var. Schulzei R. Keller. ${ }^{2}$ )

Diagnose: Blättchen oval, am Grunde meist abgerundel; weichfilzig, seidenglinzend: mit meist zahhreichen Subfuliardrïsen: Zahnung zusanmengesetzt, Zähne ziemlich tief, breit, aber scharf zugespitzt, aussen mit $2-\mathbf{6}$, innen mit 1-2 Drüsenzähnchen. Äussere Kelchblïtter mit mehreren ziemlich breiten Fiedern. Griffel dicht weisswollig behaart.

Standort: Östlich ron Berg b. Neumarkt Oberpf. (Liaslehm $430 \mathrm{~m}$ ). ${ }^{3}$ )

dadurch eine Reihe von einschränkenden Ausdrücken, wie "vorwiegend, meist, in der Regel", die solange in der Diagnose der Art logisch unzulässig sind, als es sich nicht um wirkliche Variationen handelt. Man kann solche Formen wohl unter den Varietäten auffïhren, weil man vielfach durchaus unsicher darüber bleibt, ob ihre Eigentümlichkeiten erblich geworden sind oder nicht. Nimmt man das erstere an und glaubt man an ein Fortbestehen der betr. Form (meinetwegen der var. decipiens Sagorski bei R. rubiginosa), dann wird man schliesslich gezwungen sein, solche Rosen als Unterarten oder dgl. vom Kreise der eigentlichen Art auszuschliessen und ihnen eigene Diagnosen zu geben. Das-braucht aber niclıt zu geschehen, wenn man mit Grund annimmt, dass solche Abnormitäten in verschiedenen Zeiten und an verschiedenen Orten immer wieder vorkommen, weil die Bedingungen hiefür oder die inneren und äusseren Ursachen gelegentlich immer wieder eingreifen, ohne das Gefüge der Art selbst zu lockern.

1) P. Parmentier: Recherches anatom. et taxinomiques sur 1. ros. (Annal. sc. nat. 1898).

2) Nach den Prioritätsgeselzen müsste diese Varietät wohl heissen var. venusta (Sagorski)

R. Keller. Doch mag die von der Synopsis angewandte Bezeichnung bleiben, um Unklarheiten zu vermeiden.

3) Bei der Berger Rose sind die Brakteen ganz besonders stark entwickelt und wie die Blätter seidig hehaart; die Stacheln etwas ungleich an Grösse; die Blattzähne tief und scharf eingeschnitten, mehriach bedrüst; die Inflorescenz reichblütig. Wenn nicht die Blütenstiele sehr kurz und die Stacheln etwas gebogen wären, müsste man die Rosenform von Berg zur var. cristata Chr. (= var. Andrzejowskii Déséglise) der R. tomentosa rechnen. Olfenbar ist der Unterschied zwischen den beiden Formen ein fliessender. Sagorski schreibt direkt: „Die R. venusta . ... steht einigen Formen der folgenden Gruppe ${ }^{*}$ - der Tomentosae — und der var. subvillosa Chr. und der var. cristata Chr. sehr nahe " (Rosen d. Fl v. Naumburg S. 9 f.). Die var. subvillosa hält er sogar für eine Form seiner $R$. venusta. 


\section{Iosa tomentosa smith.}

Starker Strauch mit verlängerten Ästen. Stacheln \pm gebogen, nie krummhakig, mit breitem Grunde. Blättchen breit oval bis elliptisch; Zähne breit,

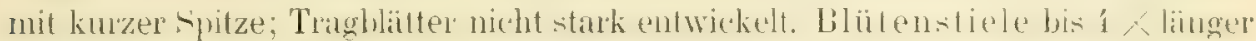
als die Kelchbecher. Kelchblätter nach dem Verblïhen abstehend bis auf-

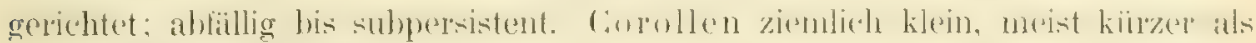

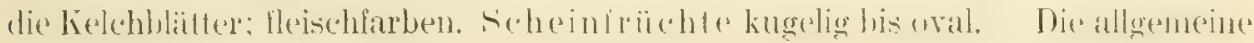
Bedrüsung schwïcher wie bei $R$. pomifera.

\section{Ubersicht der i. G. k. Formen:}

Wie schon oben bemerkt wurde, trennen wir von der eigentlichen $R$. tomentosa, wolcher die vorasstehende Definition gill, als Interart mit netreren

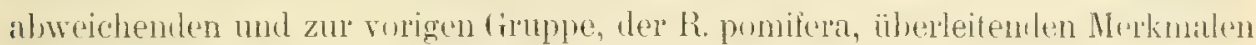
die $R$. scabriuscula H. Braun ab. Eine anschauliche Gruppierung der von der R. tomentosa dann noch übrig bleibenden Formen bietet trolzdem wegen der zahllswen C'berginge und der bei den Antoren herrschenden Lnsicherheil der Beschreibung last uniiburstegliche schwierigkeiten. Ich glicelere, ihnlich wie es bei der R. canina. dumetnum, glauca gesehieht, in drei Formentievise, die immer stärkere Zahnung und Bedrüsung der Blättchen aufweisen.

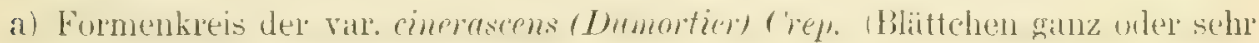
vorwiegend einfach gezahnt):

var. cinerascens (Dumortier) Ciep.

\section{f. subduplicata Borbas ${ }^{1}$ )}

b) Formenkreis der var. subglobosa (Smith) Carion (Blïttchen grob doppelt gezahnt):

var. subglobosa (Smith) Carion

1. dimorpha (Déséglise) R. Keller.

f. fallax mihi $\left.i^{2}\right)$

1. anceps miti $i^{3}$ )

1. Billotiana Crep.

var. typica Chr.

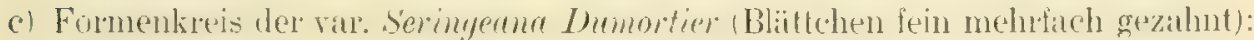

1) Die f. subdupl. Borb. ist von der var. subglobosa des nächsten Formenkreises nicht scharf zu trennen. Nach Baker (A monograph of the british roses, 1869, p. 217) unterscheiden sich die var. cinerascens und subglobosa lediglich durch einfache oder doppelte Zahnung. Da aber auch die subglob. hie und da einfache Zühne besitzt (R. Keller Syn. S. 84), so muss man der f. subduplicata Borb. jene Rosen zuschreiben, die in dieser Beziehung eine Mittelstellung einnehmen. Um zu einem Resultat zu kommen, habe ich alle Rosen unter die f. subdupl. subsumiert, welche durchschnittlich nur die Hälfte der Zähne und weniger mit einem Nebenzähnchen versehen zeigten; die reicher gezähnten rechnete ich der var. subglob. zu.

2) Fallax = trügerisch, wegen der unregelmässigen Bedrüsung der Blättchen.

3) Anceps = zweideutig, wegen der Mittelstellung dieser Rose zw. der var. subglobosa und var. cristata Chr. Die f. anceps ist eine jener Rosen, die einen beim Bestimmen zur Verzweiflung bringen wegen ihres schwankenden Charakters. 
var. Seringeana Dumovtier ${ }^{1}$ )

1. poecilacantha mihi ${ }^{2}$ )

var. cuspidatoides Crep..3)

d) Subspecies scabriuscula ( $H$. Braun) mithi ${ }^{4}$ )

(Stacheln vorwiegend gerade und an der Basis nicht auffillig verbreitert. Blättchen frin mehrlitch gezzihnt und drisig, auch an der Lnterseite \pm drüsig. Blütenstiele lang, mindestens $1 \frac{1}{2} \times$ so lang wie die Frucht. Kelchzipfel nach der Bliite aufgerichtet und anscheinend persistent. Griffel wollig.)

var. cer $\alpha$ mihi $\left.{ }^{5}\right)$

var. farinosa (Bechstein) Séringe

var. ambelliflora (Swartz) Crep. ${ }^{6}$ )

1) Ich folge der Autorität H. Brauns (in G. Beck v. Mannagetta: FI. v. Niederösterreich S. 814), wenn ich die var. Seringeana für identisch mit der var. cuspidata Godet und pseudocuspidata Crep. halte und die Priorität wie oben entscheide.

2) Der Name ist abgeleitet von Joixidas, mannigfaltig, und ixavja, Stachel.

3) Dagegen kann ich nicht mit H. Braun und A. Schwarz (Fl. v. Nbg. S. 563) finden, dass die var. cuspidatoides Crép. verschiedene Formen der Braun'schen Art scabriuscula in sich begreife. Das war allerdings die Ansicht von Scheutz und Borbas (Primit. monogr. ros. imp. Hung p. 520), aber nicht von Crépin. Denn Braun schreibt der letzlgenannten aufrechte, an der Frucht ausclanernde Kelchzipfel zu, während Crépin von seiner var. cusp. schreibt, die Kelchblätter seien „nach der Blüte bloss ausgebreitet, dann abfällig“ (Primit. mon. ros. 2. fasc. p. 128). Weil Crépin im Tảbl. anal. von 1893 bereits die R. cuspidatoides als Varietät der R. tomentosa auführt, muss ihm der volle Autorname bleiben. Dasselbe gilt für analoge Fälle.

4) Die R. scabriuscula ist nach Abbildung und Beschreibung bei Smith und Baker zu unbestimmt gehalten, was auch Crépin belont (Primit. monogr. ros. 6. fasc. p. 93). Bloss dieses steht bei Smith fest, dass die scabriusc. gerade, schlanke Stacheln that und weniger reich behaart ist wie andere Tomentosen. Von der Abfälligkeit oder Persistenz der Kelchzipiel ist nicht die Rede. Crépin urteilt an obiger Stelle von dieser Rose, dass sie eine Übergangskategorie sei, die wohl melnrere Varietäten in sich begreife. Erst H. Braun gibt eine präzise Definition in dem Artikel: „Über einige in Bayern und dem Herzogtum Salzburg wachsende Formen der Gattung Rosa" (11. Bericht der botan. Vereinigung Landshut, 1889, S. 119 ff.). Ich acceptiere die Deutung Brauns, setze aber seine Art R. scabriusc. zu einer Unterart herab, weil sie durch Übergänge mit R. tomentosa zusammenhängt (es kommen vor z. T. gebogene Stacheln, gerade Stacheln mit verbreiteter Basis, weniger deullich aufgerichtele kelchzipfol, bloss slark haarige Grillel u. dynl.). Die Behauptung Beauns, die Formen der scahriusc, hällen ganz ferale stacheln, darf iiberhaupt nicht urgiert werden; die Stacheln sind kaum jemals so vollkommen gerade wie bei der pomifera, sondern

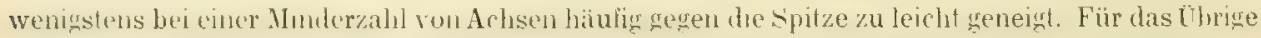
yerweise irht auf die Auslïhrumen H. Brauns selbst. Christ und R. Keller weichen in ihrer Defintion der scabriuscula bedeutend von H. Braun ab; auf welches Fundament sie sich dabei stützen, ist nnir unbekannt. Die Rose Christs erinnert mehr an die var. Seringeana Dum. oder cuspidatoides

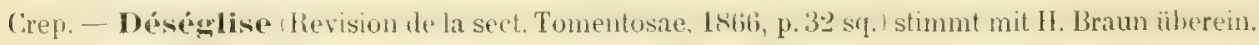

5) Im Bereich der $R$. tomentosa gibt es schon eine f. typica. Es darf also nach "Internat. Reg. d. Nomenk1. 1905 Art. 29 der gleiche Name nicht noch einmal verwendet werden. Ich musste deswegen die var. typ. H. Br. durch var, vera (= wirkliche) ersetzen und a fortiori die f. typica $\mathrm{H}$. Br. durch f. communis mihi.

6) Venn die R. umbelliflora Swartz wirklich zurückgeschlagene und abfällige Kelchblätter hätte, wie $\mathrm{R}$. Keller in der Syn. annimmt, so müsste die hier angemerkte Rose einen andern Namen erhalten. Nach Braun und J. B. v. Keller ("Nachtrag zur Flora Niederösterreichs" v. Halacsy u. Braun, Wien 1882, S. 253) sind die Kelchblätter aufrecht und bleibend. Die Originaldiagnose bei Scheutz (Bidrag etc. 1873) war mir nicht zugänglich. Borbas, der in solchen Fragen immer sehr zuverlässig ist, versichert jedoch (Primit. monogr. ros. imp. Hung. p. 520), er 
var. cristata $C h$ r.

var. subrillosa Chr.

f. communis mili ${ }^{1}$ )

1. pegnesensis H. Braun.

Diagnosen:

1. Var. cinerascens: Blättchen breiteifömig, weichfilzig beharart unterseits

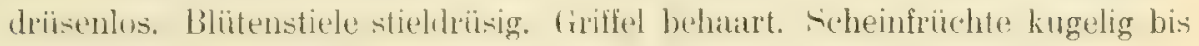
eikugelig.

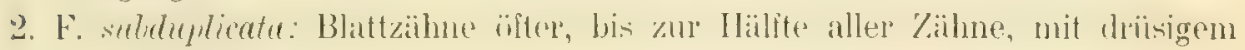
Nebenzïhnchen.

3. Ian. sulyglobosa: Blittchen oval; weichfilzig; die wenig tielen Zaihne leicht in Kerbung übergehend, manche nur einfach; Subfoliardrüsen fehlen. Kelch-

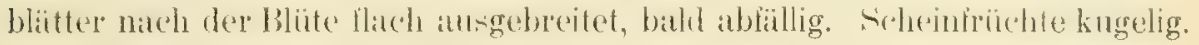

4. F. dimorpha: Blättchen schmal elliptisch oder schmal eiförmig.

5. F. fallax: Blättchen schmal eilörmig mit scharler Spitze; die meisten ohne Drïsen, einzelne aber mit Iriisen and der L'ntexseite und sogar der Oberseite.")

6. F. anceps: thacheh ungleich, pfrienlich, aber gebogen. libittehen oval bis breitoval; die grössten mit herzförmigem Grund $7 \mathrm{~cm}$ lang und $5 \mathrm{~cm}$ breit; Drïsen wie bei f. fallax, ${ }^{3}$ )

7. F. Billotiana: Bliten tragende Zweige oberwärts mehr oder minder stark behaart. Bliitenstiele etwas hehart.

8. Var. tipnica Ch\%: Scheinfrüchte oval bis länglich.

9. Var. Seringeana: Die ovalen Blïttchen in eine lange Spitze ausgezogen; unterseits reichdrüsig, zuweilen auch Drüsen auf der Oberseite. Blïtenstiele 3 bis $4 \times$ linger als die Kelchbecher. Grifel schwach behaart bis borstig. Kelchzipfel abfällig. Scheinfrüchte wenig drüsig; eiförmig bis eikugelig. ${ }^{4}$ )

10. F. precilacuntha: Stacheh äusserst vershiedm: dic grossen stark gehogen bis gerade, von verschiedener Länge; dazu mehrfach kleinere meist drüsentragende gerade Borsten unter der Inflorescenz. Griffel borstig behaart. ${ }^{5}$ )

habe schwelische Originalexemplare tesehen; sie hitten aufrechte und persistente Kelchbliatler" Rosen mit zurỉckgeschlagenen Sepalen seien vielleicht R. pseudocuspidata Crep. Scheutz selbst schrieb nach Borbas in einem Brief an ihn seiner R. umb. aufrechte Kelchblätter zu.

1) Communis, gemein.

2) Zur Ergänzung der Diagnose diene: Kelchblätter zurückgeschlagen, bald ablällig. Griffel schwach behaart. Scheinfrüchte kugelig, lang gestielt, reich bedrüst und bestachelt. - Es handelt sich um eine Ubbergangsform gegen die var. Seringeana Dum. hin.

Lat. Diagnose: Foliola anguste ovata, in apicem acutum producta; pleraque glandularum expertia, nonnulla vero glandulis non solum in inferiori sed etiam in superiori parte obsita, Cetera ut in var. subglobosa.

3) L. D.: Aculei longitudine impares, cxiles, sed incurvati. Foliola ovata aut late ovata cum basi cordiformi, usque ad longitudinem $7 \mathrm{~cm}$ et latitudinem $5 \mathrm{~cm}$ protracta; eorum glandulae ut in $f$. fallaci.

4) Crépin legt in der Beschreibung seiner R. pseudocuspidata (Primit. monogr. ros. 6. fasc. p. 753 sq.) Gewicht auf die „ovalen“ Scheinfrüchte. Ich habe die Diagnose nach seinen Angaben korrigiert.

5) L. D.: Aculei staturae diversissimae: majores vel recti vel curvi neque longitudine

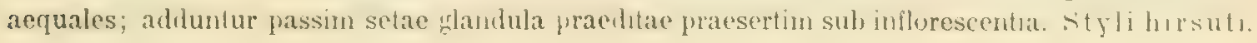


11. Var. cuspidatoides: Blïttchen oval bis breitoval. Kelchzipfel subpersistent, schliesslich abfïllig. Griffel stark haarig bis wollig. Scheinfrïchte kugelig bis eikugelig.

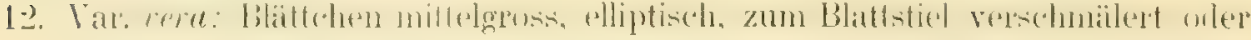
schmal zugerundet; oben nur zerstreut, unten dicht behaart, ${ }^{1}$ ) unterseits reichdrüsig. Krone meist blassrosa. Scheinfrüchte kugelig bis eikugelig.

13. Var. farinosa: Strauch niedrig, gedrungen. Blättchen klein, eiförmig; sehr kurz und fein mehrfach gezïhnt; oben grau, unten weissfilzig. Bliitenstield drüsenarm bis nackt: ${ }^{2}$ ) desgleichen die kugeligen oder eikugeligen Scheinfrüchte. Kelchzipfel kurz.

14. Var. umbelliflora: Blättchen mittelgross, lanzettlich, beiderseits zugespitzt und dicht behaart: unten dicht dribig: zuweilen mit einigen - iuperfoliardriisen. Scheinfrichte oval.

15. Var, cristata: Blïtchen mittelgross bis gross; breit oval; äusserst tief und steil gezithnt. Kuldhbitter liung. Scheinfrüchte kugelig oder eikugelig, weichstachelig.

16. Var, subvillosa: Blïttchen mittelgross, breit oval bis rundlich; beiderseits von der starken Behaarung seidig glänzend. Scheinfrïchte meist glatt, kugelig.

17. F. communis: Die Subfoliardrïsen schwächer entwickelt. Corolle tief rosa.

18. F. pernesensis: Die Blïttchen reicher drüsig. Corolle blass rosa. ${ }^{3}$ )

\section{Standorte:}

Ad 2. Oberhalb Rebdorf b. E. (Dolomit $490 \mathrm{~m}$ )

Bei Inching

An Dolomitfelsen oberhalb der Brunnmühle b. Walting a. A.

Bei Walling a. A.

Neben der Eichstïtter Strasse beim Affentaler Wirtshaus

1) Den Satz über die Behaarung habe ich aus der Definition der R. scabriuscula durch Smith-Baker genommen.

3) Die Originaldiagnose bei Rau (Enumeratio ros. c. Wirceb. sp. cresc. p. 147 sqq.) sagt über die Drïsigkeit der Blütenstiele und Früchte nichts Bestimmtes; denn ,glatt" (in der Bechstein'schen Diagnose) und ,glaber" (im eigentlichen Rau'schen Texte) heissen zunächst, haarlos", dann allerdings auch, drüsenlos“. Im Zusammenhange kann bei Rau glaber nur haarlos bedeuten, demn er schreibt von den Blitenstielen: "Pedunculi superne glabri, basi pubescentes", die Blütenstiele sind oben haarlos, unten flaumig. Wie er ferner sich ausdrückt, tragen die Blättchen auf Haupl- und Seitennerven der Unterseite Drüsen; die Scheinfrüchte sind eikugelig. Die sonstige Beschreibung Rau's entspricht mehr der Definition, welche H. Braun von seiner R. scabriuscula überhaupt gibt. Erst Christ (S. 98 f. der Ros. d. Schw.) verleiht der Definition von var. farinosa den gewöhnlich angenommenen näheren Inhalt. Er nennt die Blülenstiele „zerstreut stieldrüsig", womił er Recht haben diüfte. Der Satz jedoch, die Blättchen seien „mit körnigen Subfoliardrüsen dicht und gleichmässig überzogen gleich einer sehr drüsigen Rubiginosa *, tut dem Texte Rau's Gewalt an. M. Schulze (Jena's w. Ros. S. 4) rechnet gar Rosen „mit sehr kurzen Blïtenstielen " und mit kurzen, von den sehr entwickelten Brakteen überragten, „stacheldrüsigen Blïtenstielen zur var. farinosa Chr. ( $=$ R. far. Bechstein-Rau), Das widerspricht dem Texte von Christ und Rau; die betr. Formen scheinen in den Bereich der R. mollis oder omissa zu gehören.

3) Die Diagnosen d, beiden Form. nach H. Braun: „Uber einige in B. w. Formen d. G. Rosa" S. 121. 
a Bei Hechlingen am Hahnenkamm (Schneid!)

Umgebung von Berg b. Neumarkt Obpl.

Jurakalk b. Laaber (Killermann!)

Arl 3. Dolomitfelsen ob Wasserzell b. E.

An der Strasse Schernfeld-Schönfeld

Eingang des Heimbacher Tales b. Greding (Doggerlehm $400 \mathrm{~m}$ )

Am Fusssteig Badanhausen-Haunstetten (Malm $460 \mathrm{~m}$ )

An Strasse. Wintershofen b. Berching-Holnstein (Ialm $530 \mathrm{~m}$ )

Wald am Mittelmarterhof b. Pappenheim (530 m Prechtelsbauer!)

Mariahilfberg b. Neumarkt Oberpf. (Fl. v. Nbg.)

Sperlasberg und Ruine Velburg (Fl. v. Nbg.)

Ad 4. Waldrand links der Altmühl zw. Ilbling und Kinding (Nalm $420 \mathrm{~m}$ )

Bergwand b. Enkering i. Anlautertal (Dolomit $450 \mathrm{~m}$ )

Zw. Berg b. Neumarkt und dem, ,schwarzen Holz" (Liaslehm $450 \mathrm{~m}$ )

Ad 5. B. Rohrbach an der rechten Talwand des Trockentales gegenüber Matuern (Dolomit $480 \mathrm{~m}$ )

Ad 6. Rand einer Schlucht des Frauenbergs b. E. (Plattenkalk $520 \mathrm{~m}$ )

Ad 7. Wallersdorfer Anger b. Altdort') (Scherzer!)

Zw. Grïsberg und Prackenfels (Scherzer!)

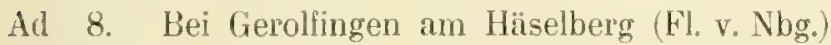

Ad 9. Nähe der Brunnmühle b. Walting a. A.

Am Wirtsberg b. Walting a. A. (Dorr!)

Suidwestl. von Berching (Doggersand)

Am Nlühlberg b. Pappenheim (Fl. v. Nbg.)

Hobelsbude b. Ammerbach i. Ries (Schneid!)

Ad 10. Waldsaum b. Emskeim (Malm $500 \mathrm{~m}$ )

An Strasse Möhren-Treuchtlingen (Schneid!)

Ad 11. An der Strasse zw. Hofstetten und Pfünz (Malm, Schneid!)

Westabhang d. Schlosses Sandsee b. Pleinfeld (Keupersand, Schneid!)

Ad 12. $\beta$ Oberhalb der Kiesgrube am Eingang d. „Anlage" E.

$\gamma$ Am Weg Riedelshof-Altenberg b. Kipfenberg (Malm $500 \mathrm{~m}$ )

An der Strasse i. Birktal b. Kipfenberg (Schneid!)

$\delta$ Links von d. Schafhausener Mühle i. Anlautertal (Malm 430 m)

$\varepsilon$ Thann b. Riedenburg

Am Nagelberg u. sonst b. Treuchtlingen (Fl. v. Nbg.)

Waldrand a. d. Strasse Mannholz-Liebenstadt b. Heideck (Doggersand $470 \mathrm{~m}$, Schneid!)

Um Breitenbrunn (Fl. v. Nbg.)

Ad 13. $\zeta$ Am linken Hang d. Posentals b. E. (Malm $440 \mathrm{~m}$ )

$\eta$ Mehrfach an d. Strasse zw. Kaserne b. E. u. Landershofen

$\vartheta$ Talgrund zw. Pfünz u. Eitensheim (Schneid!)

Bei Walling a. A.

1) Gemeint ist Altdorf b. Nürnberg. Jch habe es hieher gezogen wegen seiner Lage am Nordwestablıang des Neumarkter Jura. 
Am linken Hang d. Schambachtales b. Kipfenberg zw. Loh- und Forstermiihle (Alluvium $390 \mathrm{~m}$ )

Im hintersten linken Ast d. Schambachtales $(430 \mathrm{~m})$

Waldsaum zw. Riedelshof u. Altenberg (Schneid!)

Ad 14. Bei Walting a. A.

Am Nagelberg b. Treuchtlingen (540 m Prechtelsbauer!)

Ad 15. Schlucht d. Schelmenbergs - linke Talwand - b. E. (Dolomit $480 \mathrm{~m}$ ) * Desgleichen

Am Eichelberg b. Breitenbrunn (Fl. v. Nbg.).

\section{Ad 17. Hessental b. E.}

$\lambda$ Mehrfach b. Walting a. A. (Dorr!)

Am Weg zw. Plalzpaint u. d. Steimbrïchen (Dorr!)

Bei Isenbrunn

In Menge an d. Strasse St. Veit-Stopfenheim (Grenze Lias-Keuper)

Ad 18. $\mu$ Hïufig in Schlucht $z w$. Adamsberg $u$. Ochsenkeller b. E.

Zwischenformen: Von den im Vorstehenden angeführten Rosen tragen viole Charkktere an sich, durch die sio Verbindungen zwischen verschiedenen unserel systumatichen finphen herstellon. Besonders gilt dies von den Exemplaren der [Interant scabriuscula. Die Ruse as die Mittellorm gegen die subsp. scabriuscula hin, weil ihre Silacheh fast gerate sind. Die Rusen i) und o neigen gegen die var. cuspidatoides Crép., die eine wegen der schwïcher persistenten helchziplel, die aulere wegen der etwas gebogenen Stachelu. i' hat wenigr oder keine Drïsen am Blütenstiel und zienlich kleine Blattrohen ähnlich der var. farinosa. Dagegen zeigt die farinosa $\zeta$ öfter ziemlich reiche Drüsen an den Blïtenstielen. Ruse \& bildet wegen ihrer grossen Blïter den C'bergang zur rar. cristata. Stramch " trägt viele otwas gebogene Stacheln, die gegen den Formenkreis (c) hinweisen. Am kumpliziertesten verhïlt sich \%: Lnter Torherschen der

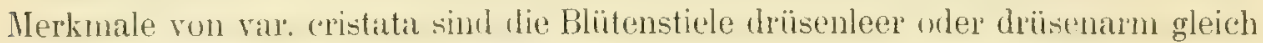
ler var. farinusa, und die sekundiren Zähnchen der Blattränder so sejeht, wit? wir es sonst nur bei der var. subglobosa gewahren. Eine Rose unter $\lambda$ hat so ansgebildet spratelige lielchziplel wie die var. cinmoiles liener, Stiick "wieler die Blïtensticle der typischen var. farinosa. Offenbar zeigen sich die Varietitten der subsp. scabrusula am wengsten scharf von einander getrennt und werden auch die Beziehungen der ganzen Lnterart zu den übrigen Formen der tomentosa

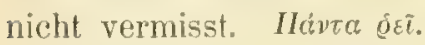

Im Gebiete gehört die $R$. tomentosa zu den an warmen sonnigen Stellen fast iiherall vorkommenden Rosen; am seltensten trilt sie im Nemmarkter Juri auf. Zuweilon zeigt sie in ansgedehnten Hecken Massenbildung: gewöhnlich steht sie jerloch an Häufigkeit hinter den Caninen und auch Rubiginosen zurïck. In Burirke dominieren dir reicher gezihnten und bedrïsten Formen. Am häuligsten gewaht nan 3 (ipuppen: 1. Die var. subglobusa mit der f. subduplicata der var, cincriseens, 2. dir Var. Seringeana, 3. die Lnterat scabrinscula; diese ist in Eiclstiatter Jurat unter atlen die hïufigste, wats äbrigens wohl auch rom übrigen Nordbayern gilt. 


\section{Sectio IV: Rubiginosae D.C.}

Stacheln vorwiegend gleichförmig; die gewöhnlich vorhandenen gross,

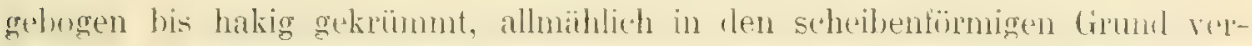

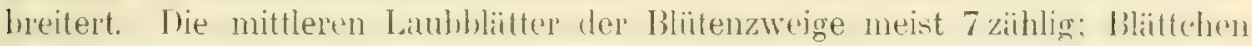
klein bis mittelgross, mit zusammengesetzter Zahnumg; nicht filzig, abex wonigstens unterseits etwas behaart; unterseits sehr reich mit stark riechenden Drïsen ausgestattet. Inflorescenz nehrblütig.

Im Gebiete und in ganz Deutschland kommen 4 Arten vor, die zu dieser Sektion gehören. Im Mittelmeergebiet und in Vorderasien finden sich noch weitere 6 Arten, ${ }^{1}$ ) nimlich die R. aryophyllacea Besser, glutinosa silhthorp et Smith, sieula Trattinik, Serafini Viviani, ferox M. V. Bieberstein und asperrima (iodet. Die exutischen Arten unterschedelen sich von den unsrigen im allgemeinen lurch mehr heteracanthe und weniger hakige statheh. L'nsere 'f Arten bilelen

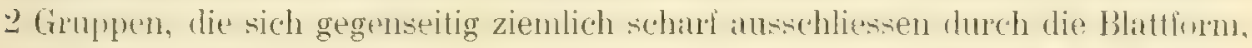
den Geruch der Blattdriisen. die Bedribung der Bliitenstiele und die Kronenfarbe. In jeder Gruppe weichen die beiden zu ihr gehörigen Rosen in ganz analogem Sinne von einander ab, nämlich im Wuchs, in der Behaarung der Grittel und in der stellung und Persisternz der Keldhblitter. In iibrigen gledichen

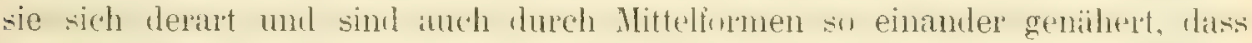

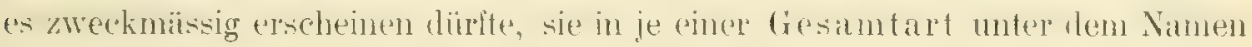
der wichtigsten Art zusammenzulassen. Christ errichtete in seiner Sectio

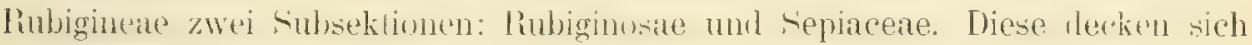
mit unseren beiden Gruppen (Gesamtartein). Eine derartige Teilung in Subsektionen, wit Christ sie vornmmt, sheint weniger zweckmässig nit liibksirht aul eine systematische Gliederung del ganzen Gattung Rowa und Sectio Ronhginusite, weil bei Beribchsichtigung ler exotivehen Arten doch tine andore Einteilung nach Subsektionen notwendig sein würde.

\section{Gesumtart Rosa rubiginosa $L$.}

Die grossen Stacheln zuweilen schwach gekrimmt. Blättchen klein

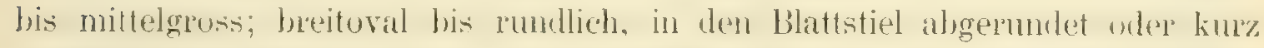

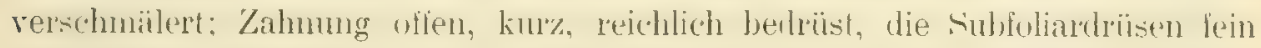

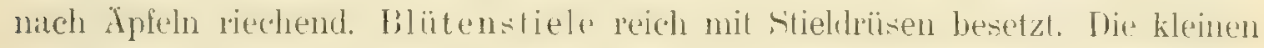
Kronen rosa bis tiefrosa oder purpurn.

\section{Einzelart liosa mbiginosa $L$.}

Strauch von untersetztem Wuchs. Stacheln öfter zweifach, die grossen Stacheln öfter schwach gekrümmt. Kronen regelmässig tiefrosa. Blütenstiele kurz (1-1,5 cm lang); Brakteen gut entwickelt. Kelchblätter subpersistent. Griffel ein kurzes lïiptehen, behart bis wollig. Schoinfrïchte vorwiegend kugelig und eikugelig.

1) Bei unserer mittelweiten Fassung des Umlanges der Art. 


\section{Ubersicht der i. G. k. Formen: $\left.{ }^{1}\right)$}

a) Formenkreis der var. umbellata (Leers) Chr. (Bestachelung ungleich, bes. an den Jahrestrieben):

var. umbellata (Leers) Chr.

f. echinocarpa (Ripart) Borbas

1. dimorphacantha (Martinis) Borbas

var. horvide Lange

var. calcophita H. Braun

var. jimprinelloides Chr.

f. spinosissima Bräuclier.

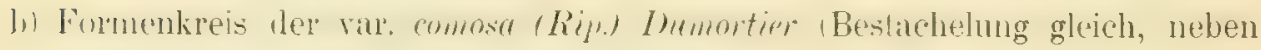
den hakigen Stacheln sehr selten Borsten):

var. comosa (Rip.) Dumortier

f. apricorum (Rip.) Borbas ${ }^{2}$ )

f. comosella (Déséglise et Ozanon) H. Braun

f. acanthophora I. B. v. Keller

var. glabriuscula Peterman

f. decipiens Sagorsti

var, jenensis M. Schulze

var. microphylla $R$. Keller

f. parvifolia Rau

1. rotundifolia Rau

f. densa (Timbal-Lagrace) Borbas

f. minuscula (Ozanon et Gillot) Crep.

f. sulicumeata Burnat

var. pseudohystivix Chr.

var. Hagellaris Chr.

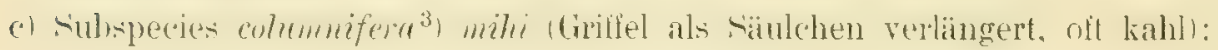

1) Ich habe die Formenkreise und womöglich auch die Formen innerhalb derselben so geordnet, dass die Rosen mit den am meisten aufgerichteten Kelchzipfeln, der stärksten Heterakanthie und den kürzesten, wolligen Griffelköpfchen den Anfang machen und diejenigen mit abfälligeren Kelchzipfeln, einerlei Stacheln und verlängerten kalılen Griffeln den Schluss. Diese leiten die Ubersicht gegen die R. micrantha' hin.

2) Die f. typica H. Braun und die f. apricorum (Rip.) Borbas unterscheiden sich nur so unbedentend voneinander, dass ich im folgenden Standortsverzeichnisse die von A. Schwarz in Fl. v. Nbg. angegelenen Fundorte der f. typica H. Br. zur f. apric. rechne. Das Vorkommen von Nadelstacheln und Drüsenborsten ist bei der f. apricorum wie der var, comosa überhaupt nichts weniger als häufig, geschweige denn konstant. Ripart sagt allerdings von seiner $\mathrm{h}$. comosa, dass die Blütenzweige mehr oder minder drüsenborstig seien, aber schon Crépin hemerkt auf S. 138 des fasc. 6. der Primit, dass dieses Merkmal auch an Originalexemplaren liparls häufig nicht zutreffe. Das Gleiche gilt nach Grépin von der R. apricorum, der bloss Déséglise Drïsenborsten an den Blütenzweigen zuschreibe.

3) Columnifer, Säulentragend, von dem Griffelsüulchen so benannt. Lat. Diagnose: Stỵli in columeilam protracti, saepius glalsi. - Vgl. zu c) Anm. 2 S. 41.

Ich führe diese Unterart ein, da ähnliche Formen, und zwar nicht bloss solche mit kahlen Griffeln, im Bezirke wie in ganz Deuischland ziemlich häufig vorkommen. Diese Unterart leitet 
var. macrostyla $\left.{ }^{1}\right)$ mithi

f. comosoides $^{2}$ ) milii

1. paupercula ${ }^{3}$ ) mihi

var. liostyla Chr.

var. Gremlii Clr.

\section{Diagnosen:}

1. Var. umbellutu: Krältiger, kuräitiger tranch. Lngleichartige Bestachelung namentlich an unteren Teil der Jahrestriebe (Bulenschïslinge) schart ausgesprochen. Blättchen gut mittelgross. Inflorescenz in der Regel leichblütig. Blütenstiele drüsig und stachelig. firiftellöplehen stark haarig bis wollig. Scheinfrichte kugelig bis eikugelig.

2. F. echinocarpa: Scheinfrüchte dicht stieldrüsig und stachelborstig.

3. F. dimmphucantha: Die schwachen hakigen Stacheln der blïtentragemlen Zweige dicht unter dem Blütenstand mit zahlreichen mehr oder minder geraden borstlichen Stacheln untermischt.

4. Var. horride: Schössling sehr stark mit grossen hakigen und kleineren, schwach gekrïmmten bis geratron stacheh bewehrt. Auch blitentrigende Zweigge, Blattstiel, Bliitenstive und Kelchbecher dicht mit lamgen driisenhosen

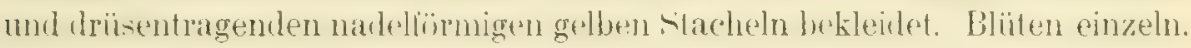

5. Var. calcophila: Die Bliitenstiele zum Teil stieldrüsig zum Teil drüsenlos.

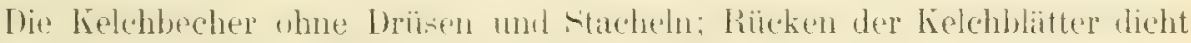
drüsig. Griffel wollig. Scheinfrüchte eikugelig bis eiförmig. ${ }^{4}$ )

6. Var. pimpinelloides: Zwergstrauch, kaum $3 \mathrm{dm}$ hoch. Blättchen so klein oder kleiner als diejenigen der $\mathrm{R}$. pimpinellifolia; fast kahl. Blüten klein. An der typischen Form sind die Blitenstiele drüsenarm und stachellos; die Scheinfrüchte klein, länglich.

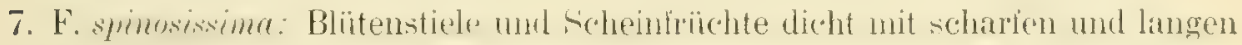
Borstenstacheln besetzt. ${ }^{5}$ )

8. Vitr. comosf Aste oft etwas verlängerl. Blätchen mittelgross bis klein. Biitensticle stielurïsig, meist ohne stacheln. Influrescenz gewöhnlich armblïtig.

zur Rosa micrantha hin, besonders wenn die Griffel auch noch kahl und die Kelchblätter unentschieden aufgerichtet sind. Selbstverständlich hängt sie aber durch die ïbrigen Merkmale mit der echten $\mathrm{R}$. rubiginosa zusammen und zwar am meisten mit dem Formenkreis der var. comosa. Solche Unterarten, welche zwischen Einzelarten einer Gruppe vermitteln, werden wir auch später kennen lernen. - Die var. fallax R. Keller würde ich als Form zu meiner var. macrostyla zichen.

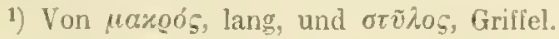

2) Der Name besagt: ähnlich der var. comosa (wegen der ausgebreiteten, bald abfälligen Kelchzipfel).

3) Pauperculus, armselig.

4) Diese Form ist kein Bastard, wie in der Fl. v. Nbg. als möglich angedeutet wird. Am Eich-

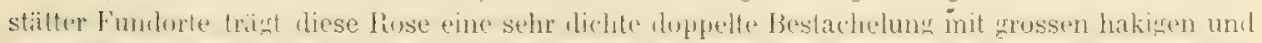

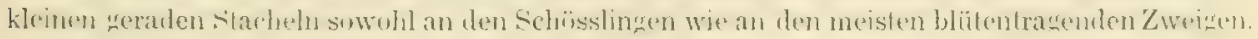
Insofern verråt sie Verwandtschait mit der var. horrida Lange.

5) Die hiesigen Exemplare haben eikugelige bis eiförmige Scheinfrüchte. Brłiucker er-

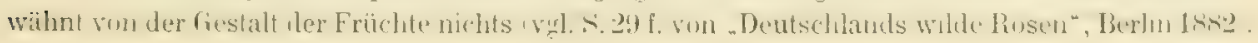




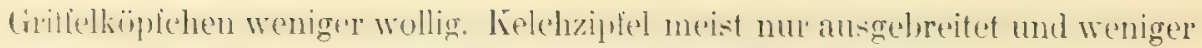
persistent als bei var. umbell. ${ }^{1}$ ) Scheinfrichte der typ. Varietät oval.

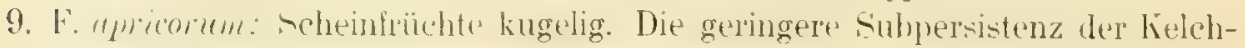
zipfel besonders ausgeprïgt.

10. F. comosella: Dis langen an den Bliitenzweigen nadellïmigen stacheln fast gerade. Die kleinen Scheinfrüchte meist etwas verlängert.

11. F. acuthophore: Hir 'Wweige mit gepaaten langen zitmlich geraden, aber doch gegen den firund verbreiterten stacheln bewehrt. Durchaus einblïtig.

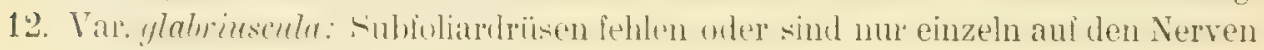
verstrent.

13. F. decipiens: Blätlchen beiderseits kahl, Scheinfrüchte eiförmig.

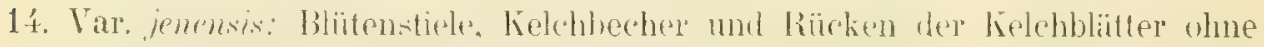
Stieldrüsen. Scheinfrïchte meist kugelig.

15. Var. microphylla: Kleiner Strauch. Blättchen klein bis sehr klein.

16. F. parvifolia: Kräftige, hakig gekrümmte Stacheln.

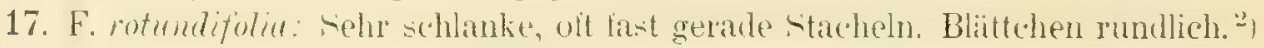

18. F. đensa: Kelchbecher länglich eiförmig.

19. F. mimsenlu: An den älteren Triehen nehen kräitigen gekrümmten Stachelu kleinere last gerarle. Blittchen lïnglieh eiförmig, olt nit keiligem Grunde, unten nur am Mittelnerv zerstreut behaart.

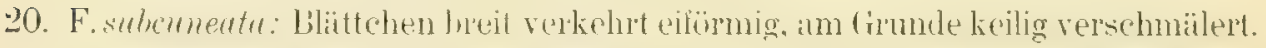

21. Var. psendolngstrir: Blätchen klein, schmal, elliptiseh, teils heilig in den Grund ver'schnäler, teils unten zugerundet. Pllanze haarlos. Blïtenstiele fein und gleichmässig stieldrüsig. Scheinfrüchte klein, kugelig.

22. Var. flayellaris: Stratuch flattrig, Aste rutenförnig vilüngert, Schüsslinge

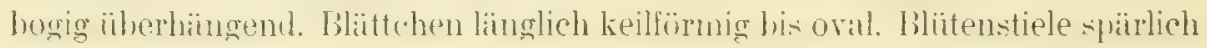
mit Stieldrüsen bekleidet. Scheinfrüchte eikugelig.

23. Var. macrostyle: Stacheln von einerled Gestalt, an den Stänmen hakig. an lten Blïlenzweigen weniger gekrïmml. Blattchen unterseits hatrig und reich drüsig. Kelchblätter nach der Blüte abstehend, bald abfällig. Griffel zu einem kleinen Säulchen verlängert, aber \pm stark behart. ${ }^{3}$ )

1) Die var. umbellata. und comosa gehen vielfach in einander iber, wie Crépin Primit. fasc. 6. S. $138 \mathrm{ff}$. nachweist. Dass die Griffelköpfchen bei comosa und apricorum weniger wollig und die Kelchzipfel weniger subpersistent sind als bei var. umbellata, behauptet Déséglise (ebd. S. 141), und habe ich auch bei hiesigen Exemplaren bemerkt. Schwächere Behaarung der Griffel lässt nach den Tatsachen der Korrelation bei Rosen auch die Persistenz oder Subpersistenz schwächer werden. Im einzelnen bleibt das Bestimmen von Exemplaren vielfach dem „Ermessen des Einzelnen überlassen. Selbst die grössten Rhodologen haben vielfach geschwankt, denn die Formenreihen fluktuieren ebenfalls indefinit.

2) Bei Rau (Enumerat. ros. p. 137) heisst es: foliola subrotunda. Es ist damit nicht mehr ausgedrückt als mit dem üblichen „breitoval". Auch Crépin legt bei f. rotund. auf die Gestalt der Blättchen wenig Gewicht. Die f. rotund. ist nach ihm eine Zwergform der var. comosa, die zuweilen Stacheln und Blättchen hervorbringe ganz wie die typische comosa (Primit, fasc. 6. p. 145).

3) Aculei aequales, in truncis falcati, in ramis florigeris minus recurvi. Foliola subtus pilosa et valde glandulosa. Sepala post anthesin patentia, mox decidua. Styli columellam efficientes elongati, \pm pilosi. (Die lat. Fassung dieser Diagnose stammt von Hrn. Scheutz und wurde - abgesehen von einer kleinen Korrektur - bereits veröffentlicht in ${ }_{n}$ Mitteilungen d. bayx. botan. Gesellschaft", 2. Bd., Mïnchen 1907, S. 46.) 
24. F. comosoides: Blättchen gross, breit oval, meist kurz in den Stiel verschmälert. Blïten in reichen Corymben. Scheinfrüchte oval (eikugelig bis länglich eiförmig). ${ }^{1}$ )

25. F. paupercula: Strauch niedrig. Blittchen klein; breit oval, gegen den Stiel abgerundet. Armblütig. Scheinfrüchte wie bei f. comosoid. ${ }^{2}$ )

26. Var. liostyla: Kleinblättrig. Griffel verlängert; kahl oder nur mit vereinzelten Haren.

27. Var. Gremlii: Stacheln lang, hakig. Laub gelblich. Kelchblätter nach der Blüte abstehend bis zurückgeschlagen, bald abfällig. Kronen milchweiss oder sehr blassrosa. Die verlägerten Griffel schwach behart.

Standorte:

Ad 1. Linke Talwand b. Ochsenkeller E. (Malm $420 \mathrm{~m}$ )

Dolomitfelsen links d. Altmühl ob Böhming (460 m)

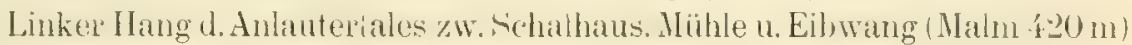
Kiplenberg an Strasse nach Buch (Nalm $410 \mathrm{~m}$ )

Schuttertal zw. Biesenhardt u. Feldmühle (Malm)

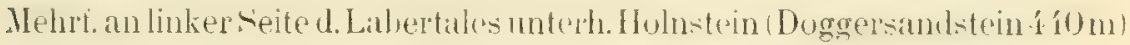

Nordwestl. v. Eichenholen b. Velburg (Malm 520 m)

Bei Pielenhofen (Killermann!)

Ad 2. Buchtal b. E. (mittl. Malm)

Neuerweg b. E. ", ,

An Strasse Dollnstein-Haunsfeld (unt. Malm)

An Fussweg b. Dorf Buch nahe Kipfenberg (Malm 535 m)

Thann b. Riedenburg

Felsen des Tachensteins ob Piedenburg (mittl. Malm)

Ad 3. Beim Herzogkeller E. (Alluvialton $410 \mathrm{~m}$ )

An den Felsen von Oberhofen b. Riedenburg (mittl. Malm)

Westl. von Liebenstadt b. Heideck (Schneid!)

Ad 4. Steinbriche beim hohen Kreuz E. (Plattenkalk $540 \mathrm{~m}$ )

Felsabhang im Trockental gegenüber Mauern (Dolomit $480 \mathrm{~m}$ )

An den Felsen von Oberhofen b. Riedenburg (mitl. Malm)

Ad 5. Am neuen Weg b. E. (Plattenkalk $515 \mathrm{~m}$ )

Mariahiliberg b. Neumarkt Oberpf. (unt. Malm, Fl. v. Nbg.)

Ad 7. Prinzensteig, rechte Talwand, b. E. (Malm $440 \mathrm{~m}$ )

Geissberg b. E. (Dolomit $470 \mathrm{~m}$ )

Ad 8. Linke ${ }^{3}$ ) und rechte Talwand d. Buchtals b. E. (Dolomit 470-490 m)

Neuerweg, linke Talwand, b. E.

Linke Talwand b. Ochsenkeller E.

Kirschenallee b. Prinzensteig, rechte 'Talwand E.

Frauenberg b. E.

1) Foliola magna, late oviformia, plerumque petiolum versus subattenuata. Corymbi floribus abundant. Receplacula fructifera ovoidea (modo breviter contracta modo longius protracta).

2) Frutex humilis. Foliola exigua, late ovata, versus petiolum rotundata. Flores pauci. Fructus ut in f. comosoid.

3) In Menge zusammen mit var. glabriuscula Peterm. f. decipiens Sagorski. 
Bei Walting a. A.

Nordostseite d. Kernbergs b. Gungolding (Dolomit $480 \mathrm{~m}$ )

Öfter am Fussweg Kipfenberg-Pfahldorf

Bei Enkering

Zw. Greding und Landerzhofen

An Dolomitfelsen zw. Kemathen und Kinding

Bei Irfersdorf (Malm $525 \mathrm{~m}$ )

Zw. Neuzell und Paulushofen (ob. Malm $512 \mathrm{~m}$ )

Arztberg b. Beilngries (Dolomit $480 \mathrm{~m}$ )

Schambach b. Riedenburg (Killermann!)

Gemein b. Waltersberg

Häufig an d. linken Seite des Labertals zw. Holnstein u. Staadorf (Malm u. Dogger)

Mehrlach zw. Lnterluirg, Heberstorf und herenhiill b. Beilngries (Malm)

Beilngries (Malm)

Häufig um Breitenbrumn (Fl. v. Nbg.)

Waldrand zw. St. Veit und Stopfenheim (Lehm d. untern Lias)

Bei Mannholz nächst Heideck (Keupersand, Schneid)!)

Mariahilfberg b. Neumarkt Oberpf. (Fl. v. Nbg.)

Am Ottenberg b. Pilsach (unt. Malm $610 \mathrm{~m}$ )

Schlossberg zu Velburg (Fl. v. Nbg.)

Gemein auf dem Malm d. Münchsbergs b. Münchshofen

Bei Lappersdorf (Killermann!)

Ad 9. Bei der Kiesgrube am Eingang der Anlage E. (Kalkgeröll $430 \mathrm{~m}$ )

Mehrfach am neuen Weg b. E. (Plattenkalk 490 u. $500 \mathrm{~m}$ )

Mehrfach am Kugelberg b. E. (Dolomit 470 u. Plattenkalk $500 \mathrm{~m}$ )

Am Weg Riedelshof-Altenberg b. Kiplenberg (Eluviallehm $490 \mathrm{~m}$ )

Bei Breitenbrunn und Dürm (Fl. v. Nbg.)

Mariahilfberg b. Neumarkt (Fl. v. Nbg.)

Am Dillberg b. Hausheim (Doggersand)

Bei Laaber (Killermann!)

Ad 10. Häufig auf unt. Malm b. Waltersberg

Ad 11. Kugelberg b. E.

Linker Talhang b. Dollnstein (Dolomit $460 \mathrm{~m}$ )

Ad 13. Linke Seite des Buchtals b. E. (Dolomit $490 \mathrm{~m}$ )

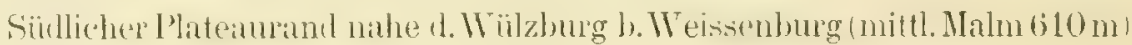

Ad 14. Keilstein b. Regensburg (Killermann!)

Ad 16. Neuerweg b. E., Nähe d. hohen Kreuzes (Plattenkalk 540 m)

Bei der Brunnmühle nächst Walting a. A. (Dorr!)

Linke Talseite b. Böhming nächst Kiplenberg (Dolomit)

Bei Kottingwörth (Dorr!)

Mefrtach an der viulscite d. Nagellnergs h. Treuchtlingen (Malm 510 m)

Edelhausen b. Laaber. (Killermann!)

Saltendorf b. Burglengenfeld (Killermann!)

Ad 17. Mehrfach am Geissberg b. E. (Dolomit u. Plattenkalk) 
Linke Seite d. Anlautertals b. d. Mühle Schafhausen (Malm 410 m)

Am Arztberg b. Beilngries (Malm 450 m) ${ }^{1}$ )

Linke Seite d. Labertales unterhalb Holnstein (Dogger)

Hinter dem Schlosse Möhren (Schneid!)

Suidabhang d. Schlossbergs Heideck (Schneid!)

Mariahilfberg b. Neumarkt (Fl. v. Nbg.)

Ad 18. Am Weg Pfalzpaint-Plahldorf (Dolomit $130 \mathrm{~m}$ )

Ad 19. Linke Seite d. Buchtals b. E. (Dolomit $490 \mathrm{~m}$ )

Ad 20. Kugelberg b. E.

Ad 21. Linke Seite des Buchtals b. E.

Linke Talseite zw. Prunn und Nenessing a. A.

Ad 22. Buchtal b. E.

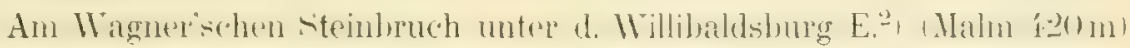

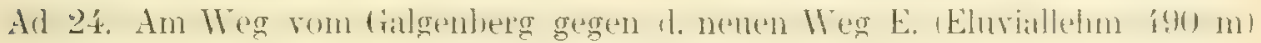

Ad 25. Geissberg b. E. am Weg z. hohen Kreuz (Plattenkalk $520 \mathrm{~m}$ )

Bei Gungolding am Weg nach Hofstetten (Dolomitblock $410 \mathrm{~m}$ )

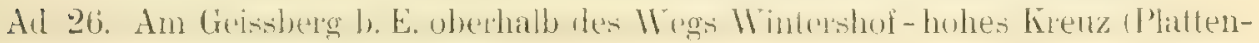
kalk 525)

Oberhalb Kinding (Dolomit $480 \mathrm{~m}$ )

Trockental b. Hieling gegenüber Ellenbrunn (Alluviallehm $420 \mathrm{~m}$ )

Linke Talwand zw. Pappenheim und Zimmern (Malm 440 m)

Bei Laaber (Killermann!)

Ar 27. Rechte sute d. Buchtals b. E. an Weg zur (Balgenhergkapelle (I)ohmit $\left.490 \mathrm{~m}),{ }^{3}\right)$

Zwischenformen und Bemerkungen: Im allgemeinen sind die Zwischen-

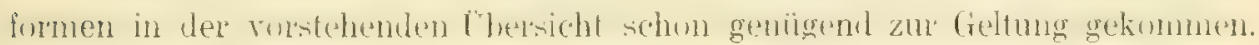

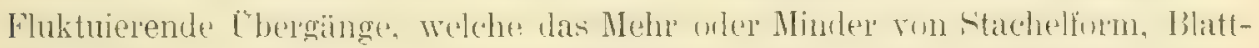

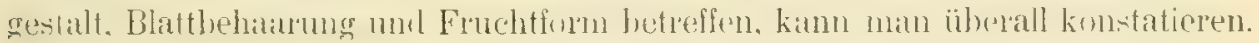

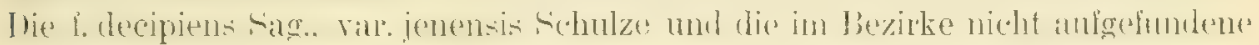

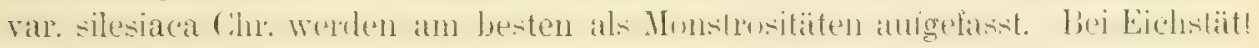
wächst die f. decipiens milten zwischen einer Vegetation von var. comosa und unterscheidet sich sonst durch nichts von den typischen Rosen. Hier ist sie also offenbar eine embryonale Hemmungsbildung od. dgl. von comosa. Jedenlalls könnte das auch bei var. umbellata usw. vorkommen. Der Formenkreis

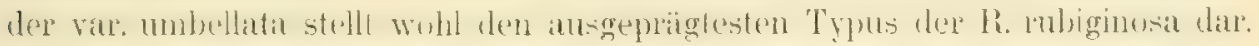

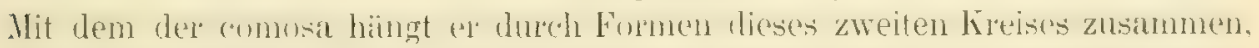

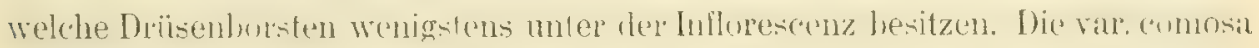

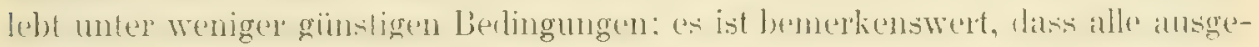

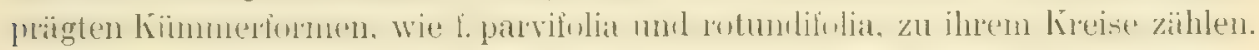

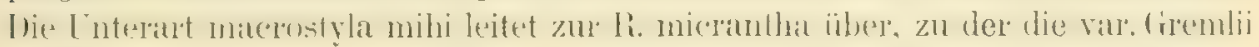

1) A. Schwarz scheint in der Fl. v. Nbg. diese Form, welche an der Westseite des Arztberges ob Beilngries hïufig vorkommt, als f. parvifolia aufzufïhren (S. 559).

2) Die Eichstätter Exemplare weichen vom Typus ab durch stärker stieldrüsige Blütenstiele.

3) Diese Eichstätter Rose fruktifiziert schwach und ist deswegen der Verdacht auf Bastardierung (mit micrantha?) nicht ganz abzuweisen. 
schon vielfach gerechnet wird, schliesst sich aber selbst an die Gruppe der

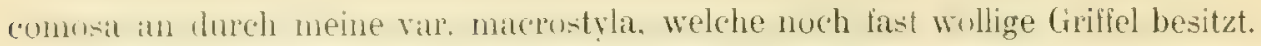

Cther die gengraphische Voubeitung der R. rubiginosa werde ich mich im Kunammenhang mit den ïbrigen Arten der Sektion äussern. Ton den Varietiten

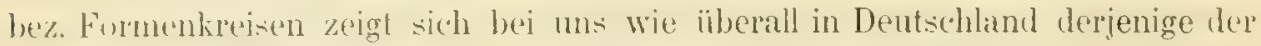
var. comosit an rerbleitetsten. Ein Einfluss von Höhenlage oder Bodenbeschatienheit anf Vardetïtonbildung ist im allgenrenen nicht benerklich: bloss die mir bekannten Ftandurte ron Kïmmerformen grhören zu den sterilsten Kulk- und Dolomithängen und sind infolge dessen im Weissjura relativ håufig.

Unter allen wilden Rosen kann man im Spätherbst die R. rubiginosa am meisten renontieren, d. h. zur zweiten blïte schreiten sehen: Bliten und gleichzextigr reife Früchte sind bei hhr gar nichts seltenes. Auch neigt sie anfallend zu Rïckschligen des Kelches, dessen sepalen als gefieflette Laubbläter auftreten. -ie besitzt tine enorme Le(benszähigkeit und übersteht aul den trockenen Weissjuatriften den schlimnsten Angriffen ron stumeswiten, Dürre, Heedenfrass und Heckenbrand.

\section{Einselart Rose micrenthe Smith.}

Strauch von flattrigem Wuchs. Sehr selten Heterakanthie, d. h. gerade Burston nelon hakigen Stacheln, ${ }^{1}$ Kelchziptel zurickgeschlagen und ablïllig. Blïtenstiele lïnger wie bei R. rubig.: 1,5)-3 ('m. Lronen klein, blass getürbt: fleischrot bis weisslich. Griffel etwas sïnlentömig hervormgend, kahl oder schwach behatrt. Scheinfrïchte meisil cilörmig, selten kugelig oder eikugelig.

\section{Ubersicht der i. G. k. Formen: ${ }^{2}$ )}

a) Formen mit Behaarung auf der unteren Blattläche:

var. typica $C h r$.

\section{f. diminuta (Boreau) H. Braun}

var. permixta (Déséglise) Borbas

f. septicola (Déséglise) Gienier ${ }^{3}$ )

f. hieteracantha mihi ${ }^{4}$ )

b) Formen mit unterseits kahlen oder nur auf dem Mittelners beharten Blattchen:

var. operta (Puget) Borbas ${ }^{5}$ )

var. hystrix (Leman) Baker

1. calcescens Burnat et Gremli

1) Crépin schreibt noch auf p. 21 des Tabl. anal. mit Unrecht: „Stacheln niemals mit Drüsenborsten gemischt." Solche Formen kommen vor, wie auch R. Keller in der Syn, angibt. An einzelnen Orten des Gebietes sind sie sogar ziemlich häufig, nur ist hier die Heterakanthie schwach und etwa der im Formenkreis der var. comosa Ros. rubigin. beobachteten entsprechend.

2) Bei der geringeren Verbreitung der R. micrantha im Bezirke gliedern wir sie nach dem Grade der Blattbehaarung in zwei wenig von einander verschiedene Formenkreise. Auch Crépin hält dafür, dass man die Formen der R. micr. in erster Linie nach dem Grade der Behaarung ordnen solle (Primit. monogr. ros. fasc. 6. p. 156).

3) Vgl. Beck's Fl. v. Niederösterreich I. S. 811.

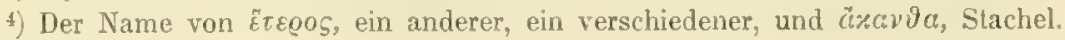

3) Schon von V. Borbas 1850 in Primit. monogr. ros. r. Hung. p. 492 als Varietät der R. micr. aufgefïhrt. 


\section{Diagnosen:}

1. Var. typica: Blättchen mittelgross bis gross; breitoval, an der Basis etwas in den Blattstiel verschmälert; oberseits spärlich, unterseits dicht behart. Scheinfrüchte eiförmig, meist ohne Stieldrüsen.

2. F. diminuta: kleine bis sehr kleine ziemlich schmale Blättchen. ${ }^{1}$ )

3. Var. permirta: Blittchen meist etwats leiner als an der var. typ. an der batis a bgerundet: Behaarung etwas schwöcher. Scheinfrüchte eilomig bis eikugelig.

4. F. septicola: Scheinfriehte kugelig. ${ }^{2}$ )

5. F. heteracentha: Strauch dentlich heterakanth durch IBeinengung von sitieldrüsen und geraden Borsten besonders unter dem Bliitenstand. Sonst wie die var. permixta. $\left.{ }^{3}\right)$

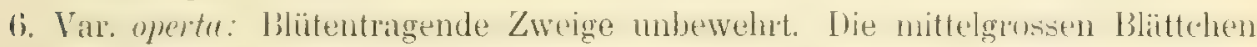
oval, unterseits höchstens am Mittelnerv deutlich behatr. Scheiniriohte wal.

7. Var. hystrix: Aste rutenförmig mit kurzen Seitenzweigen; die Blütenzweige mit gleichnäsigen kräfligen Stachehn beweht. Blätchen klein, elliptisch. merst in den Goml verschmälent. Blütenstiele lein stieldrisig. Kelchlecher länglich eiförmig, bald kahl bald drüsig. ${ }^{4}$ )

8. F. callescens: Beslachelung häulig ungleichurlig, namentlich an den blütentragenden Zweigen auch feine, nadelförmige Stacheln.

\section{Stand orte:}

Ad 1. Am neuen Weg b. E. unterhalb Wintershof (Plattenkalk $540 \mathrm{~m}$ ) Mehrmals in der Nitte des rechtsseitigen Hanges der Wolfsdrossel b. E. (Dolomit $480-490 \mathrm{~m}$ )

Sonst am Abhange des Geissberges b. E. (Dolomit $490 \mathrm{~m}$ )

Bei der Kapelle auf dem Blumenberg b. E. (Plattenkalk $550 \mathrm{~m}$ )

Neben der Strasse im Hirschgrund b. E. (Alluviallehm $420 \mathrm{~m}$ )

Mehrmals an Felsabhang nächst (ler Brummuihle b. Walting a. A. (Dolonit)

Oberhalb Isenbrunn b. Walting a. A. (mittl. Nalm)

Auf dem Haderbuck b. Kipfenberg (Diluviallehm $450 \mathrm{~m}$ )

1) Ist Zwergform der var. typica.

2) In Bezug auf die f. septicola und var. permixta herrschen bei den Rhodologen Differenzen. Nach H. Braun (Fl. v. Niederöst. und Fl. v. Nbg.) hat die septic. besonders starke Behaarung, die permixta kleinere Blättchen als die typ. In der Synopsis v. R. Keller heisst die permixta grossblättriger und kahler wie die typ. Ich folge Borbas (Prim. mon. ros. imp. Hung. p. 490 und 492) sowie insbesondere Crépin (Primit. mon. ros. 1. 6. p. 157 sq.), der sich selber wieder aul Déséglise bezieht. Nach ihm hat die permixta breite, aber meist kleinere Blätlchen als del Typus, und die septicola unterscheidet sich von ihr höchst unbedeutend, nämlich durch die kugeligen Scheinfrüchte.

3) Frutex praeter magnos aculeos glandulis stipitalis atque selis rectis munitus, praesertim subter inflorescentiam (cetera ut in var. „permixta ${ }^{4}$ ).

4) Ich bemerke zur var. hystrix und zu ähnlich gelagerten Fällen. die teils schon vorhergingen, teils noch folgen werden: Es ist durchaus unnötig, stets eine eigene f. typica von der Varietät abzusondern und in Gegensatz zu weileren unter die Varietät subsumierten Formen zu stellen. In diesem Fall gilt die Definition der Var. zugleich für die f. typica, und erklärt es sich, warum die Formen teilweise andere Eigenschaften aufweisen wie die übergeordnete Varietät. Der Gegensatz bezieht sich dann auf die in der Varietätdiagnose versteckle Diagnose der typischen Form. Die übrigen, von mir meist nicht genannten Eigenschaften von subsumierten Formen sind die gleichen wie diejenigen der Varietät und müssen aus ihrer Definition ergänzt werden. 
Aü dem Nichelsberg b. Kipfenberg (Dolomit $490 \mathrm{~m}$ )

Am Dolomitfelsen b. Manem (Erdner!)

Waldsaum b. Haslachen nächst Neuburg a. D. (Erdner!)

Ad 2. Häufig auf dem Geissberg b. E. gegen das hohe Kreuz hin (Plattenkalk $520-540 \mathrm{~m}$ )

Rieder Wald b. Neuburg (Erdner!)

Auf dem Malm des Münchsberges b. Burglengenfeld

Ad 3. Dolomitielsen am Fussweg Plalzpaint-Plahldorf ( $450 \mathrm{~m}$ )

Linke Seite des Anlautertals zw. Schlösslmühle u. Enkering (Malm $400 \mathrm{~m}$ )

Rechte Seite des Trockentals nahe Rohrbach (Dolomit $470 \mathrm{~m}$ )

Rosental b. Josholen (Erdner!)

Nordöstl. v. Liebenstadt b. Heideck (Keupersand, Schneid!)

In Masse rechts ob Langental b. Sindlbach (Malm $570 \mathrm{~m}$ )

Ad \&. Mehrere Sträucher am obern rechten Rand d. Ochsenkellertales b. E. (Plattenkalk 5:0 m)

Südl. Abhang der Wïlzburg b. Weissenburg (Doggerlehm $530 \mathrm{~m}$ )

Häufig auf dem Plateau zw. St. Veit u. Stopfenheim (unt. Lias)

Mehrfach am Waldrand zw. St. Veit 11. Güntersbach

Ad 5. Nördlich unter der Frauenbergkapelle b. E. (Plattenkalk $500 \mathrm{~m}$ )

Hochebene am rechten Rande d. Ochsenkellerschlucht b. E. (Plattenkalk

$515 \mathrm{~m}$ )

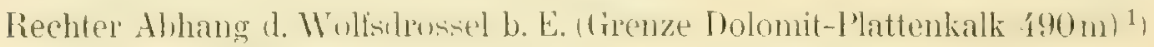
Häufig an der Sïdseite d. Nagelbergs b. Treuchtlingen (Malm $520 \mathrm{~m}$ )

Südlicher Abhang d. Wülzburg b. Weissenburg (Doggerlehm $530 \mathrm{~m}$ )

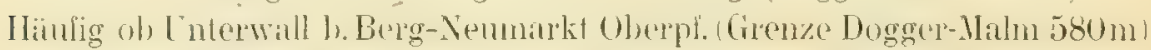

Melufach am Weg Bergh-Korlenzhofen l. Kenmakt oberpf. (Doggerlehm $170 \mathrm{~m})$

Gemein am Steinbruch und sonst rechts ob Langenthal b. Sindlbach (Grenze Dogger-Malm 520-550 m)

Ad 6. Am Odelsbach b. Berg Oberpf. (Alluviallehm)

Ob Unterwall b. Berg (Doggersandstein $520 \mathrm{~m})^{2}$ )

Ad 7. Geissberg b. E. in Nähe d. Herzogkellers (Dolomit $460 \mathrm{~m})^{3}$ )

Haderbuck b. Kipfenberg am Fussweg nach Pfahldorf (Dolomit $450 \mathrm{~m}$ )

Ad 8. Rechter Hang d. Wolfsdrossel b. E. (Grenze Dolomit-Plattenkalk $485 \mathrm{~m}$ ).

' $\mathrm{w}$ ischenformen: Ausser den in verschiedenen Anmerkungen namhaft gemachten seien erwihnt solehe zwischen 1. und 3. nach Blattform und Gestalt

1) Diese Rose nähert sich besonders auffällig der R. rubiginosa. Crépin, dem die Form vorlag, liess es sogar unentschieden, ob es sich um eine micrantha oder um einen Bastard micrantha $X$ rubiginosa handle. Letzteres halte ich für ausgeschlossen, da die Rose ganz besonders fruchtbar ist und gar keine sterilen Karpelle vorkommen. Doch schliesst sie sich an die R. rubiginosa an durch folgende Kennzeichen: Fruchtstiele nur so lang wie die Früchte; diese reich mit Drüsenborsten besetzt, kugelig; die äteren Triebe heterakanth. - Ohne Zweifel können sämtliche übrige Varietäten der R. micrantha gelegentlich Heterakanthie ausbilden, so dass in meiner f. heteracantha mehrere Formen verborgen liegen.

2) Neigt sehr gegen die var, permixta.

3) Markiert nach der Blattform den Ubergang zur var. permixta. 


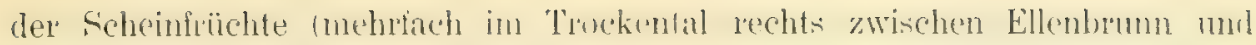
Mauern) und zwischen 4. und 5. wegen der Anfünge doppelter Bestachelung

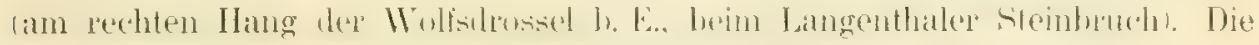
var. permixta hat wegen der runderen Blattorm und der öfter vorkommenden Heterakanthie offenbare Beziehungen zur h. rubiginosa.

Man ersieht aus dem Standortsverzeichnis, dass die Rosen von der Verwandtschaft der var. typica im Sïden, die von der Verwandtschaft der var. permixta im Norden überwiegen oder wie lefztere selbst ausschliesslich vorkommen. Mehrfach ist Massenverbreitung der R. micrantha konstatiert.

\section{Gesamtart Iosa elliptica Tumsch.}

Stacheln von einerlei Gestalt, stark hakig gekrümmt (äusserst selten mit

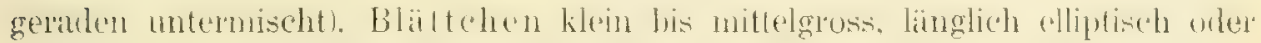

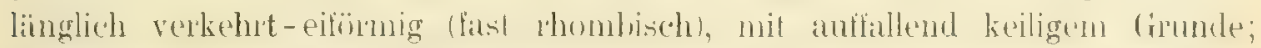

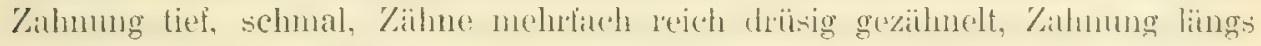

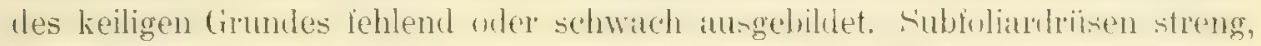
etwas harzig riechent. Blïtensticle ohne Jnïsen uder nu schwich bedribst. Kronen hellgefärbt: rosa bis weisslich.

\section{Einnelart Losu elliptica Trusch. $\left.{ }^{1}\right)$}

Strauch von untersetztem Wuchs. Griffel ein kurzes wolliges Köpfchen bildend. Bliitenstiele kurz, etwa solang wie die Kelchbecher; Brakteen gut entwickelt. Kelchblätter subpersistent. ${ }^{2}$ ) Scheinfrïchte kugelig bis oval.

Ubersicht der i. G. k. Formen: ${ }^{3}$ )

a) Formenkreis der var. Billietii:

var. Billietii (Puget) Chr.

1. Inureyinesate milie

f. lugdunensis (Déséglise) Borluas.

1) Diesem Namen gebührt die Priorität vor $R$. graveolens Grenier.

2) Man kann natürlich darüber streiten, ob die Kelchblätter der R. ellipt. persistent oder subpersistent seien. "Subpersistent" will in diesem wie in anderen Fällen lediglich besagen, dass keine Persistenz von dem Grade der R. pomifera oder pendulina vorhanden sei.

3) Auch in dieser Ubersicht wurden die Formen vorwiegend nach dem Grade der Behaarung und zwar in absteigender Linie geordnet. Auf die Irüsigkeit der Blütenstiele, welche vorkommenden Falls stets eine schwache ist, auf den Mangel an Subfoliardrüsen $u$. dgl. darf man kein allzu grosses Gewicht legen. Formen mit kahlen hervorragenden Griffeln, welche im Bezirke nicht vorkommen (wie z. B. die var. liostyla $\mathrm{R}$. Keller) würde ich zur R. agrestis und nicht zur elliptica stellen. Ob man die wichtigsten Zwischenformen zwischen diesen beiden Arten, das Gebiet der $\mathrm{R}$. inodora Fries, bei agrestis oder elliptica unterbringt, wird einerlei bleiben. Ich habe entgegen Crépin und R. Keller das letztere gewählt. Denn von der R. ellipt. weicht sie in entschiedener Weise nur durch die längeren Blütenstiele ab; die anderen Merkmale der $\mathrm{k}$. ellipt. sind bloss abgeschwächt: die Griffel weniger wollig, aber doch mindestens stark haarig; die Kelchzipfel unentschieden abstehend bis aufgerichtet. Christ erwähnt sie auch bei der R. ellipt. (graveolens). Vgl. übrigens zur R. ellipt. Crépin in Primit. fasc. 6. p. 172 sqq. bes. p. 176, der auch für diese Rose das Verschwimmen der Formenkreise ineinander konstatiert und mit besonders lebhaften Worten die unnützen Anstrengungen schildert, die er gemacht habe, um die Formen streng von einander $z u$ scheiden.

4) Von lanuginosus, wollig; wegen der stark behaarten Blättchen. 
b) Formenkreis der var. typica:

var. tylice Clir.

1. hispida 1. Schulze

1. cheriensis (Déséglise) Borbas.

c) Formenkreis der var. calcarea:

var. calcarea Chr.

f. glandulosa Sagorsti

f. gypsophila Sagorsti

subf. subhispida mihi

f. angustata M. Schulze

f. anadena Chr.

var. spinifera milie. ${ }^{1}$ )

d) Subspecies inodora (Fries) miti ${ }^{2}$ ) (Blütenstiele 1 bis $2 \times$ so lang wie die Scheinfrichte. Kelchblätter nach der Blüte abstehend, früh abfallend): var. genuina mili ${ }^{3}$ )
1. briacensis $H$. Braun
f. longipedata mithi ${ }^{4}$ )
f. dolomitica mihi. ${ }^{5}$ )

\section{Diagnosen:}

1. Var. Billietii: Bliittchen oberseits angedrückt behaart, unterseits auf der Fliche dünn-, an den Nerven dickfilzig: Battstiel filzig. - scheintrüchte eifommign.

2. F. lanuginosa: Blättchen ziemlich gross. Blütenstiele mit feinen Stiel(Iriisen besetzt. ${ }^{6}$ )

3. F. lugdunensis: Blättchen klein bis sehr klein, vorne scharf zugespitzt. Kirone rosenrot. Scheinfrüchte kugelig bis eikugelig. $\left.{ }^{\top}\right)$

\&. Var. typica: Blittchen mitlelgross: Oberseite kahl oder sehr spälich behant, Unterseite und Rand der Blätchei fläumlich; Blatstiel filzig behaart und drüsig. Krone blassrot. Scheinfrüchte eikugelig.

5. F. hispida: Blütenstiele schwach stieldrüsig, manche auch nackt.

(i. F. cheriensis: Blittchen spärlich behart. Scheinfrichte eiförmig bis lïnglich eiförmig.

7. Var. calcarea: Blättchen klein, starr, dicklich; im allgemeinen weniger behaart wie var. typ., auch haarlos. Krone lebhaft rosa, nur selten blass-

1) Spinifer: Domentragend, stachelig. - Diese Rose schliesst sich unmittelbar an die var. calcarea an, zeigt aber die bei der R. elliptica hie und da vorkommende Heterakanthie in besonders auffallender Weise.

2) Lat. Diagnose: Pedicelli receptacula fructifera longiludine vel aequantes vel bis superantes. Sepala post anthesin patentia, mox decidua.- Vgl. Anm.2 S. 41.

3) Genuinus, echt. Hier als var. genuina verwendet stalt des bei der Art R. elliptica schon einmal gebrauchten typica. Meine var. genuina hat die meisten Kennzeichen der R. inodora Fries; die übrigen beiden dienten mir zur Diagnose meiner neu errichteten subspec. inodora.

4) Longipedatus, mit langen Füssen versehen, d. h. mit langen Btütenstielen.

5) Die Rose findet sich im Bezirke an Dolomitabhängen des Frankenjura.

6) Foliola satis magna. Pedicelli tenuibus glandulis instructi.

7) Ob nicht mit gewissen formen der var. calcarea sich nahe berührend? 
rosa. Kelchblatter sehr lange ausdauernd. Scheinfrichte kugelig bis eikugelig. ${ }^{1}$ )

8. F. glandulosa: Bliitenstiele fein sticldrüsig. ${ }^{3}$ )

9. F. gypsoplita: Blättchen sehr klein, bräunlich, elliptisch. Krone nur von $2 \mathrm{~cm}$ Durchmesser. ${ }^{3}$ )

10. Subf. subhispida: Blütenstiele öfter etwas stieldrüsig.

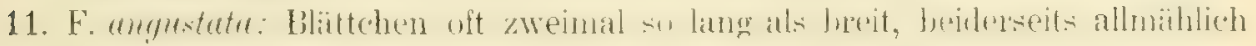
und gleichmässig verschmälert; Zahnung sehr steil.

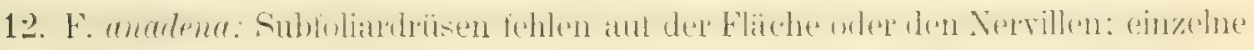
sind auf den Nerven verstreut. ${ }^{4}$ )

13. Var. spinifera: Strauch niedrig $(1 \mathrm{~m})$. Jahrestricbe dicht heterakanth bestachelt mit grossen hakig gekrümmten, kleineren gekrïmmten und geraden borstigen Stacheln. Blättchen sehr klein: durchschnittlich

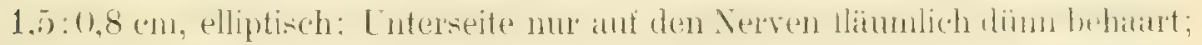

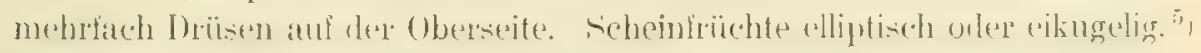

14. Var. gemina: Wuchs straff. Blättchen mittelgross, ziemlich breit; meist nur an den Nerven der Unterseite behaart; Subfoliardrüsen sehr zahl-

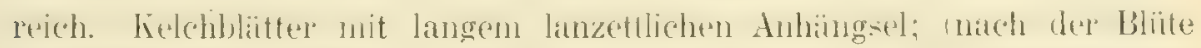

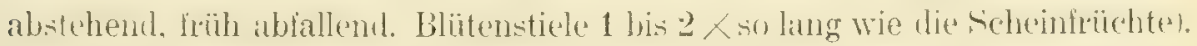
Blïten hellrosa oder weisslich. Griffelköpfchen kurz, stark haarig bis wollig. Scheinfrüchte eiförmig und elliptisch bis eikugelig. ${ }^{6}$ )

1) Die var. typica und var. calcarea sind nicht so scharf von einander unterschieden, wie die Synopsis nach Christ annimmt. Christ hat seinerzeit die Definition der calcarea nach einer

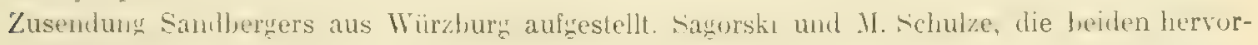
ragenden Kenner der Rosen Thüringens, wo auch nach $\mathrm{R}$. Keller die var. calc. am häufigsten vorkommt, betonen übereinstimmend den Übergang gegen die var. typ. . Sagorski schreibt (D. Ros. d. Fl. v. Naumburg S. 31): "Utbrigens ist diese Varietät" - var. calc. — "von der vorigen" - var. typ. - ,nicht scharf zu trennen, wenn auch ihre åussersten Formen sehr verschieden erscheinen. Gemein auf den Höhen und den Abhängen der Kalkberge im Saal- und Unstruttale, die extremen Formen besonders in sonnigen Lagen an den Plateaurändern". Und Schulze âussert sich über die var. calc. (Jenas w. Ros. S. 19): „Neben der rubigin. comosa die häufigste Rose des Gebietes.... Die Blättchen sind bei uns stets mehr oder weniger belıart, in der Regel auch auf der Oberfläche.... (Formen treten aui) ... mit blassrot gefärbten Corollen: am Jenzig usw. .... mit an der Scheinfrucht zurückgeschlagenen Sepalen: am Jenzig usw."

2) Schulze nennt diese wie andere stieldrüsige Formen der R. elliptica alle f. hispida. Ein solches Verfahren hat Vieles für sich. Doch kann man sich vorläufig kaum dem Zwange entziehen, jedesmal einen eigenen Namen zu geben.

3) Die Blütenstiele sind zuweilen etwas stieldrüsig, so die Exemplare von Berg. Dann ist die Beziehung zur f. glandulosa Sag. gegeben. Man kann diese Rose als subforma subhispida charakterisieren.

4) Die hiesigen Exemplare sind Hemmungsbildungen der var. calcarea, inmitten deren sie auch stehen. Es ist nicht ausgeschlossen, dass die betr. Erscheinung auch an anderen Varietäten der R. ellipt. auftrete. Sie ist ganz analog der Drîsenlosigkeit bei R. rubiginosa.

5) Frutex humilior (alt. $1 \mathrm{~m}$ ). Surculi dense spinosi diversiformibus aculeis, et majoribus aduncis et minoribus setis curvis rectisque. Foliola a dmodum exigua (fere 1,5 ad $0,8 \mathrm{~cm}$ ), elliptica; subtus tantum in nervis tenui pube vestila, supra glandulis aliquot conspersa. Receptacula fructifera ellipsoidea vel etiam globoso-oviformia.

6) Habitus brevis atque strictus. Foliola mediocria, satis lata; plerumque solum in nervis partis inferioris comata, in qua et glandulae plurimae. Sepala appendicibus longis 
15. F. briacensis: Blütentragende Zweige meist stachellos. Blättchen unterseits dicht beharet. Kelchblïtter abstehend, z. T. sogar aufgerichtet. ${ }^{1}$ ) Scheinfrïchte kugelig.

16. F. longipedata: Blättchen gross und breit, oft wenig kugelig. Sehr reichblïtig. Die mittelste Frucht auffallend lang gestielt (bis $2^{1 / 2} \times$ so lang wie die entwickelte Scheinfrucht), die übrigen etwas kürzer. Kelchzipfel schr breit gefiedert. Bliitenstiele meist stieldrüsig. Sonst wie die f. briacensis. ${ }^{2}$ )

17. F. dolomitien: Wie die typische vill gennina, aber Bliittchen muterseits stärlier behaart und Blütenstiele stieldriisig. ${ }^{3}$ )

\section{Standorte:}

Ad 1. Zwischen Denkendorf und Altenberg (Eluviallehm, Schneid!)

Ad 2. Adamsberg b. E. (Dolomitboden $490 \mathrm{~m}$ )

Häufig an Steinbiickle b. Emskeim (ob. Malm)

Südseite des Plafienbergs b. Greding (Malm $450 \mathrm{~m}$ )

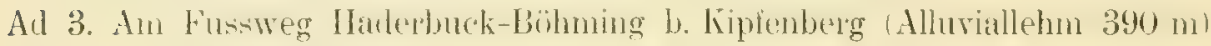

Ad 4. Links an Strasse Eichstiitt-Landershofen beim Hessental

Bei Mörnsheim ${ }^{4}$ )

Mehrmals östl. v. Buch b. Kipfenberg (lehmige Albüberdeckung $530 \mathrm{~m}$ )

Ad 5. Rechls an der língelbergstrasse b. E. und sonst an Kugelberg (Dolomit $450-470 \mathrm{~m}$ )

Sehr verbreitet ani Adamsberg b. E. (Dolomitregion $470-490 \mathrm{~m}$ )

An Frauenherg b. E. rechts vom Fusweg 11. Wasserzell (Plattenkalk '95 m)

Bei Pfahldorf (Schneid!)

Östl, von Buch b. Kipfenberg (lehmige Albüberdeckung $530 \mathrm{~m}$ )

Siidseite des Plaffenbergs b. Greding (Nalm $\{70 \mathrm{~m}$ )

Bei Emskeim am Weg nach Gammersfeld (Plattenkalk $490 \mathrm{~m}$ )

Biding b. Neuburg a. D. (Malm, Erdner!)

Südl. v. Berg b. Neumarkt Obpf. (Liaslehm $430 \mathrm{~m}$ )

Ad 6. Rechter Abhang d. Hessentals b. E. (Dolomit $480 \mathrm{~m}$ )

Ad 7. Bei den Steingruben auf dem Kugelberg b. E. (Plattenkalk $500 \mathrm{~m}$ )

Rechter oberer Rand d. Ochserkellertales b. E. (Dolomit $485 \mathrm{~m}$ )

Mehrfach bei einer Sandgrube am Fussweg Plalzpaint-Gungolding

(Diluv. Sand m. Kalkgeröll $420 \mathrm{~m}$ )

Hohe Schanz bei Neuburg a. D. (Erdner!)

lanceolatis instructa (post anthesin patentia, mox decidua. Pedicelli receptaculum longitudine vel aequantes vel bis superantes). Styli in modum capituli breves, pilosi vel etiam villosi. Pelala subrosea vel albida. Receptacula fructifera ellipsoidea, ovata, globoso-ovata.

1) Dadurch tritt die Zugehörigkeit zur R. elliptica besonders hervor.

2) Cum f. briacensi H. Braun fere consonat. At foliola longa et lata, saepe minus cuneiformia. Corymbus floribus exuberans. Pedicellus, qui receptaculum in medio collocatum sustinet, etiam fructiferum atque maturum longitudine etiam $2{ }^{1} / 2 \times$ superat; plerique pedicellorum glandulosi. Sepala appendicibus latissimis ornata.

3) Foliolorum superficies inferior comata. Pedicelli glandulosi. Cetera cum var. genuina conveniunt.

4) Hier die Blittenstiele etwas lang, also Neigung gegen die Unterart inodora. 
Bei Möhren an d. Strasse nach Treuchtlingen

Nagelberg b. Treuchtlingen (Fl. v. Nbg.)

Zw. Erlmühle u. Staadorf an d. linken Seite des Labertals (Dogger)

Håufig b. Waltersberg (unt. Malm)

Bei Winnberg (Fl. v. Nbg.)

Häufig auf d. Mariahilfberg b. Neumarkt, Oberpf. (Fl. v. Nbg.)

Keilstein b. Regensburg (Jurakalk, Killemann!)

Ad 8. Schlucht der linken Talseite b. E. (Unt. Malm $430 \mathrm{~m}$ )

Berghang links von Dollnstein (Dolomit $450 \mathrm{~m}$ )

Ad 9. Zwischen St. Sebastian u. d. Bachhauptmühle b. Breitenbrunn (Fl. v. Nbg.)

Nariahilfberg b. Neumarkt Obpi. (Il. v. Nbg.)

Auf Malm der Hochfläche d. Münchsberges b. Burglengenfeld ${ }^{1}$ )

Ad 10. Ob Unterwall b. Berg-Neumarkt (Doggerlehm $560 \mathrm{~m}$ )

Ad 11. Linke Wand einer Schlucht zW. Adamsberg u. Ochsenkellertal b. E. (Plattenkalk $500 \mathrm{~m}$ )

Am Weg von Adelschlag nach Wittenfeld (Diluviallehm)

Dillberg b. Neumarkt Oberpf. (Malm $590 \mathrm{~m}$ )

Ad 12. Buchtal b. E. am Anfang d. Fussweges nach Oberwimpasing (Malm $430 \mathrm{~m}$ )

Ad 13. Edelshausen im Laabertal b. Regensburg (Jurakalk, Killermann!)

Ad 1 i. Haderbuck b. Kiplenberg (Dolomitlelsen $420 \mathrm{~m})^{2}$ )

Schiessplatz b. Bittenbrum-Neuburg a. D. (Erdner!)

Mariahilfberg b. Neumarkt Obpf. (Fl. v. Nbg.)

Bei Pielenholen (Killermann!)

Ad 15. Bei Walting a. A. (Dorr!)

Nitte des Kernbergs nordöstl. gegen Arnsberg (Dolomit)

Am Fussweg Haderbuck-Böhming b. Kipfenberg (Alluviallehm $390 \mathrm{~m}$ )

Sandgrube b. Dietenfeld nächst Neuburg a. D. (Erdner!)

Ad 16. Linke Seite des Schuttertales gegenüber d. Feldmühle (Diluviallehm)

Waldsaum links ober d. Feldmühle (Dolomit)

Schuttertal zw. Schanz u. Bauchenberger Mühle (Erdner!)

Zw. Ellenbrunn u. Gammersfeld (Erdner! ${ }^{3}$ )

Auf dem neuen Schiessplatz b. Neuburg a. D. (Erdner) ${ }^{4}$ )

Ad 17. Mehrmals in Schlucht oberhalb des "engl. Gartens" am Geíssberg b. E.

(Grenze Dolomit-Plattenkalk $\mathbf{4 8 0 - 4 9 0 ~ m ) ~}$

Dolomitfelsen d. Brunnmühle b. Walting a. A. (Dorr!)

Mehrfach auf d. Kernberg b. Gungolding (Dolomit $420-460 \mathrm{~m}$ )

ZW. Kruth u. Dunsdorf b. Kipfenberg (Dolomit $500 \mathrm{~m}$ )

Bei llbling a. A. (Dorr!)

Im Schuttertal zw. Schanz u. Bauchenberger Mühle (Dolomit)

An Strasse Ried-Bergen (Erdner?)

1) Es ist stets der bekannte Berg westlich von Münchshofen gemeint.

${ }^{2}$ ) Weicht vom Typus ab durch stärkere Behaarung der Blattunterseite.

3) Diese Rose hat Blitensliele ohne Stieldriisen.

*) Die Rose dieses Standortes habe ich nicht geschen. Herr Erdner hat die Form überhaupt zuerst entdeckt. Sie bildet eine gute Lokalrasse des Schuttertals und seiner nächsten Umgebung. 
Zwischenformen und weitere Bemerkungen: Ausser den bereits signalisiorten Cbergang-tormen seien solche hencrkt, die dergestalt genau die Mitte zwischen der var. typica Chr. und calcarea Chr., sowie deren drüsigen Abmeichungen f. hispicla shohulze und glandulusi Sagorsi halten, dass man sich liil keine entscheiden kinn. Folche stehen \%. B. auf der J'rinzonsterghainge und auf der Hochehnente des Fauenhergs b. Eichstät. Wie in Thiurngen bewohnt

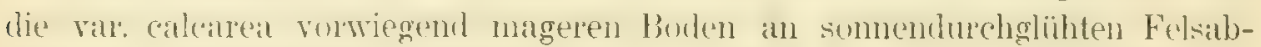
hängen. Aulfallend muss t's excheinen, in weleh hohem Plozentsatz Fomen de'r R. elliptica mit drïsigen blïtonstielen den Bezirk bewohnen. Jie 7 dort unterschiedenen stets ader vorwiegend nit drïsigen stielen versehenen Formen der R. olliptica sind ron 28 Fundorten angegeben, die ïbrigen 10 von 31. Dieses Verhälnis stellt sich aber für den sïdlichen Teil des Jura, die Eichstiitter und Neuburger (iegraul, nuch aulfallender dar. Hier zeigen die meisten husen der Art elliplica solche silieldrïsen. Auch die Thergangsformen zur R. agrestis, die wir in der Interat invelona zusammenfassten, sind in siulen viel bäufiger. Nach mseren Beohachtungen, die mit denen der Fl. v. Nbg. znsammentreflen, erscheint die R. elliptica recht enge an die Kalkhänge des Jum, besonders des weissen, gebmulen. Auch in Linterhanken und Thüringen liejt sie den Muschelkalk.

\section{Einzelart Rosu agrestis Sari. $\left.{ }^{1}\right)$}

Sitra uch wegen der velüngerten Aste von mehr flattrigen Wuchs. Bliitenstiele lang: 1 bis $2 \times$ so lang wie die Kelchbecher. Kelchzipfel nach dem Abblühen zurückgeschlagen und bald ablälig. Griffel etwas silulenlumig verfaingert, ganz kahl oder nur schwach behatrt. Scheinfröich te kugelig bis eifürnigg

Ubersicht der i. G. k. Formen:

Var. pubescens (Rapin) Chr. ${ }^{2}$ )

1. vinodora (Kerner) Borbas

1. alliflora (Opiz) H. Bram

1. belnensis (Ozanon) H. Braun

f. pinnatosepala A. Schwar ${ }^{3}$ )

1) Diesem Namen gebührt die Priorität vor R. sepium Thuillier.

2) Die var. pub. ist nach Christ zu nemnen, da Chr. sie schon in den R. d. Schw. als Varietät der R. sepium anführt, welche nur ein Synonym zu R. agrestis bildet. Alnnliches gilt von der f. vinodora (Kern.) Borbas.

H. Braun (11. Ber. d. bot. Ver. Landshut 1889 S. 116) hält R. pubescens Rap. und vinodora Kern. für synonym und ersetzt den älteren Namen pubescens durch den jïngeren vinodora, weil der Ausdruck pub. schon früher mehreremale innerhalb der Gattung Rosa zur Bezeichnung verschiedener Formen angewendet worden sei. Das verstösst aber nicht gegen die internationalen Nomenklaturregeln, wenn nur der gleiche Name nicht innerhalb derselben niederen Sippe zweimal oder mehrmal verwendet wird; innerhalb der Gattung Rosa werden faktisch ohne Anstoss recht häufig unter der obigen Bedingung die gleichen Namen verwendet. Dann müsste aber der ältere Name var. pubescens bleiben. Ich halte nun ausserdem beide Formen: pub. und vinod. nicht für identisch. Beide unterscheiden sich durch Form und Grösse der Blättchen. Freilich kann es sich um blosse Standortsmodifikationen handeln, allein mit Sicherheit ist das nicht nachgewiesen.

3) Beide Formen aufgestellt in Fl. v. Nog. S. 554 . 


\section{Iamuinea mithi ${ }^{1}$ ) \\ f. glandulosa A. Schwarz $\left.{ }^{2}\right)$}

var. typica $R$. Keller

1. arvatica (Pliget) Borbas.

1. Var. pubescens: Bätlohen gross; breit in den Sticl verschmälert; Oberfliche zerstreut, Unterseite dicht behaart; Blattstiel filzig. Krone gross. Scheinfrichte oval bis eikugelig.

2. F. vinodora: Blättchen ziemlich klein bis mittelgross, schmal und in den Stiel keilig verschmälert. Krone klein. Scheinfrucht klein, oval.

3. F. alliftora: Zweige oft mit parigen Stacheln. Blättchen klein, lanzettlich. Scheinfrichte oval.

4. F. behnensis: Scheinfrüchte kugelig. Sonst wie f. vinodora.

5. F. pinnatosepala: Blätlchen meist mittelgross. Kelchzipfel sehr verlängert, beginnend doppelt gefiedert. Blütenstiele und Griffel schwach behaart. Scheinfrüchte lisgelig.

6. F. lanuginea: Blütenstiele deutlich behart; auch Griffel fliumlich. Scheinfrichte kugelig bis eikugelig.

7. F. glandulosa: Blütenstiele schwach stieldrüsig. ${ }^{3}$ )

8. Vill: typica: Bliltchen mittelgross, linglich elliptich; mit tiefer, steil auseinander fahrender Zahnung; kahl oder nur auf der Unterseite etwas behaart; Blattstiel kahl oder schwach behart. Griffel kahl oder schwach behaart. Scheinfrüchte eilänglich.

9. F. araticu: Die kleinen Blätchen beiderents gleichmïssig verschmälert; unterseits \pm behaart. Scheinfrüchte länglich ellipsoidisch.

\section{Standorte:}

Ad 1.4) Mehrfach in der Lmgebung des Weihers hinter dem Nichelsherg b. Kiplenberg (kalkiger Lehm $470 \mathrm{~m}$ )

Im Birktal b. Kipfenberg

1) Lanugineus, wollig. - lch habe die Form lanuginea unterschieden, trolzdem sie der 1. pinnatosepala A. Schwarz sehr nahe steht, weil viel mehr hieher gehörige Roseri ohne die auffallende Kelchblattiederung vorkornmen als mit derselben. Ihre lat. Diagnose heisst: Lanugo pedicellorum manifesta. Etiam styli plumosi.

2) Siehe Anm. 3 S. $6 \dot{4}$.

3) Nach der Grösse und Form der Blättchen gehören diese Rosen bald der typischen var. pubescens an, bald der f. vinodora, vorwiegend der letzteren. Würde man das immer genau konstatiert liaben, so künnte man bei beiden etwa eine subf. subglandulosa anhängen. Die Bedrüsung der Blütenstiele ist schwach und unregelmässig, kommt aber viel häufiger vor wie sie denn auch von mir schon lange vor dem Erscheinen der Fl. v. Nbg. beobachtet wurde -, als A. Schwarz geglaubt hat. Die Unregelmässigkeit äussert sich auch darin, dass nicht jeder Strauch in jedem Jahre Drüsen an den Blütenstielen hervorbringt. Darüber weiter unten. Übrigens kommen ähnlich gelagerte Fälle auch bei anderen Rosenarten vor.

4) Die in der Fl. v. Nbg. aus dem Juragebiet angeführten Standorte gehören wohl sehr vorwiegend zur $\mathrm{f}$. vinodora. Ich habe sie bei letzterer berücksichtigt. Streng kann man über-

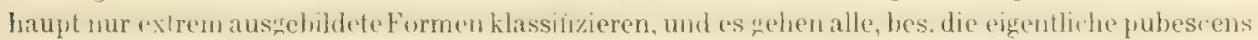
und die vinodora, je nach Standort, Jahrgang und Ast, natürlich auch Individuum, in einander über. Die kleinblättrigen hersschen im Gebiete vor, soweit es trockenen, dürren Boden gewährt. 
Rechte Seite des Trockentals b. Rohrbach (Dolomit $480 \mathrm{~m}$ )

Dolomitfelsen des Trockentals b. Mauern (Erdner!)

Im Rosental b. Joshofen (Erdner!)

Nordöstl. v. Liebenstadt b. Heideck (Keuper, Schneid!)

Ad 2. Gemein an den Abhängen d. Geissbergs und am neuen Weg b. E.

Bei Inching a. A.

Bei Walting a. A. (Dorr!)

Zw. Walting und Rieshofen (mittl. Malm)

Bei Hofstetten (Plattenkalk und Eluviallehm)

An der Distriktsstrasse Eichstitt-lïplenberg b. I’alzpaint (Alluviallehm $410 \mathrm{~m}$ )

Auf der Hochebene b. Pfahldorf $u$. am Waldrand b. den Ziegelhöfen ob Gungolding (Plattenkalk 510-530 m)

Linke Talseite b. Böhming a. A. (Dolomit)

Abhang links d. Schlösslmühle i. Anlautertal (Malm $400 \mathrm{~m}$ )

Grasranken b. Attenhofen, Greding (lehmige Albïberdeckung $510 \mathrm{~m}$ )

Felsabhang rechts d. Altmühl zw. Kemathen u. Kinding (Nalm $400 \mathrm{~m}$ )

Hochebene b. Irlahiill (Plattenkalk $530 \mathrm{~m}$ )

Häufig links oberhalb Kinding

Suidwestl. Abhang d. Arztberges b. Beilngries (Malm $440 \mathrm{~m}$ )

Oberhalb St. Anna und am Tachenstein b. Riedenburg hỉufig

Mehrlach oberhalb Neuessing

Öters an d. linken Talseite d. Altmühl zw. Altessing u. Kelheim

Bei Hofstetten (lehm. Albüberdeckung $460 \mathrm{~m}$ )

Am Waldsaum ob. d. Feldmuihle b. Wellheim

Vielfach am Kalvarienberg b. Gossheim, Ries (unt. Malm)

Talhang links von Dollnstein a. A. (Malm $430 \mathrm{~m}$ )

Häufig am Südabhang d. Nagelbergs b. Treuchtlingen (Malm $500 \mathrm{~m}$ )

Gemein am Südabhang d. Wülzburg b. Weissenburg (Sandiger Doggerlehm $550-560 \mathrm{~m}$ )

Gemein zw. Holnstein und Unterbürg an der linken Seite d. Labertals, sowie zw. Unterbürg, Hebersdor u. Kerenhüll (auf Dogger u. Nalm)

Bei Breitenbrunn und Diirrn (Fl, v. Nbg.)

Bei Waltersberg

Rings um Neumarkt Obpfz.: Winnberg, Mariahiliberg, Höhenberg, Wolistein, Ottenberg, Schathof, Kadenzhofen (nach meinen Beobachtungen u. d. Fl. v. Nbg.)

Gemein am Steinbruch b. Langental (Malm 560-580 m)

Bei Hagenhausen und Gnadenberg (Eisensandstein - Fl. v. Nbg.)

Um Hamberg b. Dasswang

Gemein auf der Hochfläche des Münchsberges b. Burglengenfeld (Malm)

Ad 3. Rieshofen b. Walting a. A.

Linke Seite d. Altmühllals zw. Arnsberg u. Böhming (Dolomit)

Bei Kipfenberg rechts d. Altmühl

Am Haderbuck b. Kipfenberg 


\section{Im Rosental b. Joshofen (Erdner!) \\ Bei Sulzbürg (Fl.v. Nbg.)}

Ad 4. Rechter Abhang d. Wolfsdrossel b. E. (Plattenkalk $500 \mathrm{~m}$ )

Linke Seite des Schuttertals zw. Schanz u. Bauchenberger Mühle

Mehrmals am Fuss des Kalvarienbergs b. Gossheim i. Ries (Malm)

Felsabhang im Trockental b. IIroting gegeniib. Ellenbrum (1) bonit isO m)

Unterhalb Holnstein an der linken Seite d. Labertales (Malm)

Zw. Unterbürg i. Labertal u. Hebersdorf (Malm)

Bei der Mariahilfkirche Neumarkt Oberpfz. (Scherzer!)

Am Steinbruch b. Langental (Malm $570 \mathrm{~m}$ )

Miltelhöhe des Münchsberges b. Burglengenfeld (Malm) ${ }^{1}$ )

Ad 5. Geissberg am Weg z. Herzogkeller b. E. (Alluviallehm $410 \mathrm{~m}$ )

Oberhalb Isenbrunn a. A. (mittl. Malm)

Bei Erlbach nächst Bertoldsheim (Herbar Du Moulin)

Ad 6. Geissberg b. E. am Steinbrecherweg (Plattenkalk $500 \mathrm{~m}$ )
$n$
weiter unten
(Malm $430 \mathrm{~m}$ )

Am Kugelberg b. E.

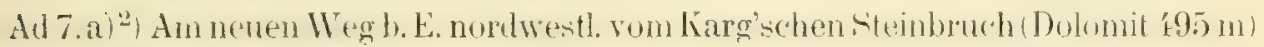

Mehrmals an der linken Seite der Wolfsdrossel b. E. (Dolomit u. Plattenkalk $490-520 \mathrm{~m}$ )

b) Mehrmals in der Nähe des oberen Herzogkellerwegs b. E. $(410-440 \mathrm{~m})$

Rechte Seite d. Buchtals b. E. oberhalb d. Wäldchens (Plattenkalk $520 \mathrm{~m})^{3}$ )

In Schlucht am südwestl. Hang d. Geissbergs b. E. (Dolomit $480 \mathrm{~m}$ )

Im Schutterial zw. Schanz u. Bauchenberger Miihle (Erdner!)

i) Bei dieser Rose entbehren viele Blattzähne, besonders der Sprösslinge, eines Nebenzähnchens. Doch unterlasse ich es, auf Grund dieses einzigen Exemplars eine neue Form zu errichten.

2) Bei den Rosen unter a) konnte ich mit Sicherheit konstatieren, dass sie in manchen Jahren Drïsen an den Blütenstielen trugen, in anderen nicht. Die Rose vom neuen Weg habe ich als gewöhnliche var. pubescens i. J. 1898 in der Flora exsiccata bavarica ausgegeben, wo man sie kontrollieren mag. I. J. 1902 zeigten sich am gleichen Strauch an den Fruchtstielen mehr oder minder reichlich Stieldrüsen. In diesem Jahre war die Entwicklung solcher Stieldrüsen auch an der unbezweifelbaren f. glandulosa, z. B. von Berg b. Neumarkt, eine viel reichlichere. Man gewahrt diese Drüsen stets am besten gegen den Beginn der Fruchtreife. Sie scheinen sich vielfach erst dann vollkommen auszubilden. 1903 und die folgenden Jalire bemerkte ich an obigem Strauch wieder nichts dergleichen. - Eine analoge Beobachtung verzeichnet übrigens schon Christ (R. d. Schw. S. 158) von seiner var. dumalis der R, canina L.: -Im sehr feuchten Sommer 1872 zeigten Exemplare bei Basel Stieldrüsen an den Blütenstielen und einzelne Drüsen auf den Kelchzipfeln, was ich in früheren Jahren an denselben Sträuchern nicht bemerkt habe." - Es wird gut seiı, auf den Unterschied sämtlicher Formen der var. pub. kein allzu grosses Gewicht zu legen. Ich habe nämlich ausser dem Angeführten auclı beobachtet, dass an Hecken, die im allgemeinen den Typus von var. pub. oder f. vinodora zeigten, einzelne Zweige, ja sogar einzelne Blüten die morphologischen Eigentümlichheiten der f. pinnatosepala oder lanuginea an sich trugen. Bei einer solchen einzelnen Blüte schien die kelchblattwucherung durch Insektenstich bewirkt, da auch das Narbensïulchen eine Bedegoargalle auîies.

3) Die zwei Striiucher dieses Standortes zeigen auf der Unterseite der Blättchen vicl weniger Drüsen und Haare - nur Mittelrippe deutlich behaart - als die typische Varietät. Sie schlagen den Weg ein zu einer Form analog der f. decipiens Sag. bei der 12. rubiginosa und der f. anadena Chr. bei der R. elliptica. 
Bei Bittenbrunn nåchst Neuburg a. D. (Erdner!)

An Weg ron der Hintermühle im Kipfenberger schambachtal nach Attenzell $(450 \mathrm{~m})$

Suidseite des Pfaffenberges b. Greding (Malm $440 \mathrm{~m}$ )

Öfter auf der Hochebene b. Kipfenberg zw. Bitz und Winden (lebm. Albiiberdeckung $510 \mathrm{~m}$ )

Nehrmals am Arztberg b. Beilngries (Malm 440)

Waldsaum nördl. Leising b. Beilngries (Doggersand $410 \mathrm{~m}$ )

Bei Rudershofen westl. Berching (unt. Malm)

Nehrfach bei Holnstein rechts und links der Laber, auch links zw. Holnstein 11. Erlmiihle ${ }^{1}$ ) (Malm)

Am Weg zw. Unterbürg und Hebersdorf (Malm)

St. Sebastian b. Breitenbrunn (Fl. v. Nbg.)

Mariahilfberg b. Neumarkt (Fl. v. Nbg.)

An sehr vielen stellen des rechtsiceitigen Talhanges ob Lnterwall b. Berg (auf Doggerlehm, Eisensandstein und Kalk des unt. Nalm 460-590 m)

Am Buchenrain zw. Berg u. Hausheim (Alluviallehm $470 \mathrm{~m}$ )

Mehrfach auf Dogger II. Malm des Dillbergs h. Hausherim (500-600 m)

Verbreitet auf dem Malm der IIochflache des Münchsbergs b. Burglengenfeld.

Ad 9. Linke Talwand zw. Kinding u. Linteremmendorf a. A. ${ }^{2}$ ) (mitll. Malm $430 \mathrm{~m}$ )

Zwischenformen: Besonders häufig trifft man auf Rosen, die zwischen den f. vinudora und belnensis stehen, 1. h. eikugelige oder teils ovale teils kugelig. sicheinfrüchte tragen (z. B. bei Eichslät in Hecken am nenen ITeg und hinter dem hohen Krenz). Bei Kiadenzholen sammelte ich die f. glandulusa mit einer Bestachelung ähnlich der f. sepioides (Ozanon) R. Keller. Eine Ruse von IValtersberg greift wie die Rose unter 9. ins (ieb)et der var. typiea iiber und steht ungelithr in der Mitte zwischen f. vinuluka und f. virgultorum (Ripart) Borbas.

An dieser Stelle muss auch das Verhältnis unserer var. pubescens zur rar. Haringiana H. Braun und R. Gizellae Borbas (in der Synopsis R. agrestis var. Gizellae R. Keller $=$ R. caryophyllacea Chr. z. T.) erörtert werden. Beide hahen kahle ader fast kahle Griftel, zurückgeschlagene lielchziptel, elliplische gegen den cirund mehr obler minder kejlige behatrte Blättchen, eikugelige bis eiformige - schonfrüchte und Blïtenstiele, die auf keinen Fall mehr Stieldrisen thagen als die f. grandulusa A. Schwa\%. Die var. Maringiana ist auf der Blattunterseite dicht hehaart, aber auch die ff. longipes $n$. neogradiensis Borbas der R. Gizellae sind es. Dazu kommt, dass wie unsere var. pubescens so die var. Haring. und R. Gizellate formen antweisen, die hehante Blitenstiele besitzen. Die 1. lungipes Buthats der R. Giz. hat endlich anch lange Blïtenstiele (sic!!) Wo ist da noch ein Unterschied zu finden? Die var. Haring. kenne ich nicht

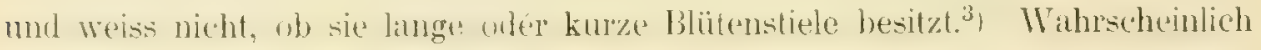
das erstere; dann wird sie als Form mit Suprafoliardrüsen zur älteren var.

1) Eine dieser Rosen zeigt eine besonders reiche Entwicklung der Drüsen an den Blütenstielen.

2) Offenbart deutliche Beziehungen zur var. pubescens.

3) Hätte die var. Haring. kurze Blütenstiele, so würde sie am besten als Form zur R. Gizellae passen. 
pubescens zu ziehen sein. Das gleiche gilt von der f. longipes Burb. der R. Giz., die zudem nach Borbas ${ }^{1}$ ) auch noch stark behaut ist. Von der f. ditrichopoda bemerkt Borbas selbst, dass sie mit der R. vinodora Kerner ganz übereinstimme mit Ausnahme ihrer behatrten und driisigen blütenstite. Auch diese kamn also lediglich als Form neben der glandulusa A. Sichwarz und lanuginea mihi ele. zur var, pubescens genommen werden. I)as un so mehr, als Borbas zuribt: ,Mit der $R$. vinodora könnten wir sie vereinigen; aber da ich die R. Gizellae wegen ihrer drüsigen Blütenstiele spezifisch von der R. sepium getrennt habe, habe ich anch die l. ditrichopoda aut jene lezogen. "2) - Die tỵische R. Gizellae keme ich nach ungarischen Excmplaren. Sie unferscheilen sich vom Formenkreis der var. pubescens dureh weniger hakige Stacheln, kleinere Blittchen mit aulfallend scharfer Zuspitzung der schmalen Zähnchen, weniges keriligen

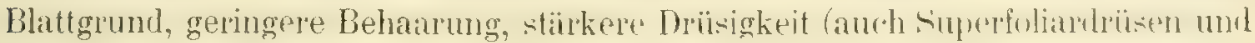
Drüsen an den Scheinfrïchten) und besonders durch die kurzen Blïlenstiele, welche nur die Länge der Scheinfrichte erreichen. Die typische $R$. Gizellae - nicht aber deren Borbasische Formen ditrichopoda mul longipes -unterscheidet sich also durch das letztgenannte Merkmal wesentlich ron der var. pub. und verrät sich als eine ausgeprägte Zwischenform zwischen den

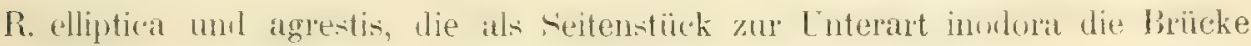
von der $\mathrm{R}$. elliptica zur var. pubescens Rosae agrestis schlägt.

Wenn R. Keller S. 126 der Synopsis die Rosen vom Formenkreis der var.

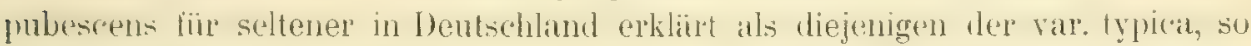
trillt das fiir unser spezielles Gebiet nicht zu und auch nicht für jenes der Fl. v. Nbg, also fast ganz Nordbayern. Im Gebiet des fränkischen Jura und der benachbaten Kenuerabhänge gehö̀t die var. Jub. zu den häuligsten Rosen überhaupt und charakterisiert mit den übrigen Rosen der Siektion Riubiginusae gerardezn die sterilen Abhänge und Schafweiden dieser Region. Sif findet sich auch neben der R. canina auf der Jurahochebene selbst verbreitet, die sonst recht arm an Rosen genannt werden muss. Bei ihrer algeneinen Vorbeitung kann es nicht ITunler nehmen, lats sie in viele Formen auseinandergeht. Ditªgrestis museres Bezinks ist also so gut wie stets reichlich behaart und offenbart auch eine sehr grosse Neigung, Drïsen an den Blätenstielen zu entwickeln. In Gegensitz dazu ist die var. typica so selten und so wenig ausgepuägt vorhanden, dass man sie ganz ausser Betracht lassen dart.

Wie wir vorhin schon andeuteten, bevorzugen die vier Arten der Sektion Rubiginosae nicht bloss warme und sonnige, sundern anch trockene standorte, die ihmen an ehesten auf den durchlissigen nach sïden exponierlen Abhängen des ans Kalkschichten zusimmengesetzten weissen Jura gebolen werlen. Hier breiten sie sich nit grossem Reichtum an Formen aus, ja bilden olt den gesimuten Bestand an foscen. An mehreren Platzen, die ich kinne, wachesen die Li. rubi-

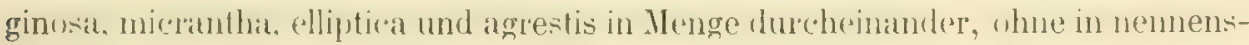
werter Weise Veranlassung zur Bildung von Bastarden zu geben. So ist es oberhalb Langenthal bei Sindellatch, an den rechtsseitigen Abhiugen des I'nter-

1) Prim. mon. ros. imp. hung. p. 479.

2) Ebd. p. 487. 
waller Tals leei lberg, am Mariahillberg bei Nemnark, auf dem Münchsberg bei

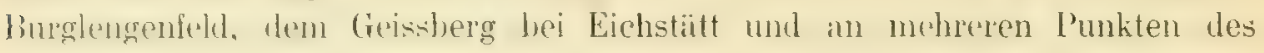
Wellheimer Trocken- und des Schuttertales. Ist der Boden gar zu steril, so cutstehen gerne Zwergformen. Auch zeigen ellipticat und agrestis grosse Neigung zur Bildung drisigger Blïlenstiele. Die Steilhänge des angrenzenden Braunjura, hes. des Eisonsindsteins, werden in der Nommatklep Gegend noch hiufig von

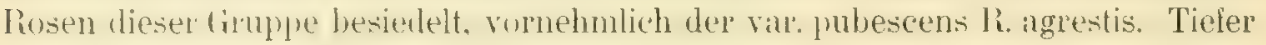
in den anstosenden heuper hinein geht die R. rubiginosa, selten agrestis, fast nie micrantha und elliptica. Die letztgenamnte hänght am Kalkboden mehr wie die ïbrigen. Die var. pubescens der R. agrest. scheint mir die für das engere Juragebiet bezeichnendste Ruse zu sein. Sie geht meiner bisherigen Erlahrung gemïss nicht auf die schwäbisch-bayrische Hochebene ïber und bewohnt anch den Keuper im Westen, dits oberplailzische Urgebirge im Osten lediglich sporadiseh in den Grenzgebieten. In Unterfranken ist sie ebenfalls unbekannt. 


\section{Sectio V: Caninae DC.}

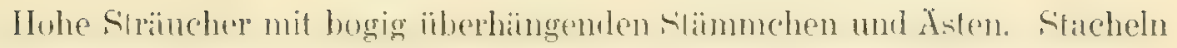

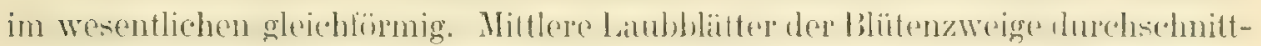
lich Tzählig: Blitfehen nittelgross bis guss: Kahnumg einlach lis zosammen-

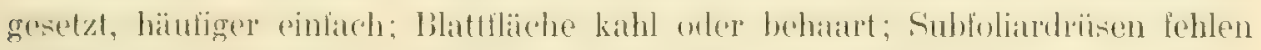

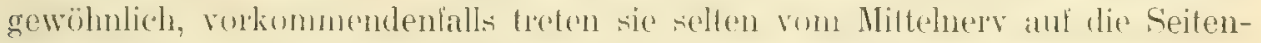
nerven oder gar auf die Nervillen über. Inflorescenz mehrblütig.

Diese Sektion enthält in Europa die meisten Arten. Sie muss auch fürs

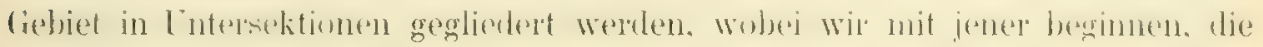
sich am natürlichsten an die Sektion Rubiginosae anschliesst.

\section{Subsectio 1: Tomentellae Crépin.}

Slacheln kurz, hakig gekrünmt, seitlich zusammengedrülckt, mit stark verdicktem breffen firunde. Blattehen I behatal: Noignng zu subfoliardrïsen und

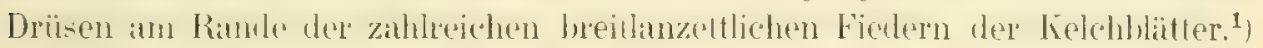

\section{liose tomentella Lémren.}

blät tehen klein bis mittelgross: breit wval mit kurz aulgesetztem Spilzchen; dicklich, mit unterseits scharf hervortretendem Aderuetz: mit kurzer, Inoiter, last

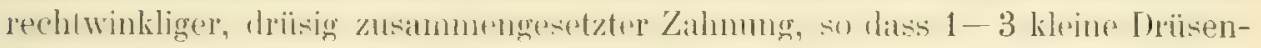

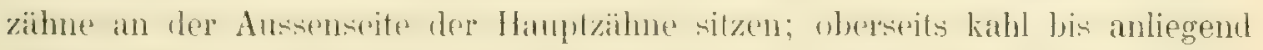
dicht behtart, unter'sits dichl anliegent behatrt bis filzig, ganz selten bloss der Mittelnerv behaart; Blaltstiele flaumig bis zottig, unterseits mit roten Drüsen

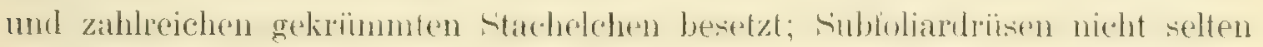

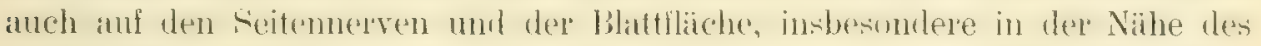
Blattrandes: Ituchblatler breit. Bliitrnstiele 1-2 con lang, meint olwas länger als die ausgebildeten Scheinfrüchte. Kelchblätter nach der Blüte zurückgeschlagen, ablällig. Kronblätter ziemlich klein, blassröllich oder weiss. Griffel etwas säulenfömig hervortretend; kahl bis stark behaart. ScheinIrüchte kugelig bis eiförmig. ${ }^{2}$ )

Ubersicht der i. G. k. Formen: ${ }^{3}$ )

a) Formen mit drüsiger Blattunterseite:

var. bohemica H. Bram

1) Die Definition der Untersektion Tomentellae wurde so gehalten, dass hier auch die R. abietina Grenier untergebracht werden kann, deren Beziehungen zur R. tomentella sowohl Crépin wie R. Keller betonen.

2) Die R. tomentella ist als Zwischenglied zwischen den Rubiginosen und Caninen aufzufassen, deswegen leidet ihre Definition etwas an Unbestimmtheit.

3) Ich habe die einfach gezahnten Formen, von denen die var. obtusifolia die bekannteste ist, als Unterart abgetrennt. Gegenüber der reichlichen Zahnung der übrigen Tomentella-Varie- 


\section{f. eminens miti ${ }^{1}$ )}

var. sepioides $R$. Keller.

b) Formen mit höchstens auf dem Mittelnerv bedrüster Blattunterseile:

var. typrica Chr.

1. simuatidens Chr.

var. affinis (Rau) Chr.

(c) Subsecies uniserrata mihie) (Blattrand volherrschent einfach gezahnt): var. obtusifolia (Descaux) Crep.

$$
\text { Diagnosen: }
$$

1. Var. bohemica: ${ }^{3}$ ) Stacheln statk. Blattstiele wallig, mit gelblichen Stacheln und grossen Drüsen; Blättchen oval bis rundlich; oben zerstreut, unten auf der Fläche dicht behaart; zuweilen Superfoliardrüsen, die Drüsen der Unterseite besonders aul den Nerven und dem Blattrand bemerklich. Blïtenstiele mittellang, kahl und drüsenlos. Krone weiss. Griffel kahl oder etwas behaart. Scheinfrüchte elliptisch oder oval.

2. F. eminens: Blätchen breit oval bis rundlich, in den stiel bald abgerundet badd etwas verschnälert; Suhfoliandrïsen zahleich. Die sïulenförmigen Griflel stark behart, fast wollig. Scheinfruchte kugelig bis (rikugelig. ${ }^{4}$

3. Var. sepuides: Stachehn zahleeich, aber wenig krältig. Blattstiel dicht behatart; Blättchen oval, beiderseits gleichförmig, am Grunde oft scharf keilförmig verschmälert; oberseits zerstreut, unterseits dichter behaart, namentlich an den Nerven; Blätchen der unteren Blätes äber die ganze Fläche

tiiten erscheint die einfache Zahnung so auffïllig. dass tie meisten Rhodologen die var. obtusifolia zur R. dumetorum ziehen. Weil sie jedoch nach Blattgestalt, Kelchzipfelfiederung und Stachelform mit der typischen R. tomentella übereinstimmt, habe ich sie mit R. Keller und Crépin bei letzterer belassen. Sie leitet aber jedenfalls durch das wichtige Merkmal der einfachen Bezahnung zur R. dumetorum über. Die mehrfach gezähnten Formen der R. tomentella ordnete ich in erster Linie nach dem Drüsenreichtum der Blätter, in zweiter nach dem Grade ihrer Behaarung. R. Keller macht die individuell so schwankende Behaarung zum obersten Einteilungsgrund. Er sieht sich infolge dessen zu vielen Inkonsequenzen genötigt. So steht die var. affinis (Rau) Chr., die nach Rau sogar auf der Blattoberfläche behaart ist, unter den kahlen, die var. Misniensis Hofmann aber (mit schliesslich allein noch haarigem Mitlelnerv!) und die var. concinna Chr. (,nur der Mittelnerv noch flaumig": R. d. Schw. S. 128) unter den stark behaarten Tomentellen.

1) Eminens = hervorragend: Eigenschaft der Griffelsäule.

2) Uniserratus: einfach gezahnt.

Diagnose der Unterart: Margo foliolorum plerumque uniserratus denticulis raro accedentibus.

3) R. Keller rechnet diese Rose zur R. agrestis (Syn. S. 127). Dass die Kelchblätter in ihrer Fiederung auffallend vom Typus der Tomentellen abweichen, erwähnt H. Braun nicht. Ich habe die Definition der Beschreibung entnommen, die Braun selber auf S. 21 f. der „Beitr. z. Kenntnis einiger Arten und Formen der Gattung Rosa" (Wien 1885) gibt.

4) Foliola late ovata vel subrotunda, petiolum versus tum rotundata tum leviter attenuata; subtus glandulis abundantia. Styli columellam imitantes valde pilosi, paene villosi. Receptacula fructifera globosa vel ovoideo-globosa.

Zur Beschreibung sei nachgetragen: Blättchen oben zerstreut anliegend, unten über die ganze Fläche dicht behaart. Blütenstiele olne Drüsen, von der ungelähren Länge der aus-

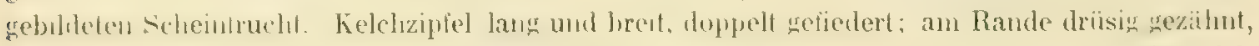
auf dem Rücken fast drüsenlos. Krone blassrötlich, fast weiss. - Die f. eminens berührt sich offenbar sehr nahe mit der von $\mathrm{R}$. Keller zur var. sepioides gezogenen forma versus caryophyllaceam M. Schulze's, nur sind die Blättchen selten keilig und die Griffel stark hervortretend. 
oder doch in der Nïhe des Randes nit zahlreichen Drisen, obere Blïlter oft bluss an den Nerven. Blïtnstiele zicmlich lang, ohne: Drüsen. Kelchbläter nur am Rande stark drüsig. Griffel kahl oder schwach behaart.

4. Var. typica: Strauch mit flattrigen Asten. Stacheln auffallend gross. Blattstiel filzig; Blättchen rundlich verkehrt eiförmig, am Grunde abgerundet; oben kahl oder schwach, unten dicht behart; nur ausnahmsweise auch auf den Seitennerven hie und da ein Drischen. Corolle weiss bis blassrölich. Griffel was hervorragend, slatk behatat bis wolligr. Scheinfrüchte kugelig bis eikugelig.

5. F. simutidens: stacheln kleiner als bein Typur. Blättehen grösser, runllich; oben fast kahl, unten an den Nerven schwach behart; Blattstiele flaumig; Blattzähne etwas geschweilt. Kronen freudig rot.

6. Var. affinis: Blattstiele haarig; Blättchen oval bis Iänglich oval, beiderseits verschmälert: unterseits nur am Mittelnerv und meist atuch am Rande zerstreut behaart. Griffel kahl oder nur mit vereinzelten Haaren. Krone blass. Scheinfrüchte kngelig bis eiförmig. ${ }^{1}$ )

7. Var ohtusifolia: Blattstien dicht behatut, fast filzig; Blattchen oval okler elliptisch, am Grunde oft schmal zugerundet; einfach gezahnt; oberseits im jugendlichen Zustand behart, unterseits dicht behart, schimmernd. Griffel stark haarig, später verkahlend. Scheinfrïchte kugelig bis eikugelig.

Standorte:

Ad 1. Mehrmals am Fussweg Eichstätt-Wintershof (Dolomit $465-470 \mathrm{~m}$ )

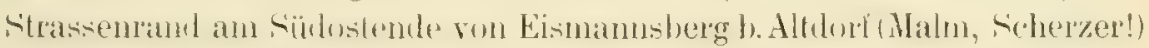

Ad 2. Am Weg Eichstätt-Wintershof (Plattenkalk $500 \mathrm{~m}$ )

Ad 3. Fehlucht der linken Talwand zw. Adamsberg u. Ochsenkeller b. E. (E.luviallehm $500 \mathrm{~m}$ )

An Fusswegr Eichstiitt-Wintershof (Grenze Dolonit-Plattenkalk igo m) In Schlucht d. Geissbergs b. E. u. sonst am Abhang d. Geissbergs (Malmkalk u. Dolomit $430-490 \mathrm{~m}$ )

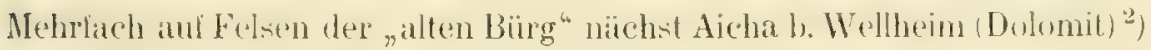
Oberhalb d. Weilers Hagenbach b. Berching (unt. Malm)

Ad 4. Rechter Abhang des Buchtals b. E. (Dolomit)

Ad 5. Nehrere Hecken am Fussweg E.-Wintershof (Dolomit $480 \mathrm{~m}$ )

Am Buchenrain zw. Berg u. Hausheim b. Neumarkt (Lehm mit Doggersand $480 \mathrm{~m}$ )

Ad 6. Nordöstl. von Liebenstadt b. Heideck (auf Keuper, Schneid!) ${ }^{3}$ )

1) Rau (Enumer. ros. p. 79) schreibt von den Blättern seiner Rosa affinis, sie seien oben flaumig, unten kahl. Oben finden sich in der Tat auch bei fast hararmen Tomentellen zerstreute Flaunbare; die Pubestenz der Blattnerven auf der Interseite scheint dem Winzburfer Bolaniker entgangen zu sein. - Die var. concinna (Lagger et Puget) Chr. findet bei Christ (R. d. Schw. S. 128 f.) im wesentlichen dieselbe Beschreibung wie die var. affinis, nur von den Blütenstielen heisst es: ,hat als montane Form kürzere Blütenstiele, die oft von den Brakteen verdeckt sind".

$\left.{ }^{2}\right)$ Diese Rose hat sehr kurze Blütenstiele. Sie wurde seinerzeit von Crépin als tomentella erkannt.

3) Hier sind die Blättchen vielfach breit oval und in den Stiel abgerundet; die Blattform geht zur var. typica über. 
Grosse Büsche am Weg Berg-Kadenzhofen b. Neumarkt, nahe letzterem (sandiger Lehm des unt. Dogger $480 \mathrm{~m}$ )

Am Gebertshof hinter der Heimburg (Fl. v. Nbg.)

Am. Schwarzholz ob. Richtheim b. Neumarkt (sand. Lehm d. unt. Dogger)

Am Ablluss des Stichbrünnls b. Berg

Am Weg zum Odelsbach b. Berg (Lehm d. ob. Lias $430 \mathrm{~m}$ )

Mehrfach am Odelsbach b. Berg (Ton, Grenze Lias-Dogger)

In Menge in lichlem Eichenhatin zwischen Gdelshach mal Heimburg([)uggerlehm mit Sand $450 \mathrm{~m}$ )

Am Ende les Thrtes -indelbach an Strase nach Langenthal (Lehm $130 \mathrm{~m}$ ) Rain b. Häuselstein nächst Altdorf (Malm, Scherzer!)

Ad 7. B. der Fuchemibhle zw. Möhren n. Treuchtlingen Alluvium, Sehneid!)

Zwischenformen: Südwestlich von Berching habe ich auf Doggersand

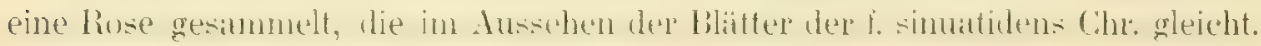
Letztere sind gross, breit oval bis rundlich, meist in den Stiel abgerundet; tief gezahnt nit geschweiften lauptzähne'n: bedeleseits auf der Flïche behart, aber anch unterl ziemlich zerstreut. Ibagegen zeignes sich die Grillel ganz kahl. Ich verzichte wegen des singuliaren lorkommens ant dies challung einer nenen Form, möchte jedoch bemerken, dass auch die Rose ad 6. von Liebenstadt Anklänge an die beschriebene Zwischenform aufweist.

- Wenn wir von der var. obtusifolia absehen; die sehr selten konstatiert,

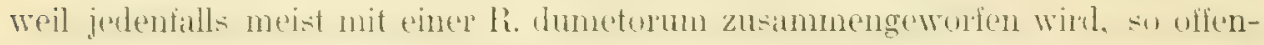
bart sich uns zwischen dem südlichen und dem nördlichen Teil des Gebietes ein auballender Lntershied: un Eichstät ̈̈berwitgen Fomen mit statkbedrüster

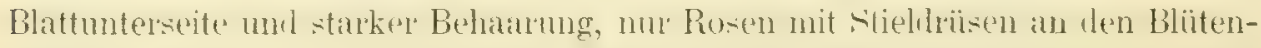

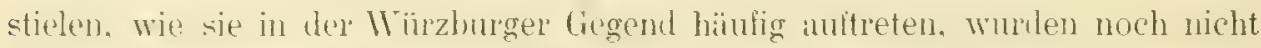
gefunden; zwischen Nemmakt, Uheppl. unl Alturf dominiert die var. affinis z. Z.

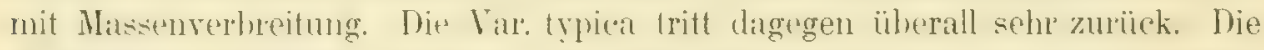
R. tomentella iibethumpt scheint nuch viel strengel an den Jüa und den ähnlichen Muschelkalk gehnnden zu soin als selhst die Gruppe ler Rubiginosa. Die drüsigen Furmen stehen an ähnlichen Plïzen wie dits Ifeinrusen, nur wollen sie entschieden mehr sohntz. Die var. attinis linde ich stets ant tiefgründigem und feuchtem Bulen, oft anch in Halbschatten höheren Gebiisches oder des lichten Waldrandes.

\section{Subsectio 2 : Eucaninae Crépin (emend. Schwertschlager).}

Stacheln am Grunde'nicht aufällig verbreitert, meist ziemlich schlank. Blätchen kahl culen behatrt: Subfoliardriten fehlen fust stets und sind nie reich

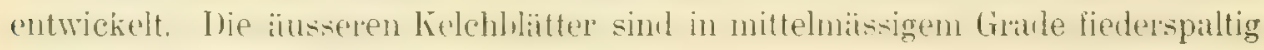
und haben schmale Fiedern.

Die im Gebiet und im ganzen deutschen Reich vorkommenden 4 Arten dieser Intersektion kömnte man wegen ihrer nahen Verwandtochat sugar zu 1 Gesantalt mit í Einzelarten zusammensehliessen, Wubei dann R. canina mit

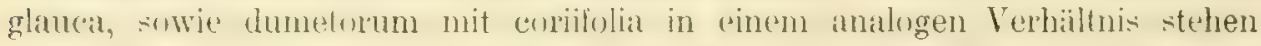
würden wie R. micrantha: rubiginosia und agrestis: elliptica. Aus Gründen der 
Klarheit und der besseren Stoffeinteilung emplichlt es sich jedenfalls 22 Geramtarten nut je 2) Einzelarten zu unterschedelen. Cirepin hat dron Zusanmenhang

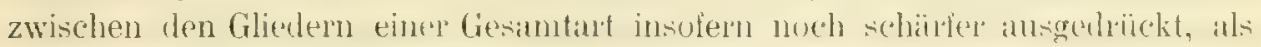

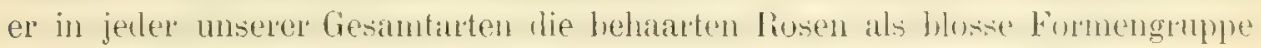

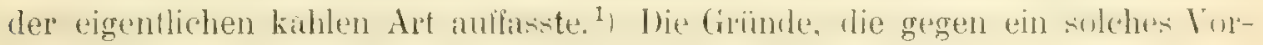
gehen sprechen, erörtert R. Keller S. 17千 f. der Synopsis 6, 1.

\section{Gesamtart Losa canina $L$.}

Hoher Strauch mit sehr verlïngerten, bogig überhängenden Äslel.

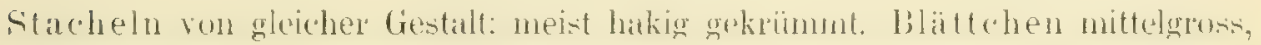

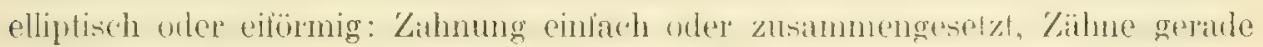

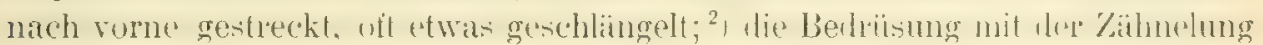

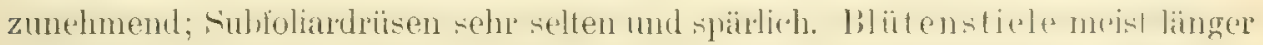

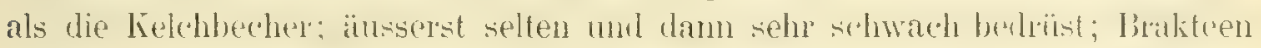

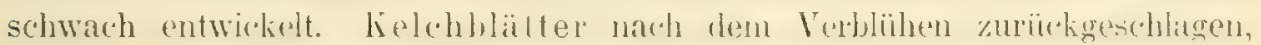
schon vor der Rötung der Frucht abfällig. Corollen blass, nur ausnahmsweise tieler gefirbt. Ciriffel kihl bis behatut, aber nie ein kurzes wolliges liöplohen

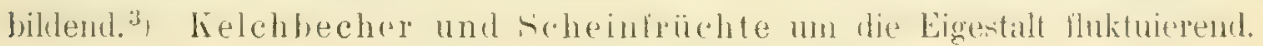

\section{Einzelurt Rose ceninl $\boldsymbol{L}$.}

Blättchen kahl oder höchstens am Blattstiel und Mittelnerv flaumig zerstreut behaart.

Die R. canina, welche man als "Durchschnittsrose" aufzufassen hat, geht bei ihrer fast universellen Verbreitung in eine wahlutl mentliche Zahl ron Varietaten

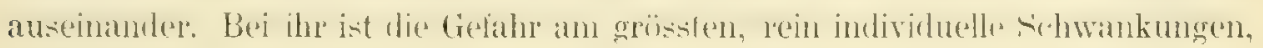

1) Tabl. anal. p. 18. 25 sq. - In den Primit. monogr. ros. fasc. 6. p. (12) 672 sqq. teilt Crépin die Sektion Caninae noch ein in: Eucaninae (R. canina und dumetorum), Coronatae (R. glauca mit corifolia) und Meridionales (R. Pouzini). Auch die R. Chavini Rapin rechnet er dort (p. $74=734$ ) nach einigem Zögern den Eucaninae zu, während er die R. montana Chaix in nähere Beziehung zur R. glauca, also den Coronatae, setzt. Im späteren Tableau anal. wird die Sectio Caninae viel weiter gefasst und begreift auch unsere Sektionen Vestitae und Rubiginosae in sich; die Eukaninen sind da zu einer Untersektion geworden, welche ausser den Arten der früheren Sectio Caninae noch die R. tomentella und abietina einschliesst. Ich habe meine vorstehende Definition der Subsect. 2: Eucaninae so eingerichtet, dass sie ausser auf die 4 gewöhnlichen hayrischen und deutschen Arten auch auf die alpinen R. Chavini (nächst canina stehend), montana (nächst glauca), rhaetica Gremli mit uriensis Lagger et Puget (nächst coriifolia) und die südliche R. Pouzini Trattinik (nächst canina) passt. Die R. abietina Grenier haben wir schon oben in der Subs. Tomentellae untergebracht. Die zulelzt erwähnten alpinen und südlichen Arten der Eucaninae weisen durch ihren verhältnismässigen Drüsenreichtum ebenfalls aul die Tomentellae, ja sogar die Rubiginosae hin.

2) Dieses Merkmal, welches R. Keller betont, erscheint mir recht zufreffend.

3) Selbst wenn Formen der R. canina ganz wollige Griffel besitzen, lassen sie sich von der R. glauca unterscheiden dadurch, dass letztere ein kurzes, polsterförmig breites Griffelköpfchen zeigt, während die echte canina ilire schlanken, etwas verlängerten Griffel aus der Diskusöffnung herausstreckt. Damit steht in Zusammenhang eine weitere im III. Teile näher zu besprechende Eigentümlichkeit: Der Diskuskanal ist bei R. canina (und dumetorum) lang und eng, bei R. glauca (und coriifolia) kurz und weit. Das lässt sich durch einen Frucht- oder Kelchbecherlängsschnitt leicht feststellen. 
wolhe gar nicht rererbt werden, in gleiche Linie mit echten Variationen zu stellen, ja sogar mehrere Formen an einem und demselben Sitrauche zu finden. Für am meisten der Gefahr ausgercelzt, lediglich individuelle Abänderungen darzustellen und systematisch übersobitzt zu werlen, halte ich folgenle Eigenschaften:

1. Die Bewehrtheil uler Lnbewehrtheit der Blïtenzweigt' in Gegensatz zu den Asten. 2. Die Farbe der Blattunterseite. Diese ist natürlich stets wegen des luthaltigen und chlorophyllamen Sichwammgeweber hasser wie die Oberseite. Andere Farbentibancen werlen entweder durch Behaameng oder durch Wachsiblerzug hervorgerufen. Stïlkere Ausbildung des letztgenamnten ist aber bhoss eine Folge somnigenen Ttandorites. 3. Nur mit Vorsicht ist die Gestalt der Scheinfrichte zu verwenden. Allerdings entsprechen sie hei jeder Varietait einem vorwiegenden Typus, gehen aber, häufig im selben Corymbus, nach zwei Seiten ïber den Typus hinaus, andass wengstens kugelige und eikugelige oder lang etlipsoidische und bloss eiförmige sich zusammen linden. Bei der Reile wird die Frucht stets voller, also kugeliger. Scheinfrichte mit wenig Nüsschen bleiben schmäler, also mehr oval. In reichen Curmben sind öfter die äusseren Frïchte kugelig. die mittleren birnfömig. '. Die Zickzackbiegung der Zweige diurfte in Aushildung wie Beurteilung kaum die nötige Sicherheit bieten. 5. Blïtrhengrund und Blittchenspitze wercheln in ihrer Forn am sellen Zweig. Nam dart bei ihrel Diagnose lediglich die vorwiegende Gestalt angeben oder die Grenzen, zwischen denen sich die Formen bewegen. Man vergesse auch nicht, dass Schössinge stets schnälere Blïtchen hathen wie bliitenzweige auch sind sie stets reicher bestachelt zum Schutz gegen Tierfrass usw.). Einzelne Haare kommen bei sehr vielen Formen der R. canina und glauca am Grunde des Blattotiels vor und können nicht berïcksichtigt werden. Jedenfalls darf man die vorbeztichelen Merkmale nicht zur ersten Gruppierung der Formen benulzen. Ich fulge den Beispiele R. Ketlers in der synopsis, bez. den spuren Christs und Crepins, wemn ich im folgenden zuerst einteile nach dex Bezihnung des Blattrandes, mit wolcher dessen Bedrïsung parallel geht. soldmu nach der Bedrüsung von Blïtenstielen und Blattunterseite. Diese Derkmale bieten eine mehr gesicherte Beurleilung. Auserdem benutze ich bei der Einteilung den Grad der Deharang der Gritlel. In zweiter Linie sehe ich auf die Form der Bliatchen, die Gestalt der Blattzïhne, der Stacheln und der Frïchte, die Blütentiube. Wir dürten freilich nicht vergessen, was übrigens anch bei anderen formenreich'n Arten zutrifit, nämlich dass die Varietäten der R. canina eine fortlaufende Kette hiklen, deren Cilieder in tinander ib)ergehen. Auch zwischen Caninen

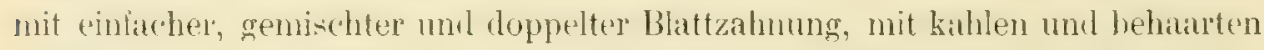
Griffeh u. s. f. existicren alle möglichen Gberginnge. Ẅir kömnen nicht alle aulführen und nuch weniger benemen - oder schom henatne wieder erkennen und hier registrieren. Lediglich bestimmte wichtigere Phasen dieser Entwicklung werden wir als dofiniede litriationen "pkennen oder nen delinieren. Noch weniger wird man verlangen können, dass wir eine völlig einwandireie

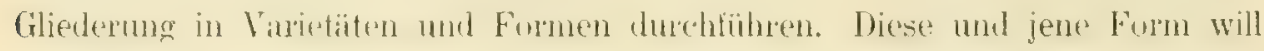
ein Anderer violleicht bei riner anderen Varietit untergethacht wissen, oder er nennt Form, was hier Varietät ist und umgekehrt. Am einfachsten wäre, nur 
gleichwertige Formen nach eincr schematischen litihenfolge aufanstellen. Allein wir mïrsen unserm Prinzip getren beiben, erinnern jedneh an dis Wort: Llrat posse nemo tenetur.

Ubersicht der i. G. k. Formen:

a) Blättchen einfach gezahnt (Uniserratae): ${ }^{1}$ )

1. Formen ohne Driisen an Blïtenstielen und Blattunterseite

(Formenkreis der R. lutetiana Léman): ${ }^{2}$ )

a Griffel \pm haarig:

var. glaucescens Destaux

var. dolosa (Godet) $R$. Keller ${ }^{3}$ )

f. corylicola $H$. Braun

var. fallens (Déséglise) Borbas ${ }^{4}$ )

var. hispidula (Ripart) R. Keller

$\beta$ Griffel wollig:

var. syntrichostyla (Ripart) H. Brann

1. dilucida (Déséglise et Ozanon) H. Braun

f. lasiostylis Borbas

2. Formen mit Drüsen an den Blütenstielen

(Formenkreis der R. andegavensis Bastard):

var, condensatu (Puget) K. Keller

f. surculosa (Woods) Smith ${ }^{5}$ )

i. Mollardiana Moutin

b) Blïllehen unregelnässig gesïgt, teils einfuch teils (bupelt ${ }^{6}$ ) (Transitoriae):

1. Formen ohne Driisen an den Bliitenstielen

a Griffel kahl:

(Formenkreis der R. spuria Puget):

var. ololeia (Kivart) H. Braun

1) Die Gruppenbezeichnungen Uniserratae, Transitoriae, Biserratae stammen von Crépin.

2) Die Rosen dieses formenkreises haben schwach drisig gewimperte Nebenblätler und drüsenlose oder mit vereinzelten Drüsen besetzte meist bestachelte Blattstiele. Die Zühne des Blattrandes entbehren der Drüsen, desgleichen die Rücken der Kelchblätter; der Rand dieser zeigt wenige Drüsen.

3) Die f. insubrica Wierzbicki, welche H. Braun (11. Ber. d. bot. Ver. Landshut S. 100) und A. Schwarz (Fl. v. Nbo.) anerkennen, unferscheidet sich m. E. nicht genügend von der var. dolosa. Zudem steht ihre Definition nicht fest.

4) Die gleiche Identität scheint zu bestehen zwischen der var. fallens und der var. (Rosa) lutetiana Leman vieler Autoren. Da dem Begriff der letzteren ein etwas schwankender und unbestimmter Inhalt gegeben wird, ist der spätere Name var. fallens vorzuziehen.

5) Déséglise erklärt im Catal. rais. p. 347 Nr. 202 seine früher aufgestellte f. edita für im wesentlichen identisch mit der R. surculosa Woods (vgl. das Inhalisverzeichnis unter f. edita = obs. :) Dagegen sprectien jedoch die eigenen Angaben von Déséglise, der auch die Diagnose von Woods' R. surc. mitteilt und sich auf Originalexemplare der letzteren durch Autopsie bezieht. Die f. edita hat nämlich kahle, die surcul. wollige Griffel; Diskus bei surc. etwas hervorragend und Blïten rosa, bei edita Blïten blass. Meine Rosen stimmen nur zur $\mathbf{R}$, surculosa Woods.

6) Die Rosen dieses Formenkreises tragen ausser dem drüsigen Nebenzähnchen bereits reichlicher Drüsen an den Blattstielen. Die doppelte Zahnung der Blättchen zeigt sich mehr an den unleren Blättern und Blältchen eines Zweiges und Blattes. 


\section{f. lanenoides milli ${ }^{1}$ ) \\ f. Swartzii Fries}

$\beta$ Griffel hatarig bis borstig:

var. spuria (Puget) Borbas

f. Hadriama mihi²)

f. monticola mihii ${ }^{3}$ )

1. oenophora J. B. Keller

var. frondosa (Steven) H. Braun

1. fissidens Borbas

f. acuminata H. Braun

var. ramosissima hall

var. latifolia mihi $i^{4}$ )

var. hispiduloides mihi ${ }^{5}$ )

Früchte oval länglich

$\gamma$ Griffel wollig orler fist wollig:

var. montivaga (Déséglise) Borbas

f. composita mithi ${ }^{6}$ )

var. intercedens $H$. Braun

var. jurensis mithi ${ }^{7}$ )

var. enoxypluylla Borbas

var. saxicola mithi ${ }^{8}$ )

var. semiliservata Borbas

var. mentacea (Puget) H. Braun

Früchte kugelig bis eikugelig

Früchte oval länglich

\section{Formen mit Drïsen an den Bliitenstielen}

(Formenkreis der R. hirtella Ripart):

var. bihariensis Borlus

1. salicetorum H. Bian

1. Theodori mili; ${ }^{9}$ )

var. vinealis (Ripart) $R$. Keller

c) Blättchen alle doppelt oder mehrfach drüsig gezïhnt ${ }^{10}$ ) (Biserratae):

1. Formen ohne Drüsen an den Blïtenstielen und der Blattunterseite

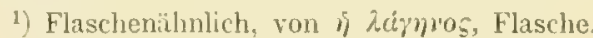

¿) Wächst am LIaderłouck = Hadriansbühel b. Kipfenberg, über welchen die Teufelsmauer, das vallum Hadriani, ins Altmiihltal hinabsteigt.

3) Monlicolus, bergbewolmend.

4) Latifolius, breitblättrig.

5) Hispiduloides = ähnlich der var. hispidula.

6) Composilus, zusammengesetzt: auf den Wechsel in der Blattzahnung bezïglich.

7) Jurensis, im fränkischen Jura zuerst gefunden.

8) Saxicolus, Felsen bewohnend.

9) Nach meinem lieben Bruder, Pl. Theodor Schwertschlager, so genannt, der mir bei Sammlung von Rosen viele Beihilfe geleistel hat.

10) Bci allen Rosen, die doppelt bis dreifach gezahnte Blättchcn aufweisen, kommen ganz gelegentlich auch zerstreute einfache Blattzähne zur Beobachtung. Rosen der Abteilung Biserratae zeigen nicht bloss am Blatlrande, sondern auch an den Blattstielen reichliche Drüsen. In Fällen des Zweifels, ob man eine Rose zu den Transitoriae oder Biserratae zählen solle, kann man das letztgenannte Merkmal zu Hilfe rufen. So geht der Reichtum an Drïsen immer weiter: schliesslich werden auch die lielchblïtter reich drüsig an den Rändern und auf dem liücken. 
(Formenkreis der R. dumalis Bechstein):

* Formen, deren Kelchblätter höchstens schwach drüsig berandet sind:

a Griffel kahl oder nur in Spuren, bes unten, behaart:

var. villosiuscula (Kipart) Borbas

f. Sabranstiyi H. Braun

var. Chaboissaei (Grenier) H. Braun

var. oreogiton $H$. Braun

1. oblongata Opiz

Früchte kugelig bis eikugelig

Früchte oval bis länglich

$\beta$ Griffel dentlich bis stark behaart:

var. nublliflora (Déséglise) Borbas

1. insignis (Grenier) Borbas

1. racemulosa H. Braun

var. laxifolia Borbas

var. Erdnevi $R$. Keller (in lit.) ${ }^{1}$ )

$\gamma$ Griffel wollig:

var, eriostyle (Ripart) Borbas

f. conspicua miti ${ }^{2}$ )

1. adunca mitii ${ }^{3}$ )

var. leuca Wiesbaur

Früchtè oval bis länglich

Früchte kugelig bis eikugelig

Fr. eilörmig

** Formen mit stark drüsig gewimperten Kelchblatträndern:

var. biserrata (Mérat) Baker

var. squarrosa (Rau) Borbas

1. disparabitis (Ozanon) H. Braun

2. Fornun mit reichster Bedritsung: Driben an den Blitenstirlen und Subfoliardrüsen (Formenkreis der R. verticillacantha Mérat):

* Formen mit Driisen an den Bliitenstielen:

var. Schottiana Séringe

f. armata mihit)

f. liypsisepala mihi ${ }^{5}$ )

auch stellen sich Drïsen auf den Nervillen der Blattunterseite ein. Biserratae haben gern kürzere Blütenstiele, stärkere Brakteen und kräftiger gefärbte Kronblitter; auch Befläumelung der Blattstiele ist bei ihnen sehr verbreitet. - Die Gliederung der Synopsis scheint mir in der Abteilung der Biserratae sehr unübersichtlich zu sein, was allerdings mehr oder minder in der Natur der Sache, d. h. der nach allen Seiten variierenden Mannigfaltigkeit der R. canina liegt. Ich habe mehr die Einteilung H. Brauns in der „Fl. von Niederösterreich" berücksichtigt, welche auch in der Fl. v. Ňgg. zu Grunde liegt.

1) Diese Form wurde von Hrn. Pf. E. Erdner in Donauwörth, dem Erforscher der Flora von Neuburg a. D., entdeckt und mir mit vielen andren Funden mitgeteilt; nach ihm hat $\mathrm{Hr}$. Prof. R. Keller die Beschreibung unter dem obigen Namen übernommen, aber bis jetzt nicht publiziert. Ich tue das also vorläufig, olne einer späteren Beurteilung von R. Keller zu präjudizieren.

2) Conspicuus, aufällig (wegen der behaarten Blïtenstiele).

3) Aduncus, krummschnäbelig; bezieht sich auf die stark gekrümmten Stacheln.

1) Von armatus, bewaffnet (wegen der reichen Bestachelung). Kelchblatt.

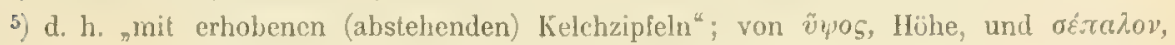


var. reginae mihi ${ }^{\perp}$ )

f. eriostyloides mili $i^{2}$ )

** Formen mit Subfoliardriisen:

rar. scabrata Crep.

*** Formen mit Subfoliardrïsen und Drüsen an den Blïtenstielen:

var. Blondaeana (Ripart) Crep.

f. St. Wallurgae mith: ${ }^{3}$ )

\section{Diagnosen:}

a)

1. Var. glancescens: Stacheln gross, wenig zahlreich. Blittchen elliptisch oder eifömig. blau hereilt; wenig gezahnt. Griffel behart. Scheinfrüchte ellipsoidisch.

2. Var. dolosa: Stacheln leicht gebogen bis fast gerade. Blättchen klein, eiförmig lanzettlich bis lanzettlich mit etwas keiligem Grunde. Scheinfrüchte eikugelig.

3. F. corylicola: Blättchen mittelgross und zur Basis abgerundet, sonst wie dolosa. Scheinfrüchte eikugelig.

f. Var, fallens: stachehn leicht gehogen bis fast gerade. Blittchen eilörmig bis rumblich elliptisch, vorne kurz zugespitz: gegen den stiel abgerundet. ${ }^{4}$ ) Scheinfrüchte ellipsoidisch.

5. Var. hispidula: Blattstiel behaart; Blättchen länglich; oberseits kahl, unterseits am Mittelnervetwas behart. Griffel behaart. Scheinfrichte eiförmig.

6. Var. syntrichostyla: Grilfel wollig hehaar, zu einer hervoragenden säule zusammengestellt. Scheinfrüchte eiförmig.

7. F. dilucida: Blättchen gross. Scheinfrüchte kugelig.

8. F. lasiostylis: Grilfel etwas kürzer. Scheintrïchte eilörnig bis lïnglich elliptisch.

9. Var. condensuta: Stieldrïsen an den Blïtenstielen spärlich. Griflel stark behaart bis fast wollig. Scheinfrüchte kugelig.

10. F. rmculosa: lieichulitige Inflorescenz. Blütenstiele z. T. stieldrüsenlos. Blüten rosa. Griffel wollig. Scheinfrüchte eikugelig. ${ }^{5}$ )

11. F. Mollardiana: Blïtenstiele ziemlich kurz: hald stieldriisig. bald stieldrüsenlos. Scheinfrüchte eiförmig.

b)

12. Vir. ololeia: Blïtenzweige wehrlos ader schwach bestachelt. Blaittchen mittelgross, eiförmig oder elliptisch, spitz. Scheinfrüchte länglich eilörmig.

1) Ich fand die Rose zuerst auf dem Frauenberg in der Nähe der Marienkapelle b. E. (mons reginae sanctorum!)

2) Eriostyloides = ähnlich der var. eriostyla.

3) Nach dem Fundorte: Neuer Weg b. E, oberhalb des Klosters St. Walburg.

1) Dass die Blättchen gegen den Stiel abgerundet seien, sagt Déséglise selbst (Cat. rais.

Nro. 155). H. Braun hat mit der gegenteiligen Behauptung also Unrecht.

5) Woods schreibt, die Scheinfrüchte dieser Rose seien late elliptica, breit elliptisch. Das darf man wohl für ungefähr eikugelig halten. 
13. F. layenoides: Hochbläter linger wie die Blïtenstiele. Kelchzipfel nach der

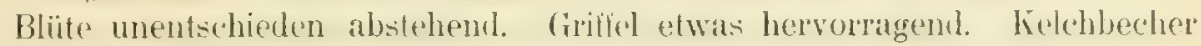
sehr langgestreckt; Scheinfrüchte fast flaschenförmig. ${ }^{1}$ )

14. F. Surartzii: Äste derb bestachelt. Blättchen gegen den Stiel schmal zugerundet oder verschmälert. Scheinfrüchte elliptisch oder eilörmig.

15. Var. spuria: Stacheln derb, aber wenig gekrümmt, an den Zweigen fast gerade. Aste aufallend rotviolett; auch Nebenblätter, Hochblätter, Blattstiele und Kelchblitter rötlich überlaufen. Blittchen oval bis elliptisch, an der basis abgerundet. Griffel schwach behant. Scheinfrïchte eiförmig.

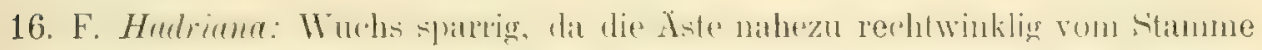
abstehen. Bestachelung sehr reich; Stacheln lang, gerade oder fast gerade. Wenig Blätter. Sonst wie die var. sp. ${ }^{2}$ )

17. F. monticola: Blättchen in den Stiel verschmälert. Kelchblätter nach dem Verblïhen teilweise abstehend. Sonst wie die var. sp. ${ }^{3}$ )

18. F. oenophora: Blättchen oval bis lanzettlich, an der Basis verschmälert bis schnal zugermetet. Schernfrichte eilimmig bis länglich eilömig. Sunst wie die var. sp.

19. Var. frondost: Blïtenzweige fast unbestachelt. Bläldehen lïnglich uval onder länglich elliptisch, in den Stiel verschmälert. Scheinfrüchte lünglich oval bis länglich ellipsoidisch.

20. F. fissidens: Blättchen in den Stiel abgerundet, unten grasgrün.

21. F. acmminata: Statheln schlank. Blättchen scharf zugespitzt, unten grangrim.

22. Var. rumosissma: Ciedrungener Zwerostranch mit fast unbewehten Achen. Blätchen klein (im Durchschnitt 1,5 cm lang und $1 \mathrm{~cm}$ breit), eiförmig, spitz und in den Stiel verschmälert. Scheinfrïchte eiförmig.

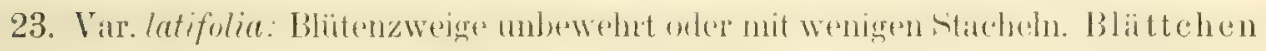
gross bis sehr gross (bis $5 \mathrm{~cm}$ lang und $3 \mathrm{~cm}$ breit); breit eiförmig; gegen den Stiel abgerundet, vorne kurz zugespitzt. Blïten gross. Kelchröhren und Scheinfrüchte oval. ${ }^{4}$ )

24. Var. hispidulvides: Stacheln dünn und leicht gebogen. Blätchen elliptisch, spitz, meist in den Stiel verschmälert; bei jungen Blättchen ist der

1) Bracteae pedicellis Iongiores. Sepala post anthesin dubie patentia. Styli leviter prominentes. Calicis tubus in longitudinem admodum extensus; receptacula fructifera formam lagenae aemulantia.

2) Frutex habitu rigido, cum rami quasi rectangulo a caule distent. Aculei plurimi, longi, rectiores. Folia pauca (Reliqua cum var. spur. concordant).

3) Foliola ad basin angustata. Sepala post anthesin partim patentia (Cetera cum var. spur. congruunt). - Die - etwas erweiterte - Diagnose wurde schon von J. Schnetz in den ${ }_{n}$ Mitteilungen d. bayr. bot. Ges. II Bd. S. 62, 1907", publiziert.

4) Rani floriferi inermes aut paene inermes. Foliola maxima (usque ad $5 \mathrm{~cm}$ longa et $3 \mathrm{~cm}$ lata); late ovalia; petiolum versus rotundata, cum apice brevi (denticuli serraturae irregularis): Flores magni (Styli pilosi). Receptacula etiam fructifera oviformia. 
Blattstiel behart. Mittelnerv mit einzelnen Seitennerven befläu-

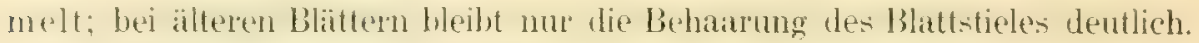
Scheinfrüchte ei- bis birnförmig. ${ }^{1}$ )

25. Var. montiraya: Zweige meist rötlich üherluten. Stircheln etwas ungleich. last gerade. Bliattchen oval bis rundlich, zur Basis abgerundet. Kelchblaitter nach der Blïte abstehend, bald abfillig. Scheinfrïchte kugelig bis eikugelig.

26. F. compresta: Zweige und Brakteen rötlich überlaulen. Bestachelung dicht, wh wirtelig. Stacheh ungleich. fein, wenigg gebogen. Blättchen oval. scharf zugespitzt, in den Stiel verschmälert; Blattrand teils einfach, teils 2- Ifach gezähnt. Grosse Brakteen, kurze Blütenstiele. Griffel wollig. Scheinfrüchte kugelig bis eiförmig. ${ }^{2}$ )

27. Var: intercedens: Blätchen gegen den Grund verschmälert. Leblchbläter zurückgeschlagen. Griffel schwach wollig.

28. Var. jurensis: Stachehn an den Blütenzweigen klein, fast gerade. Bläldehen elliptisch oder oval, mittelgross. Griffel wollig, sïulenförmig hervorragend. Scheinfrüchte kugelig。 ${ }^{3}$ )

29. Var. ewoxyhylla: Zweige rot ïherlufen. Blïtchen uval bis oval lanzettlich, an beiden Enden zugespitzt. Blütenstiele kurz. Scheinfrüchte eikugelig. $\left.{ }^{4}\right)$

30. Var. saxicola: Zierlicher Wuchs. Am Stamme aufallend ungleiche Stacheln: grusise hakige und kleine fist gerale; Stacheln an den Zweigen fast gerade. Blättchen klein, eiförmig, in den Stiel verschmälert, unten blangriun; wie die Zweige rut überlanten. Scheinfrüchte klen, ellipsuidisch. ${ }^{5}$ )

31. Var. semibiserata: Blïttchen elliptisch oder breit elliptisch, in den Stiel abgerundet.

32. Vir. mentacea: Blïtlchen zum Blattstiel verschmälert. spitz oder lang zugespitzt.

1) Aculei exiles et leviter incurvati. Foliola elliptica, acuta, in basin plerumque attenuata (irregulariter bis serrata); pili petiolorum et pubes nervi primarii in junioribus foliolis aperta, in senioribus excepto petiolo obsoleta. Receptacula fructifera ovoidea vel piritormia.

2) Aculei conferti, saepe verticillati, inaequales, tenues, paulum inclinati. Rami et bracteae rubella. Foliola ovata, argute acuminata, basin versus angustata; in margine partim simpliciter partim dupliciter et multipliciter dentata. Bracteae satis magnae, pedunculi breves. Styli villosi. Receptacula fructifera globosa vel ovoideo-globosa. - Diagnose von J. Schnetz

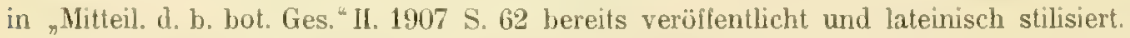

3) Aculei in ramis florigeris parvi paeneque recti. Foliola elliptica vel ovata, modicae magnitudinis. Styli villosi et instar columnae prominentes. Receptacula fructifera globosa. - Meine var. jurensis ist die unregelmässig zweifach gezähnte Parallelform der f. dilucida var. syntrichustyla des furmenkreises Uniserratae. Ebd. S. 61 im wesentlichen von J. Schnetz publiziert.

4) R. Keller bringt diese Rose bei den einfach gezähnten unter (Syn. S. 157), H. Braun registriert sie sowohl bei den Uniserratae wie bei den Transitoriae (Becks Fl. v. Niederöst. S. 783 und 785). Borbas selbst (Primit. monogr. ros. i. hung. p. 410 und 414 ) schreibt ihr serraturae nonnullae bifidae ${ }^{\star}$ zu, rechnet sie also wohl zu den Transitoriae.

5) Frutex humilis. In caulibus aculei diversae formae: majores hamosi et minores paene recti, quales etiam in ramis. Foliola parva, oviformia, ad petiolum attenuata; subtus glauca; cum ramis purpurascentia. Receptacula fructifera parva, elliptica. 
33. Var. bihariensis: Blütentragende Zweige meist unhewehrt. Blattchen eiformigg oder elliptisch, spitz. Blïtenstiele kurz. Kelchblätter auf dem Rücken drüsig. Griffel behaart. Scheinfrüchte kugelig-ellipsoidisch.

3'. F. salicetorm: Blätchen rundlich eilormig. Bliitenstiele kurz, mit spärlichen Stieldriisen besetzt. Kelchblätter auf dem Rücken ohne Drüsen. Griffel behaart. Scheinfrüchte eikugelig. ${ }^{1}$ )

35. F. Theodori: Blïtenstiele lang: $1^{1 / 2}$ bis $2 \times$ so lang wie die sicheinfrüchte. Sonst wie f. salic. ${ }^{?}$ )

36. Var. vinealis: Blättchen eiförnig. Kelchblätter atuf dem Rïcken drüsenlos. Griffel behaart. Scheinfrüchte lïnglich eiförmig.

c)

37. Var. villosiuscula: Blittchen mittelgross, elliptisch, am Grunle meist verschmälert; die untersten stumpilich und in den Sitiel abgerundet; Blattstiele dauernd behart, auch Bliitenstiele iffter etwith behaart. Hlïtenstiele lïnger wie die Brakteen. Scheinfrüchte meist eikugelig.

38. F. Sabranstiyi: Blittchen elliptisch, die untern oft fast kreisfirmig; am Rande auffullend scharf und tief gesïgt; Blattstiele behart. Blïtenstiele immer deutlich beharrt. Die kleinen Scheinfrüchte elliptisch-kugelig.

39. Var. Chaboissaei: Blättchen gross, lebhaft glänzend, breit oval mit kurzer feiner zusammengesetzter drüsiger Zahnung. Griffel kahl, verlängert. ${ }^{3}$ )

40. Var.oreogiton: Blittchen mittelgross bis klein, elliptisch; Blattstiele dauernd flaumig. Blüten fast weiss. Scheinfrủchte klein, eiförmig.

41. F. ollongata: Blättchen eiformig, zugespitzt, schart doppelt gesïgt; Blattstiele nur an den Gelenken flaumig. Scheinfrüchte eiförmig, länglich.

42. Var. mhelliflora: Stacheln an timm fast gevale. Bliitenzweige kurz, oft unbewehrt. Blättchen klein bis mittelgross, eiförmig oder elliplisch, unterseils grangrün. Krone lebhalt rosenrot. Griffel dicht hehart.4) Scheinfrüchte lünglich eiförmig.

\{3. Fo insignis: Blättchen gross, zur Basis abgerundet, unten grün. Blütenstiele kurz. Scheinfrüchte schmal eiförmig.

4́. F. racemulosa: Blätchen elliptisch, gegen den Grund verschmälert oder schmal zugerundet; unterseits grün. Blütenstiele mittellang oder lang.

45. Var. Iarifolia: stacheln stirk, gebogen bis sichelörmig gekrümmt. Blitichen entfernt stehend; verkehrt eiförmig bis lanzettlich, gegen den Grund deutlich keilig; Zähne lang vorgezogen. Krone lebhaft rot. Diskus kegelförmig. Griffel behaart. Scheinfrüchte oval.

46. Var. Erdneri: Auffallend heterakanth: am Stamme und öfter auch an den Zweigen Stacheh von allen Grössen, gebugen bis gerade, die kleinsten am geradesten und zuweilen als Driisenborsten ausgebildet. Bliitchen eiförmig

1) Ich entlehne die Diagnose dieser Form der in puncto Rosen von H. Braun abhängigen Fl. v. Nbg. Wegen der vorkommenden Nebenzähne rechne ich sie zu den Transitoriae.

2) Pedicelli 1,5 et $2 \times$ receptaculis fructiferis longiores (Cetera ut in 1. salicetorum H. Braun).

3) Ich habe die Diagnose nach der Syn. gegeben, der ich die Verantwortung überlasse

Die Rhodologen weichen in derselben stark von einander ab.

4) Die Griffel sind oft so stark behaart, dass sie ins Wollige übergehen. 
oder elliptisch, kurz zugespitzt, in den Blattstiel verschmälert oder kurz zugexundet: Blattsticle beflibunclt; manche Ziihne einfach. Blïtenstiele mittellang. Hochblältre gut auscrebildet. Kelchzipfel nach dem Verblühen zurïck-

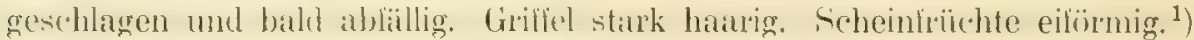

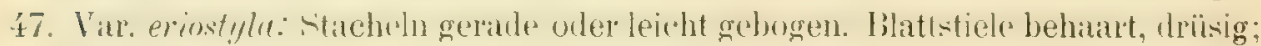
Blïtlchen eiförmig oder elliptisch. Blütenstiele kurz; Brakteen gut entwickelt. Griffel wollig, kurz säulenförmig verlängert. Scheinfrüchte kugelig bis eikugelig.

48. F. conspicua: Stacheln gekrünmt. Blütenstiele deutlich haarig. Sonst wie var. eriost. $\left.{ }^{2}\right)$

49. F. adunce: Stacheln hakigg gekrimmt. Blättchen mittelgross bis gross. ${ }^{3}$ ) Sonst wie vart. eriost.

50. Var. leuca: Blïtenstiele hast stuchellos. Blätchen verkehtt eilörmigg, keilig. Griffel fast wollig. Scheinfrïichte eiförmig.

51. Var. biserrata: Blättchen meist breit oval; Zahnung sehr zusammengesetzt; Blattstiel und Mittelnerv der Blattunterseite ziemlich dicht mit Driben versehen. Neben-, Hoch-und helohhlïtter dicht drïsig gewinupert, letztere auf dem Rücken mit einzelnen I)rïsen. Griffel dicht behatrt. Scheinfrüchte kugelig.

52. Var. squarosa: Statcheln genähert, derł. Blittchen klein: Mittelnery mit Stacheln und Driisen hesetzt. Bliitenstiele zienlich kur\%. Grilfel kur\%, borstig behaart. Scheinfrïichte eiförmig.

53. F. disparablis: Blättehon breit rundlich-elliptisch, unterseits seegrün. Kelchzipfel sehr reichlich drüsig berandet.

5.t. Var. Schottiana: Blitenzweige oft unbewehrt. Nebenbläler schmal, dicht drüsig gewimpret. zuweilen mit subloliadrüsen; Mittelnerv der Blätchen mit stielılüsen, die vereinzelt auch aul' die Seitennerven übergehtn. Blïtensticle stieldribig, mexts schwach. Kelchblitter. am Rande dicht belriist, aul dem Riieken ebenfalls stieldrïsig. Criflel etwas verlängert, zuttig behart. Scheinfrüchte klein, kugelig bis oval. ${ }^{4}$ )

1). Admiranda aculeorum diversitas: in caule et frequenter in ramis aculei magnitudine summopere variantes, recti vel curvati et minimus quisque rectissimus ac saepenumero glandula instructus. Petioli plumosi; foliola ovata vel elliptica, cum apice brevi, in basin constricta; serratura duplex admixtis quibusdan dentibus simplicibus; luracteac rohustae. Peticelli longitudinis modicae. Styli pilosiores. Receptacula fructifera ovoidea. - Nach einer briefl. Mitteilung von Hm. Erdner hat die Rose bei der Kultur in der ersten Generation die IJeterakanthie im wesentlichen beibehalten; doch wurde sie merkbar schwächer.

2) Aculei curvi. Pedicelli evidenter pubescentes (Cetera de var, eriostyla Rip.).

3) Aculei adunci. Foliola majora (Cetera in var. eriostyla Rip. describuntur).

4) Die var. Scholtiana ist eine Sammelabart, welche stark drüsige $A$ bkömmlinge verschiedener Rosen der Abteilung Biserratae in sich begreift. Daher auch die Vielgestaltigkeit, welche z. B. R. Keller S. 171 der Syn. 6. 1 hervorhebt. Stacheln, Blättchen und Fruchtgestalt können deswegen hier nicht eigentlich definiert werden. Man müsste logischerweise die var. Schott. in eine grössere Zahl von Sippen aullösen. Ich habe, um die Verwirrung nicht noch zu vermehren, mir hierin Enthaltsamkeit aufgelegt, werde aber beim Verzeicbnis der Standorte auf die Beziehungen hinweisen, welche die einzelnen meiner untersuchten Rosen zu bestimmten Formen der Biserratae unterhalten. 
55. F. armatu: Suhr reich, auch an Blïtenzweigen und Blattstielen, mit schlanken gekriimmten Stacheln bewehrt. Blittchen elliptisch bis rundlich, in den Stiel verschmälert. Scheinfrüchte oval. Sonst wie die typ. Var. ${ }^{1}$ )

56. F. hysisepala: Zweige elwas heterakanth. Blattstiele slatk behart, auch Blattmittelrippe öfter flaumig; Blättchen elliptisch, spitz, in den Stiel zugerundet oder verschmälert. Kelchzipfel abstehend, doch vor der Fruchtreife abfallend. Griffel stark behart. Scheinfrüchte länglich eiförmig. Das Ubrige wie bei var. Scholt. ${ }^{2}$ )

57. Var. remale: Stacheln des Stammes von zweierlei Gestalt: neben gekrïmmten grossen ölter auch gerade kleine; unler der Inflorescenz meist eine grössere Zahl gerader Drüsenborsten. Zweige, Blïten- und Battstiele, Neben- und Hochblibter purpun überlanten. Blattstiele haarig; Blattstiele, Mittelrippen, Rand der Hoch-, Neben- und Kelchblitter sehr reich dribig gewimpert. Kelchricken drüig. Blibtenstirlesthwath

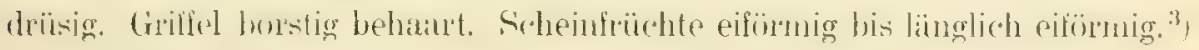

58. F. eriostyloides: Blättchen oval, spitz, in den Stiel kurz abgerundet oder verschmälert. Griffel wollig, hervorragend. Scheinfrüchte kugelig bis eikugelig. Sonst wie var. reg. ${ }^{4}$ )

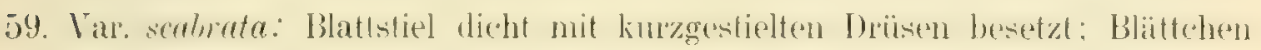
oval, gegen den Grund oft keilig verschmälert; Mittel-und Seilennerven, anch Nervillen, mit feinen Drisen besetzt (aber nicht stets bei allen Blättern). Bliitenstiele kurz, ohne Drüsen. Griffel meist dicht behart und kurz säulenförmig. Scheinfriichte kugelig. ${ }^{5}$ )

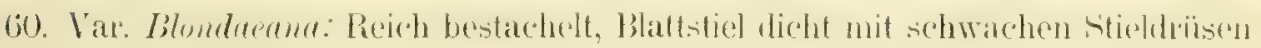

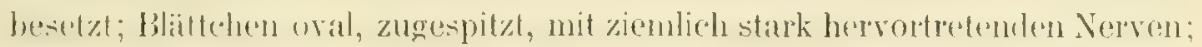
Seitennerven \pm drüsenreich (vorab an den ältesten Blättchen des Zweiges und Blattes). Blïtenstiele stieldriisenreich. Kelchblatter auf dem Rücken drüsig. Griffel behaart, oft säulenförmig verlängert.

1) Planta aculeis gracilibus sed curvis etiam in ramis et peliolis valde armata. Foliola elliptica vel subrotunda, versus petiolum angustata. Receptacula fructifera ovoidea. (Reliqua cum var. Schottiana concordant.)

2) Steht der var. Oenensis $\mathrm{R}$. Keller sehr nahe, von der sie sich hauptsächlich durch die stark behaarten Grifiel unterscheidet.

Lat. Diagn.: Aculei ramorum non plane aerquales. Petioli comosi; primarii foliolorum nervi saepius pilosuli; foliola elliptica, acula, in basin subrotundata aut subatlenuata. Sepala post anthesin patentia. sed ante maturitatem decidua. Styli valde pilosi. Receptacula fructifera oblongo-ovoidea.

3) In caule aculei duplicis staturae: alteri majores curvati, alteri minores recti; sub inflorescentia frequentes setae glandulosac. Rami, petioli, pedicelli, stipulae, bracteae purpurascentes. Petioli pubescentes; iidem cum venis primariis, stipulis, bracteis, sepalis in margine plurimis hispidi glandulis; sepala etiam in tergo hispida. Pedicelli subhispidi. Styli hirsuti. Receptacula fructifera ovoidea vel oblongo-ovoidea.

4) Foliola ovalia, acula, in basin constricta. Styli villosi, prominentes. Receptacula fructifera globosa vel subglobosa (Cetera cum var. reginae $\mathrm{m}$. congruunt).

3) Von der var. scabrata dürle Ahnliches gelten, wie von der var. Scholtiana: sie ist cin Sammeltypus. 
61. F. st. Walburyae: Blütenstiele meist arm an Stieldrüsen. Ciriffel stark hervorragend, wollig. Scheinfrüchte eilörnig. Sonst wie die var. Blond. ${ }^{1}$ )

$$
\text { Standorte: }
$$

Ad 1. Links rom Weg zum Arcoschlösschen b. Neuburg a. D. (Erdner!) Grünsberg b. Altdorf (Fl. v. Nbg.)

Ad 2. Geissberg b. E. (Plattenkalk $500 \mathrm{~m}$ )

dd 3. Wakdrand b. den Ziegelhoifen ob Gungolding (Eluriallehm $510 \mathrm{~m}$ )

Ad 4. Seitenschlucht des Kugelbergs b. E. Linke Seite des Buchtals b. E. (mittl. Malm $435 \mathrm{~m}$ ) Waldrand beim Hauptbahnhof (Kalkschiefer $500 \mathrm{~m}$ )

Ad 5. Waldsaum ob Mariastein b. E. (Kalkschiefer $510 \mathrm{~m}$ )

Ad 6. Schlucht am Adamsberg b. E.

Ad 7. Kugelberg und Adamsberg b. E. (Dolomit 460 u. $480 \mathrm{~m}$ ) Galgenberg und rechte Buchtalhänge b. E.

Mehrfach an der linken Seite des Labertals b. Staadorf Sỉdl. Abhang der Wülzburg b. Weissenburg (Doggersand $570 \mathrm{~m}$ ) Bei Unterwall nächst Berg Oberpf. (Alluvium $440 \mathrm{~m}$ )

Ad 8. Kugelberg und Prinzensteig b. E.

Strassenrand b. Häuselstein nächst Aitdorf (Werkkaik, Scherzer!)

Ad 10. Mehmias zw. Berg b. Neumarkt Oberpl. und dem rschwarzen Holz (Doggerlehm $440 \mathrm{~m}$ )

Ad 11. Anlang des Fussweges nach Wimpasing im Buchtal E. (mittl. Malm fo5m)

Ad 12. Bei Monheim (Herbar Lang!)

Ad 13. Rechte Seite des Buchtals b. E. (Plattenkalk $510 \mathrm{~m}$ )

Ad 14. Wald ob Gnadenberg (Fl, v. Nbg.)

Aıl 15). Ausgang des Heimbachertales b. linding (Duggerlehm $390 \mathrm{~m}$ )

Bei Berg Oberpf. (Doggerlehm $450 \mathrm{~m}$ )

Bei der Ruine Wolistein nächst Neumarkt Oberpf. (Fl. v. Nbg.)

Ad 16. Felsen links von Böhming b. Kipfenberg (Dolomit)

Ad 17. Am Dillberg b. Hausheim Oberpf. (Malmkalk $580 \mathrm{~m}$ )

Ad 18. Linke Seite des Buchtals b. E. (Dolomit $470 \mathrm{~m}$ )

Galgenberg b. E. (Plattenkalk $505 \mathrm{~m}$ )

Kugelberg b. E. (Mitt. Malm $420 \mathrm{~m}$ )

Mariahiliberg b. Neumarkt Oberpf. (Fl. v. Nbg.)

Ad 19. Mehrmals beim Ochsenkeller E.

Ad 20. Mehrmals auf dem Kugelberg b. E. (Plattenkalk $500 \mathrm{~m}$ u. sonst) Zw. Mühlhausen und dem Schlüpfelberg i. Sulztal (Fl. v. Nbg.)

Ad 21. Am neuen Weg b. E.

Wäldchen ob Rebdorf (Plattenkalk $510 \mathrm{~m}$ )

Waldsaum b. Haslachen nächst Neuburg a. D. (Erdner!)

Edelshausen (Killermann!)

Ad 2.-9. Zwischen (iungulding und Arnsberg a. A. (Alluviallehm m. Kalk $410 \mathrm{~m}$ )

1) Pedicelli subhispidi tantum. Styli villosi, ad instar columnae prominentes. Receptacula fructifera oviformia. (Cetera de var. Blondaeana). 
Ad 23. Adamsberg b. E. (Grenze Dolomit-Plattenkalk $490 \mathrm{~m}$ ) * Kernberg b. Gungolding (Dolomit)

Ad 24. Kugelberg b. E. (Dolomit $460 \mathrm{~m}$ )

Ad 25. Am Fussweg Gungolding-Arnsberg a. A. (Alluvium $410 \mathrm{~m}$ )

Bei Lierheim i. Ries (Schneid!)

Mariahiliberg b. Neumarkt Oberpf. (Fl. v. Nbg.)

Ad 26. Kalvarienberg b. Gossheim i. Ries (unt. Nalm)

Ad 27. Strasse b. Heimburg nächst Berg Oberpf. (Doggersand $520 \mathrm{~m}$ )

Ad 28. Fuss des Kernbergs b. Gungolding (Alluviallehm $420 \mathrm{~m}$ )

Steinbruch b. Emskeim (mittl. Schwammkalk d. Malm)

Bei Hamberg nächst Dasswang Oberpf. (Hönig!)

Ad 29. Geissberg b. E. (Grenze Dolomit-Plattenkalk 510 m) ${ }^{1}$ )

Ad 30. Galgenberg b. E. (Dolomit $470 \mathrm{~m}$ )

Ad 31. Sindwestlich ron Berching (Doggersand)

Bei Laaber (Malmkalk, Killermann!)

Ad 32. Bei Walting a. A.

Ob Leising bei Beilngries (Doggersand $410 \mathrm{~m}$ )

Bei Attenfeld zw. E. u. Neuburg a. D. (Erdner!)

Ad 33. Waldrand der linken Talseite zw. Ilbling und Kinding (Werkkalk $420 \mathrm{~m}$ ) Links ob Kinding (Dolomit $470 \mathrm{~m}$ )

Ad 34. Bei den Wielandshölen nahe Konstein (Erdner!)

Umgebung von Berg b. Neumarkt Oberpf. (Liaslehm)

Am Odelsbach b. Berg (Doggerlehm $450 \mathrm{~m}$ )

Ad 35. Anger am Weg Berg-Kadenzhofen (Doggerlehm $470 \mathrm{~m}$ )

Ob Kadenzhofen b. Neumarkt Oberpf. (Doggersand $560 \mathrm{~m}$ )

Ad 36. Berghang links Dollnstein (mitt. Malm $440 \mathrm{~m}$ )

Rand eines Eichenwaldes im Waller Tal b. Berg (Doggerlehm $440 \mathrm{~m})^{2}$ )

Ad 37. Buchtal b. E. an Weg zum Galgenberg (Dolomit)

Kugelberg b. E.

Ob Richtheim b. Berg Oberpf. (Liaslehm)

Ad 38. Sehlucht b. E. links der Altmïhl (Dolomit $490 \mathrm{~m}$ )

Auf Malm der Hochiliiche des Nünchsberges b. Burglengenfeld

Ad 39. Rechte Seite des Buchtals b. E. (Dolomit $460 \mathrm{~m}$ )

Ad 40. Frauenberg b. E., Abhang gegen Rebdorf (Grenze Dolomit-Platlenkalk $490 \mathrm{~m}$ )

Ad 41. Bei Walting a. A. (Dorr!)

Auf Malm der halben Höhe des Münchsberges b. Burglengenfeld

Ad 42. Hitllere Höhe des rechten Buchtalhanges b. E. (Dolonit)

Bei Walting a. A. (Dorr!)

Kernberg b. Gungolding (mittl. Malm $\Varangle 10 \mathrm{~m}$ )

Felsabhang b. Rohrbach i. Trockental (Dolomit $480 \mathrm{~m}$ ) 3)

Bei fünfstetten am Weg nach Gossheim (unt. Malm)

1) Wegen einer deutlichen Griffelsäule Übergang zur var. jurensis.

2) Die Früchte sind hier mehr eikugelig, ähnlich wie bei der f. salicetorum.

3 Hinneigung zur f. racemulosa H. Braun. 
Ad 43. Siidwestende von Eismannsberg b. Altdorf (Werkkalk, Scherzer!) ${ }^{1}$ )

Ad 4.4. Mehrmals auf dem Krugelberg b. E. (Plattenkalk $510 \mathrm{~m}$ u. sonst)

Mehrmals auf dem Kernberg b. Gungolding (Dolomit $440 \mathrm{~m} \mathrm{u}$. sonst)

Bittenbrumn b. Neuburg a. D. (Erdner!)

Keilstein b. Regensburg (Jurakalk, Killermann!)

Ad 45. Am Galgenberg b. E. (Dolomit $460 \mathrm{~m})^{2}$ )

Bei Walting a. A. (Dorr!)

Am Kernberg b. Gungolding

Ad 46. Bei Marxheim a. D. (Erdner!) ${ }^{3}$ )

Ad 47. Am Haderbuck b. Kipfenberg

Am Fussweg Berg-Kadenzhofen b. Neumarkt (Doggerlehm $445 \mathrm{~m}$ )

Ad 48. Am Weg von Berg b. Neumarkt zum Odelsbach (Lehm $440 \mathrm{~m}$ )

Ad 49. Niltelhöhe des Kugelbergs b. E. (Dolomit $460 \mathrm{~m}$ )

Waldrand des Blumenbergs b. E.

Waldrand des Frauenbergs b. E. (Dolomit $470 \mathrm{~m}$ )

Am Weg von Emskeim nach Gammersfeld (Plattenkalk $500 \mathrm{~m}$ )

Am Fussweg von Berg nach Kadenzhofen (Doggerlehm $445 \mathrm{~m}$ )

Ad 50. Bei Walting a. A. (Dorr!)

Ad 51. An Terrassenmauer der Westenvorstadt b. E. $(405 \mathrm{~m})^{4}$ )

Am Geissberg b. E. (Pla!tenkalk $510 \mathrm{~m}$ )

Ad 53. Am obern Weg Eichstïtt-Herzogkeller (Alluviallehm $410 \mathrm{~m}$ )

Bei Breitenbrunn (Fl. v. Nbg.)

Ad 54. Anfang des neuen Wegs b. E. (Dolomit $440 \mathrm{~m})^{\complement}$ )

Rechte Seite des Buchtals b. E. ${ }^{6}$ )

Adamsberg b. E. `)

Zweinal am rechten Hang der Wolfsdrossel b. E. (Dolomit) ${ }^{8}$ )

Am obern Weg E.-Herzogkeller (kalkiger Alluviallehm $420 \mathrm{~m})^{9}$ )

Am Mühlberg b. Wellheim (Dolomit) ${ }^{10}$ )

Steinbruch oberhalb Ried b. Neuburg (Erdner!)

Bachranken bei Bertoldsheim (Herbar Du Moulin)

Ad 55. Kernberg b. Gungolding (Dolomit $490 \mathrm{~m}$ )

1) Übergang zur f. racemulosa.

2) Die Blättchen sind hier zuweilen auch breiteilörmig und zur Basis abgerundet wle bei f. insignis.

3) Im Frühjalı 1906 sah ich eine ganz ähnliche Canine am Abhang des Galgenbergs

b. E. Ieider konnte ich zur Fruchtzeit den Strauch nicht mehr finden.

4) Blättchen elliptisch, in den Stiel etwas keilio verschmälert.

5) Wegen Blattform und eiförmiger Frucht Abkömmling der f. racemulosa H. Braun.

6) Nach der Blattform usw. Abköınmling der f. sarmentoides (Puget) H. Braun der var. rubelliflora.

7) Abkömmling der var. biserrata (Mérat) Baker.

s) Die eine dieser Rosen gehört nach Form der Blättchen und Frucht zur var. squarrosa (Rau) Borbas oder f. racemulosa H. Braun; die andere hat hervorragende wollige Griflel und kugelige Scheinfrüchte, ist also wohl ein Abkömmling der var. eriostyla.

9) Griffel und Frucht der var. eriostyla, Blättchen und Stacheln der var. laxifolia Borbas.

10) Stacheln. Blältchen und Scheinfrüchte entsprechen genau der var. laxifolia. 
Ad 56. Linke Seite d. neuen Wegs b. E. unterh. d. Kang'schen Steinbruchs (Dolonit)1) Am̈ Geissberg b. E. oberhalb d. englischen Gartens (Dolomit $470 \mathrm{~m}$ ) Südőstlich bei der Willibaldsburg E. (Dolomit $480 \mathrm{~m}$ ) Waldsaum ob der Feldmiihle b. Wellheim An Fussweg Fünfstetten-Gossheim (unt. Malm)

Ad 57. Frauenberg b. E. östl. der Kapelle (Plattenkalk $500 \mathrm{~m}$ )

Feldrain am Adamsberg b. E. (Dolomit $480 \mathrm{~m}$ )

Rechter Hang der Wolfsdrossel b. E. (Grenze Dolomit-Plattenkalk $490 \mathrm{~m}$ )

Ad 58. Rechter Hang der Wolfsdrossel b. E. (490 m)

Ad 59. Rechte Reitenschlucht des Buchtals b. E. (Lehm mit Kalkschutt)2)

Ad 61. Am neuen Weg oberhalb St. Walburg i. E. (Dolomit $450 \mathrm{~m}$ )

Auf dem Adamsberg b. E. (mittl. Malm). ${ }^{3}$ )

Schlussbemerkung: Nach der Zahl der Fundorte und selbst der Formen könnte es scheinen, als ob im Bezirke die Biserratae maleich häuligger vorkimen als die Transitoriae und lie Lniserratae. Dem dürte aber nicht so sein. Bei der Unzahl der Individuen aus der Art R. canina L., die einem überall entgegentreten, richtet man unwilkiulich sein Angenmerk mehr auf die abweichenden Formen und damit auf die stark gezahnten und. drisigen. In Wirklichkeit dürften die Transitoriae überall am hüufigsten vertreten sein.

\section{Einzelut Rosa alumetornm Thuillier.}

Blältchen mindestens am Mittelnerv der Unterseite kräftig behaart.

\section{Ubersicht der i. G. k. Formen: $\left.{ }^{4}\right)$}

a) Blättchen sehr vorwiegend einfach gezahnt:

1. Formen ohne Drüsen an Bliitenstielen und Blattunterseite

(Formenkreis der R. platyphylla Rau):

a Blättchen nur auf den Nerven der Unterseite behaart: var. urlica (Léman) Chr.

1. semiglabra (Ripart) J. B. Keller

f. acanthina (Déséglise et Ozanon) H. Braun

f. sphaerocarpa (Puget) H. Braun

var. platyphylla (Kau) Chr.

f. splicieroided mith $i^{\mathrm{b}}$ )

f. umbrosa mili ${ }^{6}$ )

var. obscura (Puget) H. Braun

1) Die Griflel erheben sich an dieser Rose zu einem hervorragenden wolligen Säulchen ähnlich einer $\hat{i}$. eriostyloides, zu der sie einen Ubergang bildet.

2) Diese Rose wurde seinerzeit von Crépin selbst bestimmt.

3) Zeigt die Eigentümlichkeiten der f. St. Walburgae weniger ausgeprägt, d. h. hat weniger Subfoliardriisen.

4) Ich gliedere analog wie bei der R. canina. Innerhall, eines Formenkreises wird in aufsteigender Reihenfolge nach dem Grade der Behaarung geordnet.

5) Sphaeroideus, kugelähnlich; wegen der kugeligen Scheinfrüchte.

6) Umbrosus, schattig; es handelt sich um eine Schattenform. 
$\beta$ Blättchen oberseits kahl oder nur in Spuren behaart; unterseits an den Nerven dicht, an der Fläche lockerer behaart; Sägezähne deutlich wimperhaarig:

var. hirta $H$. Braun

f. urbicoides (Crej.) H. Braun

var. Forsteri (Simith) H. Braun

$\gamma$ Blittchen beiderseils, unten dichter als oben, behand: Sägezähne stark wimperhaarig.

var. Thuillieri $C 7 r^{1}$ )

var. trichonewra (Ripart) Chr.

var. solstitialis (Besser) H. Braun

var. comata mili $\left.i^{2}\right)$

1. mollissima milli ${ }^{3}$ )

2. Formen mit Driisen an den Blütenstielen

(Formenkreis der R. Deseglisei Boreau): var, trichoidea (Ripart) R. Keller

b) Blättchen unregelmässig doppelt gezahnt

(Formenkreis der R. hemitricha Ripart):

1. Formen ohne Drüsen an den Bliitenstielen und ohne Subfoliardrüsen:

a Blätchen an den Nerven behaart:

var. subglabra Borlas

1. decaliata Crep.

$\beta$ Blättchen auch an der Fläche der Unterseite behaart:

var. uncinelloides (Puget) H. Braun

1. juncta (Puget) H. Braun

f. sulbuncinelloides mihit)

var. lirtifolia $H$. Braun $^{5}$ )

1. perciliata $H$. Braun

$\gamma$ Blättchen beiderseits behaart:

var. incanescens $H$. Braun

var. comatoides mithi ${ }^{6}$ )

f. fertilis mili $i^{3}$ )

f. irregularis mihi ${ }^{8}$ )

f. accertens miti ${ }^{9}$ )

1) Bei H. Braun und A. Schwarz (Fl. v. Nbg.) als var, typica aufgeführt.

2) Comatus, behaart.

3) Mollissimus, ganz weichhaarig.

4) Subuncinelloides = nahe an die var. uncinelloides herangehend.

5) Die var. hirtifolia H. Braun sowie die gleich zu erwähnende var. incanescens H. Braun sind wegen der starken Beharun der firifel und der ziemlich kurzen Blätenstiele Ubergangsformen gegen die R. coriifolia hin. R. Keller hat sie im Formenkreis der R. subcollina bei der R. coriifolia untergebracht. Ich folge jedoch dem Autor der beiden Varietäten, der sie zur R. dumetorum stellt.

${ }^{6}$ ) Comatoides $=$ ähnlich meiner var. comata.

7) Fertilis, fruchtbar; von den reichen Fruchtcorymben.

8) Irregularis, unregelmässig, weil die Blättchen bald einfach, bald doppelt, bald mehrfach gezahnt sind.

9) Accedens, eine Form, welche zu den genannten noch hinzutritt. 
2. Formen mit Drüsen an den Blütenstielen oder mit Subfoliardrüsen:

var. caesia (Baker) R. Keller

var. interposita Schlimpert

c) Blätlchen doppelt und mehrfach gezahnt

(Formenkreis der R. amblyphylla Ripart):

var. amblyphylla (Ripart) H. Braun

var. palatina mihi. ${ }^{1}$ )

Diagnosen:

1. Var. urbica: Blättchen oval, ziemlich lang zugespitzt; am Mittelnerv und sehr zerstreut an den Seitennerven behaart. Griffel behaart. Scheinfrüchte länglich oval.

2. F. semiglabra: Griffel stark behaart. Scheinfrüchte eikugelig.

3. F. acanthina: Stacheln zahlreich, zu 3-8 fast wirtelig am Stamme stehend. Griflel säulenlörnig über den Diskus verlängert, wriggstens men behatrt. Scheinfrüchte kugelig.

4. F. spharocapa: Blïtenzweige fast wehrlos. Blätthen stumpf. ${ }^{2}$ ) Griffel kahl. Scheinfrüchte kugelig.

5. Var. platypliylla: Blättchen rundlich eiförmig; oberseits kahl, unterseits am Mittelnerv und den Seitennerven behaart, selten an der Flïche selbst flaumig. Griffel behaart. Scheinfrüchte eilörmig.

6. F. sphneroidea: Scheinhïrhte kugelig, die mitllere meist birnförmig. Sumst wie die var. platyph. $\left.{ }^{3}\right)$

7. F. umlwost: Bentachelung auch an den Blïtenzweigen reichlich. Griffel kahl oder last kahl. Scheinfriichte eikugelig. ${ }^{4}$ )

8. Var. obscura: Bestachelung etwas ungleich. Behaarung der Blättchen wechselnd: bald wie bei der var. urbica bald wie der var. platyphylla. Griffel schwach behaart. Scheinfrüchte länglich eiförmig.

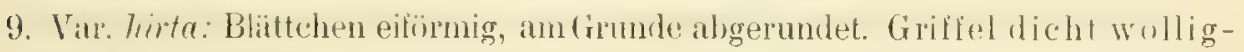
zottig. Scheinfrüchte länglich eiförmig oder verkehrt eiförmig.

10. F. urlicoides: Blättchen länglich, gegen den Grund verschmälert. Griffel weniger stark behaart.

11. Var. Forsteri: Blättchen etwas unregelmässigg gezahnt, öfter doppelt. Griffel schwach behart bis kahl. Scheinfrichte eilörnig orler ellipsindisch.

12. Var. Thuillieri: Blättchen gross, abgerundet, stumpf, mit Ausnahme der obersten, die breit oval und ganz kurz zugespitzt bis länglich sind; auf der Oberseite angedriickt diinn, auf der ganzen Unterseite dicht behatrt. Griffel behaart. Scheinfrïchte oval.

1) Palatinus, zur Płalz gehörig; vom Vorkommen in der bayr. Oberpfalz.

2) Die Blattform leitet zu derjenigen der var. platyphylla über.

3) Receptacula fructifera globosa excepto medio, quod plerumque piri formam imitatur. Cetera de var. platyph.

4) Aculeorum multitudo notabilis etiam in ramis florileris. Styli glabri vel subglabri. Receptacula fructifera subslobosa. 
13. Var. trichoneura: Bestachelung kräftig. Blättchen ziemlich klein, elliptisch bis oval; Zahnung dicht und scharf; Behaarung wie bei var. Thuill. Griffel wenig behaart. Scheinfrüchte eikugelig. ${ }^{1}$ )

14. Val: solstitialis: Hacheln leicht getengen bis list getade. Blittehen wal

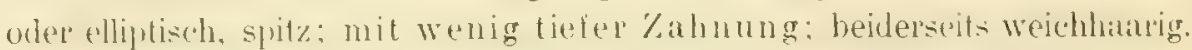
Blïtenstiele kurz, höchstens so lang wie die Scheinfrüchte. Griffel kurz, haarig. Scheinfrïichte eikugelig bis eiförmig. ${ }^{2}$ )

15. Var. comata: Strauch gross, von kompaktem Wuchse. Blättchen gross, breit oval, kurz zugespitzt, in den Stiel abgerundet; oberseits dicht anliegend behart, unterseits auch auf der Fläche filzig:

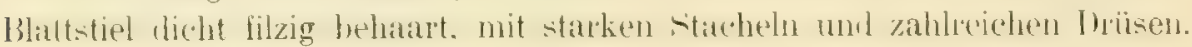
Blütenstiele kurz: $1 / 2$ bis $1 \times$ so lang wie die áusgebildeten Früchte. Kielchblätter reich und breit gefiedert, die Fiederchen stark drüsig gezithnt. Griffel stark haarig. Scheinfrilchte kugelig bis eikugelig. ${ }^{3}$ )

16. F. mollisima: Stratuch besunders reich bestachelt. anch an den Bliitenzweigen.

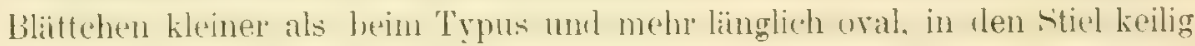
verschmälert; a uf beiden Seiten dicht filzig behaart. Griffel wollig.

17. Var. trichoidea: Blätchen breit oval, stumpl: oberseits sehr zerstreut. unterseits dichter behaart. Blïtenstiel mit spülichen stieldrüsen. Corollen weiss. Griffel behaart. Scheinfrüchte eiförmig.

1) So heisst Borbas die Frïchte. R. Keller und Christ nennen sie kugelig, H. Braun (in Becks Fl. v. N.) und A. Schwarz (Fl. v. Nbg.) eiförmig. Borbas dürfte Recht haben, denn auch Crépin (Primit. monogr. ros. fasc. 1. p. 280) schreibt von der R. trichon. Rip.: „fruits ovoidesarrondis", d. h. „eikugelige" Früchte.

2) Der var, solstit. schreibt H. Braun (in Becks Fl. v. N. 1. S. 795) wollige Griffel zu, J. B. Keller und R. Keller behaupten ,schwach haarig“. Déséglise, der im Herbar Decandolle’s die Type Bessers selbst gesehen hat, schreibt von den Grifieln: „Styles courts, velus", also: Griffel kurz, lıarig (p. 370 des Catal. rais.)

3) Diese Rose ist häufig in der näheren Umgebung von Eichstätt. Der Strauch hat wegen der starken Behaarung der Blättchen ganz das Aussehen einer R. tomentosa oder pomifera. Crépin hielt wegen der Form und Bedrïsung der Kelchblättchen nach den ihm eingesandten Proben die var. comata zuerst für eine $\mathrm{R}$. tomentella, entschied sich aber später für $R$. dumetorum, Ubergang zu tomentella. Var. com. wurde unter No. 167 in der ,Flora exsicc. bavarica ausgegeben; aui S. 19 des Bd. II (neue Folge) Denkschr. k. bot. Ges. Regensburg 1903 erschien die vorläuige Diagnose.

Ergänzung der Diagnose: Stacheln kräftig, sichelfôrmig gebogen. Blättchen vom Aussehen einer R. tomentosa, die einfachen Zähne stark gewimpert, oft in Drüse endigend, sellen mit drüsigen Nebenzähnchen; Nebenblättchen am Rande gewimpert und drüsig. Einzelne Drïsen auf dem Rücken der Kelchblätter, die an der entwickelten Frucht elwas abstehen. Kronen blassrosa bis weisslich.

Lat. Diagnose: Frutex altus, habitu robusto et adstricto. Foliola magna, late ovata, in brevem apicem producta, versus basin rotundata; supra dense et adpresse hirsuta, subtus per totam superficiem tomentosa; petioli tomentosi, validis aculeis et plurimis glandulis armati. Pedicelli breves, receptaculo fructifero dimidio breviores aut ubi plurimum illud aequantes. Sepala summopere appendiculata appendicibus longis latisque profunde incisis, in margine glandulose serratis. Styli hirsutissimi. Receplacula fructifera globosa vel subglobosa.

4) Frutex etiam in ramis florigeris plurimis aculeis munitus. Foliola minora varietale typica, oblongo-ovata, cum basi prope cuneiformi; in utraque superficie valde tomentosa. Styli villosi. 
18. Var. suluglabra: Zweige wehrlos. Blättchen eiförmig oder elliptisch; unterseits am Mittelnerv und wenigstens in der Jugend an den Seitennerven behaart. Griffel kahl oder sehr zerstreut behart. Scheinfrüchte kugelig.

19. F. decaldata: Zweige wehrlos aler bestachelt. Sermetur der Blittchen spriz, mit vielen Spaltzilnnen. Blïtenstiele behaart oder kahl. Griffel leicht behatrt. Scheinfrüchte eikugelig bis länglich eiförmig.

20. Var. uncinelloides: Blittehen nittelgross; die olern eilïnglich und meist einfach gesïgt, die untern eifömig und unregelmaissig loppelt gezahnt; oberseits fast kahl, unterseits an den Nerven dichter', an dere Fliche schwächer behart. Griffel behaart. Scheinfrüchte eikugelig.

21. F. imeta: Blittchen klein, tillimigg bis elliptisch. Griflel wenig behatat. Scheinfrüchte eiförmig bis eikugelig.

22. F. suluncinelloides: Stacheln zahlreich, lang, leicht gubugen bis grerade. Griffel schwach haarig. Scheinfrüchte länglich eiförmig. ${ }^{1}$ )

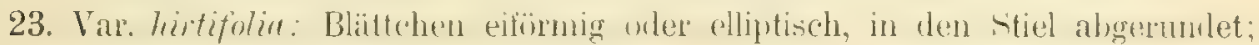
Behaarung wie bei var. uncinelloides. Griffel dicht wollig zottig. Scheinfrüchte kugelig bis eikugelig.

24. F. perciliata: Kelchzipfel am Rande drüsig gewimpert. Griffel wie 23. Scheinfrïchte ellipsoidisch bis eikugelig. ${ }^{2}$ )

25. Var. incunescens: Blätchen grosi, piörmig bis thiptisch, an der Basis abgerundet; oben anliegend, unten dicht behaart; drüsige Sekundärzähnchen meist nicht viele. Griffel wollig. Scheinfrüchte kugelig oder eikugelig.

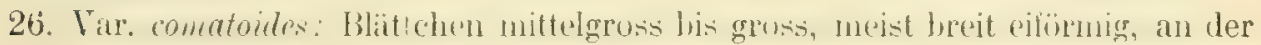
Basis abgerundet; oben dicht, unten filzig behaart; Sekundärzähnchen nur gegen den stiel zu reichlicher. Blattstiele bestachelt, filzig und drüsig. Kelchblätter reich gefiedert, die breiten Fiederchen und die Kelchblälter selbst sehr stark drüsig gewimpert. Griffel etwas vorstehend, stark behaart. Scheinfrïchte eikugelig oder kugelig. ${ }^{3}$ )

27. F. fertilis: Junge Zweige violett überlaufen. Strauch deutlich heterakanth, indem unter der Inflorescenz kleinere gerade Stacheln auftreten (neben den grosien gekrimmlen). Scheinfrüchte in sehr reichen Corymben, die birnförmige mittlere Frucht sehr kurz gestielt. ${ }^{4}$ )

1) Aculei plurimi, longi, leviter inflexi vel recti. Styli raripili. Receptacula fructifera oblongo-oviformia.

2) Die Blättchen sind nach H. Braun selbst „am Rande ungleich drüsig gesägt" (Beck's Fl. v. Nied. 1. S. 797) und "Serratur der Blättchen ist nicht völlig drüsig-doppelt" (11. Ber. bot. V. Landshut S. 110), Die Flora von Nürnberg hat also nicht Recht, wenn sie S. 548 angibt: "doppelt bis dreifach drüsig gezähnt."

3) Foliola mediocria vel magna, late ovata, basi rotundata; margine irregulariter bis serrato, denticulis secundaris praecipue versus basin accedentibus; supra villosa subtus tomentosa; petioli aculeati, tomentosi, glanduloso-hispidi. Sepala ut in var. comata valde appendiculata, margine et appendicum et sepalorum plurimis glandulis hispido. Styli aliqualiter prominentes, hirsuti. Receptacula fructifera globosa vel subglobosa.

4) Frutex aculeis duplicis formae armatus, cum praeter majores curvos sub inflorescentia setae minores rectae accedant. Numerus florum in corymbo maximus; receptaculun fructiferum intermedium piriforme et prope expers pedunculi. 
28. F. imetgularis: Die meisten \%weige tragen unregelmässig doppelt gezähnte Blättchen, manche jedoch dreifach und einzelne einfach gezähnte. ${ }^{1}$ )

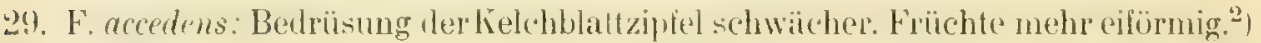

30. Var. caesia: Blïlthen nittelgross, elliptisch, meist schmal zum Stiel abgerundet; oben schwach behart, unten weichharig. Blütenstiele spärlich mit Stieldrüsen besetzt, die zuweilen auch auf die Kelchbecher übergehen. Kelchblitter am Ranke und aul dem Rücken drüsig. Kronblätter ziemlich lebhaft roł.

31. Var. interposita: Stärkere Zweige am Grunde der Laubblätter mit starken hakigen, meist gepaarten Stacheln versehen. Blatstiele dicht filzig und drïsig; Blittchen lederig, oval, in denstiel vershmälert; oben dicht angedriekl, unten filzig behaart; einzelne Blättchen mit Subfoliardrisen an den Nervillen; Zahnung ungleich, z. T. einfach z. T. doppelt; Zähne lang wimperharig. Diskus kegelfümig. (iriffel sätulenförmig sich erhebend, mehr oder minder stark behaart. Scheinfrüchte klein, kugelig.

32. Var. amblyphylla: Blättchen breit eiförmig bis rundlich, stumpf; oberseits kahl, unterseits am Mittelnerv und, wenigstens in der Jugend, an den Seitennerven behaart. Griffel kahl. Scheinfrüchte kugelig.

33. Var. palatina: Blåttchen mittelgross; länglich eiförmig bis länglich rautenförmig, zugespitzt: Oberseite anliegend, L'nterseite auf der Flïche flaumig, an den Nerven dicht behaart. Sehr reichdrüsig: Blaltzähne, Kelchzipfel, Kelchrücken, Blattstiele dicht bedrüst. Griflel schwach behaart.

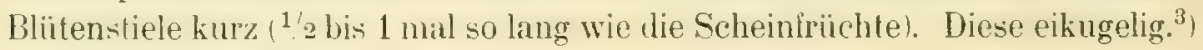

\section{Standorte:}

Ad 2. Kugelberg b. E. (Plattenkalk $500 \mathrm{~m}$ )

Ad 3. Neuer Weg b. E.

Ad 4. Wiesenweg zw. Beilngries u. der Strasse nach. Paulushofen (Alluviallehm $380 \mathrm{~m}$ )

Ad 5. Kugelberg b. E. und Kirschenallee b. E.

Bei Ellenbrunn und Gammersield (Erdner!)

Ried und Joshofen b. Neuburg a. D. (Erdner!)

Bei Hamberg nächst Dasswang Oberpf. (Hönig!)

Höhenberg b. Neumarkt Oberpi. (Nägele!)

Ad 6. Mehrmals am obern Herzogkellerweg b. E. (Malm 410-430 m)

Frauenberg b. E. am Weg zur Kapelle (Malm $440 \mathrm{~m}$ )

Kernberg b. Gungolding (Dolomit $4: 0 \mathrm{~m}$ )

1) Foliola aliquorum ramorum tripliciter, aliquorum simpliciter dentata, plurimorum imperfecte dupliciter.

2) Appendices sepalorum minus quam in var. comatoid. glandulis hispidi. Receptacula fructifera ovoidea.

3) Foliola mediocria, oblonge ovata vel oblonge rhombiformia, acuta; in margine perfecte dupliciter serrata; supra adpresse pilosa, subtus in superficie plumosa, in nervis villosa. Planta admodum glandulosa, cum denticuli, sepalorum margo et tergum, petioli glandulis abumbent. Styli raripili. ledicelli loreves: 0,5 vel ubi plurimun $1 \times$ receplaculorum longitudinem repetentes. Receptacula fructifera subglobosa. 
Am Weiher zw. Gossheim und Fünfstetten

Ad 7. Wald am Fussweg Kipfenberg-Gelbelsee (Plattenkalk $510 \mathrm{~m}$ )

Ad 8. Kernberg b. Gungolding (Dolomit $460 \mathrm{~m}$ )

Ad 9. Am obern Herzogkellerweg b. E. (Malm $430 \mathrm{~m}$ )

Ad 10. Beim Schloss Arnsberg (Dolomit $500 \mathrm{~m}$ )

Zw. Emskeim und Rohrbach

Haslachen b. Neuburg a. D. (Erdner!)

Sulzbïrg (Fl. v. Nbg.)

Ad 11. Linke Seite des Eisentals b. Eichenhofen (Malm 500 m)

Bei Velburg (Fl. v. Nbg.)

Ad 12. Waldrand des Rosentals b. E.

Unter der Kirschenallee b. E. (Dolomit $440 \mathrm{~m}$ )

Mehrmals an den Dolomitfelsen d. Brunnmühle b. Walting (Dorr!)

Am Weg Pfalzpaint-Plahldorf (Dolomit $4.10 \mathrm{~m}$ )

Schambachtal b. Arnsberg (Schneid!) ${ }^{1}$ )

Am Weg Riedelshof-Altenberg (Schneid!)

Bei Altendorf

Ad 13. Hochebene an Weg Mariastein-Obereichstailt (Plattenkalk $540 \mathrm{~m}$ )

Steinbruch b. Narxheim (Erdner!)

Unterstall und Ried b. Neuburg a. D. (Erdner!)

Oberhalb St. Anna b. Riedenburg (mittl. Malm)

Bei Edelhausen (Jurakalk, Killermanu!)

Ad 14. Hochebene des Frauenbergs b. E. (Plattenkalk $490 \mathrm{~m}$ )

Hellerberg b. Inching (Dorr!)

Kernberg b. Gungolding

Ad 15. Mehrmals an Prinzensteig und zwischen Prinzensteig und Anlage b. k. (auf Dolomit und Plattenkalk)

An sehr vielen Stellen des Kugelbergs (mehrfach neben der Strasse) und der im Osten sich anschliessenden Abhänge und Talschluchten bis zum neuen Kasernement b. E. (Dolomit und Plattenkalk $440-520 \mathrm{~m}$ )

Mehrmals b. Walting a. A. (Dorr!)

Am Haderbuck b. Kipfenberg (mittl. Malm $440 \mathrm{~m})^{2}$ )

Ad 16. Bei Rieshofen (Dorr!)

Am Kernberg b. Gungolding (Alluviallehm $410 \mathrm{~m}$ )

Ad 17. Hochebene des Kernbergs b. Gungolding (Dolomit $480 \mathrm{~m}$ )

Harttal b. Stepperg (Erdner!)

Ad 18. Trockental b. Rohrbach (Dolomit $490 \mathrm{~m}$ )

Auf Doggersand des Münchsbergs an Weg Münchshofen-Premberg

Ad 19. Höhenberg b. Neumarkt Oberpf. (Fl.v. Nbg.)

Ad 20. Frauenberg und Geissberg b. E. (Dolomit)

Bei Ellenbrunn (Herbar Du Moulin!)

Bei Laaber (Jurakalk, Killermann!)

1) Diese Rose hat nahezu wollige Griftel.

2) Dieses Exemplar hat etwas schwächer behaarte Blattoberläche und weniger reich gefiederte Kelchblätter als der Typus. 
Ad 21. Ochsenkellertal b. E. (Dolomit $450 \mathrm{~m}$ )

Am Weg Gungolding-Arnsberg (Alluviallehm)

Sehensand b. Neuburg a. D. (Erdner!)

Felsabhang im 'Trockental b. Rohrbach (Dolomit $490 \mathrm{~m}$ )

Ad 22. Kugelberg b. E. (Dolomit $430 \mathrm{~m}$ )

Beim Kreidewerk Neuburg a. D. (Erdner!)

Ad 23. Galgenberg b. E. (Dolomit $450 \mathrm{~m}$ )

Bei Enkering (Schneid!) ${ }^{1}$ )

Unterhalb Schloss Hirschberg b. Beilngries (Doggersand $420 \mathrm{~m}$ )

Hembruck b. Neuburg a. D. (Herbar Du Moulin!)

Ad 24. Galgenberg b. E. (Dolomit $450 \mathrm{~m}$ )

Ad 25. Frauenberg b. E.

Felsen der Brunnmühle b. Walting a. A.

Bei Dörndor' (Eluviallehm $530 \mathrm{~m}$ )

Leitenholz zw. Döllwang und der Deininger Bahnlinie (Fl. v. Nbg.)

Ad 26. Nehrlach am Frauenberg b. E.

Desgleichen zwischen Prinzensteig und Anlage b. E.

Links der Altmühl zw. Schleusse und Riedenburg (Alluvium $380 \mathrm{~m}$ )

Ad 27. Frauenberg b. E. (Plattenkalk $510 \mathrm{~m}$ )

In der Nähe der Schwarzach b. Enkering (Alluvium $385 \mathrm{~m}$ )

Ad 28. Abhang des Frauenbergs b. E. gegen Rebdorf

Ad 29. Am Fussweg Gungolding-Arnsberg (Alluvium)

Ad 30. Kernberg b. Gungolding (Dolomit $440 \mathrm{~m}$ )

Ad 31. Zw. Schelldorf und Dunsdorf (Schneid!)

Ad 32. Am Waldweg Kipfenberg-Gelbelsee (Dolomit $490 \mathrm{~m}$ )

Nördlicher Waldrand zw. Leising und Kottingwörth (Duggersand $105 \mathrm{~m}$ )

Ad 33. Rechle reite des Eisentales 1). Eichenhofen, ()herpf. (Malmkalk $510 \mathrm{~m}$ )

Zwischenformen: Meine var. comata und comatoides bilden eine zusammenhängende Furmenreihe: indem sich mehr und mehr Tebenzähnehen einstellen, geht die letztgenmnte ans der ersteren hervor. Es gibt Exemplare, die genau in der Nitte stehen. Ahnlich verhïlt sich Nro. 15 z 16. Vom liernberg bei Gungolding hahe ich eine Mittelform zwischen var. platyphylla und var. uncinelloides, vom Galgenlocrg b. E. eine zw. var. uncinella (Besser) H. Braun und f. perciliata H. Braun; von der Lngebung Eichstäts eine f. decalvata Crep., die gegen die f. Sabranskyi H. Braun der R. canina stark hinneigt. Und so liessen sich noch viele Beispiele anführen.

\section{Gesamtart Rosa glauca Villars.}

Strauch mittelhoch, von gedrungenerem Bau als dem der R. canina. Silacheln krïllig, meist hakig gekrümml, aber stels etwas schlanker als diejenigen der R. canina und after schwach gebogen his fast gerade. Nittlepe Laubbläiter der Bliitenzweige 5-7 zählig; Nebenb]ïttchen meist aulïillig Jreit; Blittchen mittel-

1) An dieser Rose sind die Blütenstiele reichlich mit langen Haaren besetzt. 


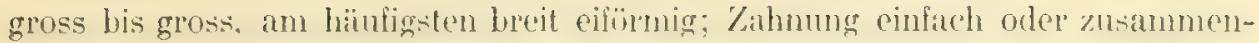

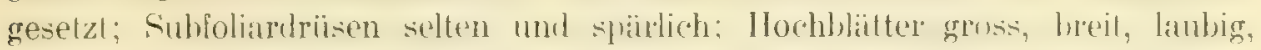

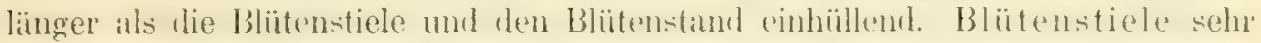
kurz; selten und schwach hedriisl. Kelehbläter nach der bliite absteheml his augerichtet, suhpersistent. Ciriffel ein wollig behatertes kures und breites

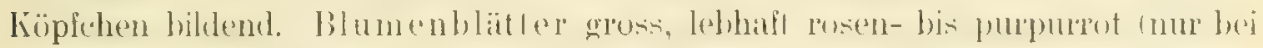
Ubergangsformen blass). Kelchbecher und Scheinfrüchte um die Kugelgestalt fluktuierend, selten langgestreckt und drüisig.

\section{Einzelart Los! glauce Villars.}

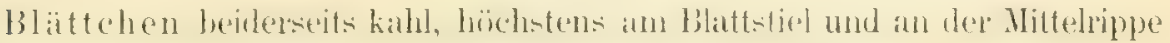
befläumelt; auf der Unterseite auffallend blaugrün bereift.

Ubersicht der i. G. k. Formen: ${ }^{1}$ )

a) Blättchen sehr vorwiegend einfach gezahnt:

(Formenteis der var. typica Chr.)

1. Drïsenarme Formen:

a Blättchen breit oval bis rundlich:

var. typica Chr.
1. Reuteri H. Braun $\left.{ }^{2}\right)$
f. pilosula $C h$.

$\beta$ Blättchen länglich oval bis lanzettlich:

var. falcata (Puget) Borbas

f. Gracetii Borbas

f. Crepiniana (Déséglise) $R$. Kéller

2. Driisenreiche Formen:

var. concomitans mithi ${ }^{3}$ )

var. alcimonensis mihi ${ }^{1}$ )

¿. separata mili $\left.i^{5}\right)$

1) Bei der Verwandischaft der R. glauca mit R. canina erscheint es zweckmässig, die Einteilung zunächst nach dem Grade der Blattzalınung zu trefien. Bei der ferneren Gruppierung lege ich Gewicht auf den Grad der Drüsigkeit und auf die Blattform. Es muss aber von jenen Varietäten, auf welche die Definition der R. gl. in vollem Sinne zutrift, als Unterart derjenige Kreis von Formen abgelrennt werden, bei welchen die Blütenstiele, die Brakteen, die Griffel und die Kelchzipfel gegen die R. canina hin abweichen.

2) H. Braun führt diese Rose als var. Reuteri Godet auf (11. Ber. bot. V. Landshut S. 92). Da jedoch Godet selbst diese Form als durchaus einfach gezähnt beschreibt und im allgemeinen mit der R. glauca typica identifiziert, hat sich Braun in Becks Fl. v. N. (I. S. 781) von seiner Definition im 11. Ber. usw. teilweise zurückgezogen. Ich halte es jecloch für zweckmässig, eine Rose als Mittelform (Zahnung!) zwischen var. typica und complicata zu unterscheiden und behalte die f. Reuteri mit der früheren Definition Brauns bei, aber natülich als f. R. H. Braun, bez. em. H. Br. Sollte dieses Verfalıren nicht Zustimmung finden, so gehören die betr. Rosen einfach zur var. typ.

3) Concomitans, die begleitende, weil sich diese Rose in Gesellschaft anderer, ähnlicher Formen fand.

4) Alcimonensis: von der Altmühl stammend. Alcmona ist der alte keltische Name für den Fluss Altminhl.

5) Separatus, getrennt; die Form ist von andern zu unterscheiden. 
b) Blättchen unregelmässig, aber vorwiegend doppelt gezahnt:

(Formenkreis der R. complicata Grenier)

1. Driisenarme Formen:

var. complicata (Grenier) Chr.

f. macrophylla Faurat

var. Sandbergeri $C \mathrm{hr}^{1}{ }^{1}$ )

1. diacantha mihi ${ }^{2}$ )

2. Driisenreiche Formen:

var. atroriridis Borbas (em. J. B. Keller)

var. caballicensis (Puget) Chr:

c) Blättchen durchaus mehrfach drüsig gezahnt:

(Formenkreis der var. myriodonta Chr.)

1. Driisenarme Formen:

var. myriodonta Chr.

f. grandiceps miti $i^{3}$ )

f. Teliophita mithi $\left.i^{4}\right)$

var. pseudofalcata $R$. Keller

f. mecocarpa mithio

2. Drüsenreiche Formen:

var. stephanocarpa (Ripart) $R$. Keller

d) Subspecies subcanina (Chr.) mihi:6)

(Brakteen schlecht entwickelt: Bliitenstiele verlängert: Kelchblatter nach der Blïte zurückgeschlagen: Griffel gestreckt und schwach hehart: diese Merkmale einzeln oder mehrere zusammen)

1. Zahnung der Blättchen einfach:

var. veridica miti ${ }^{7}$ )

1. melanophylloides J. B. Kellev

1. acutiformis $H$. Braun

1. rigida $H$. Braun

1) Nach der Diagnose von Christ selbst (R. d. Schw. S. 156) gehört die var. Sandbergeri zum Formenkreise der complicata. nicht der subcanina nur der lustruck aus:elıreitete, subpersistente Kelchzipfel ${ }^{2}$ ist etwas zweideutig). Allerdings hat Christ in der Deutung der var. Sandbergeri auch sonst mehriach geschwankt.

2) Mit zweierlei Stacheln: von dis und $\ddot{a} \% c * v ? a$.

3) Grandiceps, mit grossem Kopf; wegen der grossen Früchte.

4) Heliophilus, die Sonne liebend; die Standorte dieser Form sind sehr sonnig.

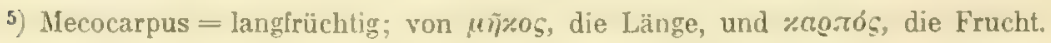

6) Die f. subcanina Christ und die R. subcanina R. Keller (1891, siehe Syn. 6,1 S. 195) haben ungefihth den Lmfang meiner subspec. subcanina, deren Diagnose ich im Obigen schärfer präzisiert habe. Mit der gewihlten Autorbezeichnung ylahe ich den Tomenklatursorschriften entsprochen zu haben. Für die var. subcanina R. Keller musste dann ein neuer Name gewählt werden, um Verwechslungen zu rermeiden. - Lat. Diagnose der subsp. subcan.: Bracteae diminutae; pedicelli prolongati; sepala post anthesin reflexa; styli porrecti ac minus hirsuti: his notis occurrentibus aut singulis aut pluribus, non vero omnibus.

7) Vergl. Internat. Reg. der bot. Nomenkl. 1905 S. 66 Empl. XXVIII. 
2. Zahnung vorwiegend doppelt:

var. diodus $R$. Keller

var. vallis fagom miti $i^{1}$ )

3. Zahnung durchaus mehrfach:

var. denticulata R. Keller

1. Dorrii milie

f. Wartmannii R. Keller

var. microphylla R. Keller

var. glandulifera $R$. Keller.

Diagnosen:

1. Var. typica: Iliittchen gross, breit oval bis fast rundlich. Scheintrichte kugelig bis eikugelig.

2. F. Renteri: Blaltrand durch einzelne Nebenzähnchen elwas unegrelmässig. Scheinfrüchte eikugelig.

3. F. pilosula: Blattstiele und zuweilen auch Mitteluerv hehatart, erstere krüftig. ${ }^{3}$ )

4. Var. falcata: Blättchen länglich oval. Scheinfrüchte oval.

5. F. Graretii: Bestachelung liräitig. Blätlchen linglich oval, klein. Kelchzipfel etwas abstehend. Scheinfrüchte eikugelig. ${ }^{4}$ )

6. F. Creprimina: Schösslinge, Nebenblittchen und junge Blättchen rötlich überlaufen. Lelehblälter nit grossem laubigem Anhängsel. Scheinfrüchte oval.

7. Vir. concomitan: Stacheln wenige, leicht gebogen bis gerade. Blättchen wie bei f. Reuteri. Kelchrücken stark drüsig, einzelne Drüsen auch an den Kelchbechern. Scheinfrüchte eikugelig. ${ }^{\circ}$ )

8. Var. alcimonensis: Slacheln schlank und fast gerade. Blättchen klein, o val, meist in den Stiel verschmälert; zuweilen ein Nebenzähnchen vorhanden. Kelchblaltrücken (l rüisig. Scheinfrüchte eikugelig bis birnfömig. ${ }^{6}$ )

1) Der Name nach dem Fundorte: Buchtal bei Eichstätt.

2) Zu Ehren meines † Freundes G. Dorr, Pfarrers in Walting a. A., eines eifrigen Floristen, dem ich auch manche Rosenform verdanke.

3) Flaumig behaart sind in der Jugend fast alle Blattstiele sämtlicher Formen der R. glauca. Es gehört also stärkere Behaarung zur Definition der f. pilosula.

4) Borbas selbst bezeichnet die Frucht als eikugelig. Meine Original-Exemplare, die Gravet in eigener Person gesammelt und Crepin bestimmt hat, tragen sogar kugelige Scheinfrichte. Die Synopsis dürfte also Unrecht haben, wenn sie von „eiförmigen" spricht.

5) Die ff. concomitans, alcimonensis und separata leiten zur var. caballicensis der zweiten Formenreihe über: Kelchrïcken drüsig, aber Blättchen vorwiegend einfach gezahnt. Die echte caballic. ist im Gebiete sehr selten.

Lat. Diagn. der var. concom.: Aculei pauci, leviter inflexi vel recti. Foliola ut in f. Reuteri var. typ. Tergum sepalorum multis obtectum glandulis; tubus etiam calicis glandulis nonnullis aspersus. Receptacula fructifera subglobosa.

6) Aculei graciles et subrecti. Foliola parva, ovata, plerumque in petiolum angustata; uniserrata, sed interdum cum glanduloso denticulo intermixto. Dorsum sepalorum glandulis obtectum. Receptacula fructifera ovoideo-globosa vel piriformia.

Von J. Schnetz ist die Diagnose mit ihrer lat. Stilisierung bereits veröffentlicht S. 113 der Mitt. der bayr. bot. Ges. Bd. II. 1908. 
9. F. sematu: Blittchen klein, elliptisch, stark in den stiel rerschmillert: etwas unregelmässig gezahnt. Kelchrücken reich bedrüst. Drüsen auch an den kugeligen Scheinfrüchten. ${ }^{1}$ )

10. Var, complicata: Blättchen mittelgross, breit oval bis mullich; unregelnäissig gesiigt, vorwiengent duppelt. Scheinfrïchte kugelig bis eikugelig, die mittlere meist birnförmig.

11. F. macrophylla: Blättchen sehr gross, bis $5 \mathrm{~cm}$ lang und $3 \mathrm{~cm}$ breit.

12. Vin. Sumllesgeri: Blïttchen ziemlich klein, breit oval, renähert; Zahnung der var. complic; mit feinen Stacheln auf dem Mittelnerv; Hochblätter gross, rot überlaufen. Kelchzipfel an der reifen Frucht abstehend. Scheinfrüchte kugelig.

13. F, diacantha: Blattstiele haarig; auf den Blattstielen besonders der Schösslingsblätter neben grossen gekrummten Stacheln und neben Stieldrüsen gerade Drüsenborsten. ${ }^{2}$ )

1't. Var. atroviridz: Blätchen schmal eifömig oder elliptisch; oberseite schwarzgıün; Zahnung sehı unregelmässig. Kelchblïtter sehr lang und schmal, ihr Rücken mit schwarzen Drüschen bestreut. Griffel weniger behart. Scheinfrïchte kugelig oder eikugelig. ${ }^{3}$ )

15. Var. cahalliensis: Blittehen wie bei var. complic.; sehr vorwiegend doppelt gesïgt. Rücken der Kelchzipfel drüsenborstig. Scheinfrüchte vorwiegend eikugelig. ${ }^{4}$ )

16. Tar. myriodontu: Blätlchen meist gloss, breit oval bis rundlich: zusammengesetzt drö̈sig gezahnt. Kelchblätter auf den Rïicken drïsenlos, am Rande 土 drïsig gewimpert, sellen ohne Drüsen. Scheintrïchte meist klein, kugelig.

17. F. grandiceps: Blütenzweige wehrlos. Blättchen sehr gross: bis $5^{1 / 2} \mathrm{~cm}$ lang und $x$ cm breit. Scheinfrüchte sehr gross, breit kugelig. ${ }^{5}$ )

18. F. heliophila: Blättchen klein, am Mittelnerv gern zusammengefaltet. Zweige, Neben- und Hochblitter, auch Blattnerven purpurn

1) Foliola parva, elliptica, manifeste ad basin cuneiformia, simpliciter serrata quibusdam denticulis secundariis accedentibus. Sepala post anthesin magis patentia quam erecta; sepalorum terga plurimis glandulis obtecta. Receptacula fructifera globosa, glandulis conspersa.

2) Petioli pubescentes; subter petiolos imprimis surculorum aculei magni curvati, setae rectae, glandulae stipitatae.

3) Diese Form ist etwas kontrovers. Die Drüsen auf dem Rücken der Kelchblätter werden von Borbas selbst nicht erwähnt, sondern zuerst von J. B. Keller (in Halacsy-Braun: Nachtrag zur Fl. v. N.), dann von H. Braun (in Bech's Fl. v. N.). Dass die Griffel nicht wollig seien, lässt J. B. Keller unberücksichtigt. Rosen mit nicht wolligen Griffeln neigen zur subsp. subcanina. Die Synopsis hat die var. atrovir. gar nicht aufgenommen.

4) Die Synopsis findet die Blättchen durchaus doppelt gesägt; Christ aber (Ros. d. Schw. S. 167) vergleicht die Zahnung mit derjenigen der var. complicala, und Borbas (I'rimit. p. \& 1 ? ) sagt von den Blättchen, sie seien „irregulariter et saepe duplicato-serrata ${ }^{\star}$. Auch bezüglich der Gestalt der Scheinfrüchte bin ich Borbas gefolgt.

5) Rami florigeri inermes. Foliola pergrandia (usque ad longitudinem $5^{1 /} / 2 \mathrm{~cm}$ et latitudinem $4 \mathrm{~cm}$ ). Receptacula fructifera maxima, late globosa. 


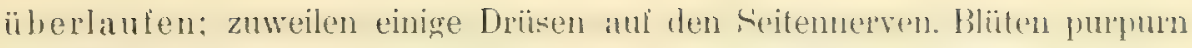
gefürbt. ${ }^{1}$ )

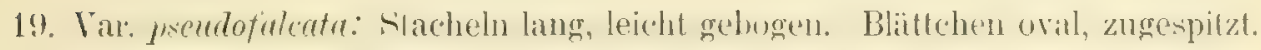
Kelchbecher länglich, unter dem Diskus halsförmig eingeschnürt. Griffel nicht weisswollig.

20. F. mecourpa: Stacheln ku1\% und gekrimmt. Keldhbeher linglieh elliptisch. Sonst wie var. pseudof. ${ }^{2}$ )

21. Var. stephanocarpa: Subtuliardrüsen an Mittel- unl Steitemnerven \pm zahlreich, bei manchen Blittern sehr sparsan. Scheinfrïchte gross, verkehrt cilomnig, sehr kurz gestielt.

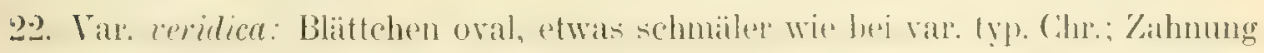

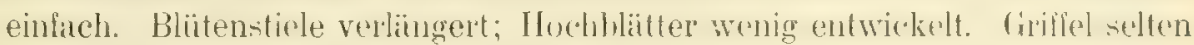
wollig. Scheinfruichte kugelig bis oval.

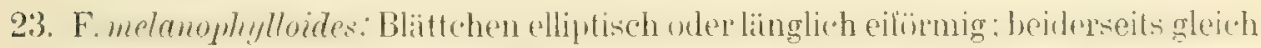

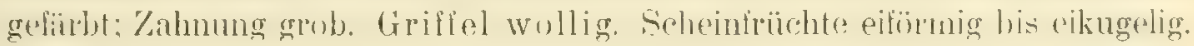

24. F, acutiformis: Blättchen länglich elliptisch, beiderseits spitz; unterseits seegrün; etwas unregelmässig gezahnt. Griffel wollig. Scheinfrüchte läglich mit langen Hals.

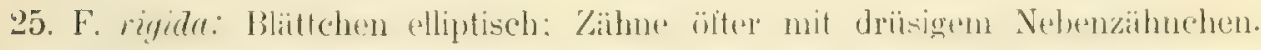
Griffel stark harig, aber nicht wollig. Scheinfruchte ellipsoidisch bis länglich.

26. Var. diodus: Blattchen ovil, + scharf zugespitzt: Hochblällep röllich violett angelaufen, meist kïrzer wie die Blütenstiele. Diese bis $21 / 2 \mathrm{~cm}$ lang. Kelch-

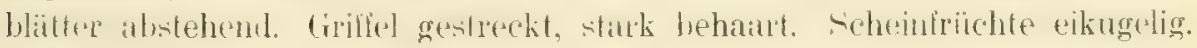

27. Var. vallis fagorm: Blättchen länglich eiförmig bis lanzettlich, beider-

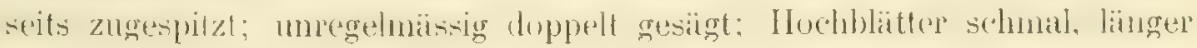
wie die Blütenstiele. Diese von der Länge der Frucht oder etwas kürzer. Kelchbliitter abstehend bis zurückgeschlagen. Griffel kurz, wollig. Scheinfriichte eikugelig (im Längsschnitt vom Typus der R. glauea gegen canina hin abweichend). ${ }^{3}$ )

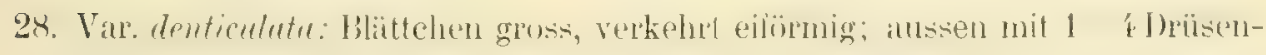
zähnchen; Brakteen gross, den Blütenstand einhüllend, rötlich violett angelaufen. Kelchzipfel teils abstehend, teils zurückgeschlagen. Griffel wollig.

1) Foliola parva; in nervo mediano saepe plicata; interdum paucis glandulis in nervis secundariis praedita. Rami, stipulae, bracteae, foliorum quoque nervi purpurascentes. Petala purpurea.

Von Hrn. J. Schnetz in Mitt. b. bot. Ges. II. Bd. S. 115 veröffentlicht mit Stilisierung der lat. Diagnose. Die Form ist eine Parallele zur f. archetypa Chr. der ersten Formenreihe.

2) Aculei breves, incurvati. Receptacula oblongo-elliptica. (Cetera ut in var. pseudofalcata.)

3) Foliola oblonge ovata aut lanceolata, utrimque acuminata; imperfecte dupliciter serrata. Bracteae pedicellis, qui longitudinem receptaculi fere aequant, longiores. Sepala patentia vel saepius reflexa. Styli abbreviati, villosi. Receptacula fructifera subglobosa . 
29. F. Dorrii: Brakteen schwach entwickelt. Sonst wie vorige. ${ }^{1}$ )

30. F. Hutmannii: Blïtenstiele verhillnismaissig lang. Griffel verlängert, haarig, aber nicht wollig. Scheinfrüchte kugelig.

31. Var. microphylla: Blïttchen klem, lïnglich eifürmig: Mittelnerv mit zahllebehen Subfoliatliisen: Blattstiel und Rand der Vebenblïter mit schwarzroten Deïsen besetzt. Kelehblätter atwtehend, driisig gewimpert. Griffel etwas verlïngert, nur behaart.' Scheinfrüchte kugelig bis eikugelig.

32. Var. glumdulifera: Blätlchen oval; mehrfach gesägt: auf den Sexitennelven \pm bedrilst: Blattstiele und Nebenblitter drïsig. Blïtenstiele kurz. Griflel borstig behaart. Scheinfrïchte kugelig.

\section{Standorte:}

Ad 1. Vielfach in Schluchten der linken Seite des Altmïhltales b. E. zwischen

Buchtal und Ochsenkeller, auch am neuen Weg über St. Walburg Oft an der Kirschenallee und sonst am Prinzensteig b. E., rechte Talseite Galgenberg b. E. (Plattenkalk $510 \mathrm{~m}$ )

Bei Pfahldorf (Eluviallehm der Hochebene)

Mehrfach neh. d. Strasse Kiplenberg-Phahldurf (Lehm m. Kalkschotter $390 \mathrm{~m}$ ) Mehrere Hexcken an Ausgang d. Hundskuchtales H. Ilbling (unt. Malm $4: 30 \mathrm{~m}$ )

Ad 2. Anfang des neuen Wegs und Galgenberg b. E. (Dolomit 440 u. $460 \mathrm{~m}$ ) Mehrmals an Kugelherg und an den benachbarten Abhängen (i)olomit 480 bis $490 \mathrm{~m}$ )

Kirschenallee b. E. (Dolomit $450 \mathrm{~m}$ )

Südl, von Eberswang b. Dollnstein (Plattenkalk $540 \mathrm{~m}$ )

Rechte Seite d. Rudershofener Tals b. Berching (Doggersand)

Ad 3. Kugelberg b. E.

Am oberen Weg z. Herzogkeller b. E. (Unt. Malm 410 m)

Ad 4. Adamsberg b. E. (Dolomit $480 \mathrm{~m}$ )

Linke Seite des Anlautertales b. d. Mühle Schafhausen (Kalk des unt. Malm $410 \mathrm{~m}$ )

Ad 5. Rechte Seite des Buchtals b. E.

An rerschitedenen Stellen des (Jchenkellertales b. E. (Dolonit $600-500 \mathrm{~m}$ )

Westl. von Treuchtlingen (Doggersand $420 \mathrm{~m}$ )

Nördlich von Gossheim i. Ries (Unt. Malm)

Ad 6. Neuer Weg b. E. (Plattenkalk $520 \mathrm{~m}$ )

Galgenberg b. E.

Ad 7. Feldranken zw. Galgenberg u. Lüften b. E. (Plattenkalk $500 \mathrm{~m}$ )

Ad 8. Zweimal an der rechten Seite des Buchtals b. E., auch in einer Seitenschlucht desselben.

Mehrfach am Galgenberg b. E. (Dolomit und Plattenkalk 440-510 m)

Zweimal am Kugelberg b. E. (Dolomit 460 u. $470 \mathrm{~m}$ )

Ad 9. Galgenberg b. E. oben (Plattenkalk $520 \mathrm{~m}$ )

1) Bracteae angustae atque breves (Cetera describuntur in var. denticulata). 
Ad 10. Fast üherall in (rebiet verbreitod, z. B.: Bui Eichsliatt an Galgenbereg mehr-

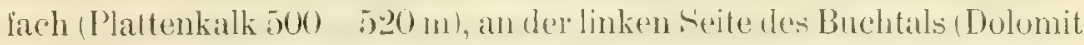
$480 \mathrm{~m}$ ), zw. Prinzensteig und Anlage (Dolomit $450 \mathrm{~m}$ ), im Ochsenkeller tal (Dolomit $480 \mathrm{~m}$ ), am Südabhang d. Willibaldsburg (Dolomit $480 \mathrm{~m}$ ) Bei Gungolding

Mehrfach an Rainen bei Pfahldorf (Eluviallehm $540 \mathrm{~m}$ )

Südwestl. Böhming b. Kipfenberg (Schneid!)

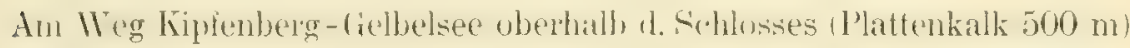
Mehrfach auf der Hochebene b. Haunstetten (lehmige Albüberdeckung) Rechte Seite des Schwarzachtales nahe Enkering (unt. Malm 420 m)

Zw. Ensfeld und Tagmersheim

Südl. von Eberswang (Plattenkalk $535 \mathrm{~m}$ )

Südabhang der Wülzburg (Malm $600 \mathrm{~m}$ )

Zw. Berg b. Neumarkt u. dem "schwarzen Holz" (Doggerlehm $450 \mathrm{~m}$ ) "Buchenrain" zw. Berg u. Hausheim (sand. Doggerlehm 470 m)

Eichenbusch am Kanal b. Meilenhofen (Liaslehm 430 m)

Sulzbürg gegen d. Gensmühle (Fl. v. Nbg.)

Ostermühle b. Helfenberg (Fl. v. Nbg.)

Rechte Seite d. Eisentales b. Eichenhofen (unt. Malm 530 m)

Auf Malm der halben Höhe des Münchsberges b. Burglengenfeld

Ad 11. Beim Ziegelstadel i. Buchtal b. E. (unt. Malm $430 \mathrm{~m}$ )

Siidneite d. Nugelbergs b. Treuchthingent (lehmiger sand des Doggtr $430 \mathrm{~m}$ )

Ad 12. Am Weg zur Galgenbergkapelle b. E.

Ad 13. Am untern Weg zw. Prinzensteig u. Anlage (Malmgeröll $420 \mathrm{~m}$ )

Ad 14. Zw. Berg b. Neumarkt u. dem Forsthaus Grossenwiese (Liaslehm)

Ad 15. Mehrmals am Galgenberg b. E. (Dolomit und Plattenkalk $440-510 \mathrm{~m}$ ) Neben Weg Antonigasse-Ochsenkeller b. E.

Ad 16. Von ähnlicher Verbreitung wie die var. complic: Um Eichstätt gemein, z. B. am Galgenberg (Plattenkalk $520 \mathrm{~m}$ ), an der linken Seite des Buchtals (Dolomit $450 \mathrm{~m}$ ), am neuen Weg (Plattenkalk $485 \mathrm{~m}$ ), am Adamsberg (Plattenkalk $480 \mathrm{~m}$ ), sehr oft am Kugelberg $450-500 \mathrm{~m}$ ), zw. Wintershof und "hohem Kreuz" (Plattenkalk $540 \mathrm{~m}$ )

Fuss des Kernbergs nahe Arnsberg (mittl. Malm $420 \mathrm{~m}$ )

An Strässchen Kinding-Enkering (Grenze Dogger-Nalm 390 m)

B. Irlahüll (Plattenkalk $530 \mathrm{~m}$ )

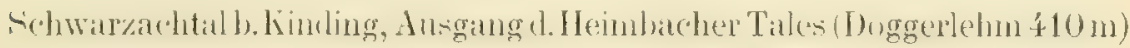

Anfang des Ottmaringer Tales b. Beilngries (Alluvium)

An Strasse Dollnstein-Haunsfeld

Mehrmals an der Strasse zw. Gossheim und den Schwalbmiihlen

Rechte Seite d: Eisentales b. Eichenhofen (Malmkalk $530 \mathrm{~m}$ )

Bei Sulzbürg (Fl. v. Nbg.)

Bei Lappersdorf und Etterzhausen, Regensburg (Killermann!)

Ad 17. An der Kirschenallee b. E. (Lehm auf Dolomit $445 \mathrm{~m}$ )

Anfang d. Steinbrecherwegs zum hohen Kreuz b. E. (Dolomit $455 \mathrm{~m}$ ) 
Ad 18. Schlucht zw. Adamsberg und Ochsenkeller b. E.

Beim Kirchhof Rebdorf (Humus mit Diluvialgerölle $430 \mathrm{~m}$ )

Dolomitfelsen ob. der Brunmmühle b. Walting (Dorr!)

Melorlach ant Maln der Hochlibche des Minchshergs b. Burglengended

Ad 19. Am Fussweg von Fünfstetten nach Gossheim (Malmkalk)

Ad 20. Hochebene nordöstl. v. Adamsberg b. E. (Plattenkalk $500 \mathrm{~m}$ )

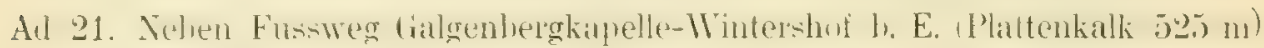
In einer rechten Seilenschlucht des Buchtals b. E. (Plattenkalk $490 \mathrm{~m}$ )

Ad 22. Bei Walting a. A. (Dorr!)

Bei Josholen (Erdner!)

Steinbruch b. Ried (krdner!)

Ad 23. Plateau d. Kermbergs b. Gungolding (Dolomit)

Ad 24. Galgenberg b. E. (Dolomit $470 \mathrm{~m}$ )

Ad 25. Abhang d. Frauenbergs gegen Rebdorf b. E. (Plattenkalk $510 \mathrm{~m}$ )

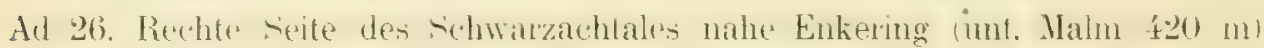

Ad 27. Hintergrund des Buchtales b. E. (Dolomit $460 \mathrm{~m}$ )

Ad 29. Am Fussweg Haunstetten-Kinding (Eluviallehm 530 m)

Westl. v. Treuchtlingen (unt. Malm $4.0 \mathrm{~m}$ )

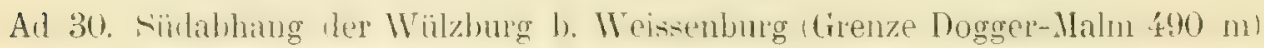

Ad 31. An Fussweg zw. Distrikts-línukenhan: E. u. Wagner'schem steinbruch (mittl. Malm $420 \mathrm{ml}$ )

Ad 3.). Piechte Sextenschluchl zw. Buchtal und fialgenberg b. L. ILehm auf Dolomit $470 \mathrm{~m}$ )

Zwischenformen: Die var. caballicensis vom Galgenberg neigen etwas

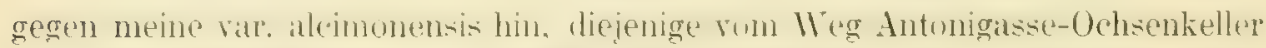
hat elwas unentachieden aufgerichtete lichlohipfel wie die Gruppe der subsp.

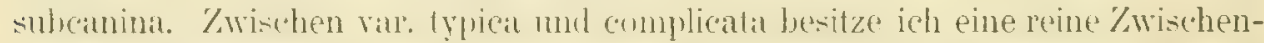

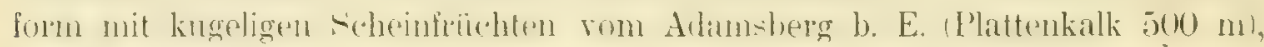

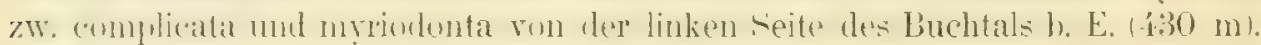
Ferner nenne ich eine var. typica, die fast f. pilosula Chr. ist, von Inching und

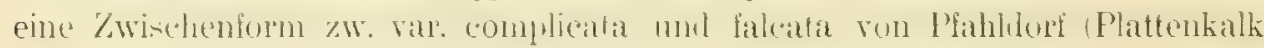
520 m). - Endlich erwähne ich einen Siranch vom Ochsenkellertal b. E. (Dolomit $480 \mathrm{~m}$ ) zur var. myriodonta gehörig: er zeigt als Monstrositiat eine übermässige Entwicklumg ler Braklexs, die sehr hïufig ans mehrfach getiederten Blättchen bestehen; auch die Kelchzipfel sind auflallend gefiedert.

In der näheren Umgebung von Eichstätt ist R. glauca in allen Formen und

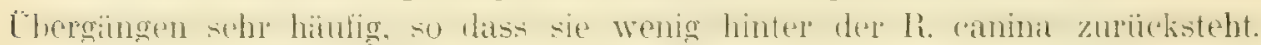

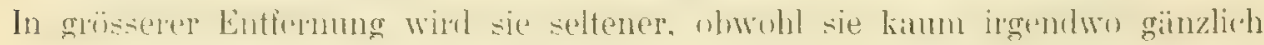
fehlt. Am wenigsten ist sie konstatiert im unteren Altmühltal von Beilngries

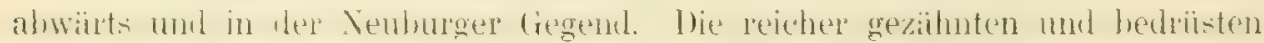

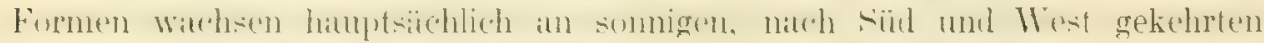

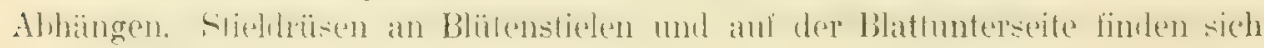
im Gebiele insserst selten. 


\section{Einzelart Rost corifolit Fries.}

Blättchen häufiger einfach gezahnt als mehrfach; mindestens an den Blattstielen und den Mittel- und Seitemnerven der Unterseite behaart.

Ubersicht der i. G. k. Formen:

a) Blättchen sehr rorwiegend einfach gezahnt:

$$
\begin{aligned}
& \text { (Formenkreis der var. typica Chr.) } \\
& \text { var. Incida Bräucher } \\
& \text { var. typica Chr. }
\end{aligned}
$$

b) Blättchen unregelmässig doppelt gezahnt:

(Formenkreis der R. frutetorum Besser)

var. vagiana (Crep.) $R$. Keller

var. frutetorum (Besser) H. Braun

f. bispinosa mithi

c) Subspecies subcollina (Ghr.) mihi:

Kelchblätter nach der Bliite zurückgeschlagen; Brakteen schlecht entwickelt; Blitenstiele verlängert; Griffel gestreckt und schwach behart: diese Merkmale einzeln oder mehrere zusammen) ${ }^{3}$ )

1. Zahnung der Blättchen einfach:

var. dimorphocarpa Borbas et H. Braun

var. incana (Kitaibel) $R$. Keller

var. scaphusiensis Chr.

2. Zahnung der Blïttchen durchaus doppelt und mehrlach:

var. Hausmannii H. Braun.

$$
\text { Diagnosen: }
$$

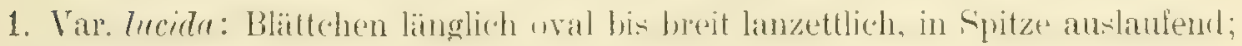
Oberseite kahl. Unterseite nur an den Nerven behaart.

2. Var. typrica: Blättchen meist breit oval; etwas unregelmässig gezahnt; ober-

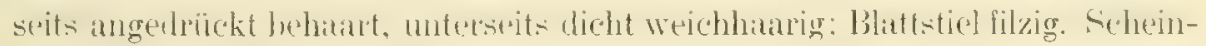
früchte kugelig bis eiförmig.

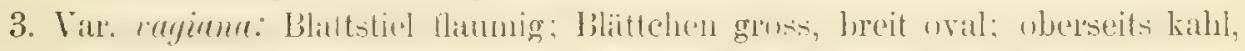
unterseits an Mittel- und Seitennerven behaart, an der Fläche kahl oder nur zerstreut behaart. Scheinfrichte eikugelig.

4. Var. frutetorum: Stacheln zahlreich, oft wirtelig. Form und Behaarung der Blättchen wie bei var. typ. Scheinfrüchte eikugelig bis eiförmig. ${ }^{*}$ )

1) lch trenne, ähnlich wie bei R. glauca, die Formen, welche durch längere Blütenstiele usw. zur R. dumetorum hinneigen, als Unterart von der typischen R. coriifolia ab. Im einzelnen gruppiere ich wieder nach dem Grade der Bezahnung, Bedrüsung und Behaarung. Formen der typischen Art mit durchaus mehrfach gezähnten Blättchen wurden im Bezirke bis jetzt nicht aufgefunden.

2) Bispinosus, mit zweierlei Stacheln versehen.

3) Lat. Diagnose wie bei subsp. subcanina: Bracteae diminutae; pedicelli prolongati; sepala post anthesin reflexa; styli porrecti ac minus hirsuti: his notis occurrentibus aut singulis aut pluribus, non vero omnibus.

4) Nach R. Keller (Syn.) ist die var. frutet. wesentlich schwächer behaart wie die var. typ.: der Blaltstiel dicht flaumig, die Unterseite nur an den Nerven. Ich folgte der Definition von 
5. F. hispinosa: Bestachelung an den blattstielen bes. der sprössinge doppelt. Blättchen etwas stärker behaart als bei var. frutet. ${ }^{1}$ )

6. Var. dimovphocurpa: Blattsticle locker behart: Blittchen elliptisch; oberseits kihl, unterseits an len Verven behant. Iblïtenstiele kurz. lichehzipfel

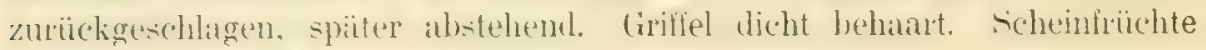
kugelig bis eiförmig.

7. Var. incana: Blattstiele wollig; Blittchen elliptisch, zuweilen mit Nebenzïlnchen: when anliegent. unten dicht bis filzig behaut. Blïtenstiele mässig lang (1-1,5) (2m). Kelchzipled zurïckgeschligen, auf dem Rücken dribenlos. Griffel wollig.

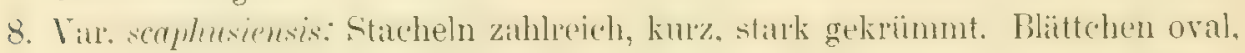
mit stumpfer, oft in Kerbung übergehender Zahnung, öfter mit Neben-

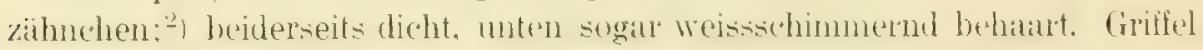
weisswollig. Kronen blassrosa bis weisslich. Scheinfriichte eikugelig.

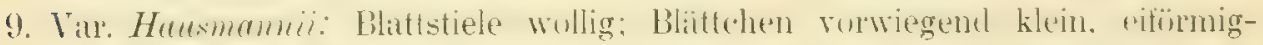

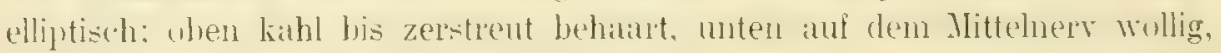
auf der Fläche anliegend behaart. Blïtenstiele ca. $1 \mathrm{~cm}$ lang. Kelçhblïtter nach der Blïte zurickgeschlagen. Grilfel wollig. Scheinfrüchte kurz eilömig.

\section{Standorte:}

Ad 1. Mehrmal: an der rechten Seite des Eisentales b. Eichenhofen, Oberpl. (unt. Malm $500-520 \mathrm{~m}$ )

Ad 2. In allen Höhenlagen des Galgenberges b. E. am Fussweg (Dolomit bis Plattenkalk $440-520 \mathrm{~m}$ )

Mehrmals westlich ron Gusshein i. R. I Lehm m, Kalkbouclien les unt. Malmu

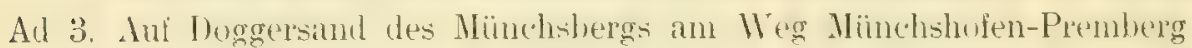

Ad 4. Zw. Kriegsstatthof u. Anhauser Hof b. Bühl i. R. (Schneid!)

Zw. Berg b. Neumarkt und dem, schwarzen Holz" (auf Liaslehm) und sonst einigemal b. Berg (Lias u. Dogger)

Ad 5. Am Galgenberg b. E. (Plattenkalk $500 \mathrm{~m}$ )

Bei WVemding an der Strasse nach Gossheim (Alluviallehm)

Zw. Gossheim und den Schwalbmühlen (Alluviallehm)

Ad 6. Galgenberg b. E. (Plattenkalk $512 \mathrm{~m}$ )

Ad 7. Galgenberg b. E. (Dolomit $450 \mathrm{~m}$ )

Ad 8. Am neuen Weg b. E.

Ad 9. Zweimal am Galgenberg b. E. (Dolomit und Plattenkalk $450-505 \mathrm{~m})^{3}$ )

H. Braun (S. 795 von Becks Fl. v. N.). Auch nach Borbas sind die Blättchen "villosa " (Prim. mon. p. 425) und auf der Unterseite stärker behaart (p. 438). S. 439 gibt er allerdings nach Exemplaren des Budapester Museums an, dass sie auf der Oberseite ${ }_{n}$ schliesslich" kahl werden.

1) Aculei in adversa parte petiolorum duplicis formae. Foliola hujus plantae magis hirsuta quam var, frutet.

Die Pflanze ist die behaarte Parallelform zu meiner f, diacantha bei der R. glauca.

2) Dadurch ist also der Übergang zu einer Gruppe von Rosen mit unregelmässig doppelter Zahnung angebahnt.

3) Diese Rosen haben nicht ganz die reiche Blattzahnung, welche der var. Hausmannii entspricht. Sie sind also Zwischenformen gegen die var. incana hin. 


\section{Sectio VI: Cinnamomeae DC. ${ }^{1}$ )}

Mittelhohe Sträncher mit flattrigem Wuchs; sehr geneigt zur Bildung auf

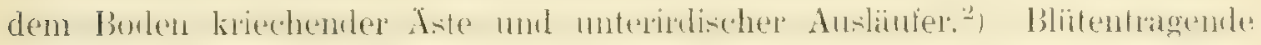
Zweige oft wehrlus, oft anch + dicht drïsig horstig: Stacheln gerate wlex ge-

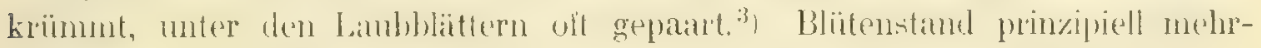

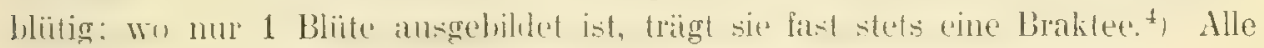
Kelchblätter ungeteilt. Blumenblätter rot.

Wegen der grossen Verschiedenheit der Stacheln werden wohl auch die

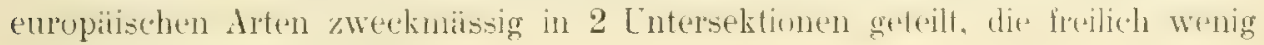
Arten unter sich begreilen.

\section{Subsectio 1: Cinnamomeae verae mihi.}

Stacheln hakig gekrïmmt, paarweise unter den Laubblïttern stehend; an

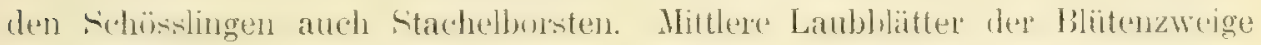

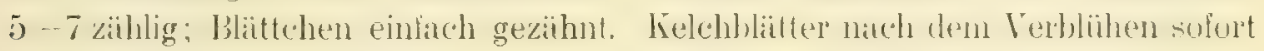
aufgerichtet und persistent. ${ }^{5}$ )

\section{Rosr cimnomomert $L$.}

Stamm und Aste mit braumroter Rinde.' Stacheln schwach; am untern Teil des crammes und der Zweige neben krätigeren oft sehr zahlresehe, dichtstehembe narleliominge ader burstliche gerade oder leichtgebogene. Neben-

1) Die R. rubrifolia Villars, die noch vor der Cinnamomea-Gruppe zu erörtern wäre, ist im Gebiete nur angepflanzt, z. B. am neuen Weg b. E. in der var. glaucescens (Wulfen) H. Braun. Andere Bergrosen der subs. Eucaninae fehlen ebenfalls. - Der Umfang der Sectio VI wurde von mir etwa im Sinne Bakers genommen. C. K. Schneider unterscheidet nach Crépin im Bereich unserer Sektion 2 Sektionen, nämlich die S. Carolinae Crép. und Cinnamomeae DC. Es ist wohl für unser Gebiet mit seinen wenigen Arten nicht notwendig, auf solche Einteilungsfragen näher einzugehen.

2) Ich halte es für wichtig, dieses Merkmal herrorzukehren, welches von vielen Autoren nicht beachtet wird. Sowohl bei der $\mathrm{R}$. cinnamomea, als blanda und pendulina drängt es sich dem Auge auf. Daher die Masse von Strüuchern der gleichen Art, die in Hecken zusammenstehen. Der Entdecker des einzigen Standortes von R. pendulina im Bezirke, Hr. Yrof. Killermann, war geradezu überrascht von der Masse der halb und ganz unterirdisch kriechenden Ausläufer dieser Rose.

3) Weil Baker in der Revised classification of roses ein allzu grosses Gewicht auf Form und Gruppierung der Stacheln legt, muss er die R. pendulina (alpina) zur Sect. Spinosissimae stellen.

4) Nach dem im Teil I S. 19 ff. Erörterten bleibt die eigentliche Endblüte stets ohne Braktee. Wo eine solche ausgebildet ist, trägt sie in der Achsel eine rudimentäre Blütenknospe, und die Inflorescenz ist dann in Wirklichkeit mehrblütig und nur scheinbar einblütig. Einblütig sind die Rosen der Sect. Spinosissimae. Als ganz seltene Ausnahmen werden hier prinzipiell mehrblütige Inflorescenzen erwähnt, $d$. h. solche, die eine Blüte mit Braktee tragen. Ebsenso selten sind bei der Sect. Cinnam. streng einblütige, d. h. einzelne Blüten auch ohne Braktee.

5) Die Persistenz der Kelchblätter wird erwähnt, um einen Unterschied gegen die - hier nicht vertretene - subs. Carolinae zu markieren. 
blättehen der schösslingshlitter eingerollt, der blïtentragenden Zweige meist zirmulich hrest, flach, mit rorgestreckten Öhrohen, unterseits behaur: Blattstiele

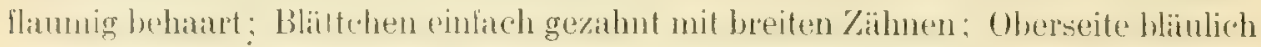

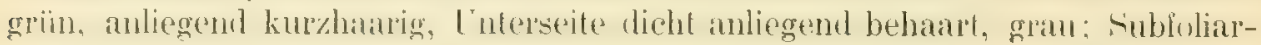
drïsen fehlen. Blütenstand einzelne oder mehrere ausgebildete Blüten umfassend. Blïtenstiele 1 bis $1 \frac{1}{2} \times$ so lang wie die Kelchbecher, von den Hochblätern unhïllt. Bhumenhlatter rot. Griftel ein grosses wolliges höplehen

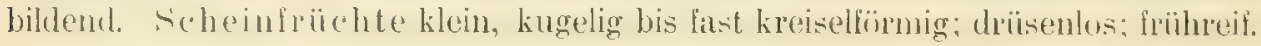

Ubersicht der i. G. k. Formen: $\left.{ }^{1}\right)$

var. typica $H$. Braun

f. (sive monstr.) foecundissima (Miinchhausen) Koch.

Diagnosen:

1. Var. typica: Eigenschaiten der Art.

2. F. foecmalisima: Blibten gefiillt vder halbgeliilt. lielchbecher nach oben erweitert.

Standorte:

Ad 1. In den verschiedensten Höhenlagen des Kugelbergs b. E. an vielen Stellen (Dolomit bis Plattenkalk $430-500 \mathrm{~m}$ )

Beim alten Holzlagerplatz Ostenvorstadt E. $(405 \mathrm{~m})$

Am Prinzensteig b. E. u. zw. Prinzensteig u. Anlage (Dolomit $430-440 \mathrm{~m}$ )

Melırfach im Birktal b. Kipfenberg (Alluvium, Schneid!)

Verbreitet im Gabelholz b. Eitensheim (Alluviallehm $380 \mathrm{~m}$ )

Im Donautal zw. Neuburg und Kelheim öfter

Häufig i. Schuttertal zw. Zell u. Segenfurter Mühle (Hofimann)

Gebiisch am Weg Ensfeld-Tagmersheim

An der Ussel zw. Itzing u. Kölburg b. Monheim (Herbar Lang!)

Waldrand an Strasse Gundelsheim-Rehau (Schneid!)

An der Strasse zw. Möhren und Treuchtlingen (Schneid!)

Rings um Wemding i. R. verbreitel, z. B. an der Strasse nach Gossheim (Schwertschlager!); zw. Wildbad und Rudelstetten, am Mühlbach b. Ammerbach, bei Otting, im Nonmenholz zw. Eulhof und Wechingen, b. Polsingen (alle letztgenannten Fundorte nach Schneid!)

Zw. Warching 1. Tagmesheim, Bayerield und Dating (Fichnizlein-Frickhinger)

Waldrand zw. Mannholz und Liebenstadt b. Heideck (Schneid!)

Schmalwiesen unweit Ellingen (Schnizlein-Frickhinger)

1) Die 1. subglabra A. Schwarz kenne ich aus der Umgebung von Weilheim in Oberbayern, jedoch nicht aus dem Gebiete. Ich bezweifle übrigens, ob sich diese Form genügend von der R. glabrifolia C. A. Heyer unterscheidet, die in Russland häufig und nach Crépin cine Varietät der R. cinmamomea mit kahlen Blåttchen und einfachen Zähnen ist (Tabl. anal. p. 9). Höchstens kann die 1 . subglabra zwischen die var. typica und die var. glabrifolia (C. $\Lambda$. Meyer) Crep. gestellt werden. 
Ad 2. Hecken am untersten Kugelberg b. E.

In der verwilderten Anlage am Adamsberg b. E.

Am Abhang zw. Prinzensteig und Anlage b. d. Aumühle

Im Spindeltal b. Wellheim

Um Neumarkt in Woffenbach, beim Bad, gegen Lähr (Fl. v. Nbg.).

Die Verbreitung der echten, ungefüllten R. cinnamomea scheint von den

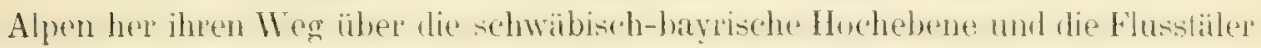
zur. Donau genommen zu haben. Von der Donau her und durch des Ries stehen die Fundurle her Eichstitt, Treuchtlingen und vielfericht Heiderck noch in pflanzongeographischem Zusammenhang mit der urspringlichen Heinat. Doch seheinen einzelne Ftandplitze b. Eichstät bereits der Vorwillepung und dadureh erfolglen Reduktion der Blumentiillung ainer kultivierten monstr. Luecondjssima ihren L'splung zu verdanken. Die unterste Ileckenreihe nämlich an lingelberg trägt golïlle und magefïlte Zimmtrusen durcheinander. Zur f. locrand. vgl. Fl. v. Nog. S. 533 , wo sehr tielfend der Zusimmenhang dieser linhturtum mit mittelalterlichen Burg- und Bauerngärten nachgewiesen ist.

\section{Subsectio 2: Alpinae Déséglise.}

Stacheln oder Borsten gerade, ungleich; meist zerstreut, selten am Blattgrund gepaart; entweder an allen Stengelteilon sehr zilhtreich oder an den obern sehr spärlich bis gänzlich fehlend.

\section{Losa blanda (itom.1)}

Unterirdische Stämmchen weit kriechend; oberirdische Äste im Alter brannot, nur am Gronde borstig; hlütentragente '/weige stets wehros. Bläter an len Lamblrieben 9zählig, sonst 5-7zählig: Blittehen ans keillömigem Grunde elliptisch oder verkehrt eiförmig länglich, meist über der Mitte am breitesten: nit einlichen nicht drïsigen Zïhnen; kihl. Blïtensiele kahl und unbewehrt. Kelchblätter auf der Scheinfrucht meist ausgebreitet. Blumenblätter weisslich oder rosa. Scheinfrüchte kugelig oder eikugelig.

Diese aus dem Osten der Ver. Staaten N. A. slammende Art tritt z. B. rben auf den Kugelberg b. E. zwischen stüuchern der R. pimpinellitolia verwildert auf.

\section{Rose pendulinu L. ${ }^{2}$ )}

Stamm unterwärts mehr oder weniger bewehrt, oberwïrts nebst den

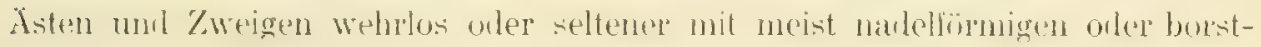

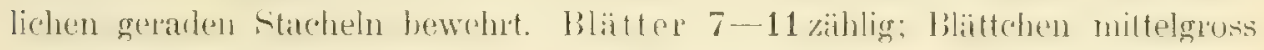
bis klein. länglich pilömng his rumblich; Zahmung mehofarh zusammengesetzt,

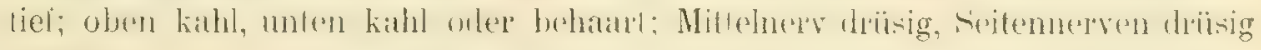

1) Synonym mit R. iraxinifolia Gmelin. Ich folge C. K. Schneider, wenn ich die R. blanda als Art und nicht als Rasse der R. virginiana Miller auflasse.

2) Synonym mit R. alpina L.: Die Prioritätsverhältnisse erörtert R. Keller in der Syn. 6, 1 S. 299. 
oler drïsenlus. Entwickelte Blüten meist einzeln stehend. Blütenstiele gewïhnlich mehrlach lïnger als der helchhecher: beide gewöhnlich drüisg: Blïtensticlo nach dem Abblibhen bogig gokrïmmt. Kelchblälter ungeteilt: anfrecht uml pressistent die soheinlrüchle krönend. Blumenblätler lebhat rosenrot his furpurn, stark in der Mitte anserandet. Griffel wollig. Sccheinfriachte kugelig bis flaschenförmig, überhängend; hellrot.

Im Bezirke: var. pubescens Koch.

Diagnose: Blütenzweige wehrlos. Blättchen länglich eiförmig; unterseits locker anliegend behart.

Diese Rose hat Hr. Prof. Killermann (Regensburg) an mehreren Stellen hei Labber auf Weis-jura atufgelunden (Schattenlige, (a. 310 m Meeresöhe). Scheinfridchte und blïtenstiele der vorliegenden Form sind etwas bedrïst: die ersteren neigen zur Flischengestalt. I) Stammchen kriechen nach briell. Mitteilung weit umber ant und unter der Bodentläche. Die geringe Fruchtharkeit (meist nur 2 in auscrebildele Nïsichen im Receptaculum) fïhre ich nicht efwa auf Bastardienung zurïck, denn diltïr fehlt jeder morphologische Grund, sundern auf die ungerigneten jetzignn Lethenshedingungen und den rersteckten Wuchs, welcher die Bestäubung durch Insekten erschwer\%. ITnter ähnlichen Bedingungen habe ich Mangel an Fruchtharkeit schon oft an R. pimpinellifolia, cimmmonea und lutea der Eichstiilter Gegend bemerkt. Erstamen erregt hei der R. pendulina ron Laaber die sn niedrige Linge. Man ist wohl berechtigt, anch in diesem Falle ein eiszeitliches Relikt anzunehmen. Kinstliche Anptlanzung scheint nach dem Siachverhalt (heträhtliche Entfernung von Wohnungen und Gärten, Stand unter Waldgebüsch) ausgeschlossen. 


\section{Sectio VII: Spinosissimae Baker.}

Mittelhohe Sträucher. Slacheln zerstreut; ungleich, die grossen lang, schlank und gerade. Blüten meist einzeln, ohne Brakteen am Stiele.

\section{Subsectio 1: Pimpinellifoliae DC.}

Mitllere Lanbblitter der blïtentragenden Zweige! - 11 zählig; obere Nebenblïtchen schmal, mit plüzlich verbreiterten stark divergierenden Öhrehen. Kelchblïtter gamzrandig, kurz. Corollen weiss oder blassrot. ${ }^{1}$ ) Reile Scheinfrüchte schwärzlich, mit violettem Saft.

\section{Rosa pimpinellifolia $\mathrm{L}$.}

Stamm merirdisch stitk verzweigt; die aullechten, oberirdischen Siammchen meist niedrign, selten übel 1 m hoch und damn etwas klelternd. Zweige sehr dicht mit lïngeren derben geraden und kürzeren nadel- bis borstentömigen Stacheln besetzt. Blättchen klein, fast kreisrund bis breit elliptisch; mit vorwiegend einkcher Zahnung und offenen kurzen Zähnen; beilerseits gewöhnlich nitsant den Stiel kahl und drüsenlos. Blïtenstiele lang, stieldrïsenlos oder seltener bedrist. Blumenblätter gross, milchweiss bis rötlich, anch mit gelbem Nagelileck. (irillel zu einem grossen wolligen Köpfchen geballt. Kelchblätter aufrecht und persistent. Scheinfrüchte zusammengedrückt kugelig (ausnahmsweise zum Eilömigen verzerel); reif schwäulich mit violetteu Saft.

Ubersicht der i. G. k. Formen:

1. Blïtenstiele ohne Stieldrüsen:

var. typica Chr.

f. macropetala Borlas

1. poteriifolia (Besser) H. Braun

var. miligera mili ${ }^{2}$ )

var. lagenoides $R$. Keller

f. erubescens miti ${ }^{3}$ )

2. Bliitenstiele mit Stieldriisen: var. spinosissima Koch.

1) Gilt nur fï die europäischen Arten der Untersektion.

2) Piliger, Haare tragend.

3) Erubescens, errötend: von den rötlich gestreiften Kronblättern. - Bei dieser Gelegenhelt sei bemerkt, dass sich die Form rosea Koch nicht aufrecht halten lässt, wie es noch R. Keller in der Syn. tut. Crépin bemerkt nämlich in seinem Aufsatz: Les roses de l'herbier de Koch (Bull. soc. roy. bot. belg. t. 32. 1893, p. 2), die Varietät rosea Kochs sei gegründet auf ein Exemplar alpina $\times$ pimpinellifolia, das vom Salève stamme. 


\section{Diagnosen:}

1. Var. typica: Bestarchelung reichlich. Zahnung der Blittchen eintach. Bliiten weiss, am Nagel ins Gelbliche spielend. Scheinfrüchte breitkugelig.

2. F. mecropetalu: Blattchen grösser als bein Typus: elliptisch bis lanzettlich, mit sichelförmig ausgezogenen Zähnen. Blumenblätter $2,5 \mathrm{~cm}$ lang.

3. F. poteriifolia: Blättchen und übrige Teile besonders klein.

千. Var. piligera: Blättchen sehr klein, rundlich, einfach gezahnt; a uf der Unterseite der Mittelnerv stark mit gelben zottigen Haaren besetzt; auch Seitennerven, Blattliache und Blattstiele \pm behart. Blütenstiele verhältnismảssig sehr lang, bis $3 \mathrm{~cm}^{1}$ )

5. Var. lagenoides: Zahnung der Blätlchen einfach. Kelchbecher oval, nach vorn flaschenförmig verschmälert.

6. F. erubesens: Kelchziplen ling. nach dem Abblïhen montschieden aufgerichtet bis zurickgeschlagen. Limmblitter im Leben violettrot gestreilt und gelleckt. Scheinfrüchte klein, sonst wie bei var. lagen. ${ }^{2}$ )

7. Var. spinosissima Koch: Zahnung der Blättchen einlach. Blütenstiele mit Stieldriisen besetzt. Bliilen weiss.

\section{Standorte:}

Ad 1. Häufig in nehreren Föhenlagen des Kugelbergs b. E. (Dukmit his Plattenkalk $445-520 \mathrm{~m}$ )

Ad 2. Kugelberg b. E. oben (Plattenkalk $520 \mathrm{~m}$ )

Ad 3. Dolomitfelsen der Anlage b. E.

Ad 4. Kugelberg b. E.

Dolomitfelsen der Anlage b. E. $\left.(450 \mathrm{~m})^{3}\right)$

Ad 6. Zweimal am Kugelberg b. E. (Dolomit 435 und Plattenkalk $510 \mathrm{~m}$ )

Ad 7. Kugelberg b. E. (Plattenkalk $495 \mathrm{~m}$ ).

Zwischenformen: Ausser den in Anm, ${ }^{3}$ ) angegebenen zeigen verschiedene

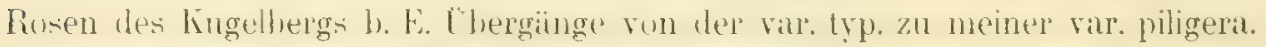
Die f. macropetala klettert dort bis '2 $\mathrm{m}$ Höhe.

1) Foliola perexigua, rotundata; simpliciter serrata; subtus in nervo primario pilis flavis abunde vestita, etiam in nervis secundariis, nervillis, petiolis \pm hirsuta. Pedicelli pro rata parte longissimi, usque ad longitudinem $3 \mathrm{~cm}$.

2) Sepala longa, post anthesin dubia, utrum erigantur an reflectantur. Petala viva virgis et maculis violaceis distincta. Receptacula fructifera parva, ut in var. Jagenoidi ovoidea et in figuram lagenulae producta.

H. Dingler gibt in seinem Aulsatz: „Neuere Beobachtungen in der Gattung Rosa" Engler's bot. Jahrb. 1908, 40. Bd. Beibl. 93 S. 102) eine „Ubersicht der pimpinellifolia-Formen Unterfrankéns". Eine dort neu aufgestellte Form achras kommt meiner erubescens nahe. Ich habe meine Form unter No. 521 schon längst in der Flora exsicc. bav. ausgegeben, die dazu gehörige Diagnose ist aber noch immer nicht in den "Denkschriften der $k$. bot. Ges. Regensburg" veröffentlicht worden. Der Mangel an Fruchtbarkeit ist bei der f. erubescens auffälig. spricht aber bei dem Umstande, dass in hiesiger Gegend alle R. pimpin. wenige ansgebildete Nüsschen im Fruchtbecher zeigen, nicht unbedingt für eine Bastardierung.

3) Diese Pflanze ist wohl wegen des trockenen und sterilen Felsbodens eine winzig kleine Zwergform (oberirdische Stämmchen durchschnittlich nur $10 \mathrm{~cm}$ hoch!), also hierin an die f. poleriifolia sich anschliessend. Ausserdem zeigen die Kronblätler öfter rötliche Streifen gleich der f. erubescens. 


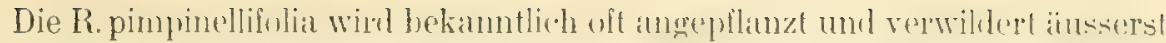

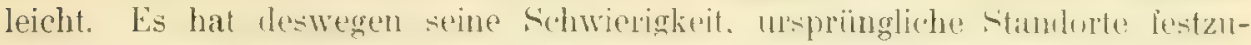
stellen. Ich glaube nicht, dass der in der Fl. v. Nbg. erwähnte Fundort zu

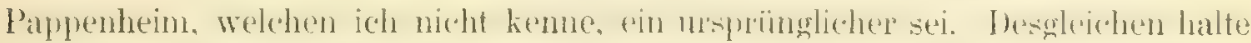

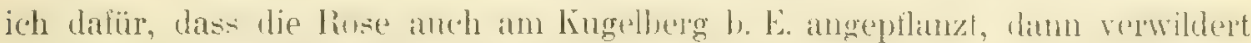

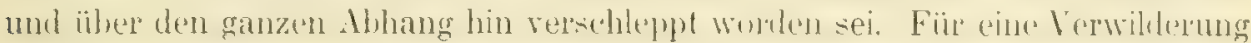

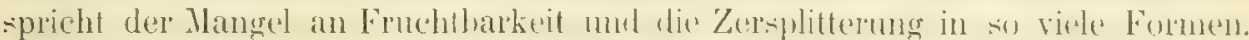
Die 2 Standorte in der Anlage b. E. machen einen besseren Eindruck, doch bin ich auch hier nicht sicher, weil die Eichstätter Rosen so ganz isoliert im

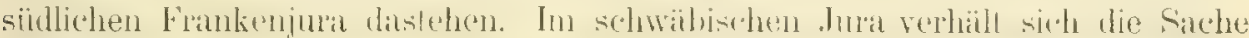
anders.

\section{Subsectio 2: Luteae Crépin.}

Vittlere bläter der Blïtenzweige 5 Tzählig: olere Tebenblïtehen wenig

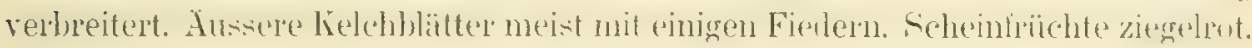

\section{Rosa luter Miller.}

Hoher Strauch. Stacheln gerade, zwischen den grossen am unteren Teil des stammes viele slachellorsten. Nobenhlialtchen nicht odel nur schwach

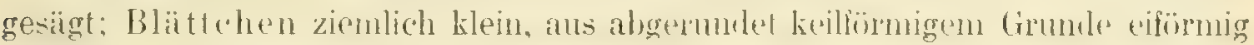

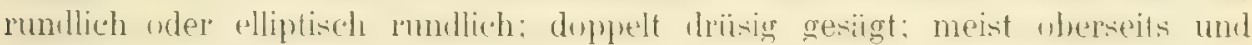
unterseits kahl sowie ohne Drüsen. Blïten zu 1-3, gross, gelb. Kelchzipfel lang zugespitzt nit etwas verbreiterten Anhängsel, drïsenstachelig. Griffel behaart. Scheinfrüchte kugelig, bei uns fehlschlagend.

Diese asiatisehe oft angepflanzte hose ${ }^{1}$, ist in ungeliilter Form an mehrepen Stellen am lingelberg h. E. verwildert; nach deo Fl. v. Nbg. anch un Röjekingen am Häselberg.

1) Vgl. S. $\left.25 \mathrm{Anm}^{3}\right)$. 


\section{Die Bastarde.}

Allgemeines über Rosenbastarde wurde schon im I. Teil bemerkt. Varietïtenmichlinge künuen leicht künstlich hervorgerufen und in der freien Vatur erzongt werden, lasen sich aber kaum nachlräglich an merpholugichen Merkmalen des lebenden Strauches erkennen. Wir beschränken uns also nuf die

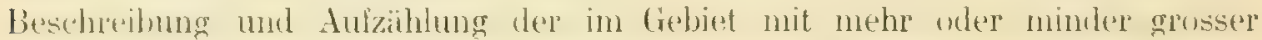

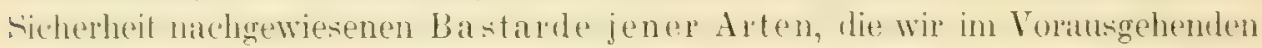
behandelten. Dass ein Bastard vorliege, datür war aus früher erörterten Grinden mir in erster Linie massgebend die Wahrnehmung geminderter Fruchtbarkeit, indem scheinhïchte entwerler gar nicht ansgebildet wurlen oder doch eine verhillnisnässig sehe geringe Zahl reiler Nüsschen enthielten. Dic Mischmng der morphologischen Charaktere ist natimlich ebenballs stets eine Folge der Hybridisation: man kann aber jedentalls nicht umgekehrt aus der beobachtung einer sulehen Mischung allein die Bastaphatur erschliessen, da auch Virlation schedubar Mischcharaktere erzergt, mol manche sichere Bastarde in der ersten (iencration bluss Eigenschalten eines Elter wahruehnen lassen. Inmerhin vermag lie Beoluchtumg einer Mischung von Eigenschaften an zweiter stelle auf die Spur ron Iỵhiden zu fïhren. Welche bestimmte Eltern jeweilig in Frage kummen. Wurle mud wird aus der Analye der morphologischen Eigenschalten

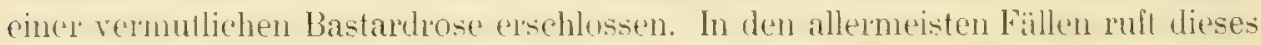
Verfahren eine mehr oder minder grosise Lnsicherheit hervor. Nur ansgedehnte unl zeiflich lange lortgesetzle lúlurversuche künnten ein exakteres Lrgebnis lielern, da roraussichtlich allmählich die spaltung des Bastards in seine Konponenten nach den Mentel'schen Regeh vder sonstwie eintreten wiinde. Allein fïrs frste kömnten bluss solche Batstarle einer derartigen experinentellen Behandlung unterworten werden, die eine grenïgende Fruchtbarkeit besissen, sodas stets wenigstens einige Nïswhen \%u heinung gelangten. Fürs zweite erfordern sulde Versuche bei dem langsimmen Wachstum der Rosen einen inmen:en Auband von Mühe und Zeit, withrend ein Resultat erst nach lïngeren Jahren der Kultur zu erwarten wire. Nur grosse Institute mit zahlreichen Arbeitsklïften dürfen sich an die Lösung solcher Aufgaben heranwagen.

Die Forderung, dass ein angeblicher Bastard zwischen seinen Eltern atforuhden werden miibse, halle ich fïl zol streng. Man kann hörehstens verlangen, dass die Elternarlen in der weiteren Lingegend ftanderte besitzon oder doch hesasstul. Die hehruhtenden Insekten durchiliegen ja grösirere läime zur liewimmung von Pollen und Nektar, desglejehen Vögel, Welche elwa Bastard-

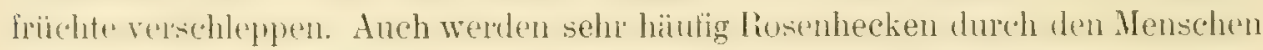
ansgerndet wer sterhen infolge allgememer ungïnstiger Verinderungen in einer Flur ab. Fin bistard steht alsu möglicherweise in einer Flurabteilung, die

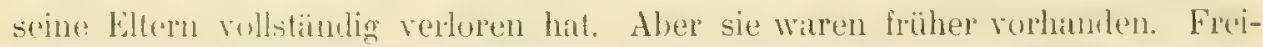
lich bleiht es lïr ditº Konstatierung cines bastarts ein günstiges Leichen, wenn die vermutlichen Eltern in der Nïhe wachsen. 
Was die Reihenfolge betriff, in der ich die Bastarde bespreche, so bediene ich mich ungetahn der Ordnung, in welcher man in der anmominchen Chenie die Verbindungen erörtert. Wie hier alie Reihenfolge des Systems der Elemente masigebend ist, und hei jodem Elenent jedesmal dic Verbindmigen mit den vorhergehenden Elementen angeliihrt werden, so lege ich meine ()minung der liosenarten zu grunde und bespreche stets die Bastarle einer im Gyslem folgenden Art mit den sorher behandelten Arten. Also z. B.: wril ich begonnen habe mit li. arvensis, der die R. gallica, Jumbillii, pomitera, tomentusa folgten, bespreche ich an erster Stelle die Hybride arvensis $\times$ gallica, dann würden folgen die im Gebiet allerdings nicht vohandenen arvensis $\times$ Jundzillii, gallica $\times$ Jundzillii nsw. Der nächste ron mir wirklich behandelte Bastard ist gallical $\times$ tomento:a.

In der Beschreibung der Hybriden ist es besonders schwierig, rein individuelle und zulibllige Ziige von den charakteristischen zu scheiden; wenn dats iaberthaupt möglich erscheint. Das Endziel der Dolinition miiste sein, am Bablarel gesondert jene Eigensohaften hervor\%uheben, tie er ron Vater, und diejenigen, die er von der Mutter hat. In der Namengebung müsste dann die Varietät und sogar die Form ilmen Ausdruck finden, die dem Bastard von seiten beider Eltern zu grumle liegt, sowie die Prïponteranz eines Falstors. Ich müsste alon beispielsweise unter Berïrksichtigung dex Nomenklatureegehn mich atsilrücken: R. arvensis Huds, yai. typica R. Kell. f. ovata Desv. $X$ R. gallica L. var. pumila H. Br. f. muscipula R. Kell. Nur in den wenigsten Füllen wird die rein morpho-

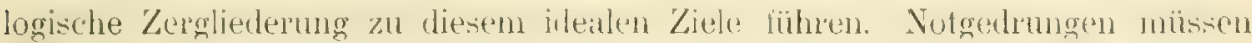
dann weitläufige Beschreibungen an die Stelle treten, und wo Bastarde von

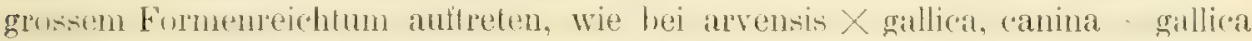
11. dgl., ist es angezeigl, sie anlentungsweice in Varielilen und Furmen zu gliedern, wie die reinen Arten. Dann sind aber auch entsprechende Sach- und Autornamen notwendig, wie man sich durch einen Blick in die Synopsis von R. K. leicht überzeugen kitmn. Jeder Bastant ist eine Verbindung zweier Formen, bei uns auch zwelè Arten; man wïrde also somem Wesen entsprochen, wenn man ihn als comb. (combinatio = Verbindung zweier Eilemente) bezeichncte. Allein liin

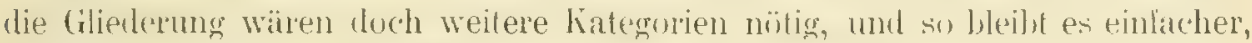
wie eben bemerkt, die Begrifle var. und f. anzuwenden. Nur muss man wissen, dats diese Bezrichnmgen hier meigentlich angewendet werden, mul dass die ginze Methule einen Notbehelf darstellt. Bei der grussen Varbutinnsbeite der Bastarde, ja schon der grossen Kombinationsmöglichkeit dercellen, liegt schliesslieh die Gefahr vor, dass man gallängt wird, für nahezu jeden netu aufgefundenen Mischling eine? neue Form zu errichten und sie rein individuell zu beschreiben, ob man will oder nicht.

\section{Sectio Gallicanae DC.}

\section{1. arvensis IIuds. $\times$ gallica $\mathrm{L}$.}

Diesen Bastand lassen holgemle Kennzeichen vermuten: Situmm mil diunen Asten, kriechenel ader klimmend. Stacheln schwach, mit Borsten und Inrüsen

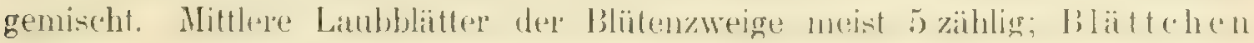
starr, unterseits blassgrin mit stark hervortretendem Adernetz, hier 
ohne Drisen; Zahnung einfach mit rundlichen Zähnen, etwa vorhandene Nebenzähnchen sehr klein. Blüten einzeln oder zu wenigen vereinigt, langgestiolt; Ilochbläter fehlend nder klein. Blumenhläter gloss, ron der Farbe der R. arv. bis zu der der gallica. Griffel kurz bis langgestreckt, frei oder in einer Siule vereint.

Ubersicht der i. G. k. Formen.

a) Griffel verlängert:

var. howida mithi ${ }^{1}$ )

var. hybrida (Schleicher) R. Keller

var. ensfeldensis mihi $i^{2}$ )

b) Griffel erheblich kïrzer als die inneren Staubblätter:

var. nummulifolia (Vuliotinovic) $R$. Keller

1. hispidior mihi $\left.{ }^{3}\right)$

var. geminata (Rau) Boullu.

\section{Diagnosen:}

1. Var. horrida: Die Achsen sehr stark heterakanth, auch die grossen Stacheln nur geneigt, nicht gekrümmt. Blättchen mittelgross, gegen den Stiel abgerundet; oben kahl, unten, auch anf der Fläche, zerstrent behart; Hauptzïhne abgemulet, mesis mit 1 bis 2 drîsigen Nebenzähndhen versehen. Bliiten gross, beich. Blïtenstiele sehr lang (bis 5 cmu) diese wie die lielchbecher sehr drüsig und stachelig. Griffel verlängert, kahl; unten verwachsen, ganz oben frei. Entwickelt gar keine reifen Scheinfrüchte. ${ }^{*}$ )

2. Var. hybrida: Strauch aufrecht mit starken Stacheln und sparsamen Drüsenborsten. Blattstiel und Blättchen unterseits behart; Zähne vorwiegend einfach. Kronbliitter gross, weissgelblich. Griffel lang, oben frei; der ganzen Lïnge nach behart, unten stark. Unfruchtbar.

3. Var. ensfeldensis: Strauch niedrig; Achsen sturk mit Drïsenborsten besetzt. Blättchen gross, lederig; beiderseits kahl; drüsig doppelt gezahnt. Blälensticle mittellang, reich drïsig. Blïten rötlich. Kelchziplel kurz, meist unbefiedert, auf den Riicken wechsehnd drüsig. Griffel von der Länge der

1) Horridus, stachelig, von der starken Bewehrung dieser Rose.

2) Ensfeldensis, nach dem Fundorte, dem Dorfe Ensfeld b. Eichstätt, benannt.

3) Hispidior, stärker borstig:

4) Die Rose kommt der f. decipiens (Boreau) R. Kell. am nächsten. - Obwohl es sich bei den Bastarden mehr um Beschreibungen als Diagnosen handelt, lasse ich doch bei neu aufgestellten Formen die lat. Ubersetzung folgen:

Caules aculeis duplicis formae valde muniti; aculei etiam magni solum inflexi, non curvati. Foliola mediocria, in petiolum rotundata; insuper glabra, subtus etiam in superficie sparse hirsuta; dentibus primariis rolundatis, uno vel duobus denticulis glandiferis instructis. Petala magna, pallida. Pedicelli longissimi (usque ad $5 \mathrm{~cm}$ ); sicut et tubi calicum admodum glandulosi et setosi. Styli prolongati, glabri; in basi coaliti, in summo apice liberi. Planta absolute sterilis. 
Staubgefüsse; unten verwachsen, oben frei; unten behart, oben kahl. Steril. ${ }^{1}$ )

4. Var. mummlifolia: Aste und Zweige spärlich mit Nadelborsten besetzt; Blattstiel flaumig; Blätlchen ziemlich klein, rundlich eiförmig; rorherrschend einfach gezahnt; unterseits namentlich an den Nerven behaart. Kelchblätter kurz, last einfach, auf dem Rücken drüisenlos, an Rand drüsig gewimpert. Griffelköpfchen kurz, kugelig, kahl.

5. F. hispidior: Strauch niederliegend; Achsen reichlich mit Borsten und Stacheln besetzt, ältere Aste mit krïlig gekrïmmten. Blättchen mittelgross,

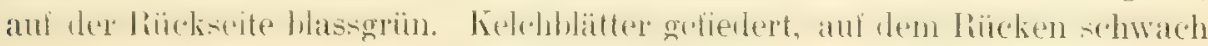
drüsig. Blüten rötlich. Sonst wie vorige. $\left.{ }^{2}\right)$

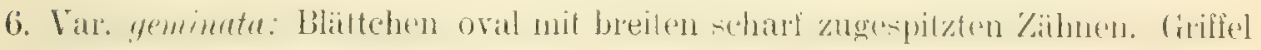
behaart. Sonst wie var. nummulifolia.

\section{Standole:}

Ad 1. Holzkirchen b. Rain (Zinsmeister!)

Ad 2. Bei Ensfeld nächst Dollnstein (Lutz!)

Ad 3.

Ad 5. Am Waldweg zw. Eberswang und Hagenacker b. Dollnstein (Plattenkalk $500 \mathrm{~m})^{3}$ )

Ad 6. Waldrand b. Igstetten (Erdner!)

Ausserdem enthält das Herb. Du Moulin in Neuburg a. D. eine wahrscheinliche arvensis $X$ gallica vom Buckschlag b. Bertoldsheim.

Der gleiche Bastard und zwar Abteilg. a) ist bezeugt von Gammersfeld b) Wellheim (Erdner!).

Im Nachstehenden mache ich den Versuch, an den genauer bestimmten vier bastaten die Eigenschalten nath den Elternarlen ansascheiden und anch die speziellen Formen zu bestimmen, die in den Eltern gewirkt haben. Wo die Diagnosen nicht ausreichen, gehe ich in der Sortierung der Eigenschaften auf die Individuen zurück, die mir in der Natur oder im Herbar vorliegen. Eine blosse Beeinflussung nach dem Mehr oder Minder von seiten des andern Elter wird durch + oder - ausgedrückt, welches der Bezeichnung der Eigenschaften angehängt wird. Keinem wird übrigens zweifelhaft sein, dass eine sichere scheidung der väledichen und mitterlichen Eigenschaften nur dureh den Kulturversuch möglich wäre, und jedem wird deutlich werden, dass bei

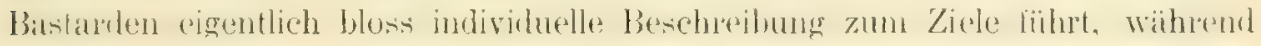

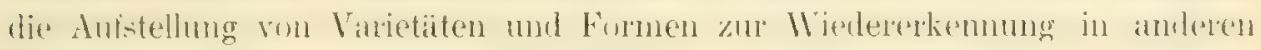
Fällen und Gegenden nicht immer dient.

1) Frutex humilis; caules setis glanduligeris armatissimi. Foliola magna, rigida vel coriacea;

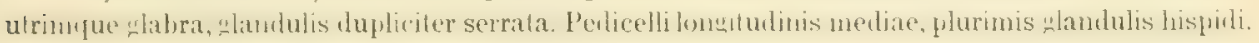
Sepala brevia, appendicibus rarissime instructa; in tergo \pm hispida. Petala subrubicunda. Styli longitudine stamina aequantes; in basi coaliti et hirsuti, in apice liberi et glabri. Planta sterilis.

2) Frutex procumbens; caules setis et aculeis abunde armati, adultiores rami satis curvis. Foliola mediocria, subtus valde pallida. Sepala appendiculata, in tergo subhispida. Pelala subrubea. Cetera de var. nummulifolia.

3) Diese Rose könnte auch für eine dumetorum $X$ gallica angesehen werden. Crépin, dem sie vorlag, entschied sich für arvensis $X$ gallica. Am Fundorte steht sie in der Nähe der Eltern. 
Var. horvida $m$.

$R$. arvensis

Achsen:

Blättchen: Grösse, Form d. Zähne Blïten:

Stiele: Läinge

Krone: Farbe

Kelch: Form d. K.blättchen, Mangel d. Befiederung +

Griffel: Länge, Verwachsung -, Kahlheit

Resultat: Var. typica R. Kell. X var. pumila H. Br. f. muscipula R. Kell.
R. gallica

Rieiche Heterakanthie, Form der Stacheln

Gestalt u. Behaarung d. Bl., Reichtum der Zähnelung

Bedrüsung

Grösse

Bedrüsung d. K.blättchen
Achsen: Form u. Zahl d. Stach. + Blättchen: Armut d. Zahnung + Bliiten:

Stiele: Brakteen vorhanden

Krone: Farbe

Kelch:

Griffel: Länge, Verwachsung --,

Var. bibracteata Ser. f. umbellata God. $X$ var. pumila H. Br.

Var. ensfeldensis $m$.

Achsen: Wuchs

Blättchen: Kahlheit

Blitten:

Stiele: Lânge

Krone: Grösse +

Kelch: Form d. K.blättchen,

Mangel d. Befiederung +

Griffel: Linge, Verwachsung -
Art des Wuchses

Grösse, Behaarung, Form der Blättchen, Form der Zähne

Långe, Bedrüsung

Grösse

Befiederung —, Bedrüsung

Behaarung

Var. typica H. Br. $X$ var. pumila $H . B r$.

Var. nummulifolia $R$. Kell. $f$. hispidior m.

Achsen: Wuchs, Form d. Stach. -

Blättchen: Form, Zahnung +, Gestalt d. Zähne

Bliiten:

Stiele: Lïnge

Krone: Grösse +

Kelch:

Griffel: Kalsheit
Heterakanthie

Grösse, Consistenz, Reichtum der Zahnung

Länge, Bedrüsung, Mangel der Brakteen Farbe -

Drüsigkeit -

\section{Behaarung -}

Helerakanthie

Grösse, Behaarung

Bedrüisung

Farbe -

Fiederung, Bedrüsung -

Form

Var. typica R. Kell. $X$ var. austriaca $H . B r$. 
Wie eine Prïfung dieser Tabellen ergibt, erweist sich die P. gall. mïchtiger in der ('bertragung ihrer Ëgenschaften als die arv. Letztere verem, wenigstens nach den hiesigen Beispielen, vorwiegend (in 3 von 4 Fillent die Läinge und Verwachsung der Giriffel; die gall, dagegen war stets bestimmend lïr die reiche Bedrisung des Bliitenstieles und der Kolchblïtter und vorwiegend fiir die Heteratinhie der Achsen, Form der Stacheln, Grösse und Beharung der Blïttchen. Die Farbe der Krone glich in der Hälfte der Fälle jener der arv., in der anderen Hälite verspiid man einen schwachen Einlluss der gall. Alle anderen Merkmale schwanken unentschieden hin und her.

\section{Sectio Vestitae Chr.}

\section{R. gallicr L. $\times$ tomentose Sm.}

Für diesen Bastard sprechen: Ziemlich nicderer Wuchs. II eterakanthie besonders an den Bliitenzweigen. Laubbläter 5-7 zïhlig; beiderseits, unlen dicht, beharet; meist mit Subfoliardriisen; mittelgross bis gross, in den Stiel abgerundet; vorherrschend zusammengesetzt gezahnt. Blütenstiele lang, dicht drüsig. Kéchblaitler lang, gefiedert, am Rande und aut dem Rücken drïsig; nach der Blïte meist zurürkgechlagen. Blumenkrone fleisehrot bis purpurn. Griffel behaart.

Ubersicht der i. G. k. Formen:

a) Formenkreis der eglandulosi R. Kell. (subloliardrïsen fehlen oder troten nur einzeln auf):

var. typica M. Schulze

var. Heimerlii $H$. Braun

\section{Wiegmannii II. Schulze $\left.{ }^{1}\right)$}

b) Formenkreis der adenophora R. Kell. (Subfoliardrüsen vorhanden):

var. cristata $C$. Dufft

var. scabriuscula M. Schulze

var. farinosa M. Schulze.

\section{Diagnosen:}

1. Var. typica: Stratuch stark bestachelt, reich an Borstendrüsen. Blätlchen breit elliptisch, an Grunde breit abgerundet; scharf und grob doppelt gezahnt. Kelchblätter oval, wie die langen Blütenstiele reich mit Stacheldrỉsen besetzt. Griffel mässig behaart.

2. Var. Heimertii: Bliittchen elliptisch-eif̈rmig oder verkehrt eiförnigg, am Rande sehr ungleich aber nicht tief, einfach oder doppelt gesägt. Kelchbecher oval. Griffel dicht behaart.

3. F. Wiegmammi: Zahmung der Blättchen wie vorhin; diese stark entwick 1 lt, am Grunde breit abgerundet, vorne meist abgestumpft. Griffel behaar bis wollig.

1) Die R. Heimerlii und Wiegmannii unterscheiden sich so wenig von einander, dass ich die letztgenannte als Form der ersteren subsumierte. Mein Exemplar hat zudem an einigen Zweigen Blätter, die zur echten Heimerlii überleiten. 


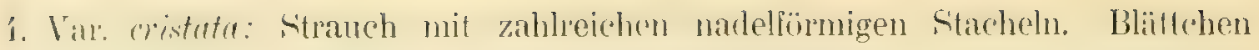
mittelgross bis gross, oval, am Grunde abgerundet; Zahnung sehr zusammengesetzt; Zähne tief, offen, spitz. Subfoliardrisen, sehr spärlich. Blïtenstiele bis $4 \mathrm{~cm}$ lang, wie die Kelchbecher dicht stieldrüsig.

5. Viar. scabriuscula: Blittchen meist gross, oval, in den Stiel abgerundet: Zaihne breit, offen, scharf zugespitzt; Subfoliardrisen an den untern Blättern sehr zahlreich, an den obern oft spärlich bis verschwindend.

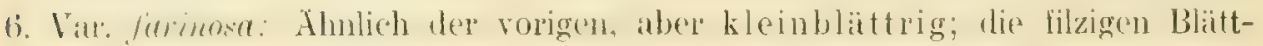
chen namentlich gegen Rand und Spitze hin reich an Subfoliardrüsen.

\section{Standorte:}

A1 1. Reichlich auf der Nordostseite des Kenmbergs b. Arnsherg (Toulomit $480 \mathrm{~m}$ ) Am Inchinger Berg (Malm, Dorr!)

Ad 3. Inchinger Berg am Buchenhüller Weg (Malm, Dorr!)

Ad 4. Massenhaft und sehr typisch an linken Inang des Altmiahltales b. Dollnstein, Nähe der Ziegelei (Malmkalk $425 \mathrm{~m}$ )

Ad 5. Nomnenholz i. Ries, am Weg Eulenhof-Wechingen (Alluviallehm, Schnetd!)

Ad 6. Abhang über der Brunnmühle b. Walting a. A. (Dolomit).

Die hier beschriebenen Bastarde der R. gallica und tomentosa tragen in ihrem Aussehen so sehr die Charaktere der tomentosa an sich, dass man erst durch ihn mehr oder minder vollstïndige sterilitit auf ihre hỵbride Natur aufmerksim gemacht wird INo. 1 wirll nath meinen Erfahrungen die leeren Scheinfrüchte sehr bald ab, die übrigen behalten einzelne, aber mit nur $1-3$ Nïsschen). Sie wären also nach der internationalen Nomenklatur als R. gallica $x<$ tomentosa zu bezeichnen. Lediglich die Heterakanthie und etwas stïlkere Bedrïsmg der Blattzähne weist deutlich gegen die R. gall. hin. Besonders ist es Gestalt und Behaarung der Blättchen, welche sofort einen Abkönmling des toment. erkemen lassen. Die Läinge der Blütenstiele, deren Bedrüsung u. a. ist eine Eigentümlichkeit beider Arten. Es erscheint an meinem Naterial unmöghich, mit einiger Sicherheit die Varictiten namhatt zu nachen, welche bei der bastardierung mitgemirkt haben. I.h habe nur den Einlpuek gewommen, dass auf Seite der R. tom. bei Nro. 1 und 3 die var. subglobosa,

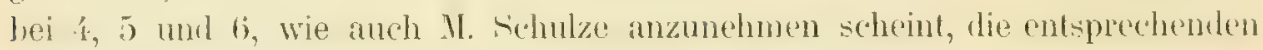
Varieläten der Subsp. scabriuscula $m$, in Frage kommen.

\section{Sectio Rubiginosae DC.}

\section{L. microntha Sm. X rubiginosa $L$.}

Bei der nahen habituellen Verwandtschaft der beiden Eltern kann dieser

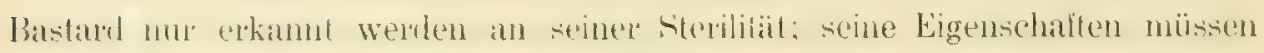

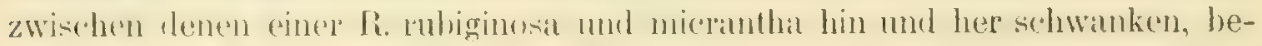
sonders was die Helerakanthie, den Wuchs, dies Bliitenfarbe, die Gestalt der Blïtchen, die: Lä̈nge und beharamg der Griffel anbelangt. Die Exemplare, welche ich in unserem Gebiete als diesen Bastard anspreche, sind ganz steril, d. b. 
werfen die Früchte schon vor Beginn der Rötung ab. Die Eltern sind beide überall, wo der Bastarl gehunden wurde, gemein. Merkwïrdigg heriht es allerdings, dass so nah verwandte Rosen keine fruchtbaren Hybriden bilden!

\section{Standorte:}

1. In einer Schlucht der linken Talseite b. E. zw. Adamsberg und Ochsenkeller.

2. An zwei Stellen der Wolfsdrossel b. E. (Dolomit 450 und $480 \mathrm{~m}$ ).

Die Pflanze unter 1. hat von der R. rub. kompakten Wuchs, ziemlich kurze Blütenstiele bei gut ausgebildeten Brakteen; von der R. micr. die zwischen der var. typica Chr. und permixta Borb. schwankende Form der Blättchen. Die Stacheln sind einerled, stark hakig; die Griflel sinl zwar kur\%, aber ganz wher nahezu kahl; Farbe der Krone wurde nicht beobachtet. Ergebnis etwa:

R. micrantha var. typica Chr. $X<$ rubiginosa var, comosa Dum.

Die Rosen unter 2. unterscheiden sich von einer R. micrantha var. permixta Burb. t. hetracantha m. (Wuchs llattrig. zuweilen einzelne Triisenlonsten unter den hakigen Stichehn, Blïttchen ctwas gegen die var. typica. Chr. neigend, Krone blassrosa, Griffel kahl) lediglich durch das ein wenig kïrzere Griffelköptchen und die Storilitiil. Da letzlere zwar die Bastandnatul' ankïndigt, aber gar kein weiteres Merkmal beibringt, das über den Kreis der Gevantart Li. puhiginosa hinauswiese, musste wie folgt entschieden werden. Ergebnis also:

R. micrantha var. permixla Borb. f, heteracantha m. $>\times$ R. rubiginosa.

\section{R. agrestis Savi $\times$ ellipticu Tausch.}

Auf S. 4 f. Bd. Il der "Milteilungen der bayrischen botanischen Gesellschaft" beschreibt Hr. J. Schnetz als neu den vermutlichen Bastard $R$. agr. $X$ ellipt., welehen er bei Münnerstall 1905 gefunden hat. Sehom seit 1901 berobathle ich an

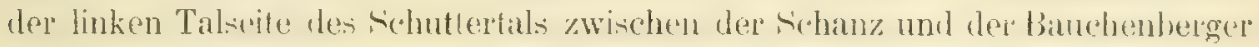
Mühle zwei strä̈lucher, die in ihpen Merknalen zwischen der Li. agr. mul elliph.

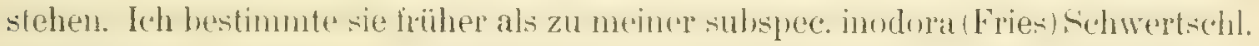
var. genuina Schwortschl. f. longipedata schwertschl. gehörig; diese ganze linterant stehl ja in der Mitle zwirchen den beiden genammen Arten. Die tuzwaifelhalt und aljährlich zum Vurschein kommende stark geminderte Fruchlbarkeit dep beiden Sträucher bestimmt mich jetzt, sie ebenfalls — freilich mit der nötigen

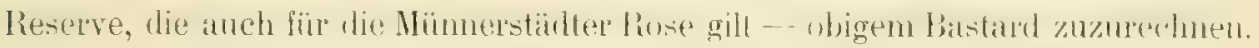
Diese Strïucher setzen wenig Fridchte an, die gebildeten sind öfter taub, die ïbrigen enthalten 3-5 reife Nüsschen.

In der Beschreibung der Eigenschaften des Bastards kann ich mich kurz fassen: es ist eine $R$. agrestis Savi var. pubescens Chr. f. vinodora Borb., welche

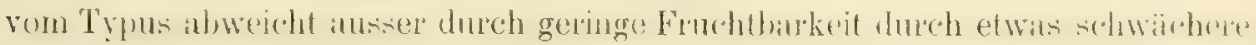
Bestachelung mit diinneren Stacheln, durch einzelne Drüsen an den laugen

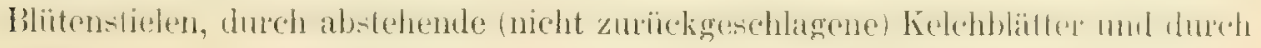
stark harige kurze Griffel. 
IV enn ich vorliegende hose richtig verstehe, so ist ihre Formel zu schreiben:

R. agrestis var. pubescens Chr. f. vinodora Borb. $>\times$ R. elliptica Tausch

var. typica Chr. f. hispida Schulze.

J. Schnetz bezieht seine Rose wohl mit Recht auf die R. ellipt. var. calcarea Chr. Vielleicht stecken in Formenkreis der Lnterart inodora noch nanche Bastarde.

\section{Sectio Caninae D C.}

\section{T2. arrensis Huds. $X$ comina $L$.}

Dieser Bastard wäre neu für die deulsche Flora, wenn er mit Sicherheit lewiesen werden könnte. Eine vielleicht hieher gehörige Form fand ich im Blülezustand neben dem Wahweg zwischen Biesenhandt und der Fehiniihle

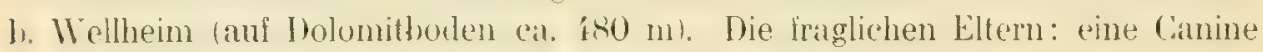
des Formenkreises dumalis Berhst. und eine R. arvensis var. typlica R. Kell. f. osata Desv. wuchsen dimeben. Das Merkwiirlige an dieser Rose sind lange, zu einer etwats dicken fianle verklebte Griffel, die durchaus stark harig, unten sogar wollig siml. Alle übrigen Eigenschaften entiprechen rollkommen der R. can. var. eriostyla Borb. 1, adumca m. Wuchs ziemlich niedrig. Ciepin, dem diese Rose vorgelegt wurde, meinte, es kïnte sich $u m$ eine zuliallige Misibildung der R. canina hamdeln. Da ich leider ausser stande mich befind, den Stratch im Stadium der Fruchtreife zu untersuchen, muss eine Entscheilung vorderhand ausgesetzt bleiben.

\section{R. canina $L_{0} \times$ gallica $L$.}

Fïr diese Krenzung sprechen: Niedriger bis halbhoher $\left(1 / 2-1^{1 / 2}\right.$ m) Wuchs. dïnne Zweige; heterakanthe stacheln: noben grosisen olt stak gekiommten kleinere borstenfömige; Nerven der Blattchen meist stark herrortretend, diese kahl oder höchstens an den Nerven der Unterseite behart, meist mit Subfoliardrüsen; lielchbecher wenigstens an Grunde drüsenborstig, Kelchblätter aul dem Rï̈cken drüsig, ïussere Kolchziptel stark geliedert; Blïtenstiele verlängert, drüsig; Kronen gross, lebhaft rosa.

Ubersicht der i. G. k. Formen:

a) Blättchen vorwiegend einfach gezahnt:

var. macrantha $R$. Keller

b) Bl. unregelmaissig doppelt gezahnt:

var. dryadea Ripart

c) Bl. vorwiegend doppelt bis mehrfach gezahnt:

var. Kosinsciana Besser

1. mornica Borbas

var. laeta mili. ${ }^{1}$ )

Diagnosen:

1. Var. macrantha: Blättchen mittelgross bis sehr gross, mit offener, hin und wiederdopuelter Zahnung: Blattstiele flammig behatart; Neben-

1) Laetus, fröhlich, wegen der hellpurpurnen Blütenfarbe. 
blïter untersits flaumig. Laubliatter bisweilen an Nittelnery behatrt. Kelchbecher linglich oval. Griffel etwas behart.

2. Var. dryadea: Strauch mit kräftigen, am Grunde verbreiterten

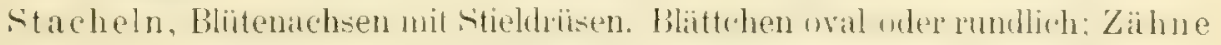
tief, z. T. einfach, vorherrschend doppelt. Blütenstiele kurz, stiel-

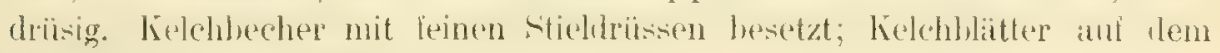
Rücken drüsig. Griffel behaart.

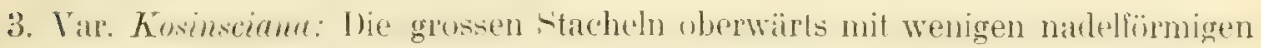
vermischt. Blätlchen breit, rundlich elliptisch; Zähne tief, scharf zugespitzt. Blätenstiele mil stiedrüsen mul ctachelhorsten. Kelchblätter auf dem Rücken reichlich mit Stieldrüsen besetzt. Griffel wollig behaart.

4. F. morarica. Blütenachsen reichlich mit Drisen und Nadelborsten besetzt. Blättchen schmäler, die untersten mit vereinzelten Subfoliardrüsen. Blïtenstiele lang und reichlich mit solchen besetzt.

5. Var. laeta: Strauch $1 \frac{1 / 2}{2}$ hoch kletternd, mit schlaffen Asten. Die grossen Stacheln schmal und leicht gebogen, an den Blïtenzweigen sehr reichlich mit Nadeln und Drüsenborsten gemischt. Blätchen sehw gross, elliptisch. meist zugespitzt, mit flammigen Blattstielen; sehr reich mehrfach gezahnt, die grösseren Zïhne nicht tief, sondern bogig ausgerandet: Mittelnex stark drüsig, auch auf den Seitemerven einzelne subfoliardrïsen. Blïtenstiele lang, wenig drüsig, desgleichen Kelchbecher und Kelchblattrücken ohne Drüsen. Corollen wenig klemer als bei der echten R. gallica, lebhaft purpurn. Griffel haarig. Selten Scheinfrichte ansetzend, diese immer steril. ${ }^{1}$ )

\section{Standorte:}

Ad 1. Krammetsberg b. Neuburg a. D. (Erdner zwischen den Eltern!) ${ }^{2}$ )

Ad 2. Erdfall b. Pfahldorf (Plattenkalk $520 \mathrm{~m}$ - zwischen den Eiltern)

Ad 3. Waldrand nahe Hieting b. Wellheim (unterer Nalm $420 \mathrm{~m}$ - Nähe (der Eltern $)^{3}$ )

1) Diese Rose gehört in die Nähe der var. protea (Ripart) Crep. Crépin hielt sie, bevor er ihre gänzliche Sterilität beachtete, für eine blosse Varietät von $\mathbf{R}$. gallica, so sehr ähnelt sie dieser letzteren. Ich habe 1906 auch die Pollenkörner von X var. laeta $\mathrm{m}$. untersucht: sie sind über $70 \%$ rudimentär.

Frutex altitudinis fere $1^{1 / 2} \mathrm{~m}$; scandens ramis laxis. Aculei magni angusti et leviter inflexi, quibus in ramis florigeris plurimae setae glandulaeque stipitatae admiscentur. Foliola maxima, elliptica, plerumque acuminata; petiolis plumosis; plurimis denticulis secundaris et tertiariis serrata, dentibus primariis non argutis sed in arcus sinuatis; nervo mediano multis, collateralibus aliquot glandulis hispidis. Pedicelli longi, subhispidi; tubi calicum et terga glandularum expertia. Petala R. gallica vera paullo inferiora, laete purpurea. Styli pilosi. Receptacula rara, nunquam fructifera.

2) Die Rose dieses Fundortes ist etwas weniger behaart und etwas stårker gezahnt, als die Diagnose erlaubt. Die Blättchen zeigen gewöhnlich an der obern Hälfte des Blättchens ganz einfache Zahnung, an der untern meist 1, sogar öfter 2 Nebenzähnchen. Es ist also die Uberleitung zum Formenkreis b) gegeben.

3) Die vorliegende Rose ist auf dem Iücken der Kelchblätter ziemlich schwach bedrüst, sonst entspricht sie der var. Kos. - Hier sei gleich angelügt, dass Borbas (Primit. monogr. ros. 


\section{Zitzelsheim b. Neuburg (Erdner!)}

\section{Bertoldsheim}

Ad \&. Rieder Gemeindewald b. Neuburg a. D. (Erdner!)

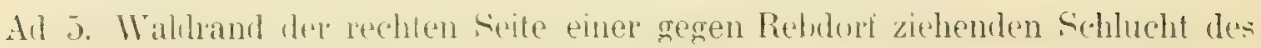
Frauenbergs b. E. (Plattenkalk $520 \mathrm{~m}$ ).

Mehr wie je zuvor kommt einem bei der Sortierung der hierher gehörigen

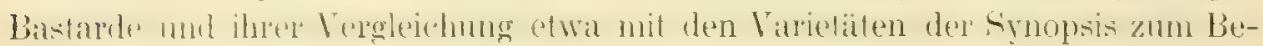

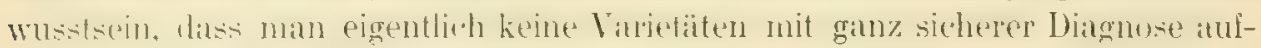
stellen kann. Jeder Autor hat sein vorliegendes Individum mehr oder minder individnell beschrieben. Zwei sn tomenreiche Rosen (man denke an L. eanina!)

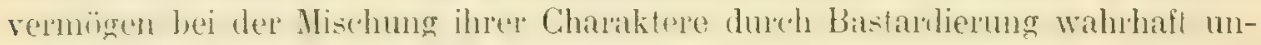
endlich viele lombinationern hervorzubringen. Es ist gar nicht wahrselednlich, dass sich eine grössere Reihe von Individuen finde, die in genügend vielen Merkmalen ühereinslimmen, sulass man sir in eime hategorie (Varielat. Form) zusammenstellen kann. Dazı kommt, dass an einem und demselben Zweige, einem und demselben Blatte Eigenschaften der zwei Eltern auftreten (die Blätter sind z. B. an der oberen Hälfte einfach gezahnt, an der unteren 2 bis 3 fach). Auch wird durch die oberflächliche Sortierung nach Varietäten die Erkemutnis kitum gefordert. inwicweit ein Bastart ein Compustum zweier Arten

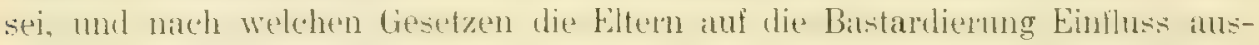
üben. Ich will deswegen auch hier wieder versuchen, an vier mir am besten hebannten Bastarden canina ২ Gallica die Eigensehalten nach den Eltern auseinamble zu suchen, ähnlich wie es uhen bezïglich arvensis $\lambda$ gallica gesthah. Ich tue das ausschliesslich auf Grund der Untersuchung der mir in natura bekannten und im Herbar vorliegenden Individuen; auf andere derselben Varietiten wird die Beschreibung höchstens entfernt passen.

Var. macrantha R. Kell.

R. canina

\section{Achsen:}

Blättchen: Grösse, Zahnung + Bliiten:

\section{Stiel: Länge +}

Krone:

Kelch: Kahlheit d. Kelches u. d.

K.blattrïcken
R. gallica

Wuchs +, Gestalt der Stacheln-, Heterakanthie -

Gestalt, Adernetz, Befläumelung

Drïisigkeit

Farbe - Grösse -

\section{Griffel:}

$\mathrm{R}$. canina Kreis Uniserratae $\times \mathrm{R}$. gallica var. austriaca $\mathrm{H} . \mathrm{Br}$.

p. 405) von einer R. Waitziana var. Kosinsciana Bess. spricht, die er ,e Suevia boica (Bertolzheim)“ im Herb. Richteri gesehen habe. Es handelt sich offenbar un Bertoldsheim b. Neuburg und den Sammler Graf Du Moulin. Auf die Autorität von Borbas hin ist also unter 3, auch Bertoldsheim als Fundort anzureihen. 
Var. dryadea Rip.

Achsen: Wuchs, Form der grossen Ieterakanthie -

Stacheln

Blättchen: Grösse, Gestalt $\mid$ Adernetz, Befläumelung

Blïten: Zahnung

Stiel: Länge

Krone: (nicht beobachtet)

Kelch: Form u. Kahlheit d. Kelchs Griffel:

\section{Drüsigkeit -}

Drüsigkeit der Kelchblattrücken

R. canina Kreis Transitorine $>\times R$. gallica var. pumila $\mathrm{H}$. Br.

Var. Kosinsciane Bess.

Achsen:

Blättchen: Form der Zähne

Bliiten:

Stiel:

Krone:

Kelch: Becher kahl

Griffel:

Wuchs, Form d. gross. Stach., HeterakanthieGrösse - u. Form d. Blittchen, Adernetz, Befläumelung, Drüsen

Bedrüsung, Länge -

Grösse -, Farbe -

Kelchblattrücken drüsig -

R. canina var. eriostyla Borb. $X<R$, gallica var. pumila H. Br.

Vir. laeta $m$.

Achsen: Höhe d. Strauches

Blittchen:

Blüten:

Stiel: Drüsenmangel +

Krone:

Kelch: Kahlheit von Kelch und Kelchblattriicken

Griffel:

Schlaffer Wuchs, Form d. gross. Stacheln Heterakanthie

Grösse und Gestalt d. Blättchen, Adernetz, Form der Zähne, Drüsigkeit

Länge -

Grösse -, Farbe

Form und Behaarung

R. can. var. eriostyla Borb. $X<R$. gall. var. elata Chr.

Die Eltern der vier besmochenen Bastarde werlen nach den Eigenschaften nur mit einer gewissen Wahrscheinlichkeil vernutet: buss bei der a var. aryadea stehen sie mit Sicherheit fest, da ihre Formen, zwirchen welchen der Bitstard wächst, seinerzeit hestimmt wurden. Bei ¿ der obigen Hybriden präponderiert die R. gallica, bei 1 die R. canina. Unter den einzelnen Eigenschaften setzte stets durch die R. g. ihre Heterakanthie, das starme Adernetz und die bleiche Farbe der Blattuntersegite, die Farbe und Grösse deer lirone; die li. e. lediglich die Kahlheit (Drïsenfreiheit) der Kelchbecher. Vorwiegend (in 3 Fällen unter f́) stamnte von der $\mathrm{R}$. g. die Befliumelung und diestalt der Blittrhen, die Be-

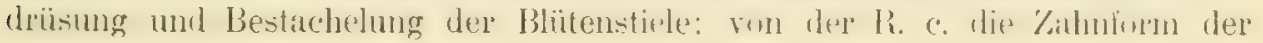


13]ittchen. Inerakanthie, Farbe und Givise der lirone zeigten sich stets durch den Einfluss der R. c. etwas beeinträchtigt; die Länge der Stiele war stets geringer als bei der reinen K. g. The ïbrigen Eigenschalten schwankten je nach dem Bastard hin und her. Die Sterilitit war in allen von mir beobachteten Fïllen vollstiundig, d. h. es wurden gar keine reifen Nüsschen gebildet. Im fimsien und fimzen zeigle sich dir li. gallicea gerchlechtlich stärter als die R. canina.

\section{R. cruina L. X.Tundzillii Besser.}

Dicser Bastard wird demjenigen zwischen der R. canina und gatlica ähnlich soin. sich jednch unterscheden duch geringere his fehlende Ileterakanthie, durch stirkere und stärker gekrïmmte stuchelu, durch schwïcher hedriste

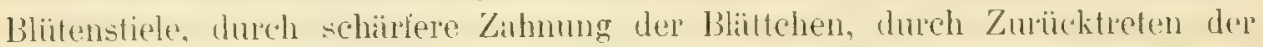
Drüsen an Blätren und lielchlechern, durch etwas geringere Sterilitit, dem die R. Jundzillii ist an sich schon der canina viel näher verwandt als die gallica.

Im Folgenden beschreibe ich kurz den Bastard von dem zuerst zu

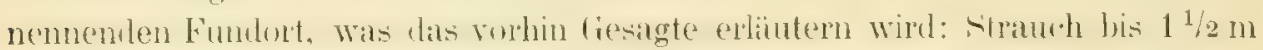
hoch: Ftacheln derb uml hakig gekrïmmt. Inïrenborsten sehr seltem. The rejehlich mittedgrusien Blätehen breit wal bis länglich oral: kurz zugespitzt: Zahmung hïulig oben xinfach, unten zusammengrsedzt. Zaihne scharl: herrortretendes

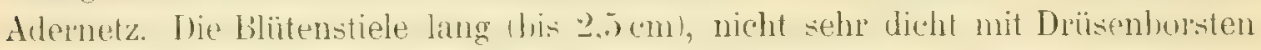
ohne Stacheln besetzt. Kronen sehr gross (bis $8 \mathrm{~cm}$ im Durchmesser), hell pupurn getirlot. Kelchrïcken mit Stichdritsen besetzt. Griffel etwis hervorrugxond, borstig. Sicheinfriichte kihl, von der Form derjenigen der R. Jundzillii mit bald abtailigen, zurïckgeschlagenen kelchzipleh; werden metist reichlich angesetzt und reifen auch, enthalten aber nur 1-4 Nïsschen oder sind ganz leer. - Die Rose des zweiten Fundorts stimmt gut mit der des ersten überein. Die Eltern kommen an beiden Orten vor.

Standorte: Nordostseite des Kernbergs b. Arnsberg (Dolomit $480 \mathrm{~m})^{1}$ ) Inchinger Berg (Dolomit $460 \mathrm{~m}$, Dorr!) ${ }^{2}$ )

Wahrscheinliche Formel:

R. canina var. syntrichustyla H. Br. $X<$ Jundzillii var. typica R. Kell. f. typica Chr.

\section{R. canina $L . \times$ rubiginosa $\left.L .^{3}\right)$}

Dieser Bastard ist meines Wissens aus Deutschland noch nicht beschrieben. Um einen Bastard handelt es sich bei der von mir beschriebenen Rose: die

1) Am angegebenen Platze stehen 2 Sträucher dieser Rose. Sie gewähren zur Blïtezeit mit ihrer Unzahl riesiger, tiefroter Blïten einen herrlichen Anblick, ziehen freilich auch eine Unzahl rïuberischer Insekten an. Das ist die schönste wilde Rose, die ich kenne. Ihre Nüsschen kommen mit etwa $10 \%$ nach meinen Versuchen zur Keimung.

-) Dieser Bastard hat weniger grosse Kronen; die langen Blütenstiele zeigen sehr selten ein Drüschen; die Blättchen sind etwas reicher gezahnt.

3) Eine vorläufige Mitteilung über diesen und andere nach meiner Ansicht noch nicht bescluriebene Bastarde des Gebietes erschien $1907 \mathrm{im} \mathrm{Xl.} \mathrm{Bd.} \mathrm{der} \mathrm{„Berichte} \mathrm{bayr.} \mathrm{bot.} \mathrm{Ges."} \mathrm{unter}$ dem Titel: „Uber einige für Bayern neue Rosenarten und mehrere überhaupt neue Artbastarde von Rosen" S. 170 f?. 
allermeisten Sicheinfrichte entwickeln sich gar nicht, sombern fallen natch dre Bliite bald ab: dor Rest ist laub oder enthailt nur 1 -2) Niisschen. Irh habe sie eine Reihe von Jahren in Freien beobachtel und auch Copin mehronats vorgelegt.

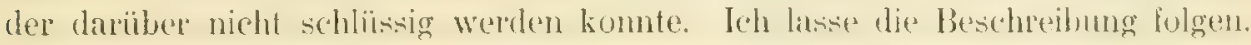

Wuchs niedrig. Strath kompakt; etwas heterakinth: hakige, grosse Stareheln sind mit kleinen naldeörmigen, meist drïsenlusen Bursten gemischt, am deutlichston

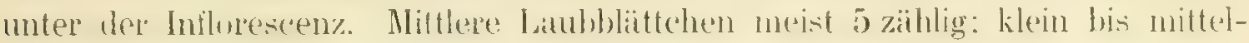
gross, von der rundlichen form der li. rubiginosa, in den sitiel breit abgermolet; nur auf dem Miltelnerv und dem Blattstiel bedriist und auf dem letzteren be-

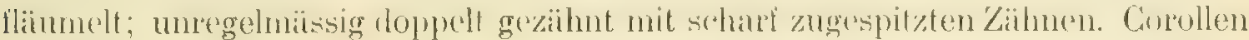
klein bis mittelgross wie bei der R. canina, aber lebhalt rosa gefïrbt. Blüten-

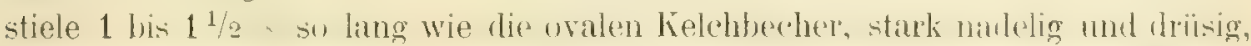
desgleichen die Basis der Scheinfrühte. Kolchblitter goliendert, an der Frucht

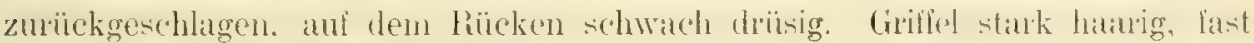
wollig; etwas hervorragend.

Ausser der R. rub. könnte noch die gallica oder Jundzillii in Fragc kommen, das scheint mir jeduch anseschlossen durch die geringe Betonung des Ader-

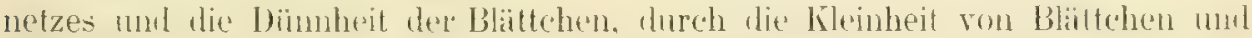

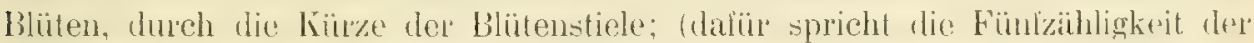
Laubbliiter und die dentliche Heterakanthie). Wahrscheinliche Formel:

R. canina Kreis Uniserratae $X$ rubiginosa var. umbellata Chr.

Standort: Mehrere Sträucher in Mittelhöhe der Wolfsdrossel b. E., rechter Abhang (Dolomil $460 \mathrm{~m}$. Rosen der Rubiginosa- und Caninagruppen kommen hier in Menge vor; gallica und Jundzillii fehlen).

\section{R. Alumetorum Thuillier $\times$ gallica $L$.}

Diesem zienlich hähfigen baskarl entsprechen folgende allgemeine Eigenschatten: Ltatcheln meist zweifach, die grösceren gebugen his hakenfürmig, die kleineren gerarle, brstenfümig. Blätchen mittelguss lis guss, star, volwiegend rundlich oval; meist einfach gezahnt; oberseits kahl oder sehwach behaart, unterseits samt dem Blattstiel dichter; Corollen gross; Blïtenstiele bis $4 X$ so lang wie die Kelchbecher, bedrüst; Griffel behaart.

$$
\text { Ubersicht der i. G. k. Formen: }{ }^{1} \text { ) }
$$

a) Blättchen einfach gezahnt:

var. collina (Jacquin) $R$. Keller

1. vineticola $H$. Braun

var. Boreykiana (Besser) $R$. Keller

1. grandiflora mihi $\left.i^{2}\right)$

1) Ich teile in erster Linie ein nach der Bezahnung, in zweiter nach der Behaarung der Blättchen; auf den Grad der Heterakanthie lege ich in diesem Fall weniger Gewicht.

2) Grandiflorus, grossblütig. 
b) Blättchen unregelmässig doppelt gezahnt:

var. alba $R$. Keller

c) Blïttchen zwei- und mehrlach gezahnt:

var. interposita $R$. Keller.

\section{Diagnosen:}

1. Var. collina: Strauch sehwach heterakanth. Blättchen meist breit oval, oberseits kahl, unterseits nur an den Nerven behaart, selten an der Fliche llanmig. Blïtensticle und Rücken der kelchblitter bedrüst, oft schwach. Blüten rosenrot. Griffel wollig.

2. F. vineticala: Doppelte Bezahnung der Blältchen ölter eingestreut.

3. Var. Boreyliana: Strauch stark heterakanth. Blattchen oberseits anliegend, unten stark, an den Nerven wie am Blatistiel oft filzig behaart. Bliitenstiele driisig und weichstachelig, desgleichen \pm die Kelchbecher; auch Rücken der Kelchblätter stark drüsig.

4. F. grandiflora: Fast einfich hestachelt. Blättchen und Blülen gruss, letztere ron der Grösse der R. gallica. ${ }^{1}$ )

5. Var. alba: Der var. Boreyk. nahe stehend, aber: Bestachelung kaum heterakanth; Stacheln sehwach, nur gebogen. Blittchen grosi bis mittelgross; rundlich elliptisch bis fast kreisrund, in den Stiel abgerundet; Zahnung meist unregelmässig doppelt; Unterseite und Stiel behaart. Blütenstiple verlingurt, wie Kelchblattricken und helchbecher borstig und doüsig. Blumenblätter weiss. Ganz steril.

6. Var. interposita: Blättchen mittelgross, rundlich oval und in den Stiel abgerundet; mit abstehenden Zühnen und aussen 1-3 Drüsenzähnchen, zuweilen ohne solche; oben kahl oder zerstreut, unten auf die Nerven locker hehaurt, am Rinde gewimpert. Blïtenstiele lang, reich driisig. Griffel hehant, kurz säulenförmig.

\section{Stand orte:}

Arl 1. Eingang des Spindeltals b. Wellheim, rechts (unt. Malm $430 \mathrm{~m})^{2}$ ) Burgwald b. Neuburg a. D. (Erdner!)

Aı 2. Hecke beim Saliter nỉchst Neuburg a. D. (Erdner!)

Ad 3. Mehrlach an Dolomitfelsen ob der Brunnmühle b. Walting a. A. (Dorr!)

Ad 4. Bei Isenbrunn a. A. (mittl. Malm 420 m, Dorr!)

Ad 5. Verwildert am Adamsberg b. E. (Dolomit $480 \mathrm{~m})^{3}$ )

Ad 6. Zweimal zw. Ellenbrunn u. Gammersfeld b. Wellheim (Malm, Erdner!)

1) Aculei paene uniformes. Foliola atque petala grandia; haec magnitudinem in R. gallica aequant.

2) Die Form von Crépin bestäligt, No. 3 (Walting) und 4 wenigstens als dumetorum $X$ gallica von ihm anerkannt. Die $\mathrm{R}$. alba vom Adamsberg wurde als solche von ihm bestimmt.

3) Diese Rose blüht teils einfach teils halbgefüllt. 
Im Nachfolgenden will ich wiederum bei 5 Fornen nach den mir in natu'a vorliegenden Exemplaren die Eigenschaften ausscheiden:

Var. collina R. Kell.

\section{R. dumetorum}

Achsen: Form der gross. Stacheln Blättchen: Grösse, Form, Bezahn., Blüten: Zahnform, Behaarung

Stiel: Länge -

Krone:

Kelch: Drüsenmangel

Griffel:
R. gallica

Wuchs -, Heterakanthie -

Adernetz

$$
\begin{aligned}
& \text { Bedrüsung } \\
& \text { Grösse -, Farbe- } \\
& \text { Form - } \\
& \text { Länge, Behaarung }
\end{aligned}
$$

R. dumetorum var. platyphylla Chr. $X$ gallica var. haplodonta Borb. (?)

Var. Boreytiana R. Kell.

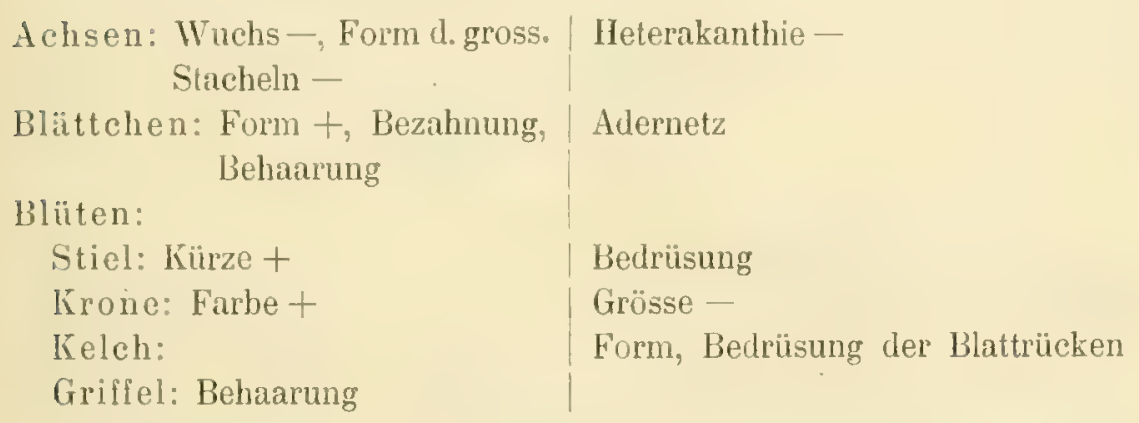

R. dumetorum var. 'Thuillieri Chr. $\times$ gallica var. punila $\mathrm{H} . \mathrm{Br}$.

F. grandiftora $m$.

Achsen: Wuchs, Mangel d. Heter- | Form d. Stacheln akanthie

Blättchen: Form +, Bezahnung, | Grösse, Adernetz Zahnform, Behaarung

Blïten:

Stiel:

Krone:

Kelch: Form +, Befiederung, Mangel an Drüsen der Blätter

Griffel:

Länge -, Bedrüsung -

Grösse, Farbe

R. dumetorum var. comata $\mathrm{m}$. $\times$ gallica var. austriaca $\mathrm{H}$. Br. 
Var. alba R. Kell.

Achsen: Wuchs, Mangel d. Heterakanthie

Blättchen: Behaarung

Bliiten:

Stiel:

Krone: Farbe

Kelch:

Griffel:

\section{Form der Stacheln}

Form, Grösse, Zahnung -, Zahnform, Adernetz

\author{
Länge -, Bedrïsung \\ Grösse - \\ Fiederung, Blattrïckenbedrüsün, Becher- \\ bedrïsung \\ Länge, Behaarung
}

R. dumetorum cf. var. Thuill. Chr. $x<$ gallica.

Var. interposita $R$. Kell.

Achsen: Wuchs-, Bestachelung + Blïtchen: Grösse, Beharmg Blüten :

Stiel:

Krone:

Kelch: Befiederung

Griffel:
Form d. grossen Stacheln +

Grad d. Zühnelung , Form -, Adernetz

Länge - , Bedrüsung

beobachtet

Bedrüsung d. Blattrücken -

Lỉnge, Behaarung

R. dumetorum var. hirtifolia $\mathrm{H} . \mathrm{Br} . X<$ gallica var, pumila $\mathrm{H}$. Br.

Ich brauche wohl nicht anzufïgen, dass die Angabe der vermutlichen Eltern lediglich auf Schätzung beruht. Nur bei No. 3 dürfte die var. pumila von R. gall. nicht zu bezweifeln sein, da sie ummittelbar neben dem Bastard wächst. In allen fünf analysierten Fällen überwiegt der Typus der R. g. in den Blïten, in der Mehrzahl der Fïlle jener der R. dum, in den Achsen und Blätchen. In allen Fiallen hat sich die R. g. behauptet durch das hervortretende Adernetz der Blattunterseite, die Bedrüsung der Blütenstiele und die Grösse der hrone; die R. dum. durch die Beharung der Blättchen. Meistens (千:1) weisen auf R.g. Lïnge und Behatarung der Griffel, auf R. dum. der höhere und krältigere Wuchs der Strüucher. Die ïbrigen Merkmale zeigen sich schwankend je nach dem Bastard oder sinl an jedem Bastard mentschieden ansgeprägt, bezw. gemildert durch den Einlluss des anderen kinmponenten. Das gilt besonders von der Grösse und Form der Blätthen, der Länge der Blïtenstiele, der Form der Brakteen, Farbe der Krone und der Heterakanthie der Achsen.

\section{R. Aumetorum Thuillier $\times$ Inudzillii Besser.}

Von der Hybride dumetorum $X$ gallica wird sich diese voraussichtlich untelscherden lureh mangehule chler ganz geringe Heterakanthie, ïherhaupt geringe Bedlüsung der Blïtchen, Iblitenstiele und Kelchhlätter: durch weniger Jange Blïtenstiele; stärkere Slarheln. K. Keller tïhrt dum. $X$ Jundz. in der 
Synopsis nicht auf. Die von nir unten beschriebenen zwei Exemplare sind sicher Bastarde, bei beiden wurden Früchte gar nicht beobachtet. Ihr Gesamtaussehen sowie die Nachbarschaft der Eltern verweisen sie hierher. Demungeachtet will ich nicht mit voller Sicherheit auf obiger Erklïrung bestehen. Standorte: Dolonitfelsricken des neuen Wegs b. E. ('470 m neben R. Jundzillii Bess. f. latifolia Chr.)

Feldrain b. Hessellohe, Neuburg a. D. (zwischen R. Jundz. var. typ. R. Kell. f. typica Chr., Erdner!)

Beschreibung der ersten Pilanze: Niedriges Sträuchlein ohne Heterakanthie; Stacheln gebogen, schwach. Blittchen mittelgross, hreit oval, in den Sitiel verschmïlert; umregelmässig doppelt gezahnt; Adernetz hervortretend; oben zerstrent, unten aul der Fliche schwach, an den Nerven stäker behatis, am Rand gewimpert; Blattstiel behaart. Blütenstiole 1 bis $1^{1 / 2} \times$ so ling wie die ovalen Kelchbecher; nur mit vereinzelten Drïsen und Borsten besetzt. Aussere Kelchblitter lang und stark gefiedert, auf dem Riicken drisenlıs. Griffel schwach behaart. Krone lebhaft rosa.

Die Rose Erdners hat Zwergwuchs; schnülere Blätchen mit rowas stäkerer Beharung und fast rein doppelt gezahnl; Bliilenstiele schwach drïsig; Blïten blass. Ich war geneigt, sie fïr eine reine dnmetorum var. caesia (Baker) R. Kell. zu halten, so sehr hat sie das Aussehen einer dımetorum. Mein Exemplar hat den Habitus einer schwächlichen Jundzillii.

\section{I. dumetom Thuillien $\times$ tomentosn Smith.}

Dieser Bastard ist ehenfalls noch nicht beschrieben. Obwohl die Sterilität der vorliegenden Rose nicht lange genug beubachtet werden konnte - der Sitrauch wurde später nicht mehr aufgefunden —, stehe ich wegen der wunderhaten Mischung der Chamaktere und des Schwankens der Eigenschaften sogar nach einzelnen Zweigen und Blüten nicht an, die Ruse hieher zur rechnen. Standort: Bei Isenbrunn i. Altmühltal (Dorr!)

Beschreibung: Strauch mittelhoch, mit einerlei Stacheln; diese je nach lor Gröse gehogen his gekrümmt, jednch dïnn. Blittchen mittelgross bis gross (his $i^{1}{ }^{2}$ cm lang $u m$ l 3 breit), breit oval, meist kurz in den Stiel verschmälert; unregumässig gezähnt, die oheren gewöhnlich einlach, die unteren mit Nebenzïhnchen, manche Blätter auch ganz mit sinfach gezähnten Blittchen; when dicht anliengend, unten filzig behaart, Blattstiel filzig; whe Subfoliardrïsen. Blütenstiele

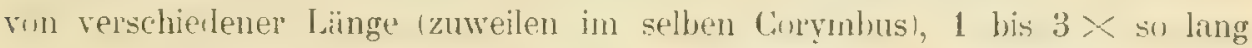
wie die Kelchbecher, hald reich bedrïst mul hestachelt, bald armdrüsig, bald kahl. Der Kelchbecher an Grunde öfter driisig: lielchblattrïcken meist reich besluis, Relchziptel an Rande sehr reich gezahnt und bedrist. Kronen rosa, mittelgross. Griffel schwach behaart.

Ich halte diese Rose fïr

$\mathrm{R}$. dumetorum var. comata $\mathrm{m}$. $\times$ tomentosa var. subglobosa Carion. 


\section{R. Anmetovm Thallier $\times$ micrantha Smith.}

Auch dieser Bastard wird hier zum erstenmal beschrieben. Ich fand ihn an Waldrand gegeniiber dem Torlstatel der Feldmiihle b. Wellheim (auf Dulomitboden).

Beschreihung: Hoher, schr flittriger Stranch. Einerlei Stacheln: diese hakig gekriummt, krättig. Blittchen mittelgross, elliptisch, an beiden Enden zugespitzt: ungleich doppelt bis dreilach gezahnt, aber auch manche einfache Zähnchen: oben angedrïckt, unten fast filzig hehatert, desgleichen dite Blattstiele; diese stark drüsig, die Blattunterseite ungleich drïsig, indem dit muristen Blätlchen die vielen Drüsen einer micranthat zeigen. manche aber auch schwach hedriist sind. Blïtensliele ungleich lang (1 bis $1 \frac{1}{2} \times$ die seht langgestreckten Kelchbecher), in miltlerem (irade hrüsig und borstig. Kelchblätter in lange bedrüste Zipfel ausgezogen und gefiedert; anf dem Rücken sehr schwarh drisigg; an der angesetzten Frucht straff zurickgeschlagen. Kronen nicht hoobachtet. Griffel genau wie bei R. micr: ein kahles dünnes Säulchen. Die Früchte alle steril und bald abfillig.

Das Aussehen med die meisten Eigentiumlichkeiten sind die einer R. mich. Abrr durch welche andere Rose sind die Nodifikationen eingetreten? Es kann nur eine stark behatarte in Frage kommen, da die Behaarung der bibittchen die einer micr. weit überschreitet. Tomentosa ist zu verwerfen, weil die Bedriisung der Blïtenstiele und Kelche sine stirkere, die Länge der Blïtensticle bedeutender und die Form der Stacheln eine andere sein müsste. Coriifolia komnt in der Gegend nicht vor und liesse strammeren Wuchs, liüzere Blïtrnstiele, stirlkere Brakteen und andere Griffel erwarten. Dagegen trelfen wir im Sichuttertal natirlich verschiedene Formen der $R$, dumetormm und $R$. micrantha var. typica Chr. und permixta Borb.

Wahrscheinliche Formel:

R. dumetorum var. trichoneura Chr. $X<$ micrantha var. typica Chr.

\section{I. gallica L. $\times$ glaned Villars.}

Ton dieser Hyhride sind regehnäsig folgende Eigenschaften zui erwarten: Heterakanthie, die grösseren Stacheln hakigg gekrümmt: Blätchen mittelgrusio lis sehr gross: eilönnig bis rundich eibunig: mit hervortretendem ddernetz; Bliitenstiele verkiirzt, drisig; lironen gross, lebhaft hellpurpurn; Kelchzipfel abstehend; Griffel ein wolliges Köpfchen bildend.

Das vorliegende Exemplar zeigt folgende Eigenschatten: Mittelhoher Wuchs: mïssige Heterakanthie, indem hesonders unter der Inflorescenz Borsten eingemischt sinul; die grossen Stacheln stark hakig gekrümmt. Blättehen mittelgross his gross, eiformig bis rundlich eilörnig, die grossen Blittchen in den Blattstiel ahgerundet: letzterer flïunlich; Blättchen etwas unrogelmäissig mehrfach gezahnt, die Zïhne von der Form der li. glauca. Blütenstiele ziemlich kurz, durchschnittlich von der Lïnge der vvizlen Scheinfrïchte: mit stieldrüsen und Stachelchen hesetzt. Kronen über Mittelgrösse, alle lebhaft hellpurpurn. 
lielchzipfel nach der blüte meist abstehend, nicht zurüekgeschlag(n, an der Scheinfrucht lange bleibend; lekchblattrïcken bedrüst. Griffel ein wolliges, etwas hervorragendes hïptchen bildend. Scheinfrichte zahlecich angexpet, aber höchstens \& Nüsschen enthaltend. ${ }^{1}$ Der Bastard deckt sich ungefaihn mit $X$ var. myriodonta Schulze.

Sein Standort ist: eine lange IIeckenreihe an rechten Ausgang des Herrengrundes b. E. (Lehm auf unterem Malm, $410 \mathrm{~m}$ ).

\section{R. glauch Villu's $\times$.Jumlallii Besser.}

Wenn man meinen Ausführungen zustimmt, ist auch dieser Bastard neu d. h. nuch unbeschrieben. Crépin, dem die Pllanze des unten gekennzeichneten Fundortes vorlag, hielt meine Dentung für möglich, aber auch canna $X$ Jundzillii nicht für ausgeschlossen.

Strauch ziemlich niedrig, aber krïtig und gedrungen; iiber eine gröiscere Bodensirecke durch Ausliuler verbreitet. Stacheln stark gebogen bis hakig gekrümm, sehr selten eine gerale Borste zeigend also zuweilen Heterakanthie bemerkbar. Bliittchen mittelgross, oval bis breit oval, in den stiel meist abgerundet; doppelt gezïhnt, in den unteren Partien der Zweige reichlicher als in den obern, Zühne scharf und tief, mit scharior Spitze: Allernetz hervortretend: Blattstiele drüsig, slachelig und fläumlich: Blütensticle verschiculen lang: $1 / 2-21 / 2 \times$ so lang wie die Kelchbecher; nur sehr selten ein einzelnes Drüschen vorhanden; Brakteen meist stark entwickelt und so lang wit die Blitenstiele. Kronen mittelgross, lebhatt rosa, sehr wohlriechend. Kelchbïtter nach der Blüte gewähnlivh abstehend, auf den Rücken unbulruist. Griffelköpfehen stark wollig. Scheinfrïchte von der Form ler R. Jundzillii; zwar häulig angesetzt, aber dir meisten bald abfillig, die bleibenden nit 1-2 Niisschen.

Standort: Nordostseite des Kernbergs bei Arnsberg (Dolomit $450 \mathrm{~m}$ ).

Wahrscheinliche Formel:

R. glauca var. complicata Gren. X Jundzillii var, typica R. Kell.

\section{I. glauca Vill. $\times$ tomentosa Smith.}

In einer Schlucht des Schelmenbergs b. E. beobachte ich seit Jahren eine Iose, ibber deren Charakter ich nicht ins Reine kommen kann. In manchem Jahr setzt sie gar keine oder nur sterile Scheinfrüchte an, in anderen - z. B. 190 f - werden ziemlich viele Friichle gebililet, die bis 12 Nüsschen enthalten.

1) Das Aussehen dieser Rose entspricht dem der R. Jundzillii, sodass Crépin zuerst, als ihı Exemplare ohne Früclıte vorlasen, sie als helerakanthe R. Jundzillii bestimnte; nur the hakigen stacheln gefielen ihm nicht. Als er Frïchte sah, fïllte er die Diaçnose canina $X$ wallica. Irh glaube jedoch oben die Bestimmung gallica $X$ glauca serechtfertigt zu haben. Die stammellern stehen zwar nicht in nächster Nähe, wachsen aber bei Eichstätt hüufig bis gemein. Ich könnte höchstens noch glauca $\times$ Jundzillii einigermaassen gelten lassen. 


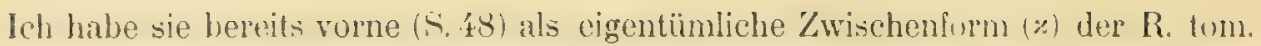
var. cristata Chr. erwihnt. Denn die meisten Eigenschaften hat sie von dieser Varietiat, bloss sind die Kelchbecher und heheinfriichte rein kugelig, whe Drüsen: die Blïtenstiele $2 \times$ so lang wie die Kelchbecher, gewöhnlich tragen nur die Stiele der mittleren Frucht eines Corymbus Drüsen und Stachelchen. Die Sekundiurzïhne der Blatträuder sind aufallend seicht, während die Hauptzähne sehr tief eingreiten. Bei der sturken Entwicklung der Hochbliiter, der Subpersistenz der Kelehziplel, der Wolligkeit der Griffelköplehen wïrde ich lür deu genannten Batart stimmen, falls die Hybridilat zugegeben werden hömte.

\section{R. corifolin Fries $\times$ dumetomm Thuillier.}

Diese Rose zählt zu den interessantesten Bastarden, die ich im Gebiete cntdeckt habe. Die terilitit ist fast vollkommen, denn Frïchte werden äusser'st sclten angesetzt: die wenigen, welche ich im Verlat mehrerer Jihre heubathten komnte, enthalten 1-2 Nïsschen. Dabei musste man aber, ohne die Sterilitit zu kemnen, die Rose als eine typische corilfolia Fr. ansehen, so sehr stimmen ihre Eigenschaften mit dieser Art. ${ }^{1}$ )

Der Strauch zeigt untersetzten Wuchs $\left(1^{1 / 2} \mathrm{~m}\right)$; Stacheln von einerlei Beschaffenheit, duch diejenigen am Stamme mehr gekrimmt, die an den Zweigen fast gurde und schwach. Blittchen meist etwas unter Nittelgröise, elliptisch, an beiden Enden zugespitzt; einfach gezahnt, selten mit Nebenzähnchen; oberseits anliegend, unterseits auch auf der Flitche wie der Blattstiel licht behant. Blïtentiele kurz, in den breiten Hochblättern rersteckt. Kronen lebhalt rot, mittelgruss. Die reich gefiederten Kelchblïtter aufgerichtet, noch an der roten Scheinfrucht vorhanden. Griffelköpfchen wollig. Scheinfrüchte oval.

Standorte: Franenberg b. E. in der Nithe der Kanelle (Plattenkalk $510 \mathrm{~m}$ ).

Als zweiten Faktor kann man nach obigen Eigenschaften lediglich eine R. caniua, dumetorum oder glanca annehnen. Das letztere hätte Manches für sich, wenn fin unfruchtbarer bastard zwischen corilfolia uml glauca iblerhaupt denkbar wïre. Bei der starken Behatrung entsehied ich nich für Kreuzung mit einer einfach oder höchstens unregelmïssig doppelt gezahnten dumetorum, deren von curifolia abweichende Eigenschalten aber in rorliegendem falle fast gar nicht zur Geltung kommen, also etwa:

R. coriifolia Fr. var. typiea Chr. $>$, Alumetorum Thuill. var. solstitialis H. Br."2)

1) Crépin, dem auch dieser Bastard, aber ohne Früchte, vorlag, hat ihn einfach für R.corïfolia erklärt. Es handelt sich hier also um einen "falschen" oder "einseitigen" Bastard, wie deren auch für Rubus, Fragarja, Vitis, Oenothera u. a. nachgewiesen wurden (vergl. C. Fruwirth: Allgem. Züchtungslehre der landwirtsch. Kulturpflanzen, 2. Aufl. Berlin, 1905, S. 120).

2) Die var. solst. kommt auf dem Frauenberg in der Nähe des besprochenen Bastards vor; die var. typ. der coriff. ist bei E. nicht selten. - Das Durchschnittsbild durch die eben angeselzte Scheinfrucht meiner dum. $X$ coriif. spricht ebenfalls deutlich für die Beeinflussung einer coriff, durch canina oder dumetorum. 


\section{Sectio Cinnamomeae DC.}

\section{R. cinnamomen $L_{0} \times$ gallica $L_{0}$ (:) \\ (R. turbinate Aiton)}

Diese früher håufig kultivierte Rose, die Frankfurter Rose, wächst auf einer Strassenstiitzmaner nehen der Buchtalziegelei Eichstatt in zahlreichen Strüuchern verwildert, weswegen sie als Bestanteil der Juraflont hier angelührt wird. Crépin und nach ihm auch R. Keller (Syn, 6,1 S. 52) halten sie für einen Bastard der gallica mit der comnamonea, won die Mopholugite recht gut stimml. Ich finde jedoch auflitlig. dats sie, Wenigstens b. E., nach meinen genauen Beobachtungen so spät blüht. II ihremd die übrigen Batsarde ziemlich deutlich die mittlere Zeit zwischen den respektiven I)aten ihrer Eltern einhalten oder noch etwas frïher sich entwickeln, bliht meine R. turb. ungelïhr 16 Tage nach der R. cinmamomea am gleichen Platze und allerdings 2 Tilge vor der. R. gallica an den entsprechenden Plitzen. Mit der letztem als Parens hat sie sicher zu tun; ob auch mit der erstern? Doch lassen wir die Entscheidung dahingestellt.

Beschreibung: Strauch hoch, heterakanth, stacheln spärlich, teils gerade teils gebogen, Bliitentriebe in der Regel whe Stacheln. Nebenblïtter der Bliitentriebe und Ilochblätter sehr verbeitert; die ovalen ${ }^{1}$ ) blïttchen einfach gesïgt, etwas lederig; oben kahl, unten aut den Mitteher'v behart, purpurn ${ }^{2}$ ). Blütenstiele stieldrïsig. Kéchblätler ungeteilt, nach dem Verblïhen aufrecht. Kelchbecher breit kreiselförmig. Die halbgefüllte Corolle lebhaft rot.

1) Als Beispiel der Ungenauigkeit, mit der die morphologischen Begriffe der Blatlform öfter auch in den besten Floren behandelt werden, diene, dass die Synopsis auf S. 52 von der R. turbinata schreibt: „Blättchen oval bis eiförmig" (sic!).

2) So die Synopsis. Meine Exemplare, die Crépin selbst als R. turbinata bestimmte, haben reicher behaarte etwas breite Blättchen; die Oberseite ist zerstreut flaumig, die stark graugrüne Unterseite anliegend, und die Nerven sind kurz aber dicht behaart. 


\section{TEIL:}

\section{Die Phylogenie der Rosen und die Vorbedingungen für die Erkenntnis ihres natürlichen Zusammenhanges.}

Wir haben im Vorausgehenden das System der Rosen unseres Bezirkes dureh Abwäigung und Kritik der äusseren, morphologischen, Eigenschatten aller heobachteten Formen gebildet. Die imeren, histulugischen, Verschiedenheiten kimen bloss beim Verhältnis der Arten und Sektionen zu einander einigermasisen in Betracht. Noch weniger Anhaltspunkte scheint zunichst die Erforschung der Physinlugie, Biologie und Okologie der Rosen für die Erkenntnis ihres systumitischen Zusammenhanges zu bieten. Aber dennoch müssen wir mit Benutzung aller gebotenen Hilfsmittel, unter denen das physiologische Experiment, der Zürch-

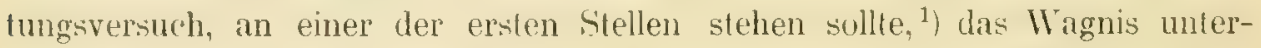
nehmen, uns auf eine höhere Stufe der Erkenntnis imnerhalb der Gattung Rosia zu erheben. Wie steht es mit der natürlichen Verwandschaft der im Bezirk beobachteten Formen und jener der Rosen überhaupt? Liisst sich eine sulche begrïnden und wie? Das endgiltige und allein berechtigte System der Rosen muss denn doch auf ihren genetischen Zusammenhang, ihre Deszenlenz, basiert werden. Man kam ja zweifeln, nb man das Prinzip der Deszendenz fïr den Gesamtbereich der Organismenwelt durchführen soll und darf. Aber soviel ist sicher: innerhalb unserer Gattung hosa gibt es eine solche unbeschreibliches Formentiille und eine solch unendliche Zahl ron Utbergangshildmengen, dass wir zwichen ihnen das Verhältnis von Lrache und Wirkung anerkennen müssen und damit die Nolwendigkeit, Formen von Formen abzuleiten, auch jeizige von trïheren und einheimische von fremden, europäische von asiatischen. So bleibt bei allen Schwierigkeiten, die sich in der Gegenwart noch gegen eine tiefore Frkenntnis aultïmen, unser Ideal: das phylogenetische System der Rosen. Dann (rhält anch die scheinbare Willkür der nach allen Seiten auseinander gehtnden

1) Kulturversuche bei Rosen in dem erforderlichen grossen Massstabe erheischen so lange Zeit und eine solche Arbeitslast, dass sie bis jetzt noch niemals zur Lösung von allgemeinen Abstammungsiragen angewendet wurden. Der Veriasser konnte leider auch nur verhältnismässig wenge Punkte experimentell prifen, sondern musste sich meist auf die gewissenhafte Beobachtung in der Natur und auf die kritische Verwertung der Literatur beschränken. 
Eigenschaften ihre Numen, weil sie zuriickgelührt werden auf kausile Einwirkungen der Naturkrailte vom aurstn und auf gesetzmässige Entwicklungen der lebenden Substanz von innen. Wir werden uns in diesem Teil zwar vorwiegend auf die Erfahrungen und Beobachungen innerhalb de's Bezirkes stïtzen, aller zur crewinnung vorn allgemeinen Re'sultaten auf die Rosen Bayerns, Eurupas und der ganzen nördlichen Halłkugel in unseren Deduktionen ühergreiten. Xur bitten wir den Leser zu bedenken, dass wir höchstens einige Bausteine zur Errichtung de's projektierten Gebäudes liefern künnen; dass es sich um einen Versuch handelt, und nicht un ein vollendetes Werk. Dazu wäre auch die Zeit noch nicht gekommen. 


\section{Erster Abschnitt:}

\section{Anpassung der Eigenschaften von Rosen an äussere Verhältnisse (Ökologie der Rosen). ${ }^{3}$ )}

Wir müssen als Grundsatz festhalten, dass jene (morphologischen und histolugis(hen) Eigenschaften der Pilanzen, welche festen Bestand selber haben und hiedurch auch den Bestand des Individums verbürgen, den äusseren Verhäitnissen angepasst sind, unter denen sie leben; überhaupt: dass die Eigenschitten der Lebewesen eine Art Spiegrelbild der ïusseren Faktoren darstellen, da jeder (rganismus in hamonicher Wechelbeziehung \%u Aussenwelt steht. Als solche Faktoren bezeichnet Schimper ${ }^{2}$ ) für die Pllanzenwelt: das Wasser, die Wiime, das Licht, die Lult, den Borlen, die Tiere; dem ist anzufügen: die Menschen. Diese Faktoren fassen wir gewöhnlich zusammen unter den Begriffen des lilimas und des Standortes, welche je nach dem Wechsel der Jahreszeiten und Jahre ihren Einfluss geltend machen.

\section{Kapitel: Das Wasser.}

Die Rosen sind Tropophyten, d. h. sie haben meist einen gemässigt hydrophilen vder mesophytischen Charakter während der Vegetationsperiode des sommers und einen xerophiten während der Zeit des Laubmangels im Winter. Natïrlich zeigt sich die Iydrophilie hauptsächlich an den Laubblïttern. Als hervorragendes lienuzeichen (les wasserliebenden Laubblattes führt Schimper ${ }^{3}$ ) die Iydathoden aul. Auffallenderweise enwähnt kein histologischer Autor, auch Pamentier nicht in den "Recherches sur le genre rosiel", solche bei der der Gattung Rosa. Sie fehlen aber keineswegs. Nach einer brieflichen Mitteilung von Hrn. Prof. Haberlandt in Graz fand er durch mein Ansuchen reranlasst bei funer grelegentlichen Durchmusterung junger Blätter der Gartenrose Maréchal Niel „auf der Oberseite der Blattzïhne Gruppen ron 8-12 Wasserspalten und darmnter kleinzelliges farbloses fipithengewebe." ${ }^{4}$ ) Da diese Rose als Teerose ein Abkömmling der subspec. R. fragrans Thory und damit der R. indica Lindley bezw. chinensis .Iacquin ist, ${ }^{5}$ ) wurde clanit wenigstens für letztere das Vorkommen von Hydathoden bewiesen. Seitden konnte ich sellost Wasserspalten auf und zwischen Blattzithnen bei R. canina, dumetomm, glauca, cinnumomea und pomifora konstatieren.

1) Vgl. W. Pfeffer: Pflanzenphysiologie. Leipzig Bd. I, 2. Aufl. 1897 S. 8.

2) A. F. W. Schimper: Pflanzengeographie auf physiologischer Grundlage. Jena 1898, S. 3 fi.

3) Ebd. S. 23.

4) Herr Prof. Haberlandt, dem auch an dieser Stelle bestens gedankt sei, in lit. Vgl. dessen "Physiologische Pflanzenanatomie", 2. Aufl., Leipzig 1896, S. 417 ff.: die Hydathoden.

5) Nach der Synopsis 6,1 S. 45 und P. Lambert: Katalog. Trier 1906 S. 19. 
Damit steht in Einklang das Ergebnis von Kulturversuchen, die ich mit R. polyentha hort. (R. indica Lindl. X multiflora Thunh.) und R. Wichurnianu hort. (R. multiflora Thunb. X Wichurae ('rep.) ${ }^{1}$ ) angestellt habe. Die Exemplare, welche bei einem Maximum von Fenchtigkeit in Luft und Buden liultur unter Giasglocke) erzogen worden waren, zeigten wider meine antingliche Erwartung verglichen mit den Kontrulexemplaren stets eine Vermehrung der Zïhno drs Blittrandes und der hier befindlichen Drïsen, aber auch jener der Blattnerven und der sipreite, während die Ausbildung der Drüsen und Stacheln fine mangelhalte wurle, die Bläter und Achsen etwas etiolierten und die Trubspitzen mehrfach rerkümmerten. Ich erkläre mir diese Erscheinung, dass die Zahb der Ziihne bis auf das zwei- und dreifiche anwohs, ans der primituen Vermehnug der Wasserspalten, wodurch sich die Blitter und die Pilanze ïberhaupt der grösseren Feuchtigkeit des Medimus anpassten. Durch die Vermehrung der Wasserspalten Wurle sekundïr die Zuhnung und durch die Chorliilhng nil Wasser als wirksamem Reiz auch die Berlrüsung eine reichlichere fes werelen alle Hautbestandteile durch ühergrosse Fenchtigkeit hypertrophisch).

Auch unter den Verhältnissen der frejen Natur antworten die Rosen auf reichlichere Wasserzufuhr mit Vermehrung der Drüsen. Schon Christ schreiht in den , Rusen d. Schweiz" (S. 158) von seiner var. dumalis der R. canima: "In sehr feuchten Sommer 1872 zeigten Exemplare bei Busel Gliellrïsen an den Blïtenstielen und einzelne Drüsen auf den lielchzipfeln, was ich in früheren Jahren an denselben strüuchern nicht bemerkt habe." Dasselbe habe ich an

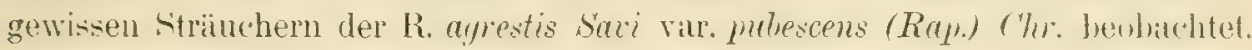

1) Bestimmung nach Lamberts Katalog S. 15 und 47. Diese Gartenrosen wurden gewälılt, weil sie sehr schnellwïchsig sind und schion im ersten Jahre ein Resultat ersehen lassen. Ich bezog die Samen von der Gärtnerei Haage und Schmidt in Erfurt. Jedesmal wurden je 3 Tüpfe mit Nüisschen der gleichen Form besit und :3 verschiedenen Kulturbedingungen ausosetzt: 1. Kultur bei einem Optimum von Licht, Feuchtigkeit und Wärme; 2. K. bei einem Optimum von Licht und Wärme, aber einem Minimum von Feuchtigkeit; 3 . $\mathrm{K}$. unter Glasglocke bei einem Maximum von Feuchtigkeit in Luft und Boden, einem Optimum von Licht und Wärme. Ich stellte die betr. Kulturversuche in den Jahren 1903 und 1905 an.

2) Die Drüsen bezw. Drüsenzotten scheinen bei den Rosen überhaupt an das System der Wasserleitun, die Gefïshïindel, angeschlossen zu sein. Eine genaue Besichtigung cines liosenblattes mit Subfoliardrüsen, z. B. von einer normalen R. rubiginosa, ergibt, dass sämlliche Stieldrüsen auf der Epidermis über den Blattnerven sitzen. Der Hauptnerv ist fast bei allen Rosenarlen und Rosenformen mit Drïsen bedacht, damn folyen die Seitennerven und Nervilen. Auch bei der reichst bedrüsten Rose sitzen die Drüsenzotten niemals auf dem eigentlichen Mesophyll, sondern a f den feinen und feinsten Nervillen. Den umgekehrten Gang nimmt die Verarmung eines Rosenblattes an Drüsen. Die Drüsenarmut der 1. decipiens Sag. z. B. (R. rubiginosa) zeigt sich in verschiedenen Graden: zuerst bleiben die Nervillen frei von Drüsen, dann erst die Seitennerven; der Hauptnerv trägt auch bei der decip. solche. - Ahnlich sind die Drüsen von Blatt- und Blütenstielen, sowie von Kelchblättern an die Gefissbindel angeschlossen. Es scheint das Auswachsen von Epidermiszellengruppen zu Drüsen eben nur an Stellen möglich zu sein, die vom darunterliegenden Gefässsystem eine reichere Versorgung mit Wasser erhalten. - Das Gleiche gilt für die Hare wenigstens des Blattes; sie folgen ebenfalls dem Zug der Nerven und finden sich deswegen vorwiegend an der Blattunterseite zunächst am Hauptnerv, dann auf •den Seitennerven und Nervillen, nicht aber über dem nervenlosen Mesophyll. 
In gew ihnnlichen Jahren zeigten sie keine Spur ron Stieldrïsen an den Blïtenstiven, woron man sich leicht ïlewzengen kann, denn ich hahe sie fribler in

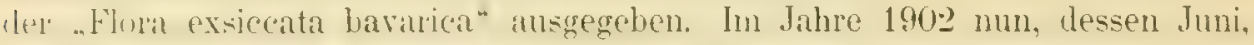
Juli und August kïhl und regnerisch waren, trugen sie ziemlich reichlich foine -tivhrüsen an den Blïtenstielen und gehörten so auf einmal der f. glondulosa

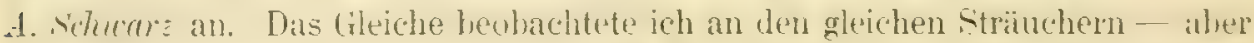
in riel geringertan Grale in Jahre 1908 (regnerischer Sommer!) Ein weiteres

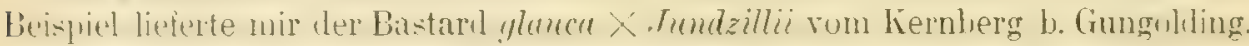

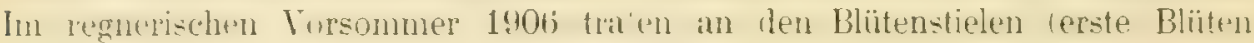
offen am 9.6.) viel mehr Stieldrisen aul, als sonst.

Auch den umgekehrten Fall habe ich schon beobachtet, nämlich dass Prisen, die ich fribher als f. glomdulusa A. Schu. eingelegt hatte. in tinem truckenen Jahre an sellen Strauche ohne Drüsen anftraten. Man wird hier also sigen miiscen: Die var. pubescens hat die atavistische Neigung, wie andere Rustn der lubiginsa-(iruple Drüsen an den Blitenslielen zu entwickeln. Dazu abrer. dars sie withlich autreten, gehürt ein gewisses Mass vou Feuchtigkent. Ahn-

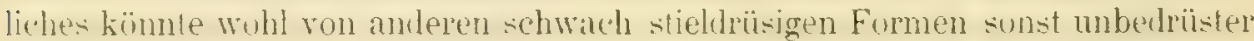
Arten gelten, wie.sie bei der R. canina, glauca u. dgl. vorkommen. ${ }^{1}$ ) Dass die bulrusung an sulchen Rusen je nach dem Jahre stark wechselt. haben anch andere Beobachter gefunden. ${ }^{2}$ )

Cher den Einluss eines feuchten Kilimas aul die Blattzahmung der P'llanzen strlten IV. Brenner. E. Isslel und G. Bonniter Lntersuchungen uml Velsuche an. Feuchtigkeit wie Trockenheit miissen hier phrsiologisch, nicht bloss physikalisch gemommen werten. Für tas Leben dep Ptlanze ist ein Substat, so setn e. von Ilasser durchdrungen sein mag, doch als trocken zu bezeichnen. wenn die Pilanze ihn kein Wasser entuehmen kimn. Darum wirl nhysiologische Truckenheit entweeler durch die Absorption herabetzende oder durch die Transpiration fïrdernde äusere Fakforen, am häuligsten jedoch durch die Kombination ron Einflïssen aus beiden Gruppen bexlingt. ${ }^{\star 3}$ ) Sulche Faktoren sind: der geringe Gehalt des Bodens an freien Wasser, ter Reichtum des Bodens an geloisten silzen und Hunussïuren, die niedere Temperatur les Bodens: aber auch die Trockenheit und Verdinnung der Lubt, hohe Luftemperatur uml intensives Licht. Wenn nach $W^{*}$. Brenner Eichen nit ganzrandigen oder schwach gelappten Blattern in Cregenden nit fenchterem Klima einwandern. sn crhalten sie meist Bläter nit slärerer Lappung, ja mit stachelspitzigem Rande. Tgl. hesonders (Qnercus sessiliflona Sun. und suber L.* $)$ Seine Ansicht ïber die

1) Die Bedrüsung ist in solchen Fällen stets schwach und am Anfang der Blïtezeit oft kann bemerklich; erst im spätsonmer treten die stieldrüsen an den Blütenstielen deutlicher auf.

2) So Hr. Schnetz an Münnerstädter Rosen (briefl.) - Weitere Beispiele von dem Wechsel der Bedrüsung je nach dem Jahre (ohne dass der Einfluss von Feuchtigkeit oder Trockenheit beriicksichtigt wurde) führt J. Guttin p. 27 seiner Schrift an: Le genre Rosa dans l'Eure, Caen 189.. Die betr. Beobachtungen stammen von Fr. Crépin und W. Gérard und beziehen sich auf IR. elliptica italienische Npen und glauca Ifranzijsische Vogesen ; beidemale handelt es sich um Bedrüsung der Blütenstiele.

3) A. F. W. Schimper: Pflanzengeographie S. 6.

1 W. Bremer: Klima und Blatt hei der Gattung Quercus. Flura 1902. Vul. hes. S. 145 ff. 
Ardaptionen der Bläter won Chempodimm fasst E. Issler in die Minte zusammon: ,Bestäubung. Blattfärbung, Blattgrösse, Blatlform, Zathung hängen in sehr vichlen Fällen rom Standort ab. Trockener, besonnter Boden bedingt kleine, ganzranlige, dicht bestiubte Blitter (Blasenhare als Wasterbehilter), Lellohter, schattiger Standort grosse stark gezähnte nicht oder nur schwach besläubte Bläter." ${ }^{1}$ ) Ein analoges hesultat hatten schon die in ungukdurter Richtung sich bewegenden Versuche G. Bumber's ergeben. der verschimlonm Pflanzen des gemässigten feuchteren Europa im trockenen Milfelnereklimb zïchtete. Wegen der hier tentrelenden stïkeren Belichtung, hüheren Wärmu und im Jahr zweimal eintretenden grossen Trockenheit wurden die Blätter am hande weniger gezahnt, lederig, erhelten starkere blatheren: Zworge und Blütenstände wurden stark ausgespreizt. ${ }^{2}$ )

Es darf also wohl keinem Zweifel unterliegen, dass auch die Rosen unter dem Einllusse konstanter physiologischer Fuchtigkeit zur Vermehrumg dor biallzähne und der Epidermisemergenzen neigen und diese Vermehrung zu den Merkmalen der Hydrophilie gehört oder besier gesagt zu den Merkmalen drs Hydrophytismus und der Hydrophohe, denn diese Adaption kaun mehr onlre minder augezwungen sein. Es ist vielleicht getattet, in der stiukeron Zuhmumg der Rosenblättchen ein Fortschreiten im Grade der Fiederung zu sehen.

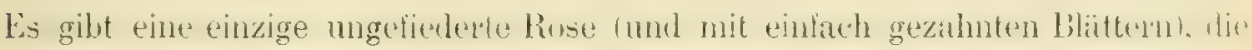

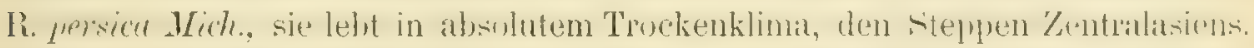
Alle übrigen Losen tragen goliederte Bläticr. Je mehr die Fienlerung zunimmt.

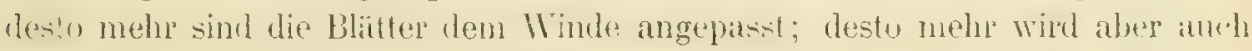
eben durch den Wind ihre Transpiration vermehrt und dadurch ein Gegengewicht gegen die schädlichen Einflüsse allzu grosser Feuchtigkeit im Boden und in der Luft geschaflen. Bei allen Rosen sieht man in die Ziilne des Blattrandes mehr odep minder sonkrecht gegen den Blattand Nerven anslaufen. Bei den einfach gezahnten sind es nur Sekundärnerven, während die iibrige Nervatur an Rande parallel geht und sich gregenseitig rerflicht; bei den mehrlach gezahuten ziehern in die Zähne höheres Ordnung anch Tertiäl- mul

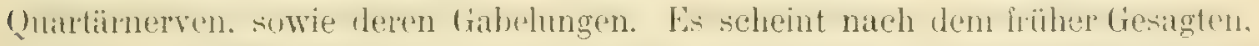

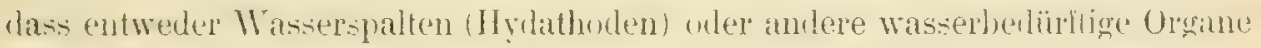
(Drïsen) am Ende dieser blinden Nervenäste sitzen. Gern belienne ich, wie lis"

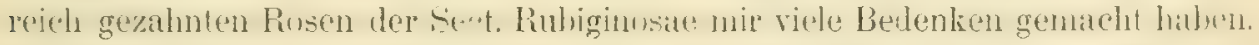
sie bewohnen jetzt rorwiegend trockene standerte, wenn sie anch nicht ansschliussich an dieselben gebunden sind. Allein die jetzt vorhandench morpho-

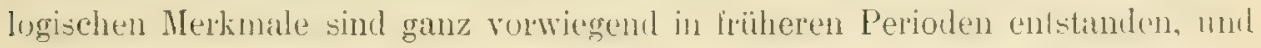

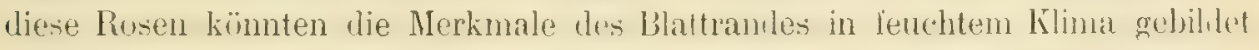
und bis jetzt in trockenem bewahrt haben, vielleicht weil sie den trockineren Shandnete durch anderweitige Verïnderungen sich anpassten. Mahrscheinlicher ist es jedoch, dass, wie wir später hören werden, auf die Zahnung des Blattrandes auch noch andere Faktoren einwirken.

1) E. Issler: „Eingeschleppte Chenopodien" (Allg. bot. Zeitschr. 1902 S. $175 \mathrm{Anm}$, ¿2).

2) Gaston Bonnier: Compt. rend. 1899 t. 129 p. 1207 sqq. (nach der Naturw. Rundschau 1900 S. $175 \mathrm{ff.}$ ) 
In ganzen ist ja der hydrophile Charakter an den Laubblätern der Rose nicht stark ausgeprägt, ja eine Anzahl Arten südlicher Regionen haben Blätter mit vorwiegend xerophytischen Eigenschaften. Dahin gehören die mỵtusartigen Lederblätter (Bliittchen dick, einfach mit seichten Zähnen gesïgt, kahl, crlinzend, ausdauernd) der R. semperivens L. (Mitteheergebiet), der Varietiiten lunficuspis Bertoloni (Indien) und Leschenaultiana Wight et Arn. (Indien), der R. moschatu Willer und anderer von der Sect. Synstylae. ${ }^{1}$ ) Auch die bei uns viel kultivierte R. mugasa Thumberg hat in ihren Rumelblätern xerophilen Typus. Enullich deutet die starre fast lederige Beschaffenheit und das auflillig hervortretende Adernelz hei den Blïtchen von R. gallica L., Jundzillii Bess. und tomentellu Lem. auf die Anpassung an warme, trockene Standorte; die Blïtter von gallica sind ausserdem etwas wintergrün.

Bekannt ist der ursächliche Zusimmenhang zwischen übergrosser Trockenheit und Nanismus (Zwergwuchs). Gr. Kums und seine Schüler haben in mehreren Arbeiten üher den Namismus der Würzburger Wellenkalkpflanzen gehandelt. ${ }^{2}$ ) Ihre Versuche und Beobachtung(n beziehen sich allerdings zunächst ant krantigł und einjährige Planzen, doch ist auch rom Nanismus einer Rose, der R. pimpinellifolia, die Rede. Gegenüber einer normalen Planze sinkt z. B. die Lïnge vines Fiederblättchens von 19) auf 9, die Breite von 12 auf $7 \mathrm{~mm}^{3}$ ) Ahnliche Verhältnisse wie der Wïr\%burger Wellenkalk zeigt olt der Frankendulunit, wonn aut steilem Abhang zur Durchlïssigkeit des Bodens sich Mangel an Krume, starke Besonnung und Fehlen de's Windschutzes gesellen. Unter solchen Umstïnden kann man 7. B. auf dem Grissberg b. Eichstät aber anch an vielen anderen Punkten Zwerge besonders ler $R$. mbiginosa und canina finden; ein winziger Zwerg der R. pimpinellifolia (Stammhöhe $10 \mathrm{~cm}$ ) wächst auf einem Dolomitfelsen der Anlage bei E. Zwerge der R. rubiginosa haben schon sehr frïh als R.rotundifolia und parvifolia Rau Beachtung gefunden. Es ist aber mehr als zweilelhaft, ob sie den Rang einer Varietiit beanspruchen liönnen. Fïl die kratartigen Zwerge wenigstens hat Gr. Kraus nachgewiesen, dass sie niclrt nur aus ihren unmittelbaren aus Samen erzogenen Abkömmlingen, sondern selber in Normalboden verpflanzt auch sufort zu Normalindividuen auswachsen. also vergiingliche rein zeitliche Anpassungen oder Modifikationen darstellen. Ilïchst wahrscheinlich verhalten sich viele Holzpilanzen, also auch Zwergrosen. ähnlich, wenn nicht etwa der Einfluss des Standortes durch viele Generationen hindurch den Nanismus gefestight hat. Doch vermag nur das Experiment fiewisheit zu verschalfen. Eine von mir am Geissherg b. E. gemachte Beubachtung spricht sthr für die (rwähnte Wahrscheinlirhkeit. Mehrere Strüucher von R. rulriginosa 1. rotundifolia $R$ au, von denen ein Teil der Wurzeln in den Bereich von neu a: gelegten gedïngten und zuweilen bewïsserten Bamscheilsen einer Allecpflanzung gelangt waren, treiben seitdem (3 Jahre!) aus dem alten Stamm neur

1) Siehe A. Hansgirg: Phyllobiologie, Leipzig 1903 bes. S. 144 ff. 170 ff. 405 ff, Hanswirn ninmt die R. longicuspis und Leschenaultiana als Arten, die massgebendsten Autoren jedoch wie Crépin (S. 295 ff. der Primit. monogr. ros. 5. fasc.) fassen sie als Varietäten oder Unterarten der R. moschata.

2. Siehe inshes. Gr. Kraus: Cher d. Nanisuus unserer Wellenkalkpflanzen, Würzburyc 1906.

3) Ebd. S. 28. 
Triebe, die nach der Blattgrösse und den ïbrigen Eigenschaften den Charakter einer Zwergform ganz verloren haben und reine var, comosa geworden sind.

An dieser Stelle muss auf das verschiedene Verhalten hingewiesen werden, welches die Blattflichen der Rosen gegen Benelzung durch Wisser aulweisen. Durch Beobachtung bei Regenwetter und durch Versuch hin ich zu dem untenstehenden Resultat hezüglich der einheimischen Rosen gekommen.

I. Absolut unbenetzbar auf beiden Blattilichen sind:

R. mbrifolia, glauca, cinnamomea, ariensis, gallica.

1I. Unbenetzbar bis schwach benetzbar:

R. canina, dumetorum, coriffolia, lutea, pimpinellifolia; pomifera, tomentosa. III. Auf beiden Seiten leicht benetzbar, unten schneller:

$R$. muiginosa, micrantha, elliptica, agrestis, tomentella.

Die Rosen der ersten Kategorie tragen so starke - z. T. stäbchen- und haarförmige - Wachsausscheidungen auf der Epidermis, dass Wassur nicht adhärieren kann. Die Rosen unter II. haben teils schwächere Wachsausscheidungen, falls sie an sonnigen Pliitzen stehen, teils Haare, welche dop Benetzung Widerstand leisten. K. fomifer und tomentosa werden um so leichter benetzl, je mehr Drüsen sie besitzen. Auf der Oberseite nehmen sie das Wisser schwierig an; ebenso aul der Unterseite, wenn die Subfoliardriisen fehlen: aber stark drïsige Formen wie var. farinosa, Seringeama u. dgl. benetzen sich last so leicht wie die Rosen unter III. Die Rosen dieser III. Kullegorie, welche alle + Drïsen und Haare auf den Blätern tragen, nehmen das Wasser nicht bluss schuell auf, sondern bleiben auch auffallend lange feucht. Sire cutbehren de's Wachses, und das Drïsensekret nimmt Fenchtigkeit an, anch den nirchtlichen Tau. Sollten diese Rosen nicht am Ende befühigt sein, Wasser durch die Blätfer aufzusaugen? Als Organ der Wasseraulsangung kimnten die einzelligen Inare dienen, welche an der Basis blasig aufgetrieben sind. Solches wïre eine xerophytische Eigenschaft. Ich habe jedoch keine leweisenden histologischen Lntersuchungen angestellt. Wïre obiges der Fall, so würde die Haarbekleilung der liosen unter III. als biversale Anpassung aufufassen seim, nüulich einerseits als positives (konverses) Organ zur Verwertung gelegentlich darogebotenen Wassel's, anderseits als negatives (adverses) Schutzmittel gegen das Chermass von Licht und Wïme, hez. von Trockenheit. Uher den zwoiten Punkt werden wir uns jedoch besser an anderem Orte verbreiten.

\section{Kapitel: Die Wärme (Temperatur).}

Die Rosen halten sich von den Extremen der Temperatur ferne, indem sje den ïussersten Norden wio dem Niederungsgebiet der Tropen fehlen: sie gehören im allgemeinen der genäissigten \%one (ler nördlichen Halbkugel an und gehen noch in die Gebirge der Tropen nördlich des Aquator ïber. Innerhall) dieser Grenzen bevorzugen sie jedoch wirmere Lagen, was innig nit ihrem Lichtbedürinis zusammenhängt.

Von hohem Interesse für die Klarlegung ihrer geographischen und verwandtschaftlichen Beziehungen wïre es, wonn die Methoden der' P'hïnolugre

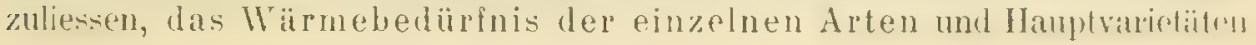


in exakter Weice zu bestimmen. Das ist bekanntlich nicht der Fall. Doch darf man auch nicht das Kind mit dem Bade ausschïtten. Durch vorsichtige und unlassende Beobachtung der Blüte- und Reilezeit der Rosen lassen sich inmerhin wertrolle Anhaltspmkte mach dieser Richtung gewimnon. Zu rag sind die Angaben der meisten Autoren, die hüchsteus bemerken: in clieser Gegend blüht diese liose otwas frïher als eine zweite u. dgl. Etwas genatuere Angaben wenigstens über Fruchtreife unteriänkischer Rosen macht H. Dingler. ${ }^{1}$ I.h selbst habe seit einer Reihe von Jahren auf die Blüte- und Reifezeit der um Eichstät so rexichen Rosenllora geachtet und in den Sommern 190ti-190s mich beniiht, dureh unzihlige Exkursionen auch rechnerisch darstelibare Resultate

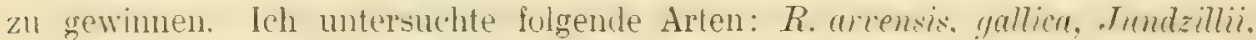
pomifer, tomentosa (gewöhnliche und sulche der Unterart sculriuscula), rulni-

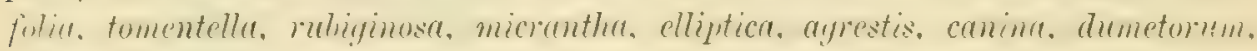

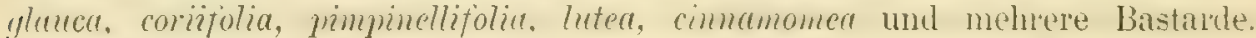
Meine Methode war hei der beohachtung der Blüten diese: Ich suchte den Zeitpunkt zu bestimmen (Nonatstag), an den die ersten lifiten eines Strauches sich öfneten. Mir genïgte eine einzige offene Blïte, falls die nächsten linospen ebenfalls an Aublechen waren: eine ganz singuläre. gleichsam unmotivierte Blïte, die einigemal den Vorliuler machte, wurle nicht berücksichtigt. subsidiail wulle unter Lustiuden atuch angegeben, wann der strauch in voller bliite stand, und wie lange nach den allgemeinen Verblïhen einzelne líronen noch geölfinet waren. Da Formen der $\mathrm{R}$. canima überall wuchen, und ich zuror konstatiert hatte, dass an gleichem Shandurte Varietäten der dwei Abteilungen Cniserratae, 'Transituriac und Biserratae ammähernd gleichzeitig erblihen und verbluhen, wurden die Daten des ersten Aufblïhens bei simtlichen Rosenarten anf vine R. canina des jeweiligen Sianlortes der anderen Rosenart hezogen unl so fuir alle beobachteten liosen die relative Zeitdillerenz des Aufblïhens gegenuibut dem der R. canina ïberhaupt festgestellt. Das erzielte Resultat rendient musomehr Verlanen, ron je mehr standurlen und in je mehr Jahren eine bestimmte liose mit der $\mathrm{R}$. canina verglichen wude. weil individuelle und zulïllige meteorulogische Besomlerheiten auf diese Iteise mushïdlich gemacht werden. Als Bitsis meiner Lntersuchungen habe ich das Jahr 1906 angenommen und tie Ergebnisse in den Jahren 1907 und 1908 nachgepriat, wobei ich mich beniihte. anderes Material an amleren Lokilititen zu benïtzen als 1906. Fïr dieses Jahr muss roraubemerkt werden. dass das Wefter bis Mitte Mai schön und warm, von da aber bis Mitte Juni kalt und regnerisch war (in Eichstät trat anch Hagel auf): erst von Mitte Juni an wurde es wieder wïmer, und selzten die normalen Witterungsverhälnisses ein. Die Entwickelung eines Teiles der liusen wure

1) Besonders S. 11 ff. seiner sehr wertvollen Abhandlung: Versuch einer Erklärung gerwisser

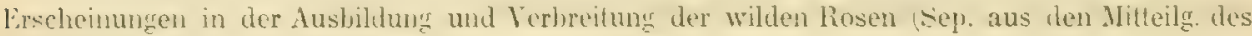
naturw. Ver. Aschaffenburg 1907).

Von Fr. Crépin existiert ein Aufsatz über unser Thema: Recherches a faire pour établir exactement les époques de floraison et de maturation des espèces dans le genre Rosa (Bull. soc. bot. Belg. t. 28. 1889 p. 60-67). Er beklagt sich aber hier nur über die Unsicherheit der Angalen und die schwierigkeit der L'ntersuchunc und fordert zu exakten Forschungen auf, olme einen geejgneten Weg anzugeben. 
deshalb am Anfang rerzögert und lie eines andern später zusanmengedrängl. Dis traf insbesondere die Frühblither R. pimpinellifolia, cinnmomea, punifera, glauca. Der Winter 1906 auf 1907 war limg, ziemlich kalt unl schnerrepich.

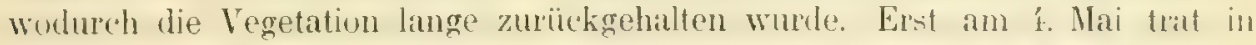
der Eichstïtter Gegend warmes und truckenes Wetter ein: Mitte Mat his zweite? Wuche Juni erfolgte wie 1906 ein Rückschlig mit kühlem und regnerischem Welter. Der ganze Summer war ziemlich kühl, erst August und hiphtenther im allgeneinen schön und mittelnässig warm. In grussen und ganzen entwickelten sich 1907 die Rosen wie andere Blïtenpflanzen recht Langsan. sellst die Fruchtreite rerzögerte sich in Vergleich mit früheren Jahren. Cher. dats Jahr 1908 folgen einige Notizen später.

Dies unten folgende Tabelle gibt die Zahl der Tage an, un welche eine linse

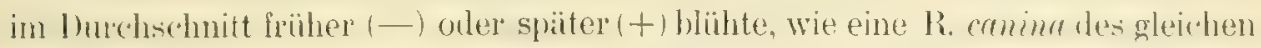
Standortes. Die R. eanina hat in der Tabelle die Ziffer 0 als Vergleichszahl.

\section{R. canina: 0}

\begin{tabular}{|c|c|c|c|c|c|}
\hline I'impinellifolia $\ldots .$. & $\begin{array}{l}1906 \\
-\quad 12\end{array}$ & $\begin{array}{r}1907 \\
1\end{array}$ & & 1908 & $\begin{array}{l}\text { Durchschnitt } \\
-13\end{array}$ \\
\hline Cinnamomea....... & -9 & & & & $-10,5$ \\
\hline 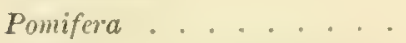 & - 8 & & & -3 & $-\quad 5,5$ \\
\hline Tomentosa subsp. scabriusc. $\left.{ }^{1}\right)$ & -7 & - & 7 & & -7 \\
\hline Glanca ......... & -3 & - & 2 & & $-\quad 2,5$ \\
\hline Coniifolia ......... & -1 & & & & \\
\hline Rubrifolia . . . . . & +1 & + & 1 & & +1 \\
\hline Lutea . . . . . . & & - & & +1 & \\
\hline 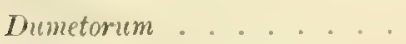 & +2 & & & & \\
\hline Nicrantha . . . . . & +3 & & & & \\
\hline$J_{1 n n d z i l l i i} \ldots \ldots$ & +4 & & & & \\
\hline Rubiginosa ........ & +4 & + & 3 & & $+3,5$ \\
\hline Elliptica . . . . & +8 & & & & \\
\hline Gallica .... & +9 & & & & \\
\hline Arcensis . . . & +9 & & & & \\
\hline Tomentella ${ }^{2}$ ) . . . . . & +11 & + & 6 & & $+8,5$ \\
\hline Tomentosa (gewöhnliche) ${ }^{3}$ ). . & +11 & + & 4 & & $+7,5$ \\
\hline Agrestis . . . . . . . . & +14 & & & & \\
\hline Glauca $\times$ Jundzillii ... & $-\tilde{5}$ & & & & \\
\hline Canina $\times$ Jundzillii ... & 0 & & & & \\
\hline Canina $\times$ tomentosa $\ldots$. & & & & & \\
\hline Canina $\times$ gallica..... & & & & & \\
\hline Cinnamomea $\times$ gallica ... & + & & & & \\
\hline
\end{tabular}

1) Subsp. scabriuscula in dem Teil 11 angenommenen Sinn und Umfang. 1906 beobachtete ich die var. farinosa, 1907 die var. vera m. Von R. canina, glauca und dumetorum wurden stets all. Furnenkreise berïcksichtigt, von pimpinellifolia und rubiscinosa verschiedene der wichligsten Formen. Bei der $\mathrm{R}$. arvensis handelt es sich um die f. umbellata, bei der gallica um die var. austriaca und pumila, bei Jundzillii um die var. Pugeti, bei pomifera um die var. recondita, bei micrantha um die var. typica, bei elliptica um die f. hispida der var. typica und um die var. calcarea, bei coriifolia um die var. typica, bei rubrifolia um die angepflanzte var. glaucescens (Wulfen) R. Keller, bei agrestis um die var. pub.

2) Von der R. tomentella wurden 1906 die var. bohemica und f. sinuatidens, 1907 var. scpioides beobachtet.

3) In beiden Jahren Formen der var, subglobosa. 
Selbstrestindlich dïrfen die in vorstehender Tabelle angeführten Zahlen bei dem relativ noch geringen Lomfang der Lutersuchungen und der Möglichkeit individueller Variationen und störender äıserer Einflïsse nicht allzusehr urgiert, und muss rine weite Fehlergrenze angenommen werden. Am meisten T'rtrauen verhienen die Angaben ïlıer Rosen, die in verschiedenen Jahrgingen heobachtet wurken, und von den ats. d. I. 1906i stammenden Daten die iaber

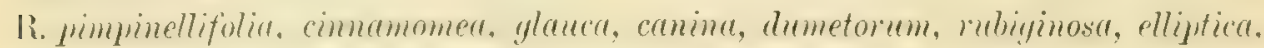
arjestis, weil hier stets mehrere Exemplare der gleichen Form und verschiedront Formen der gleichen Ant ron mehreren Stamborten kontrolliert wurden. Die angeogebenen Zahlen sind in diesem Falle abgerundete Mittelzahlen. In J. 1907 zeigen dis R. pimpinelliblia, cimamomea. glauca, rubrifolia, mbiginosa im Vergleich zu

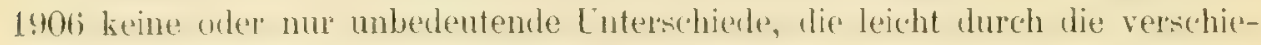
dene Witterung edklirt werden kömen. R. tomentosa in var. sul)glohusia erscheint "Wwas verfrüht, desgleichen tomentella. Das mag durch die Witterung mitbedingt

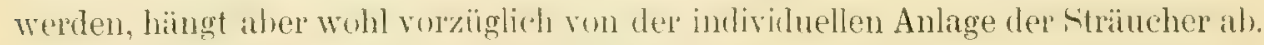
Ich habe hesunders grosse individuelle Schwankungen bei der R. rubiginosa var. romusa benlachtet. Am wichtigsten war mir, konstatieren zu können, dass die Formen der subspec. scahriuscula konstant viel früher blühen, als die Varietiten der gewöhnlichen tomentusa. Var. farmosa i. J. 1906 und typica i. J. 1907 waren der R. canina um 7 Tage voraus, die gewöhnliche tomentosa var. subglobosa im Mittel beider Jahre um \& Tage verspätet, also eine Differenz von 15 Tagen.

'Zu den ubigen Daten sei noch das Folgende hemerkt. Aul dem Geissberg b. E. stamden am 8.6. 1906 R. glauca und canina in voller Blïte, mierantha fing an zu biihen, rubiginosa var. comusa zeigte noch keine Blïte. An 12. Juli waren an einer bestimmten Lokalitä des neuen Weges b. E. R. glauca und auch arvensis bereits verblüht: canina und dumetorum zeiglen an einzelnen Büschen noch mehrere Blïten, wïhrend die meisten ebenlalls schon verblibthatten; dagegen wiren rubiginosa und agrestis var. pubescens an fast allen thäuchern noch nit einem Viertel bis Sechstel ihrer Blïten versehen. Auch an 19. Juli zeigten sich in der Nïhe noch einzelne Blïten von canina; agrestis var. pub. hatle last verblüht; an den lubiginosit- und nicrantha-Striucheln zïhlte ich noch je 1-10 13liiten. An 20. Juli sind an liugelberg glauca, canina, dunetorun, elliptica verblüht (die Frichte von pimpinellifolia bereits braunschwarz), aber noch ein-

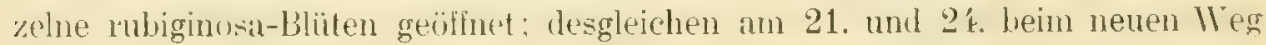
mbiginusa und agrestis var. pub.; an 29.7. in elwas schattiger Lage am Prinzensteig immer noch ein paar Bliten von rubiginosa. Diese Rose scheint die lïngste Blütendauer zu haben, denn ich beobachtete bereits am 4.6. in ähnlicher Lage des neuen Wreges offene Bliiten. Rubiginosa remontiert auch an hïufigsten von allen Wildrosen, d. h. zeigt neue Blüten zwischen reifen Früchten, wie ich das sowohl bei Eichstiatt als in der Neumakter Gegend im September umi ()klnher schon hïulig gesehen habe. Zum V'ergleich mit den angefïhrten genaueren Zahlen notiere ich die Reihenfolge der Blïtenentwicklung der Rusen Fichstatts, wie ich sie nach den allgemeinen Eindruck bereits 1899 in meinem Tagehuche niedergeschriehen hahe: "Zuerst blïht R. pimpinellilolia Ende Mati, dann cinnamomea Anfang Juni, dann glauca Nitte Juni und elwas später sodann 
canina und dumetorum, wihrend vereinzelte rubiginosa, gallica und elliptica autauchen. Zuletzt kommen micrantha und endlich agrestis var. pul)," Ich habe 1899 lediglich die micrantha etwas zu spät angesetzt.

Obwohl die Zeit der Blattentfaltung im Frühahr (und der Fruchtreife im Ilerbst) weniger prïzis angegeben werlen können, habe ich die crstere ebenfalls in den Jahren 1907 und 1908 kontrolliert. Als Datum wurde der Tag eingetragen, an welchem die Oberfläche eines Blittchens dentlich sichthar wall. Ahnlich we frïher hestimmle ich die Zeit relativ zur Li, canina als dem Mittelwert:

R. canina: 0

\begin{tabular}{|c|c|c|c|c|c|c|c|c|c|}
\hline & & & & & & & 1907 & 1908 & Durchsch \\
\hline Pimpinellifolia (mehrere & Var: & & & & . & & -3 & & \\
\hline Cinnamomea ..... & . . & & . & . & . . & & -2 & -6 & -4 \\
\hline Tomentosa subsp. scabr. & (var & & far & & $o s a$ & & -1 & $\pm 0,5$ & -1 \\
\hline Glauca (versch. Var.) . & & & . & . & . & & $-0,5$ & $\pm 0,5$ & $-0,5$ \\
\hline Tomentella (var. bohem.) & 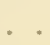 & & & & . & & 0 & $\pm 0,5$ & 0 \\
\hline Rubrifolia (angepilanzt) & . & & 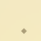 & 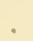 & . & & 0 & +2 & +1 \\
\hline Lutea (verwildert) . . & & & & & . & & 0 & & \\
\hline Arvensis (var. typ.) & & & & . & . & & +1 & & \\
\hline Rubiginosa (mehrere Var. & & & . & . & . & & +1 & $\pm 0,5$ & +1 \\
\hline Dumetorum (var. platyphy & $y l l a)$ & & . & - & . & & & +1 & \\
\hline Micrantha (var, typ.). & . & & - & . & . & . & $+1,5$ & $\pm 0,5$ & $+1,5$ \\
\hline Gallica (var. pumila). . & & & & & . & & +2 & & \\
\hline Agrestis (var. pub.) . & & & . & . & . & & +3 & +7 & +5 \\
\hline Elliptica (var. typ.) & & & . & . & . & . & +4 & +6 & +5 \\
\hline Dumetorum (var. comata) & & & & & . & & +5 & +7 & +6 \\
\hline Pomifera ...... & & & . & & . & & & +7 & \\
\hline
\end{tabular}

Gegenüber dex biütweit drängt sich die Blaltontwicklung der rerschiedenen

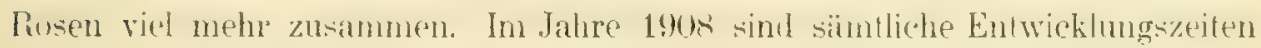
nach ter R. canina: () verspatet, ta das IV elter plitzlich wieter reguerisch und rauh (sogatr Schneefäle?) geworden war (Anbug Mai). Lmgekehrt ist dee - Abstand von cinnamomea zu gross, weil nach einem langen Winter um die betreftemde Zeit pliotzlich sehr wames IVettre eingesetzt hatte. Jor hosen unit $\pm 0,5$ zeigten keinen wh einen nur minimalen Interschied gegenüber $190 \%$. In grosien und ganz'n geht die Entwicklungstolge der Bläter jener der Bliiten parallel, doch gibt es ein fatar aulfallende Ausnahmen. Sehr spit entwickeln sich die Blittchen ron pomilera und von meine's var. comata der R. dumetorum: tomentella beschleunigt die Entfaltung seiner Blätter.

Uber die Fruchtreife habe ich zunächst i. J. 1906 nur ganz allgemeine Benbachtungen angesteflt. Am 25. 7. zeigte die R. pimpinellifolia in guter Lage des liugelberges b. E. (sibdwestliche Exposition) vollkommen reife Frïche rom schwalzer Farbe, währent am gleichen Platze noch einzedne rubiginusa-blibten geijfnct waten. Die Reife der cinnamomea lolgte dort nach $6-8$ Tagen. An 15.) September waren ausser den genamnten bereits genusseif (weich) auch die in ähulicher Lage wachsenden pomifera und rubrifolia. Die andern Lisen zeigrten

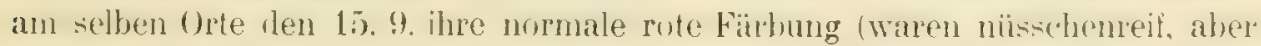
nicht genusseif, die jedoch bei glauca und corifolia schon um esine Wuehe 
frïher augetreten war. Die agrestis var. pub. hatte trotz ihrer späten bliitezeit bei der Fruchtreife die übrigen Rosen erreicht. ${ }^{1}$ )

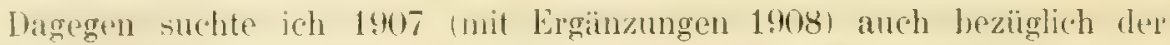
Fruchtrefife beohathlungen zu gewinnem, die eine rechnerische Znsammenstellung zuliessen. Zu distm Zwerke unterschied ich zwischen Voll reife und Genussreife. Die ersteres wird bezeichnet durch die Auslïrbung der foheinfrichle und betrifft solvhe mit ganz reifen und keimlihhigen Nïsschen; die zweile tritt später ein: das Fruchtfleisch ist weich, wenn auch missfärbig geworden und hat die für Tiere, Vögel u. dgl., zum Genuss einladende Qualität erlangt. Eine Bestimmung der Genussreife schloss ich als zu verschwommen aus; den Eintritt

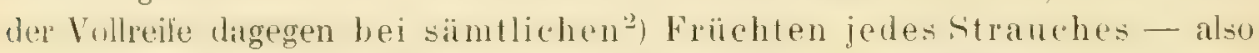
nicht bei den ersten oder bei einzelnen - suchte ich in ähnlicher Weise relativ festzulegen, wie ich es mit der blatt- und Blïtenentwicklung gemacht habe: bloss habe ich in letztern Falle den Anfang, bei den Frïchten das Ende des Prozesses markiert. Ich wählte zu diesem Behufe eine Anzahl von Standorten in der Niihe Eichstitts aus, an welchen R. canina zusammen nit andern Rosen vorkommt. Fast alle Standorte wurden $7-9$ mal besucht, einige wenige sehr entfernte nur ein paar mal. Ich konnte so auch die allmähliche Reifung der Rosenfrüchte ïberwachen. Zwar verhielten sich die einzehen Arten nicht ganz gleich, indem manche vom Anfang der Färbung einzelner Früchte bis zur

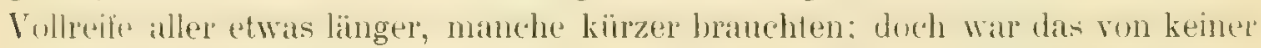

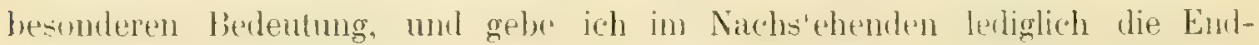
beobachtung: alle Frïchte vollreif. Ich habe wiederum die Zeit der R. canina mit () angesetzt, aber nur die Formenkreise Iniserratae und Thansitoriate benutzt, denn die Biserratae weichen bei der Fruchtreife von den anderen Formen gewöhnlich ab.

\section{R. canina: 0}

\begin{tabular}{|c|c|c|}
\hline Pimpinellifolia (Mittel mehrerer Var.) & -49 & Dumetomm (var. comata) \\
\hline Cimnamomea (mehrere Standorte) & -43 & Jundzillii (var. Pug.) . . \\
\hline Agrestis var pub. . . . . & -15 & Dumetorum (var. platyph.) \\
\hline Tomentella (var. boh. und sepioid.). & -15 & Tomentosa (var. subglob.). \\
\hline Tomentosa subsp. scabr. (var. vera) & -9 & Canina (Formenkr. Biserrat.) \\
\hline Glauca (mehrere Var.) . . . & -8 & Micrantha (mehrere Var.). \\
\hline Rubiginosa (var. umbell. u. comos.) & -7 & Dazu 1908: \\
\hline Elliptica (mehrere Var.) . . & -7 & Pomifera (var. recondita) .... \\
\hline
\end{tabular}

1) Vgl. dazu die Angaben bei H. Dingler („Versuch einer Erklärung" usw. Mitteilg, naturw. Ver. Aschaffenburg 1907 S. 11-14). Seine - allgemein gehaltenen - Bemerkungen über Blütezeit stimmen im wesentlichen mit meinen Beobachtungen überein. Dass die Fruchtreife bei R. glauca wie den übrigen Rosen mit persistenten und subpersistenten Kelchzipleln 4 Wochen friher stattfinde, als die der R. canina und überhaupt der Rosen mit ablälligen Kelchblättern, ist $m$. E. übertrieben, anch wenn man hier die Genussreife nimmt. Ein Beispiel: die R. tomentella var. affinis der Umgebung von Neumarkt Oberpf. war i. J. 1899, wo ich sie für die Fl. exsicc. bav. einlegte, am 19. Sept. schon etwas weich, ist überhaupt auffallend früh genussreif, früher als rubiginosa und elliptica. Uber die Vollreife der Rosen folgen ohnehin im Text genauere Angaben.

2) Der Begriff "sämllich" wurde in moralischer Allgemeinheit genommen; denn einzelne seltene Ausnahmen - einzelne auffallend schnell oder auffallend langsam reifende Scheinfrüchte eines Corymbus oder eines Zweiges - mussten unberücksichtigt bleiben. 
Bei den mit? bezeichneten Rosen ist das Resultat durch irgend welche Fehlerequellen unsicher. Individuelle Verwhombenheiten traten anch in der Frucht-

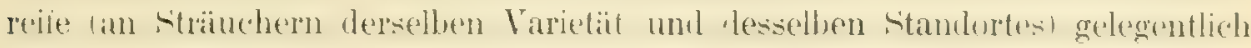

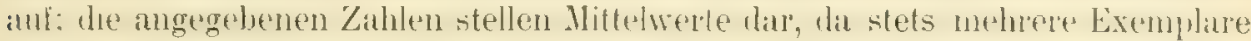
wenigstens der gleichen Varietït beobachtet wurden. In hohem Grade auffallend ist die frühe Reifezeit bei $R$. tomentella und $R$. agrestis var. pubescens, denn beide Rosen blïhen gerade besonders spät. Auch die var. comata der

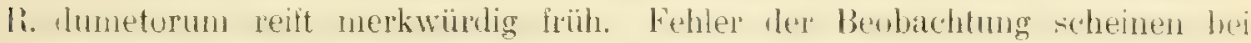

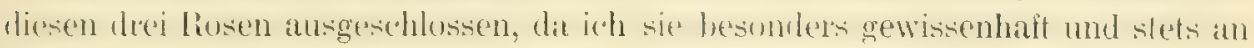
medrexen standerten und an mehreren Fxemplaren studiert, anch hinlïnglich

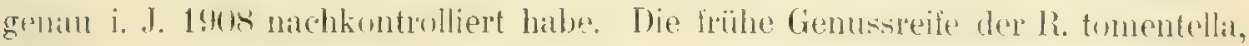
welche ihrer frïhen Volleife entspricht, ist mir wie oben erwähnt schon viel friiher - i.J.1899 - an der var. affinis von der Neumarkter Gegend aufgefallen.

Wenn wir bloss auf die Zeit des Aufblïhens unser Augenmerk richten, so lassen sich deutlich unter unseren Rosen 3 Gruppen unterscheiden:

1) Spiitblüher: Die Rosen mit offenbar südlichem Ursprung und vorwiegend sïdlicher V'rbletung, welche zur Entwicklung einer grö̈sselen Wirmesumme bedïrten, als: R. arrpusis, gallica, . Tundzillui, tomentella, Sect. Rulniginosar, die Formen der gewöhnlichen tomentosa.

2) Frühblüher: Nordische und Gebirgsrosen, welche bald genügende Wirme finden, nämlich pimpinellifolia, cimnamomea, pomifere, subspec. scalurinscula der tomentosa, in schwächeren Grale glanca und coriitolia. Rubrifolia liis:st sich an dem Eichstiitter Fundplatze als angepflanzt nicht diskutieren.

3) Die Rosen der gemïssigten Ebene: canina, dumetorum.

Losen mit stiukeres Beharung. coritolia und dumelorum, blihhen später als die analogen unbehauten Parallelarten glauca und canina, weil die Hanre auch ein Shotzmittel gegen die Licht- und Wämewirkung darstellen; die siirkst beharte lumetorum, meine var. comala, blüht am spätesten unfer allen ihrer Art. Wïrle die pumilera gan\% glatt sein, so kime ihr vielleicht, wenigstens hicuzulande, ungelïhr die Blïtezeit der schwachhatrigen R. cimnamomén zu. Tie Rosen sind so emplindlich gegenïber den Abstufungen von Licht und Temperatur, dass schon ein Minimum von Beschattung das Aufblïhen verglichen nit einem zunïchs tehenden gleichen strauche verzïgert. Hiefiir ein schlagendes Beispiel! Zwei parallele Reihen von Baischen derselben finpinelliblia-Form sind when am Kugelberg b. E. duch eine dizwischen stehtnule Hecke wn liguster getrennl, sodass die eine lieihe nördliche, die andere siunlirhe Exprsition eshilt. I) le letzlgenamnte blïhte am 22. 5., die erstgenamnte am 20. 6. des gleichen Jahres; also, obwohl nur einen Schritt getrennt, um einen Monat später. Die var. comata der R. dumetorum öfinete auf dem Frantuberg in sonst uffener, somiger Iage die ersten Blïten an 17.6., un 7 Tage später wie anl dem Kugelberge, wo die Hecken eine rein südliche Lage hatten.

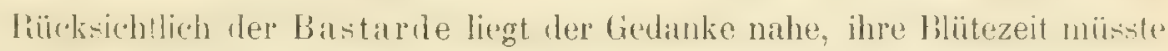
eine Art Mittel zwischen den Blïtezeiten der beiden Eltern darstellen. Genau

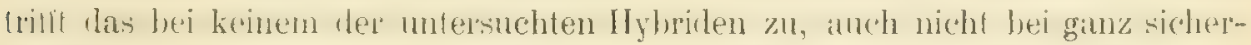

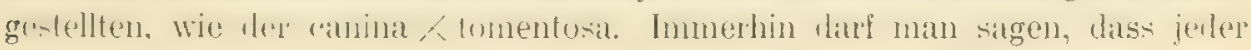


Compunent den seiner Blitezeit enteprechenden beschlemigenden oder varzägernten Einfluss auf dis Comprositum, den Bastart, ansibbt. Die meisten meiner Bastarde blihten etwas frïher, als dem Mittehert ihrer Zusammensetzung entipräche. Selbstrerstindlich muss den Ahweichungen rom Nittel ein weiler. Splelraum gewihint werelen, denn es kann in Buzug aul die Bliilezeit ebensogut

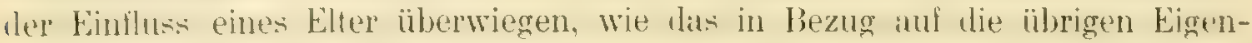
schalten del Fall ist. Die Gartencentifolie bliht nach meinen Beobachtungun ungulith gleichzeitig mit der R. gallica. Das spricht lïr ihre Deutung als gefülltr orientalische Form dieser Art, gegen ihre Erkliirung als Bastard.

Die Ergebnisse der Reilebeobachtungen wollen wir erst später wïrdigen und zwar im Zusammenhalt mit den Lehren, die aus der Entwicklung von Bliite und Blatt hervorgehen. Doch sei schon in voraus atumerksam genacht aul das vershiedene Verhalten der Arten der Sectio hubiginosae, die späte Reilezeit der R. canina, die frühe aller Gebirgrosen. Die Arten pimpinellifolia, cimamomea, tomentusa, glanca verhalten sich gan\% gleichmässig nach allen drei Beobachtungsreihen.

Ein Punkt, den H. v. Mayr für die Holzgewächse im allgemeinen hervorhebt, verdient vielleicht auch bei den Rosen gelegentliche Berïcksichtigung, nïnlich: wenn Holzarten in ein um eine Kleingkeit wärmeres Klima rersetzt werden, akklimatisieren sie sich sehr grut und befinden sich dauernd sehr wohl. "Dagegen gibt das Verpllanzen ans der wirmeren in die kiihlere Zone in allgeneinen ungïnstige Resultate", die P'llanzen erleiden Beschädigungen jeder Art, reifen selten Früchte $u$. dgl. ${ }^{1}$ )

Un des immeren Zusammenhanges willen hesprechen wir die Bedeulung des Anthocyans beim nächsten Kapitel.

\section{Kapitel: Das Licht.}

Manche der Aupassungen, welche wir beim IVisser (Thockenheit) und der Wiime beschrieben. sind ganz oder teilweise durch das Licht bedingt, dis Wärmestrahlen mit sich führt.

Unter den wenigen positiven Einwirkungen des Lichtes auf die Organansbildung der hosen kamn wohl mit Recht genannt werden die Runzelung dor Laubblätchen bei der R. rugosia. Durch die (hier nicht sehr bedentend auftretende) Runzelung der Blattoberfläche wird ein Teil des chlorophyllführenden Mesuphỵls den Einwirkungen der direkten bestrahlung entzogen und empläingt so einen merklichen Lichtschutz.

Die R. yallica besiedelt mit Vorliebe äusserst somnige liaine und Abhïnge. In diesem Falle bildet sie sich gerne zur var. lumila (.Jacr.) $H$. Braun aus, die ihre Laubhlittchen längs der Miltelrippe + nach oben zusammengelaltet träigt. Je splitzer der Winkel wird, unter welchen die beiden Blatthälften zusammenstusstn, umsomehr ist dias Palisadengewebe der Blattoberliiche gegen die chloruphyllzerstörenten Wirkungen des grellen Somnenlichtes geschïtzt. Auch bei der R. canina und glauca kann man Ansïtze zu dieser Blattlaltung gewahren: über-

1) 11. Mayr: Die Waldungen von Norlanerika, München 1890, S. 365 fl. 
haupt neigen junge Rosenblittchen zu dieser Shohutzstellung. Irh habe cine 1. heliophila $m$. bei der var. myriodonta Chr. der $\mathrm{R}$. glauca errichtet, welche unter dem Einflusse sehr somnigrer stambote dieses Merkmal besmulers gerne zejgूt. Sohr intensives Licht wirkt niah den Beobachtungen von (x. Bomier und liener v. Marilum anch hemmenel aul das IVachstum der Blatter und Achsen.

Der Mangel des lichtes elzengt die sug. Sichattenblätter, d. h. nicht bhs die Rosen. sondern alle lichtliebenden P'lanzen vergü̈ssera ihre lichtabsorbierenter und assinilierende Blattuberliache, wihrend die Ibicke des Blattes abmimnt.

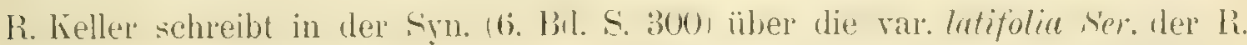
pemblime $L$. wörtlich: "Nich meinen vieljährgen Beobarchtungen in Brühlhachtale bei liyhurg (Winterthu') ist var. lat. eine Standortsmodilikation, die durch die besmuleren Beleuchtungsverhältnisse bedingt wird. Der gleiche Strüch, der am schattigen Standorte ausserordentlich grosse Laubbläter nancndlich an den Schösslingen trieb, wurde, nachdem er infolge eines Kahlschlages einen sonnigen Standort erhielt, normalbliattigg." ${ }_{1}$ Schwacher und zerstreuter Beleuchlung ist heе uns eigentlich nur die meist an Waldrändern, in Waldblissen und im Gebüsch Withsende li. arvensis angepasst. Die übrigen unserer Rosen suchen das direkte Licht und zeigen die obige Schattenmodifikation.

Meines Wissens noch niemals betont wurde das Verhältnis von Grösse und liestalt der Schösslings-zu den sonstigen Laubblittern der Ruse. Es zeigen nïnlich die ersten, untersten Blätchen der ans dem Bulen kummenten Ansläuferschösslinge die offenkundigen Charaktere der Etiolierung infolge ihrer Anlage und Ausbildung im Schatten les Eribudens. Die untersten sinel whne alle Blattspreite, schuppenförnige Niederbliiter: aber auch die weiter nach oben folgenten sind relativ klein und mit ganz schmaler Spreite versehen. Erst die obersten Blatter der Bodenschösilinge und diejenigen der unfruchtharen Langtriebe exhalten eine normale Beschallenheit und eine Grösse, welche diejenige an fertilen Zweigen meist beträchtlich ïberragt. ${ }^{2}$ ) Diese Blattbeschallenheit desi sich entwickelnden Sprösslings hat den Nutzen, Naterial zu sparen, Wo die Asinilation noch nicht erfolgen kann, und das Ausschieben der Achsen ats dem Boden zu erleichtern.

Als ein Schutzmittel gegen das Licht und die Temperaturextreme werden dies Hare gebildet. K. Baument hat nachgewiesen, dass die Hanbekleidung

1) Die abnehmende Beleuchtung und dadurch erfolgende geringere Transpiration ist es, auf welche W. Brenner (a. a. O. S. 135) bei verschiedenen japanischen und javanischen Eichen die beobachtete Tendenz zu stärkerer Zahnbildung zurückführt. - Alle Schattenblätter von Eichen zeigen nach Brenner schwächere Konsistenz. Die Versuche, welche J. Bergen an immerurunen Pflanzen angestellt hat (nach der But. Zeitung 1905 No. Y), führten ebenfalls zu den Resultat: Die Schattenblätter sind stets grösser und schwächer transpiricrent. die Somenb)ätter kleiner, dicker, mit nach unten eingerollten Blatträndern.

2) Vorläufig sei schon hier angemerkt, dass auch die unteren Stacheln eines Sprosses vom Typus abweichen: sie sind nämlich stets viel dünner und gerader als diejenigen von fertigen Achsen. Es fehlt die hakige Krüunmung nach unten, welche inshesondere die stitcheln der Sect. Rubiginosae und Caninae auszeichnet. Bei dieser Abweichung dïrtten erstens mechantselis. Lrsachen mitspielen, zweitens das Werfallen des Zweckes einer Schutzvorrichtun. We sie hakige Stacheln darstellen, bei bodenständigen Sprösslingen. 
von Blïttern lecht betriichtliche Mengen von Licht- (und damit Wïme-) strahlen zerstrent und auf diese Weise vom Blattgewehe ablenkt. So wurde ein seiner Filzbeklevilung an der Uberseite beraubtes blatt von Centaurea candidissima

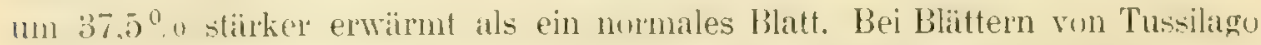

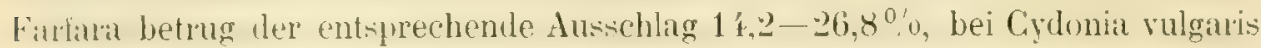
11.8 usw. $\left.{ }^{1}\right)$ Es wird demzufolge bei den Rosen nicht anders sein, und die Uatirbeklerilnug zunäichst ein Schutzmittel gegen Licht- und Wämeschädigmng ditrstellen. Dit' Schäilen der auch in tropischen und subtropischen Wiisten-

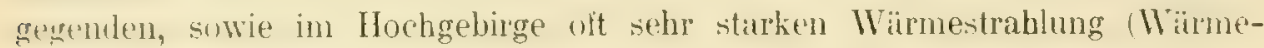
abgabe gegen die Atmosphäre) werten duch die Haarbedeckung ebenfalls gronildert, also Kälteschutz erzielt. Alle disse Schä̈ligungen wirken am verhïngnisvollsten bei jungen Blättern und in Kilima der gemässigten Erdenzonen im Frühlinge, der Entwicklungszeit der Blitter und des pflanzlichen Lebens iilerhaupt. Wir finden deswegen häufig wie bei anderen Pflanzen so bei den lissen eine Behaarung junger Blätchen auf beiden reiten, die später wieder verschwindet oder stark abnimmt (die Blïttchen verkahlen). Starke Anthocyanbildung (von ihr weiter unten) gewäht ähnlichen Schutz; wo sie eintritt, fïllt die Hatrbedeckung aus und umgekeht. Die Unterseite ist stärker behaart, weil sie dem wasserführenden System näher liegt (mechanischer Grund!); auch ist sie hei der Enthaltung der jungen Blittler nach aussen gekehrt und hat deswegen stiitkeren Schutz notwendig. Gewöhnlich werden die Haare an Blättern und Achsen auch als Schutzmittel gegen allzu starke Transpiration, also gegen Trockenhteif angesehen, besonder's wenn die Spaltöfnungen mit Haaren überwathen sind. $\left.{ }^{2}\right)$ Ist der Haarfilz dicht, wie bei R. tomentosa, manchen coriifolia und dumetorum, so kann man das auch für die Unterseite, die bei Rosen allein Stomata trügt, gelten lissen. Wenn jedoch nur Mittel- und Sekundirrnerven behart sind, wie bei vielen erwachsenen Varietäten dieser Rosen, kinn von Transpirationsschutz kaum mehr die Rede sein. Rosen, die regelmaissig weder Haate noch reichlicheres Anthocyan auf den Blättern entwickeln, verraten eine besonder's gemässigte, von Extremen des Lichtes, der Luftbewegung und der Temperatur freie Heimat. Hier wäre insbesontere zu nennen: R. comim.

Wir kommen endlich auf die wichtige Rolle zu sprechen, welche das Anthreyan orler Cyanthhyll ${ }^{3}$ im Leben und in der Beschatfenheit der Organe wie bei andern Pllanzen so insbesondere bei den Rosen spielt. Um den Gedankengangr nicht zu unterbrechen, fassen wir hier Alles zusanmen, was äber diesen Gegenstand beim Genus Rosa zu bemerken ist, obgleich Manches ehenso gnt bein Kapitel vom Einfluss der Wäme und Anteres in jenem von der liedentung der Luft (Alpenpflanzen!) seine Siclle finlen könnte. Anthocyan int , der Gruprenname für die besonders in belichteten Pllanzenteilen häulig vorkonmmenton polen his blauen Farbstoffe, welche sich in Siate der Zellen gelöst

1) K. Baumert: Experimentelle Untersuchungen über Lichtschutzeinrichtungen an grünen Blättern (Beitr. z. Biologie d. Pflanz, 1907 Bd. 9 - von mir zitiert nach „Naturw. Rundschau" 1908 S. 358 f.).

2) Vgl. hiezu G. Haberlandt: Physiologische Pflanzenanatomie, 2. Aull. Leipzig 1S96 S. 110 ff.

3) Auch „Erythrophyll ${ }^{*}$. 
finden."1) Im engeren Sinne versteht man iarunter die Farbstolle der" Winrotgruppe, die gegen Sïmren wie Alkalien sehr empfindlich sind:") im weiterem gehöron dazu auch diejenigen des Riibenrots. Tber ihre chemische Natur steht noch immer nichts. Ficheres lest. Nich Gantier besteht das "Onocyan" blanel"

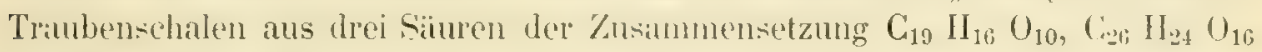
und $\left.C_{17} \mathrm{H}_{18} \mathrm{O}_{10} ;{ }^{*}\right)$ nach Vilitor Grafe alls zwei urganischen Verbindungen

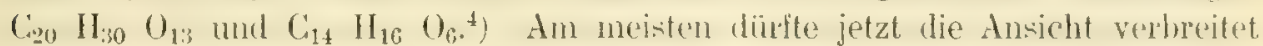
sein, es hamble sich nm Verbindungen ron Gerbstolfcharakter, elwa Girbstoffghlukuside. Den ITeg zum Verständnis der ükulugischen und physiologischen benleulung des Anthocyans hat uns bereits Kerner von Marilam in der el'sten Aullage seines geistrollen Buches: "Pilanzenleben" (Leipzig 1891) crifinet, wo er an versehiedenen Stellen der beiden Bände üher das Anthocyan der Pilanzen im allgemeinen spricht. Andere Forscher, wie H. Molisch, O. Gertz, h. Karzer, G. Tischler, L. Buscalioni, G. Polace, O. Richter, H. Fischer, (r. Klets, ()verton, B. Lilforss und $\mathrm{I}^{\mathrm{T}}$. Palladin schritten aul diesem Wege weiter. ${ }^{5}$ ) Meine Ansichten Imrl Resultate rïcksichtlich des Anthocyans besonders bei den Rosen lasse ich in fulgenden Leitsïtzen zusammen: 1) In der Gattung Rosa bilden Anthocvanc (und zwar Öneyanin den Fabbstolf der roten kronen, der blaurolen, roten und bläulichen Blätter (zusammen mit Chhrophyll - R. rubrifolia, R. glauca), der roten Blattnerven nnd Vebenblitter, der violettschwarzen (R. pimpinellifolia) und roten ${ }^{6}$ Friichte und der bläulichrolen und robramen Rinden (R. cinmanomea). 2) Für seine Entstehung ist neben einer gewissen Anlage vor allem in Ansuruch zu nehmen stiukere Ernährmng. Diese wird gewöhnlich erziclt durch rine stïrkere Assinilationstätigkeit; diese aber zeigt sich abhängig vom ciratd der

1) S. 201 v. H. Euler: Grundlage und Ergebnisse der Pflanzenchemie I. Teil, Braunschweig 1908.

2) Gewöhnlich liest man über die Farbenreaktionen des Anthocyans unrichtige oder doch ungenaue Angaben. Wie man sich an dem bequemsten Material, dem Absud von Rotkohl oder Blaukraut, leicht äberzeugen kan, hat clieses Anthocyan in viilig neutraler Lisumg blaue Farbe, durch Spuren von Såure wird es rot und durch Alkalien oder Basen grün. Da bei der Entwicklum der Blätter und sonstiger Pflanzenteile im Frähjahr der Zellsaft Pflanzensïuren umi saure Salze enthält, bedingt dann vorhandenes Anthocyan stets rote Färbung der beir. Organe. Das Onocyanin der lebenden Traubenschale ist mehr blau (blaue Trauben!); im stels melir oder minder säurehaltigen Wein gelöst wird es aber entschieden rot (roter Wein!). Wenn junge, sich eben entfaltende Blüten von Pulmonaria und anderen Boraginaceen rot, und ältere, angeblich schon befruchtete, blau erscheinen, so beruht das nach meiner Ansicht ebenlalls auf dem Vorhandensein von Säuren in sich entwickelnden Zellen und dem Verschwinden derselben nach dem Auswachsen. Das Rot der Apfel, der Früchte von Rosen und vielen anderen Pflanzen und der Laub- und Kronblätter der Rosen gehört ebenfalls zur önocyaningruppe, denn es lässt sich nach meiner Untersuchung sehr leicht durch verdünnte Natronlauge ïber Blau nach Grian überfílhren. Alkalische Reaktion ist in der Natur wohl kaum jemals zu beobachten, also auch nicht die Grünfärbung des Cyanophylls.

3) Bei Euler: Grundlage usw. S. 202.

4) Naturwiss. Rundschau 1907 S. 293.

5) Vgl. den zusammenfassenden Artikel ïber "Anthocyanbildung" von E. Kister in: Progressus rei botanicae II. Bd. 4. Heft S. 512 ff. (Jena, 1908) und das Sammelreferat „Ober Anthocyane" von G. Tobler (Naturwissensch. Rundschau, 1907 S. 652 ff.)

6) Nicht etwa "Caroten" (Rübengelb). 
Belichtung, vielleicht anch von der Vermehtung der ultraviuletten Strahlen. Die bei Torwundung häulig zu beobitchtende lukile Anthocyanbildung beruht elenkills and der lokalen Zunahme der Nihrstulte infolge ron Regentutionsstrimungen. ${ }^{1}$ ) 3i Dje Entstehung von Anthoryan wird bergüsligt dureh lialte

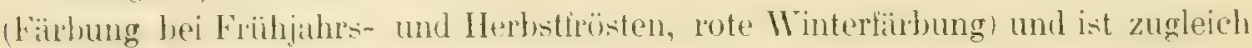
eine Anpassung zur Abwehr der schädlichen Eüwirkungen der lï̈lte, da durch

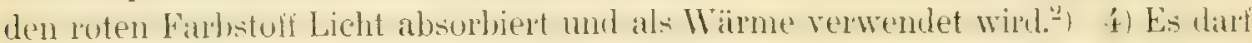
die (fuantitative Lorrelation nicht iibersehen werden, welche zwischen der Bildung ron Anthocyun und der Behaarung von Planzenteilen besteht: beille stehen im ungrkehrten V'erhälnis zu einander. Wo die Beharmong schiitzt, wirkt das Licht und die Kälte weniger ein, und ist das Anthocyan auch überflüssig.

Nach Kerner ${ }^{3}$ ) stimmen alle Beobachter darin überein, dass die Menge des Anthocyan mit der stïkeren oder schwächeren besonnung der betrelienden P'lamzenteile zu- oder abnimmt. Auch die spaiteren Erklïmugen schalten das Licht als wichtigsten Faktor für die Assinilation und damit die kntstehung des Anthocyuns nicht ans. Ireil in den Gelirgsgegenden mit zunehmenter Jöhe die Inlensitil der Somnenstrahlung wirchst, treten an den Pflanzen in hohen (ithirgslagen die Mirkungen des Lichtes in besonders ansgepräigter Weise lorvor. Pilanzen der Ebene, welche Kemer in seinen alpinen Versuchsgarten auf dem Blastr (2195m) bei Matrei übertug, entwickelten in ihren weisen Kromen violettes Anthocyan (z. B. Libanotis montana) vder verstiitkten die rutviolette Farbe ihrer lironen in auffallender Wrise (Agrustemma Githago, Campanula musili, Lotus corniculatus usw.); wieder andere, und zwar sehr viele, bidelen Anthocyan in Iochblätern und Liubblittern. Ahnlich wirkt ununterbrochene clektrische Beleuchlung, deren Reichtum an ultravioletten Strahlen bekinnt ist. Die ultravinlelten Strahlen sind nach Sachs auch bei der Blütenbildung üherhaupt in hervorragendem Masse beteiligt. ${ }^{4}$ Wenden wir das Gesagte auf die Rosen an! Rosen des Hoch- und Mittelgebirges zeichnen sich durch reiche Bildung ron Anthocyan in allen Blattorganen aus und bewahen diese Eigentümlichkeit wenigstens lingere Zeit hindurch anch in niedrigeten liegionen. Das auffallendste Beispiel liefert die R. mbrifolia Till. Blälter und

1) Nach W. Palladin gehen die Anthocyane durch Oxydationsvorgänge aus gewissen Chromogenen hervor, welch' letztere als Sauerstoffübertriger von der Oxydase (Oxydationslement I auf die zu oxydierenden Substanzen dienen. Es wird hier also das Hauptgewicht bei der Erklärung der Bildung von Anthocyanen auf vermelirte Oxydation und nicht auf vermehrte Assimilation bz. Belichtung gelegt. Vermehrte Belichtung und Assimilation vergrössern die Anthocyanbildung dadurch, dass der Veratmung (Oxydation) grösserer Spielraum gerfeben und auch die nachherige Reduktion zu farblosen Chromogenen verhindert wird. (Ber. d. bot. Ges. 1908 S. 378; Ref, in "Naturw. Rundsch." 1908 S. 523 ff.) Diese Hypothese hat ihre schwachen Seiten, erklärt aber besonders gut das Auftreten von Anthocyan bei Verwundungen und dem buminenten Absterben von Pflanzenteilen, weil hier die Oxydationsprozesse besonders lebhafte sint.

B. Lidforss ll her den biolog. Eflekt d. Anthoryans in „Bot. Notiser", Lund 1909, S. 65-81; nimint als Basis Zucker und Gerbstoffe an.

2) Weil Anthocyan in seinem Absorptionsspektrum sich komplementär zu Chlorophyll verhält, lïsst es die assimilierenden und zugleich das Chlorophyll zerstürenden Lichtstrahlen hurch. Es kamm also nicht, wie Kerner will, als Lichtschutz dienen, dagewen wohl als hälteschutz.

3) Pflanzenleben II. S. 504.

4) Schimper a. a. 0. S. 73 und 67 . 
Achsenorgane sind auf allen Seiten mit Anfhoryan effïllt:12 daher das dekonative. an Kupfer erinnernde Aussehen dieser häulig angenflanzten Ruse: ulen eigentünlichen Schimmer erhalten ihe Bläter dureh Wachsbildungen aud der Epidermis.

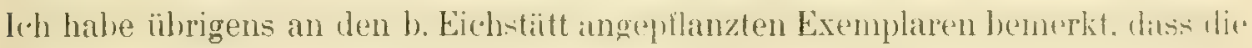
Blätchen zunächst bei der Entwicklung ats der linuspe arm an Anthucyan waren

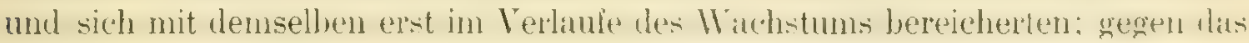
Ende des Hochsommers trat jefloch dor Anthoyangebalt relativ wieder gesen dats

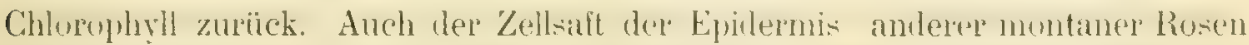
ist reich an Anthoeyan und verleiht den Blätchen vine dunkelviolettgrïne Tönnng.

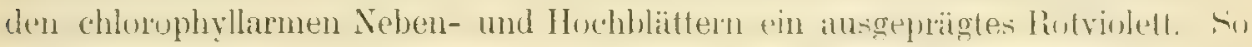
bei der R. glauca Till. (deswegen ron Godet zuerst R. rubrifolia genamut), der R.

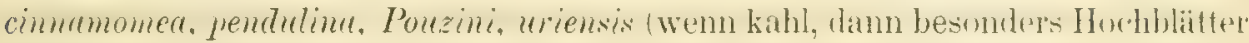
rot angelaulen), montana (Neben- und Hochblätter violett überlauleu): anch li. frimpinellifolia zeigt etwas den bläulichen Schimmer der Blättchen. Ganz dazn stimmt die Korrelation mit der Behatrung: alle Gebirgstosen nit stark buhatrten Blätchen entbehren des Anthocyans. su h. pomifera, corifolin, die screbriusculn-Gruppe der R. tomentosn. R. alietina; die rubiginosa-Gruppe zeigh sinurn

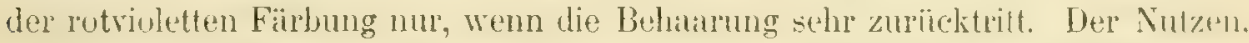
den diss Anthocyan den Gebrirgsiosen gewähth, wird also durch dite Behaurung elenfalls gurantiert, oder - Anthocyan wird nicht gebillet. weil die Besumnung durch das Haarkleid abgeschwächt wird. - Auch die Kronen der fiel)irgisusen Weisen eine kriftigere, dureh unseren Farbstoff bewirkte Färbung and, man denke

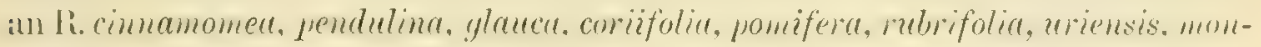

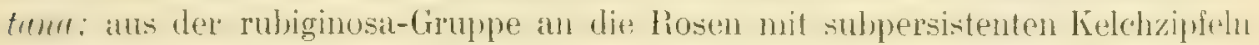
und wolligen (irilfeln, also) R. relieginose und elliptice (var. culderea!), withrend micrantha und agrestis blase Fïrbung besitzen. Eine auffillige Ausudhme maroht

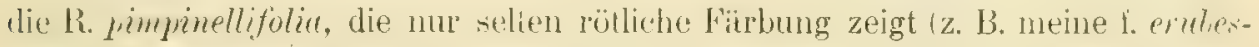
cens). Aber merkwärdiger Wejse ist dafür Fruchthecher, Kelch und Frucht um su reicher an Anthocyan, welches die reile Frucht schliesslich ganz schwar\% tiirbt. ${ }^{-3}$

Kerner glaubt mit Unrecht, das Anthocyan sei als Schutzmittel für das darunter liegende Chlorophỵll ausgebildet; aber mit Recht, dass es als flumreszierender Farbstoff Licht in Wiirme umzusetzen und so der Planze zu niitzen vermigge. ${ }^{3}$ Er führl zahlreiche beispiele an zu Erhürtung seiner Ansichl. Dasdas Anthocyan in den Blättern und Blattschuppen als Schutzmittel gegen den Frost ausgebildet werde, habe ich in gar manchem rauhen Frïhjahre beobachtet. So nahmen in Frïhjahre 1902, wo noch im Hai in Ëichstät Räckschläge bis - $1^{0}$, in Irä̈rburg sugar bis - $3^{0}$ Ciels. beohachtet wurden, und das kalte Wetter andanternd seine Wirkungen auf die Vegelation geltend machte, sowohl die schon ganz (ntwickelten (Ribes Grossularia) als dis nuch nicht ganz entfalteten Blätter nachträglich eine aullallend ruthrames Färbung an. Ich beobachtete dies besonders stark an der Oberseite von Blälferh

1) Das Anthocyan erfüllt hier nach meiner Untersuchung den Zellsaft der Epidermiszelien hauptsächlich über den Gefässbündeln, Nerven und Nervillen.

2) Ob nicht die Frühreife der Frucht von R. pimp. zum Teil auch von der starken Anthocjanbildung bedingt wird?

3) Kerner a. a. O. I. S. 486, II. S. 216. 
dep lietherize, an Blattrand von Acer "ampestre, an Lonicera Xylosteum, Conylus Avellana, Vihurnm Lantana, an ganzen Blatt (Uher- mol Lnterseite) von Ribes Grusularia (fast in jedem Frihiahr zu sehen), auch etwas an Weiss- und liotfuchen, sowie an hosen. Gewöhnlich ist die Farbe einseitig ansgebihet und sitzt an derjenigen Seite, die der rauhen Luf ${ }^{1}$ ) an meisten ausgesetzt ist: an

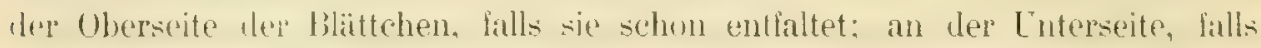
sic zwar alls der linuspe entschliipht, aber nuch zusammengelaltet sind: lediglich an libultand, halls sie then aus der hnopu heranslugen. Besonder's intensiv rot sind auch die Knospenschuppen, z. B. beim Feldahorn und bei vielen

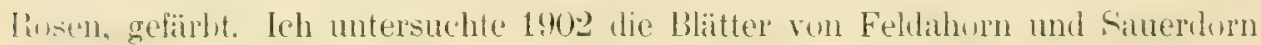
mikroskmprets und fomd, dass die Fatbe ron purpurotem Zellsilf herrïhrt, de' auch dibe Mesuphỵllzellen der betr. Seite, also entweder das Palisaden- ale. S'chwammparenchyn, erfüllt, und zwar last ohne Lücken alle Zellen. Dingler' macht cbenfalls aul die Anthoeyathldung bei Rosen während der Entaltungsferinde autmerksam, sowie auf die: Assymetrie, mil der dieser Farbstofi anf der Unterseite der sich entwickelnden Blättchen auftritt. Er bildet sich eben nur an den zuerst treigelegten Blattliichen. ${ }^{2}$ ) Lexchte Anthocyandildung ist ïhrigens: bei der Knospenenthaltung der unhehataten hosen ganz allgemein; sie verschwindef jedtoch neist wieder, wenn die Lichtgewihrung cine grössere geworden und der Schutzzweck weggelallen ist. Die angeliihnten Beobachtungen heweisen jedenlalls, dass bei eintretender liiite das Anthocyan atultritt und in irgend einer Weise den protoplasmatischen Inhalt der Zellen gegen Frostbeschädigung schützt; ${ }^{3}$, ub durch Wïmeerzeugung, ist wahrscheinlich, aber nicht sicher. Wichtig erscheint auch die Beantwortung der Frage, ob das Anthucyan der Pflanzen in erster Linie durch den Frost und in zweiter durch das Licht hervorgebracht wird, oler in welchem Verhältnisse diese zwei Falitıren überhaupt zu einander stehen. Vielleicht gibt daruber die Tatsache einigen Aufschluss, dass bei sehr rielen Pllanzen der nördlichen Kilimate, und insbesondert des Ilochgebirges, eine zweite Jahresperive der Anthocyanbildung aultritt, nämlich im Herbste vor dem Laubfall. Auch hier wird Anthocyan erzeugt durch die kombinierte Wirkung von Licht und gelindem Frost. Pleffer schreibt: "Auch ist ötters die herbstliche Rotfärbung ron der Belenchtung abhängig. die erst Erfolg hat, nachdem sich im Spätjahre die Reaktionslähigkeit einstellte, deren Ausbildung vielfach durch niedere Temperatur beschleunigt zu werden scheint. Von tinel Erniedrigung bis unter den Gefrierpunkt und gleidhzeitiger Belenchtung hängt ferner die Vorfirbung der Conileren im Winter ab, die durch las Aulteten eines bramen Farbstoffes und dureh die partielle Desorganisation der Chlorophyllkïrper herbeigeführt wird." $\left.{ }^{4}\right)$ Weil nun zweifelsohnt leststeht, lass das Licht

1) Und dem Lichte? Dieses wirkt wenigstens bei der einseitigen Entstelung von Anthocyan mit.

2) G. Dingler: , thber Assymetrie in der Drüsenanordnung und Rotfärbung bei den Ficderblittchen mancher Rosen." Aschafenburg 1906 (Sep. aus. Mitt. d. naturw. Ver. A. S. 8 f.)

3) B. Lidforss betont ebenfalls die hohe Resistenz rotblätteriger Pflanzenvarietäten gegen

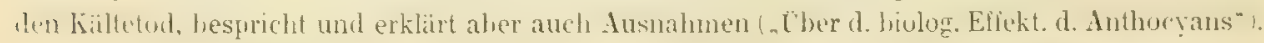

4) W. Pfeffer: Pflanzenphysiologie. 2. Aufl. Leipzig, I. Bd. 1897 S. 497 f. - Das Phänomen der herbstlichen Rotärbung schildert Kerner besonders eindrucksvoll a. a. O. I. S. 453 If. 
allein, ohne Frost, starke Bildung von Anthoryan hervorpuft fRotfiulung der Friichte an der Sonnenseitu, während im umgekehrten Fall hödhstens gian\%

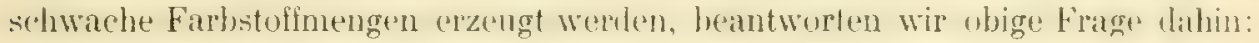
starke Besonnung ruft die Bildung ron Anthocyan hervor; dieselbe wird jedoch erst dann merklich, wenn Erniedrigung der Temperatur bis zum Gefrierpunkt dazutritt. Durch die Bildung von Anthocyan ver-

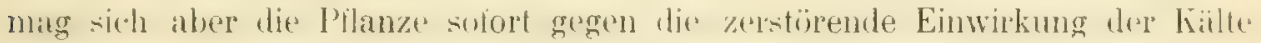
zu schützen, indem sie sichtbare Sonnenstrahlen in Wärme umwandelt.

Und nun verstehen wir ganz den Reichtum der Gebirgspflanzen und der

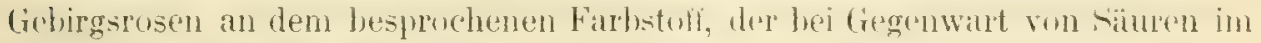
Zellsalt verschiedene Abstulungen von hot zeigh, sonst mehr blan und in chlorufhylhaltigen Teilen blaugrün anssieht. J)as fiebirgsklima konnzedohnet sich sowohl durch grelle Lichteinwirkungen bei Tage als auch durch Frostrückschläge bei Nacht selbst in der Vegetationsperiode. Diese äusieren Vorbältnisse schufen unmittelbar katusil oder erzeugten mittellar durh Anpassung den Farbentypus der montanen Rosen.

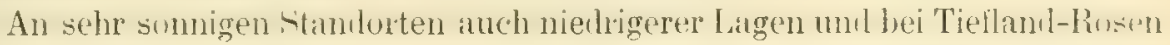
kinn man häufig beobachten. wie die nicht durch Haare geschiitzten Leitungsbahnen, also die Blattnerven und Blattstiele, eine auffallende rote Anthrcyinfirbung andweisen, die dem Mesophyll nicht eignet. Ausiter den in don.

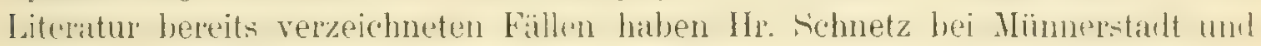
ich bei Eichstät solche Formen hauptäichlich im bereich der h. glanca uml

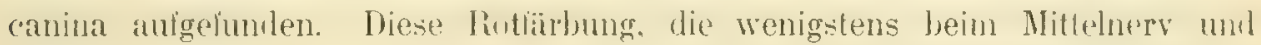
Blattstiel anch auf der Obersedte des Blattes deutlich werden kann, wind bei ungemein vielen Pflanzenarten und in Humlerten von Planzenfamilien linstatiert. Sie reicht nach lierner gerade soweit, wie die darunter liegenden (iefissthündelschreden. Sie kann weder eine Bedeutung fïr das Chlorophyll hesitzen, da die entiprechenden Gewebe desiselhen enthehren, noch darf man etwa gemäsis den modernen Èkläungsversuchen an eine Erzengung von Anthocyan durch Nibhrstoffiiberiluss Stärke der (ielä-shïndelscheilen!) oder dgl. allein denken. Tas wird Wohl ausgeschlussen durch den Lmsland, dass an beharten titielen und Nerven. die gerarle so reich an Stiake sind wie kahle, Farbstotibildung unterbleibt vider bei spärlicher Behandung nur spurenweise antritt. Durch die Haare wird uflenbar das Agens abgehalten. Welches zun̈̈rhst die Anthocyane hervornft. l'rmagg dies ein anderes $z u$ sein als ein solches, welches von aussen einwirkt, also wiederum Licht uni tiefe Temperalur? Darum entsteht die Rotlanbung der Norven schon in Frihgiahr an den eben ans den Linospenschupen trelenden nuch zusammengelalleten blittchen und verbreitet sich viellach erst von dit und rom Blattrande aus auf die Nervillen und die übrige Blattiläche. Das lïst sich besonders deutlich an der R. rulwifolia beobachten, die anfïnglich blosis an Nerven und Blatland Anthoryan zeight, nach einer Woche aber bereits auch auf der (Oberläche der Blittchen solches entwickelt. ${ }^{1}$ So angesehen wirt as auch verständlich, wio die blattnerven vom Lichte gerötet werlen kïmmen. die doch an auscrebildeten Blïtchen hauptsïchlich ant der Lnterseite aus dem

1) Beobachtung an im Freien bei Eichstält gepflanzten Exemplaren der R. rubrifolia. 
Mesuphyll hervontreten. Die Farbung entwickelt sich eben zuerst an der in del limspe nach oben gekehrten morphologischen Lnterseite und bleibf hernach Imter Lunsianden bei der definitiven Ausbildung und Stellung des Blattes "rhallen. Hervorgerufen durch gemeinsame Einwirkung von Licht und häite pussistient sie ansnithmsweise wegen der ïhervollen Produktion oller durch rine Ant Entwickelungohemunng, die dem Blatte zeitlebens juvenilen Chankfer belïsst, der wohl öfter sogar vererbt wird ( $\mathrm{R}$. canina var. montixaga $\mathrm{u}$. dgl.). Iramm abes entsteht gerade aut den Nerven und nicht ebensogut anf denk Mrsiphyll, ja zuerit aut letzterem die fragliche Fïrbung? Antwort: weil Licht иm! Tompreatur ant ein vorhanlenes Nïhrstolsubstrat einwirken müssen, um in ihm Anthocyan zu erzengen. Nährstoffe wandorn aber, wenigstens im FribGuhr ror der vollendeten blattentwicklnng und im Herbst bei der Rïckwanderming der Assimilate ins Holz, ausirchliesslich in den Geliistoündeln und in den sie ungebenden Gefässbüudelscheilen. Es gelmont also auch die modermste Ansicht von der Anthoeyanbildung zu ihrem Recht. - Selbst das Licht. allein (ohne Kitite genïgt äter zur Rothirbung won Leitungshahnen. Die Hauptbattstiele ron Rosen wie liejengen von Lirsehenblïttern u. a. pllegen durch die Sommersume aul der ()herseite dumbler rot gelinbt zu werlen, als es die Einwirkungen des Frühlings aul der Lnterseite vermägen. Junge Achsen ron Rusen sim wie bekamnt auf der Sonnenseite in der Regel durels Anlhocyanbildung rotbriun getitbt. Betrifit das den ganzen Lmbing der Zweige. wie bei der R. cinnmmea. su haben zur Entstehung sulcher Formen andere klimatische Verhälnisse serit Jahrtansemden oder vor Jihntausenden milgewirkt, zunächst aber die hïlte einer nordischen Pflanzenregion.

\section{Kapitel: Die Luft.}

Wenn wir vom Wassergehalt der Luft absehen, welcher im Kapitel rom Wilssere hinlainglich Berïcksichtigung gefunden hat, kam sie eine differenzierende Ënwirkung aut Planzen erlangen durch ihre Buregung. Die Rosen zeigen sich in inren blïltern dem Winde angepast, dem sie besitzen Fielerblätchen vom Typus der Eschenblätter. ${ }^{1}$ ) In der Tat wachsen sie sehr vorwiegend an frexu. den Minde ausgesetzten Abhängen und schützen durch die Elastizitiat umi fichankellewegung ihre Blitter vor mechanischen Verletzungen. Ihre in Fieder zerschnitenen Blattspreiten hesitzen durch die Vergrösserung der Transpiration eine erhöhte Assimilationstätigkeit.

Bei zunehmender Meereshöhe nimmt entsprechend der Luftdruck ab.

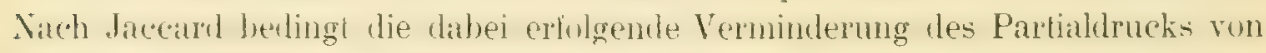
Sintertulf trotem ein beschlemigles Wachstum, zweitens eine reichere V'erzwrigung der Achen und 1 Tureln. $^{2}$ ) Freilich wid dieser Einfluss erst bei sehr betrïchtichen Höhen deutlich, und mag es lraglich erscheinen, ob wir ihn für die cmoüischen Gebirgsosen in Rechnung setzen clïrlen. Es wird jedoch an der Stelle sein, hier beim hapitel ron der laft und der Verschiedenheit des

\footnotetext{
1) A. Hansgirg: Phyllobiologie, S. 127.
}

,2) Bei Schimper a. a. O. S. 78 f. 
Lufthlucks auf eine der wichtigsten morpholugischen Eigentïmlichkeiton von Ciebirgsasen einzugehen, ihre Abweichungen in Wuchs, Bildung der Frachtbecher samt lielchen und der Griffel. Dats Höhenklina wim charakterisiort ausser dureh die Abnahme von Luitdruck und Sauerstoffspannung durch krätigere Insulation und grösseren Reichtum des Lichtes an stitrker hrechbotren

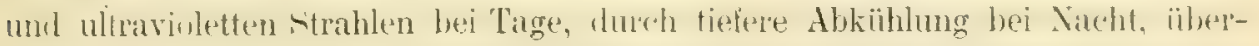
hatupt bei der geringen Wïmestrahlenabsomption durch Emiedrigung len

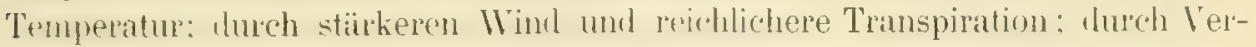
mohrung der Niederschliggen, wengstens bis zu einer gewissen Höhe: durch

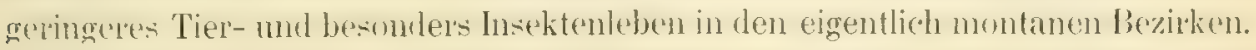
Inen Einfluss, Whehen die Eigentiumlichkeiten des Lichtes, der Temperatur und der Hydrometeore auf die Rosen des Gebirges ausüben, haben wir schon bespruchen. Die alpinen hosen zeigen eine geringere Bewehrung durch Shatheh

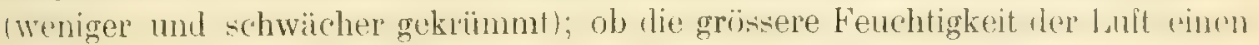
Einfluss wenigstens auf die Form der Stacheln ausübe, ist fraglich. Wahrscheinlich ist ein anderer Faktor heranzuziehen, und kommen wir spiiter aul diesen Punkt zu reden. Dagegen ist es sehr auffallend, dass Gebirgsrosen von

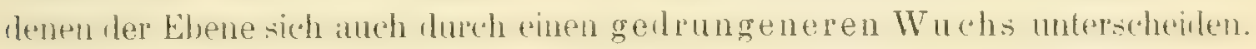
Dieser Habitus tritt uns, wenn wir uns auf europäische Rosen beschrïnken,

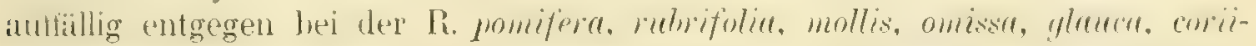

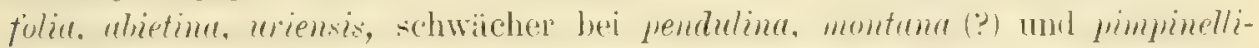
fotia, sowie der R. cimnamomea, die aber gerade in hochalpinen Varietäten, wie der var. fulgens $C h$. vom Wallis durch Kurzästigkeit sich auszeichnet.

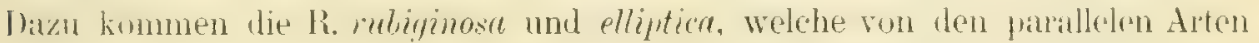
micrantha und agrestis durch gerlpungenen Wuchs verschieden sind. Es sind das, vorläufig bemerkt, auch die Arten, welche die nachher zu besprechenden

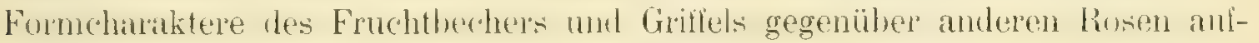
weisen. Der kompakte Wuchs von Gebirgsrosen scheint nun aber bedingt

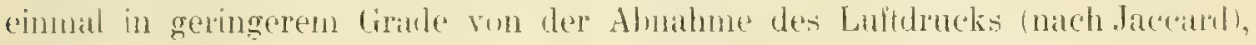
dann - und dies wird in den meisten Fällen wichtiger sein - von der starken Luitbewegung; denn die Verkïrzung der Achsen stellt eine Schutzatupasiung dar. Ausserdem bewirkt das intensivere Licht der Bergregion nath Bomier und Kerner eine Verkürzung der Achsen. Jedenfalls haben die Versuche der beiden genannten Forscher bewiesen, dass die Versetzung von

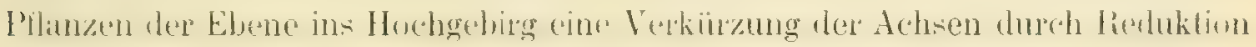
ihrer Länge (nicht etwa eine Verringerung der Internodienzahl) zur Folge hatte. $\left.{ }^{1}\right)$ - Ich mache auf eine wichtige Konsequenz der Achsenverkürzung

1) Her. $\therefore$ Weinzierl (Wien) hielt auf der 79. Versammlung deutscher Naturforscher und Xrzte zu Dresden, 1907, einen Vortrag ïber: „Heranzüchtung von neuea Pflanzenformen unter dem Einfluss des Alpenklimas". Der Vortragende hat mit Futterpflanzen und Unkrautgrïsern der Ebene experimentiert und nach seiner Aussage durch die Kultur water dem Einflusse des Alpenklimas eine Anzahl neuer Kulturpllanzen für den Alpenfutlerbau gewonnen Nach ihm äussert sich der Einfluss des Alpenklimas, in morphologischer Hinsicht hauptsïchlich in ciner Verkïrzung der Stengel (Internodien), in ciner dichteren Stellung der Blätter, in einer Vertrüsserung der Blaltspreiten und in stärkerer Aushildung von Ausläufern wie der vegetativen Organe überhaupt. Durch das zuletzt genannte Mlerkmal wird naturgemäss die Lebensdauer 
aulmertsimn. Wril die Influnesenz der Rusen mur das uberste Siück des Sprosses darstelit, müssen auch bei ihr die Achsenorgane montaner Rosen sich verkïrzen, folglich auch die Blïtenstiele der einzelnen Blüten. ${ }^{1}$ ) livhirgsusen haben deswegen ganz vorwiegend kurze Blittenstiele, so h. pomifera

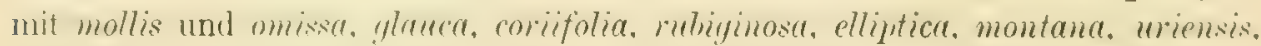
cinnumomen. Ëngè wechseln stark, pimpineflifolia und pendulina haben merkwiirdign Wrise zicmlich lange Bliitenstiele. Bei ihnen ist aber auch der untersetole Wuchs nicht su statk ausgenriggt. Woher die Abweichung zu erkliaren ist, kam ich vorliutig nicht sagen. R. pimpinellilolia zeigt äbrigens mehrfach - Hhwankungen, durch die sie sich ron den typischen Gebirgstusen entiernt. Leide erscheinen lïnger gestielt als sie wirklich sind, weil sie der Hochblïtler enthehren, während Rosen mit breiten und grossen Hochblittern - entsprechend der Breite und Grösse der Blättchen überhaupt - wie R. pomifera, glauca, coriifolia - ihre Blütenstiele fast verschwinden lassen.

Wir wenden uns nun zu jenen beiden Merkmalen der Bergrosen, persistente oder subpersistente Kelchzipfel und wollige Griffel, welche mit einander in Korrelation zu stehen scheinen. Zuerst J. G. Baker, dam Burnat und Gremli haben auf sie die Anfmerksankeit gelenkt; II. Christ ist auf diese und die andern Eigentümlichkeiten der Bergensen näher eingegangen. ${ }^{2}$ ) Gegeniiber den Einwendungen Crephins rechtertigt der verdienstrolle Rosenfurscher I. Dinglev die, Aufstellungen Christs in durchaus ïberzengender Wrise: für birgrusen oder doch nordische Rusen sind obige beide Merkmale in der Tat bezedchend; etwaige Ausnahmen können durch zufïllige störende Einflïsse erklärt werden. ${ }^{3}$ ) Dingler stellt anch einen ,Erklärungsversuch" auf, ${ }^{4}$ ) der aus der Biologie des Rosenkelches argumentiert. aber weniger auf die Wolligkeit der Grillel als die Persistenz der Kelchblätter bei Bergrusen Rücksicht nimmt. Er fasst die Kelchblitter als Assimilationsorgane auf, die, wenn sie linger elhalten bleiben, "hurch ihre fortgesetzte assimilatorische Tätigkeit zu gnunsten der sich entwickelnden Scheinfrucht in Betracht kommen." Dadurch wird in einem sonst wenig geeigneten Klima lebenden Bergrosen genït. In der Tat

der Pflanzen verlängert und die Erhaltung der Art von der in der alpinen Region unsicheren Vermehrung durch Samen unabhängig gemacht." (Naturw. Rundschau 1907 S. 618.) - Ein Teil dieser Beobachtungen bestätigt frühere Erfahrungen von Bonnier und Kerner, die zuletzt genannte dient zur Bestätigung meiner Erklïrung der montanen Eigsentïmlichkeiten von Kelch, Kelchblittern und Grilfeln, welche in Texte auf den iolwenden Seiten gegeben wird und schon niedergeschrieben war, als der Vortrag v. Weinzierls verüffentlicht wurde.

1) H. Christ in den „Ros. d. Schw." S. 26 lässt die Inflorescenz bei Gebirgsrosen unabhängig von den übrigen Achsenorganen durch die spiztere aber eneroischere Entwicklun sich verkürzen.

2) J. G. Baker: A monograph of the british roses, 1869; Burnat und Gremli: Les roses des alpes maritimes, 1872. H. Christ: Mllgemeine Erobehnisse aus der systematischen Arbeit am Genus Rosa, 1884: - Ich entnehme diese Hinweise dem Auisatz H. Dingler's: „Versuch einer Erklärung gewisser Erscheinungen in der Ausbildung und Verbreitung der wilden Rosen"

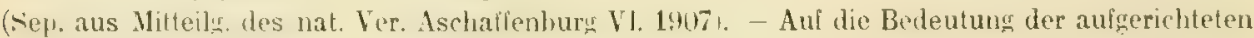
Kelchblätter für Bergrosen hat übrigens Christ schon 1873 in den „Ros. d. Schw." hingewiesen: siehe S. 19 f.

3) H. Dingler a. a. 0. S. 3-9.

4. A. a. 0. s. 9 fi. 
reilen sie ihre Frïchte verhïlnismäsigig früh. Dazu kommt, dass dulch dats ,vollstimdige Zusammenschlagen del Kelehzipfel ïber der Fruchtbechermündung das Eindringen von Wasser bei den so häufigen Sommerregen des Gebirges besser verhintert wird." Dingler betont lemer den Nutzen, welchen dats Auirichten der Kelchziptel gewährt, weil dulureh die Somnenstrahlen frei anf die Frucht wirken und sie fräher zul Reife hringen kömen. - Zur Kritik bemerke ich Folgendes: Lin mit dem zuletzt rorgebeachten Grunde zu beginnern, so scheint mir der Lnterschied zwischen den Rosen, die ten Kelch anfrichten (Bergrosen) und jenen, die ihn bald abwerfen (Ebenenposen) allzu geringlïgig, als datsis es. bei der Reile der Frucht durch direktes licht in Belracht kommen kïnnte. Der

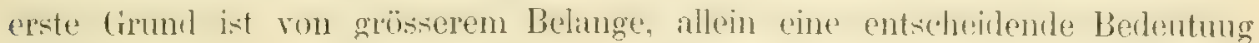
vermag ich ihm nicht zuzuerkennen. Sowie die Rötung der Scheinfrüchte beginnt, entarten die persistentern Kelchzipfel fleischig, und die subpersistenten verlieren das assimilierende Chlorophyll. Bes den subpersistenten Arten wie R. glancal, coriifolia, abietina u. ä. bleiben die lielchziplel häulig nu abstuhent und rermindem durch ditse Stellung den prätendierten Nutzen. Tiei cinigen persistenten sind die lelchziplel ausserst diintig entwickelt, aber auch boi den übrigen der alpinen Gruppe - gerade im Gegensatz zu den breiten und reich befiederten Kelchblättern der canina, dumetorum, tomentella - von einer so geringen Spreitenauslehnung, dass ihre assimilatorische Potenz. recht klein sein muss. Dazu kommt: Die Dingler'sche Iypothese beriicksichtigt die Korrelation oder "Verkoppelung" zwischen lielchblatt-itellumg und Griftelheschaffenheit gar nicht, welehe doch nach algemeinen Urteil vorhanden ist.

Ich habe nir durch langjïhrige Berbachtungen und Untersuchungen der Fruchtbecher von Rosen eine andere Ansicht gebildet. Schon im ersten Teile S. 21 habe ich auf den vaschiedenen Bau der Receptakeln, insbesondere des Diskts und in Abhängigkeit davon der Griffelsiiulen hingewiesen. Die Tatel II erlïutert diese Verhälnisie an unseren einheimischen Rusenaten nach dem lebenten Mordell. Als extremste Formen sind mir aufgefallen einer'seits die R. yallica (sehr hoher, schmaler Griffelkanal) und arensis (sehr breites Diskuspolster), anderseits bei exhomischen Rosen die R. pomifer und pimprinellifolia sehr weiter, kurzer Kanal; sehr schmaler Diskus), bei Exoten die R. microphylla. ${ }^{3}$ )

Die weite Diskusöfnung bedingt nun erstens bei flen persistenten und subpersistenten Rosen ein breites, gewöhnlich kurzes und fast stets wolliges Griflelköplchen; bei den ïlrigen eine schmale, dafür höhere (iriffelsiule, die kahl, behart oder wollig ${ }^{2}$ ) sein kann. In echter Korrelation stehen also nicht Persistenz und wollige Griffel, sondern Persistenz und breites

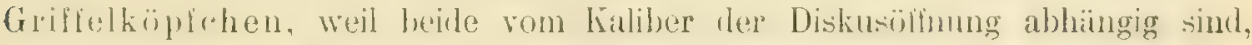
was ich zunächst lïr dats Grihtlköptehen bewiosen habe. Kímze und wollige Behatrung der Griffel kommt, weil den Bergrosem nïtzlich, gewöhnlich dazu.

1) Die Fruchtbecherdurchschnitte, welche C. K. Schneider S. 539-587 seines „Illustr. Handb. d. Laubholzkunde ${ }^{*} \mathrm{Bd}$. 1. gibt, enisprechen meist meinen Aufstellungen.

2) Stark wollige, aber lange Griffelsäulchen finden sich sowohl bei der R. canina als R. dumetorum; die kurzen Griffelköpfchen der R. rubiginosa und elliptica sind ölter schwach behaart. 
Der geschilderte Bau des Fruchtbechers ermöglicht zweitens die Auf-

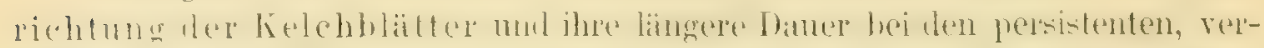

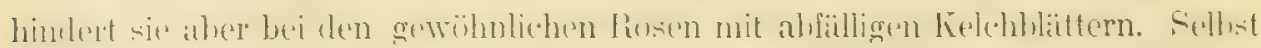

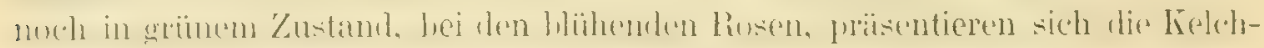
blitter der letztgenannten Kategorie als dünne, durch den Diskus von der

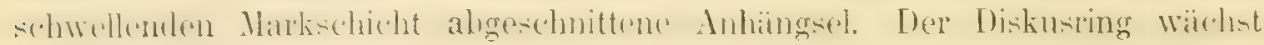
mit dem Reifen der Frucht so entschieden fort, dass er die beim Aulblïhen

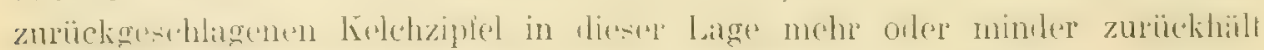
und durch die Entziehung der Nährstoffzufuhr bald zur Atrophie und zum

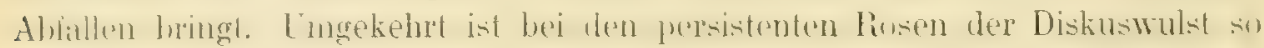
wenig entwickelt, dass er sich indifferent verhält. Man muss annehmen, dass

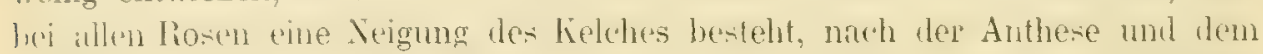

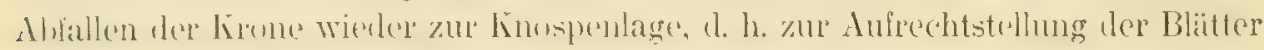

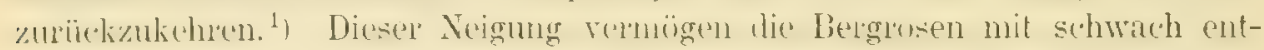
wickeltem [)iskuswulst nachzukummen, die anderen gewohnlich nicht. In fenchten Summern, wïhemul woleher dite lelchblitter lïnger lebensfrisch bleiben, veruit solbst die R. comina und dumetormm die Tendenz ilne kelchbä̈ter aufzurichten. loh habe im nissen sommer 1906 hei hedulen Arten selu häufig abstehende

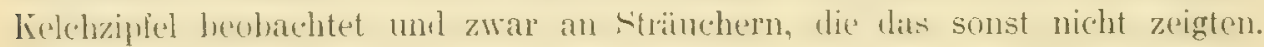
I. J. 1907. war das Wetter Mitte Juni bis Mitte Juli kalt und feucht; infolge dessen sah ich an einer R. canima var. syntrichostyla meist abstehende lieleh-

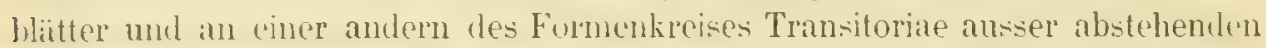
sugia ganz aufgerichtete. Duch waren diese lielchbläter am 17. 7. bereits am Verirocknen. Ohne meine frühere liemntnis del Sträuchel hätte ich vielledcht geglaubl, eine subeanina vor mir zu haben. An schattigen Standorten hale, ich noch an 21.7. 1907 zweifelluse Caminen mit frischen, abstehenden Kelchbiittchen bemerkt, desgleichen R. dumetormm vill.comatu. Auch im Sommer 1908 matchte ich einge hierher gehörige Bublchtungen. Das ron mir geschilderte Verhalten bezeugt übrigens schon Christ in den "Ros. d. Schweiz" für die R. arensis (nlang dautrnde lielchziplel") und nach Rapin für eine R. crmina am Saleve (. Kelchziptel nuch an der roten Fucht"). Ferner: . Anderseits kommt es nach Gulut in insnahmsweise trockemen Summern vor, dass selbst mollissma ${ }^{2}$ ) die Kelchzipfel abwirft." Im trockenen Klima von Eichstätt ist die dort an-

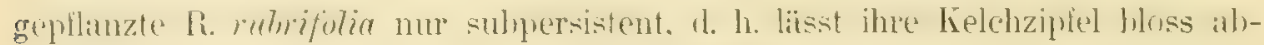
stehen und wirft sie noch vor der Fruchtreife ganz ab, ähnlich wie es die

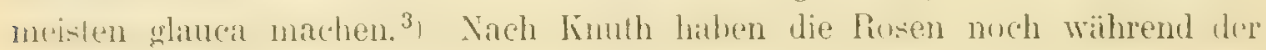

1) Das Gleiche weist Ewert für die nahe verwandten Pomaceen Apfel und Birne nach (in seiner Schrift: "Die Parthenokarpie", Berlin 1908).

2) Pomilera. - Christ R. d. Schw. S. 20.

3) Meine f. erubescens der R. pimpinellifolia steht nach ihrem Fruchtbecherlängsschnitt in der Mitte zwischen dem Typus der pimpinellifolia und dem der canina, d. h. hat zwar ziemlich schmalen Diskus, aber auch einen verschmälerten Diskuskanal. Sie verhält sich hiedurch und die infolge dessen \pm zurückgeschlagenen Kelchzipfel zur genuinen R. pimpinellifolia ähnlich wie die Formen der Unterart subcanina zur wahren R. glauca. Es ist wohl der niedere Standort, welcher die Eichståtter pimpinellifolia zu solchen Variationen bringt. Ahnich scheint es sich mit den von Dingler aufgeslellten f. achras, sublagenoides und katakalyx aus Unteriranken 


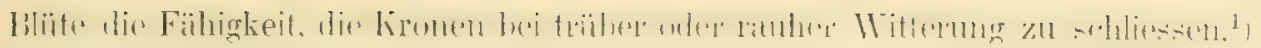

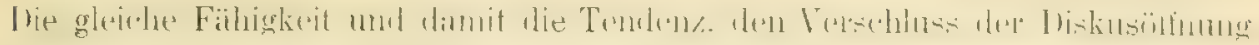
durch die Aufrichtung der Bliittchen zu bewirken, haben wohl auch die Kelche. Freilich folgt der Kelch dieser Verschlussbewegung der Krone viel langsamer und dirum unvollkommen oder gar nicht bemerkbar.

Ich hege nun die OUberzeugung, der tiefste Grund für die Verschiedenheit

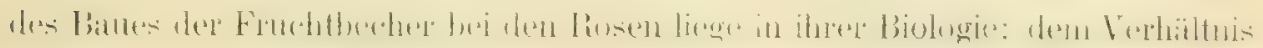

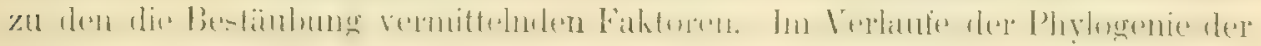
Rosen hat sich offenbar eine Verïnderung insolern vollzogen, als die Rosen allmählich von der ausschliesslichen Insektenbestäubung bezw. Fremdbestäubung zur fakultativen und schliesslich vorwiegenden Selbstbestïubung übergegangen sind. Der Diskus hat den histologischen Bau

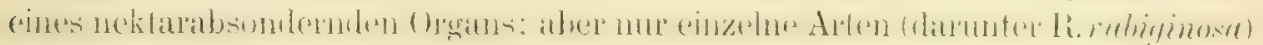

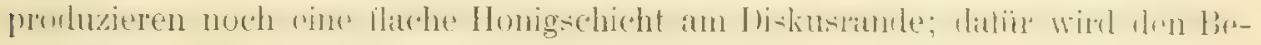

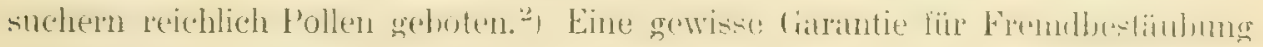
ist gegeben, wenn die Griffelsäule mehr oder minder weit vorsteht, ${ }^{3}$ ) wie es an extrensten bei der R. arrensis, aber annïherungsweise hei allen Libenen-

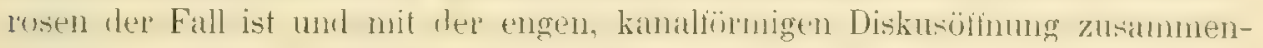

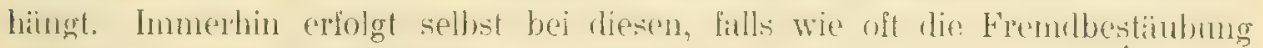
ausbleibt, dafür folbsthestäbung. Ein seht grosier Teil der Insedienbesucher

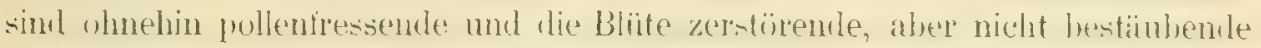
Koleopteren. Des besuch bestiubenter Insektesn, also namentlich vom Dipteren

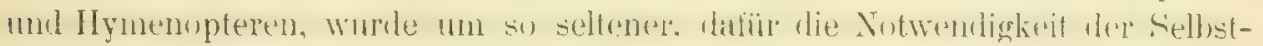

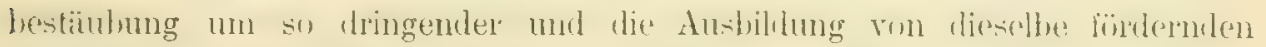
morphulugischen Organen un so notwenliger, je weiter die Tiosen im Hochgebirge viler gegen den Norden zu vordrangen. Das Honiggewebe des Diskus verkümmerte, die cirilfelsäule verkürzte sich, ratür bildeten die Griflel in der

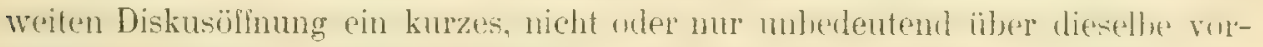

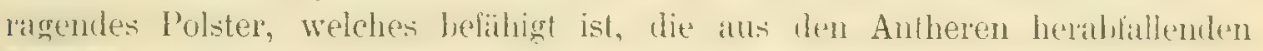

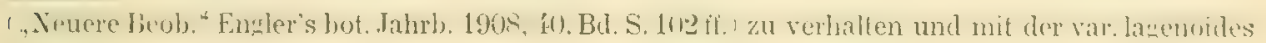
R. Kell. (?). In Unterfranken erscheinen bei der geringen Meereshöhe und dem warmen Klima auch Formen der Unterklassen subcanina und subcollina besonders häufig.

1) P. Knnth: Handhuch der Blitenbiologie. Leipzig. I. Bd. 1898 S. 98.

2) Nach Knuth: H. d. Blïtenbiologie, II. Bd. S. 352 ff.

3) Das mit Pollen beladene Insekt stösst beim Anflug an die vorstehende Griffelsäule und deponiert an ihr den Blütenstaub. Die Rosen sind nach ihren jetzigen biologischen Verhältnissen Pollenblumen geworden, d. h. sie bieten, soweit sie überhaupt noch Insektenbesuch erhalten, denselben nur Pollen. Allen Pollenblumen sind besonders auffällig hervorstehende Griffel eigen. Merkwürdig und bezeichnend muss es also genannt werden, dass jene unserer Rosen, welche die lïngsten Griffel besitzt, die R. arvensis, a uch den meisten und fertilsten l'ollen produziert. - Knuth schreibt (S. 352 f. Bd. II), anfünglich werde durch die bestehenden Blïteneinrichtungen sowohl bei R. canina als arvensis Fremabestaubung vermittelt, später, und zwar bei ausbleibendem Insektenbesuch immer, trete spontane Selbstbestaubung ein, indem Pollen au? die Narbe hinabfalie. Das letztere kann wohl bei R. canina eintreten, aber schwerlich bei R. arvensis, deren Narbe in solcher Höhe steht. Also ist auch aus diesem frunde die 1. arvensis - und sind wohl alle Rosen der Gruppe Synstylae - der Fremdbestaubung durch Insekten noch mehr angepasst als alle übrigen, voral, die Gebirgsrosen mit weitem Diskus und kurzem Griffelköpfchen. 
Pollenkïrnex andzulangen und ihnex Bestimmung znznliihnen. Dies wird um so

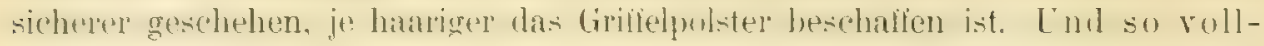
zog sich als erste und wichtigste Anpassung der Bergrosen an die Selbstbestäubung beim regelmaissigen Unterbleiben der Fremdbestäubung: die Bildung einer weiten Diskusöfnung mit schmalem Diskusring wer atophiestes Nektargewebe enthält und mit einem breiten,

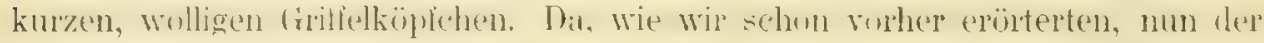
liekh seiner nie verlorenen Tomdenz, sich antzurichten. folgen konnte, weisen die montanem liosen als sekundïres, aher mehr in dir Augen fallendes Merkmal an

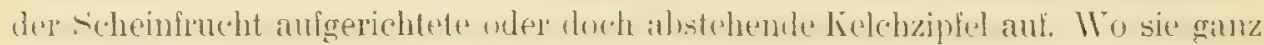

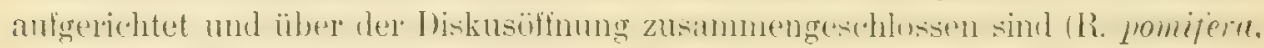
cimnamomea usw.), vermögen sie auch, wie Dingler 1. c. bemerkt, die Karpelle bezw. Nösschen vor dem Platzregen und dem Trebel der Ilochergionen mel vielleveht auch vor räuberischen besuchen ungebetener Insektengïste zul schülzen. Doch scheint mir diese Anpassung mehr untergeordneter Natur zu sein. ${ }^{1}$ )

In drei Abstufungen drücken also die Rosen ihre Adaption für das rauhe Berg- und nordische Klima durch Entfernung von der vorwiegenden Frenul-

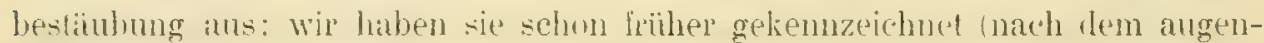
fïligsten Nerkmal. aber nicht nach lem entschedendstent als 1. Rosen mit abliblligen Kelchzipleln renger Diskusolfmung, längerer (iriffelsïnle), 2. Rosen mit

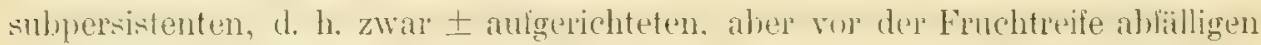
Kelchzipfeln (mittelweiter üfnung, kuzem, stark harigem Grifelköplchen), 3. Rusen mit persistenten, d. h. nicht nur volikommen angerichteten, sondern norh an der reifen Frucht erhaltenen Kelchzipfeln (weiter offumg, kuzem, wolligem Griffelpolster). L: lenchtet ein, dass Imginntige ïussere Eintlïsse: dancrnder Standort im Tieflande, trockenes, warmes lílima u. dgl., die Tendenz äussern werden, umgekehrt die Rosen unter 3. zur Klasse 2. und die unter Kilasse 2. zur Klisse 1. herabzudrüchen. Infolge desen beobachten wir z. B. bei Eichsiatt die R. rubrifolu mit subpersistenten Kelchllattern und lingeren

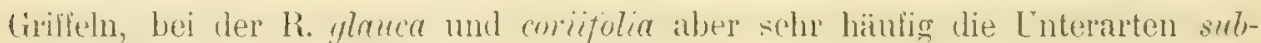
cuminu und subollina. deren helchblïtter I zurickgeschlagen, deren Griffel lïnger und wenger wollig, deren Blütenstiele ebenfalls verlängert sind. Das Gileiche gilt für die macrostyla-Furmen der R. ruhingos. Cbethampt lassen die liosen der pubiginosit-Grupue die geringste Adaption ans Bergklina erkennen, anch rubiginosa und elliptica, nicht bloss die zu 1. zählenden micrantha mul agrestis.

\section{Kapitel: Der Boden.}

Gewisse Eigenschalten des Bodens hïngen von seinen Begiehumgen zum Licht (z. B. sïuliche Exposition ron Abhängen), zur Wïrne und zur Feuchligheit

1) Würden die Bergrosen die Fähigkeit mehrerer anderer Gebirgspflanzen (wie des Helianthemum guttatum) besitzen oder besessen haben, sofort nach der Offnung der Blüten die Kronblätter abzuwerfen und durch die Erhebung der Kelchblätter die Staubbeutel an die Narben anzupassen und so Selbstbestäubung liervorzurufen, so wäre das freilich elwas Arderes und eine primäre Einrichtung (Vgl. den Auisatz von E. Löwe im biolog. Zentralblatt 1906: „Bemerkungen zu Burck: Mutationen usw." S. 179 und 199). 
ab. Wir haben sie bei der Erörterung dieser Faktoren schon behandelt. I) (1 Wassergehalt des Bodens hat am meisten Einfluss auf das Gedeihen der Planzen. Die Rosen lieben odel vertragen finen nubl trockenen Buden; ann stärsten

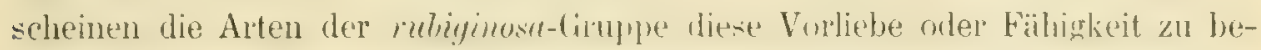
sitzen, durch welche sie vor anderen Rosen an solchen Standorten sich be-

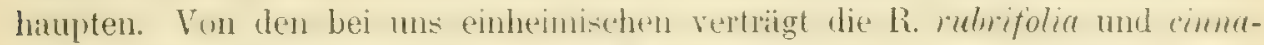
momea viele Bulentenchtigkeit. Die h. rubrinlia sah ich oft auf ganz nassen Alpenwiesen (z. B. bei Radein in Sïrltirel und hes Zermatt); dier cinnamonncat wächst auch bei uns girne and lenchten Alluvial-, jat Sumplbüblen 1\%. B. im Gabelhulze bei Ingolstalt, an vielen fiellen des líe's u. dgh.) In Huchgebirge gehören übrigens solche Bülen trotzilem zu ten physiologisch trockenen, da sie Nachts meist gefrieren und so ausgiebige Wasseraufnahme verhindern.

Inahhängig von obigen unterscheilet man physikalische mul chemische Eignenschalten des Bodens. Ersere gipleln in der Lorngrösse und in Zasammenhang der Bodenpartiliel. Die Rosen zeigen sich in dieser Beziehung sehr geniig-

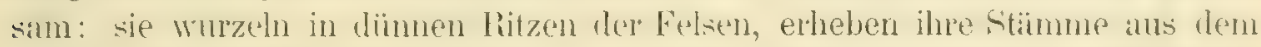

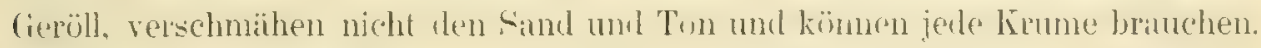
In luckerem Burlen treiben sie reichlichere Ansläuler: freilich anch, wenn ihre oberirlischen Stammchen häufig zertrelen, verbannt orlex abgemäht werden. Das begegnet besonders häufig der Feldex und haine liehenden li. gullicu.

Ein Buden, welleher alle Nihnstoffe in zuredchendem Masse enthält, also ein Inchtbarer', rermag selbstrerstindlich auch den liosensträuchern das Optimum ihres Cieleihens zu lningen. Sie erreichen auf solehem buden ihe Maximathöhe und ihre Blüten die Maxinalgriöse. Doch duldet man sie sellen auf gulem Boden, und deswegen kann man oft Zwergwuchs an Rosen konstatieren, der von dem Mangel der Nïhrstoffe und jenem der Feuchtigkeit herrührt.

Besonders gerne werden die Rosen als kalkliebend bezeichnet und die Katkgebirge als ihre eigentlichen Bildungsstitten und Heimatländer. Su schreibl Christ: ,Fassen wir zurest die schweizerische Jura-Kette vom falde bis zun fohdflhausel Hügelland ins Auge, so kamn wohl gesigt werden, dass dieses Gebirg ler privilegierte liusengarten Europas ist". ${ }^{1}$ ) "Das Gemälde des Verbreitung der Rosenarten ïber den Jura hin erweckt die Vorstellumg eines solchen Reichtums, dass ungestucht der Gedanke sich einstellt, es möchte diesere in Kilina und Lnterlage (kalk) hen Rosen so congeniule Bezirk gar whl der Bihlungs-

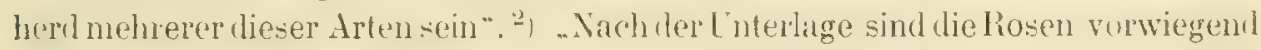
dem Kalkgebirge zugetan. jerluch ohne Auschliesslichkeit". ${ }^{3}$ ) In Bayem getten der Frankenjura und die Muschelkalkhöhen Lutertrankens als bevorzughte Stitten der Rosen. Warming begnügt sich zu bemerken: „Andere Pflanzen werden als besunders kalkliebende angeliiht, die einen Boden mit vielem kohlensauren Kalk nicht verlassen, z. B. Papilionaceen, Rosifloren, Labiaten, viele Orchidaceen usw." 4)

1) II. Christ: D. IR. d. Schw. S. 7.

2) Ebd. S. 11.

3) Ebd. S. 14.

4) E. Wamming: Lehrbuch d, ökolog. Pflanzengeographie. Ubers. v. E. Knoblauch. Berlin, 1896, S. 75 . 
Was ist nun von dieser "Kalkliebe" der Rosen zu halten? Wenn sie in chemischem Sinne aufgefasst wird, so ist von unseren mitteleuropäischen

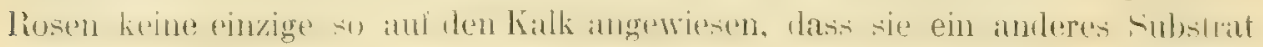
ausschlösse. O. Sendtner behauptet ron der R. amensis: „Eine strenge Kalkpflanze". ${ }^{\text {) }}$ Die R. a. kommt jedoch in Bayern sowohl auf Alluvialböden der

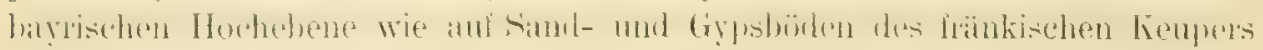
vor. Andere Rosenartel sind noch weniger mit Ausschliesslichkeit an den Kalk gebunden; in Sachsen gehören zu den gewöhnlichen Sträuchern sehr

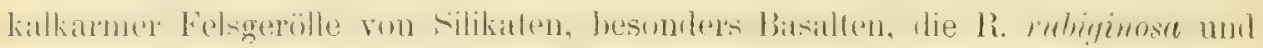
Jundzillii. ${ }^{2}$ ) Einige Varieläten scheinen sogar ein anderes Substrat zu bevorzugen, bezw. von diesem erzeugt zu werden. So die var. doleritica Chr. der

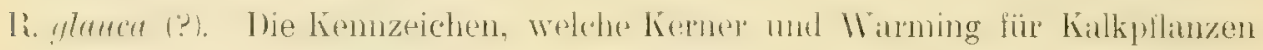
im Gegensatz zu Parallelformen nuf anderem Substrat angeben (stïrkere Behaarung, blaugrïne Blätler, grössere und bleichere Corollen), sind weder für

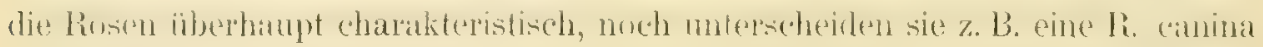
und glauca des Kalkbodens von der des Keupersandes usw. Man wird also wohl sagen miissen: Die Rosen vermögen viel Kalk im Boden zu ertragen und sind insoferne kalkzeigend, doch kommt die unleugbare Tatsache, dass sie Kalkberge bevorzugen, zum Teil auf Rechnung der physikalischen oder

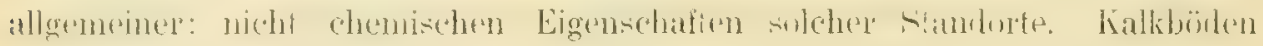
sind nämlich warm und durchlässig, also trocken; die Rosen aber lieben einen solchen Boden mit ganz wenigen Ausuat)men.

\section{Liapitel: Das Zusammenleben mit anderen Organismen.}

Wohl nur in wenigen Fällen lässt sich ein nütżlicher oder schädlicher umbildender Einfluss anderer Pflanzen au: Rosen konstatieren. Die R. amensis bedarf eines leichten Lichtschutzes durch Gebüsch und wächst deswegen vor-

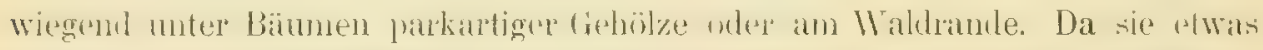

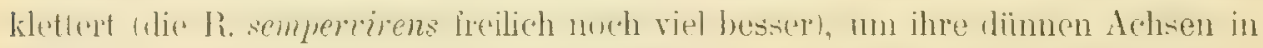
die Höhe zu hringen, ist sie auch ans diesem firmude aul buschiges Terrain angewiesen mul hreitet ïber andere Hecken ihreschlanken Trishe aus. Die gekrümmten

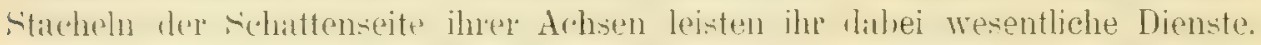
In geringeren Cirarle finden wir diese Wachstunsverhälnisse wieder bei der

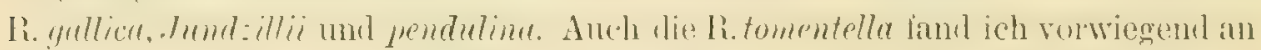

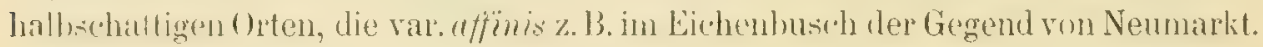

Ein Verhältnis der Rosen zu den Tieren besteht unter Ausbildung morphulurischer Chanklere nach zwei Pichtungen hin, einer negativen: sie schülzen sich gegen schïdliche Tiere, und einer positiven: sie locken Tiere an für die Bestäubung und für die Verbreitung der Samen.

Ich beginne mit der Besprechung der positiven Seite. Wir haben bereits frïhere die prinzipiellen Punkte trörlert. Welche fïr die Bestïubung der Rosen

1) O. Sendtuer: Die Vegetationsverhältnisse des bayr. Waldes, München 1860, S. 22 \{.

2) O. Drude: Deutschlands Pflanzengeographie, Stuttgart I. Bd. 1896, S. 378. 


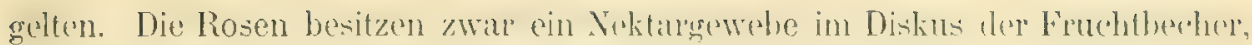
aber nur sehr wenige Arten soudern etwas Nektar in Wirklichkeit ab. Dazu gehört unsere R. vutriginosa, welche auch etwas proterogyn ist (nach Knuth).

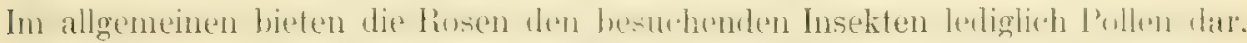
welcher in sehr reichlicher Menge erzeugt wird. Bei ausbleibender Fremd-

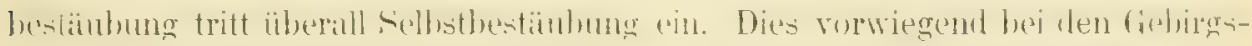

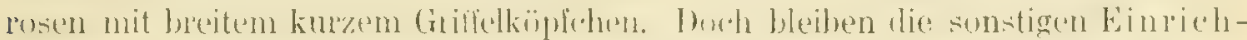
tungen fïr Insektenbesuch bei allen Arten bestehen. Die lirunblittere bilikn

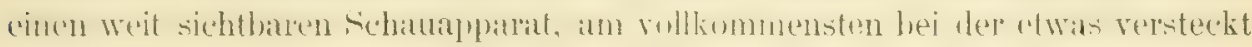
lebenden R. gallica: hier vereinigen sich Grösse, lebhafte Farbe, und starker Geruch zur Anlockung von Insekten. Vom Geruch wissen wir freilich nicht so genau, welche Rolle er spielt. Es ist keineswegs ausgemacht, ob Geriiche wie diejenigen der meisten Rosen, die dem Menschen angenehm, dies in gleicher Weise für die Tiere sind. Jedenfalls kommt es hier auch auf die Ordnung

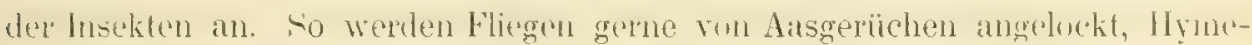
nopteren von Honiggerüchen. Die $\mathrm{R}$. arvensis wächst vielfach an schattigen, versteckten Orten. Dafïr ist ihr schanaparat organisiept, demn die fenchtend weisse Farbe ihrer Kronen wirkt im Dunkel besser wie selbst ein Purpurrot. Ausserdem strönt sie ${ }^{1}$ einen sehr statken, lïr den Menschen last widerlichen mul keineswegs "posenhaften" Duit aus (rgl, den Wanzengeruch der li. lutent. Dir R. a. pilsst sich anch durch ihre linge (iriffelsïule am meisten untop allen

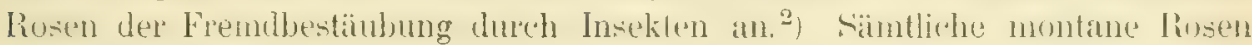
- mit Ausnahme der pimpinellifolia - zeichnen sich vor den parallelen Arten durch tielere Färbung der Krone aus, was beim Vergleich der R. glauca mit dre canina, der coriffolia mit der dumetorum, der mhiginosa mit der micrantha am besten hervortritt (die R. elliptica iiberalgi wenigstens in den rale. calcaren

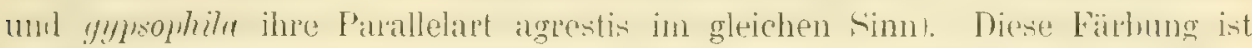

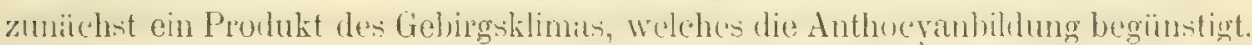
Sice hat aber auch eine biologische Bedentung, indem durch dic tiefere frathes

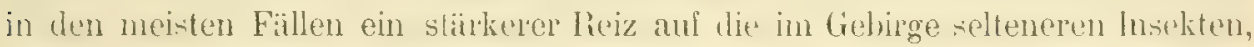
lesonders Hymenopteren, ausgeiilst werklen wird. Doch ist wohl nicht seht viel Gewicht auf diese Zweckbeziehung zu legen.

Uber die Verbreitung der Hagebutten durch Tiere åtussert sich

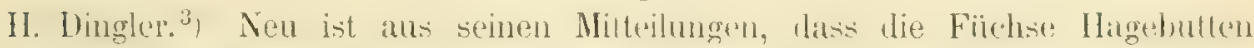

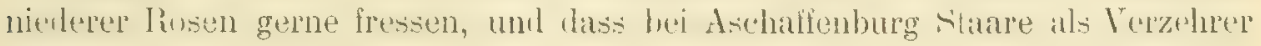
derselben von ihm bemerkt wurden. Altum gibt noch Amseln, Drosseln und

1) Der Duit liesse auf Fliegenbestäuber schliessen. Knuth gibt (Handbuch d. Blütenbiologie Bd. II. S. 355) keine Bestäuber an, und ich selbst habe ebenfalls keine hieher gehöriger Beobachtungen gemacht. Übrigens riecht die $\mathrm{R}$. pimpinellifolia ähnlich, wenn auch weniger unangenehm. Bei ihr nennt Knulh a. a. O. pollenfressende Musciden neben Hummeln als Besucher; nach meinen Erfahrungen wird die R. p. am meisten durch Käler, besonders die Antheren und

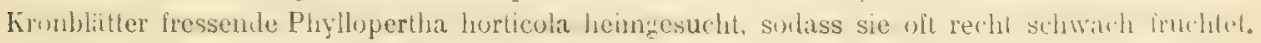

?) Die, Reinheit" (Freiheit von missbildeten Zellen) des Pollens der R. arv. hängt woh! mit ihrer Begünstigung des Insektenbesuches zusammen.

3) "Versuch einer Erklärung" S. 16 f. 
Bitkhühner an, ${ }^{1}$ Kerner Dohlen. ${ }^{2}$ Jedenlalls sind e's ganz vorzugsweise Vögel, welche durch das Verzehren des in Herbst oder erst im Winter weich gewordenn Fruchtfleisches und die Entleerung der Exkremente mit den keimfïhigen Nüsschen zur Verbreitung der Rosen beitragen. Natürlich sind jene Rosen am meisten begïnstigt, wolche die aulfallendste Fruchtfarbe und das am besten entwickelte Fruchtfleisch besitzen. Missfirbig bram und zugleich mit lederigem Fruchtfleisch versehen scheint unsere R. gallica wenig geeignet, Vögel zur Verzehrung ihrer Früchte amzulocken. I) Fre Fïhte der rubiginusa-Gruppe besitzen gleichfalls zientich dümnes, schlecht schmeckendes Fruchtfleisch. Ahnlich verhalten sich arvensis, rubriblia und pimpinellifolia. Dagegen produzieren pomifera und die Rosen von der nächsten Verwandtschaft der eamima mit der letztgenannten selbst das im weichen Zustand best schmeckende Fleisch. Sie werden darum auch von Menschen vorwiegend zur Bereitung des Ilagebuttemmarkes eingesammelt. Die Harbe scheint, wenn wir von der R. gillica absehen, bei allen, auch der schwarzfrïhtigen pimpinellifolia, gleichmitssig gut geeignet, die Aufmerksamkeit der Tiere aul sich zu ziehen. Nur nuss bemerkt werden, dass gerade im Winter, wenn die Tiere vorwiegend an rlie weichen Rosenfrichte gehen, sie meist etwas brämlich missfarbig geworden sind und ihre rote Lockfarbe mehr oder minder eingebüsst haben. ${ }^{3}$ ) Gegen die Angriffe von Vierfïsslern wie Mïusen, welche nach Kerner die Samennïsschen gerne verzehren, sind die am Stranche hängenden IIngełutten durch die Stacheln des Blütenstamles und cler Zweige 'geschützt. ${ }^{4}$ ) Daraus würde folgen, dass die schlecht hewehrten Rusen wie arvensis, penclula wenigstens in mïusereichen Ciegenden eine schlechte Aussicht aul Vermehrung durch samen hätten. Nur das Verzehren der unreifen Frucht verbietet sich stets durch die ein Jucken auslösende Behaarung der Karpelle und Griffel.

Es scheint also bei Rosen genïgend für die Vermehrung durch Beihille von Tieren, welche die Samen verschleppen, gesorght zu sein. Trotzden kann man last nie in Freien junge Sitrüucher beobachten, die, von älteren isoliert stehend, mit Sicherheit oder duch Wahrscheinlichkeit aul frische Aussaat zuriackzulühren wïren.5 ${ }^{5}$ Immer und immer wieder haudelt es sich um stockbildung

1) B. Altum: Der Vogel und sein Leben. 5. Aufl. Münster 1875, S. 253, 256, 260. Woht mit Recht macht Graf v. Solms-Laubach ( Allgeneine Pflanzengeographie", 1905 s. 133 f. auf den Unstand aufmerksan, dass Samen im Nanen kümerfressender Vüggel zerstört werden. Birkhühner könnten also zur Verbreitung von Rosen nur beitragen, wenn sie die Nüsschen aus dem Kropf auswerfen wïrden.

2) Kerner a. a. O. II. S. 438.

3) Dingler glaubt, dass die etwas früher reifenden Gebirgsrosen dadurch einen Vorteil vor den später reifenden Ebenenrosen errungen und sie so vom Hochland verdrängt haben, weil die Früchte der Gebirgsrosen dann an ihrem Standort noch Vögel finden und ausgesät werden (a. a. 0. S. 17 f.). Der Vorteil besteht, ist aber wohl kaum von grossem Gewichte.

4) Kerner, Pflanzenleben II. S. 438 f.

3) Ich kenne aus der Umgebung Eichstätts sicher aus Samen benachbarter, jedoch genügend weit entfernter Strüucher entstandene ne'ue P'flanzen lediglich von der R. pimpinellifolia und ayrestis var. pubescens. Die letztgenannte ist mir auch als linwanderin vom höher gelegenen Weissjura in den Sand des Braunjura aus der Neumarkter Gegend erinnerlich. 
durch Ausliufer, gar nicht selten aus den untersten Stammpartieen ron abgehauenen oder abgebrannten Sträuchern. Die Keimung der lasennüsschou scheint von mehreren zufälligen Bedingungen abhängig zu sein. ${ }^{1}$ ) Zudem tritt ihrer Vermehrung aus Sumen unser Kulturleben auf dem Lande (I'flege der Acker und Wiesen, Beniitzung der Weiden und Rainel und in ler Nähe der Städte (Einsammeln der Scheintrüchte zu Hagebuttenmark u. (lgl.) leindlich tntgegen. Infolge dessen hat die Reproduktion der Rosen aus Samen an Wichtigk'st verloren, mol ist viellach an ihre stolle gerïckt die vegetative Vermehrung orler besser die Erhaltung und allmähliche Vergrösserung der Hecken durch Auslitulerlifdung. Wenn ich mich nicht irre, so hat sich, wie ich in Anschluss an früher (iesagtes hemerke, dit Fortplanzung der Rosen im Lanfe der Zeiten so entwickelt: zuerst sexnelle Vermehrung nach Fremdbestïubung, dann sexuelle Vermehrung nach Selbsthestiubung, jetzt vielfach nur mehr vegetative henroduktiun. IVtgen des Furtschreitens dieser Tendenz hat wohl die Mehrzahl der Rosinarten so schlecht entwickelte Pollenkörner, bis über $50 \%$ taube.

Besonders auffällig entwickelt sind bei den Rosen die Schutzeinrichtungen gegen Tierfrass; dass die Stacheln hierher gehören, unterliegt keinem Zweifel. Bei allen Rosen - selbst die R. pendulina entbehrt. ihre' nichl gänzlich - zeigen sich mit Stachehn beweht die Achsen (mintestens die stäkeren), meist auch die Riuckseite der Blattsticle und der Mittenerv, zuweilen selbst die Blïtenstiele. Die Stacheln varieren nach Grösse, Stiirke und Gestalt entsprechend teils den Arten und Varietïten teils dem Alter und dem Ptlanzenorgan; zuweilen treten am gleichen stranch stacheln verschiedener Gestalt und Grösse auf (Heterakanthie).

Bei allen Rosen tragen die unausgewachsenen Bodenschösslinge ïber den Niederblittern reichlichere, aber auch schlankere und geradere Stacheln als die älteren Stammparticen und erwachsenen Zweige. Vom ökologischen standpunkte aus liegt die Exklïung nahe: Die Bewalfnung ist eine reichere, weil die jungen Triebe des Schutzes an meisten herlïrfen, und die

1) Uber die Keimung der Rosen aus den Samen findet man die verschiedensten Angaben. Nach dem bekannten Systematiker M. Jordau, dem Urheber del "kleinen Arten", lehalten die Nïsschen ihre Keimkraft 2-3 Jahre. Sollen sie im nächslen Frühjahre aufgehen, so dürfen sie nicht später als im Juli oder Anfang August gesät werden; geschieht es im Herbst oder Winter, so gehen sie erst im Frühjahr des zweiten Jahres auf. Sie brauchen eine Art Vortreiben durch die Wärme (Auszug aus einem Briefe Jordans an E. Burnet, mitgeteilt in dessen Ùbersetzungswerk: Le genre Rosa .... par le Dr. H. Christ, Genève et Bale 1885 1. 11 Anm. 1.1 Dagesen sagt M. Bornet, on eifriger Züchter von Cistus und linsa, es gingen die meisten reifen Samen, wenn im Oktober gesät, schon im März oder April des folgenden Jahres auf (Le genre Rosa p. 36, Anm. 1). Ahnlich drückt sich das geschälzle Gartenbuch von

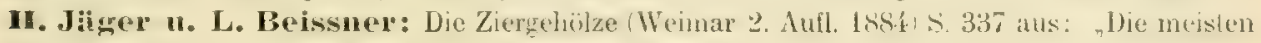
Rosen lassen sich aus Samen erziehen, welcher, wenn gleich im Herbst nach der Reife ausgesät, im nächsten Frühjahr aufgeht, ausserdem 2 Jahre in der Erde liegt." Meine persönlichen Erlahrungen stimmen mit den Angaben Jordans übercin; Rosen gingen aus selbst gesammelten Früchlchen vom Spätherbst an gesät immer erst im Frỉhling des zweiten Jahres auf. Nur von Gärtnern bezogene Samen keimten, wenn im Frühling gesät, schon im gleichen Jahre; vielleicht stammten diese gekauften Früchtchen nicht vom Jahre vorher, sondern vom vorvorigen Jahre. 
Stacheln sind weniger gekrümmt, weil die Krïmmung nach unten bei der Haltung grösserer Pllanzenfresser, die von oben herab die hervorbrechenden Triebe angreifen, keinen Zweck hätte. So nabe liegend diese - teleologische - Erklïrung scheint, glaube ich doch, dass die Bewehrung junger Triebe rein

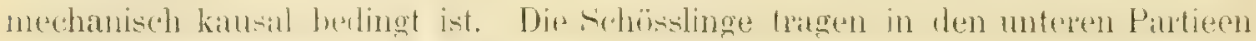

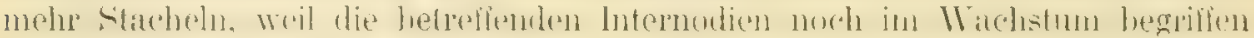
ihre volle Lïnge nicht erreicht haben, und die bereits auitretenden Stacheln dann relativ (aber kaum absolut) zur Stammoberfläche zahlreicher sind. Die

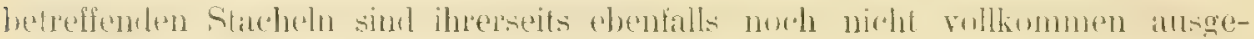
bildet, also dünn und schlank, aber auch noch nicht krumm oder gar hakig. Denn diese Form von Stacheln ist eine Art Alterserscheinung und bildet sich bei jenen Rosen, die überhaupt solche entwickeln, erst nachträglich aus den gerade angelegten heraus, wie wir nachher eröltern werden. Dieses Verhältnis der Stacheln an jungen Achsen überhaupt (nicht bloss an den Bodenschösslingen) zu denen iilterer Stammpartieen führt bisweilen zu Abweichungen von der typischen Beschaffenheit der Art und zur Varietälenbildung. Es kamn nämlich vorkommen, dass die Pllanze die fragliche Umbildung der Siacheln nicht vornimmt und diese auch an älteren Achsenorganen embryonale Beschaffenheit bewahren, also schlank, zart und gerade bleiben. So entstehen,

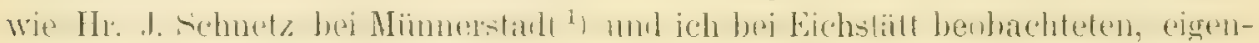

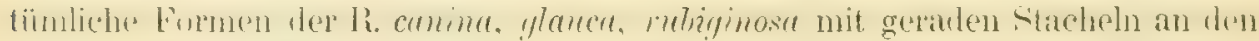

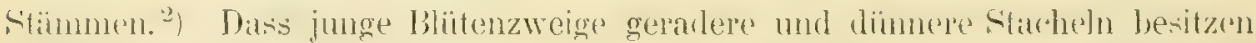

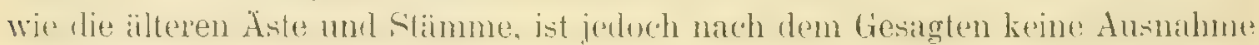

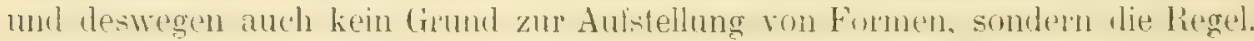

Durch die Stacheln, welche an den fertig gebildeten älteren Achsen stehen, unterscheiden sich die Rosen merklich von einander. Wenn wir uns auf die europäischen Rosen beschränken und zwar auf die typischen Formen jeder Art, so haben wir zu konstatieren, dass ein 'Teil gerade

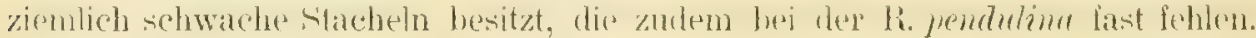
Ausser ihr gehören zu dieser Abteilung die R. pomifera mit mollis, rubrifolia, montana, sicula, glutinose, subspec. scabriuscula der tomentosa, pimpinellifolia, lutea. Eine zweite Abteilung umfasst Rosen mil leicht gekrümmten oder

1) J. Sehnetz in lit.

2) Die var. Erdneri (R. Keller) der R. canina gehört wolıl auch hieher. - Auffallender Weise gibt Christ (Ros. d. Schw. S. 16) zu, dass die Jahrestriebe , eines vermehrten Schutzes gegen die Angriffe von aussen“ bedürfen; das geschehe aber dadurch, dass, bei sonst geradstachligen Arten die zarlen sterilen Jahrestriebe am häuligsten krumme grüssere Stacheln zeigen". Waldner (Europ. Ros. S. 19) schreibt dieses nach, jedoch mit der Erweiterung: „Es ist nicht zu übersehen, dass bei sonst geradstachligen Typen die sterilen Teile auch krumme Stacheln haben können, oder krummstachlige a uch gerade." Ich lasse das ganz dahingestellt, was bei den höher am Stamme ausbrechenden Jahrestrieben geschieht, muss aber bei meiner Erfahrung stehen bleiben, dass die Bodenschüsslinge nach der im Text angegebenen Art und Weise ihre Stacheln entwickeln. Ich habe übrigens auch bei den sterilen Trieben der älteren Aste nie etwas von dem bemerkt, was Chr, und WV, berichten. Meine Ansicht vertreten auch die "Nachträge z. Flora v. Niederösterreich" von Halacsy und Braun (J. B. v. Keller) S. 180. 
zwar hakigen aber sehr schwachen Stacheln, häufig mit geraden Drüsen-

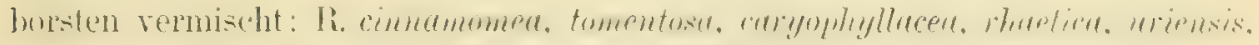

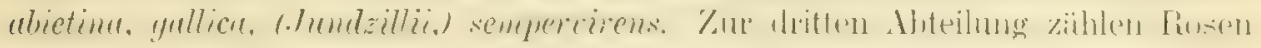

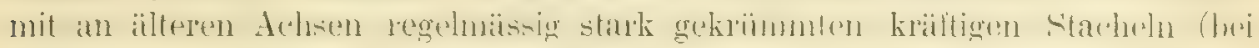

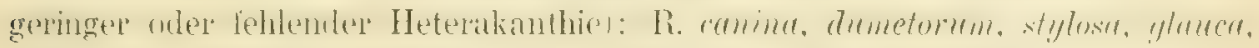
coriifolia, anensis, besonders aber mbiyinosa, micrantha, elliptica, agrestis,

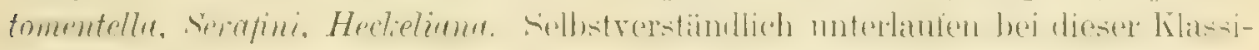

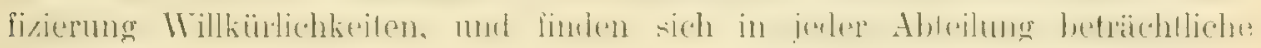
Unterschiede unter den einzelnen Arten und selbst Varietaten sowie Uber-

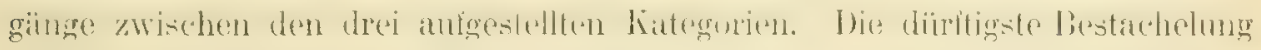
mit den schwächsten Stacheln weist die R. pendulina auf, die kräftigsten Haken wie Falkenschnäbel bilden R. elliptica und agrestis aus. Glauca und coriifolia haben stets etwas schlankere und geradere Stacheln wie die verwandten canina und dumetorum. Die älteren Stacheln der gallica sind zwar

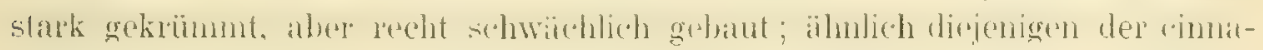
momea, die sonst eine recht lange Stachelbasis aufweisen, wenigstens bei den Exemplaren der Eichstätter Gegend. R. pimpinellifolia trägt an den Achsen,

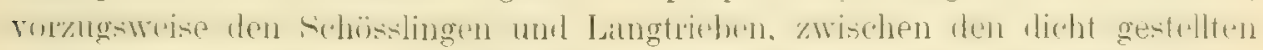

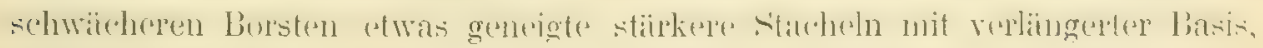
wobei durch die reiche Bestachelung einiger Ersatz für die Schwäche der meisten Stacheln geboten wird. Zwischen der typischen R. tomentosa und

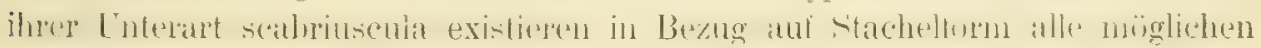
Uberginge.

Morphologisch muss a ufallen, dass die geraden Stacheln eine kegelfömige Gestalt und eine schmale Basis besitzen, mit der sie auf der Rinde der Achsen aufstehen; die krummen besitzen eine verbreiterte Basis, um so breiter, je stärker die Krümmung; Krïmmung und Basisverbreiterung sind stets nach unten

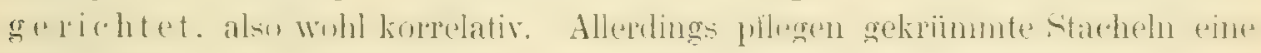
nach beiden Seiten, oben und unten, ausgedehnte Basis zu besitzen, nur ist die Verbreiterung nach unten ungleich grösser. Es wird dadurch eine ausser-

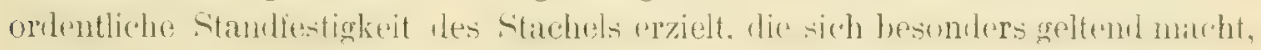
wenn ein Druck von der Oberseite her aul das Organ trifft. Der Wachstumsvorgang, durch den die eigentümliche Form krummer Stacheln erzielt wird, scheint der folgende zu sein. Der junge noch weiche und gerade Stachel, der

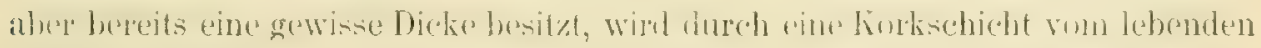

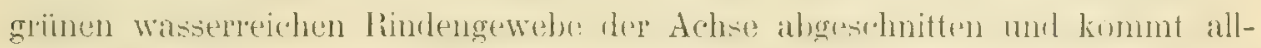

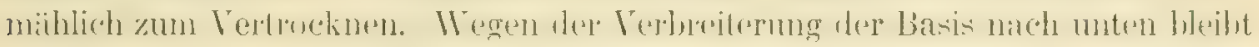

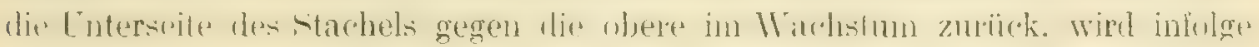
dessen kürzer und konkav, so dass schliesslich, bis der Stachel ganz tot ge-

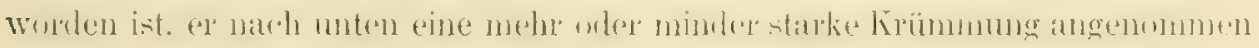

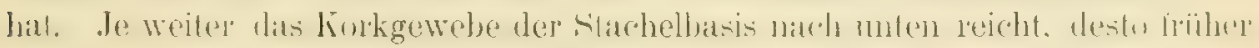

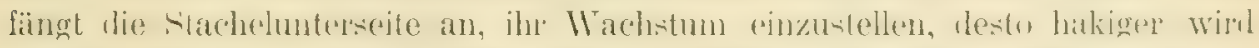

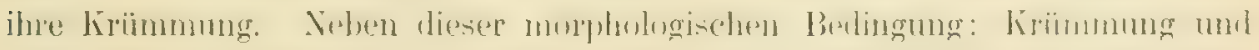

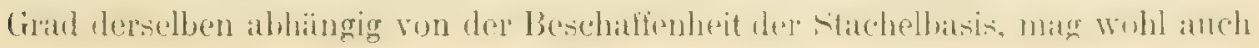


der IV assergehalt des Rindengewebes. der umgebenden Luit und des Bodens einen Einlusis ausibben. Willner behauptet sogatr in Anschluss an Hegetschweiler. dite geraden Stacheln der Himberratrauches und einiger hosen krümmten sich wan somniger Lage", während gerade Stacheln durch Fenchtigkeit und Schatten bedingt wïrden. ${ }^{1}$ ) In der 'Tat neigen Rosen, welche einen schattigen Standort haben, dazu, ihre an normalen Orten tỵisch gekrimmten Stacheh mehr wher minder gerade zu strecken, z. B. Waldiormen der R. rubiginos. Schattenformen der R. Jundzillii.

Ist es nun etwa der Einfluss eines äusseren mechanischen Reizes, etwa der Gravitation oder des Lichtes. auf welehen die Rose mit Bildung eines gekrimmten Sachels pusitiv (Geotropisnus oder negativ (Heliotrupismus) reagient? Dafiur sfricht meines Wissens keine Tatsache, riehnehr greift hier der öknlogische Faktor der Beziehung zur Tierwelt bestimmend ein. Wenn wir die Bestachelung der Rosen mustern, nuss uns aufallen, dass die Arten mit den schwäthsten und geradesten Gtacheln dem Hochgehirge und den Norden angehüren. Das gilt für die exotischen Arten R. sericen (Himalaya), lutea larmenische und tibetanische Gebirge), renthina (Alai. Mungoleil, aricularis (Norden und Gebirge dreier Weltteilet, durtrict (Dahurien, Mandschurei), pisocurpu Nevada, Oregonl, riminica, nitidu usw; aber ebensogut für die olen bei der ersten Alfeihng genannten. Die Rusen dieser Abteilung tragen den geschilderten Charakter in stiorkerer, die der zweiten in schwäicherer Ansprïgung, und sellst ans der dritten verraten R. glanca und coriffolia ihre Vorliebe für die montane Region auch lurch schwichere, weniger krumme - tatheln. Eine eigent Erklärung erfordem die R. gallica nit sempervirens einer-. R. rubiginusia nit ellipticar anderseits. Die erstgenannten sind betide südliche Fornen vorwiegend der Ebene, die letzlgenamnten haben etwas montane Charaktere. wenn auch nicht besonders allsgeprïgte, an sich. Die cntsprechende Erklïrung wirl an šchlusse gegeben werden, demn sie schliesst sich an die Erörterung der unhestrittenten (iebirgsrosen an. Nicht $11 n$ eine Anpassung an alpines oder Ebenen-Klima handelt es sich bri der Btstachelung, somdern um eine Anpassung an die Tierwelt, um Zunphubie ,Lundström.l. Jene Rusen, welche die Angriffe weidenden Grussviehes, malürlich des wilden, zn fürchten haben, tragen starke. getsümmte - Tacheh als Schutzvorrichtung: die andern verschmühen diesen Schutz ganz uler teilweise. Die eigenlichen Hochgehirge beherhergen hein (irssivieh: dessen Heimat sind die Elenen tieferer Regionem, welche, beron der Mtnsch eingriti, von Herden der Rinder un\} Antilnpen wimmelten. Auf de’n Menschen, der seine Zahmen Rinder aul die Alpen der Gebirge treibl, hat natürlich die

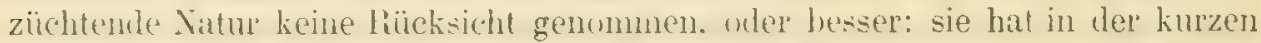
histurischen Zeit mit ihm nicht in der Anpassung sichrilt halten kümen. Schate und Ziegen. Steinböcke, Gemsen halten sich in der rein alpinen Zone bis zu jener des ewigen chchess anf und kommen für die Rusen nicht in Betracht. welche

1) Waldner: Europ. Ros. S. 19. - Vgl. Naturw. Rundsch. 1908 S. 192, wo auf Versuche Lothelier's humewiesen wirk, denen zufolse die Lumbihung unterdriikt wirl - zu gunsten von Stengel- und Blattentwicklung - wenn man die Pflanze in einer mit llasserdampf gesättigten Atmosphäre kultiviert. 
im allgeneinen, auch wenn es sich 1 m frebirgsarten handelt, nicht so hoch gehen. Geschah das ausnahmsweise, so wurden weitere Schutzmittel (wie

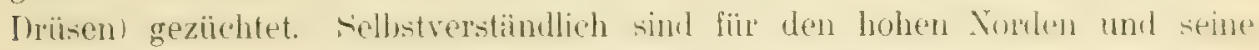

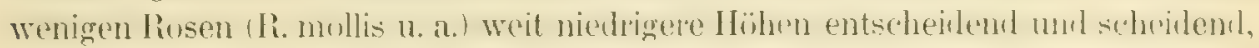
als wie für die gemässigte und subtropische Zone. Ist eine Rose der Ebene

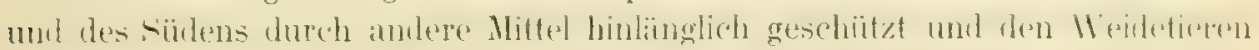

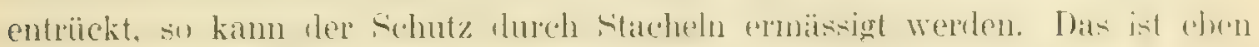

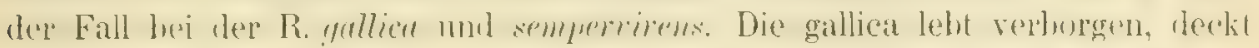

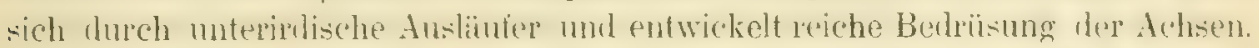

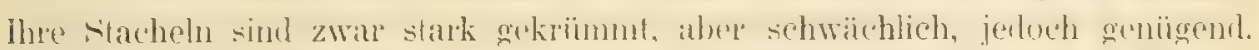

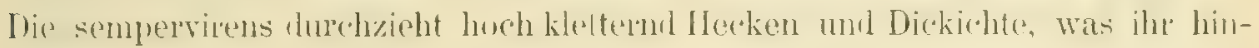
lïnglich Schutz verleiht. R. Jundzillii ist viel schwächer bedrüst als gallica.

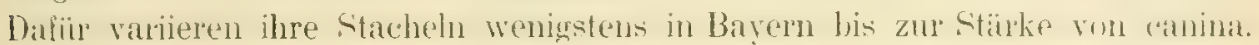

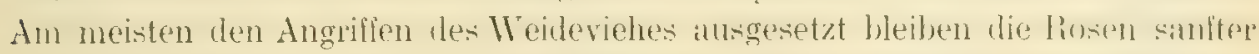
und wamer Abhänge, also solcher Stundorte, wie sie hesonders der rubiginusiGruppe zukommen. Iter finden wir nebest der Bedrïsmng noch dis slätkste

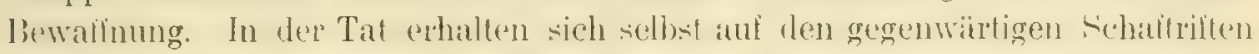

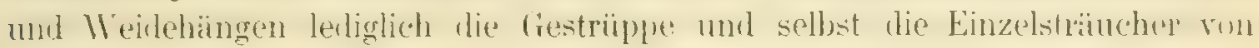

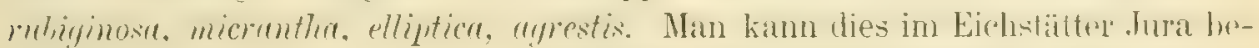
obachlen, desien Hänge von den schatherden verwistet werten, und auch im Jura rom Veumatrkt. Die gewaltigen Iteckenbestänle auf den quelligen Platean-

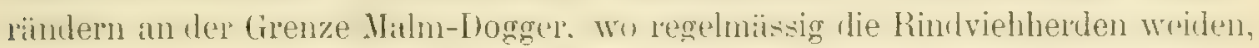

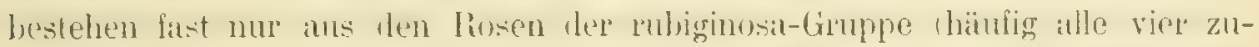

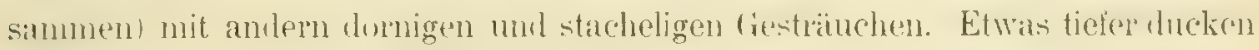
sich anch die tomentella-Hecken vor den Angriffen des Viehes. Die Arten rubiginosa und elliptiea gehen viel weiter in den Nonden hinat als ihre Parallelformen micrantha und agrestis. S̈jo weisen deswegen einzelne, duch schwäher antogrenügte Merkmale dieser geogruphischen Vtrbreitung ant (subpersistente

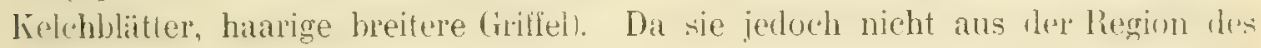
Girssiches ich ganz entlernlen, behielten sie ihre Schutzwaffen bei. Absolut scharle Grenzen zwischen Gebirgs- mol fieflandrosen existieren ja übshanpt nicht. Jelenfalls hat die Auslese duroh das weidemle Grostrieh einen heprotragerulent Einfluss ant die Anskildung der stacheln bei den Rosen ausgeibt. Irh glaube,

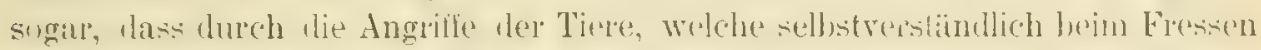

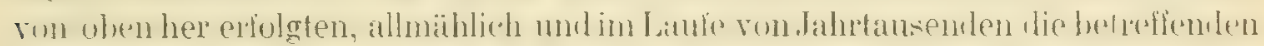

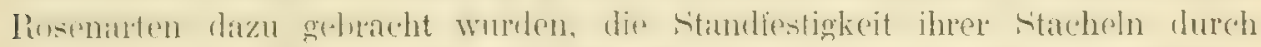

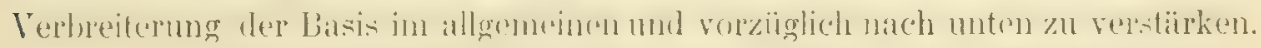

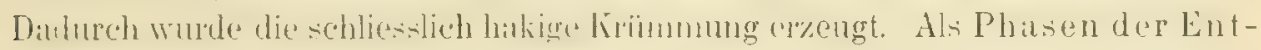
wickelung der Rosenstacheln dürfen also bezeichnet werden: erstens, Begröndung aller Möglichkeit einer Auslese durch die Fähigkeit der Rosen,

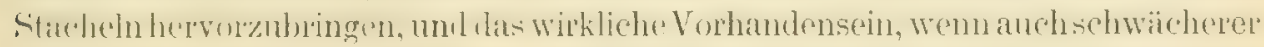

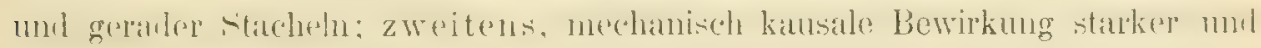

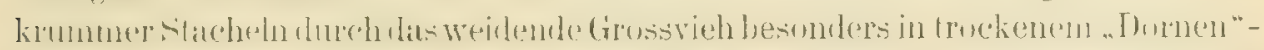

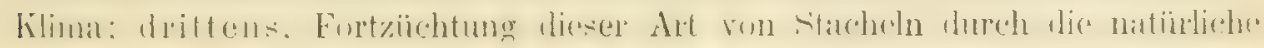

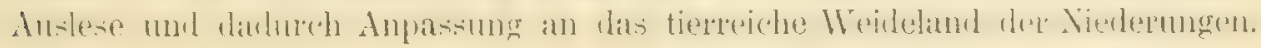


Die Bewaffnung der Blattstiele mit nach rückwïls gekrünmten Stachehn dient hiufig der Erleichterung des, Spreizklimmens" der kletternden Rosen. So sind die Blattstacheln wohl aulzulassen bei R. multiflora, anemonaeflora, sempertirens, arensis, chinensis, damascena, tomentella, abietina. Viele andere

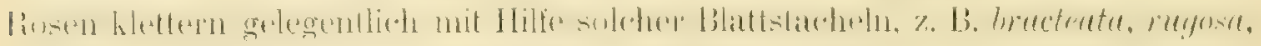
sulpluarea, foliolosa, sect. Rubiginosae, tomentosa, camina. Sie fehlen ganz bei cinnamomea und den Carolinae sowie der R. pendulina. - Jene Rosen, welche

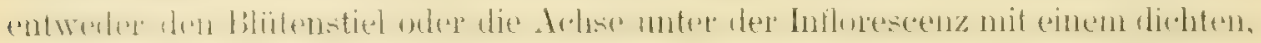

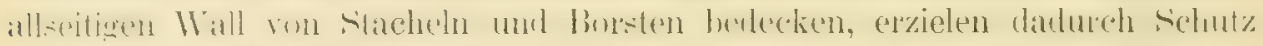

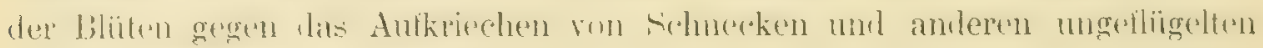
Kleintieren, bes. Insekten und deren Larven. Die geflïgelten Imagines werden

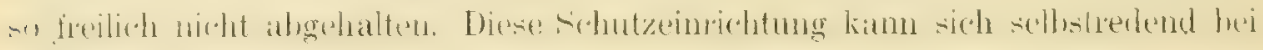
allen Rosen finden, welche überhaupt zur Bildung von Stacheln und Drüsenborsten neigen.

Die typische Heterakanthie steht wohl in kausaler Beziehung zum

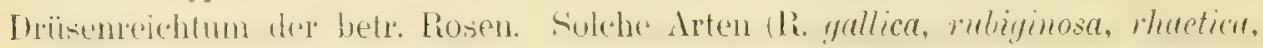
in geringerem Grade .Tundzillii, micrantha, elliptica, tomentosa) haben auch

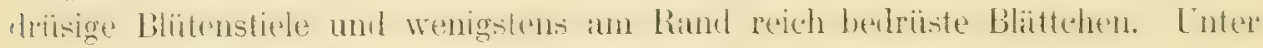

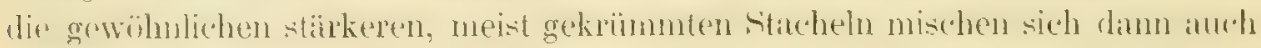
- den Achsen entsprechend stärkere - Drüsen in der Form von Drïsenborsten. Manche Risen zeigen jeduch Heterakanthic, ohne dass bei ihnen Inoisenhorsten

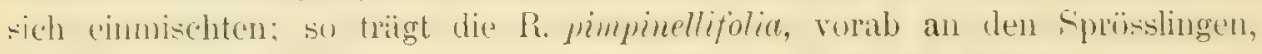
noben der Vielzahl gerader schwacher stacheln einzelne stäkere nit etwas verbreiterter Basis.

Damit haben wir den Übergang gefunden zur Besprechung der Drüsen. Sie finden sich sowohl an den Achen (Zweigen. Blïtenstielen) als den Bliittern (Laub-, Konleh- und sogar Kronblättern) in allen Grösien und Ausbilklungstopmen: Drïsenpulpillen, ungestielte Drüschen, langsticlige Drüisenzotten. Die stärksten D) üsenzotten unterscheilen sich von den Sitachelbursten lediglich dureh das

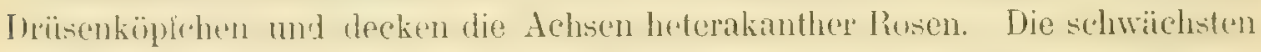

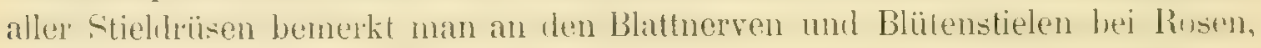

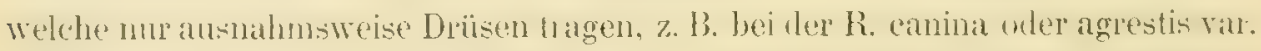

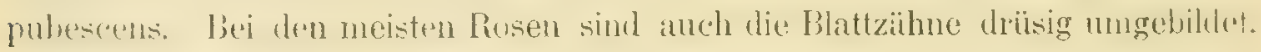
Im Gegensatz zu den Borsten und Deckhaaren muss der Nutzen der Driisen

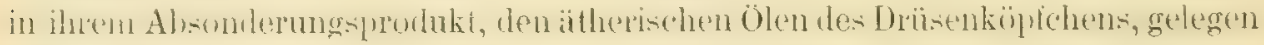
sein. Hierüher wurde bis jetzt nichts Sicheres bekannt. Nach einigen duforen

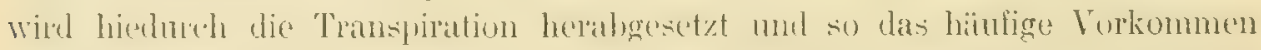

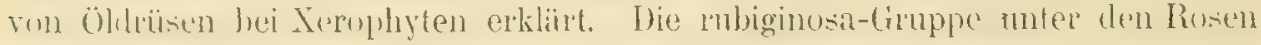

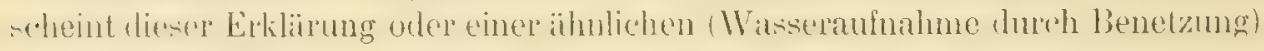

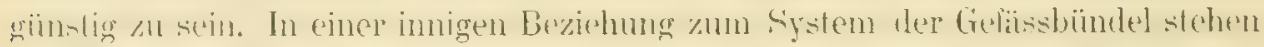

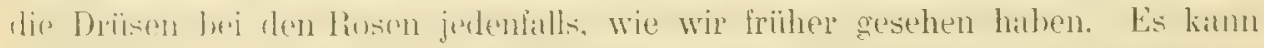

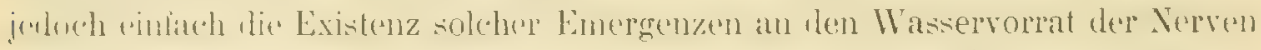

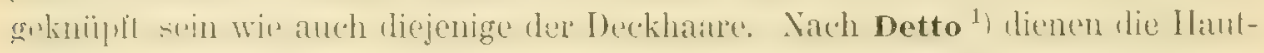
drïsen der Xerophyten, die er vorwiegend aus den Familien der Labiaten,

1) „Flora" 1903 Bd. 92 S. 147-199. 


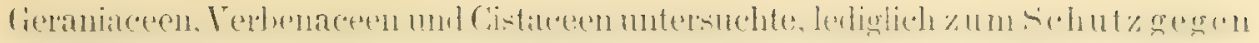

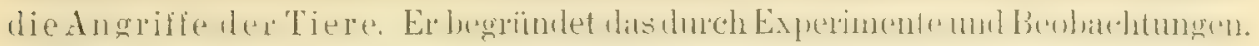
Kleinere Tiere wie Schnecken und Ameisen, aber auch grössere wie Kaninchen

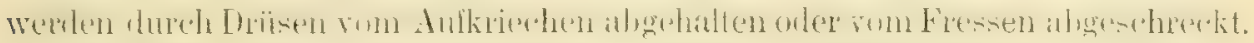

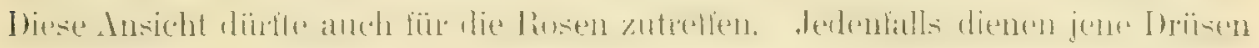
zum Schutze der jungen eben aus der Knospe hervorbrechenden Blältchen,

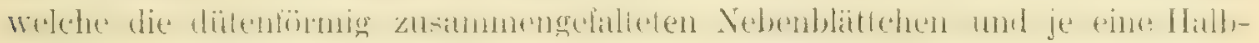

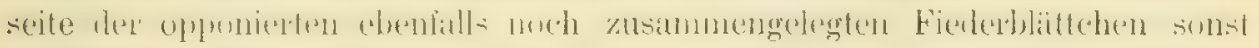

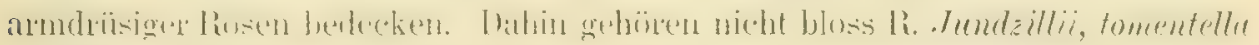
u. dgl., sondem auch gewisse Formen der R. canina, glauca, coriafolia, pimpi-

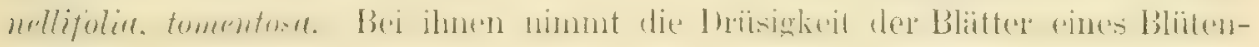
zweiges ron unten mach oben und an den unteren Blättern auch die Drüsigkeit

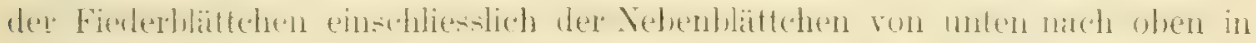

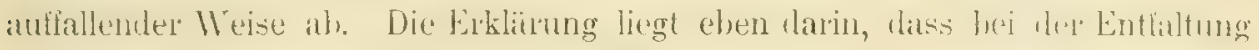

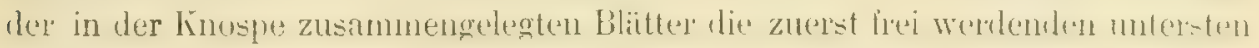
Elemente, dis [nlerseiten der Tebenblittchen, die obern Elemente vor dem

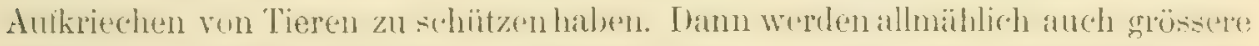

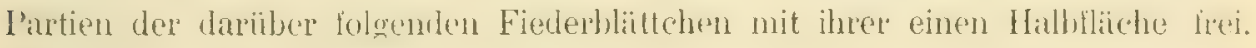
Sie zeigen wenigstens noch Drüsen an den Seiten- und Mittelnerven, sowie den Blattzähnen und rehindern zunächst den Zutrilt schädigender Kriechtiere und Fresser. Erst die obersten Fiederblättchen der obern Blälter entwickeln bloss mehr Drüsen am Mittelnerv uml den Blatziahnen. Daduch finded anch die entschiedene IIalbseitigkeit der Subloliardrïsen (duftreten bloss aul der einen

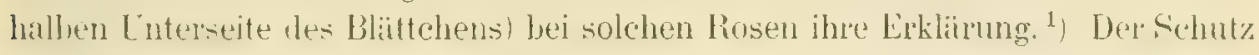
der hunspen durch eine solche Drüisenentwicklung der untersten Fiedern ist so wichtig, dass selhst Rosen, die keine spur von Drïscn aul der Lnterseite der Blittchen solbst auweisen, wenigstens noch hospenschupen und Nebenblïtlchen mit Drüsen reichlich versehen. Ich habe das in Frühjahr bei meiner var. comentu der R. dumetomm und auch bei der var. biserrata der R. canina beobachtet. Selhst die lieimblitter sonst unberlüister Rosen, wie der R. canina, sind nuit. Drïsenhataren gewinpert. Diss die unteren blïlter und Blätchen bei Rusen von mittlerer und schwacher Bendïsung stärker veler anch allein mit Driis-n versehen sint, ist nach dem Vorstehenten eine allgeneine und gesetzmïsige: Erscheinung, kunn alsu nicht zur Diagnose von Variföten Verwendung finden.

Es gibt wohl kaum Rosenarten, die unter keinen Umständen, also bei keiner

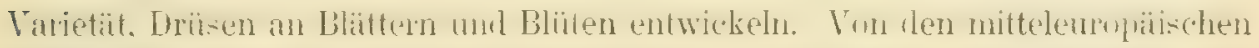

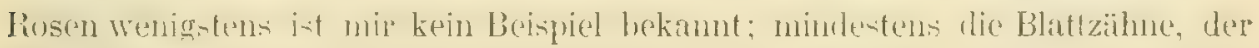

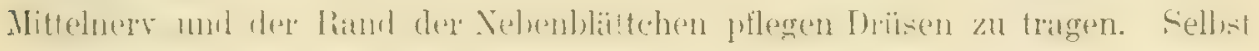
in der ganzen Sectio Caninae, auch bei R. canina und glauca, steigert sich die

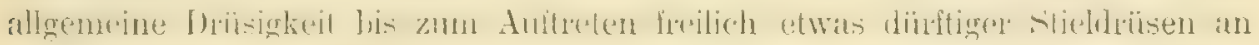

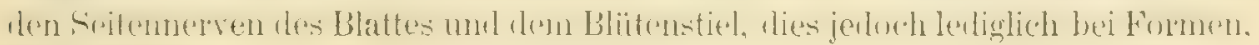

1) Diese assymetriscbe Stellung der Drüsen bespricht zum erstenmale in durchaus zuIreffender und überzeugender Weise H. Dingler in den nitteil. d. nat. Ver. Aschaffenburg"

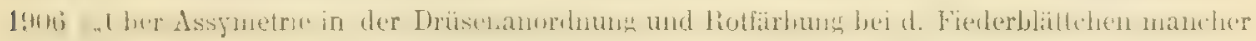
liostent". 
deren Blattahnung mehrfach drüsig znsammengesetzt ist. Solche neigen schliesslich atuch zu schwacher Fleterakanthies. Den grïsten Drüsenreichtum zeigen bei uns die Sektionen der Vestitae mit R. pomifera und tomentosa und der Ruldignosce. Dic tomentosia entbehrt zuweilen der Subloliandrïsen fsehr selten anch der Blïlenstieldrisen), die Gesantart elliptica gewöhnlich der Drüten an Blütenstielen. Bei der R. tomentosa gilt ebenfalls die liegel: je reicher die Zahnung der Blïttchen, desto grösser auch die Zahl der Subloliarlrüsen. Diese I'mnkte scherinen in horrelation zol stehen, wagegen die bulrïsung der Blütenstive mit dem Auftreten ron Drïsen an den Achsen zusammenhängt. ${ }^{1}$ ) frejlich gratuelle L’nterschiede zeigl. Auch die R. micrantha ist zuweilen wie blütenstieldrisig, so heterakanth; elliptica und agrestis enthehren gewöhnlich der Drïsen wie an Blïtenstielen so an den Achsen. Dits Bekleidung der Ansinensorite ter lielchblitter mit Dribsen geht wohl im allgeneinen parallel mit derjenigen der Litublattmenterseite, doch giht es wegen der Wichtigkeit der Kelchblalthliusen fïr den Blïtenschulz viele Ausnahmen infolge selbstïndiger Entwirklung.

Einen rerhïltnismässig schwathen Drüsenschutz an de'n Blätlern haben wiederun die Gebirgsosen, ron denen manche gar keine Subfoliardpüson besitzen wie R. pendulina, mbrifolia, dimanomea, pimpinellifolin, Charini. P'onzini. manche schwach und monegelnlissig hedrïst sind, wie montrna. uriensis, ahietina: pomifera allein matcht durch reichliche subloliardrüsen tine Ausnahme.

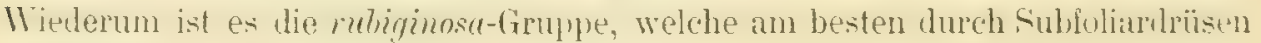
geschützt ist. Da aber auch eine Reihe von Rosen der Niederung und der Mittelgebirgsregion (die Eu('aninen) regelmässig keine Subluliartrüsen träigt. wird man die ükologische Berleutung der Drïsen an den Blïtem nicht allzu huch anshlagen diurfen. Jedenfalls scheinen sie nicht mit Sicherhesit gegen weirlendes Grossvich zu schützen, sondem bloss gegen aulkriechendes lileingetier wie Schnecken uml Ameisen. Da kann aber selhst eine schwïchere Bedrüsung zu ausgiebigem Schutz der sich entwickelnden knospen dienen. Wo Drïsen an hen

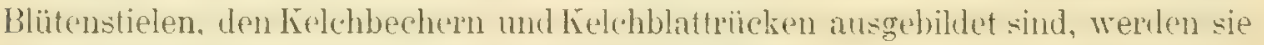

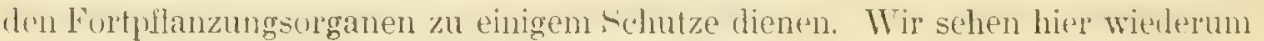
die Gruppe der rubiginosa besonder's begïnstigl, dann die Sectio Vestitae.

Gegen die wichtigsten aller Rosenfeinde, die fliegenden Insekten, schüizen jednch weder stacheln noch Drüsen hefriedigend, anch wenn sie noch so stark ausgebiluet sind. Insbesondere die lïifer gehören zu den ärgsten Feinden der Wildrosen. Der Rusenblattkifer und der Junikiifer remichten häufig die meisten der Blüten eines Stockes. Ahuliches ist zu sugen von der Tätigkeit der

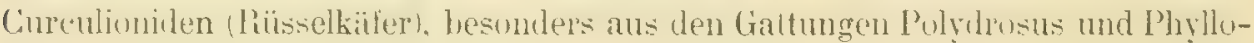
bius. Answerst häufig hemerkt man die Wickel ron Tortsieinen und spannem. In den halb entwickelten Kinospen leben die hampen und verzehren Blätter mit

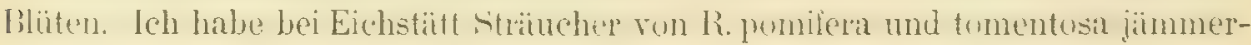
lich zugerichtet gesehen; elliptica und sellst ruhiginosa wird nicht verschont, wenn anch vielleicht weniger gern angegriffen. Ausserordentlich lediten die

1) Die Blütenstiele sind Achsenorgane und stimmen mit deren histologischem Bau überein. Das betont z. B. Parmentier (a. a. O. S. 9) für das Rindenparenchym. 
drïsen- und hatarlosen Ciminen, inshesmdere R. glanca und rubribulia. Weniger machen sich im Fresen bermerklich Blattlinse nud Blattraupen sowie die in

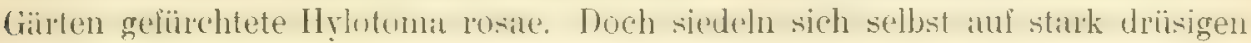
ruhiginosia und tomentria Aphiden an. lalls die Büsche schaltig stohen. Die Blïtenkmospen ron R. lutea und pimpinellifolia fand ich besonders bïulig ron einem lihyndhites angestuchen und am stiel abgeschnitten. In grosisen und

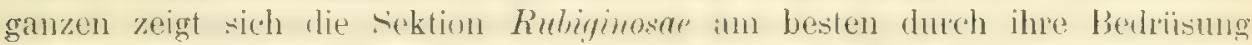
gegen tierische Feinle geschiitzt: an schwiohsten ein Teil der echten ciebirgsrosen, die dieses Schutzes an ihren natiudichen standonten inteilich wenigen bedïrfen. In tieferen Lagen, sei es dass sie sich dort seit der Eiszeit erhalten

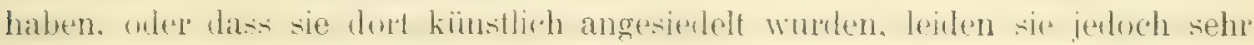
unter den Angriffen der lnseklen. Das gleiche gilt ron anderen an wine L.nkalibit nur verwilderten Arten, wie bei uns von der R. lutea. Mangels richtiger Anpasimg und der gerigneten Schntzmittel gelangen von ihnen olt kaum ein paar Kunspen zum Autblïhen und erfahrungsgentïst (h. luteal meist keine einzige Bliite zur Furhtbilitung. Stoh mangelhafte Fruktifizierung, die alledings anch auf Mangel an bextiubem zuriickgeührt werten kïnnte, dart geratezu als ein Kennzeichen der Verwilderung aufgefasst werden.

Die Hare werden bei Rosen wohl selten als Schutzmittel gegen Tiere in Betracht kommen; wenigstens lïst sich für eine solche Bedeutung der Haarbekleidung von Blättern nichts Entscheidendes anführen. Ich habe selbst gesehen, wie besonders stark behaarte Rosen (meine var. comata der R. dumetormm) ron Ziegen angefressen wurden, ohwohl kein Mangel an sonstigem Futter bestand. ()h die Haare unter [mständen gegen die Inlizierung durch Postspuren 11. dgl. sichern. bleihe dahingestelit. Erst gar die schwache Befläumelung, welche zuweilen an Blütenstielen und Zweigen aultith, ist unmöglich von ökologischer Bedeutung.

Menschliche Tätigkeit hat im Verlaufe der Zeit fördernd und hemme in das Freiletuen der Rosen eingegriffen, wenn auch meist nicht als eigentlicher ökologischer Faktor. ${ }^{1}$ ) Bei einer Reihe von Rosenarten lassen sich in rielen Gegenden die natïrichen Grenzen schwer ziehen oder Freistand und Verwilderung kaum unterscheiden. In Nittelalter witr noch ror der Herschaft der Centifolie die R. cimnamomea allgemein in Líloster-, Burg- und Banerngïten in Kultur, allerdings meist in der gefïllten Form var. foecundissima Muenchhausen. ${ }^{2}$ ) Daraus ist sie vielfach verwildert und gar nicht selten zur ungefiillt blühenden Stanmform zurückgekehrt. Alle Standorte zwischen Eichstät und der Nordgrenze Batyems müssen aus ler angegebenen Lronche als natürliche bezweifelt werden, da lie R. cinnamomea von den Alpen her mit Sicherheit nur bis ins Domantal und dessen niichste L Ingebung durch natioliche Agentien vorgedrungen

1) Es sei gestattet, um des Zusammenhanges willen einige Daten einzugliedern, welche

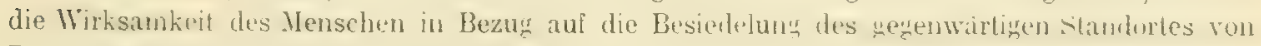
Rosen belrefien, also mehr geographischer als ökologischer Natur sind.

2) Vgl. die interessanten Belege für Nordbayern in der Fl. von Nümberg S. 534. Daselbst S. 532 und 535 auch entsprechende Nachweise für die R. alba und turbinata. - Für das Gebiet dieses Buches stehen die entsprechenden Daten in Teil II. 
ist, Relikte aus der Eiszeit aber sehr selten vorkommen dürften. Auch die Fumlute der h. pimpinellifolin loiden an dieser Lnsicherheit, da sie ebentalls seit langer 'Zeit kultivient wird und sehn leicht rerwihlert. In heschrïnkterem Lnfange gelten ansserhalb der Alpen ähnliche Erwigungen von dor R. pomifera. wiblurend iiber Verwihlesungen der $\Gamma$. allo hort. (verwildert ebenfalls oft einfach

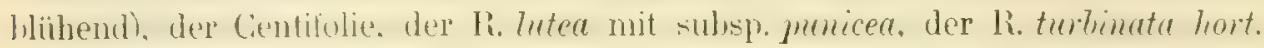
kein Zweilel bestehen kann. Giiter wird sich ihnen als hänfiger Gartenfliochtling die R. rugual heigesellen. Vielledeht hängen anch einge standurte der R. gallica mit alten Kulturstätten zusammen.

Im Jura bringt es die Beweidung trockener Abhänge durch Schafe nit sich, dass an solchen Plitzen nur jene Rosen erhalten bleiben, welche einen besonders ansgiebigen sichutz durch Stacheln und Drïsen besitzen uud herverragend wilerstandsfibhg gegen Trockenheit sind. Wir troflen hier deswegen die oft ansschliessliche Besiedelung durch Arten der Seklion Rubiginosue und insbecondere die muliginos selbst. Freilich, ausgedehnte Hecken sind selten, es ïberwiegen exingeh stehende Exemplare, weil die Schäfer zu den besonders eifrigen Vertilgem jeder Art vm Bum und Strauch auf ihen Triften gehören. Die R. gallice ist am meisten von allen Rosen der Gefahr ausgesetzt. beim Mähen ron Foldern und dem Absicheln von Gras mitbetroffen zu werden; sie witchst eben gerne aul offenen Feldern und an somngen Grasrainen. Durch das Abmïhen wird sie nicht unterdrïckt, aber zu einer besondern Art von Wachstum und zu gewissen Anpassungen gezwungen. Ihre unterirdische Ausliuferbildung steigert sich ins Lngeheure, dabei bleiben die oberirdischen Zweige sehr kurz, die Blïtchen neigen zur Verkleinerung, wihrend dies stacheln und Drïsen sich vermehren. Ich habe mehrere grosse Erdaille bei Plahldorf ganz mit P. gallica ansgefüllt gesehen, die fast jühlich abgeschnitten und so zur ïbemï̈ssigen Ausläuferbildung angeregt wurde. Ausserst selten findet man seit langer Zoit unberührte Vegetationen der Ir. g. In diesem Falle werden, wie schon in syctematischen Toil benerkt wurde, die oberirdischen Achsen his $3 \mathrm{~m}$ lang und kriechen ähnlich der P. arvensis über den Boden und über cinander selbst hin, cin undurchdringliches (iestriippe bildend. Damm fruchten sie auch sehr reichlich. Wogegen die oft abgeschnittenen Exemplare selten reife Früchte tragen. Die R. Jund:illii trillt ebenfalls hïufig das - fhichisal, abgesichelt und abgebrannt zu werden. Sie kommt dann zu einer ähnlichen Ausliulerbildung bei niodrigem Muchs. wogegen unberühte Ifecken derselben ziemlich hoch und straff wachsen. Beim tichlagen des Wakles werden die Lebensbedingungen der R. arensis etwas verähdert: sie wird zunäichst sehr licht gestrellt mul am likettern verhindert. (Ob) datureh Anpassmom entstehen, weiss ich nicht. Gegen atle äbrigen Rusen, welehe in Freien lehen und hohe büsche bilden, wird hentzutage der Vernichtmugstieng wroffnet, vieliach nicht zu Zwecken der Meliorierung ron Ödungen,

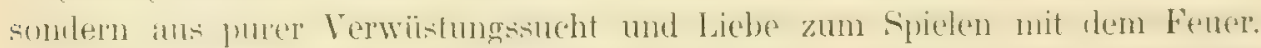

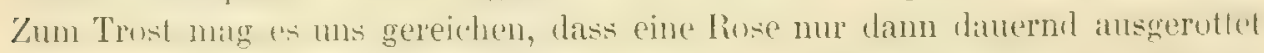
wird, wenn ihre Wurzeln ansgehauen, vder ihre Triebe mehrmals abgebramt.

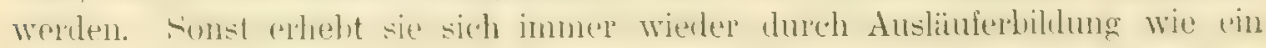
Phönix aus der Asche. 
7. Kapitel: Art und Weise, wie bei den Rosen die Anpassungen erfolgen.

In den vorstehenden Kapiteln wurden die Anpassungen der Rosen an ihre

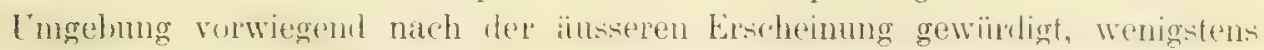

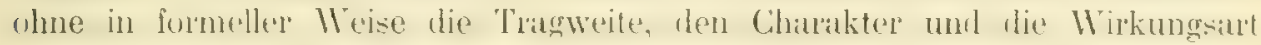

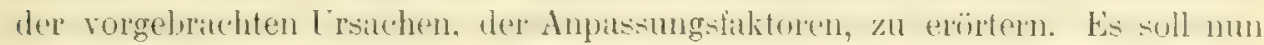

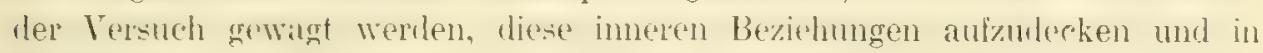
ïbersichtlicher Form zu behandeln. Freilich werden wir zunächst über eine gewisse Wahrscheinlichkeit selten hinauskommen.

Die bis jetzt aufgestellten Anpassungsthenrien' ${ }^{1}$ ) ekliaren die Anpassung

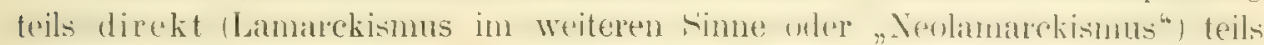
indirekt (Darwinismus oder Selektionslehre). Die direkte Ampissumg ist nur in den seltensten Fälen eigentliche Mrchanomorphose, d. h. nechanisch kansid vom Anpassungstaktor belingt (z. B. Schichachsen muter Winddruck). (iewohnlich wirl es sich um eine Reizerscheinung handeln: Der äussere Fakton wirkt als heiz. aut den die lebendige substanz in einer vorderhand unerlidarlichen umul wohl sicher auch später einmal nur ans dent IVesen der lebendigen substanz. erklärbaren Weise mit einer zweckmässigen Formveränderung reagiert. In diesen sinne spricht man also von Xëno- oler ditimnorphosen im allgemeinen; von Photo-, Bary-, Hydromorphosen usw. je nach der Natur des Faktors im besondern. Die funktionelle oder quantitative Anpassung: Förderung oder Reduktion durch Gebrauch wee Nichigebrach von Organen (Lananckismus in engeren sinne) gehört auch zur direkten Anpassung. Oh, der Schwerpunkt der direkten Anpassung aul dite Lmbormung der äusseren Organe (änssere, äklugische Anhassung) oder der inneren tiewebe (innere, physiolugische Anpassung) mit ihrer Funktion fällt, braucht selten unterschieden zu werden. Bei der indirekten oder gezüchteten Anpassung werden die nötigen Abainderungen (Variationen) voransgesetzt. Sie entstehen von selbst zutälig wder hurch innere Gesetze benlingt und kennzeichnen sich als kleinere Abwoichungen (Fluktnationen) oder als spunghalt andretende grössere (Nutationen im sinne von Nägeli und de Vries). Auf jeden Fall vollzieht hier erst die Naturauslese dureh Ausnetzung des Lnpassumlen und Begünstigung des Pasifulen die eigentliche Anpassung an die Anssenwelt. Würde nan bei der indireklen Anpassung lie Seletilinn nicht anchennen wollen, so hälte math als einzigen Ausweg dine

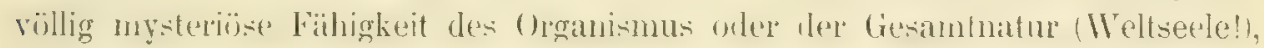
Veränderungen zu produzieren, lie den äusseren Fakluren des Nilien entspräichen, whe dass diene letzeren irgend einen realen Ënflus anf das Leleweren ansgräht hätten (bex realem Einfluss hamlelte es sich ja um direkte Anparsungl. Jede Anpassung, welche zur Phylogenese beiträgt, und solche müssen

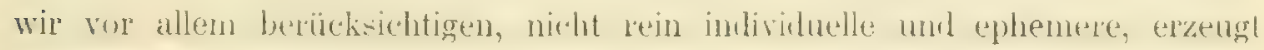

1) Vgl. die , Ubersicht über die ükologischen Erscheinungen bei den mitteleuropäischen

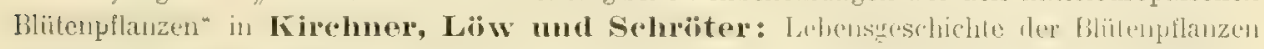
Europas, Stutlgart 1904 fi. Bd. I. S. 6 f. - Dazu Abs. II der ${ }_{n}$ Allgemeinen Pflanzengeographie" (Leipzig 1905) von Graf zu Solms-Laubach. 


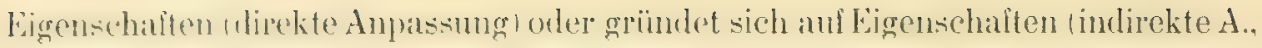
Selektion), welche von den Eltern auf die Kinder und weiteren Nachkommen vererbt werden. Die strengen Anhäger einer ansschlinstich herrschenden sulektion bestroilen die Erblichleit aller anlänglich individuell, also anch der durch direkte Anpassung, erworbenen Eigensehaften. Die direkte Anpassung wïrte also nach ihmen keinerdei Beteutung für die linklärung der latsärhlich varebten Ligenschaften des Ruen und für die Anfstelung eines natïlichen Fystems derselben besitz'n. Wir haben nicht die Aulgabe, in eine allgemene Erörterung dieso Streithage cinzutreten, lenterken aher, dass die modernen Bolaniker überwiegend für die Vererblichkeit der dureh direkte Anpassung epworlenen Eigenschalten - wenigstens unter gewissen hatulen eintreten, und dahin geht auch unsere eigene Ansicht. Nicht jede im individuellen Leben erworbene Eigenschall wird vererbt, und nicht jedte vererble wird fiir alle Zukmult weiter äbertragen, sondern vererbl werden bloss solche, welche tiơ genug dem Organismus eingeprïgt wurlen; zunärhst labil, später, wenn dit :̈usseren Einwirkungen auf die Nachkonmen im gleichen Sinne fortamern, fester und frster. Selzt aber in l'erlatu der Deszendenz eine umgekehrte Beeinflusing ein, so können die erworbenen Anpassungen anch wiefer umgeprïgt und vernichtet woden. Die vorausgehenden wie die fulgenden Credankengänge der vorliegenden Studie lassen Wrnigstens die grosse Wahrscheinlichkeit erkemnen, die für die Vererbung vieler direkter Anpassungen spricht. Bei andern sei die Erblichkeit in Frage gelassen, oder sie wird von uns selbst gar nicht verfochten. Ich bin und bleibe der Moinmo, dass direkte und indirekte Anpassung am Aulban des Verwandtschaltskreises der Rosen von jeher gearbeitef haben und noch arbeiten. Darum suche ich auch die Spuren der Selektion zu entdecken und zu verwerten.

Die innere Natur der Anpassungen bei den Rosen bespricht man wohl am besten und dem Gange induktiver Forschung am entsprechendsten in der frïher eingehaltenen Reihenfolge der Faltoren, welche den Anpassungen die Direktion geben.

1) Das Wasser. - Der Nanismus aul trockenen und nährstofiarmen Böden wird direkt in mechanisch-katsaler Weise bewirkt, indem weniger und besonder's kleinere Zellen der in Frage kummenden Ciewebe beim Mangel des nötigen Banmaterials gebihlet werden. Sowie dieser Mangel aubürt, vergrïssern sich die noch bildungsfïhigen oder neu entstehenden Elemente. - Die Vermchrung der IIasserspalten. und infolgedessen der Blattiahne und Randdrüsen ist eine Reizel'scheinung, hervorgerufen durch den Cberdruck des im Cielisssystem befindlichen Wasiers, Wenn die Pllanzen in allzu fenchtem Mediun kulliviert werden. Lm Selektion kann es sich hier natiulich nicht handeln, weil die Erscheinung durch bloss einmalige Kultur hervorgerufen wurde. Dass Drïsen und Haare in vermehrter 'Zahl produziert werden, beruht freilich ant der irgendwie in (Organis-

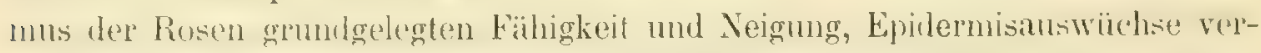
schiedener dit lervoryuhingen. L'm lieizorginge handelt es sich auch, wenn die Rosen durch ein Haarkleid ihre Blitter gegen das Ubermass von Transpiration whe T'rockenheit schiitzen. Man könnte zwar an sich anch an einen 
durch lange Zeiträume hingedehnten Selektionsvorgang denken; da aber, wie viele Lubturversuche zeigten, die starke Behatrung von Alpenpllanzen (z. B.

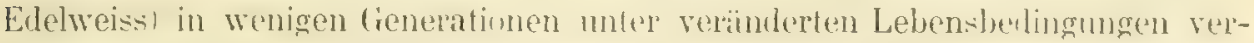

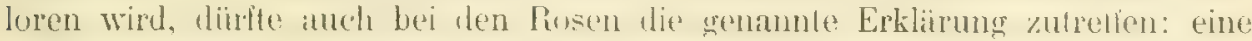
gewisse Anzahl von Generationen oder vielleicht auch der durch Aus. läufer- und Sprossbildung verlängerte Aufenthalt eines individuellen

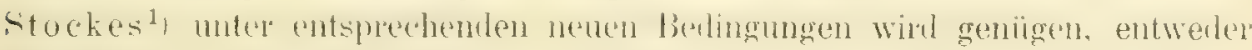

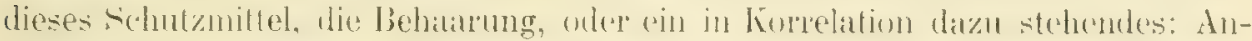

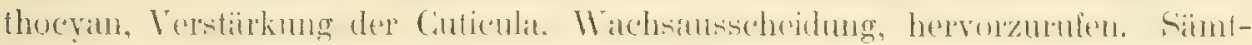

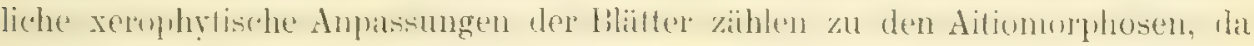
sie dem Experiment zugänglich sind.

2) Die Waime. - Die verschiedene Zeit der Blatt- und Bliitenentwicklung

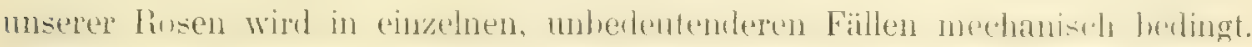

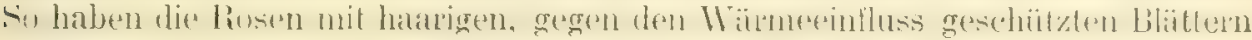

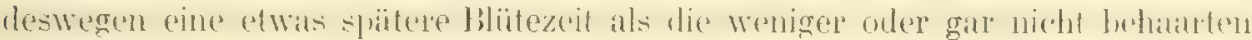

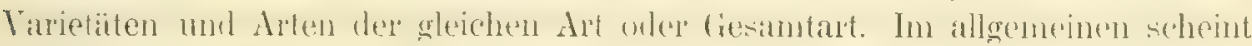
juloch die Vurehimbuheit der zeitlichen Entwicklungsphasen durch Verexhmus früherer, an anderenstamlonten gewnnener Anpassmmgen verursacht zu werlen, so dass im Gebirge entstandene Rosenarten anch in niedriger Lage mit einer

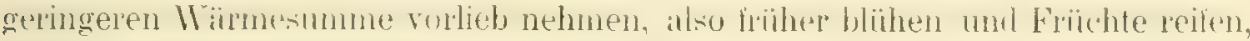

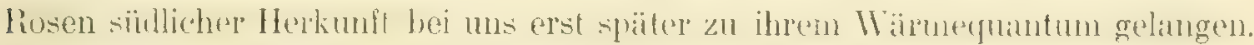
Ob mopholugische Eigentiunlidheiten datnit in Kasammenhang stehen, ist un-

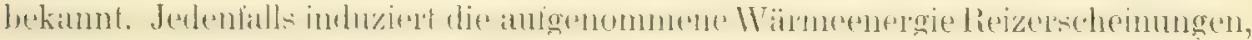
die sich in Wachstumsvorgängen auslösen.

3) Das Licht. - Es scheint mir nicht ganz unmöglich, dass infolge äusserer

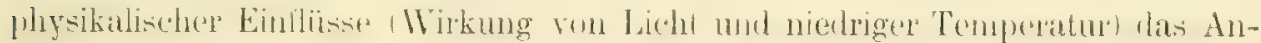

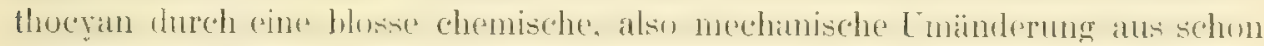

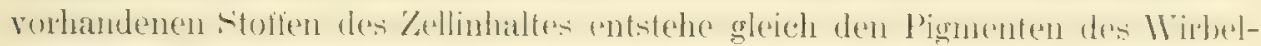

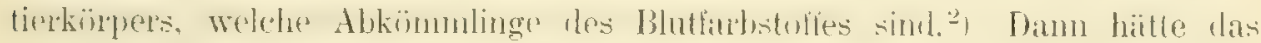

1) Die Fixierung individuell erworbener Eigenschaften, sodass sie sicher vererbt werden, kann bei Rosen statt der Einwirkung gleicher Reizfaktoren auf mehrere sexuelle Generationen leichter und sicherer erzielt werden durch das Verharren der vegetativen Abkömmlinge, der aus Bodenschösslingen entstandenen Tochtersträucher, angleichem Standorte. Vielleicht hängt die starke Varietätenbildung der Rosen auch mit der Möglichkeit zusammen, auf die angedeutete Weise individuell erworbene Eigenschaften leicht fixieren und erwerben zu können!

$\left.{ }^{2}\right)$ Anthocyan tritt in manchen Fällen wohl sicher als blosses Zersetzungsprodukt auf. Dieser Umstand wurde schon melrfach beobachtet und häufig aul die stärkeren Oxydationsprozesse in der Nähe von Wunden $u$. dgl. zurückgeführt. Ich habe dergleichen an Rosen ebenfalls mehrfach beobachtet. So fïrbt sich die Umgebung einer Schnitt- oder Zerrungswunde an Rosenachsen durch Anthocyanbildung innerhalb des Rindengewebes rot. Desgleichen tragen stets rote Färbung die Auswïchse (Bedegoare), die durch den Slich der Rosengallwespe, und die Cecidien, die von Milben, Blattläusen usw. hervorgerufen werden. Freilich wirkt auch lier das Licht mit. Ich habe an abgeknickten Zweigen der R. pimpincllifolia beobachtet, dass ihre Blättchen sich rot färbten und zwar bloss an jener Seite, die vom Licht getroffen wurde, gleichgillig ob) es die Unter- oder Oberseite der Blättchen betraf. Am 16. Sept. 1907 traf ich im Buchtal b. E. eine hochstämmige $R$. canina, an der ein Ast abgeknickt war, aber noch lebte. Alle seine Blätter zeigten durchaus rote Nerven. Es schien hier die Rolfärbung mit der Stoffrückwanderung aus dem absterbenden Ast in Beziehung zu stehen. 


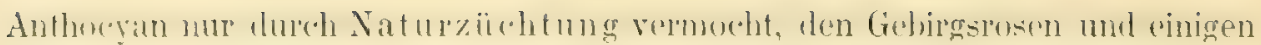

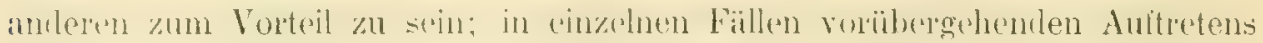

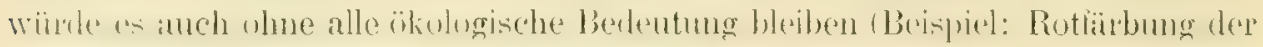

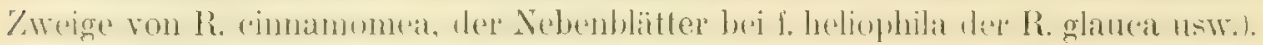

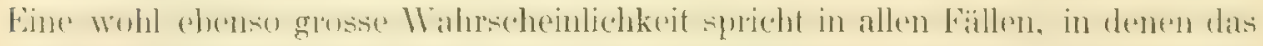

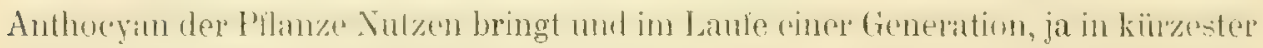

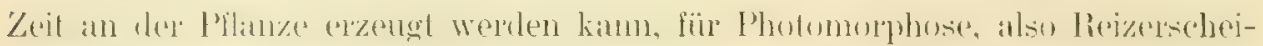

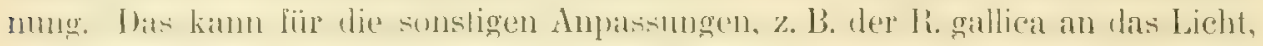

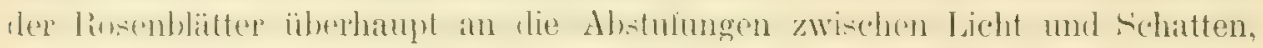
fiir die Fiblierungsmerkmale an fohösingen gitr nicht bezweifalt werden. Die

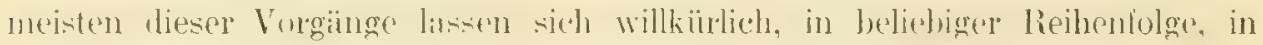

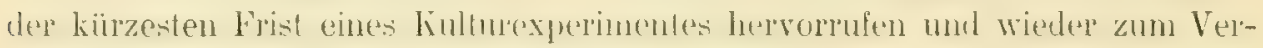
schwinten bringen. Es liwgt nichts dureh langsante selektimn Fixiertes in ihnen: bloss die Fähigkeit zur Morphose ist da, diese selbst mehr oder minder labil.

Ubrigens lelırt uns gerade das Anthocyan, dass der gleiche äusscre Einfluss, also z. B. die Lichtbestrahlung, nicht überall an den gleichen Organen, ja nicht einmal an allen Teilen des. gleichen Organs an dem gleichen Individumm diesulbe Wirkung hervorblingen muss. So ist die ganze Blite von Aesculus Hippocastanun L. Weiss mit wenig Rot, das Sattmal dagegen stark anthoryanot;

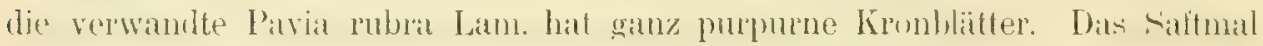
der Viola-Arten ist carotengelb, der Rest der Krone bei den meisten Arten dunkel anthocyanblau. Diese Eigentiunlichkeiten sind vererbbar und rererht. Die Dillerenziterung in Pezug anf die. Farbe mus irgend einmal mehr oder minder selbständig aufgetreten sein, d. h. unabhängig rom Lichteinfluss, wohl dureh Mutation. Jede Art von Aupassung ist grundgelegt in gewissen inneren Befähigungen des Organismus und vielfich auch bedingt vom Lischoinen mutativer, zunächst nicht auf Nülzlichkeit gerichteler Eigenschaften.

4) Die Luft. - Die Anpassung der Rosenblätter an den Wind (durch ihre Fiederung) ist nach meiner Ansicht zwar unbestreitbar, aber ein ganz zulälligres Ergebusis. Die Fienlerung entstand durch irgend welehe Vardation, etwa Mutation; sie lyringl der l'ilanze Nutzen, aber so geringen. dass sie ohne diese morphologische Begalung ebenfalls gut lebensfihig wiire, also auch keine Selektion cintrelen konnte. $\left.{ }^{1}\right)$ - Der gedrungene Muchs der Gebirgssusen und

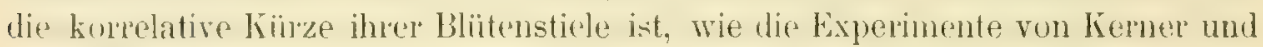
Bomnier beweisen, eine kombinierte Reizwirkung rom Wind. Verminterung des

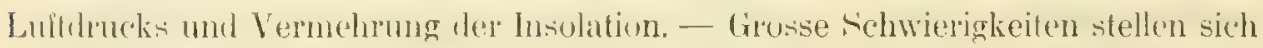
der Auflïsung der lielch- und Diskusinpassungen bei montanen Rosen entgegen. Ist der ron mir greschilderto Gang dieser Anpassungen del wirkliche, so hat dio

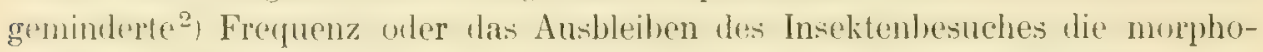
logischen Verinderungen an Fruchtbecher und biskus bewirkt, cinerseits das

1) Andere Rosaceen, wie Potentilla anserina, haben reichgefiederte Blätter, die dem Boden

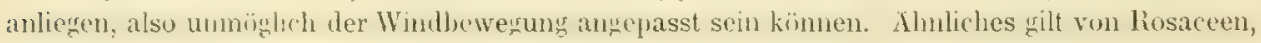
die Fiederblätter und dabei einen sehr niedrigen Wuchs besitzen, wie die übrigen Potentillen, Fragaria, Geum.

2) Selbst bei den Ebenenrosen ist eine Minderung des Insektenbesuches morphologisch zu konstatieren: das Nektargewebe sondert nicht mehr ab. 
Lmiltze - Nektar und Nektargewehe - ontlernt oder beschnänkt, anch die Grilfel-

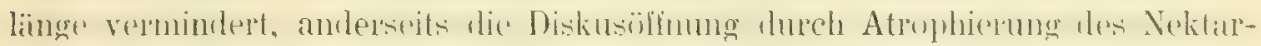
gewebes erweitert. Man wird also an Reduktion durch Nichtgebrauch von

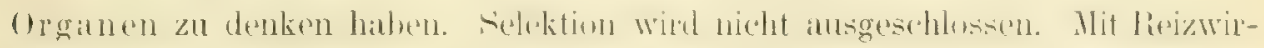
kung kann ich mich in diesem Falle nicht befreunden. Auch die Tendenz von montanen Arten, wie der R. glauea, in der Form subcanina Verhälnisse der R. canina zu imitieren, wird darauf zurückgeführt werden müssen, dass solche Rosen an den entsprechenden Standorten sich wieder in aufsteigender Linie

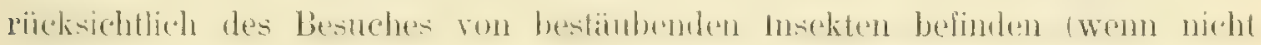

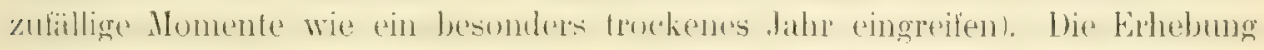

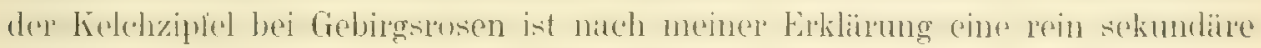

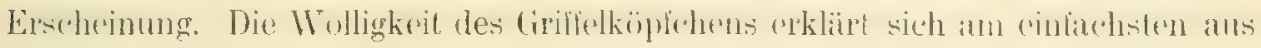

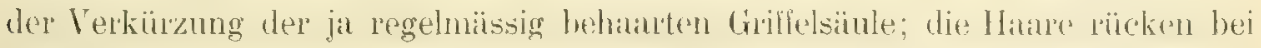

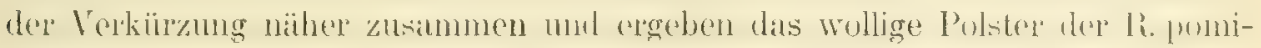

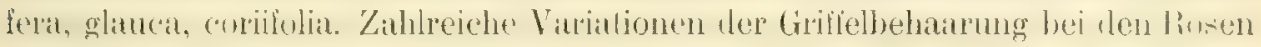
haben übrigens mit Anpassung nichts zu tun.

5) Der Boden. - Die Fähigkeit der Rosen, viel Kalk zu ertragen und auf soldem Boden andere strüucher zu verdrängen, beruht wohl anl einer inneren Anpassung ihrer Gewebe bez. Zellenpmotoplasmen, die man als fewöhnung bezetchnen muss. Dieve Gewöhnung erfolgte an Bildungsherden der Rosenuraren uml wurde vererbt. Wuran dicse innere, direkte Ampassung zorilickzuliihren ist Lnschädlichmachung der Calciunsalze durch Entfurnung aus dem Stolfwechsel? saleklive geringe Auhahme dersellen ans dem Boden? - bleibt unbekannt.

6) Das Zusammenleben mit andern Organismen. - Lrsprïnglich waren die Rosen durch Grösse und Farbe des Schaunpluals, Duft mol Nektargewebe der Bestäubung durch Insekten vorzüglich angepatsit. Diese Anplasinng von Blumen und Insekten bildet ein algeneines Kiapitel der Ökologie, das bei den Rusen allein nicht erschöplend betprochen werden kann. Jedenfalls spielen hier Reizerscheinungen keine Rolle, wenn man den Plianzen nicht positiv Verstant zuschreiben will. Entweder handelt es sich um einen speziell durch einen schöpler eingerichteten Parallelismus zwischen P'llanzen und Tieren, oder un langwierige Shektionsvorgïnge auf Grund der varierenden Blïtenelemente voler un heides zusammen. Dex Anlockungsapparat der Rosen ist nachträglich z.um Teil rudinentär geworden: die Nektarabsomlerung hat fast ganz aulgehört, und das Vektargewebe wumb atrophisch, an stäksten bei ten montanen liosen mit schmalem Diskus. Am meisten unter den einheimischen Rosen scheinen der Fremdbestänhung treu geblichen zu scin die R. rubiginosa (Corollenfarbe, Duft, Nektar), gallice (chehaupparat, Duft, breiter Diskus) und arrensis (fiur Wialdesdiister berechnete Blïtenfarbe, Dult, Griffelsiule, Diskus, rollkommener Pollen). Kune dieser drei Rosen ist in ausgepräigter Weise montan. Ihre vollkommenen Aupassungen an Insektenbesuch haben der rïckläufigen Richtung an meistun Stanl gehalten und exfreuen sich immer noch der Wirkung aul Inswkten. I)ie tiefirole Blittenfarbe der montanen Rosen brancht keine erhaltene Anpatsinng zn sein, da sie einfach mit der reichen Anthocyanentwicklung aller Inxhgebirgspflanzen zusammenhängt. 
Wie bei don meisten Anpassungen an Tiere scheint Reizwirkung bei der Entelehung von farhe und lischmack der Rosenfiuchte ansgeschlussen, und wir haben ledighlich die Wahl zwirchen der Zu*ammenordung von pllanzlichen

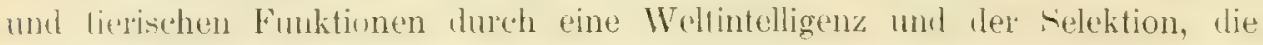

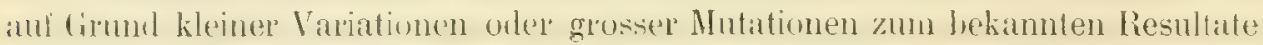
lïhrte. Mit dem l'roblem der Fuchtanpasisung an die samenverbreibenten

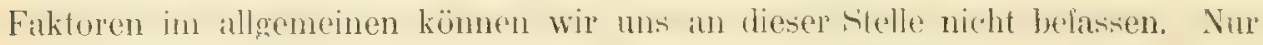
soviel sei bencrkt: die Anpassung und ihre kleinen Modifikationen innerhalb der spexiellen Gattung liusa werken lech auf jeden Fall rein physischen sekundiiren Ursachen iberlassen werden müssen. Wir entscheiden uns also auch hier für Selektion, nämlich insoweit Anpassung überhaupt vorliegt. Denn wie wir hüher sahen, geht sie in keinem Falle tiel und tritt hïulig gral nich in Aktion.

Für die Verhälnisse bei den Stacheln kann nicht einerlei Erklärung gegeben werden. Die stärkere Bewehrung der Schösslinge ist nach meiner

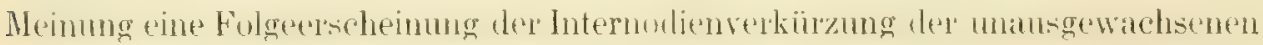
Stammregion. Der Nutzen, den sie durch relative Vermelıming der Stacheln

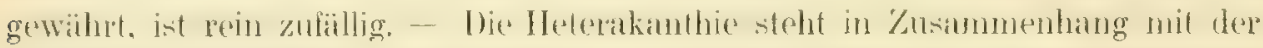

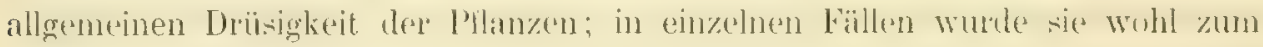
Nutzen der betreffenden Art oder Varietät weiter gezüchtet. - Die Bildung krummer stacheln beruht prinair aut morpholugisehen Vorausietzungen, die run

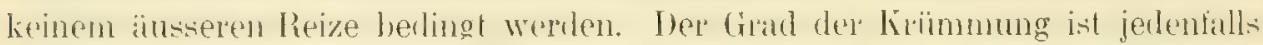

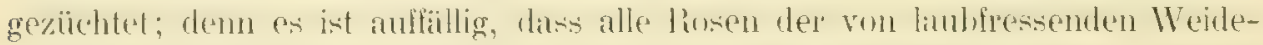
tieren sehr getihndeten Standorte besunders krumme Stathehn besilzen. Andere Rosen komnten sich dort nicht hallen. livin ernithrungsmechanisch haben vitlleicht tonckene standorte auch direkt zur bildung gekrümmter stacheh beigetragen. Die anzelnen Phatsen der Ansleste wuden bereits - 173 klargelegt.

Dass die Rosen überhaupt Stacheln und Drüsen tragen können, beruht

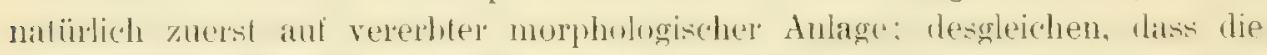

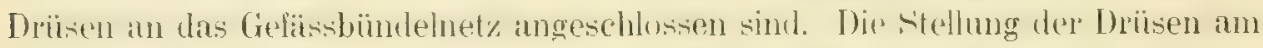
Rosenstranch dentet auf tidnutz gegen Tiene und zwatr vorwegend Fichutz der

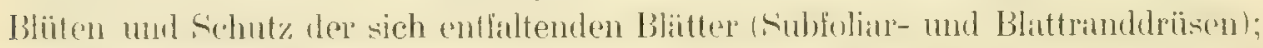
also , ichutz gegen nimlere, von unten anfiriechende 'Tiere in der ersten Phase des Warhstum. Die Entwicklung der Drïsen an den Blätenstielengeht parallel mit dem Drïsenreichtum der Achsen und ist zunåchst noch ohne biologische

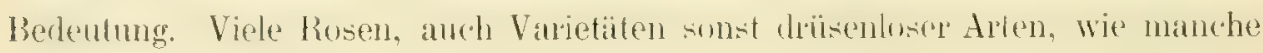
cannina und glauca, die f. glamdulosa der var. pubescens li. agrestis, die hispiden

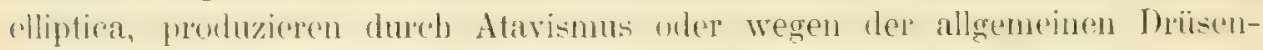

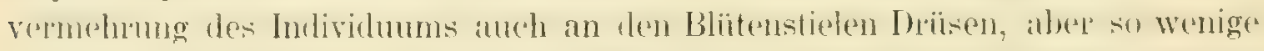
und so schwärhliche, dass sie durchats keinen schulzzwerek erlïllen kömmen. Erst rovhlichere, borstige Bedrïsung fïhrt eingermasisen zum Ziele. Eine solvhe

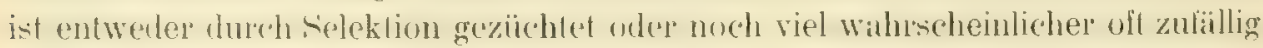
gehildet, demn man sieht in der Natur keine hervorstecheme Begünstigung solcher Rusen gegenuiber anderen. - Dats tatsächliche Aultreten von Driisen und ihre Vermehrung an den Blatträndern, Blattunterseiten und Kelehb) ättern wid in einer Reihe von Fällen, die teils durch Experinent teils durch 
Naturbeobachtung feststehen, mechanisch-liansal verubarht durch den Cherhluek

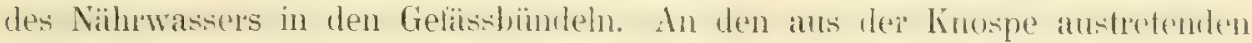

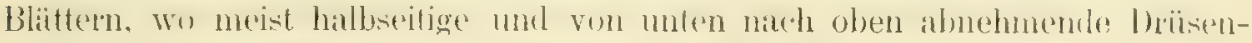
entwicklung zur Beobachtung gelaugl mul zorar parallel nit andoger Anthocran-

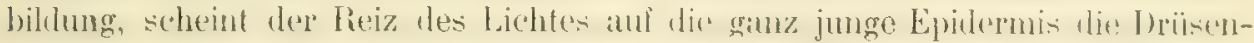

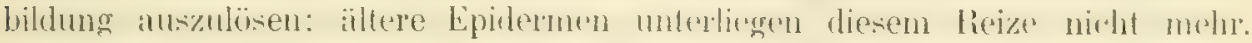

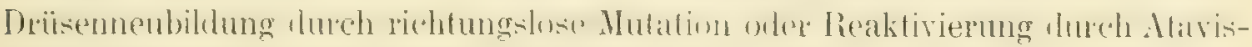
mus ohne älssere Vertusachmor ist an sich möglich, aber nicht bewiesen und

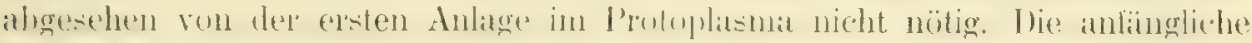

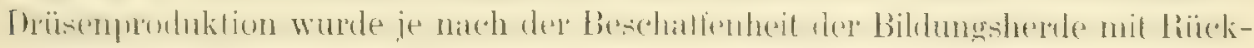

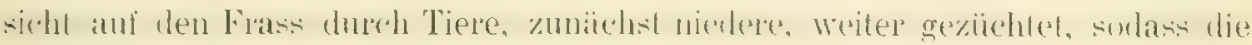
Rosen jener Standorte, welche am reichsten an Insekten und an Weidetieren

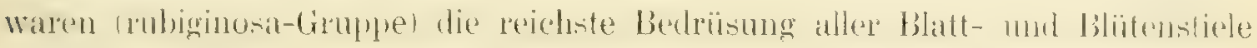
erwarben. Reichere Bedrïsung der Achsen (Heterakanthie), wie bei der

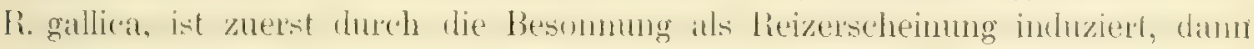
mit Rüicksicht auf den offenen Standort weiter gezüchtet. Die Lösung des An-

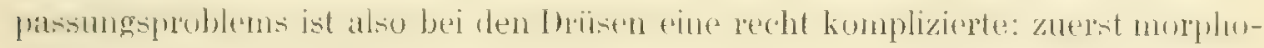

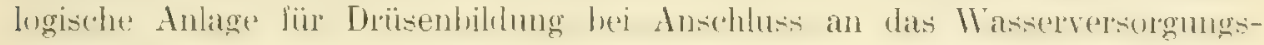

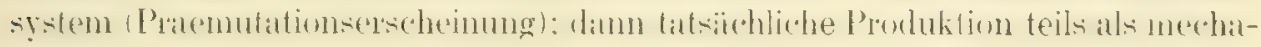
nischer Effekt, teils als physiologische Wirkung (des Lichts); endlich in der

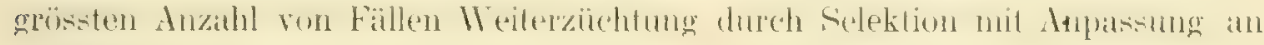
das Tierleben.

Nun erst kann auch der Versuch gemacht werden, der Zahnung des

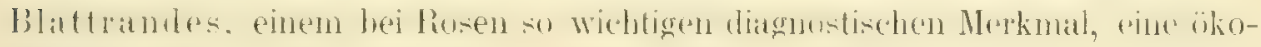
logische Seite abzugewinnen. Ob die Blïtter einel" Rose mehr oder minder

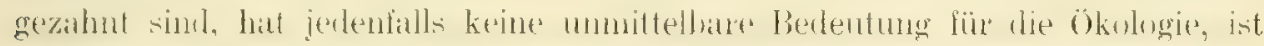
also keine Anpassung. Der Grad der Zahnung ist jedoch eine Folge von Anpassungen. Wir haben gesehen, dass wahrscheinlich mit der Zahl der

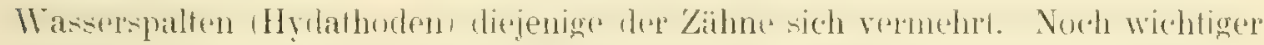

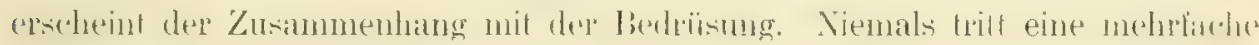

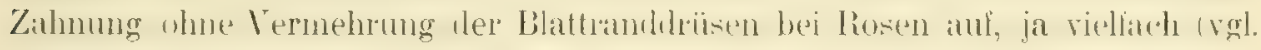
R. Gallicat, lubiginosa, elliptical kimn man schwee die Grenze zichen zwischen

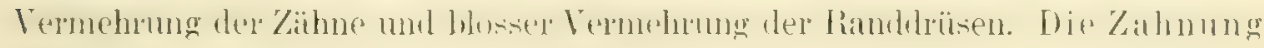
wird von der Bedrüsung morphologisch hervorgerulen. Sie dient in den meisten Fällen als Kennzeichen der Anpassung an reicheres, Schaden

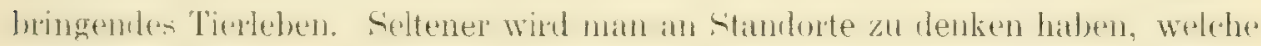
durch den hohen Feuchtigkeitsgehalt der Luft oder des Bodens einen Nähr-

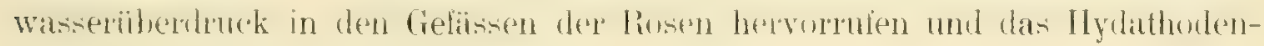
system in besonderer Weise anregen.

Durch das Eingreifen des Menschen wird zuweilen eine rein negative

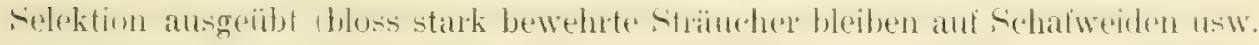

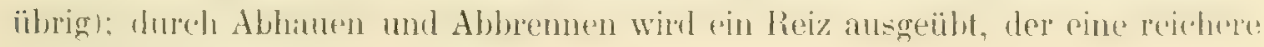
Auslïuferbildung zur Folge hat.

Leider erlaubt es der gegenwïrtige Stand der experimentellen Rosenforschung nicht, in allen Fällen rom Anpatsinng zu einer sicheren und evidenten 


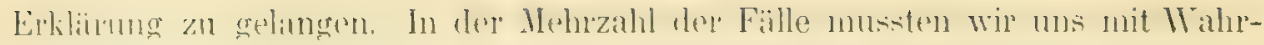

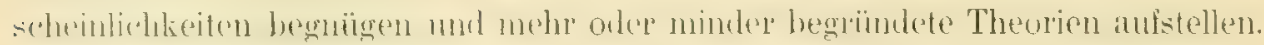
Dies vorausgesetzt ergibt sich als Resultat: es walten bei der Anpassung der Rosen verschiedene Formen. Direkte Ampassung überwiegt in der Form der Aitiomorphose (Reizerscheinung). Zur dir. A. rechnen wir auch die je einmal

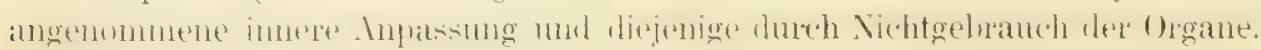
Indirekte Anpassung (Selektion) ist ebenfalls in einer Anzahl von Fällen gar

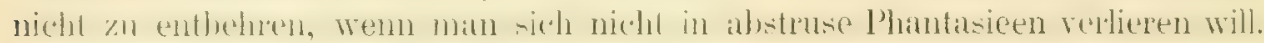
Es wirken öfter mehrere Arten ron Anpassung zusammen, oder es ist Konvergenz anzunehmen, $d . h$. bald ist es die eine, bald die andere Anpassung,

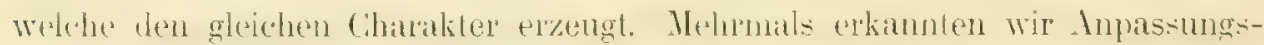
morphosen als rein mechanisch verursacht. Die Anpassung selbst erscheint

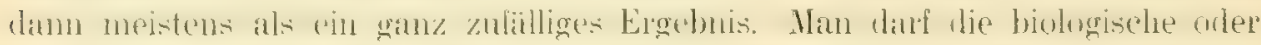

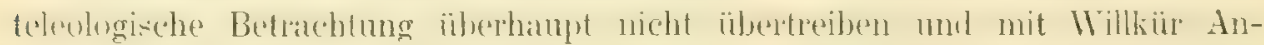

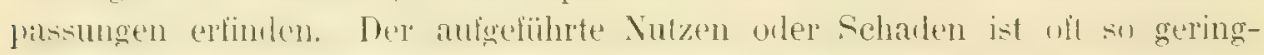
fïgig oder problematisch, dats man hesser von ihm gia nicht spricht. besonders wenn man für sine Eigenschatt telenlogische Gründe anzulühen weiss, für deren Gegenteil man sofort ebenfalls Momente anzugeben in der Lage wire. 


\section{Zweiter Abschnitt:}

Untersuchung der im Gebiet konstatierten Arten, Varietäten und Formen auf den Unterschied zwischen Anpassungs- und Organisations-Merkmalen; Korrekturen am üblichen System.

In diesem Abschnitt stelle ich mir die Aufgabe, an der Hand der im ersten

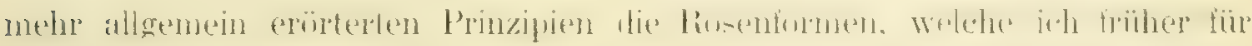

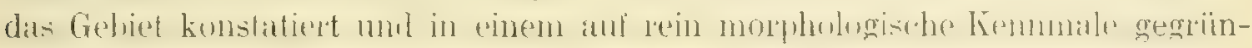

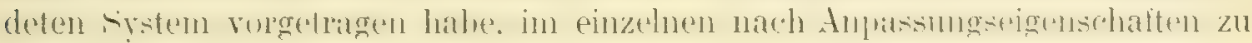
durchforschen. Es wird sich dann herausstellen, ob noch andere Merkmale an ihnen hervortreten, die nicht aus Anpassung zu erklären, vielmehr auf freie Variation zurückzufïhren sind. Man hat solche Eigenschaiten als system-

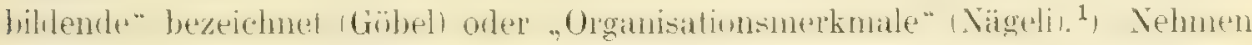

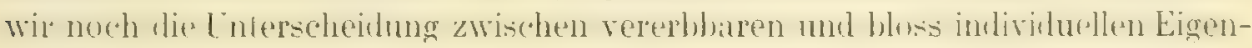
schaiten hinzu, so wird ein mehrfach verändertes Bild des systematischen

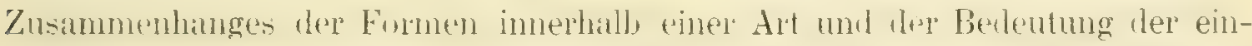

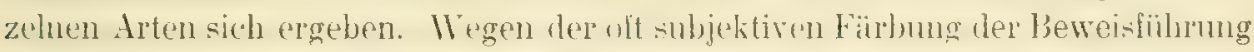

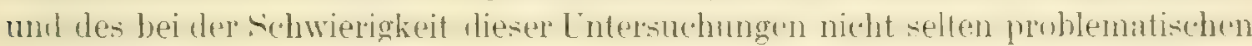
Charakters der Anfstellungen kimn man trot\%len aul das herkimmliche System des zweiten Teiles dieser Arbeit zur Zeit nicht verzichten.

\section{Sect. I: Synstylae DC.}

\section{R. aremsis Huds.}

Von den im Gebiet beobachteten Formen ist die var. bilnacteata Ser. nfenbar eine Hypertrophie. hervorgerufen durch beromler's giunstigen staulurt (fruchtbaren, feuchten Boden usw.). Darum zeigt sie in der extremen Ausbilhung (f. umbellata rod.) auch eint nzehr- bis reichblitige Inllorescenz. Dit

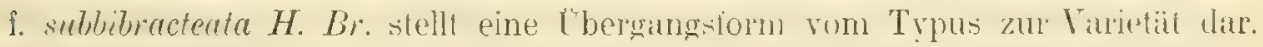
Mir erscheint es kaum fraglich, dass die Var. hihr. nicht vererdst wiml und zu den rein individuellen Anstbilshngen gehört. Die vat. biverrata Crep. hïngt durch

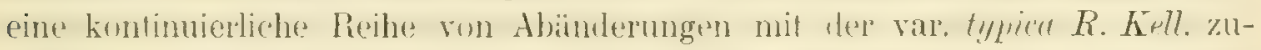
sammen; natch dem Fribleren ist dit. Zahnmog ein Anpassungsmerkmal, wite auch

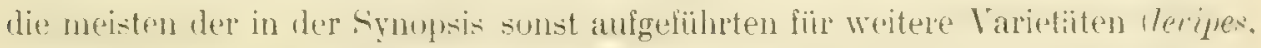

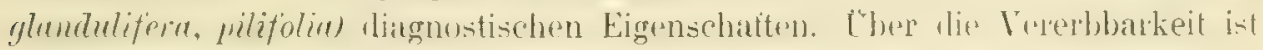
nichts bekannt. Die Formen ovata Desv. und repens Borb. der var. typ. gehen

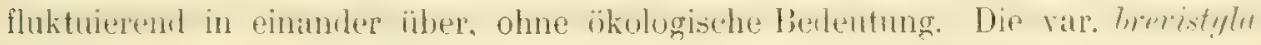

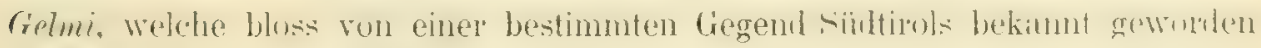

1) Vgl. hiezu C. v. Naigeli: Mechanisch-physiologische Theorie der Abstammungslehre (München und Leipzig 1881): „III. Ursachen der Veränderung" S. 102-183 bes. S. 138 ff. 
ist, hal Ëigenschatlen. die den wesentlichen ler Art ja der Sektion widersprechen, nïmlich eine kure bis köplchentömige Grillelsiäule, deren einzelne (irillel nicht

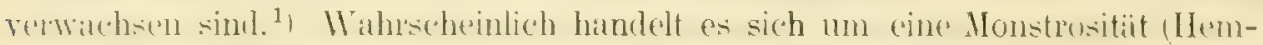

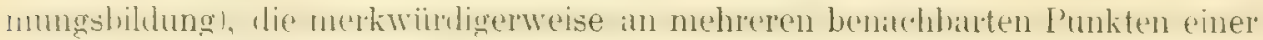
liegreml andral. Wran nieht. su hätten wir in der var. brevist. eine Mutalion zu

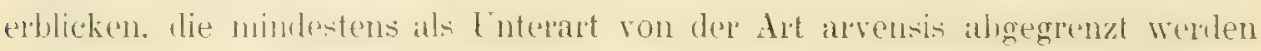
müsste. Die mir bekannten bayrischen Rosen der Art arv. zeigen jedenfalls keine Form, die eine Mutation darstellt, nur 2 Formen (ocata und repens), die mit dem Typus ane liette klemster fluktuierender anpassungskel Variationen biliterl. Alle ïbrigen Formen Bayerns und noch mehr des sïdlichen Franken-

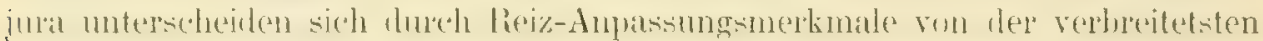
var. typica R. Kell. Von ihnen werden verschiedene nicht erblich sein. Doch fehlt das Kulturexperiment.

Unter den diagnostischen Merkmalen der R. arv. charakterisieren die einen

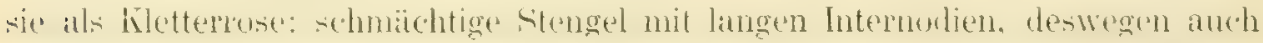

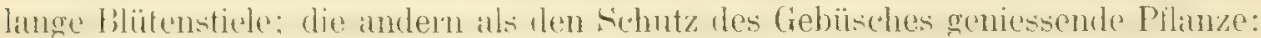
schwathe Behatrung, Bestachehmg und Bendrüsung, infolgo des letzten Limstander

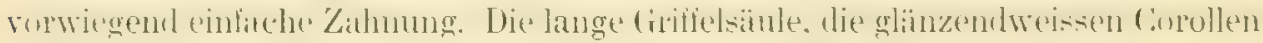

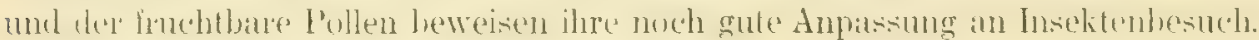

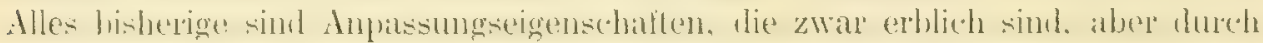

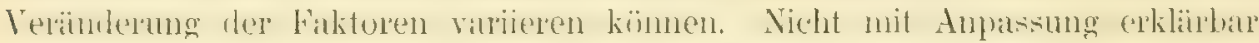

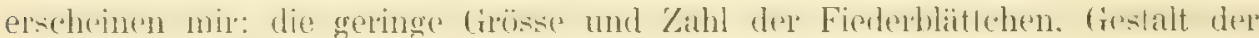

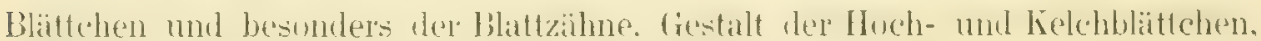

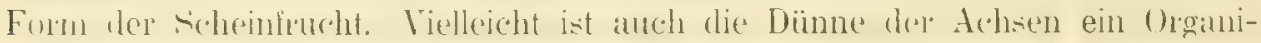

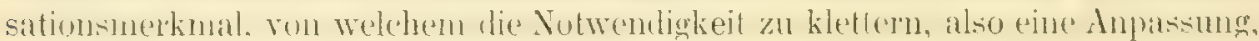

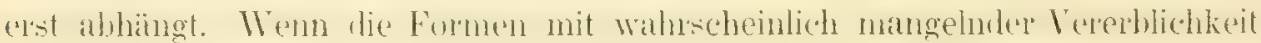
aus dem Verzeichnis ausgeschlossen würden, so hätten wir für das Gebiet nur Var. typica mit f. orata und repens

Var. biserrate.

\section{Sect. II: Gallicanae DC.}

\section{I. gallica L.}

Diese Rose stellt sich dar als Bewohnerin warmer, sonniger Halden, die zwar durch schmächtigen Bau der Achsen und die Form der Blattzähne der

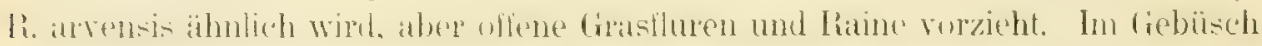
nimmt sie gelegentlich den Wuchs der arvensis an (= var. elata Chr.). Vielleicht ist sie ursprünglich eine Kiletterrose der südlichen Gebüschlluren, der Macchien der Mittelmeerlïnder. Wo sie bei uns als var. elata klettert, verliert

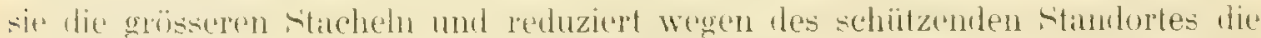

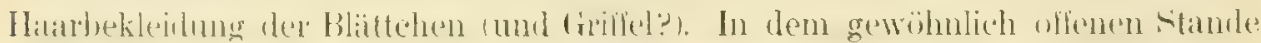

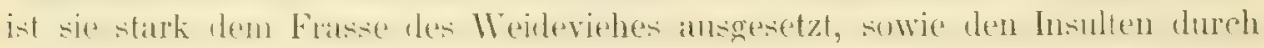

1) So schreibt Gelmi selbst (Deutsche bot. Monatsschr. 1884 und: Le rose del Trentino, Trento 1886 S. 42). - Bei der typischen R. arvensis sind, wie man sich bei geringer Vergrösserung leicht überzeugt, die einzelnen Griffel äusserlich mit einander verwachsen, aber noch in ihrer Sonderung kenntlich. 


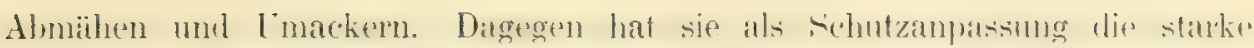

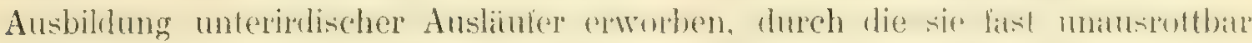

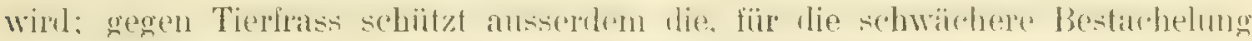

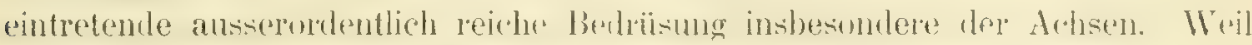
sie oft halbversteckt unter Gras und Stauden lebt, lockt sie die Besliuber an

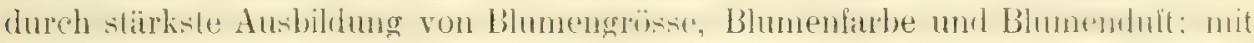

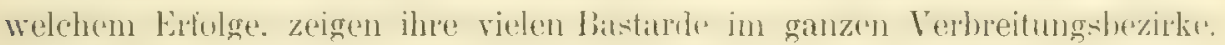

Wegen des allgemeinen Drüsenreichtums der Art, der auch zur reicheren

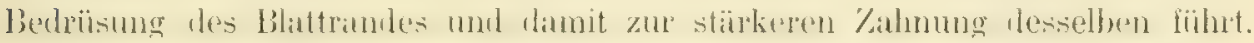

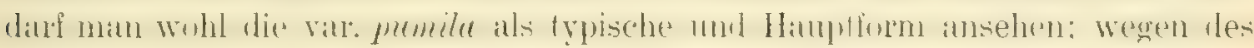

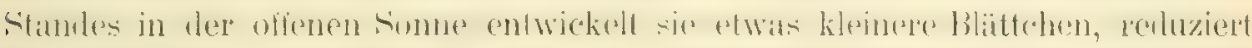

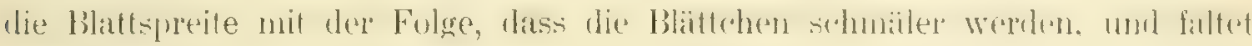
die Blättchen an der Mittelrippe nach oben (Licht- und Wärmeschutz). Die Drüsigkeit und Bezahnung nehmen zu in der f. muscipula und ab in der var. austriaca, welche mit der f. haplodonta den Gipfel der Verarmung an Drüsen

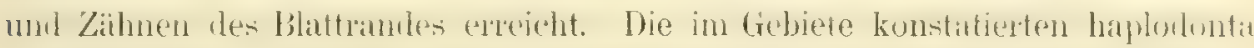
tragen iiberhaupt den Charakler von Kämmerlornen: die Pllanzen wurten regelmiissigr abgeschnitlen veler abgebrannt. Alle hiesigen Furmen sind reichlich durch nininale Clbergänge verbunden. Sämtliche charakteristische Eigenschaften derselben, auch der var. officinalis Thor, lassen sich durch Anpassung erklïren: die der hiesigen haplodunta sind nicht erblich. Aurh die? moisten diagurostischen Eigenschatten der iibrigen eurnpäischen Formen verdanken dex Rieiz-Anpassung ihre Entstehung. Freilich mag gelegentlich Selektion an fluktnierender Variation (Formenkreis der liostyla Burb.l oder Mutation (Organisationsmerkmale!) gearbeitet haben. Ich kann aber dafür kein sicheres Beispiel angeben.

Von den Eigenschaiten der Art sind ausser den bereits angeführten auch nuch andere durch Anpassung geworden: so ent-prechen dio ledergen, winterharten Blätter dem Mediterranklima. Die Armblütigkeit dep Corymben hängl mit dem schlaffen Wuchs zusammen, die lederige Konsistenz der scheinfrucht und deren Farbe vielleicht mit den trockenen Standorten. Nicht durch Anpissung können zur Zeit erklät werden: die Zahl der Fierledhlallchen, die Art

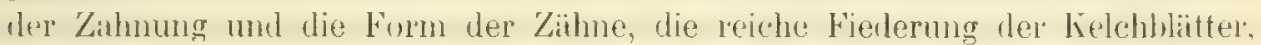

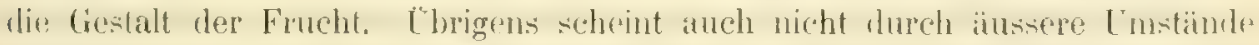
erklärt werlen zu kömnen, warum die Anpassing z. B. an Insektenbesuch bei der

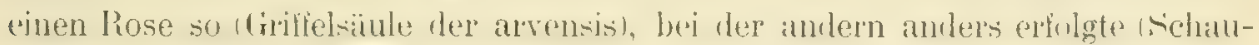
ipparat der gallicat). Wenigstens geht die Entstehung in so lene Zeiten zurick. dass wir nicht imstande sind, uns daribler eine begriindete Tor tellung zo machen.

\section{R. Tumd:illii Bess.}

Ls ist wohl am zweckmässigsten, an der R. J. zwei IIauptvarietititen zu

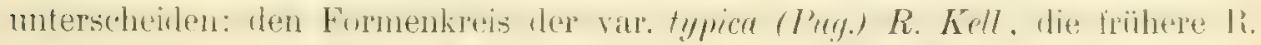

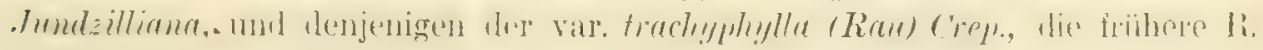

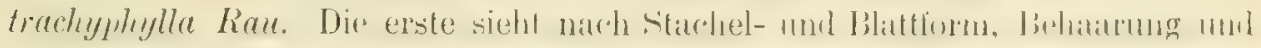

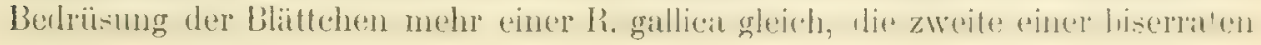


canitna. Ieh will dimit nicht die Hypothese christs und R. Kellers verteidigen, dass es sich bei der R. Jundz. um einen primären, jetzt ganz lebensfïhig gewortenon Bastant zwischen der R. galliea mol einer Cimina handele. Jedentalls müsste eine mehrfach gezähnte Canina in Betracht gezogen werden, da die

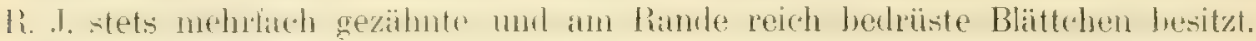

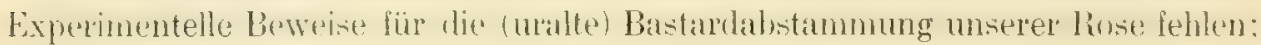
sie sieht nur so aus, wie wenn der betreffende Bastard vorhanden wäre, kann aber thensogut whe legitime "/wischenform zwischen den Gallicanat verae und Canninte darstellen, wolïr anch ihre sehr grosse Fruchtbarkeit und ihre von gallical abreichende geograuhische V'erbreitung sprechen. In siidlichen Bayern kommt die R. gallica noch vor, während die R. J. fehlt. Wie wir schon früher dargelegt haben, eignet anch ler R. I. ein grosses Lichl- und Wämebediurnis; bei Verletzungen deroberirlischen Teile macht sie reichlich von der Bildung unterindischer Anstinler (iebrauch und wird so in niederem Ituchs erhalten. Schont man sie, so bildet unsere Rose mittelhohe Sträucher. Unter Umstïnden wird sie gezwungen, unter dem -ichutz anderer Hecken zu vegetieren. So scheint mir die Zwergform var. Aliothii r'm, entstanden zu sein. Die slark heterakanthen Furmen, wie sie in Interfruken häuliger, hier bloss andeutungsweise vorkommen, mïssen als IVirkung eines wämeren Klimas und eines offeneren, dem Tiertrass mohr ansgesetzten Standes dirckt an die var. typica angeschlossen werden. deren Extreme sie bilden. Wo die R. J. ohne alle Drüsen an den Blïtenstielen auftritt, handelt es sich wohl um eine sporadische Hemmungsbilung, ähnlich der vitr. jenensis Sichulze bei der R. pubiginosa. Im Gebiete sime ïbrigens alle Jundzillii hereits schwächer stithlrii-ig als z. B. in Lntertranken. Die stirkere Behaarung der (im Gebiet nicht vorkommenten) var. Kremsensis (J. Kem.) R. Kell. schliest sich an die var. typica durch l'bergänge an. Man sieht ein, dass die allermeisten Kemmmale der Varietiilcn ans Reiz-Anpassung hervorgehen. Eine Aunahme macht inshesomdere die Blatform: der eine Fomenkreis (var. typ.) hat mehr breiturale (Extrem = l. latifolia (hr.), der andere (var. trach.) schmal elliplische umb lang zugespitzle biattchen. Beide sind aber durch fluktuierende Variation untremnhar verbunten. Die Gestalt der Frucht fluktuierl von kugelig bis lïnglich wal. Dagegen ist immer sehr bezeichnent die ebentalls durch Ampassung kaum zu erkiärende jeweilige Form der Blätchen und unch neh" diejenige der Blatlzïhne, die scharf, spritz, eigentümlich nach aussen gestreckt und mehruals drïsig weiter gezähnt sind. Die Anpassungen kïmnen in ganz gleidher Weise surohl beim Blattypus der var. typ. als dem der trach. atuftreten und beziehen sich je nach den Varietïten mit einem \pm auf: Insektenbesuch

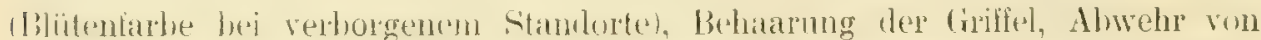

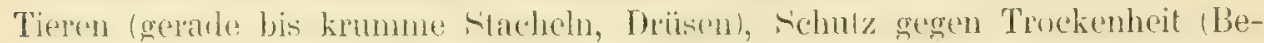

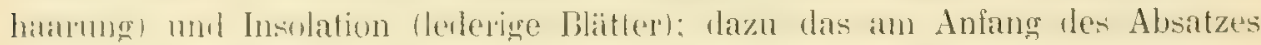

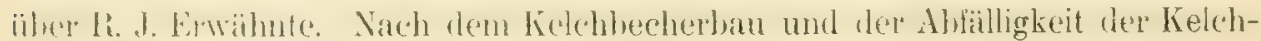
zipfel gehört die R. Jundzillii zu den Rosen der niederen Lagen.

Von der R. gallica weicht die R. Jundzillii, als Art gelasst, sowohl durch Anpassungs- wie Organisationsmerkmale ab. Zu den ersteren gehören der straffere Wurchs, die Gestalt der meist starkeren und krümonern stacheln, die 


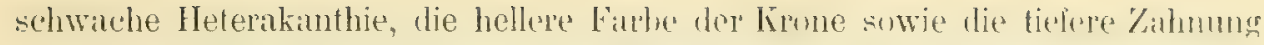

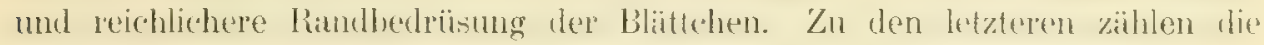
reichere Inflorescenz (?) und die grössere Zahl (7) der Fiederblättchen.

\section{Sect. III: Vestitae Chr.}

\section{7. tomentosa Sm.}

Die drei Formenkreise der var, cinerascens, subglobosa und Seringenna unterscheiden sich dureh den Grad der Blattzahnung, die bei den reicher ge-

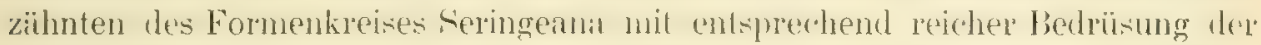

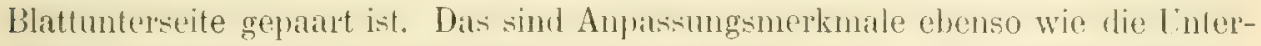
schiede der Stacheln bei den ti. fallax und anceps m. oder der Ciriflelbehatrung bei der var. Seringena und ihrer f. poecilacanthe m. Dass Zähnung des Bhattrandes und Drïsigkeit der Blattliiche', aber atrh Betruisung der bliitensticle gern Hand in Hond gehen, also auf eine allgemeine Neigung der Epidermis hinweisen. Drüsen in rerschielenem Grade zn produzieren, zeigen die im Gebiete nicht konslatierten var. formulenta, lamuginosa, alsatica. Diese siml vielfach gezahnt und entbehren der Drïsen nicht hoss an der Blattunterseste, sondern. wat für eine R. tomentusa verwumlerlich ist, anch an den Biütenstielen. Damil entfernen sich diese Rosen am meisten vom Typus der Art. Da sie aber gelegentlich einzelne Stieldrüsen an dem Blittentielen erzengen, handelt es sich wohl um eine vererbte Hemmungshildung (wie bei der var. jenensis der li. rubiginosa), und braucht man diesen Mangel bei der Definition der Art nicht zu berücksichtigen. Die [bergïnge zwischen Fomenkreis a) und b) sind ganz fliessend, so dass keine reale Grenze zwischen f. subduplicata Borb. der var. cinerascens und zwischen der var. subglobosa gezogen werden kann. Auch die Formen der var. typica Chr. nihtern sich ofl ganz dem Formenkreis (s) in Bezug auf Blattzahnung. Ëne grössere Mutilion hrancht hier nicht angenommen zu werden.

Die Unterart scabriuscula, wie ich sie nach Braun umgrenzt habe, spielt genglaphisch in nördlichen Bayern eine wichtigere Rolle als die formen der typischen Art. Die Gestalt ihrer Stacholn mul die Persistenz ihrer Kelchziplel charakterisieren sie in höherem Grade als Rose der montanen und tieramen hegion, wite das tür die Art fomentusal somst zutrifft. Sie nähert sich licdureh der R. pomilera. Vermittelt sie nun zwischen dieser und der gewöhnlichen Ii. tomentusia durch direkle Anpassung, sulcklion oder richtungslose Varjation? Fïr Selektion spricht nichls. digegens scheinen die L'nterschiedte eine Mutation wahrscheinlich zu machen, die entweder von der R. pom. oder tom. anhob und sprungweise arbeitete. Trotzdem glaube ich auch in diesem Falle direkte Anpilsoung amuehmen zu mïssen. IJurch Gestalt, B(zahmung und Bedrüsung der

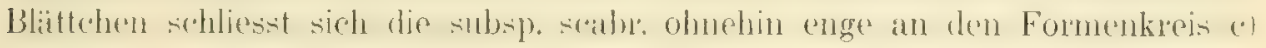

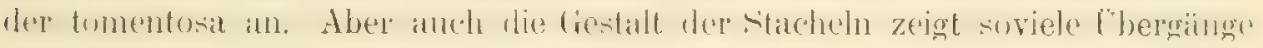
zwischen dem Typus und der Unterart, dass man oft in Zweifel gerït, wohin man eine bestimmte Rose stellen soll. Nicht viel anders steht es mit der Per-

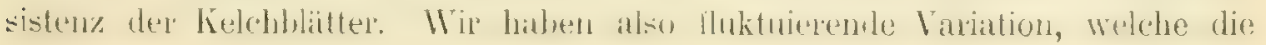


Beziehung anf monlane Einfliisese so deutlich verrät. dass die direkte Anpasisung kaum in Zweifel steht. Ahnlich erkläron sich eine Reihe von Formunterschieden innerhalb der Unterart scabr. selbst.

Auf sprunghalter Mutation ofler fluktuierender Varialion beruhen offonbar abe Interschiede der Furmen, welche sich ant die Gestalt dex Blätchen und dex

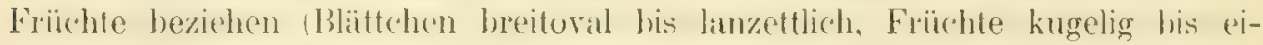
lïnglich). Auch hier sind der lJorgänge soviel, dass die eigentliche Mutation kanm zutrilt. In tinzelnen Föllen kömnte die schmale fiestalt der Blattchen sugar darauf beruhen, dass die embryonale Formung der untersten, ersten Sprossinternodien später beibehalten wird.

Die wesentlichen, aber durch die subsp. scabriuscula vermittelten Unterschiede zwischen der $\mathrm{R}$. tomentosa und $\mathrm{R}$. pomifera, wie wir sie schon vorne

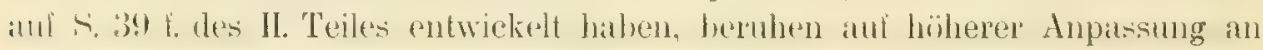
das Gebirge und einen tierarmen Glandort hinsichtlich ter Ri. pomifera. Diggegen finden wir in den Chamkteren der Sect. Vestitae, mu welcher beide Risen gethören, nehen Anpassungseigenschaften (hohem und stranmem Wuchs, geringer his Phlender Heterakanthie, reichlicher Bedriismng der Blitter und Blütenstiele) vorwiegend Srstemmerkmale: Zahl und Form der Blittchen, beträchtliche Durchschnittsgrösse derselben, Reichbliuligkeit.

\section{Sect. IV: Rubiginosae DC.}

\section{R. mbiginosa L.}

Die von mir augestellte Unterart columnifera bringt die R. rubiginosa in ähnliche Beziehung zur micrantha, we subsp. scabriuscula m. die R. pomifera und tomentosa verbindet. Und zwar sind die var. liostyla und Gremlii noch näher mit der R. mier. verwandt wie meine var, macrostyla. Der Charakter einer Bergrose geht durch die Verlïngerung und das Kahwerden der Grifel, sowie die Abfailligkeit der Kelchblitter in den einer Tiellandrose über. Hier ist eine allmähliche Reiz-Anpassung erfolgt.

Die zwei Formenkreise der var. umbellata und comosa sind, auch nach dem Zeugnisse von Crepin, keineswegs scharf getremnt, smolern fluktuieren in einander ïber. Der Kreis der umbellata trägt die Schutzmittel gegen Tierfrass in ausgepräigterer Weise an sich wie derjenige der comosa. Im einzelnen lassen die Formen nur Linterschiede der Reizanpassung erkennen. Eine ganze Reihe von Formen unterscheidet sich durch Nanismus von andern: es ist wahrscheinlich, dass sie, als rein individuelle Vardalonen, keine Exisfenzberechtigung im vystem besitzen. Dahin rechne $i \cdot h$ bei dem liveis der comosa die ganze var. microply,lla $R$. Kell., wenigstens die Il. parifolia und rotundifolia Rau, weleht man als Kümmerformen zur var. comosa und deren Unterabarten zu stellen

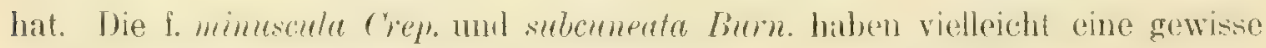
Existemaberechtignng wegen der keiligen Blattforn. In Formenkrois der mubellata wäre die hïmnnerform pimpinelloides ("hr. noch näher zu untersuchen. Der Mangel an Drüsen am Blütenstiele (var. jenensis Schulze und teilweise var. 


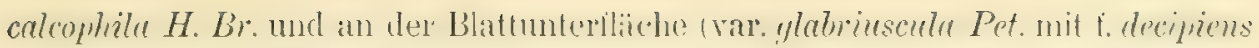

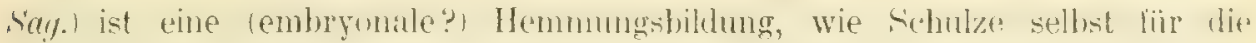

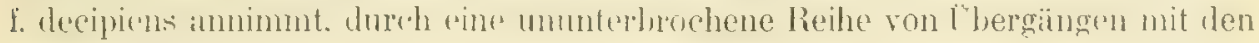
normalen formen verbunden. Iba es sich also sozusagen um patholugische Varte-

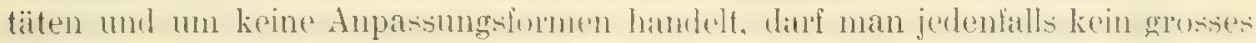

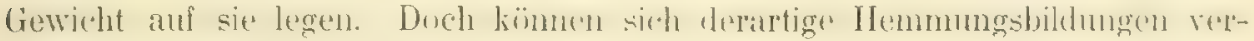
erben. Ich habe Kulturversuche mit f. decipiens Sag. und f. anadena Chr. der R. elliptica angestellt. Die Drüsenarmut beider ist auch in der ersten Generation genau in gleichem Grade aufgetreten. Die Samen stammten

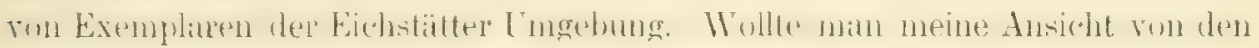

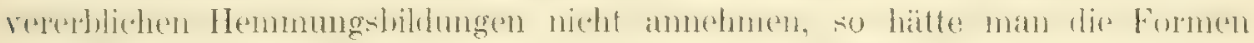

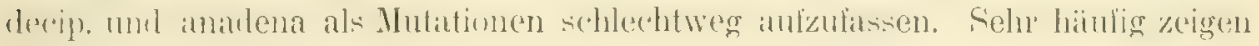
sich bei der R. rubiginosa schwach gekrümmte bis gerade Stacheln. In vielen Fällen wird auch hier die embryonale Bilinng der sprossantänge lanternd sich erhalten haben (= Monstrosität, nicht Varietäl); in anderen mag Anpassung an lierheie, z. B. Waldgeschützte, lokidititen eingetreten sein. Auch die blatse Farbe der Corollen von var. Gremlii Chr. scheint auf einer weitverbreiteten Enhwcklungshemmung (pathologisch, ob erbliahg? zu bepuhes, uml kommt selbstrerstindlich. wie ich mich an untertiänkischen Formen der h. rubiginusa iiberzengt, auch an lurch Ciritfel- und stachelbildung ganz abweichenden liarietäten, also in ganz anderen Kombinationen, vor.

Anpassungsireie flukfuierende Tariation ist bei der Art rubiginosia hälufig zu konstatieren : sprungweise Mutation zu Oromisationsverschiedenheit bennerkte ich bei den Formen des Gebietes nicht.

\section{T. mieremthre Sm.}

Auch hier lïsst las im Gebiel gesanmelte Material ansser in oft kam merklicher Weise schwinkenden Merkmalen der direkten Anpassung bloss lluktuierende Variation der Organisationsmerkmale erkemen (z. B. Blattgrund der var. typucu und permirta). Die Grade ler Beharung kömnen von Reizanpassung, aber anch von Bildungshemmung hedingt sein. Ninisnen von vergänglichem Chatrakter sind auch hier zu Varietäten gestempelt worden (f. diminuta $H$. Br.)

\section{Ir. elliptica Tamsch.}

Die Anpasinug an den montanen Standort ist am weitesten gediehen bei

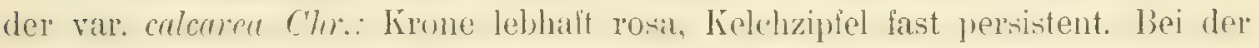
ganzen Lnterat inodora $m$. dagegen wude sie, erkennbar in der Abfälligkeil del Kelchblitter, der Lïnge der Blütenstiele und der geringen Behaarung der Griffel, soweit zuriurkgenträngl, dass viele Autoren Rusen dieser Gruppe zu R. agrestis Sav. stellen. Fïr den Grad der Behaarung gilt das oben bei R. micrantha

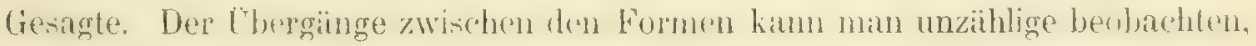

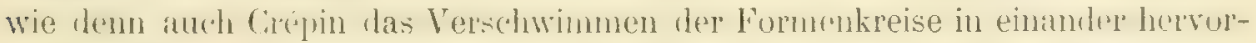

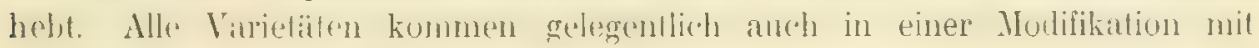


Sticldrïsen an den Blütenstielen ror. Da die Bedrüsung immer recht schwäichlich ist, handelt es sich un einen Atavismus: Das innerhalb der Sektion Rubiginosae vorwiegende und in den Vortahren existierende, aber irgend einmal latent gewordene Merkmal wird durch Variation wieder erweckt. Zuweilen mag die Blütenstielbedrüsung nur gelegentlich und rurïbergehend auftrelen: ausgelöst durch ein abnorm feuchtes Jahr. Fluktuierende anpassungslose Variation bodingt bei R. ellipt, einen geringfügigen Wechsel in der Form der Früchte und Blïlchen. Die f, anadena Chr. entspricht in der Erklärung der f. decipiens Sag. bei der R. rubig. Eine Differenz, die zur Annahme einer Mutation (im -ime einer grösseren Variation) berechligte, existiert whl nicht unter den durch Anpassung nicht erklïbaren Formen des Gebietes und wohl auch nicht bei der $R$. ellipt. überhaupt.

Wenn wir in Zu-ammenhang simtliche Eigenschaften auführen, nach denen die bekamnteren Formen der R. elliptica in der mittelenropäischen Flora variieren, so ergibt sich folgendes Bild: ${ }^{1}$ )

Stacheln: einförmig hakig bis doppelgestaltig.

Bıattchen: Grösse = klein, mittel, gross.

Gestalt $=$ keilig bis rundlich.

Behaarung = beiderseitig, einseitig; schwach bis filzig.

Bedruisung = Mangel an Subfoliardrüsen bis Vorkommen von Subfoliardriisen.

Zahnung = etwas wechselnde Form der Zähne.

Bliten: Farbe = weiss bis lebhaft rot.

Stiel = verschieden lang; drůsenlos und drüsig.

Kelch $=$ Blätter abfällig bis subpersistent, verschiedene

Grade der Fiederung.

Griffel = kahl bis wollig; kurz bis vorragend.

Scheinfrichte: Form = kugelig bis eilänglich.

Grösse $=$ klein bis mittel.

Wie wir friiher erörterten tritt die Heterakanthie bei den Stacheln verkoppelt mit dem Grade der allgemeinen Drüsigheit der Planze auf. Die Varierung der Blaittchen nach der Grösse beluht auf Ninismus oder den Graden der Ernährung; nach der Gestalt anf fluktuierend wechselnden Organisationsmerkmalen; nach der Behaarung auf Reiz-Anpassung und Bildungshemmung; nach ler Bedrüsung auf Reiz-Anpassung und Bildungshemmung; nach der Zahnung auf ganz geringiügiger fluktuiertuler Urganisalionsverschiedenheit. Die Bliiten variieren nath der Farbe der Corolle ilurch Reiz-Aupassung oder Bildungshenmmug; nach der Siliellïnge dureh Reizanpassung (?); nach der Stielbedriisung durch verschiedene Grule des Alavismus; nach der lielchblatpersistenz durch Reiz-Aupas-tung, nach der lielchblattlenderung durch geringfügige Organisationsverschichlenheit; nach der Grilfelhehatenng durch lieiz-Anpassung, der Griflel-

1) Der durchschossene Druck kennzeichnet bei Eigenschaften den Frequenz-Durchschnitt; bei Angabe der äussersten Grenzen eines Umlanges liegt der Durchschnitt in der Mitte, falls die Anwendung des durchschossenen Druckes unmöglich ist. Z. B. Farbe weiss bis lebhaft rot: die meisten Blüten sind ganz blassrosa. 
lïnge desgleichen. Die Tarierung der Scheinfrüehte nach des Form beruht auf

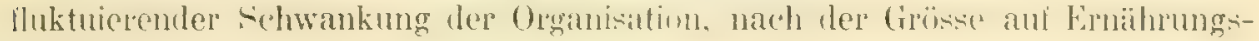
modifikationen.

Die Komplikation der anfgestellten Fumen der R. elliptica rïht unn vor allen davon her, dass de angetiihnten Merknale an einer einzelnen Rose in allen denkbaren liombinationen ropkommen können, von denen relativ wenige in gesetzmässiger Verkoppelung stehen wit ofwa persistente Kelchzipfol, weite Diskusiffnung und wollige Griflel. Einzelnt Merkmale sind roin individuell und nicht vererblich (Ernährungsmodibikationen), die anderen veremlich und hereits vererht. Mit grozer Wrahrseheinlichkeit hat nichl etwa die Deszendenz eines einzelnen Indivilums zahlreiche heterogene Eigenschalten selbstimdig epworben und vererbt, sundern die sexuelle Mischung hat die kombinationen allnählich hervorgerufen.

\section{T. agrestis Savi.}

Die Fumen mit drüsigen Blütenstielen fasse ich wegen der relativ schwachen Entwicklung der Drïsen als atavistische, diejenigen mit schwacher Bedrüsung der Blattunterflache als Henmmgsbildungen. Die var. vinndora Kern. düıte von Nanismus verursacht sein und eine lediglich individuelle, wem auch an sterilen Gehirgsabhängen der Alpen und des Jura verloreitete, Mulilikation darstellen. Die meisten Formen dor var. mebescens Rap. unterscheiden sich von einander durch geringliigige Organisationsmerkmale; die ganze var. pub. vun der typica $R$. Kell. durch die Behaarung, also cin Merkmal, das sowohl auf Anpassung als auf Hemmung zuriickgefühtt werden katun (falls man von stark behaarten Varieliten zu schwach behaarten in der Betrachtung übergeht). Der Kreis der var. Gizellne Bor\%, lïllı, wie im II. Teil erörtert, teils mit dem der var. pubescens zusammen, teils stellt er durch die kurzen Bliitenstiele eine Himneigung zar R. elliptica dar; die kurz'n Bliitenstiele dürften korrelat sein mit dem untersetzten Wuchs und eine Anpassung an montane Ungebung veruten.

Es leuchtet ein, dass die Glieder der beiden Artenpaare, R. rubiginosa + micrantha, R. elliptica + agrestis, sich von einander durch Anpassungsner $\mathrm{km}$ ale unterscheiden. Micrantha und agrestis haben im Bau des Receptaculums und der Griffel und in der Entwicklung der Kelchblitter rom montanen Typus sich weit entfernt; es hestehn aber durch Zwischenformen Bricken gegen die R. mb. und ellipt. hin. Dagegen ist es vor allem die Organisation im engeren Sime, welche die Gesantat rubiginosa von der Gesamtart elliptica trennt. Dahin gehört die so verschiedene Gestalt der Blättchen und Blaltzilhne und de:L

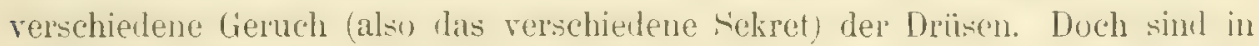
der Differentialdingnose auch einige etwas fluktuierende Anpassungsmerkmale enlhalten, nämlich die stärkere Bexlrüstmg der Blïtenstiele und eine spurenhatle Heterakanthie innerhalb dop Gesantart rubiginosid. - Die Sektimsmerkmalt?

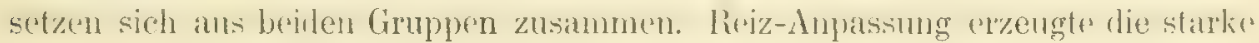

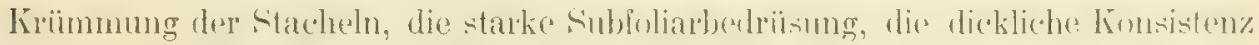

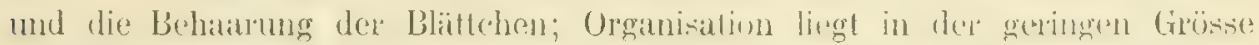

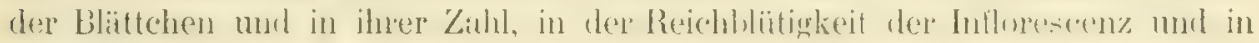
der Kleinheit der Corollen. 


\section{Sectio V: Caninae DC.}

\section{R. tomentella Lem.}

R. tomentella variiert in erster Linie nach dem Grade der Bedrüsung (von Ballibirchen und Blitenstielen), in zweiter nach der Intensitit der Behaurung. Diese anch hier mil mendlich kleinen Lntershisden in einander iibergehenden Eigenschalten haten wir shon an anderen Rosen äter gewïldigl. Der Formenkreis der subspec. miserrata $m$. hebt sich vom sonstigen Gebiet der R. tom. ruliallend durch die pinfache Blattzithmung ab. Das dentet an Verammug des Systems der Randdriisen und Hydathoden und muss von uns dem früher Gesigten entsprechend als eine Anpassungserschemung andgefasst werlen. Wenn man die var. obtusifolia zur R. dumetorum rechnet, so muss man die eigen-

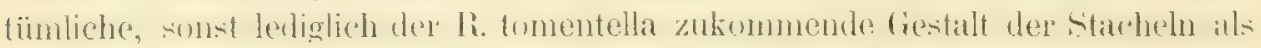

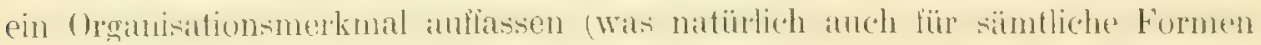
der R. tom. gilt) und die übrigen Merkmale auf analoge Weise wie bei der R. dum. überhanpt erklïren. IHrigens beweist die vilr. thatica $R$. Kell. durch ilıe beginnende mehrfache Zähnung den Zusammenhang der var. obhusifolia mit der R. fonentella. - Von Organisationsmerkmalen innerhalb ler R. Iomentella lassen sich ausserdem nur unbedentende Abweichungen der Blatlfurm, der Blattzähne und der Fruchtgestalt aulfïhren. Die Variation der Blättchenform bewegt sich zwischen schmaloval mit keiligem Grunde und lïugerer Blatlspitze (rar. sepioides $R$. Kell.) und hreitoval mit etwas herzlürmigem (rrunde und kurz aufgespitzlem Spitzchen (Vir. simatidens (hr.). Es existieren alle denkharen Lberginge; auch bleibt die Blattform am selben Strauche, ja selben Blatte nicht ganz gleich.

\section{R. camina $\mathrm{L}$.}

Von der R. can. sind unzählige Formen beschrieben worden, und auch in unserem Verzeichnis ist sie mit der grössten Anzahl von Nummen vertreten. Woher kommt das? Erstens erfreut sich R. can. der weilesten Verbreitung, elscheint ïberall als die hinfigste ihres Geschlechts und nicht selten als die einzige Verlpelerin. Deswegen muss ihr auch mehr Beathtung geschenkt werden, und erstreckt sich die hatrsublende Tätigkeit der Autoren vorab aul sie. E- gibt aber anch keine Rose, bei der, wie auch R. Keller in der Synopsis hervorhebt, eine grösicere Anzahl rein individneller Modilikalionen als legitime Varietäten beschrieben wurden. Für die Kritik ist es unendlich schwierig, aus den langatmigen Beschreibungen etwas Gieifhares abzusondern und sich ain richtiges Lrteil zu bilden. Vielisch grumber in die Lituratur eingelibhrte Abaten noch tazu aul ungen̈̈gend gesammelten und beobachteten Exemplaren. Doch muss auch zweitens zu-

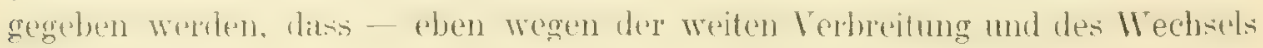
¿usserer Einflüsse - die Hundsrose mehr variert wie jede andere Art.

\section{Schema der wichtigsten Variationen von $R$. canina.}

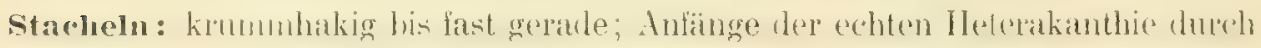
das Auftreten von Drüsenborsten (Regel: einförmig krummhakig). 
Blattchen: Grösse = klein bis gross (Regel: miltel).

Gestalt = breit oval bis lanzettlich; stumpf oder zugespitzt; Blattgrund herzförmig, rundlich bis keilig (Regel: schmal oval, zugespitzt).

Zahnung $=$ ejnfach bis mehrfach druisig zusammengesetzt (Regel: unregelmässig zweifach gesägt).

Bedrüsung $=$ ohne alle Drüsen bis zum Auftreten von Drüsen an Blattstielen, Blatizïhnen, den Nerven und Nervillen (Regel: Blattstiel, Blattzähne und Mittelnerv måssig drüsig). Behaarung = ganz kahI, zuweilen Flaum an Blattstiel und Mittelnerv (Regel: kahl).

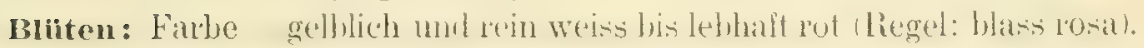
Grösse = kleine bis mittlere Corolle (Regel: mittel).

Stiel = kurz bis lang; zuweilen befläumelt und drüsig (Regel: lang, kahl).

Kelch $=$ Blätter zurückgeschlagen bis abstehend; Kelchblaltrücken kahl bis drüsig, desgleichen Blattränder (Regel: Blätter zurïckgeschlagen, an Rand und auf Rücken sehwach drüsig).

Griffel = kahl bis wollig; mittellang bis säulenförmig (Regel: haarig und mittellang).

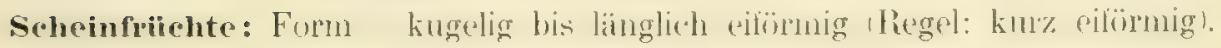

Grösse $=$ klein bis gross (Regel: mittel).

In Korrelation stehen von diesen Eigenschaften die Drüsigkeit und der (imal der Blattahnumg: meist anch die Bedrisung der Blattunterseite umd die Heterakanthie der Achsen, sowic die Randzähnung der Kelchblitter. Alle äbrigen Eigenschaften rarriteren nach meiner Kemntnis selbstindig, und es ist nateh flen Geselzen der I'ernutationslehre leicht einzusehen, welche L'nnassen ron rinfarhen und liombinationsformen bei der R. canina nöglich und wirlich sind.

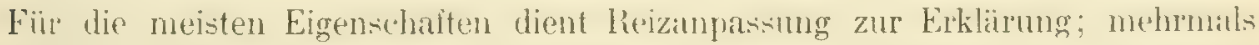
ist die indirekte Anpassung durch Selektion (Forn der Stachehn, Drïsenreichtum)

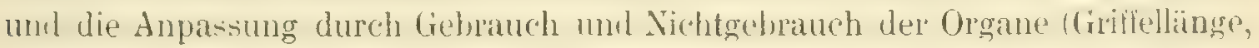
Kelchablibligkeit) wahrscheinlich. Organisationsmerkmale finde ich in der Forn der. Scheintribchte und Blätchen, allch der brakteen. Nichtebliche Standurtimmdifikitionen dürften insbesondere solche sein. Welche aul der Griosse mul

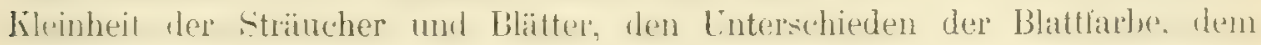
Zickzack der Achsen u. dgl. beruhes. Die Cherginge inuerhalb aller hategorien von Eigenschatten sind gerate bei der R. anina unmerklich, weil unendlich klein. ${ }^{1}$, Dies gilt besonders von der Form. Zahmung und liandbedrüsung der Blittchen: aber anch von den atufiallenderen Abweichungen rom Typus, alson

1) Die Eigenschaften der R. canina fluktuieren so sehr um eine gewisse Mittellinie, dass es mir, wenn man einmal diese Linie verlässt, als reine Willkür des Formen beschreibenden Aulors erscheint, wo er stehen bleibt und eine Diagnose aufstellt. Je mehr Formen beschrieben werden, umsomehr Ubergänge werden konstatiert. Die Kunst besteht schliesslich nicht darin, Neues zu beschreiben, sondern die Miltellinie und die äussersten Grenzen festzulegen. 
ron der Berlüinng der Blütenstiele und der Blatlunterseite. Diese ist fast stets so schwach, dass sie als eine Art Zwangsbildung durch die Zunahme der Drisenproduktion überhaupt aufgelasst werden muss.

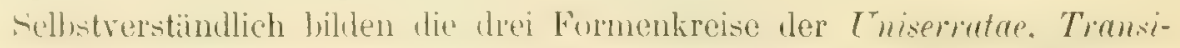
torine und Biservatae keine natïrlichen (iruppen, sondern künstliche Notbehelfe. von denen sich in minchen Fällen erkemen lïst, dass sie eine Entwicklungsteihe

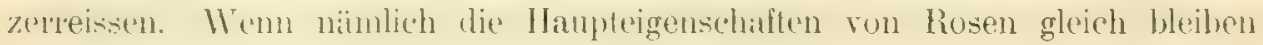
und nur der Grad der Bezahnung wechselt, so tut man wohl, diese Formen in vine Lieihe zusimmenzustellen. Nach meiner Ansicht gehören beispielsworse zu solchen Entwicklungsreihen:

I. Uniserratae

Var. syntrichostyla $H$. Br. (i. dilucida $H . B r$.)

Var. glaucescens Desv.
II. Transitoriae

juensis $m$.

frondose Stex:

spuria Bort.

(mit f. oenoph. Hadr.)

montivaga Borb.

versuta $H$. Br.
III. Biserratae

eriostyla Borb.

sarmentoides Puy. laxifolia Borb.

rubelliflora Borl. biserrate Bak.

Alle Formen mit schwacher Bedrüsung der Blütenstiele und der Blattunterseite sollten eigentlich zu jener Virrietit gestellt werden, nit der sie in den ïbrigen Ëgenschaften übereinstimmen. Ich habe das rome mit meinen Ilerbatexemplaren der var. Schottiana versucht; so halte ich anch die l. edita R. Kell. fïr ein stieldrüsiges Vorkommen der f. dilucida $\mathrm{H}$. Br. (var. syntrichostyla). Es ist jedoch nicht möglich, hier tiefere Ëingriffe in das herkömmliche system zu machen, solange die Diagnosen in der bisherigen Unständlichkeit und Unbestimmtheit gehallen werden und solange einerseits in der Natur viel zu wenig und viel zu kurze Zeit auf die gemeinsamen Züge geachtet, anderseits zuviel auf Herbarplanzen vertraut wird, die z. B. auch von der Varialion einzelner Knospen am Strauche nichts erzählen. Es hat ja sogar Auturen gegeben, die Specimina in den Verkehr brachten, die nicht zu ihrer Beschreibung passten, oler die in ihren eigenen Herbarien nicht zusammengehörige Zweige unter einem Namen verwahrten. - Natürlich könnte man Entwicklungreihen auch nach anderen (iesichtspunkten als der Blaltzahnung aufstellen. Für sehr nahe verwandt nach Blatt- und Bliitenheschaffenheit halte ich $z$. B. anch die val. reginae $m$. (mit f. eriostyloides m.). var. scalmata (rep). und var. Blondaeana Crej). (mit 1. st. Walburgae m.). Als eine Art Vorstufe zu dieser Gruppe treten im Gebicte die var. bisenata Bak. und squarosa Borb. mit f. disparabilis $H$. Br. auf. Varietiten der R. canina, welche Beziehungen zu anderen Arten herstellen, werden wir später besprechen.

\section{R. ammetomm. Thuillier.}

Die Formen der R. dum. lassen sich anseheinend in ihnlicher Weise gruppieren wie diejenigen der R. canina. doch fallen bei genauerer Erwïgung beIräichlliche Lnterschiede auf. Vor allem sind mehrfach gezïhnte Varietiten bei 
der R. dum. viel seltener, was im (iebiete secht hervortritt. Demn die R. canina erweist sich hier häufig stark gezahnt und nit Drïsen ansgestattel; dagegen finden wir die R. dum. meist einfach gezahnt mul - wenigitens an Blättehen und Blüfenstielen - Irüsenarm. Auch zodgt sie last nie wollige Grillelsäulen. lebhafte Blïtenfarbe und Hetrakanthie. Ioh kïnnte mit Sicherheit keine Entwicklungsreihe der R. can., etwa die del var. syntrichostyla, angeben, die in den Bereich der R. dum. durch zunehmende Behatrumg übergriffe. Offenbar vertreten sich hier die Hautgebilde Hare und Drisen gegenseitig: diejenigen Glieder der Gesamiart R. canina. Welche Haare an den Blattilichen produzieren, entwickeln dafiir keine oder wenige Drüsen. ${ }^{1}$ ) Es muss doch auffallen, dass eine einzige Irarietït, die var. interpositu Sdhlimp.. Subloliardrüsen, und zwar nit unregelnässigem Aultreten, zeigt. Wegen der geringen Neigung zur Drüsenbildung bleiben die Ränder der Blïtchen mit Vorliebe einfach gezahnt. Dagegen besitzen einzelne Varietäten reich mit Drüsen besetzte Kelchblattrünter, die zudem entsprechend stark gefiedert sind, und so den Anschluss zur R. tmnentella vermitteh. Hieher gehört neine var. comafa. Dieselbe geht durch Vermehrung der Blattzïhne successive in die var. comatoides $m$. mit mehreren Furmen, darunter einer etwas heterakanthen (f. fertilis m.) über. Die Formenreihe meiner var. comata prïgt ihre Eigenart nicht bloss in Morphologisehen aus, sondern ist auch als Rasse sehr gut lokal begrenzt. Ilüulig in der nächsten Ungebung von Eichstaitt geht sie sporadisch altmiihlabwärts bis Riedenburg und greilt noch ins benachbarte Schwarzachtal bei Enkering ïber. Ihre aullallendste Eigentümlichkeit ist die habituelle Ahnlichkeit mit der R. tomentosa (cf. var. cinerascens f. subduplicata und var. subglobosa) wegen der breituvalen, sehr stark behaarten Laubblittehen und des strammen Wruchses und die Ahnlichkeit mit R. tomentella wegen Form und Bedrüsung der Kelchblätter. Um diesen Typus herum variiert sie einmal durch ein \pm der Behaarung und Kelchbedrïsung, dann durch ein Fortschreiten bis zur doppelten 'Zahnung, zur leichten Heterakanthie der Achsen und zur Verïnderung der Fruchtgestalt (ron kugelig zu oval). Die mehrfache Bezahnung und die Heterakanthie hängen mit der Vermehrung der Drüsen zusammen und gehören wie die meisten ïbrigen Merkmale zu den Anpassungseigenschaften; die Form der Blätchen und der Frïchte zähle ich wie immer zu den Organisationsmerkmalen. - Anch die var. hirta $H$. $B r$. und hirtifolia $H$. Br.gehören in eine Entwicklungsreilie, die sich hauptsiachlich nach der Blaltzahnung abstuft, desgleichen var. perciliata $H . \mathrm{Br}$. und var. palatina $m .{ }^{2}$ ) Weiteres über Zwischenformen innerhalb der Art dunetorum wurde schon im II. Teile bemerkt. Im übrigen handelt es sich ähnlich wie bei der R. can. vorwiegend un fluktuierende Anpassungs-, selten um unbedentende Organisationsmerkmale.

1) Ich kenne umgekehrt eine R. tomentosa aus der Umgebung von Münnerstadt, welche fast haarlos, dafür aber sehr reichlich bedrüst ist, auch Suprafoliardrüsen hat.

s) Nach dem Grade der Bezahnung ergibt sich für die angeführten Rosen das Schema:

Var. comata $m$. Var. hirta $H . B r$.
II

Var. comatoides $m$.

Var hirtifolia $H, B r$.

Var. perciliata $H . B r$. Var, palatina $m$. 


\section{T. glanca J'illurs.}

Auch bei der R. gl. durchlaufen die Blättchen alle Grade der Zahmung, womil Hand in Hand die Bedrüsung der Blattrinder, Weniger direngige der bliitenstiele. goht. Dagegen ist die einzige latrietit Mittelemronats mit Subfoliardrüsen, die val: glumblifere $R$. Kell, auch mehrfach grzahnt. Von der Li. canina unterscheridel sich die gl. hauptsitchlich durch ihren stäkere ansgepräigten nontamen Chatrakter. Dieser findet sich beträghtlich abgeschwieht in der subsp. suldrminu, depen Formen also Zwischenglieder zw, camina und ghama darstellen. In Gegenden, deren Gebirgscharakter weng ausgenoügt ist. ïberwiegen fast die Rosen dieser Unterart ïber die normalen Glauca's. Im höchsten Grade lässt sich das aul den Muschelkalkhügeln Lntertrankens bentrken. Der aufmerksame Beobachter erkennt hier die Wirkung nachtrïglicher entgegengesetzter Anparsung auf Merkmale, die früher ebenfalls durch Anpassung an dats Ciebirgsteben entstanden waren. Man ist ïhrigens rücksichtlich der subsp. subaninat betrüchtlichen Täuschungen ausgesetzt. Denn da in manchen Jahren auch echte canina-Formen mit etwas abstehenden Kelchzipfeln autrelets. in andern die lielchblatter der echten glanca an Submersistenz rerlieru und bald abfallen, kann man vorïhergehende Er'scheinumgen zu Varietüten stempln. Ohne danemde Beobachtung im Freien vermag man nichts Sicheres zu sagen, höchstens gibt der Lïngschnilt durch das Receptaculum einen Anbaltspunlit. - Als Beroform enthält die R. glauca in Blättern, Rinde und Blütenkronen reichlich Anthocyan. Manche Formen charakterisieren sich hiemach als Exzessivbilungen (z. B. meine f. heliophila), andere als Hemmungs- oder Terarmungsbildungen (z. B. gewisse glauca-Varietäten mit weisslichen Bliten). Von diesen bleibt es ohne Kulturversuche ebrifalls unsicher, ob Vererbung eingetreten ist. - A Alle Formen und Formenkrejse sind bei unserer Art durch reichliche Zwischenbilungen rerknüput, über die man das Nötige in Teil II nachlesen mag. I)as I'erhältnis zwischen Anpassungs- und Organisationsmerkmalen bleibt ungekihr das Gleiche wie bei der R. canina. - Eine sehr homologe Entwicklungsreihe lurch die drei Girale der Bezahmung hindurch bihlen die typischen var. typira ('hr. (mit. f.

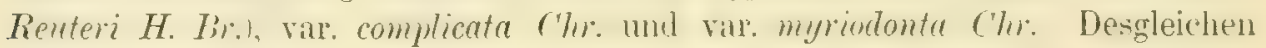
stehen in närhster Beziehung die einfach geziihnte var. falcatr Bort). und die mehrfach geziihnte var. pseudofalcatu R. Kell., Zwischenglied vielleicht die unregelmässig gezahnte var. atrorivids Borl. oder eine ähnlicho. Meine var. concomitans verhält sich mit ihren drüsigen lielchblittrïcken zur var: typuca

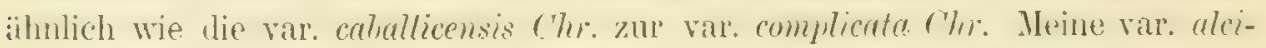
monensis bildet in gleicher Meise Iurch die Drüsigkeit der Kelchblattrïckenl die: var. falcata Borl., und meine f. separata die f. Graretii Boil. weiter. So stchen wenigstens die hievigen Ghancat-Formen in einem durchsichtigen Verhïltnisse ron Anpassungen zu einamler. Die f. macrophylla Fatr. scheint eine blusse: Enährungsmodilikation zu scin, vielleicht desgleichen die f. frandiceps m. ulie: erste der gewöhnlichen complicata, der zweite dep var. myrodonta gegenüber. Wahrscheinlich liesoen sich die Rousen der subsp. subcanina auf entsprechende der Hanptart zuriickfïhren, wenn sie geniigend in Fornen gegliendert wären. 


\section{R. comiliolia Fries.}

Die R. coriif. ist im Gebiete schlecht entwickelt, ganz im Gegensatz zu R. glauca. Sie neigt hier durchaus gegen die R. dumetorum hin, indem sie

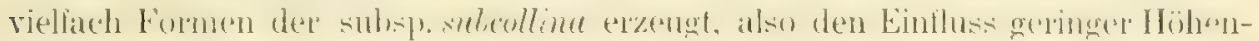

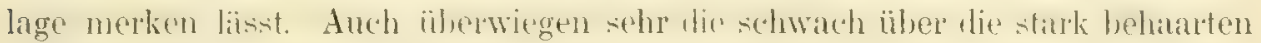

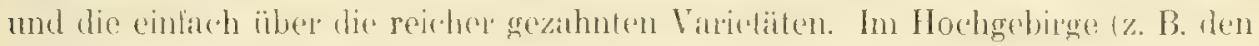
Suidalpen) ist das anders. Die R. coriif. ist da ganz reich gegliedert, ungefähr im selben Sinne wie die R. glanca. In unserem Mittelgebirge und Flachlande scheint also die R. corif. nachtriglich in der Rückbildung begriffen, was von einer Zurückanpassung an die seit der Eiszeit veränderten Lebensbedingungen hemübrt. - Uber die hiesigen Formen glaube ich nichts weiler bemerken zu sollen.

Das Verhältnis der Arten innerhalb der sect. Caninae zu einander ist ein

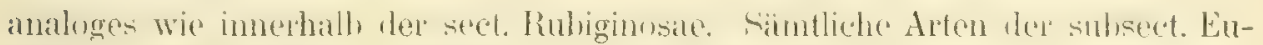

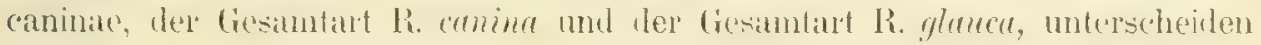
sich von einander durch blosse Anpassungsmerkmale. Die Gesamtart

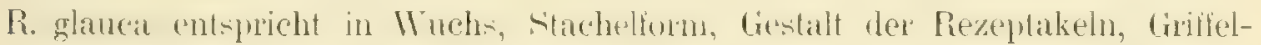
heschatenheit, Subpersistenz, Ilochblatt- uml Biitenstielentwicklung, Corollenfarbe dex montanen Euwirkung: die Gesambut canina gehört den nienteren liegionen an. Innephalh beiler Gesumlarten gliedert die Blattbehatung sekundïre

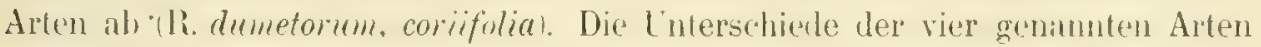
werden durch Zwischentomen und Zwischemmberten unendlich klein trgl. sulsep. subcanina, subcollina, var. montivaga einerseits, die leicht beharten Formen der R. canina und R. glauca anderseits). -- Der Trennung der Subektionen Encanina und Tomentellate dagegen liegen ansser weniger berlentenden Anpastmgseigenschatten hänligore Bedribung der Tomentellac an Blättern und Kelchfiedern sowie dickliche Konsistenz der Bliltchen mit hervotretendem Arlenetz) rorwiegend Organisationsmerkmale zu Gromde. Bede Subsektionen besitzen eine eigentiinliche Blattchen- und Zahniom. ganz verschiedene stardetbildıng

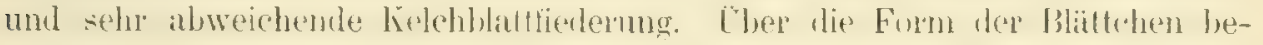

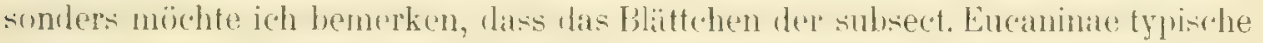
Eiform besitzt. dasjenige der subsect. Tomentellate aber ein kleines Spitzrhen auf eine rundliche Blattlibche aufgeretzt zeigt. Dio Art fomentella endlich weicht

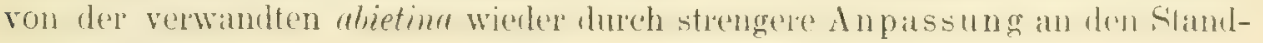
ort der Ebene ab. Durch die Unterart uniserrata der R. tomentella und durch verschiedene Varieläten der R. dumetomm, darunter meine var. comata und

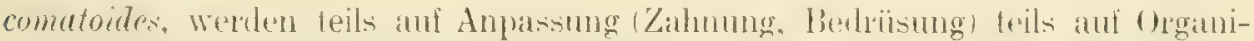

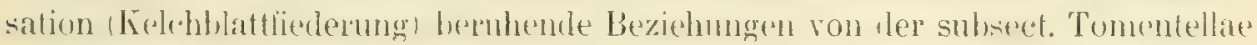
zur subsect. Eucaninae hergestellt.

Die Diagnose der ganzen Sect. V: Caninae zeigt uns sowohl Anpassungen

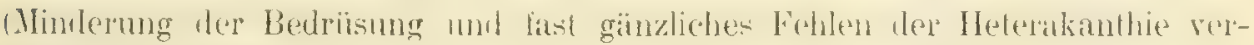

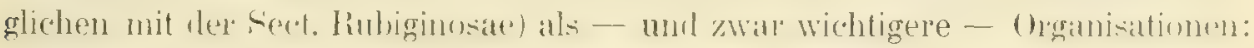

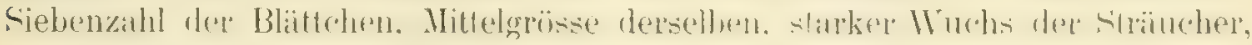

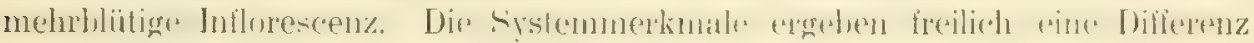
nur gegen die folgende, nicht gegen die vorausgehende Sektion hin. 


\section{Sect. VI: Cinnamomeae DC.}

Vum Zusammenhang der Furmen innerhalb der Arten dieser fektim kam ich gar nichts berichten, da die R. blanda Ait. im Gebiete nur verwildert, die R. pendulina $L$. abere und die R. cimmomomen L. bloss in je einter tinzigen Form

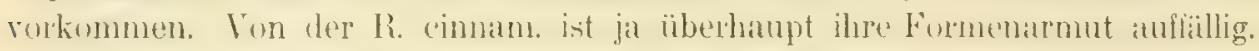
Trotz ihner Hänfigheit im siidwestlichen Teil des Gebietes wude nicht pinmal die f. subglabra Schwarz entdecht. Diese im nördlichen Bayern wie auf der sohwälisch-bayrischen Hochehene (b. Weilheim) konstatiente Fom stellt rine Ahchwächung der montanen oder arktischen Eigenschaften dar. wie die rar. follyens ( hr. des Oherwallis eine Verstarkung des montanen Charakters bertentet.

Den Arten der ganzen sect. Cinnamomeae kommt durch die Persistenz fler aufrechten Kelchblätter und andere danit in steter Verkuppelung stehenden Ëgenschaften die Aupassung an das Gebirge zu. Zur Organisation gehört: Stacheln ofl gepaal; Sträncher mittelgross mit statker Ausläuferbildung: Lelchblätter am Rande einfach; Inflorescenz prinzipiell mehrblütig.

Die drei im Gebiete einheimischen oder rerwilderten Arten unterscheiden sich untereinander vorwiegend durch Organisationsmerkmale, aber auch dureh eigentïmliche Anpassungen. So hat die R. pendulind mehrfache Zahnung und die schwidchste Bestachelung. Iberhaupt ist bei ihr der montane Charakter am meisten ausgepräigt, bei der R. Bunda am schwibchsten (mur ausgebreitete Kelchziplel, blasse Blïten, fehlende Beharung). Starke Anthocyubildung zeigen die drei Arten in ihren Blätlchen und der Rinde, bes, cimamomen; einige montane Eigentiinlichkeiten lehlen bei der ganzen (iruppe (kurze Bliitenstiele und slarke Hochblitter kommen ihr nicht zu). Cimnamomea und blanda sind heterakanth. - Als trennende Organisationsmerkmale führe ich auf: Die Stacheln (am seltensten geparar bei h. pendulinu, an der auch die gekrümmten fehlen), die Zahl der Blïtchen (cinn. und bl. 5-9, pend. 7-11 zählig), die Gestalt der Blïtchen, Blattzïhne und Nebenblïtler, die Form der Frïchte und Fruchtstiele (Scheinfrüchte bei cinn. und 3\%. kugelig, bei pend. flaschenfömig, Fruchtstiele bei yend. meist zurïckgekrïmmt). Cimamomea und blanda stehen in ganz naher Verwandtschait nach den meisten Beziehungen.

\section{Sect. VII: Spinosissimae Bak.}

\section{R. pimpinellifolin $\boldsymbol{L}$.}

Die R. p. ist nach der Synopsis "eine kalkliebende Felsenpflanze" raber ihr Torkommen in den Sinddünen der nordiriesischen Inseln!?). Wohl ist es richtiger zu sagen: eine P'llanze rorwiegend des Nordens bis Nurwegen und Sibirien) und der höheren (rebirge (bis $2000 \mathrm{~m}$ ). Da sie seit dem friben Mittelalter ïberall in Eurmpa angepllanzt wurde, kann man bei sehr vielen der jetzigen Standorte nicht mil Sicherheit unterschejilen, ob sie ursprüngliche seien oder vun Verwilderung herühren (die jin auch meilenweit ihre Wirkungen iussern himm). Mir wenigstens erscheinen nicht bloss die Eichstätter Fundorte zweilelhaft, 
sondern auch die rheinplälzischen mul unlerfränkischen. Gerade die liegenden mil jetzigem oder früherem Weinban sind auf verwilderte limen veriachtig. Alle domestizierten Organismen vatieren mehr wie die wilden; daher mag os sich erklären, dass hier in Eichstätt soviele Formen an einer beschränkten

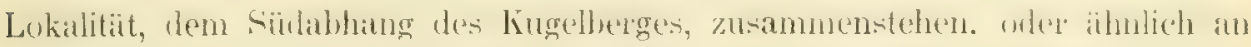
den nicht näher bezichueten I'atzo Lnterfankins, ron dem J)ingler berichtet. ${ }^{1}$

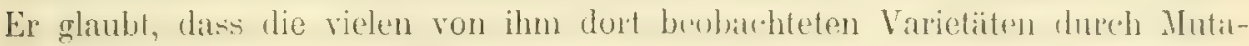
tion in der Gegenwart entstanden seien. Ich lasse das in dieser allgemeinen Auslrucksweise dahingestellt. Für den Kugelherg b. F. schoint mir die Erliärung durch anpassungstuse .Hutation fïr die l. pillygere m. 1mungïnglich zu sein. Eine? Anzahl anderer Merkmale als dits Auftreten sulch anfiallender liehatumg mïssen zwar ebenfalls als systematische erklärt werden, fluktuieren jedoch in unentschiedener Weise und gehören zu den gewöhnlichen Variationen. Sor die Bedrisung der Blibtenstiele. Von den meisten kann man aber Anpasinngsursachen angeben, sowohl was die Fornen unserer Standurte als die h. pimp. äberhaupt betriff. Diese Ruse kriecht gern in hasen und treibt unterirdische: Ausliufer. Sie wird nm sehr häulig abgeschnitten und abgeweidet. Datureh wird sie zun Austreiben einer Unmasse von Budenschösslingen veranlasst, dit? besonders dicht bestachelt sind (var. Mathonettiz $R$. Kell., megalacantha Borb.). Aui gutem Boden und zwischen hohem Gebiisch werden ihre Asle lang und schwach bestachelt, die Blïtthen grösser und länger, die Corollen ebenfalls grösser (i. macropetala Borl.). Auf nahrungsarmem Boden und in der Vegetation dur(h mechanische Insulte gestört treiben die dinn zwergigen Pflanzen besonder's kleine und mehr rumbliche Blätchen (1. poteriifolia $\mathrm{H} . \mathrm{Br} .{ }^{2}{ }^{2}$ ) Bloss verwilderte Strüucher haben häulig geringe Fruchtharkeit; in den Scheinfrüchten reifen wenige Nïsschen, und die Früchte selber verraten die Tendenz, ihro lingelgestalt etwas gegen das Eiförmige zu verändern. Doch werden Formen mit ausgeprägter Ei- und Flaschenfrucht und zuriickgeschlagenen, abliilligen lielchzipfeln besser als Rückanpassung an mildes Ehenenklima aufgelasst (i. erubescen: m.. var. lagenoides $R$. Kell., l. achras Dingl., cataculy, Dingl.). Die zusammengeselzte. Zahnung der Blättchen steht bei der R. pimp. in deutlicher Korrelation nit der allgemeinen Bedrïsung, auch derjenigen der Blattunterseite (var. Rivartii R. Kell.. myriacantha ser.) und wird nach den von uns vorgetragenen Prinzipien ebenfalls auf Anpassung zurïckgeführt. 'Zwischenstufen zwischen einfacher und zusammengesetzter Zahnung treten sehr häufig aud, desgleichen Spuren von Anthocyanbildung in den Corollen.

An Charakter der ganzen sect. Spinosissimae künnen wir lediglich Organisationsmerkmale gewahren: miltelgrosse bis kleine Strüucher, zerstrente Stacheln, prinzipielle Einblütigkeit mit Fehlen der Brakteen, kugelige Frïchte.

Zun Cuterschiede der R. mimpinellifolia und luter dienen von Anpassinng:merkmalen die Zahmung der Blïttehen, die Farbe der Kronen und Frïchle (?); von Organisationsmerkmalen die Grösse des Stranches, die Ausläulerbilhuns (stärker bei R. pimp.), die Grösse und Gestalt der Blättchen, Blattzähnes und

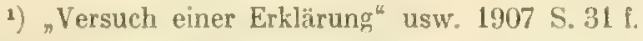

2) Die hiesigen Exemplare stehen auf beschattetem, ganz sterilem Dolomitfels. 
Nebenblätter, die Zahl der Fiederblättchen (9-10 bei pimp., $5-7$ bei lut.), die Fum der lielchbätter (bei pimp. kum, bei lut. lang), die Strenge der Einblütigkeit ( $\mathrm{R}$. lut. hat ausnahmsweise 2-3 Bliiten).

Wenn wir die ganze Erörterung über Anpassungs- und Organisationsmonkmale bei den linsen des Gebictes überhlicken, so ergiht sich als Resullat: innerhalb der Aren varieren die Formen sehr vorwegend nach Anpassungs-

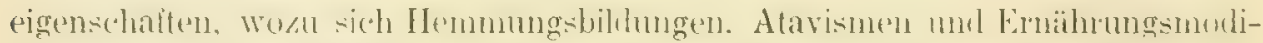

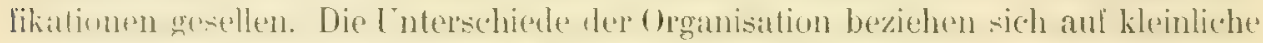
Fluktuatimen derselhen Organe, die bu höheren Kategorjen äter sprumgweise sich unterscheiden. Sektionen und Gesamtarten basieren ausschliesslich his buriegend aul Lnterdhieden der Organisalion und nicht der Anpassung. Doch haben wir zu bemerken, diss simtliche Arten unserer Lntersektion Encaninate lediglich duch Anpas-ung sich unterscheden. Das gledche gilt von den Arten einer Gesamtart, also R. mbiginosi nul micruntha, elliplica und agrestis. (Tielleicht wärle es sich empfehlen, auch die 'f Arten de's subs. Eucaninae in eine Gesantapt R. canina zusammenzulassen.) Auf die Frage, ob nicht etwa die Systemmerkmale ursprünglich aus nicht nehr rerstandenen Anpassungen sich entwickelt hätten, wie Reinke u. a. wollen, künnen wir hier nicht näher eingehen. Es wären dam jedentalls die ersteren früher, dhe letzteren, suweit sie jetat nuch als solche erlemntlich sind, später entstanden. Aler man vernag darüber nichts Gewisses zu entscheiden. Wahrscheinlich ist es im Anschluss an die Verhältnisse bei anderen Gattungen nicht, dass bed Liosa die Mehmahl der systemmerkmale von autiquierten Anpassungen herrihre. In einzelnen Fälen mag es zugegeben werlen. Die sichtung der Anpassungseigenschatten nach prinzipiellen Unterschieden (direkte und indirekte Anpassung usw.) hahen wir schm trïher versucht; Selektionsvorgänge, welche indirekte Anpassung hervorrufen, glaubten wir annehmen zu müssen für die Bildung und Farbe der Corollen; den Geschmack und diu Konsistenz, sowie die Firbe der Frïchle; gewisse Extrembildungen bei Stacheln und Drüsen; Begünstigung der Ausliuferbildung: vielleicht anch teilweise fïr die Entstehung der montanen Beschalfenheit des Receptaculums und ihre Fulgen. Selektion griff also nach unserer Ansicht ein im Verhältnis der Varietälen einer Art zu einander und der Arten innerhalb einer Gesamtart. 


\section{Dritter Abschnitt:}

\section{Die Deszendenz der europäischen Rosenarten.}

Bevor wir in eine Diskussion der Blutsverwandtschaft der europäischen

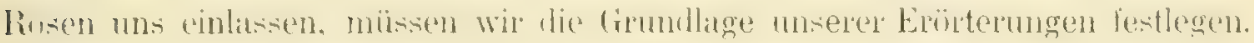

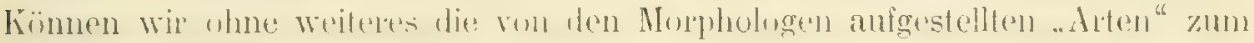

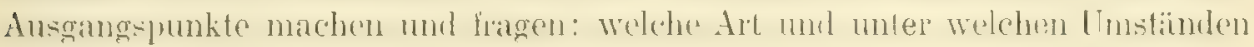
ist sie aus einer anderen hervorgegangen? Sind wirklich "diese" Arten oder

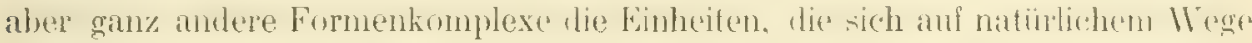
gebildet und ron finander abgegrenzt haben? Ich glaube, dass wir nit vollen Rechte uns auf die herkïmmlichen Wullektiv-Arten beziehen. Für ihre natioliche Begrenzung sprechen die Tatsachen der Bildung steriler Bastarde. ${ }^{1}$ ) Nicht bloss die Bastarde der sektionen und Lintersektionen untereinamler zeigron fine sehr stark geminderte his fohlende Fluchtharkeit, sondern selbst Bastarles von Arten, welche einander morpholugisch äusserst nahe stehen, wie R. micrmutha

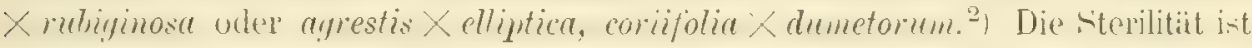
es gerale in den meisten Fällen gewesen. Welche aul einen Bastard zwischen den anerkannten lollektiv-Arten aufnelksan machte, und die Beobschlung der Mischung seiner morphologischen Chanktere samt rershiedenen Nebenunstïnlen fiihrte dann mehr uler mimber sicher zur Entzifferung der Eltern. Freilich heweist nur das Experiment mit absuluter Evidenz, welchen Bastard man vor sich habe. Allein dieser Beweis lässt sich bequem bloss zur Denonstration kïnstlicher Bastarde fïhren, I. h. nan kann, wenn man willkïrlich durch Kreuzbestäulung einen Basturd crhalten hat, mit Evidenz soine Eltern und deren Einfluss auf das Produkt angeben. Müsste ich jedoch einen in der Natur vorliegenden, an sich lediglich Wathrscheinlichen Bastarl entritsoln, so wäre as. die Fruchtbarkeit desselben voratsgesetzl, immerhin Iraglich. ob el bei ficlbsthestaubung sich und seine Nachkommen nach den Mendel'schen Regeln aullüsen und die ursprïnglichen Komponenten vermaten wiirle. Deswegen und hei der Langwierigkeit von hulturversuchen an Inlzgewächosen wie de'n lusen begnïgt man sich in der liegel mit der Erforschung von Bastanden

1) Die Sterilität wird in der ersten Generation am besten gewürdigt'an dem Fehlen oder

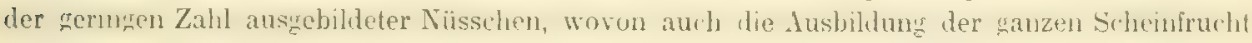
abhängt. Wie wir früher sahen, ist die Mangelhaltigkeit der Pollenkörner kein so sicheres

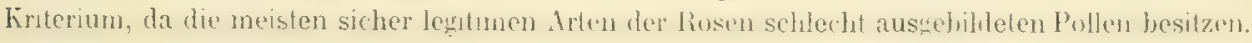
In einer zweilen Generation müsste der Kulturversuch eine Entscheidung bringen, falls überhaupt Nüsschen in der ersten gebildet worden sind. Dergleichen Versuche sind aber äusserst selten vorgenommen worden. Ich selber habe an der Rose canina XJundzillii vom Kornberg bei Gungolding Kulturversuche angestellt. Die an sich schon wenigen ausgebildeten Nüsschen keimten rur zu etwa $10 \%$.

2) Siehe die entsprechenden Seiten der Synopsis (R. Keller). Vgl. auch meinen Aufsatz: „Über einige für Bayern neue Rosenarten und mehrere überhaupt neue Artbastarde von Rosen" („Berichte ${ }^{2}$ der bay̧r. bot. Ges. XI. Bd. 1907, S. 170 ff.). 
auf den Wege der Beobachtung und gelangt auch so zu ciner genïgenden Sïcherheit. $\left.{ }^{1}\right)$ Die gänzliche oder teilweise Sterilität der im Feren rorkommenden Batumle deutel auf eine Dishrmonie ihrer elterlichen Keimanlagen, die sich zunächst in einer Zorstörung jener Organe ausspricht, wolche die Anlagen enthalten, mischen und ïberlielern. Danit ist aber auch klar angedeutet eint vorhandene Abrgrenzung, Individualisierung und Stabilisierung jener Arten, welche den Bastart als nicht daureml lebenslihhiges Proulukt erzeugten. Wir dürten also nil vollem liecht von den herkömmlichen hollektivilten als fixen und in ler (itgenwart vorderhand, relativ, begrenzten Einheiten ausgehen. Ob sie sich nichl etwa moch untel dem Finflusse äusserer oder innerer Faktoren im Verlanfe der Zeit verändern werden, geht uns hier nicht an. Die erblichen Varietitlen, also schliesslich die "Elementaruten" von de Vries, zeigen sich innerhalb einer" Kollektivart in gewöhnlichen Sinne so nahe verwandt, dass man an ihn'n hreuzungsprodukten keine Sterilitiit bemerken kann, eher das fiegenteil. Solche Varietiitenmischlinge muss es in reichen Rosengegenten massenhaft geben, aber wir kennen sie nicht, weil sie sich nicht durch ['nfruchtbarkeit oder ein sonstiges Zeichen bemerklich machen; ein Beweis dafür, diss ihre Eltern sich immer noch mischen und zu keinen abgesonderten Lebenseinheiten geworden sind. Wir werden also auch aus diesem Grunde unsere Erörterungen über Deszendenz besser auf die herkömmlichen Kollektivarten beschränken.

Man sollte meinen, an besten vermöchte der verschiedene Grad der Sterilitït bei Bastarden einen Fingerzeig abzugeben für die Bestimmung der nüheren oler entfernteren Blutsverwandtschaft der Elternarten. Dieses Vorgehen versprache aber einen Erfolg zunichst wieder bloss bei experinentellen Bastardierungsversuchen. Die nur beobachteten Bastarle sind häufig gerale mit Bezug auf den Grad ihrer Fruchtbarkeit ungenau beschrieben; zudem stehen die Eltern nicht stets ausser Frage. Nun hängt aber auch die Tatsache und der Grad der Sterilität nicht imner bloss rom Grad der Blutsverwandtschaft im allgemeinen, sundern auch von speziellen Bedingungen der Generationsorgane ab. Das lehrt die Erfahrung bei Pflanzen wie bei Tieren. Es würden also selbst Experinente mit bekannten Eltern und ersichtlichem Erfolge nicht mit Gewissheit vom Grade der Sterilitiat eines Bastards anf den Grad der Blutsverwandischélt seinel Erzeuger schliessen lassen. Wir müssen uns jedenfalls nach anderen lírterien für die Bestimmung dess Abhängigkeitsverhälnisses von Rusenurten umsehen, insoweit die rein morphologischen Kemneichen Deutung, Erläuterung und Ergänzung bedürfen.

\section{Kapitel: Die Organisationsmerkmale.}

Den Rosen eignet eine Reihe von Charakteren, die sich nicht aus der Anplasing an gegenwittig wirksine anssere Fikloren erklären lissen. Wir

1) Ich bestreite nicht den anderweitigen grossen Nutzen künstlicher Bastardierungsexperimente auch bei Rosen. So liesse sich z. B. nachweisen, ob Bastardierung zwischen zwei Formen überhaupt möglich sei. Eine etwaige Unmöglichkeit könnte beruhen entweder auf der Disharmonie der in den Chromosomen oder sonstwie gebundenen Lebenspotenzen oder auf den Mangel der sog. ${ }_{n}$ sexuellen Affinitä ${ }^{\star}$, der wohl in den meisten Fällen auf die Diskrepanz der beiderseitigen Geschlechtsorgane zurückzuführen ist. 
haben sie als Organisations- oder Systommerkmale kennen gelernt. Diese Chaublitere

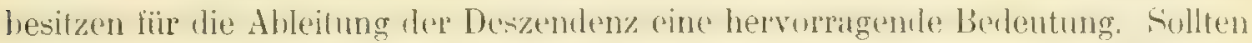
sie ganz oder teilweise, wie eine Anzihl von Forscherm annimmt, alten in der geologischen Vurzeit entstudenen und jetzl nicht mehr entribcellaren Anpassungen entsplechen, weil alle Ëgenschatten sulche der Anpaswnng seitu, sn miïsten wir in ihnen eben die Siruren und Ihatsen des frïheren lintwicklungsganges elblicken, nath dem wir suchen. (iibt es aber, wohin meint Cletzengung geht, einen prinzipielien Interschiod zwischen beiden, nämlich den Eigenschiflen der Urganisation und der Anpassungr, so wim gleichsam das límohengeribst des Gattungs- und Familiensystems von den Fystemmerkmalen gehildet, und es schreitet die Systementwicklumg nach inneren hiäten mul Geselzen auf dem Wege äusserlich richtungstuser (nicht von äusseren Fakturen belingter) Variation und Mutation rolwirts, indem sile ihre sichitte durch die l'rouluktion der Organisations- oder systemmerkmale bezeichnet. Rusen, die mmittellar von einander abstammen, werlen die meisten derartigen (ihathtere gemeinsan besitzen: iiberhaupt alle, wenn sie nur durch Anpassung atls einander hervorgegangen sind; alle bis auf einen olter wenige, wenn die zweite Art durch Mutation ans der ersten entstand. Rosen, die entferntere I)eszendenten einer Stammitt darstellen, werden weniger Organmerkmale mit ihr teilen, als nahere I eszendenten.

Wir beginnen mit der Besprechung der Merkmale an Achsen. Von den europäischen Rosen zeigen die dünnsten Stengel und längsten Internodien R. arrensis Huds. und sempervens $L$. Sie sind dadurch bereits gezwngen in Gebiisch zu klettern, wie dieses bei den Exoten R. multiflora Thunb, setigcia Rich, und Banksine $R$. Br. in noch viel höherem Masse der Fall ist. Auf dem ebenen Boden kriechen R. arv. u. semperv, teilweise unter Bildung unterirdischer Ausläufer. Eine weitere Anzahl europäischer Rosen besitat ebcnlalls recht dünne Stengel und dazu das Vermögen unteriolische Ausliulter zu bilden in mexist höherem Grade wie die R. arv. In absteigender Linie geordnet sind das: R. gallica L., cinnamomea L., pendulina L., pimpinellifolia L., . Jundzillii L. die letztgenannte hat zwar sehr reiche Ausliuberbildung Slelle nach gallica aber weniger schlanke oberiodische Aste, wodurch sie sich den Rosen um couna nïhert). Jedentulls erweisen sich in diesem Punkte cimmanomea, pendulina und

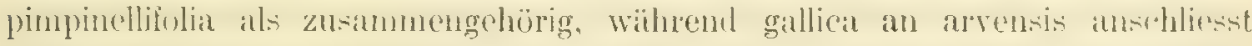

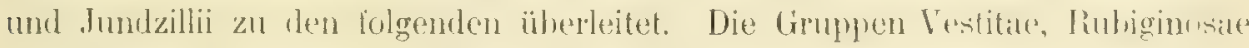
und Caninas verhalten sich ziemlich gleichlömig, stehen rürksichtlich der Aus-

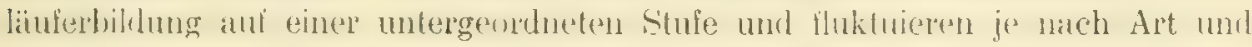
Varietit zwischen knappen und schlallem Wuchse, ohne jo das Hingegossene von

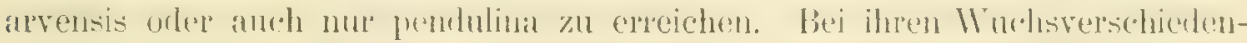

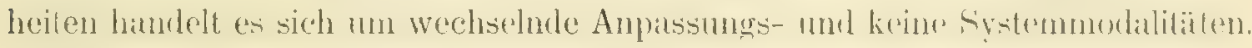

Fassen wir die Blatter ins Auge, so erzeugt zuerst die ' $\mathrm{k}$ hl der Fiederblätlchen mittlerer Blütenzweige mehrere Gruppen. Abgesehen von der $R$.

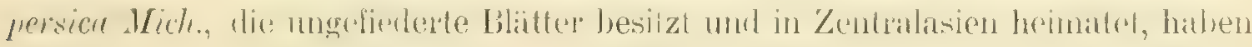

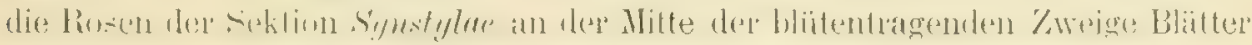
mit 3-7 Fiederblätchen, die europäischen mit sempervirens und arensis 5-7,

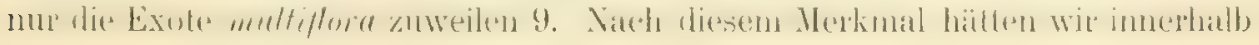


der Sektion Synstylae 2 Gruppen: R. setigera und anemoniflora mit 3, die

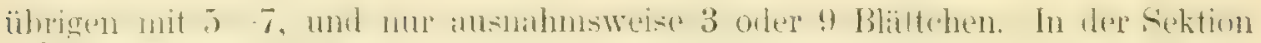

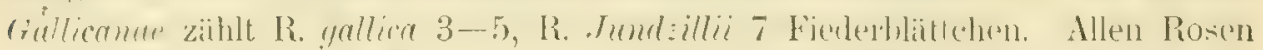

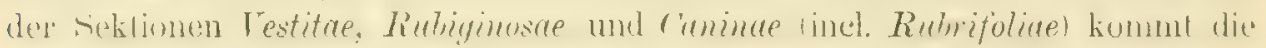

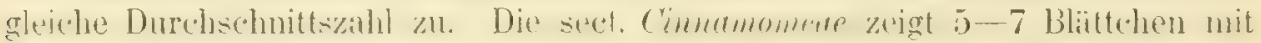

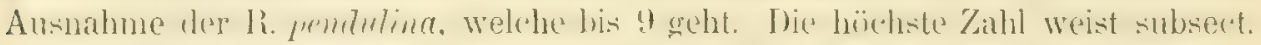

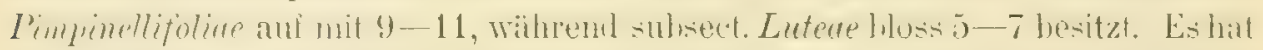

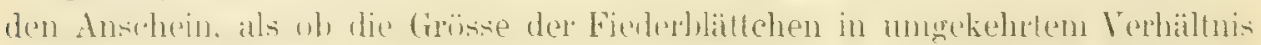

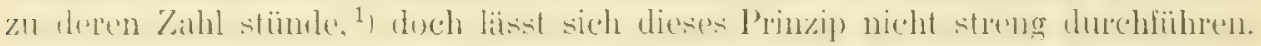

Nach der durchschnittlichen Grösse der Blättchen ragen unter den

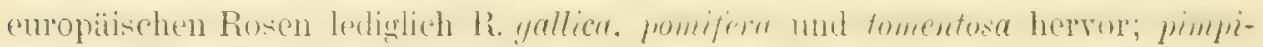

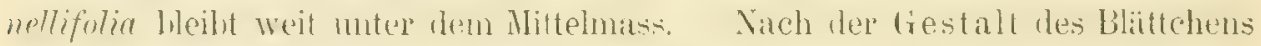

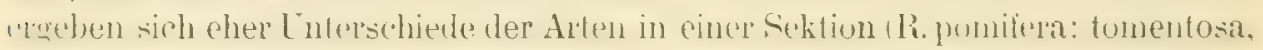
rubiginusa: elliptical und fluktuitrendes Vatiationen imnerhalb der Arten. als Dillerenzen hïherer Kategnien; hie kifom ist und heibt die vorherrschente. Für das wichtigste halle ich die Form der Blattzähne, wozu anch diegenige

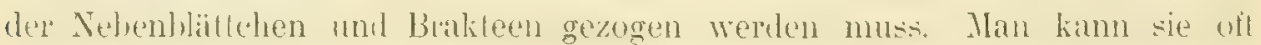
schwierig becheiben und mus sie in vivo studieren; als Hilimiltel kïnnen die photugraphischen Abbildungen bei Waldner"2) dienen. (harakteristisch sind

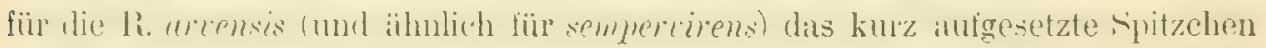
der Zühne, für gullicu die breiten, geschweilten kurspitzigen Zähne, leren Drüsen selten bis zur Bildung eines deutlichen Nebenzïhndhens fortschreiten. F. Jundzillii hat ginz andere, mit der subsect. Eucaninie mehr hammonieremde Zahnung: steil gestellte, langgespitzte Zïhne mit deutlichen Sekundirzähnchen. Diesubsect. Encunince und die subsect. Ruhrifolice zeichnen sich ans durch lange, spitze, oft muregelnaisig konvergierende und divergierende, wenig offene Ziihne; die Zahnung bei subsect. Rubrif. ist nur etwas soichter. Davon weicht die subsect. Tomentellae athillend durch die kurze, breite, fast rochwinklige Zahmung der Jucit ovalen Bliatchen ab, welche gewöhnlich eine kume fist mumotivient anfgeretzle spitze zeigen. Der Typus ron h. pomifera mul R. fomentesu ist ziem-

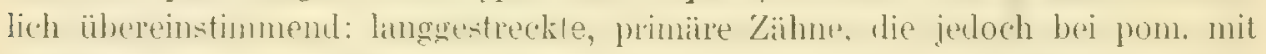
gerarlen. bei tom. mit geschweilem Rïeken verlaulen. Die Zahnung von $R$.

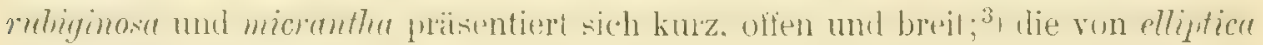
mul ayrestis lang, spitz und weniger vom Blattrand abstehend; anch bleibt der Blaltrand gegen den Sitiel undeutlich bis nicht gezihnt. Die R. cimamomea $L$. und blanda tit. haben sehr grosise Mhlichkeit, atuch in der Blatlform. Die Zähne jednch untercheilen sich aullillig: R. cinn. hat breite geschweilte etwats liegend kurzgerpizte Zähne, R. bl. schmale, stark liegende: in eine laingere

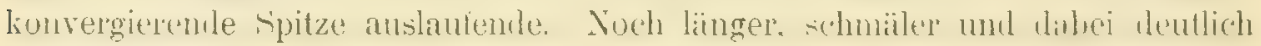
von Ilanplleil des dahes ahgesetzt, gewöhnlich nach immen grekrïmmt ist die

1) Die R. microphylla Roxb. entwickelt 11-15 zäblige Blüttchen.

2) H. Waldner: Über europ. Rosentypen, 18s5. - Die Holzschnitle bei Sagorski (die R. d. Fl. v. N.) und selbst bei C. K. Schneider (Handb. d. L.) sind für cine genaue Beurteilung nicht geeignet.

3) Ich kann nicht finden, dass die R. micrantha in der Zahnung deutlich von rubiginosa abweicht, höchstens sind die Zähne an mehr länglichen Blällchen auch etwas länger. 
Zahnspitze der R. pendulina L. Auch deren sekundäre Zähnehe'n verhalten sich ähnlich. Die Blittchen der h. jumpinellifolia zeigen seharfe, kurz gespitzte, rechtwinklich abstehende Zähne. Man darl übrigens nieht übersohen, dass mit

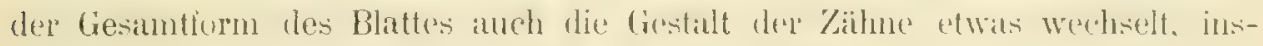

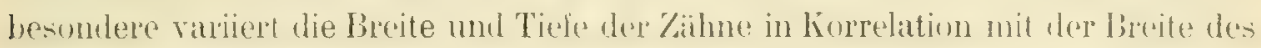

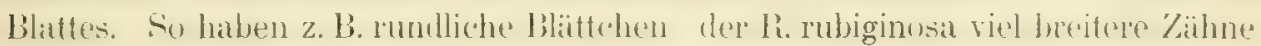
als covale. Aurh der Winkel. unter dem die Zähne vom Blathande abstehen, wird

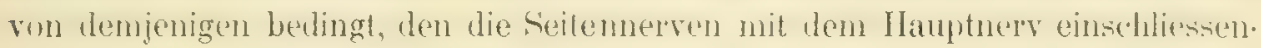

Betreffs der sexnellen Organe können wir uns kurz fassen. Eine streng rinblütige Intlorescenz hat hei uns nur die R. pimpinellifolia, prinzipiell mehn-.

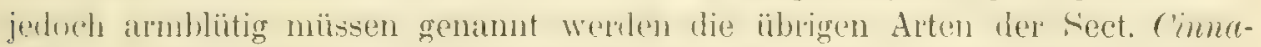
momeae, spimosissimae und synstylae, sowie die R. gallica. Reicher biüh R. . Jundsillii und die sect. Testifae, an reichsten die sect. Caninue und busmblers Rubiginosae. Die Fiederung der Kelchblïltchen fehlt oder ist nul ganz schwach

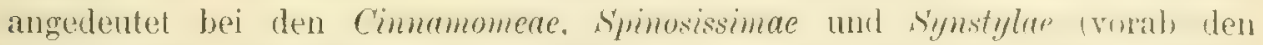
enropäischen); besonders reich entwickft kommt sie ror bei der subsact. Tommetellue, der R. stylosa Dest, und Jundzillii, sowie eingen Varieliten der R. dumpform, welche gegen dir R. tomentedla himmeigen. - Aufiallende Grösse der

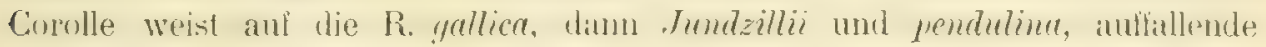

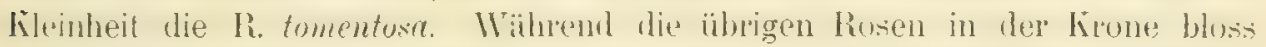
Anthocyanrot bilden, entwicken die Arten der sect. Pimpinellifolire in derselben

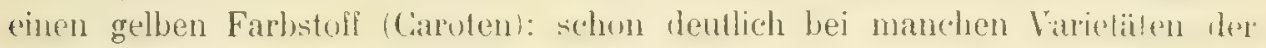
R. pimpinellifolia. slark bei R. Lutea und den exotischen Arlen der teklion. Beji Arten anderep Gruppen tritt das (ielb) nul spurenhalt auf. so R. sericen Limull,

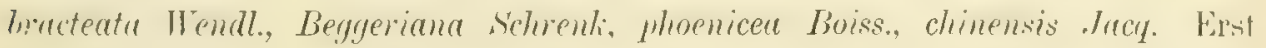
R. Bantisiae R. Br: und die ganz abweichende R. persica Mich. sind wieder sattgelb gefïrbt. - Die troheinfrüchte haben eine kugelig-kreiselförnige Gestalt bei R. pimminellifolia und annähornd bei cimnamomen, anch die meisten Arten ihrer Sektionen verhalten sich so, wïhrend andere Rosen die Eiform zeigen. Bekanntlich weicht auch die Fruchtlarbe ler R. pimp. nerkwïrlig ab, lie bei ihr wie der R. xanthina von der gleichen Untersektion ein Schwarzrot ist.

Von den Hautorganen (Hatle, Stacheln, Drïsen) wage ich lediglich dit? Zwrizahl der stacheln unter den Nebenblätern mit Sicherheit zu den Organmokmalen zu rechnen. Dieses Merkmal eignet unserer R. cinnamomea, überhaupt den Sektionen C"mumomene, Bracteatae und Microphyllate. Vielleicht gehoint hieher auch die Gestalt der Stacheln von R. tomentella.

Im Grossen und Ganzen stimmt die Erörterung der Organmerkmale in ihnem Ergebns mit den ïblichen Systen, das wir in zweiten Teile wimlergeguen haben. In vieler Beziehung zeigen l'bereinstimmung die Sektionen Caminue, I'estitae, Rubrginosae und die L'ntersektion Jundzillianae. Cirépin fasste sie alle in seiner sect. IV: Caninac zusimmen ${ }^{1}$ ) und trennte. Wohl unichtiger Heise, die li. stylosa Desv. als sect. II: Stylosae davon ab. Doch erscheint diesto Cropin'sche Einteilung aus praktischen Gründen unvorteilhatt, weil sine stkt.

1) Fr. Crépin: Tableau analỵtique d. roses, 1892 , p. 26 f. 
Caminat allzu mulangreich wird. Nateh den Chatrakteren der Blïtter nïhert sich musere subsed. Tomentellae der seot. Rubiginosae, während sich die subsect. Rubrifolve inniger an die subsect. Eucuminde anschliesst. Die Blattchataktere gahen

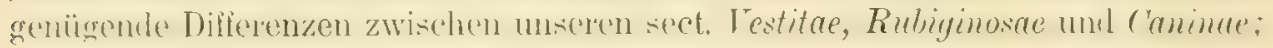

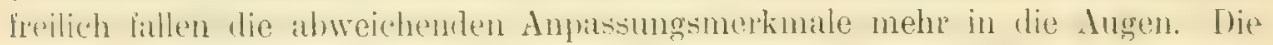

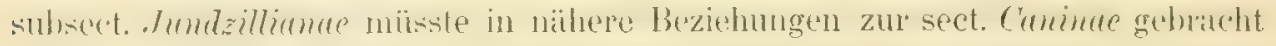

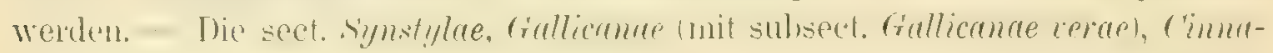
momea und Spinosissimae weichen viel weiter von den bisher besprochenen

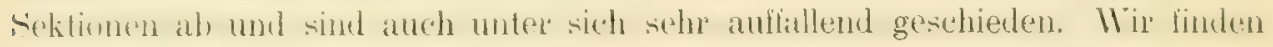
lei ihnen mehr Beziehungen zu asiatischen und amerikanischen Rosen als bei der sect. Caninae Crépins (incl. der R. stylosa). Unsere sect. Vestitae mit den Hauptgliedern R. pomifera und tomentosa bewihnte sich bei der Analyse, - wir haben die beiden subsect. Tomentusac und Villusie Crepins zusammengezogen -; desgleichen die Abtremmug der R. tomentella mit ahietina als subsect. Tomentellae.

2. Kapitel: Die jetzige geographische Verbreitung der europiaschen Arten im Zusammenhalt mit ihrer jährlichen Vegetationsperiode; Entwurf eines Stammbaums der Rosen.

A) Es folgt zunächst (ine Clbersicht der gengraphischen Verbeitung innerhalb der sect. Cinnamomeae nach ihren eurupäischen, d. h. in Europa vorkommenden Arten: ${ }^{1}$ )

\begin{tabular}{|c|c|c|}
\hline & Europa: & Asien: \\
\hline 1. acicularis Lindl. & $\begin{array}{l}\text { Nordeuropa (I,app- } \\
\text { land, Finnland, Nord- } \\
\text { u. Nordostrussland). }\end{array}$ & $\begin{array}{l}\text { Sibirien, Usungarei. } \\
\text { Altai, Mandschurei, } \\
\text { Sachalin, Japan, } \\
\text { Nordchina. }\end{array}$ \\
\hline
\end{tabular}

R. cinnamomea $L$.

Skandinavien, last ganz Russland, Berggegenden Mitteleuropas (Jura, Alpen bis $2100 \mathrm{~m}$ ). Ob wild im Harz, in Böhmen, Thüringen, Nordbayern?

R. pendulina $L$.
Westsibirien, Altai, Kaukasus, Trans- kaukasien, Armenien.

Nordamerika:

Nördliches und nordwestliches Nordamerika bis zu den Rocky Mountains und Texas.

Hoch- «. viele Mittel-
gebirge Zentraleuro-
pas (Pyrenäen, Sier-
ren Nord- und Mittel-
spaniens, Alpen,
Apenninen, Cevennen, |
Jura, Vogesen,
Schwarzwald,
Böhmerwald, dina-
rische Alpen, Kar-
pathen, Balkan, cin-
zeln in der Rhön und
im südl. Frankenjura)
bis 2500 m. Nördlich
bis Erzgebirge u. Su-
deten. Fehlt im westl.
Mitteldeutschland.

1) Ich gebe die Daten der geographischen Verbreitung der Rosen im allgemeinen nach Fr. Crépin (Tabl. anal.), J. G. Baker (A revised classification), R. Keller (Synopsis von Aschers. u. Gr.) und C. K. Schneider (Illustr. Handb. d. Laubholzkunde I); im speziellen Gebiet nach meinen eigenen Beobachtungen. 
Die Sektion der Cinnamomeae hat ihre eigentliche Heimat in Nordasien und Nordamerika. Von Nordasien aus ist sie bis in die Gebirge Zentral-

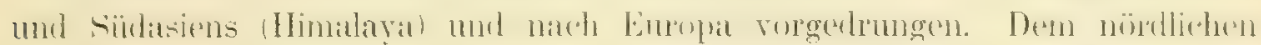
Amerika gehören 10-13 Arten an, ganz Asien 9 Arten; 1 (R. pendulina) ist auf Europa beschränkt, 1 (R. cimncmomea) gehört Europa und Asicn an, 1 ( $R$.

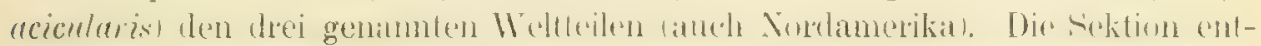
stand und entwickelte sich offenbar zu einer Zeit, da zwischen Sibirien und Alaschka noch eine Landbriicke bestand. Das war im Tertiär der Fall, wo bis zur Diluvialzeit Nordasien und Nordamerika eine Landmasse bilideten. ${ }^{1}$ ) Auf diese Weise konnte $\mathrm{R}$. acicularis in den drei Weltteilen Fuss fassen; in Europa ist sie wohl erst nach der Eiszeit von Sibirien hereingewandert und über den hüchsten Norden nicht hinausgekommen. Die R, cimumomea entshund später im Altagebet oler im westlehen Sibirien, das, wie ganz. Nordasitn in der Eiszoit fast gretscherfrei war. Von dit hat sie die Reise nach Russland und zum dentscolen Süden angetreten. Von R. acicularis stammt sie keinesfalls direkt ab, ist auch mit anderen asiatischen Arlen der Gruppe näher verwandt. Es erscheint mir als gewiss, dass sie zur Eiszeit den vom Eise frejgebliebenen Toil Rarshands und Mitheldeutschlands feinchliessich des Frankenjura und dep schwibischbilyrischen Huchebene) besiedde und ersil während der Interglateialzeilen und nilch dem Aubören der V'ereisumg sich auf lie klimatisch zusagenden Gebirge

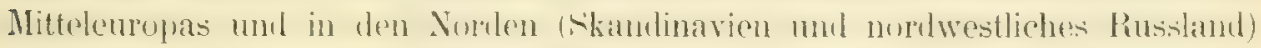

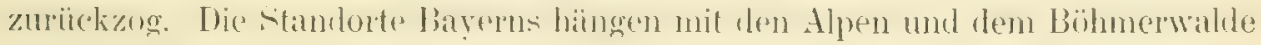
zusammen (Eiszeitrelikte sind nicht ausgeschlossen). R. cinnam. ist eine nordische und erst in zweiter Linie eine Gebirgsform. So fehlen ihr einigo Merkmale der alpinen Anpassung: ihr Wuchs ist ziemlich flattrig und drmgenäss die Blütenstiellänge nicht unbetrichtlich (die var. fulyens ("hr. ist übrigens an ihren hochalpinen Standort - Oberwallis — besser angepasst). Aul die hochnordische Abstammung oble die Entstehung in eiszeiflichem Klinat deutet auch der Umstand, dass die R. cinn. auffallend früh im Jahre sich entwickelt und verhältnismässig noch zeiliger ihre Früchte reift. Nach meinen

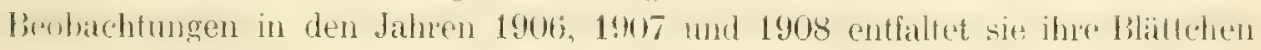
2-6 Tage vor der R. canina, ihre ersten Blüten im Mittel 11 und reift ihre

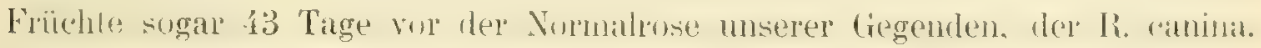

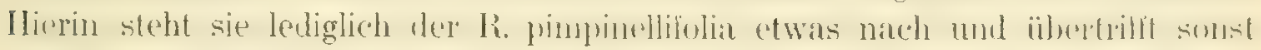

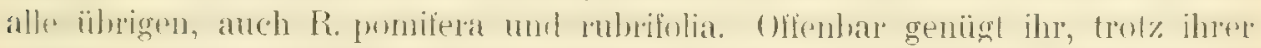

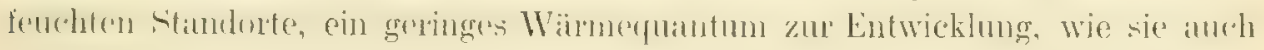

1) Vgl. u. a. die Tafel II bei E. Kóken: „Die Vorwelt", Leipzig 1893. Die „Lethaea geognostica" III. Teil, 2. Bd. erste Abteilung (1903) S. 33 schreibt: "Wahrscheinlich auch noch im Anfange des Quartärs bestund im Gebiet der Behringsstrasse ein Zusammenhang zwischen den Landmassen Asiens und Amerikas" (Fr. Frech). - Reste von Rosen werden bereits aus dem Oligocän (Alttertiär) von Bonn und dem Eocïn von Florissant in Nordamerika beschriehen. Gegen letztere verhält sich Schenk im „Handbuch der Paläontologie“ von K. Zittel, II. Abt. Paläophytologie (München 1890, S. 667 f.) zicmlich ablehnend. Die prähistorischen Stationen der Schweiz, Schweizersbild u. a., lassen erkennen, dass am Ende der Eiszeit die Hagelutten der R. canina als Nahrungsmittel dienten. Diese Rose war also jedenfalls bereits im Diluvium in Mitteleuropa verbreitet (p. 96 von H. Clrist: La flore de la Suisse, Bale 1907, supplément). 
in ihrer vigentlichen Heimat, in der Epoche der Kunsolidierung ihner Eigenschafters. eine relativ kurze Vegelationszeit zur Vertïgung hatte: den kurzen. aluer wegen des andautemlen Verweilens der Somme über dem Horizont lichlund wïmereichen nordischen Sommer.

Leider war ich nicht imstande, die R. pendulina $L$. in ähnlicher Weise auf

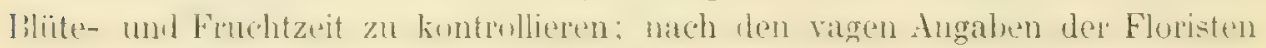
blïht und reift sie ebenfalls sehr frïh. Sie muss sich von der R. cinnamomea

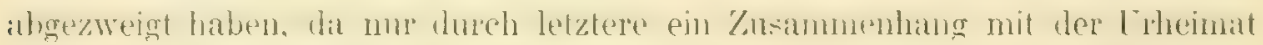

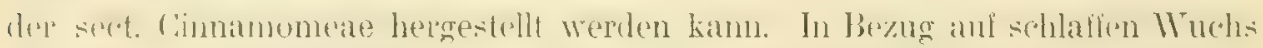

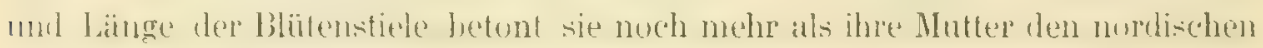
Lrsprung in Gegensitz zum rein alpinen Charakter. Ihre schwathe Bestacherlung ist jerbeh eine nachtü̈gliche Anpassumg an lis tierame Gebirge, die sich

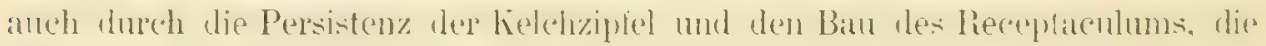

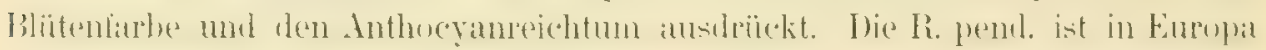

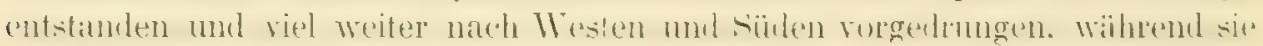

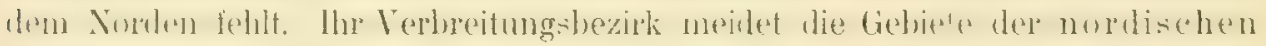
Eizentrelgletscherung und deckt sich ungebihe mit jenten Teilen des mittleren

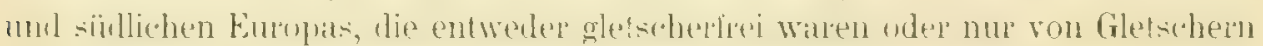

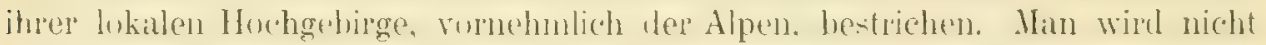
lehl gehen, wemn man annimnt, dass sie am Ende der Eiszeit in ihrem öst-

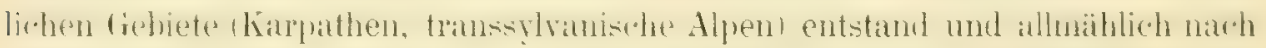
11 esten und siblen vordrang. Die ballkatuhalbinsed hat sie noch fast ganz bu-

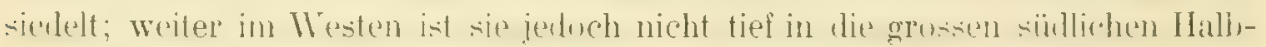
inseh (Italien, sponien) eingednungen, noch weniger an die Inseln des Mittelmeres, die an Ende des Diluvimns durch keine Landbribcken mehr in Verbindung nut dem Kontinent slunden. Die Zwischenräume zwischen den Hoch- und Mittelgebirgen konnte sie leicht hudehqueren, weil sie an Schluse der Eiszeit nuch sehr kïhles. Penchtes Klima besascen. Als aber die mittlexe Jahreswäme gegen den Beginn der genlogischen Gegenwart immer mehr stieg und die Lulfeuchtiglieit ahnahn, heschrïnlte sie sich aut die höheren Gebirge und deren unnittelbares Vorlind 1\%. B. die höheren Partien der bayr. Huchebene beim Peissenberg). Finzelne eiszeitliche wler nacheiszeitliche Relikte nachen uns auf ihre friblere: weitere Vorbertung anfmerksam, so der interessante, so nidrige Standort hod Lataber in sïdöstlichen Flankenjura $\left(310\right.$ m) mul derjenige in der Rhön.1 ${ }^{\mathbf{1}}$ In

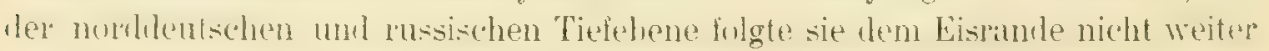

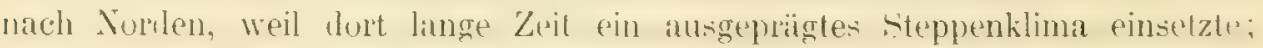

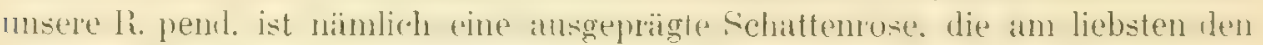
forchten Waldrand an Berghïnge'n beredelt und anch gernes sich hritehent durch unterirdische Ausliufer verbreitet - auch so ein echtes Glied der Cinnamomea-Gruppe.

Wir schliessen die R. pimpinellifolia gleich dieser Gruppe an. Die Rosen

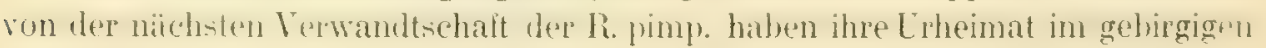

1) An Kreuzberg bei $750 \mathrm{~m}$ (entdeckt von Ade, mitgeteilt von M. Goldschmidt in dessen ,Flora d. Rhöngebirges" VI., Würzburg 1908, S. 270 f.). 


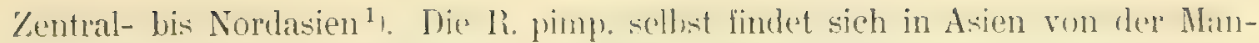

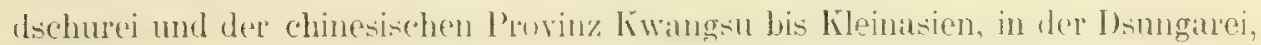
Bucharei, in Armenien, Tumskankasitn mel Turkestan. In Eumpat hat sie das

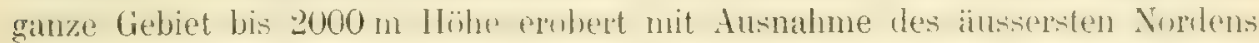
von Skandinavien und Rusitund, sowie Grichenlands und der Inseln des Mittelmeeres. Ihre Verbreilung zeigt aber viele Lücken, und noch öfter erscheint es zweifelhaft, wo sie einheimisch, und wo sie nur verwildert ist. Im schwï-

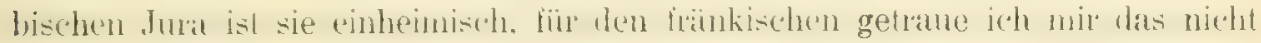
sicher zu behaupten. Sicher wild ist sie ebenfalls im Schweizer Jura und in

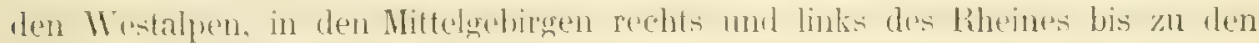

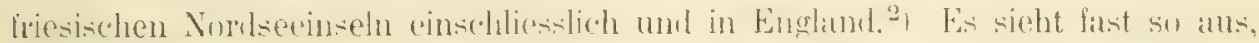
wie wenn diese Rose von den Westalpen und dem Schweizer Jura aus durch die Rheinsenke, ev. verschwenmt durch rheinische Gewässer, an die Nordsee und nach den britischen Inseln gelangt wïre, als sie noch mit dem Festlande

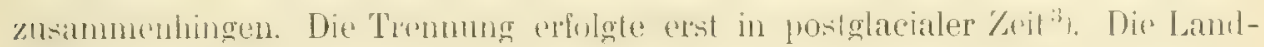

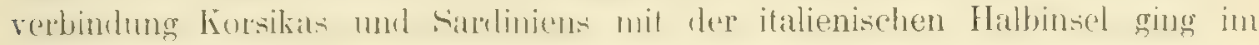

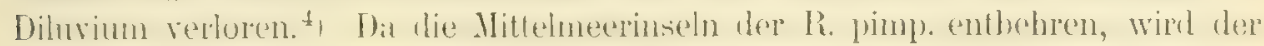
Wanderzug dieser liuse anch im viilen Europats erst nach der Eišeit culer im Anchlosice an diesclbe stattgefunden haben. Als wahrscheinliches Resultat

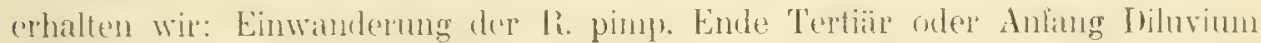
von Nordosten her in Europa, Hauptverbreitung in ziemlich später Zeit, im

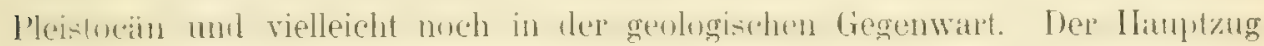
der Wanderung ging von Nordost nach Sïdwesl, später von Sïden nach dem Norden, dem sich zurückziehenden Eise folgend. - Die R. pimp. blüht und

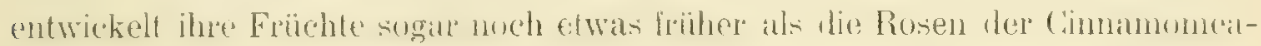

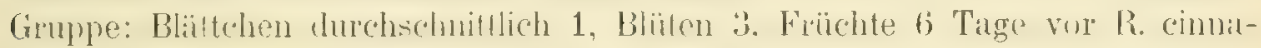
momea und volle 49 Tage vor R. canina! Man wird hier den kombinierten Einfluss nordischer Entstehung und der Wanderung hinter dem Diluvialeise

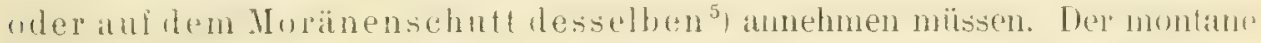
Chankter ist bei der R. pimp. kanm stälker tentwickelt als bri der cimamomera.

1) Wenn man die Umgrenzung der sect. Spinosissimae nach Baker einhält, gehören auch

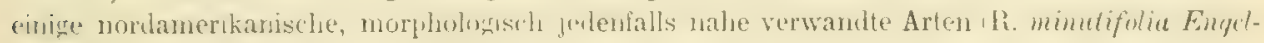
mann, stellata Wootton - Südkalıfornien und Neumexiko) hieher; selbst R. pendulina und blanda Aiton nimmt Baker zu den Spinosissimae. Von ihrer geographischen Verbreitung wäre dann bezüglich dieser Sektion das Gleiche zu sagen, wie von der sect. Cinnamomeae.

2) Nach J. G. Baker ( ${ }_{n}$ A monograph of the british roses", S. 202, 1869) kommt sie noch in den schottischen Hochlanden, auch in ganz Irland vor; sie sei die einzige isländische Rose (? wohl nicht wild, denn sonst hätle, was ganz unbezeugt ist, Island nach der Eiszeit noch eine Landverbindung mit Europa haben müssen). An der Meeresküste bevorzuge sie den Sand, im Innern des Landes den Kalkstein (Also doch wegen der physikalischen Beschaffenheit, in der beide Bodenarten etwas Gemeinsames haben, der Durchlässigkeit für Wasser).

3) Siehe A. Hettner: „Grundzüge der Länderkunde", I. Bd., Europa, Leipzig 1907, S. 107, und ,Lethaea geognostica" III. Teil, 2. Bd. Erste Abt. S. 23: "Die vollkommene Gleichartigkeit der quartären Formen weist darauf hin, dass England erst nach dem liückzug des Eises den Zusammenhang mit dem Continent verlor."

4) M. Neumayr: „Erdgeschichte", 2. Aufl., II. Bd., 1895, S. 486.

5) Aul S. 4 f. der Lethaea geognostica, III. Teil, 2. Bd. Erste Abt. macht F. Frech auf die wichtige Tatsache aufmerksam, dass die Morïnen auf den gewaltigen Gletschern am Mlt. 
B) Die Rosen der Sektion Synstylae (12-1't drten) dürfen als Miltel-

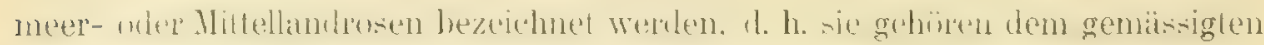

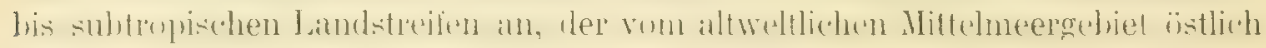
bis zum stillen Ozean zieht und von den Zoologen, wenn auch nicht in der

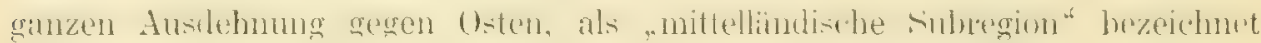
wird. ${ }^{1}$ ) Einige ron diesen Rosen gehen ziemlich weit nach China und Japan

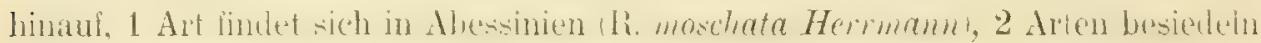
Südeuropa, ron denen die R. sempervirens $L$. auch in ganz Nordafrika wächst.

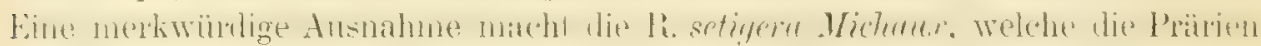
der östlichen Vereinigten Staaten bis nach Texas hinunter schmückt. Ist sie

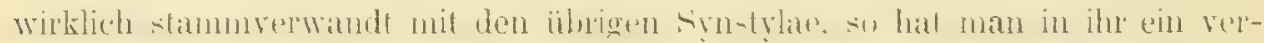

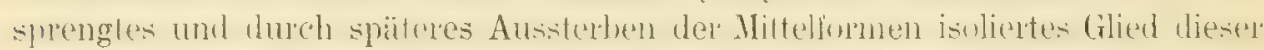

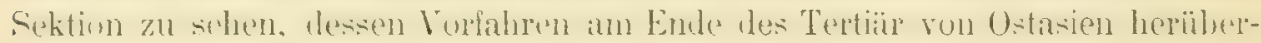
gekommen sind gleich den Cinnamomeae. Die beiden jetzt in Europa einheimischen Arten, R. sempertirms L. und arensis Huds. welehe in sildenrupit vitalach durcheinander warhsen und regelnhäsig Baslarde bilden, wurten jeden-

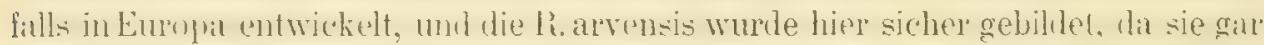

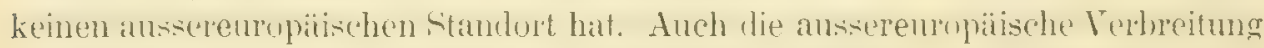
der R. semperv. kam auf Europa zurïckgehïht werlen. Der einzige Standort in der Troas Kleinasiens erklärt sich an einfachsten durch sekundäre Verschleppung. Nach Narokko, Algerien und Tunisien abel rermuchle die Rose

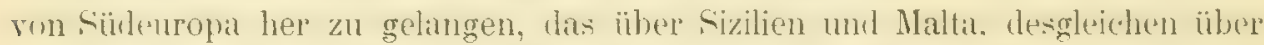
Gibraltar, bis gegen das Ende des Diluviums nit Aprika in Verbindung stund. Durch diese wanderte anch der afrikanische Elephant, das Mähnenschal und del' Makakenaffe umgekehrt nach Eumpa ein. $\left.{ }^{-2}\right)$ Als Hulter der immergrümen R. sempervirens, die auch in anderes Bezichung den Charakter der sïdlichen Mittelmeerllora an sich trägt. bin ich geneigt. die R. moschata Hermann anzunehmen. Die letalgenannte ist murphulugisch der srmpervirens so mahe stehend, dasis Crépin noch i. J. 1869 die R. ruscinonensis Desegl. et Gren., welche eine rerwilderte Rasse der moschatia dirstell. zur li, semperv rechnete." Als eigent-

Elias in Alaschka sogar ausgedehnte Wälder (15-20 engl. Quadratmeilen) von Balsamfichten, Kiefern, Birken, Erlen. Weiden und Ahornen tragen mit dichtem Unterholz von Heidelbeergestrüpp! Es ist also wohl unrichtig anzunehmen, im Gebiet der eiszeitlichen Vergletscherung sei die GrossFlora ganz vernichtet gewesen. Nordische und abgehärtete Formen (R. cinnamomea, acicularis, pendulina, pimpinellifolia) vermochten auf dem Eise selbst auszuhalten nach Analogie der Verhältnisse am Mt. Elias.

I) Vg]. z. B. R. Lydekker: Die geographische Verbreitung und geologische Entwicklung der Säugeticre." Ubbers. Siebert. 2. Aufl. Jena 1901, S. $48: 3 \mathrm{ff}$.

2) R. Lydekker: „Die geogr. Verbr." usw. S. 457 und M. Neumayr: „Erdgeschichte." II. Bd., Seite 409.

3) Fr. Crépin: Primitiae monogr. rosarum, fasc. 1. p. 256. $1 \mathrm{~m}$ Tableau analyt. (1893) p. 5 sq. stellt er sie richtig zur R. moschata. - Sollte man R. 1n. und sempervir. nicht in nähere Verbindung setzen wollen, so würde sich vielleicht ein Ausweg durch die ebenfalls schr ähnliche R. phoenicen Boissier bieten. Dieselbe besiedelt Kleinasien: Taurus, Syrien, Libanon, und kommt nach Crépin (Tabl. analyt. p. 5) ${ }_{n}$ sehr selten $^{"}$ auch in der europäischen Türkei vor. Die ungelähre Enlwick]ungsreihe, die geographisch besonders einleuchten würde, wïre dann

$$
\text { R. moschata } \longrightarrow \text { phoenicea } \longrightarrow \text { semperirens. }
$$




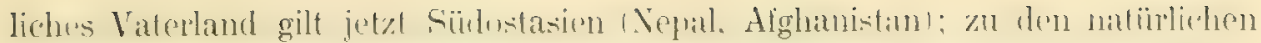

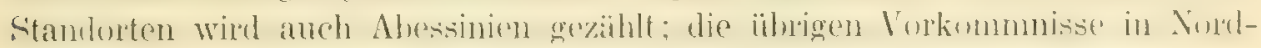

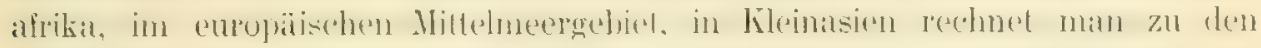
Verwilderungen. Es wind aber doch wohl baglich sein, ob nicht Fumbute sich darunter befinden, die auf natürlichem Wege von den zuerst genannten sich

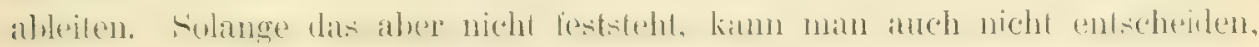

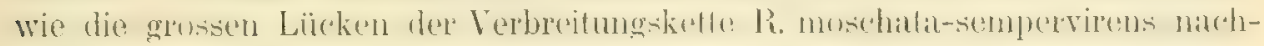

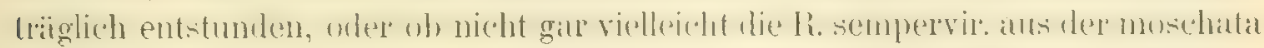

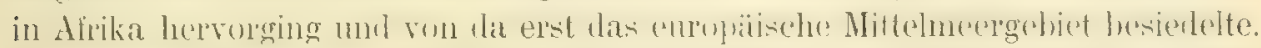

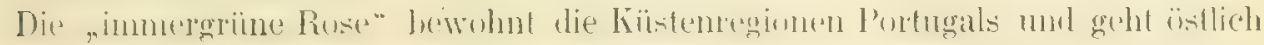
bis zur Balkanhalbinsel, nördlich bis zur Loinemibulung und ins (irbirge bis etwa $700 \mathrm{~m}$.

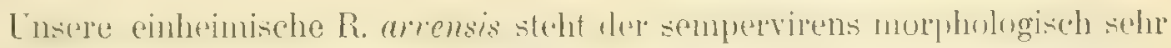

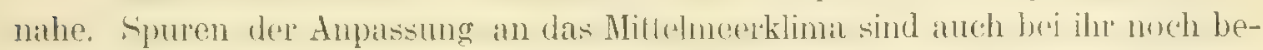

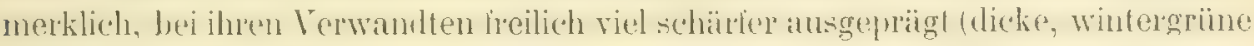
blätlchen usw.). Nach ihner Entwicklungszeit veruät sich die R. arv. ehenfalls als

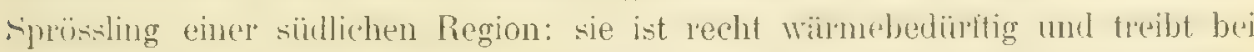
Eichslätt ihre blätchen 1 und ihre Blüten 9 Tage nach der canina ans, ungolähr gleichzeitig mit der gallica. Fine Gebirganpassumg isl nicht vorhanden, obwohl sie bis $1100 \mathrm{~m}$ in den Zentralalpen ansteigt. Während sie cingen Gegenden des europäischen Mittelneergethetes lehlt, auch in ganz Sïdrusslant, geht sie anch nicht sehr weit in den Norden Europas hinul, charakteristicher Mreise höher in Westen mit seinem mililen Klima, wo sie die britischen Inseln noch bewohnt, aber auch hier nach dem Zeugnisse Bakers in Nonlen Englands viel seltener ist als im süden. ${ }^{1}$ ) Ihre nördliche Grenze sinkt von $52^{00} 33^{\prime \prime}$ in Hannover aul $\therefore 7^{0}$ in Lnginn. Was das rechtspheinische Buyern anlangt, so fehlt sie im bay-

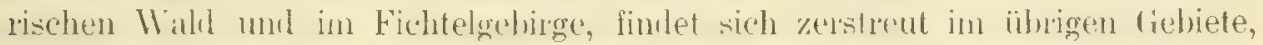
häulig in Frankenjüa besonders der Eichstiller Ciegent und gemein ant der oberen Huchebene, den Vorbergen und den bayrischen Kalkilpen. Die blusse Kalkarmut kann es nicht sein, welche die R. arv. vom bayrischen Wald fern hält, da sie Sand- und Gineisiböden am Meeresstrand und in ren Zentralalpen bewohnt; cher flieht sie stagnierende Fenchtigkeit, tielen Iumus und den lichtlosen Urwald mit seinen enormen Schneemassen im Winter. Sie liebt eben wie die $R$, semperv, das Macchiengebüsch anf warnen, porösem, sonnigem fiandort. - Als nördliche Sippe ist sie wohl vor der Eiszeit in Westeuropa aus der P. semperv. hervorgegangen und, als ihre Chatralre bereils gefestigt waren, weiter nach Norden und nach Osten gewandert. Datsis sie in Sïdbayern und

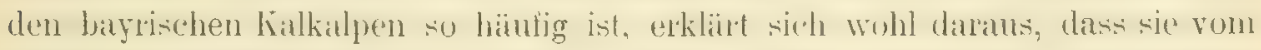
schwablsch-fränkischen Jura her in sneben eistrei geworkene pllanzenleere? Ciebiete rinwandern und sie un so reichlicher beiceldn konnte. Der Böhmerwald

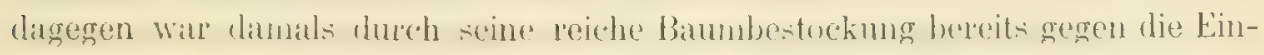
wanderung von Westen her abgesperrt. Die Reise nach dem Süden hat sie

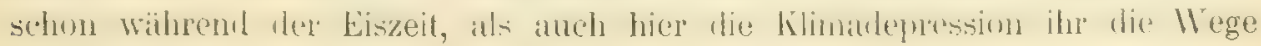

1) J. G. Baker: A monograph of th. brit. ros. p. 242. 
ehnete. angetrelen und so ihrer Stammmutter im Mittelmeergebiet Konkurenz gomatht. Nan fasst gewöhnlich die R. pervens Grenier, dic als arvensis-ïhnliche sempervirens oder als sempervirens-ähnliche arvensis nach ihren ligenschalten sich darstellt, als Bastard arvensis $X$ sempervirens anf. Ihre lincht-

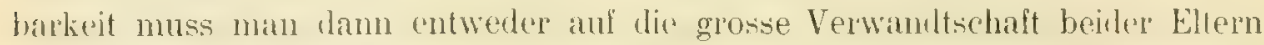
zuriicklïhren oller ähnlich wie bei der Cihrist'schen Auflassung der R. Jundzillii Bess. anf längit erlolgte Stabilisierung und Konsolidierung des aus alten Zeilen stammenten lineruzungsproduktes. ${ }^{1}$, Ist dem aber der Geulanke ganz auszuschliessem, dass in ihr Nachliommen und Zwischenstulen der Entwicklung vom sempervirens zu arvensis uns erhalten geblieben sind? Formen dex R. pervirens beobachtet man besonders hïufig gerade in Südirankreich.

C) Unsere R. gallica stammt aus Westasien, wo sie in Kleinasien, Armenien und in westlichen Transkankasimn häufig ist. Für ihre westasiatische Ileimat

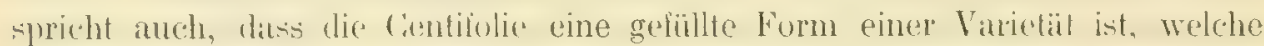
in den Wähdern des öslichen lisukasus rotkommt. Desgleichen stanmt der (iallica-Bastand li. damascena Mill., die "Ölrose" Bulgariens, aus Vorderasien. Der sïdlichen Ilemat entrupechen die Entwicklungszeiten: Blättchen 's Tage, Blüten 9 Tage nach der $R$. canina. Von da wanderte unsere $R$. gall. nach

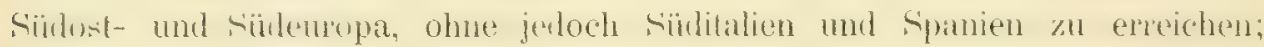
auch im westlichsten und nördlichsten Teile Frankreichs fehlt sie. In Zentraleuropa findet sie sich noch in den Rheinlanden (nicht in Belgien und Gross-

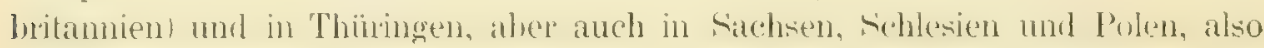
im Osten relativ in höheren Breiten (bei dem kontinentalen Klima!) als im Westen. Das stimmt am besten zu der Annahme, dass sie nach Deutschland in postuliluvialer Zeit ebenlalls von südosten her gelangt ist. Es ist also wohl an lichligsten, die R. gall, als zur "pontischen" Pflanzengruppe gehörig anzu-

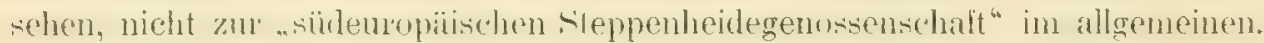

Die R. Jundzillii nähert sich morphologisch, wie wir früher sahen, auf-

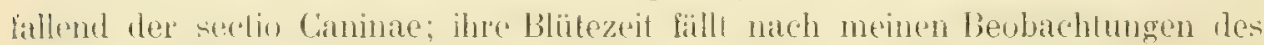

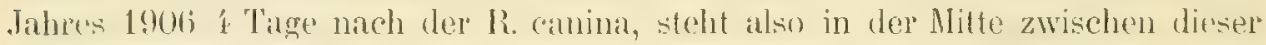
und der noch späteren R. gallica. Auch wenn man die R. Jundzillii für einen Bastard der gallica hail, muss man ihr ein hohes Alter und als Heimat dhenfalls Westasien zuschroiben, wo sit? Amenien und Westranskankasien hewohnt. In Europa besiedell sie mehr dits Zentrum des Kontinents: Sïdrusblant, Osterpeich-Lngarn, Deutschland, Sehweiz, Frankerch. In Deutschland selbst fehll sie dem Vorden und desgleichen dem äussersten Siaden; in Bayern wenigntens ist sie sidulich der Dunau kitum zu finden und anch nicht in Gsten gegen bïhnerwald unel Fichtelgebirge hin, während die R. Gallica lusch las ganze Gobiet vorkommt. Am häufigsten diurfte die R. Jundz. in Unterlanken (Muschellkalk) und in Keupergebet Bayerns sein. Das jetzige Verbreitungsgebiel in Zentralturopa rleckt sirh ziemlich bahgesehen von der jedenlalls esst spätre besiedelten Schweiz) mil dran Lindstreilen, der zwischen der nordischen mul der alpinen Vereisung samt den mumittelbar vorliegenden Ablluss- und Schotteregionen

1) Siehe R. Keller: Syn. S. 43 ff. 
freigthlieben war. Sollte die R. Jumbillii hereits während der Intyten Eiszeit umb unmittelbar am Schlusse derselben, also etwas vor der R. gallica bei uns eingewandert sein? Oder wie ist ihre Verbreitung sonst zu erklären? lch weiss darüber nichts Sicheres zu sagen, wie auch nicht über den Anschluss der R. gall. und Jundz. an andere Rosen. J. G. Baker rechnet in A revised classification of roses" S. 76 auch die R. sancta Richard aus Abessinien zur Sektion der Gallicanae als eine selbständige Art. Nach dem Katalog v. P. Lambert ${ }^{1}$ ) handelt es sich dabei um eine einfach blühende Varietït der R. damascena, also eines Abkömmlings der R. gallica. Sonst käme auch Ostafrika für die Heimat der Gallicanae in Frage.

D) Den Ursprung der sectio Canina müssen wir ebenfalls nach Westasien verlegen, wo die R. canina bereits ihre Abkömmlinge dumetorum, glauca und coriifolia gebildet hatte, oder wo die Urart bereits in die vier Arten R. canina usw, zerfallen war. Denn diese vier Rosen sind alle in Westasien vorhanden, glauca und coriifolia bis Transkaukasien und Armenien. R. canina und dumetorum hesierledn atusserdem ganz Entopat lansgenommen Norwegen nönlich ron $68^{\circ} 13^{\prime}$ und Nordrussland) bis zu einer Meereshöhe von $1600 \mathrm{~m}$ in den Westalpen und dazu Nordafrika, während gl. und cor. in Nordafrika fehlen und in

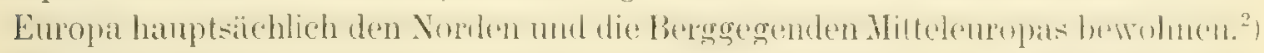

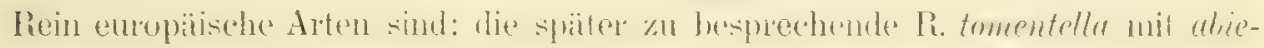

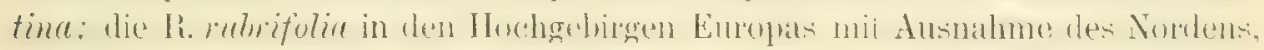
Spaniens und der Inseln (bis $1500 \mathrm{~m}$ in den West-, 950 in den niederösterreichischen Alpen); die R. stylosa Dest in Westeufopa von Grossbritannien

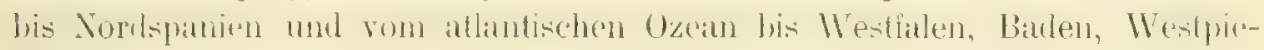
mont; ${ }^{3}$ ) die lokal beschrïnkten alpinen R. rhaetica, Chavini, uriensis; die der glauea nächst verwandte in den Zentral- und Westalpen, aber auch in den

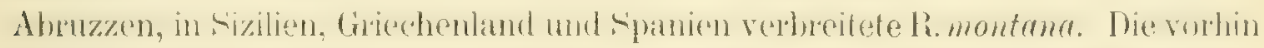
genamnten Riosen entstaniten oflenbar in Enmpa in eince der fiegenvart munitlel-

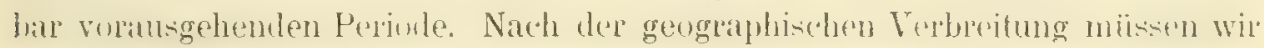
annehmen, dass R. glauca und coriifolia später als canina und dumetorum entstanden und über Zentraleuropa sich verbreiteten, denn sie haben den IVeg

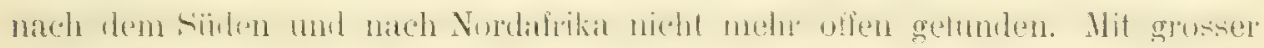
Sicherheit waren die R. canina und dumetorum schon im Jungtertiär in Europa

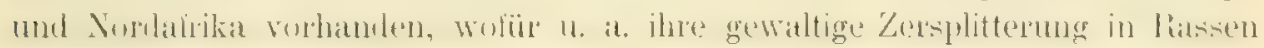

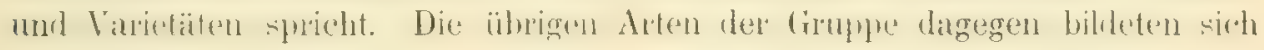

1) Ausgabe 1906 S. 56 .

2) Eine Kontroverse wurde durch die R. Montezumae II. B. et $K$. (= R. mexicana aut.) hervorgerufen, welche in Mexiko schon von $\Lambda$, von Humboldt entdeckt worden war und allgemein zur subsect. Eucaninae gestellt wird, ja zur R. canina selbst, von der sie eine biserrate Varietät darstellt. Nach Crépin (Primit. monogr. ros. lasc. \&. S. 75 sq.) kann es sich lediglich um eine alte Verwilderung der R. canina handeln, die durch die spanischen Eroberer in Mexiko eingeschleppt wurde.

3) Nach meiner Ansicht kann die R. stylosa höchstens zum Range einer subsectio der Caninae erhoben werden; vielleicht würde man sje am besten zwischen $\mathbf{R}$. dumetorum und tomentella stellen. Sehr viele dumetorum zeigen etwas konische Disci, dumet. und tomentella ausserdem oft bez. regelmässig stark verbreiterte Kelchblaltanhängsel. 
aus und wanderten im Diluvium und nach demselben. Die R. stylosa hat sich von dumetorum oder tomentella etwa im Diluvium noch vor der Lostremung der britischen Inseln vom Kontinent abgezweigt.

Ganz merkwürdig ist die Verbreitung der R. glauca und ähnlich coriifolia in Bayern (Analoges scheint in Württemberg der Fall zu sein). R. gl. gehört

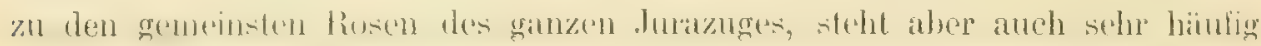

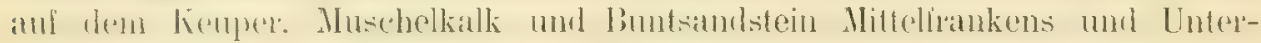
frankens. Gegen den Böhmerwald zu wird sie selten, noch seltener auf der

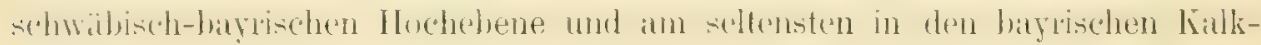
alpen, die allerdings überhaupt äusserst arm an Rosen sind (man vergleiche dimnt die ganz ähnliche Verbreitung der L. Jundzillii). Nur in der Gegend von Mittenwald wurden R. gl. und cor. öfter konstatiert. Für eine montane Rose wie gl. und cor. sollte man das gerade Gegenteil erwarten. Man kommt unwillliülich zur Idee, die beiden Rosen hätten sich wïhrend der Eiszeit von der R. canina abgesondert und auf den grossenteils eisfreien europäischen und dentshen Mittelgebirgen und Hïgenlimblern angesiedelt. Nach dem Diluvium

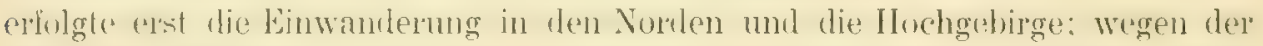

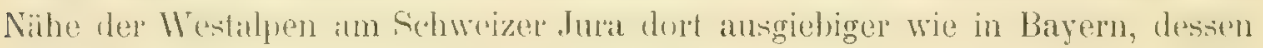
siidlich der Donau gelegener Teil lange wegen der Abschmelzgewiasser mul

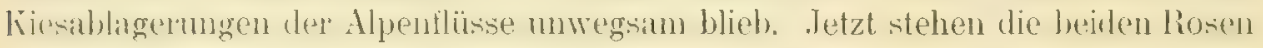
hïulig in Giogenden, deren mildes Kinna dinen gewissen Gegensatz zur ganzen Organisation der montanen Rosen bildet. Infolge desisen weisen sulche Dislrikte (L'nterfanken!) cinem besondern Roichtum an liückschlagshormen zur R. ranina bezw. dumetorum auf, als welche ich die Formen des Kreises der $\mathrm{R}$. subcanina und subcollina auflasse.

Die Arten dumetorum, glauca und coriifolia weichen, wie wir früher nachgewienen haben, von camina dureh hlosse Anpassungsmerkmale ab; glauca und corifolia dureh Anpassung vorwiegend an montants kinat Lnter den iibrigen

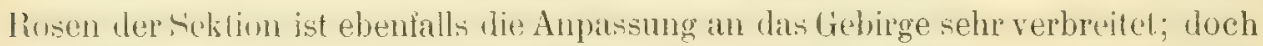
untersherilen anch Sistemmerkmale. Die verwandschaflichen Beziehnngen (recheinen bach allem, wenigstens bei der subsect. Eucaninate, als recht wahe. Dass die R. canina selbst aus einer Heimat mit mildem oder zur Vegetationszuit rechl wamtm, lamg smmigem Klina stammt mol seitclem in wesentichen keine andere Anpassung angenommen hat, ergibt sich alls den relativ späten

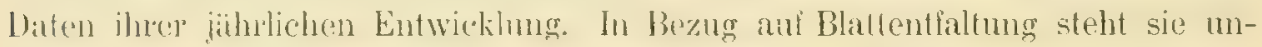
gobihr in dor Milte zwischen don ührigen hosen des Gebietes; das gleiche gilt von der Blütezeit. Ihre Früchte reift sie aber so späl, dass, soweit meine Bowhachungen reichen, bloss die gुewohntiche R. tomentosa mul R. micranthat noch etwas hinter ihr zurückbleiben, und das nicht einmal, wenn man den

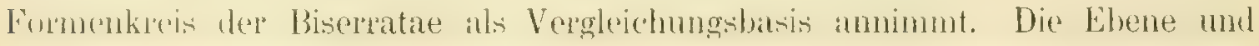
das niedere Hügelland der gemäissigten Zone geben der R. canina zwar nur mittelmässig viel Licht und Wärme, aber lange Zeit, so dass die Frïchte bis

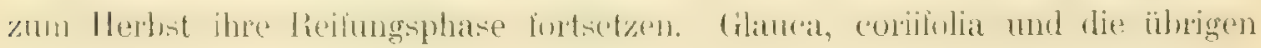
Gebirgsrosen der Gruppe entwickeln sich etwas schneller, da sie sich an die

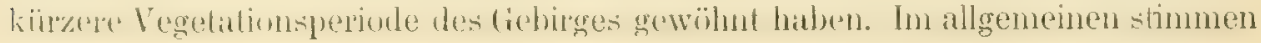




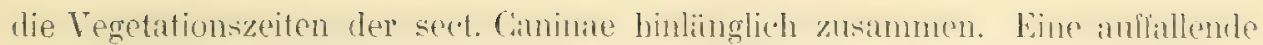
Abweichung ergeben jedoch R. tomentella und dumetomu var. comata m. Beide

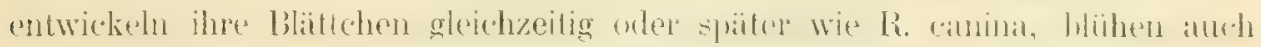
später wie dieselbe ( $R$. tomentella im Durchschnitt zweier Jahre etwa 9 Tage nach can.); ihre Früchte aber alle färbt die var. comata aus bis 7 und die

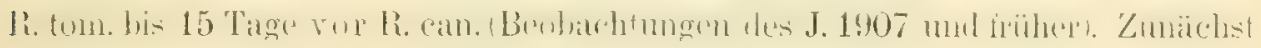
sieht man, dass die var. comata nicht bloss morphologisch, sondem auch physiologisch den Ubergang zur R. Lomentella vermittelt und vielleicht trotz der - ja schwankenden - Meinung Crépins besser zu letzterer als zu R. dumetormm

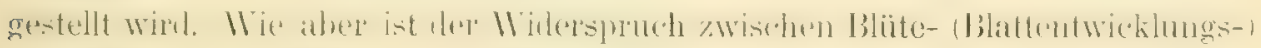
und Reifezeit zu erklären? Die späte Blüte entspricht den Standorten, die R.

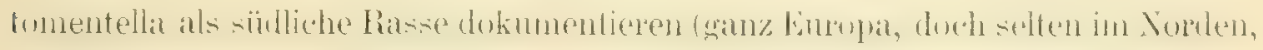
nur mehr im belgischen Flachland - ihre Schwester R. abietina im Berg- und

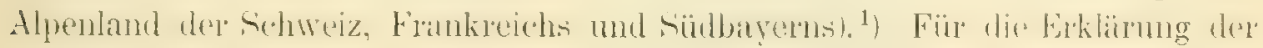
Reifezeit ist man jedoch auf blosse vage Vernutungen angewiesen. Entsland vielleicht die R. tomentella zuerst in einer abietina-ähnlichen Form im Hoch-

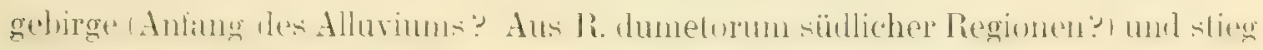

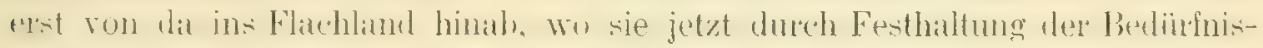

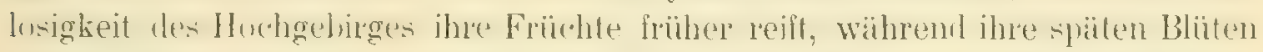

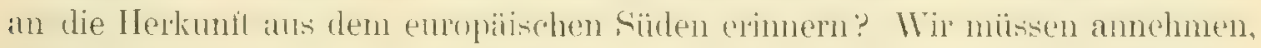
dass die Rosen als zoochore Planzen sehr langsam wandern und da reichlich Zeit haben, Anpassungen zu erwerben und erworbene halb oder ganz umzuprägen, zu verwischen oder zu verstärken.

Wenn wir uns um weitere Anschlitsse der sectio Caninae umsehen, so biefet sich sufort die setel. Indicae Thorg dar, R. giganted (ollet (Oberbirma) und chinensis Jucruin (- imlica L. ex parte) undassend. Morphohgisch stehen sich beide Rusengrupten su nalie, dass baker, dessen Geranteinteilung wir

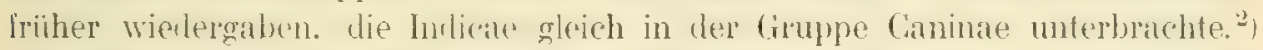
Jedentalls lehrt uns diese nahe Verwandtschall soviel, dass misere Caninen zonannmen nnit den sünlichen Indicate ihre Urheinat im südlichen Zentralasien oder in Südchina zu suchen haben.

E) Falls wir zunächst von Anpassungsmerkmalen absehen und die System-

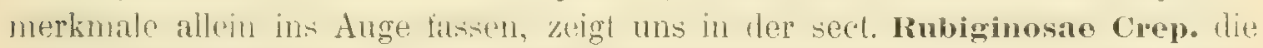

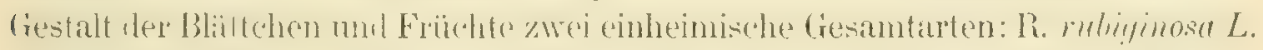

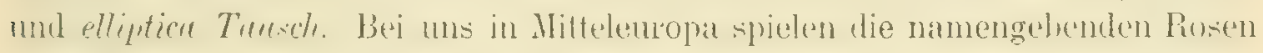
dieser Ge:antidten die Hamprolle: lats wirl jeluch anders. Wenn wir dats ganze

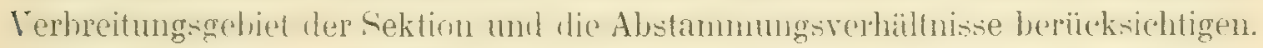

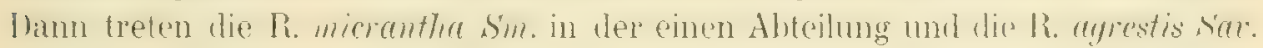
in der andern an die erste Stelle. Die zunächst folgende Tabelle weist auf die

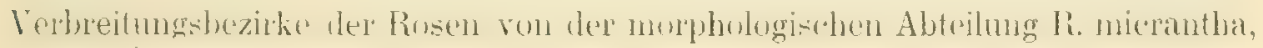
bezw. rubiginosa:

1) Von Hrn. Dr. Kollmam an dem und um den Peissenberg gefunden und zwar in einer neuen Form (siehe „Berichte d. bayr. bot. Ges." XI. Bd. 1907 S. 171).

2) A revis. classification of roses" (Journ. Linn. soc. 1905 p. 76). - Andere Autoren stellen die Indicae zwischen die Synstylae und Caninae. 
\begin{tabular}{l|c} 
& Europa: \\
R. micrantha Sm. & Europa mit Ausnahme
\end{tabular} des Nordens, im Nordwesten bis Schottland; Westalpen bis $1400 \mathrm{~m}$; fehlt im nordwestdeutschen Flachland; selten in Schlesien u. Mähren.

\section{R. glutinosa Silth. et $\mathrm{Sm}$.}

R. ferox $M . B$.
R. sicula Tratt.

R. rutriginosa $L$.

Siebenbürgen, Krim.

Seealpen Italiens und gegenden von Sizilien, Spanien, Griechenland.
Asien:
Kleinasien, Armenien, Kaukasus.
Afrika :
Marokko, Algerien, Tunesien.

Kleinasien, Syrien, Armenien, Kaukasus, Transkaukasien, Persien. Frankreichs; Berg-

Kleinasien, Kaukasus.

Westliches Kleinasien.

Marokko, Algerien.

\section{Mitteleurona, wird sel- ten im Süden iSïdalpen bis $1.400 \mathrm{~m}$ ) und hört auf im Norden; noch in Grossbritannien und Skandinavien, nicht in Mittel-u. Nordrussland.}

Der montane Charabter (weite Diskusöfnumg, subpersistente Kolchziplel, kurze blütenstiele nimmt in dere lieiler von R. micrantha bis gegen R. rubiginusa allmählich zu. Nach der geographischen Verhreitung zu schliessen sind die erstgenannten drei Rosen (h. nice.. glut., fer.), die anch den Niederungscharakter zithnlich ähereinstimmend zeigen, ein I'rodukt Wïmerer Ebenen Vorderasiens. Die li. glutinosia ist am weitesten nach Sïdost, die R. micrantha dagegen am weitesten gegen den IV isten vorgedrungen und hat so nicht bluss das mittlere und siblliche Enropal, sondern atuch Nomdarika okkupiert. Miltelemopa scheint durch sie, jedenfalls vor der Eiszeit (Grossbritannien!), von Südwesten her besiedelt worden zu sein. Die R. sicula hat sich meines Erachtens unter dem Einflus gehirgiger Lmgebung von der R. glutinusa abgezweigt und ist weiter wie diese getemmen, nämlich bis Sinanien und Marokko. I'nsere R. rubiginusia alex' muss eine Tuchler der micrantha sein, erzengt noch ror der Fiszeit im milteleuroprischen Bergland umd ihre Mutter im Nomden unsares Kontinents äberholem. Die R. rubig. ist weitaus die gemeinste der Arten ihrer Sektion im mittleren Europal, so auch in Bayern, wo sie nirgendwo fehlt. Die R. micrantha findet sich in Bayern recht selten, noch am häuligsten im Gebiete des fränkischen Jura, besonlers der Altmïhlalb. Kwischembrmen zwischen rubig, und nicr. existieren hïufig genug (von mir in ler subspec. colmmifera zusammengelasst). Unsere

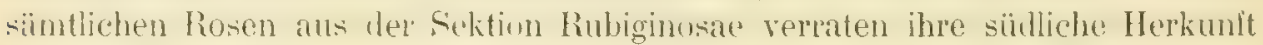

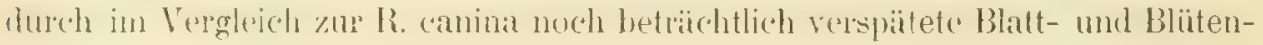
entwicklung (a. Blatt: R. rub. +1 ; micr. $+1,5$; ellipt. im Mittel +5 ; agrestis im Mittel + 5. b. Blüte: rub. $+3,5$; micr. +3 ; ellipt. +8 ; agr. +14 ). Bei der Fruchtreile ïberholt die R. rubig. als montane form die R. canina ( 7), während die micr. hinter iłn zurïckbleibt $(+5)$. Der beträchtliche linterschied bezïglich

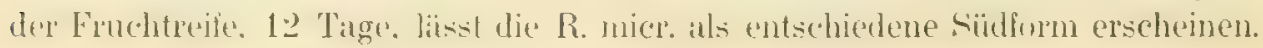


Die geographische Verbreitung der näheren Verwandten von R. agrestis Sav. wird im folgenden ersichtlich:

R. agrestis Sar:

R. Serafini Vix:

R. caryophyllacea Bess.

R. elliptica Tausch.

$$
\text { Europa: }
$$

Ahnlich wie micrantha. aber weniger weit gegen Norden; selten in Dänemark und Schweden: fehlt in Nordwestdeutschland u. in Grossbritannien (Westalpen bis $1300 \mathrm{~m}$ ).

Italien mit Korsika, Sardinien und Sizilien; Rumelien.

Niederösterreich,UngarnKroatien; Westrussland.

Bergregion Mitteleuropas (Westalpen bis $2000 \mathrm{~m}$ ); Osten Englands u. Frankreichs.

\author{
Asien: | Airika: \\ vacat | Marokko, Algerien, \\ Tunesien.
}

vacat

vacal

vacal

Von diesen Rosen sind Serafini und caryophyllacea südosteuropäische 'Zwischenformen zwischen agrestis und elliptica, aber mehr vom Charakter der agrestis, die ron der letzteren auf ihrer Wanderung sich abgetrennt haben. Agrestis und elliptica können direkt ans cinander entstanden sein, da sie einander ausserordentlich ähroh, vicle Zwischenformen bilden (subspecies inndora) und sich iberhaupt zu einander nur verhalten wie die Anpassungsform der Ebene zu der des Mittelgebirges. Agrestis aber ist die ältere Rose mit der ausgedehnteren Verbreitung. Sie hat wohl ron Europa aus im Tertiä Norlafrika erobert. Zugleich besiedelt agrestis mehr den süuden, elliptica mehr den Norden von Europa. Auch ellipt. entstand schon vor der Eiszeit, weil sie noch in Ostengland vorkommt. Ich wage kaum als Vermutung zu äussern, dass die arrestis selbst ron der R. micrantha ausgegangen sei. Im Formenkreis dieser letzleren Rise kommen keilige Blattchen schon bisweilen vor, auch pflegen die Blattchen der micr. ïberhaupt mehr oval uni weniger rundlich zu sein wie diejenigen del rubiginosa. Die Heterakanthie trilt gleicherweise bei agrestis und micrantha höchst selten aut. Beide haben durch schlaffen Wuchs, zurückgeschlagene lielchzipfel, kahle hervorragende Griffel die Anpassung an das Klima der Tiefregion allsgeprägt. Agrestis zählt in Bayern nichl viel mehr Standorte als micrantha. Anch sie besiedelt vorwiegend den Frankenjura und strahlt von da über den hruper bis gegen die Muschelkalkregion Interfrankens aus; und zwar ist es ausschliesslich die var. pulsescens $f a p$. mit ihren vielen Formen. Eine andere Varietiil wurde kaum gehuden. ${ }^{1}$ ) In Bayern und in ganz Dentschland hat die R. elliptica cine grössere Zahl von Sitandorten epobert. Nit der R. tomentella (und der var. comata m. (ler R. dumetorum) teilt die Rose agrestis, wenigstens

1) Ich habe zwar im systematischen Teil eine f. arvatica $P u g$. der var. typica $R$. Kell. vom Altmähltal b. Kinding angeseben. Alein auch diese trïgt nahe Bezichungen zur var. pubescens zur Srhau. - Reicher entwichelt ist die R. arrestis vor allem in Ostereich-Lugarn und Siideuropa. 
unsere var. pubescens, die schwer zu verstehende Eigentümlichkeit, dass sie

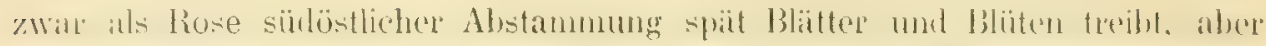

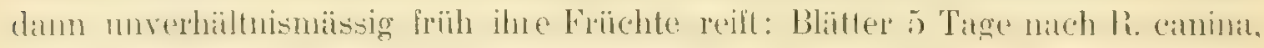
Blüten 14 Trge, Früchte jedoch im Durchschnitt 15 Tage vor del Ilundorose! Sie hat also eine sehr abgekïrzte Vegetationsperionle. Ith kimm

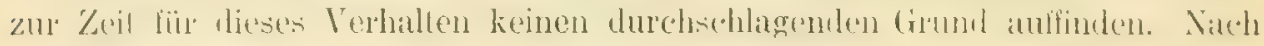

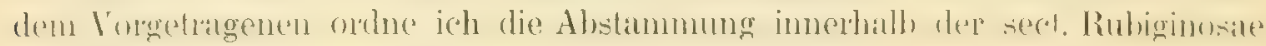
wie folgt:

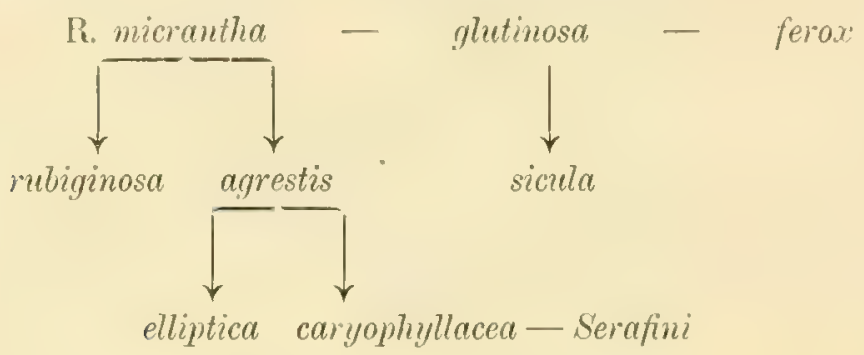

F) Für die Sektion Vestitae Chr. kommen als Arten nach dem früher (iesagten ${ }^{1}$ ) lediglich R. pomifera Herm. und R. fomentose sim. in Betracht. Crepin steflt versuchsweise die R. Hecleliuna Tratt. hieher, zu seiner subsect. Tumentusite. $\left.{ }^{2}\right)$ Diese sïdeuropäische Art ILnteritalien, vizilien. Griechenland mit extremer Anpassung an frockenstes Höhenklina ist jedoch ungeniegend bekamut, und da sie nach der ganzen beschaffenheit ihres. Sprosses anch Verwandtschaft nit den Rubiginosae, vielleicht der li. sicula, verü̈t, wollen wir sie unberïcksichtigt lassen. R. pomifera und tomentosa besiedeln Vorderasien: die exsgemante Anatolien, Amenien, den Kankasus und Transkankasien, in der Varietät oder Unterart R. mollis angeblich auch Kurdistan und Persien; die letatgenaunte hat einen kleineren Verthreitungskreis, inden sie sich ant das östliche Kleouasien und das liaukasusgebiet beschü̈nkt. In Europa lrewohnt die R. pomifera fast alle Hoch- und Mittelgebirge Europas mit Ausnahme des äussersten siidens bis zu einer Mereshöhe von $2000 \mathrm{~m}$; auch das noreldentsche Flachland. West- und Tïdrussland. In Norden und Nurdwesten Lumpas tritt sie romiegend in die Form der $R$. mollis aul; so in belgien, Grossbritannien, Skindinavien. Die Lnterart omedsa lehlt nicht dem miltel- und nordenropaisechen Hochgelirge, geht aber anch tiefer jns Hügolland herah, z. B. in Baycrn, Thüringen, Sachsen, Posen, Zentralfrankreich. R. tomentosa fehlt nur in den südlichsten Regionen Europas. Der Formenkreis der R. jomifera umfasst lauter

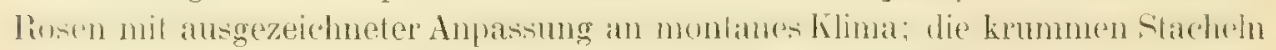

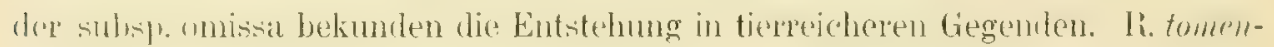
tosa ist eine Rose tieferer Regionen, weist aber in der subsp. scabriuscula

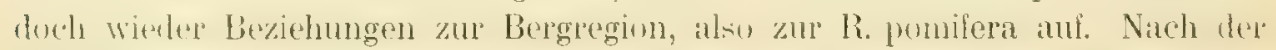
gongraphischen Verheitung wird anch diesmal Vorderasien als Ileimal her

1) S. 6it f.

2) Tabl. analyt. p. 27. - Baker (A revis, classification of roses p. 78) führt die $\mathrm{R}$. Heck. chenfalls bei den "Villosae" (= Vestitae) auf, stellt sie aber unmiltelbar vor die Rubiginosae. 
Sektion anzusprechen sein, die schon dort in ihre Hauptarten auseinandergefallen war. Die Wanderung erlolgte wohl über den Kaukasus und Sïdrussland nach dem zentralen und westlichen Europa und zwar schon vor der Eiszeit, da Grossbritannien von der Sektion noch erreicht worden ist. Skandinavien freilich wird nach der Eiszeit wieder von Süden und Südosten her besiedelt worden sein. Die Verbreitung der subsp. scabriuscula in Bayem deutet an, dass dieser Formenkreis während der Eiszeit in den rom Eise frei-

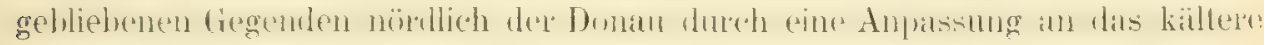
Klima dieser Epoche entstund oder doch festen Fuss fasste. Bayern sudlich der Donau zeigt viel sellener Rosen dieser Unterart. Aber auch die R. pomifera

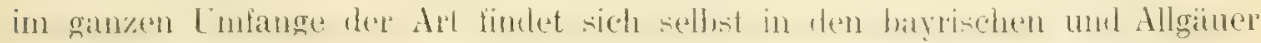

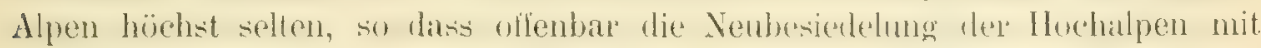

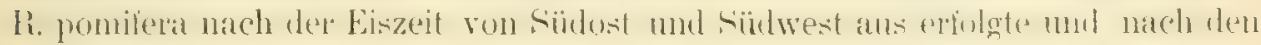
Nordketten der Ostalpen nicht mehr genïgend durchdrang.

Die Zeiten der Blatt-, Bliiten- und Fruchtentwicklung kennzeichnen R. pomifera und subsp. scabriuscula der tomentosa als Gebirgsformen: frühes Aublïhen und fribzeitige Fruchtreile. Die R. pomifelat hat dagegen bei Eichstätt ihre Blätter i. J. 1908 recht spät ausgetrieben (7 Tage nach R. canina). Es ist wohl anf eine solch einzelne beobuchlumg winer verwilderten liose biann etwas zu geben; würde das jedoch allgemein bei R. pomifera stattfinden, so wïre es vielleicht als Reminiszenz an die siidliche Bergheimat zu erklären. R. tomentosa - ohne den Formenkreis scabriuscula - beginnt ihre Blütezeit im Durchschnitt zweier Jahre ca. 8 Tage nach der R. canina und zeigt reife

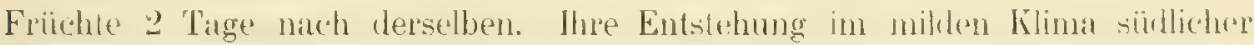
Ebenen mit langer Vegetationsperiode ist also in ihren phänologivehen Chatrakter gut ausgeprägt. Ich halte fïr interessant, auch hier noch einmal dataul hinzuweisen, dass mehrere von mir beobachtete Formen der subsp. scabr., die von allen Autoren zur R. tomentosa gezïhlt, alser nicht als Linterat abgegrouzt werden, im Durchschnitt 15 Tage vor den äbrigen Formen dex tonsentusia hïhen und 11 Tage vor denselben ihre Frïchte ausgefïrbt haben. Das spricht doch sehr für eine Abtrennung des fraglichen Formenkreises.

Wir haben im Vorstehenden angenommen, dass die europäischen - und damit auch die deutschen - Rosen aus Asien einwanderten, soweit sie nicht in unserem Kontinente selbst von asiatischen Linien sich abzweigten. Diese

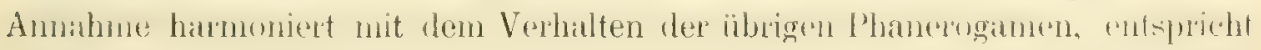
dem viel grösseren Areal, welches Rosen unserer europäischen Sektionen in Asien einnehmen, und auch der Art und Weise, wie die Rosen wandern. Sie sind ausgeprägt zoochor, d. h. sie werden in der Natur durch Tiere verbreitet, welche die Hagebutten fressen und die Niisschen mil ihren Diunger anf ilnen Wanderungen ausstreuen. So scheint die Verbreitung wenigstens der Rosen

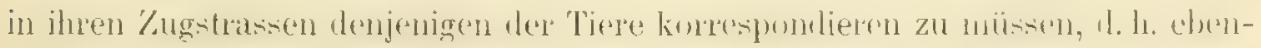
falls aut eine asjatische Urbeimat zu deuten. Nebenbei konstatieren wir, dass also die Rosen nur sehr langsam wandern können, da ihnen die Verbreitung

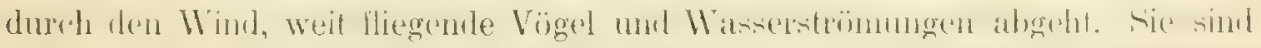

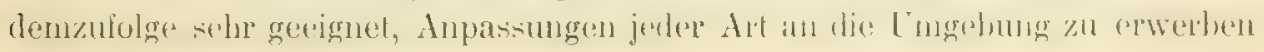


und erworbene zu mulitizieren. Ihre Polymorphie hängt offenbar anch mit diesem Umstande zusammen.

Die geographische Verbroitung der hosen zeigh uns zwei grosise Zugstrassen, auf welchen die Einwanderung in Europa erfolgte: von Nordosten her, aus dep Altagegend, kimen die Sektimen Cinnammeae und Spinosissimat alle ïhrigen vertneiteten sich von ciudosten her, etwa ans Persien oder Armenien, ïber Vorderasien und die Balkanhalbinsel in unsere hegionen. Zwei besunders widhlige Sektimen, die sect. Synstylate und die seet. Caninae diese durch ilne Vruwandts(haft mit der R. indica), dazu die sect. Spinosissinae, ${ }^{1}$ ) zeigen nuch elwas weiter, nämlich gegen das mittlere und südliche China. Da man mit

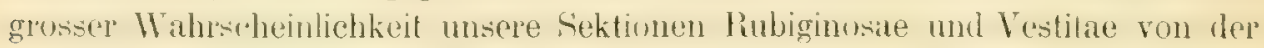
sect. Caninae abzuleiten hat, gelangt man für die Rosen zu einem Zentrum, welches Christ überhaupt als das wichtigste der eurasiatischen Floria erklärt, mämlich: das siabwestliche (:hina. $\left.{ }^{2}\right)$ Selbst die scheinbar so unabhängige und rexche Planzenwelt Japans stellt sich nur als ein kimmerlicher Ableger der Flora Südchinas dar. Und gar erst die europäischen Familien und Gattungen! Es ist die Regel, dass sie in siudwestlichen Chna nit einem Reichtum an Arten anftreten, der die Zahl der europäischen um ein Viellaches übertrifit und dort, im Herzen Asiens, die wahre Heimat aller dieser Sippen vermuten lässt. Davon macht eine gewisse Ausnahme lediglich die Mittelmeerflora im

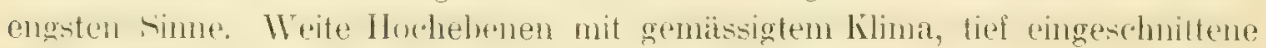

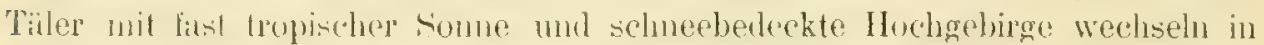

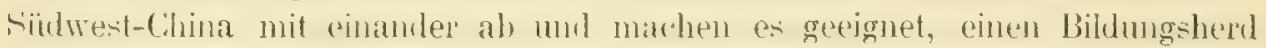
der Planzenwelt abzugeben. Von da füht die eine Verbreitungshinie längs der südseite des Himalaya über Persien. die andere ïber die zentralasiatischen Gebirgsketten und den Altai nach Sibirien und Europa. Die afrikanischen Rusen haben sich ron der ersten Linie oder ron eurupäischen vtïmmen abgezweigt; die anerikanischen werden direkt ron China übor dic Mandschntei nach Alaschka gelangh sein, ofler sie haben teilweise zunächst die sibirische Linie eingeschlagen.

In der folgonden Tabelle nit den zugehörigen Anmerkungen rersuche ich fiir das rechtsheinische Bayern und speziell den Frankenjura die Hege anzugeben, aut denen sich die Einwanderung der vorhandenen Rosenarten vollzog, und die Koit (geologisch), in welcher dieses geschah. Die Angaben erfolgen summarisch auf Cirund des fröher erörterten Iateriales und haben selbstrerstïndlich nur grössere oder geringere Wahrscheinlichkeit für sich. ${ }^{3}$ )

1) Wie ihre Verbreilung zeigt, haben die R. pimpinellifolia und xanthina von China aus sowohl nach Südost als nach Norden und Nordost sich gewandt.

2) H. Christ: La flore de la Suisse et ses origines. Ed. française. Bale, 1907. Supplément p. 73 sqq.

3) Vgl, zu dieser Tabelle die allgemeinen Angaben bei H. Dingler: ,Versuch einer Erklärung" usw. S. 33-36. Auf Grund ganz anderer Erwägungen bin ich vielfach zu den gleichen liesultafon gekommen. Doch lege ich kein so grosses Gewicht auf die son. Berurosen und wlaube insbesundere, dass wihrend der Eiszeit in den eisfrei geblichenen I)istrikten Mitteleuropas, z. I3. des Frankenjura, die Rosenflora nicht ausstarb, im Gegenteil zur Artenbildung angeregt wurde. 
Art:

Richtung des Einzuges:

R. cimnamomea . . . Von Norden's)

pendulina. . . . . Osten²)

pimpinellifolia... . "Norden

arrensis . . . . . Westen

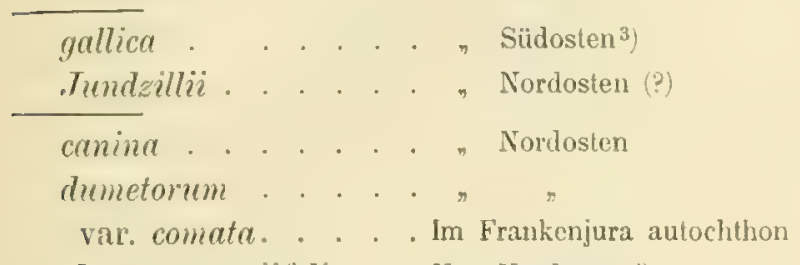

glauca u. coriifolia . . Von Nordosten ${ }^{*}$ )

tomentella. . . . . . , Südwesten

abietina. . . . . . 7 ,

mbrifolia.... $n \quad n$ der Alpen ${ }^{6}$ )

micrantha. . . . . , Südosten und Nordosten

rubiginosa. . . . . "Norden

agrestis . . . . . . . Südosten und Nordosten

elliptica. . . . . . , Norilen

pomifera . . . . , Südwesten der Alpen ${ }^{7}$

subsp. omissa. . . Norden

tomentosa . . . . n Südosten und Nordosten

subsp. scabriuscula. . In Mitteldeutschl. autochthon. ${ }^{8}$ )
Zeit des Einzuges:

Anfang Eiszeit

Ende Eiszeil

Diluvium

Anfang Eiszeit

Nachdiluviale Steppenzeit

Eiszeit (?)

Ende Tertiär

Eiszeit

Nach der Eiszeil

Ende Tertiär

Anfang Eiszeit

Ende Tertiär

Anfang Eiszeit

Ende Eiszeit

Eiszeit

Ende Tertiär

Eiszeit.

1) Diese Rose hat sich nach der Eiszeit in die höheren Gebirge (Alpen, Böhmerwald) und deren Vorland zurückgezogen. Die Standorte des Frankenjura stehen mit denen der bayr. Hochebene in Verbindung.

2) Unmittelbar von den Ostalpen und dem Böhmerwald aus, mittelbar von den Karpathen. Ist als Relikt noch häufig im Alpenvorlande (Peissenberg usw.) und sehr selten im Frankenjura (Laaber) und in der Rhön zu finden, häufiger im Schwabenjura.

3) Auch für die Schweiz wird angenommen, dass die R. gall. mit Rhamnus saxatilis und anderen Pllanzen von Nordosten her, von l'annonien, durch das Donautal gekommen sind. Für die Schweizer xerothermische Flora waren die Zufuhrstrassen entweder das Donautal oder die Linie von Südirankreich her am Ostfuss des Jura entlang (H. Christ: La flore de la Suisse, suppl. p. 35 u. 36 ).

4) Die Zentral- und Westalpen wurden nach der Eiszeit von diesen beiden Rosen aus dem Süden und Westen besetzt. Durch die Senken im Kammverlauf der bayr. Alpen (Fernpass, Scharnitz, Inntal) drangen einige Kolonien nach dem südbayr. Alpenvorlande durch (z. B. bei Mittenwald). Im allgemeinen wurde jedoch Südbayern nach der Eiszeit mit diesen und anderen Rosen von Norden aus besiedelt, und darum nimmt der Reichtum an Rosen, auch montanen, gegen Bayerns Süden vielfach bis zum Verschwinden ab.

5) Von der Schweiz her. So erklären sich am besten die Standorte um den Peissenberg.

-) Desgleichen. Im Mittel- und Ostzug der bayr. Alpen ist diese Rose gar nicht mehr zu finden, während sie z. B. in Südtirol (Radein!) oft massenhaft auftritt.

$\left.{ }^{7}\right)$ Wie vorhin. Die R. pomilera ist gemein in den westlichen Zentralalpen, ganz sporadisch im Allgäu, dann fehlend.

- Rosen dieser Gruppe überwiegen in den drei fränkischen Kreisen und in Thüringen woit die anderen tomentosa-Formen; in Südbayern ist es umgekehrt. 
Das rechtsheinische Bayern zerfïlt in zwei rücksichtlich der Pflanzenwanderungen im Tertiär und Guartu scharfgetremule Regionen: Batyern nördlich und Bayern südlich der Donaulinie. Der Norden war spätestens seit dem

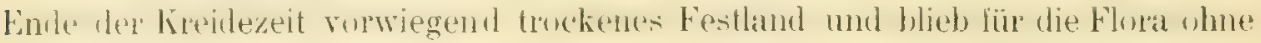
wesentliche Lnterbrechung bis zur Gegenwart bewolnbatr. Sïdbayern war noch

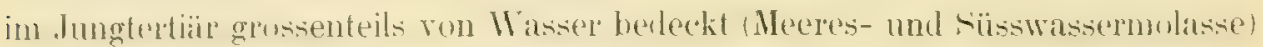
und wurde in der Eiszeit eine wohl nur gegen die Donau zu stellenweise unterbrochene Pflanzenwiiste. Bis in die Breite von München reichten die Giletsher: von da ab verherten die Gegend die Masser- und Geroilziige. Welche an der Gletscherstirn entsprangen. So musste wohl in der auf die Eiszeit folgenden Periode das ganze Land südlich der jetzt erst im modernen Sinn existierenden Donau durch Einwanderung neu besiedelt werden. Einzelne alquine oder montane Arten von Rosen drangen vom Süden, durch das Inntal und andere Passeinschartungen, sürich ins bayrische Alpenland ein; ${ }^{1}$ ) andere von Westen und Südwesten. Im allgemeinen wurde der von Eis, Wasser und

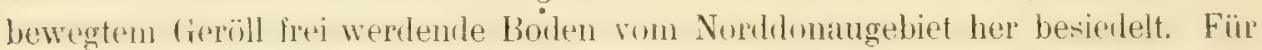
manche Rusen war dieses Neuland äbeshanpt ungïnstig; lïr alle übrigen wal die

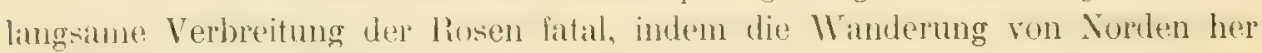
allmählich durch die Ifaldbedeckung verhindert wurde. Lnd so verstehen wir die Armut des schwäbisch-baypischen Ilochelvene an Rosen. die nit der Anü̈herung ans Gehirge immer mehr zunimmt. Figentlich alpine Formen. wie R. Pubrilolia und ponifera, lehlten nördich der Donau und wanderten höchstens vom benachbarten Alpengebiet ein, aber nur bis an die (irenze Bayerns; manche wie $R$. montana, miensis u. dgl. kamen gar nicht his zum Allgiu, geschweige denn weiter.

Das bayrische Norddonauland, insbesondere der für Rosen so günstige Frankenjura und das unterhänkisch-thïringische Muschelkalkgebiet, sind sicherlich seit dem Jungteptiär durch die ganze Ëizeit hindurch ein Vaterland und Entwicklungsherd der Rosen gehlieben, wite dies anch Christ schon in seinen „Rosen der s'chweiz“" $\left.{ }^{2}\right)$ lür den doch höheren Sichweizer Jura annimmt. Gegenwiirtig lailit im bayrischen Jura und Muschelkalkgebiete die bunte Jischung von

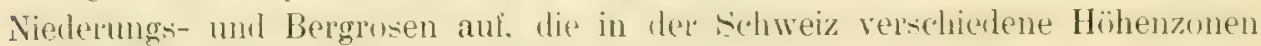
bewohnen. Die R. glanea wächst bei uns neben der R. canina, die elliptica neben der agrestis; R. cimmanemea, arvensis, gallical, Jundzillii, pimpinedlifolia

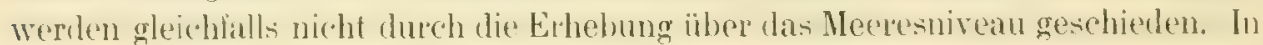
nnserm nierleren Hägelland $(300-600 \mathrm{~m})$ haben lediglich edaphische Ernährungsund Belichlungstaktoren eine gewisse Belentumg. Diese T)urcheinanderwiufelung von Pilanzengenossenschaften heluht wohl auf den Kilimaverinderungen. die seit dem Tertiär eingetreten sind. Formen der Ebene und des warmen Südwatens werden zunichst sich angesiedelt haben; dam wurde das kima in der Eiszeit rauhte und auch tiir die Einwanderung aler Erzengung ron Bergrosen gevigut. Hernach wurde ts wieder trockener mul milder. Weil aber die Kima-

1) Auf diese Zugangsstrasse nach der Eiszeit macht besonders aufmerksam Christ in „Flore d. 1. Suisse", suppl. p. 23. Er führt den Reichtum der östlichen (österreichischen) Kalkalpen

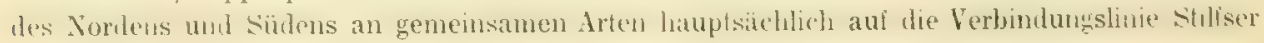
Joch - Unterengadin - Inntal zurück.

$2,57-11$. 


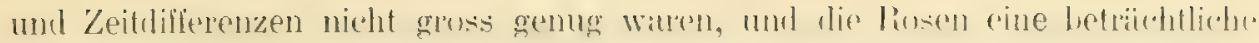

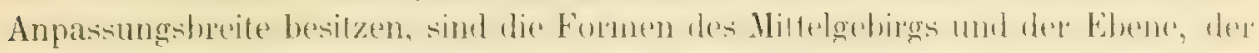
feuchten und trockenen Luft im gleichen Lande halten geblieben und haben

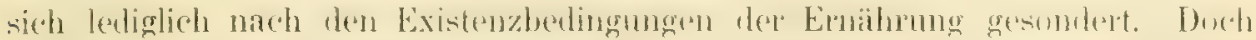

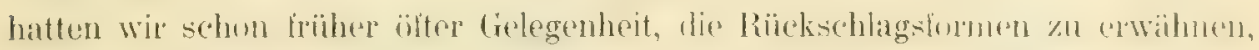

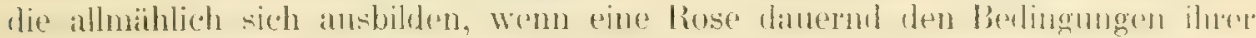
ersten Entstehung entzogen wird. So erklirt sich die subsp. subcanina und

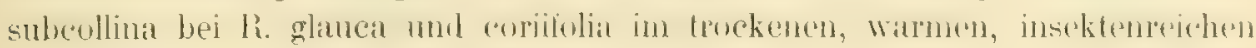
Hügellande; so neigen hinwieder die $\mathrm{R}$. canina und tomentella in rauheren Lagen und nassen Jahren zur Ausbildung von Früchten mit subpersistenten

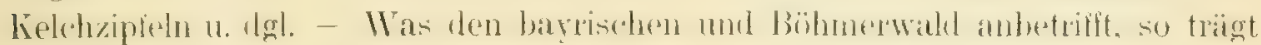

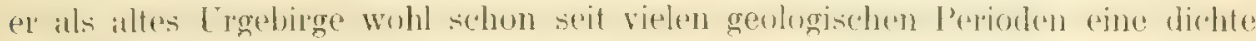

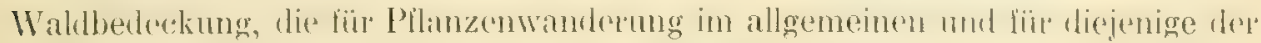

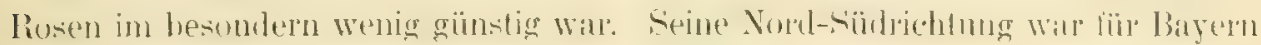
gewiss ein ganz spezielles Ilindernis für die Ausbreitung südosteuropäischer

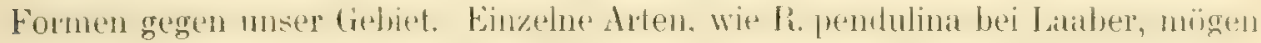
jedoch mit dem bayrischen Wald in lokaler Beziehung stehen.

In der Konsequenz aller bisherigen Erörterungen habe ich mir die in der umstehemlen thersicht dargelegle Meinung binsichtlich der verwandischattlichen

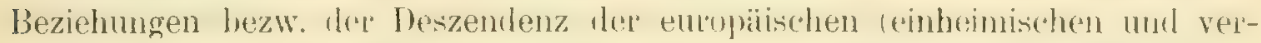
widerten) Rosen innerhatb jeder Sektion gehildet. Die wagrechlen Abstammungs-

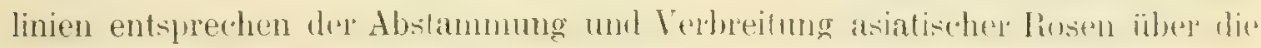

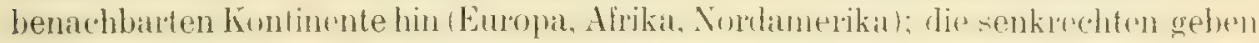

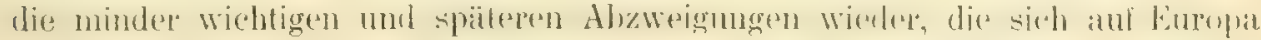
beschränkten. Ein Pfeil ohne Feder $(\longrightarrow)$, der die Abstammung markiert, benlentet, dass nach meine' Ansidat die betreflende Ruse vorwiegend dureh eine

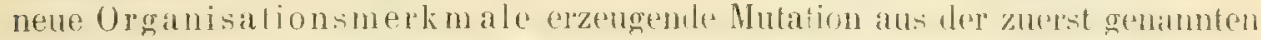
hervorging: ein Pleil mit Feder $\longrightarrow$ ) bedeutel eine verändorte Anpassung als erzengente Ursache. Den drten mit zurückgeschlagenen helchzipfoln und enger

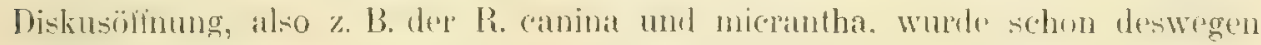
grössere Bedentung und höheres Alter eingeräumt, weil sie im liegensatz zu den Parallelformen mit persistenten Kelchzipeln der pllamenfremullichen wamen Ebene, der Urheimat der Flora, entsprechen.

Anschliessend versinnlicht das Schema: „Die Deszendenz der Gattung Rosa" mane Ausicht über den Kasammenhang der Sektionen, welche man in dieser Gattung unterscheidet. Ich habe nich im allgemeinen an die Einteilumg Bakers in "A revised classilikation of roses" (1905) gehalten, aber auch die

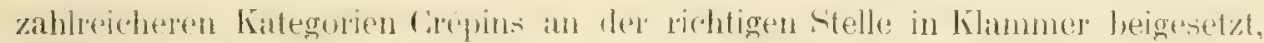
z. B. Cinnamomeae (incl. Carolinae et Sericeae). Die Kreise mit I und II be-

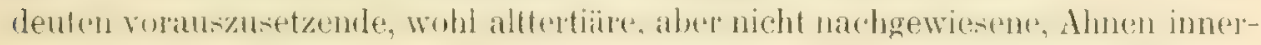
halb der Entwicklungsreihe. Ich leite also nicht von einer lebenden Sektion, etwa Cinnamomeae (Parmentier!) die übrigen Sektionen und Arien ab. Die

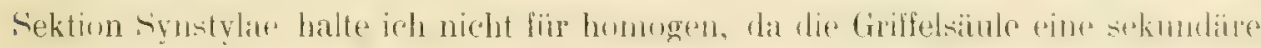

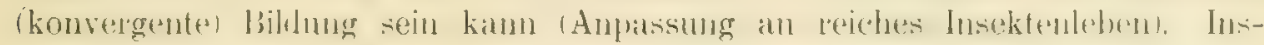

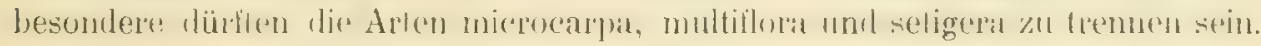


Die Deszendenz der europäischen Rosen:

Sect. Cinnamomeae $\left\{\begin{array}{l}\mathrm{R} \text {. acicularis } \longrightarrow \mathrm{R} \text {. blanda } \\ \longrightarrow \mathrm{R} \text {. cimnamomea }\end{array}\right.$

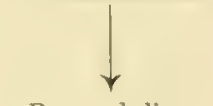

Sect. Spinosissima $\left\{\begin{array}{l}\mathrm{R}, \text { pimpinellifolia } \\ \mathrm{R}, \text { lutea }\end{array}\right.$

Sect. Synstylae $\left\{\begin{array}{l}\text { R. phoenicea } \\ \text { R. moschata } \longrightarrow \text { R. sempervirens }\end{array}\right.$

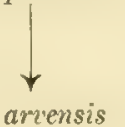

R. ariensis

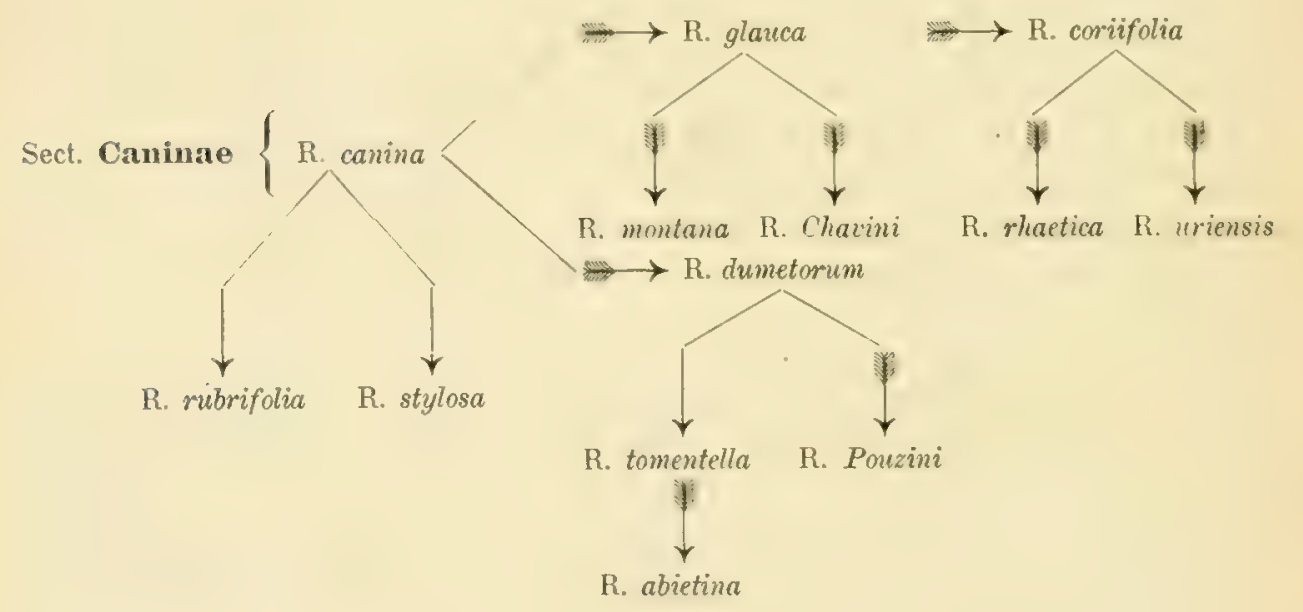

Sect. Rubiginosae $\left\{\begin{array}{l}\text { R. ferox } \\ \text { R. glutinosa } \rightarrow-\longrightarrow \text { R. sicula } \\ \text { R. micrantha } \longrightarrow \text { R. agrestis }\end{array}\right.$

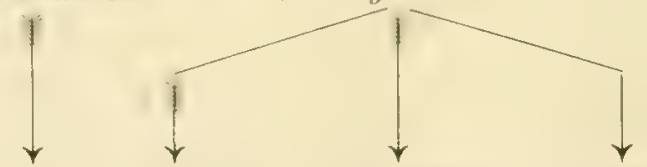

R. rubiginosa R. elliptica R. caryophyllacea R. Serafini

Sect. Vestitae $\{$ R. tomentosa $\longrightarrow$ R. pomifera

Sect. Gallicas $\left\{\begin{array}{l}\text { R. gallica } \\ \text { R. Jundzillii }\end{array}\right.$ 
Die Deszendenz der Gattung Rosa:

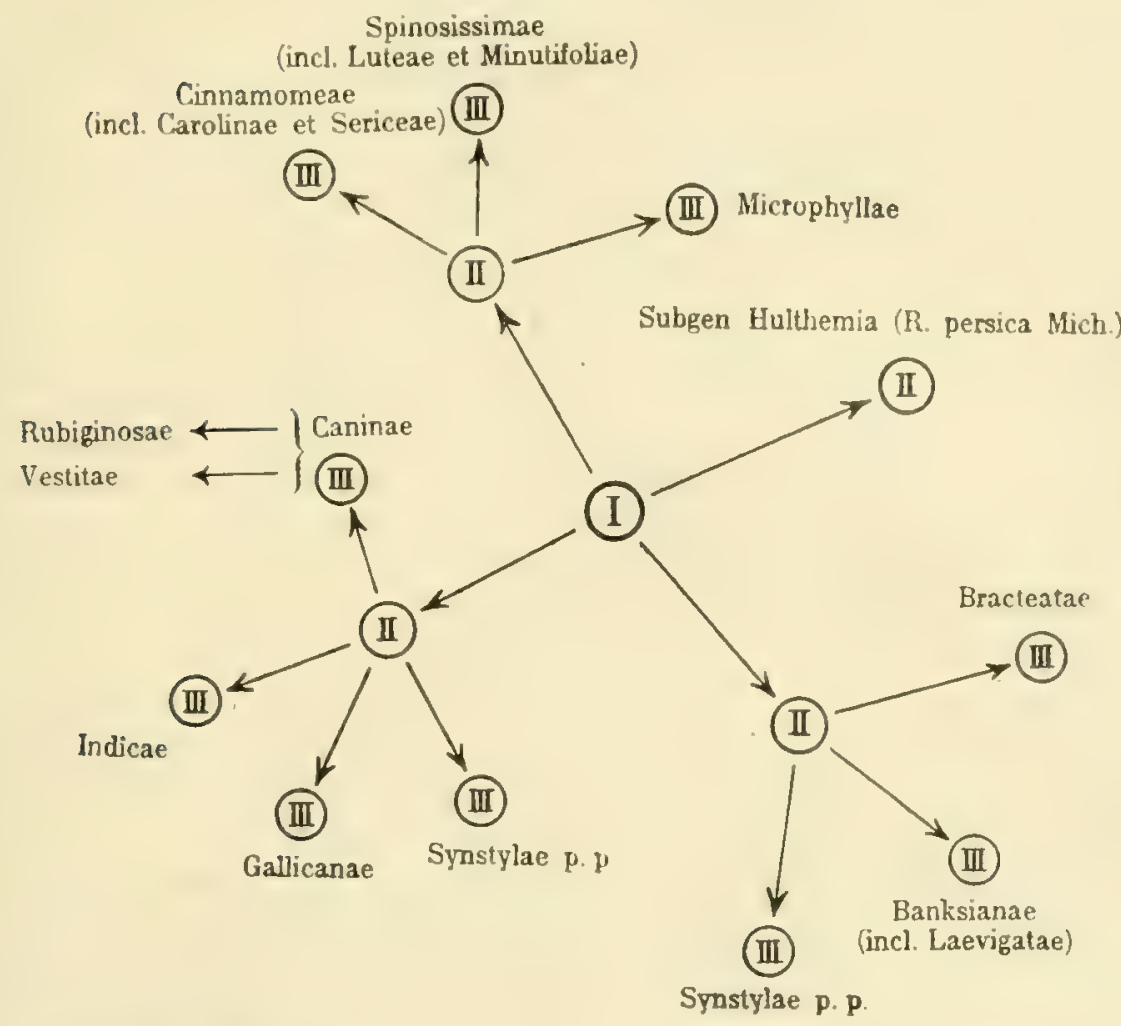

(Schluss von Seite 227)

Die ersten beiden knïplen wegen der Bildung ihrer Nebenblätter u. a. bei den Banksiae und Bracteitae an. Duch schliesst der engere Zweck meiner Arbeit rlie eigentliche Diskussion über diesen Punkt und das Gesamtsystem der Rosen aus. Ich wollte dieses Kapitel durch die Vorführung ubigen Stammbaumes zu einem formellen Abschluss' bringen. Die Erforschung der nichteuropäischen Rosen erlaubt durchaus noch kein endgiltiges Urteil.

\section{Kapitel: Ausblicke auf das allgemeine Deszendenzproblem.}

In diesen letzten Kapitel wollen wir nicht etwa das heikle P'roblen der allgemeinen Abstammungslehre a priori erörtern und zu einem wenigstens hyputhetischen Abschlusse bringen, sondern in Auswahl nud mehr indukliv gewise Folgerungen zichen und einge Sitze kunstatieren, die sich ans unserer nun

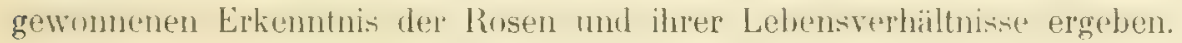

Ich habe schon früher mit Nägeli, Göbel und anderen teils botanischen teils zoologischen Autoren bei den Ptlanzen im allgemeinen und den finsen im hesondern die morphologisch-bistologischen Eigenschalten in Oromisations(System-) und Anpassungsmerkmale abgeteilt. Sorlinn wudun dir Faktoren besprochen und nach ihree Wirksankeit analysiert, welche die Anpassungen der 
Rosen hervorzurufen scheinen. Nach meiner Ansicht überwiegt direkte An-

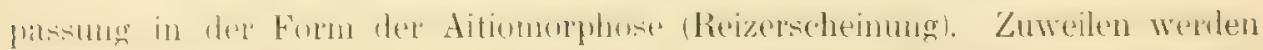

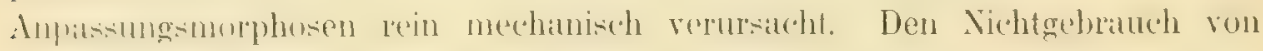

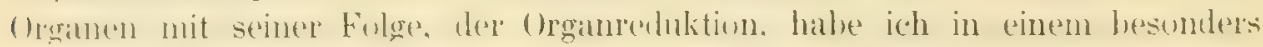

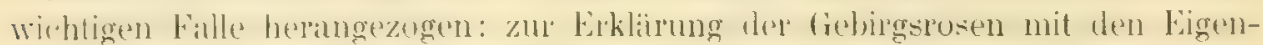
tiimlichleiten ihrer lielchbiltung. Ënmal nahm ich anch imere Anpassung an.

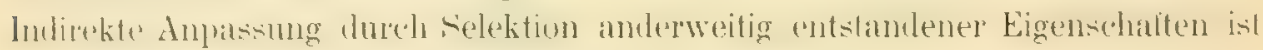
in einer Anzahl von Fällen absolut nicht zu ungehen. ${ }^{1}$ )

Da ich die Anpassungen für die Systembildung und die Abstammungsgeschichte der Rosen verwerte, muss ich sie, wenigstens unter gewissen Be-

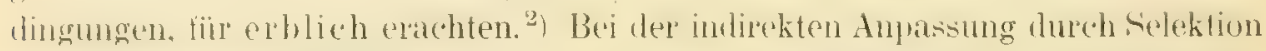
ist das selbstrerstindlich, weil eine Voraussolyung des ganzen Vorganges. Tatsachen, wolche stringent die V'erelumg direkter Anpassungen beweisen. kimn

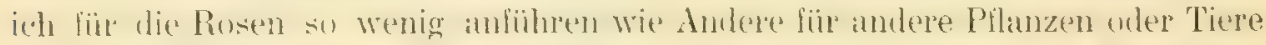
und deren Phylogenie. Dep aufmedkante Leser whol jeluch eine Masse ron Bunbuhtungen gefunden hahen, deren Erklärung am wahrscheinlichsten mol natiolichsten durch die Ammahme von direkter Anpassung und deren Vrererbung erfolgt. M. E. läst sich überhant litin stringenter Beweis für diese

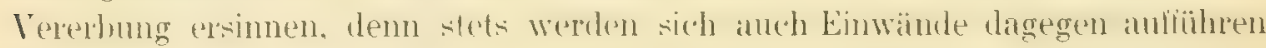
lassen. Einmal kann man ja doch gewiss selten zwingend nachweisen, dass

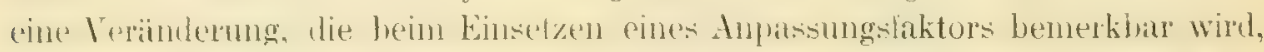
gerate in Folge dieser Einwirkung und nich etwa aus inneren Giumlen des Organismus eintrat. Erhält man aber auch zweitens von seinen Gegnern das Zugeständuis, dass es sich wirklich um eine - individuelle - Ampassung hamble, weil jentromal beim Fingreifon des ïusseren Faktors die Verönderung an Organismus eintrete, so ist der Schritt vou der individuellen zur Sippen- (erblichen) Anpasimg noch nicht gemacht. Iter hin ich der Ansicht. dass es die zeithichen Schlanken, welche der menschlichen Beohachtung und Lntersuchung gezogen

1) Konsequenter Weise ist $\mathbf{H}$. de Vries gegen jede direkle Anpassung. Er behauptet

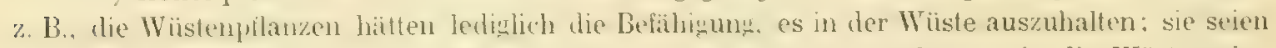
anderswo durch Mutation entstanden und wïchsen auch anderswo besser; in die Wïste seien

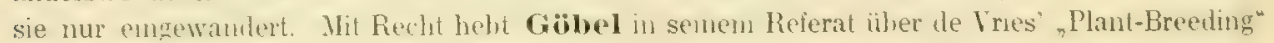
(Biolog. Centralbl. 1908, S. 1 ff.) dagegen hervor, die Wüstenpflanzen hätten Organe, die ausschliesslich für die Wüste bestimmt und passend seien; sie können also anderswo mit diesen Orwanen nicht wleich zul beslehen. - Ther de Rïckbildung von Organen sagt E. Sehultz in seiner stultie "Ther ontogenetsche und flyylogenctische Rürkbildungen" "Biolog. Centralbl. 1908, S. 67\%: "Was ist nun die Lrsache der Rückbildung eimes (Iryanes? Zweifellos ist es der Nichtfelorauch dieses Grwanes in Leben der einzehen Individuen, welcher den Schwoud desselben in der Stammesgeschichte verursacht." - A. Handlirseh endlich gibt auch so ziemlich meiner Ansicht ïber die Evolution bei den Rosen Ausdruck, wenn er in seinem Autoreferat über "Die fossilen Insekten" (Neues Jahrb. \&. Min. usw. 1908, Bd. II. S. 283) schreibt: „Den Schluss des Werkes bilden deszendenztheretischu Erörterungen. die zu dem Satze führen, die Evolulion gehe aul Grund der direkten Finwirkun! iusserer Faktoren, funktioneller Anpassung und Vererbung erworbener Eigenschaften vor sich und werde durch verschiedene Arten von Selektion in weiteren Sime, durch die Konstitution der Orșanismen, dic physikalisch-chemische Möglichkeit und durch den Zufall gefördert, begrenzt und reguliert."

3) Dass die Anpassungen vererben, nchmen auch Klebs, (?) Wettstein, Driesch, Reinke, Handlirsch und Andere an. 
sind, nicht gestatten, einen zwingenden Tatsachenbeweis zu liefern, sondern uns immer auf den Weg mehr oder minder wahrscheinlicher Deduktionen verweisen. $\left.{ }^{1}\right)$ Offenbar mïssen die anpassenden Faktoren lange Zeit hindurch auf die Anpassungssubstanz einwirken, ehe eine sichere Vererbung von direkten Anpassungen erfolgt. Zumächst wird die Spur,

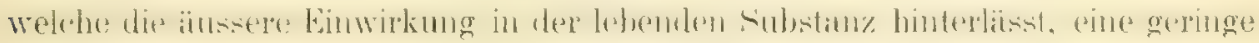
sein; sie bleibt in der nächsten Generation meist latent, wenn auch real. Erst

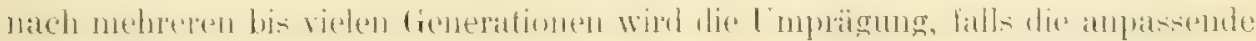
Beeinflussung fortdauert, so stark, dass ein Aupassungsmerkmal auch offen zu Tage tritt. Ohne Zweifel muss ron Anfang an das Keimplasma ron den peri-

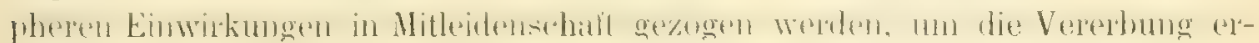

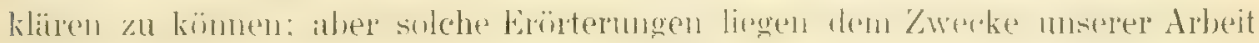
zu ferne, als dass wir aul sie eingehen diirten. Also: wenn eine hose mehrere

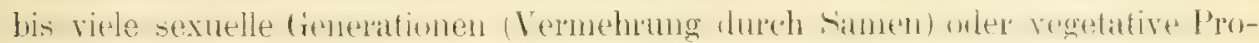

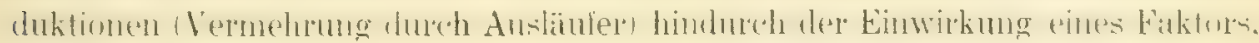

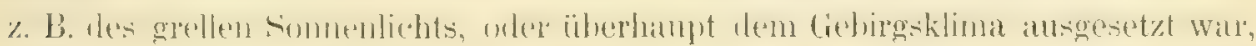

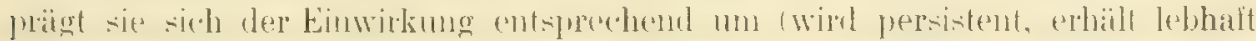
anthocyanrote Kronen und untersetzten Wuchs) und vererbt sodann diese Umprägung offensichtig weiter: es ist ein Stamm von Gebirgsrosen entstanden. Die meisten Einfliisse sind imstande, umändernd schon auf das erste Indivi-

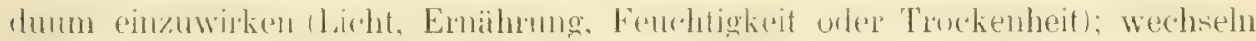
sie während des individuellen Lebens, etwa nach dem Klimacharakter der einzelnen Jahre, so wechselı auch die Eigenschaften der Pflanze in etwas, sie

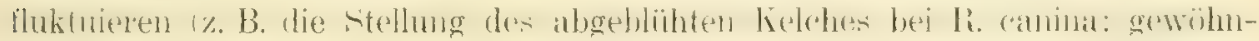

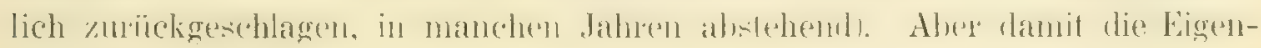
schaft befestigt wird und vererbt werden kann, muss der äussere Faktor sich

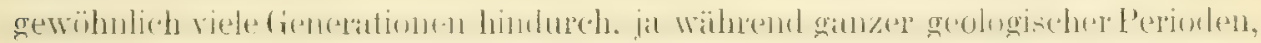

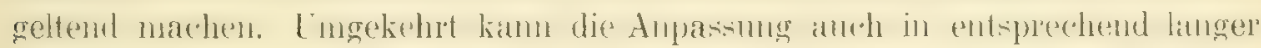

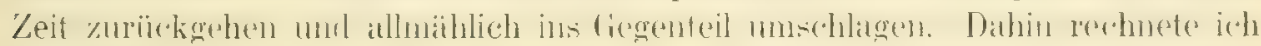

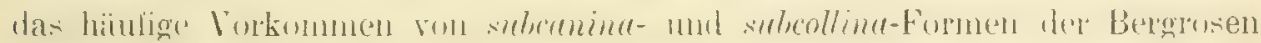
glanca und corïfolia in den jetzigen milden, trockenen und relativ niederen

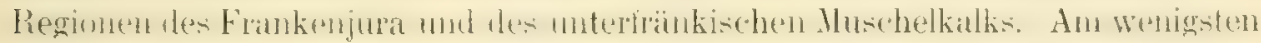

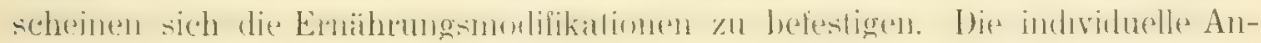

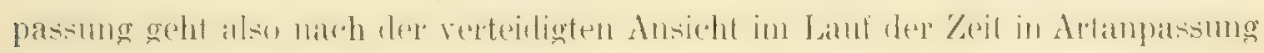

1) Bei den Tieren und dem Menschen mögen die Verhältnisse günstiger liegen. Ich wenigstens wüsste nicht, wie man z. B. die Krankheiten (Epilepsie, Paralyse, Manie) der Kinder von Säufern, die selbst geistesgesund blieben und auch in ihrer Ahnenreihe keine geistesgestörten Aszendenten hatten, anders erklüren könnte, als durch Vererbung individuell erworbener Schädlichkeiten, wenn auch nicht gerade „dnpassungen". Die medizinische Wissenschaft hält Vererbung für selbstverständlich. - Klebs erklärt zunächst nur die, imneren Bedingungen" ciner Pflanze für erblich, und nicht ,erworbene Eigenschaften". Da nach ihm jedoch die inneren Bedingungen ,erworben" werden und zwar unter konstanter Einwirkung äusserer Einflïsse, so weicht meine Ansicht von der seinigen sachlich kaum ab; denn auch ich muss eine Beeinflussung durch åussere Agentien, , bis auf's Keimplasma", eben das System ,innerer Bedingungen" vorauswehen lassen, wenn die Vererbung eintreten soll (Vgl. G. Klebs: ,Willkürliche Entwicklungsänderungen bei l'flanzen", Jena 1903, bes. Kap. VII S. 156 ff.). 


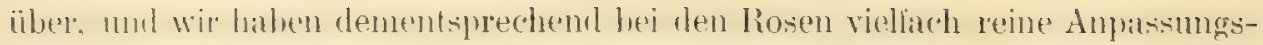
arten unterschieden wie die R. dumetomm, glauca, coriffolia. Wegen des allmählichun Enlstehens einer individuellen und riner Artanpassung haben wir hier das Hauptgebiet der fluktuierenden Variation zu suchen. Da die klimatischen Einfliisse wohl stels eine grössere Anzahl ron Individnen beriblum, (mi-

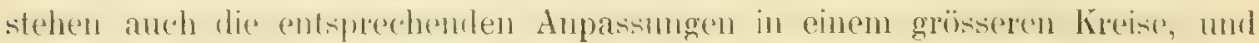
werden die so herausgebildeten Rassen und Arten eine mehrwurzelige Abkunft haben.

Die sog. Anpassungsbreite besteht tür das pflanzliche Einzel-Individuum in seiner Fähigkeit, von der gegenwärtigen Adaption an die äusseren Verhïtnisso nach oben (strigerung) oter unten (Minderung) also + abweichen, ja auch ganz neue Adaptionen je nach Bedarf erwerben zu können, bezw. zu müssen. Diese Breite ist stets abhängig von der bis dahin erworbenen morphohogischen und physiobogischen lieschaffonheit und erscheint in den pinzelnen Zeitmonenten der Entwicklung mbedentend, dagegen gross bei summierung der ganzen in Betracht kommenden Entwicklungszeit. Für die Pflanzenart, die ja eine Summe von Individue'l datstellt, wirl die Anpassungsbreite ersichtlich gemacht dur h die Amplitude der Abweichnngen um ein mittleres Hass ciner ins Auge gefassten Eigtuschalt nach oben unl unten. wie sie - die Abweichungen uns vorgeführt werden in jenen Einzelindividnen, die wir nach Zeit und Raum verteilt zur betreffenden Art rechnen. So können wir dergleichen Variationskurven entwerten \%. B. liir die Dritsigkeit an den Bibittern aller Individuen. die man seit der Entstehung der Art R. 'gallica auf der ganzen Erde gefunden hat. Oder ähnlich fïr die Heterakinthic der H. rubiginosa. Le+i einer Sippe besteht also die Anpatsongublete in der Summe der pusitiven und negativen Variationen um den Mittelwert.

Wie wir Seite 204 konstatierten, werden Organisationsmerkmale um s) häufiger und wichliger, zu je höheren Kategorien des Systens wir atsteigen. In den kleinsten Abteilungen fluktuieren sie ummerklich hin und her, in den grösteren setzen sie mehr sprungweise ein. Es erschien mus sehr unwahrschein-

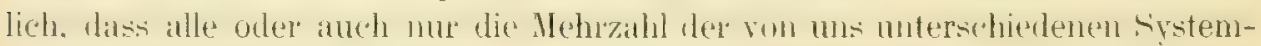
eigenschatten uspounglich aus- 1 mu nicht meht rerständlichen - Anpatsoumgen hervorgegangen seien. Denn die klimatischen mol edaphischen Faktoren haben sich seil dem Anfunge des Tertiär, in wolches wohl hanphöichlich die Entwicklung des Genus Rosa fällt, nicht derartig veränderl, dass Ampassungen von damals

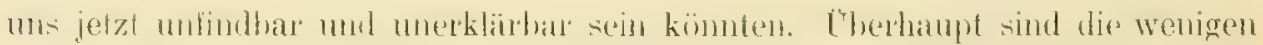
Anpassungslaktoren allein nicht imstande, wie die Verfechter der Identität von Organisations- und Anpassungsmerkmalen wollen, die unendlich reiche und die immer höher steigende Entwicklung der Pllanzenwelt hervorzurufen. Einzelne

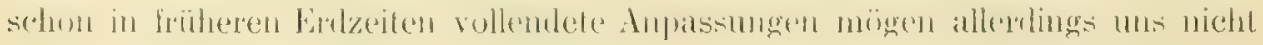

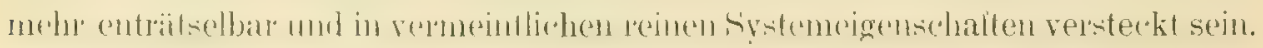

Können aber nicht umgekehrt Systemmerkmale zu Anpassungen werden? Fiir die indirekte Anpassung durch Selektion, welche wir in einzelnen Fällen

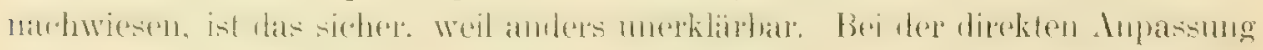
kommen jedoch neue Eigenschaften zu den systematischen hinzı oder ver- 


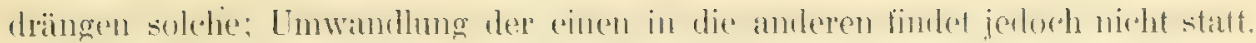

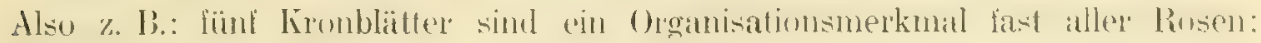
wenn die Kronen stalt rosa sich purpurn fürben, kommt Anpassung an das Gebirgsklima zur Fintzahl himzu; nur dat Substrat, der limmblatlkreis, ist fiir beide Klaksen von Merkmalen gemeinsam. Ferner: die eikngelige (iestalt der

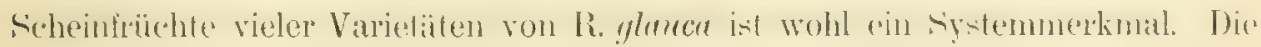
mittlere Frucht eines Corymbus jedoch erhält cine ausgeprö̈gte und gams ah-

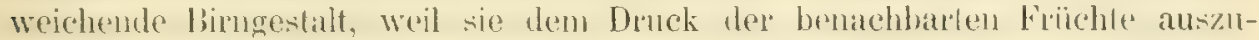
weichen, sich ihm anzupassen hat. Es wird alsu eine Systemeigedschatt durch Anpassung verdrïngt.

Auch die Organisationsmerkmale unterliegen der Veränderung, sie variieren. Mit W. O. Focke ${ }^{1}$ ) glaube ich, man tue am besten, Stufen oder Grade der Variation zu unterscheiden, nicht aber diesen Graden wesentlich vershtedenen Inhalt zu greben. Es gibt hier fluktuierende Varialion, bei welcher rlie System-

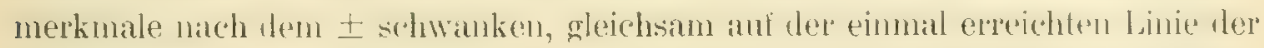
Entwicklung hin and her pentels. Dit Unterschiede zwischen den pinzehen I'hasen sind oft unendlich klein. Dahin rechue ich die kleinen Abweichnogen von

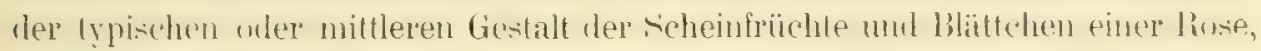
von der gewöhnlichen Zahl der Fiedern an mittleren Bliitenzweigen, dere normalen Fiederung der Kelchblïtchen u. dgl. Fïr die Fluktuation der Systemmerkmale

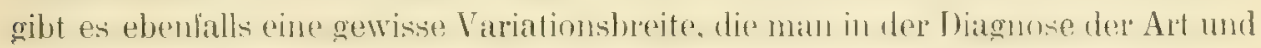
Form zwerkmäissig ansdrïckt. Wird die Variationsbreite mit rimmmale, durch einen Entwicklomgsakt deutlich B̈bersehrilten, so kamm man das Mutal ion nemnen.

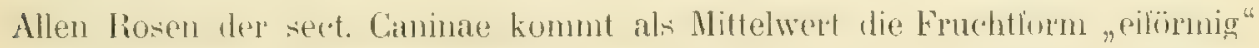
zu. Um diesen Mittelwert herun fluktuieren die einzelnen Varietiaten mit unendlicher Mamnighaltigkeit in mendlich kleinen Abweichungen. Wïrde mun eine

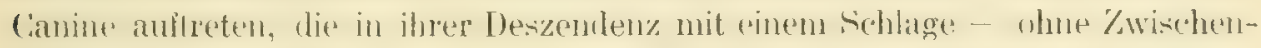
slulen die Fruchtform "oval" in "kugelig" abünderte, so wäle das erine Mutalion.

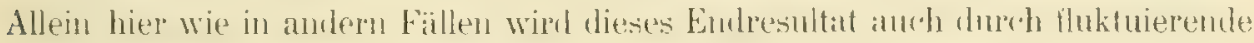

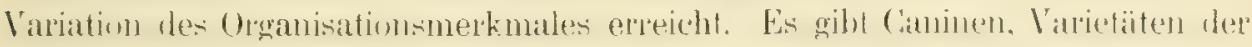
R. canina L., z. B. var. syntrichostyla, var. jurensis m., var, eriostyla, mil voll-

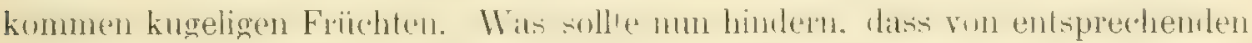

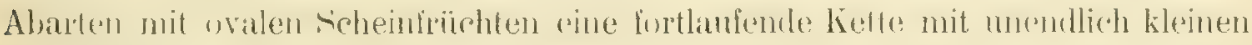
Unterschieden bis zur syntrichostyla etc. leitete? Solche Ketten haben wir,

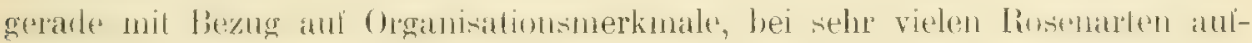
gefunden. Man hat sich da eben zu denken, dass eine aus inneren Gründen

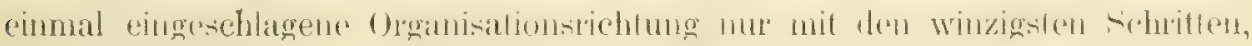
vielleicht einem bei jeder neuen Generation, ein neues Ziel erreicht. Die von mir gerade als wirklich konslatierten Ketten mag man vielleicht als beweiskrültig verwerfen, weil es sich möglicherweise nicht um wirkliche Deszendenz

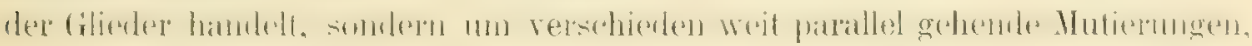
die in eine künstliche Reihe zusammengefasst werden. Allein denkbar, ohne

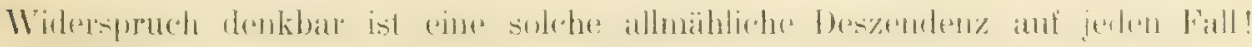

1) „Uber örtlich getrenntes oder geselliges Vorkommeu verwandter P'llanzenforınen (Naturw. Wochenschr. Bd. 8. S. 81 ff.). 


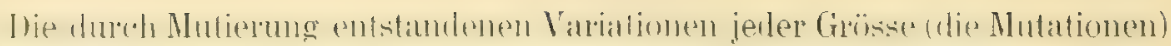
sind erblich und werden mit einer sicheren Konstanz vererbt. Sie können aber selbst wieder variieren bezw. mutieren, und der Salz von ihrer konstanten Ver-

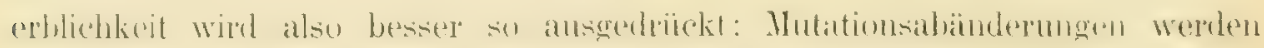
sofort und so lange vererbt, als nicht neue Nutationen an ihre Stelle treten. Ich glaube, dass man auch eine Mutalionsbreite als möglich und sogar wahrscheinlich annehmen muss. D. h.: in der Konstitution der Art - auch der

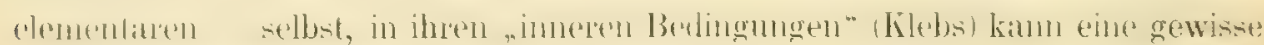

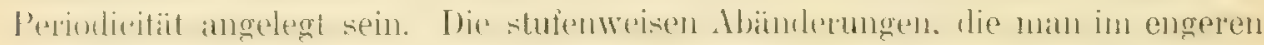
Sime Mlutationen nennt, kehren unter Unständen öfter wieder, also mehrmal

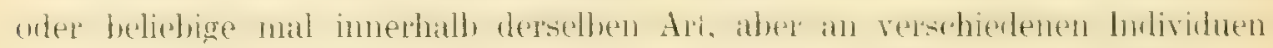
and meist an verschiedenen Standorten. So mögen die Mutationen, die de Vries

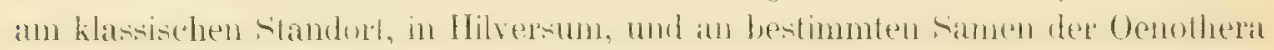

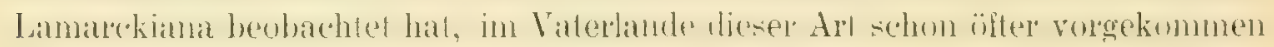
sein, und mögen auch in Europa an anderen Plätzen noch oft vorkommen. Äussere Verhältuisse wiirden dam als - nicht bestimmende, sondern bloss -

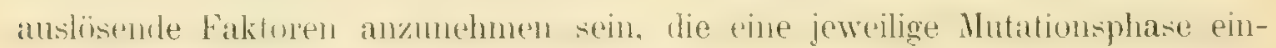
leiten. Ohne selbst ganz aufzuhören würde in solcher Phase eine Art gleichsam neue Arten um sich verstrenen, dann ruhen, um später vielleicht wieder in Eruption zu treten. Es gäbe dann eine Entwicklung nach Organisationsmerkmalen unter Fortbestand der alten Art.

Wenn ich durch diese und frïhere Annahmen ron dem Gedankengange H. de Vries" abweiche, so plädiere ich jedenfalls dafür, rïcksichtlich aller Abindermogen, welche die Entstehumg von Organisationsmerknalen im Gegensitz zu den Anpassungen bewirken, das Wort „mutienen" zu gebranchen, allerdings ob es sich nun um kleinste oder grössle Variationen handle. Es wird hiedurch zwar

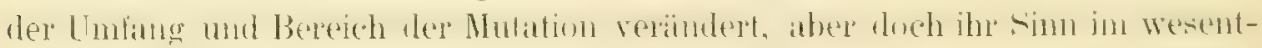
lichen beibehalten. In den Elternindividuen, also meinelwegen den Urrosen, ruht eine gewiste Entwicklungstihhigkeit. Spontan. al h. durch intracellulïre und

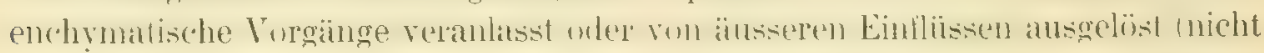

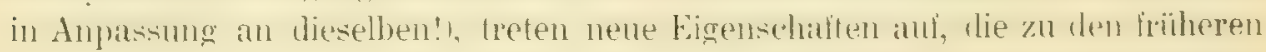
sich summieren, sie erweitern oder auch zurïckdrängen. Diese neuen Eigenschalten zuigen sich zuweilen schon an Ellerindividum in der Form der hunspen-

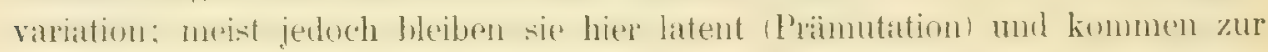

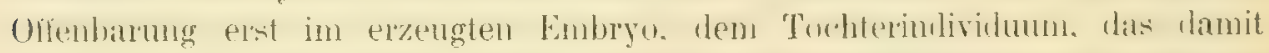

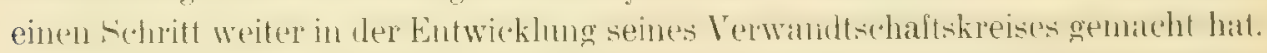

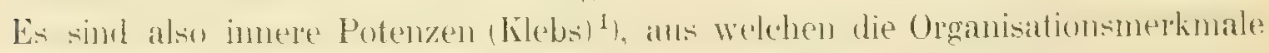
herrorgehen. Dazu gesellt sich num als nolwemlige Erweiterung die Anpassumg an

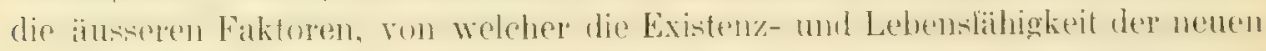
Form abhängt. Und so greifen, wie H. Driesch ${ }^{2}$ ) will, Mutation und Adaption ineinander, weit entfernt, sich auszuschliessen. Die Eigenschalten jedes

1) G. Klebs: "Über künstliche Metamorphosen" (Abh. d. nat. Ges. Halle 1906, Bd. 25. $\therefore \quad 1: 33$ if.

2) I. Driesch: "Kritisches und Polemisches" (Biol. Centralbl. Bd. 21. 1902, S. 189). 
Individums und jeder Sippe sind eine harmonische Verbindung teils von Organisations- teils von Anpassungsmerkmalen. ${ }^{2}$ )

De Vries will nur vorderhand noch den weiteren oder kollektiven Artbegriff gelten lassen, den auch wir unserem System der europäischen Rosen zu Grunde gelegt haben. Sobald es die Verhältnisse gestatten, muss nach ihm als Grundlage des gesamten Pllanzensystems die kleine Art im Simne Jordans oder die

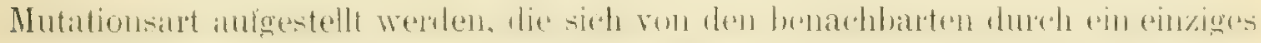

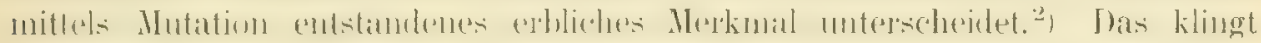
tatsichlich in der Theorie sehr einfach und einlenchtend. Aber in Wirklichkeit

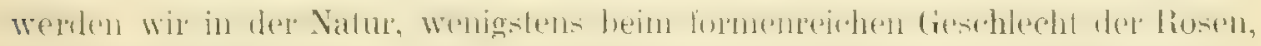

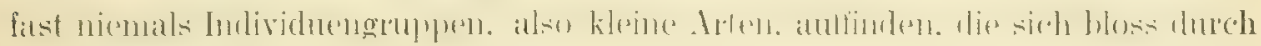
ein einziges präzis definiertes Mlerkmal unterscheiden. Man gehe an der Hand der Synopsis die Varietätsdiagnosen R. Kellers durch und entscheide, ob die

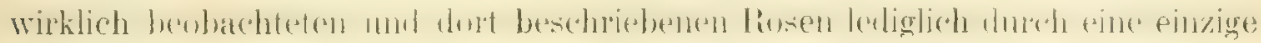

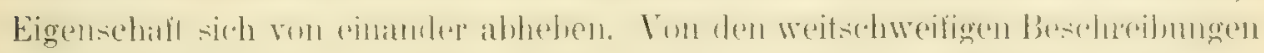
vieler Rhodologen will ich gar nicht reden, weil sie fïr jede Form soviele Eigenschaften als bezeichnend bringen, dass man keine sichere Grenze gegen die

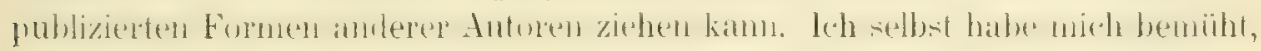
alle Diagnosen fremder Autoren auf ein möglichstes Ninimum zu reduzieren und meine eigenen so einfach als möglich zu gestalten. Trotzdem sind auch in meinem Verzeichnisse selbst kleine Formen gewöhnlich durch mehrere diagnostische Eigenschaften gekennzeichnet. Und wenn man auch annimmi, unter

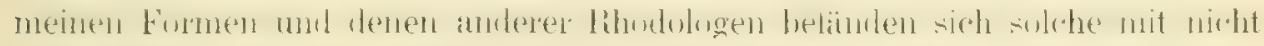

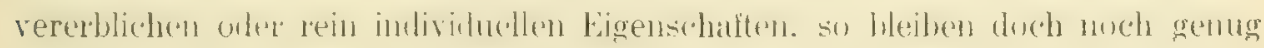
andere ïbrig. Nun gibt merkwîrdiger Weise de Vries die Pluralität der dia-

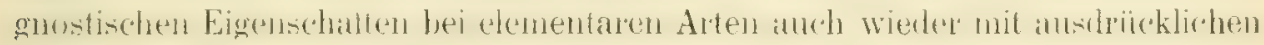
Worten zu: "Wir wissen, dass die elementaren Arten, auch die am nächsten verwandten, sich nicht in einem einzigen Merkmal rom cinander miterseheiden, sondern fast in allen ihren Organen und Eigenschaften. Die Differenz zweier närhst rewandter Furmen erforlert wf eine sehr lange und auscedronte Ida-

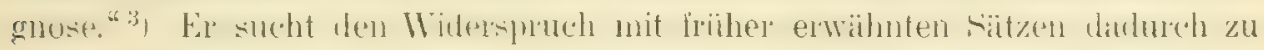

1) Es will mich fast bedünken, wie wenn die Rosen - und vielleicht alle Pflanzen sofort nach dem Eintritt einer Mutation die grösste Befähigung hätten, die neu erworbene Systemeigenschaft an die äusseren Verhältnisse anzupassen und die Anpassung festzuhalten. Im Laufe des Lebens einer neuen Sippe wird diese Anpassungsiähigkeit oder Plastizität geringer, gerade wie die gleiche Fähigkeit im Leben eines Individuums. Es ist doch auifällig, wie die montanen Charaktere von Rosen gleich der glanca und coriifolia seit den Jahrtausenden, da sie sich ausbildeten, in den niederen Gegenden Nordbayerns zwar etwas ins Schwanken gerieten (die subsp. subcanina und subcollina!), aber im wesentlichen sich noch erhielten. Gleiches gilt von dem zähen Festhalten der ursprünglichen phänologischen Zeiten bei R. canina usw.

2) H. de Vries: Die Nutationstheorie. Leipzig 1901. I..Bd. \$ 5 und \$ 21.

3) "Die Mutationstheorie" Bd. 1. S. 42. - Vgl. S. 305, wo die durch Mlutation entstandene Eigenschait als, innere oder primäre ${ }^{6 i}$ bezeichnet wird, welche durch Wechsclwirkung mił den einzelnen Organen in mehreren äusseren Merkmalen sichthar wird. „Oder mit anderen Worten, die neue Art kennzeichnet sich in der Regel nicht durch eine einzige neue Eigenschaft, sondern dadurch, dass viele oder alle Organe in bestimmter Weise umgestaltet wurden." 
heben, dass er behauptel, die ganze Diagnose sei als der Ausdruck eines ein-

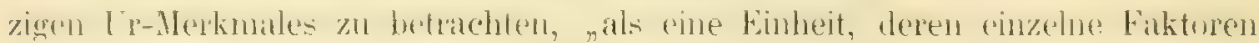
abre nicht von einumber getrenut in die Esscheinung treten kimmen. Theoretisch

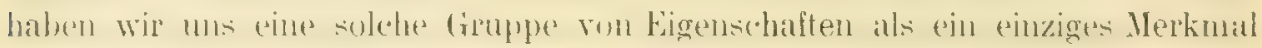
zu Genken." - Wie sollen wir das verstehen? Will de Vries behaupten, diese mehreren Faktoren stïnden in Korrelation zu einander? Es scheint fast so.

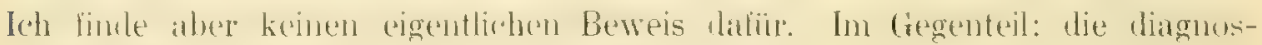

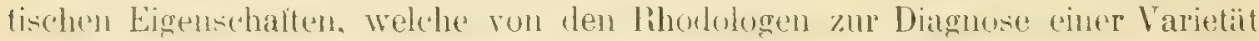

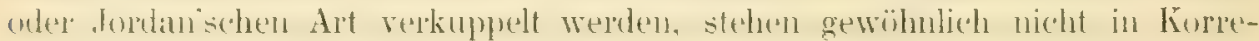
lation zu einander, wenn man Korrelation im ïblichen Sinne auffasst. Als ein

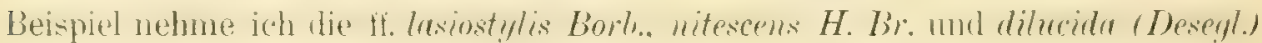
$H$. $\mathrm{Br}$. der R. canina, welche einander sehr nahe verwandt und Untergruppen

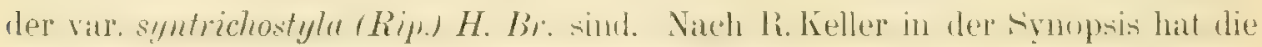

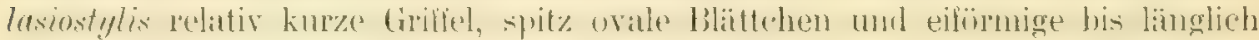
elliptische Scheinfribchte; lie nitescens lange Griffel, grosse und breite Blittchen

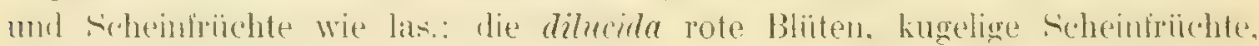

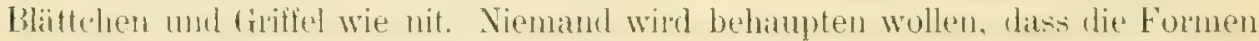

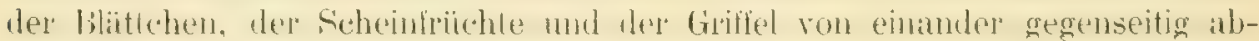

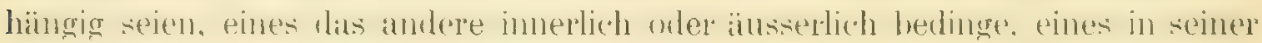
Bestimmtheit ohne die Bestimmtheit des andern nicht existieren könne. In der Tat treten sie hier in beliebiger Kombination auf und werden in noch manch anderer gefunden werden. Diese diagnostischen Faktoren stehen also nicht in Korrelation zu einander. Und so in unzähligen ähnlichen Fäillen.

Trolzdem glaube ich, in der zitierten Behauptung von de Vries eine Wahrheit erkennen zu müssen; ich rechtfertige sie aber mit Hilfe der Unterscheidung von Anpassmgs- uns Organisationsmerkmalem. Zumächst rollzieht

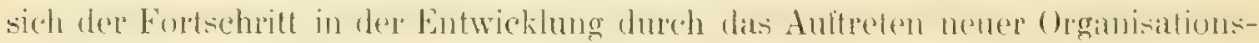
merkmale - eines genïgt - infolge von Mutation. Dieses neue Merkmal muss

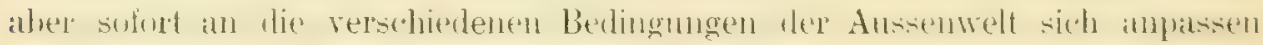
mber sich durch Aupassungseigenschaften ergänzen, die elentalls zum liesitz und Wesen des nenen Entwicklungsgliedes hinzutreten. Und nicht bloss die

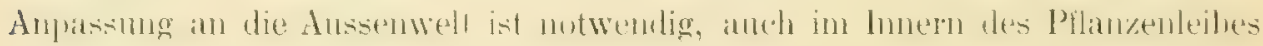
bedingt eine neue Eigenschaft, ein nenes Gewebe, ein neues Organ Veränderungen der schon vorhandenen. Indem wir eine innere Anpassung anerkennen, kommen wir vielleicht dem erwähnten Gedanken von de Vries noch näbre: dis exine prinaite Figenschaft hedingl durch Wechsolwirkmng mit den einzclnen Organen eine Reihe von anderen. So erblickt nach erfolgter Mutation die neue Art das licht der Welt infolge innerer Anpassung stets nicht als blosse Elementar- sondern als komplexe Art, die sofort durch Anpassung an die äusseren Faktoren noch weitere Komplikation annimmt oder durch Addierung von Anpassungseigenschaften gewöhnlicher Art noch mehr zur ,Sammelart wird. Der Kem der Deszendenz wird immer gegeben durch die Mutationen, welche Systemmerkmale erzengen; aber auch den äusseren Apparat der Anpassungen dïrfen wir nicht rernachliissigen. Vielfach trilt er schärfer in die Augen als die Merkmale der Organi- 


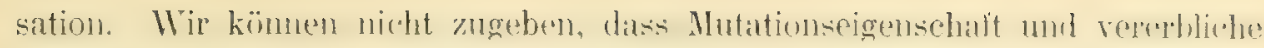

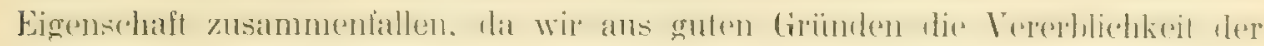

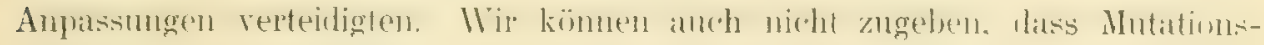
arten, „kleine Arlen" Jordans und die meisten Varietäten oder Formen der Floristen, wenn sie vererblich sind, ohne weiteres identisch seien. Denn die kleinen Arten sind wit hurch Mnpassungen gekennzedichnet, und bei den Varietïten des herkömmlichen Systems kann es sich un Organisationsmermale, un Anpassmasmerkmale und un .lischungen bedide handeln. Man wirl wohl anch nie zum Zitele kummen, alle mutativen Eigtenschallen ans dem Kern des Ëgenschaftenkonplexes heransishälen und mit sicherheit als sulde beweisen zu können. Endlich sind wir weit davon entfernt, dats die kollektive ader" komplexe Art aul den Aussterbeetal geselzt wird. Man ist lediglich thenretisch imstande, Sippen zu erdenken, die von anderen dureh ein einziges Kömmnal abweichen, z. B. durch einen anderen Grad der Blattzihnung oder die rerschichlent lainge der Griffel. In ganz seltenen Fiallen mag dies anch in der Nalur vorkmmmen. Aber die enorme Mehrheit ron wirklich existiementen sipnen, selbst due kiteinsten Furmen, sind kullektiv. Jedes existierende Individum besteht ans ciner Menge von Organen: jedes derselben rermag für sich zu mutieren und die andern zu berinflussen; jerles unterliegt bestänlig den ungestaltenden Einiliissen der Aussenwelt, denen es durch dnpasung und Erzengung von Anpassungseigenschaiten hegegnet. Dieste Fïlle verindernder L'saldhen bewirkt nach den Gesetzen der Pemmatimslehre. dass die L'nterschiede schon zwischen den Individuen und mehr nuch zwischen dens sipen mit hoher Wahrscheinlichkeit mehrfache, und die Sippen also de facto gewöhnlich komplexe sind.

Ja, es gibt uns die Natur selbst einen Fingerzeig dafür, dass nur komplexe Sippen und zwar gerade unser alten komplexen oder kollekliven Arten, mit. denen wir auch im II. Teil operiert haben, vollkommen konsolidiert sind. Ich

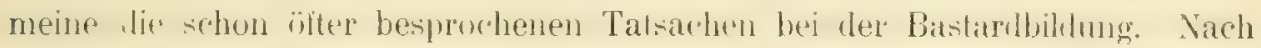
den bisherigen Erlahrungen wirlerstreben der Znsimmenschwejssung ihrer artkonstifnimenden Elentente ledigglich die grossen, komplexen Rusenarlen. beweis: die vollknnmone oder teilwrise, jedenfalls merkliche, Sterilität hem Akte der ersten Befruchtung vder der allentalls in erster Generation erzeuglen Hybriden. Ilie kleinen Arten lissen sideh nach allgemeiner Cberzengung beliehig mischen; wenigstens worlen in dex Ihodulugischen literatu keine Bastump zwischen den niedersten Systemklassen (also zwischen den Formen, nicht einmal den Varietätent angefiihnt, ehen weil sie mangels der sterilität nicht kenntlich sind. Ja, die Mardhlinge zwischen soldhen kleinen Formen, welche sirher hïulfg gebildet werlen, geben Anlass zur Entstehmg nener Sippen, weil sile unbeschränkt fruchtbar sind und sich and nicht inmer bes weilenen Generationen natch den Mendelschen Regehn in ihre Komponenten anlanspalten branchen. ${ }^{1}$ ) Die kloinen Arten existieren demufolge nur als Komponenten oder Elemente

1) De Vries lässt die Mendel'schen Regeln bei Bastardierungen bloss für retrogressive

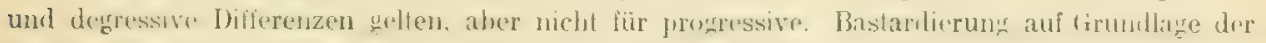
letzteren führt zur Bildung neuer Arten ( Die Mutationstheorie", Bd. II. S. V). - Die den

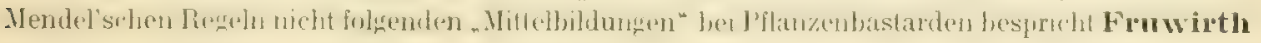
S. 116 ff. S. 124 von "Allgemeine Züchtungslehre" 2. Aufl. 1905. - An dieser Stelle sei auch 
der grossen, besitzen aber nicht die Rechte selbständiger Arten, sind nicht volltommen subsistent, weil sie sich nicht unbedingt in ihrer Sonderexistenz, ihrer Individualiät, zu behaupten vermögen. Ich leugne nicht die Wichtigkeit der Artenelemente oder elementaren Arten, wie ich auch nicht die absolute

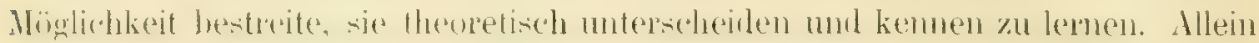
ich fasse sie als Charaktere, deren jede subsistierende Art viele in sich ver-

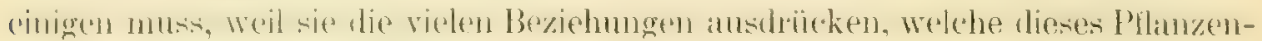

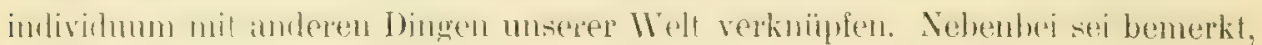
dass grosse Arten, die durch blosse Ampassungsmerkmale charakterisiert sind,

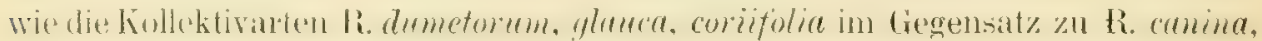
die Kollektivarten micrantha und agrestis im Gegensatz zu nubiginosa und elliptica, ebenfalls den Schutz der Sterilitit ihrer Bastarde geniessen, wie micrantha $X$ mbiginosa usw. beweisen. Diese Erwïgungen haben sich mir beim Studium der Rosen auigedrïngt.

Man kann zum Schlusse die Frage aufwerfen, ob unsere Erfahrungen zur

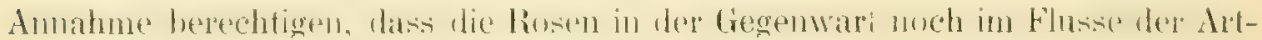
bildung begrilfen seien. Ich antworte: Die Anpassung ist sicher noch tätig und

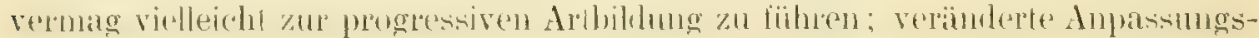

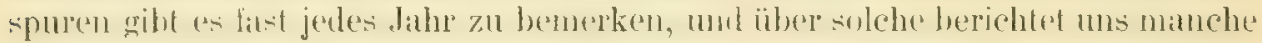

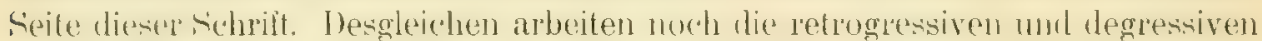
Faktoren, wie Atavismus 11. dgl. Anzeichen wirklicher in der Gegenwart durchgetibhter Mutationen vermüchte ich kaum anzugeden. Dingler glanbt an solche bei einer von ihm entreckten pimprinellifolia-Ansiodelung Lnterthankens; $\left.{ }^{1}\right)$ doch

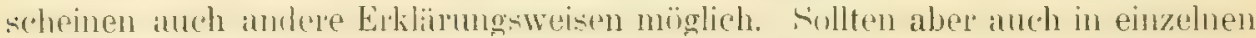
Fïllen echle Mutationen vorkommen, so werden sie nicht viel bedeuten und noch weniger am Gesamtbild der Gattung Rosa ändern. Der Lebensbestand der Rosen ist im Rückgang begriffen, schon deswegen, weil sie nach meiner fruher entwickelten Ansicht grossenteils von der Frend- zur Selbstbestiubung, und bei dem Mangel geeignter Vepbreitumgsmittel der Fribchte

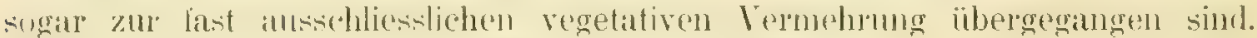
Datzu kommen die vielen Eingriffe von terite des Menschen, die nich bluss direkt zerstören, sondern auch den Zusammenhang der Pflanzen- und Tiergenossen-

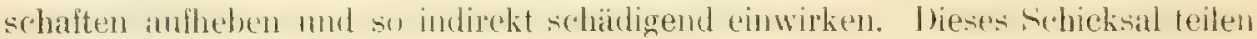
die Rosen mit vielen anderen Lebewesen.

auf die Ubersicht hingewiesen, welche de Vries (Mutationsth. Bd. I. S. 460 f. Vgl. Bd. Il. S. 636 ff.) über die Entstehung neuer Arten nach seiner Ansicht gibt:

A) Unter Bildung neuer Eigenschaften (progressive Arthildung).

B) Ohne Bildung neuer Eigenschaften:

$B_{1}$ Durch das Latentwerden vorhandener Eigenschaften: Retrogressive Artbildung, Atavismus z. T.

$\mathrm{B}_{2}$ Durch Aktivierung latenter Eigenschaften: Degressive Artbildung a) aus taxinomen Anomalien,

b) als eigentlicher Atavismus.

$\mathrm{B}_{3}$ Aus Bastarden.

Unter Eigenschaften versteht de Vries natürlich nur Mutationseigenschaften. Der Anpassung räumt er wenig Spielraum ein; sie ist ihm eine vorwiegend selektive.

1) "Versuch einer Erklärung" usw. S. 31 f. 


\section{Benützte Literatur:}

Altum B., Der Vogel und sein Leben. 5. Aufl. Münster 1875.

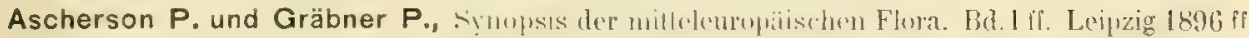
(Die Gattung Rosa VI. 1., 1900, von R. Keller bearbeitet.)

Atlas topographischer von Bayern, 1:50000. München.

Baker J. G., A monograph of the british roses (Journ. Linn, soc. London 1869).

A revised classilication of roses (Ebd. v. 37. London 1905).

Beck G. von Mannagetta, Flora von Niederösterreich. Wien 1890-1893.

(Die Gattung Rosa von H. Braun bearbeitet.)

Berichte der bayr. botanischen Gesellschaft. Bes. Bd. IV. München 1896.

Blümmel E. K., Rhodologische Miscellaneen (Bot. Contralbl. 1899 Nr. 37/38).

Borbas V., Primitiae monographiae rosarum imperii Hungarici. Budapest 1880 (Text teils lateinisch teils ungarisch).

Botanische Zeitung, II. Abt. Leipzig 1905-1908.

Bräucker Th., Deutschlands wilde Rosen. Berlin 1882.

Braun H., Beiträge zur Kenntnis einiger Arten und Formen der Gattung Rosa (Verh. zool. bot. Ges. Wien 188à).

Uber einige in Bayern und im Herzogtum Salzburg wachsende Formen der Gattung Rosa (11. Ber. hot. Ver. Landshut 1889).

Brenner W., Klima und Blatt bei der Gattung Quercus (Flora 1902).

Burnat E. et Gremli A., Les roses des alpes maritimes. Genève et Bale 1879.

Supplément ì la monographie des ros. d. alp. mar. 1882-83.

Christ H., Die Rosen der Schweiz. Basel 1837.

Le genre Rosa. Résultats généraux etc. Trad. E. Burnat. Genève et Bale 1885.

La flore de la Suisse. Ed. franç. nouvelle. Bale-Genève-Lyon 1907.

Crantz H. J. N., Stirpium austriacarum ed. altera. Ps. L. Viennae 1769. und

Jacquin N. J., Florae austriacae icones. Vol. H. Viennae 1774.

Crépin Fr., Primitiae monographiae rosarum - Matériaux pour servir à l'histoire des roses Fasc. 1-6. 1869-188: (Bull. soc. bot. Belg. Bruxelles et Gand).

Recherches sur l'état de devéloppement des grains de pollen dans diverses espèces du genre Rose (Bull. soc. bot. belg. t. 28. Bruxelles 1889).

Recherches a faire pour étahlir exactement les époçues de floraison et de naturation des espèces dans le genre Rosa (Bull. soc. bot. Belg. t. 28. Brux. 1889).

Les roses récoltées par. M. Paul Sintenis dans l'Arménie turque en 1889 (Bull. soc. bot. Belg. t. 29. Brux. 1890).

Tableau analytique des roses européennes (Bull. soc. bot. Belg. t. 31. Brux. 1892).

Les roses de l'herbier de Koch (Bull. soc. bot. Belg. t. 32. 1893).

Rosae hybridae (Bull. soc. bot. Belg. t. 33. 1894).

Remarques sur l'inflorescence des Rosa (Bull. soc. bot. Belg. t, 34. 1895).

La question de la priorité des noms spécifiques envisagée au point de vue du genre Rosa (Bull. lerb. Boissier. Genève 1897).

Les variations parallèles (Bull. soc. bot. Belg. t. 36. 1897),

Correns C., Uber Vererbungrsgesetze. Berlin 1905.

Denkschriften der kgl. botanischen Gesellschaft in Regensburg. Neue Folge II. Bd. 1903.

Déséglise A., Revision de la section Tomentosa du genre Rosa. Angers 1866.

Catalogue raisonnée ou énumération méthodique des espèces du genre Rosier (Bull. soc. bot. Belg. t. 15. Bruxelles 1876). 
Dingler H., l'] mancher Rosen (Mitt. naturw. Ver. Aschaffenburg 1906).

Versuch einer Erklärung gewisser Erscheinungen in der Ausbildung und Verbreitung der wilden Rosen (Ebd. 1907).

Neuere Beobachtungen in der Gattung Rosa (Engler's bot. Jahrb. 40. Bd. 1908. Beibl. 93).

Driesch H., Kritisches und Polemisches (Biol. Centralbl. 1903).

Drude O., Deulschlands Pflanzengeographie. Bd. If. Stuttgart $1896 \mathrm{ff}$.

Du Mortier M. B., Monographie des roses de la flore belge. Gand 1867.

Engler A. und Prantl A, Die natürlichen Pflanzenfamilien. Tl. I-IV. 1889 ff. Leipzig.

(Das Gen. Rosa in Tl. III. 3. Abt. bearbeitet von W. Focke 1888.)

Euler H., Grundlage und Ergebnisse der Pflanzenchemie. I. Teil. Braunschweig 1908.

Formanek E., Rosen des Hochgesenkes. Wien 1887.

Frech Fr., Lethaea geognostica. III. Tl. Bd. 2. Stuttgart 1903 If.

Fruwirth C., Allgemene Zïclituntrslehre der landwirtschaftl. Kulturpflanzen. ¿.. Aufl. Berlin 1905.

Garcke A., Illustrierte Flora von Deutschland. 19. Aufl. Berlin 1903.

Gelmi E., Le rose del Trentino. Trento 1886.

Godet Ch. H., Flore du Jura. Neuchatel 1853.

Supplément à la flore da Jura. Neuchatel 1869.

Göbel K., Organographie der Pflanzen. 2 Tle. Jena 1898-1901.

Götz W., Geographisch-hislorisches Handbuch von Bayern. 2 Bde. München 1895-1898.

Goldschmidt M., Flora des Rhöngebirges. I-VI. Würzburg 1900-1908.

Gradmann R., Das Pflanzenleben der schwäbischen Alb. 2 Tle. 2. Aufl. Tübingen 1900.

Gremli A., Exkursionsflora für die Schweiz. 8. Aufl. Aarau 1896.

Gümbel W. von, Geognostische Karte des Königreichs Bayern. 1: 100000. Vierte Abt. Kassel 1887-1891 und B1. Regensburg der zw. Abt. Gotha 1868.

Guttin J., Le genre Rosa dans l'Eure. Caen 189 .

Haberland G., Physiologische Pflanzenanatomie. 2. Aufl. Leipzig 1896.

Halacsy E. und Braun H., Nachträge zur Flora von Niederösterreich. Wien 1882.

(Die Gattung Rosa von J. B. von Keller.)

Hallier E., Wohlfarth R. und Brand A., Kenchs Synopsis der deutschen und Schweizer Flora,

3 Bde. Leipzig 1892-1907.

(Das Genus Rosa in Bd. 1 von W. Focke.)

Hansgirg A., Phyllobiologie. Leipzig 1903.

Hasse A. W., Die Rosen Westialens. Münster 1891.

Schliussel zur Einführung in das Studium der mitteleuropäischen Rosen. Karlsruhe 1896.

Hettner A., Grundzüge der Länderkunde. I. Bd. Leipzig 1907.

Hoffmann Ph., Lxkursionsflora für die Flussurebiete der Altmïhl sowie der schwäbischen und untern fränk. Rezat. Eichstätt 1879.

Jäger $\mathbf{H}$. und Beissner L., Die Ziergehölze. 2. Aufl. Weimar 188千.

Ihne E., Ihänolugische karle des Frühlingseinzuges in Mittelourona Petermann's Mitt. 1905.

Internationale Regeln der botanischen Nomenklatur, angenommen vom internat. bot. Kongress zu Wien 1905. G. Fischer, Jena 1906.

Issler E., Eingeschleppte Chenopodien (Allg. bot. Zeitschr. 1902).

Kerner von Marilaun A., Pflanzenleben. 2 Bd. Leipzig 1888-1891.

Klebs G., Wilkürliche Entwicklungsänderungen bei Pflanzen. Jena 1903.

Uber künstliche Metamorphosen (Abh. Nat. Ges. Halle 1906).

Kirchner O., Löwe E. und Schröter C., L.elrensweschichte der Blätenq̧flanzen Mitteleuropras. Bd. I ff. Stuttgart $190 \dot{4}$ ff.

Knuth P., Handbuch der Blütenbiologie. 3 Bd. Leipzig 1898-1905.

Koken E, Die Vorwelt. Leipzig 1893.

Kraus Gr., Uber den Nanismus unserer Wellenkalkpflanzen. Würzburg 1905.

Küster E., Anthocyanbildung. (Progressus rei bolanicae Bd. II. Heft 4. Jena 1908.)

Kuntze O., Nomenclaturae botanicae codex brevis maturus. Stuttgart 1903.

Lambert P., Katalog (über Rosen usw.) Trier 1905-1906. 
Lidforss B., Uber den biologischen Ellekt des Anthocyans (Bot. Notiser S. 65 ff.) Lund 1909.

Lindley M. S., Monographie du genre rosiel (Traduct. De Prouville). Paris 1824.

Löw E., Bemerkungen zu Burck: Mutationen (Biol. Centralbl. 1906).

Lydekker R., Die geographische Verbreitung und geologische Entwicklung der Säugetiere. Ubers. Siebert. 2. Aufl. Jena 1901.

Mayr H., Die Waldungen von Nordamerika, München 1890.

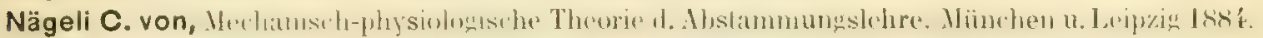

Naturwissenschaftliche Rundschau. Braunschwrig 1900-1908.

Neumayr M., Erdgeschichte. 2. Aufl. 2 Bde. Leipzig 1895.

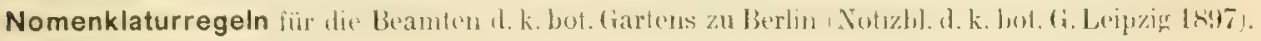

Parmentier P., Recherches anatomiques et taxinomiques sur le genre Rosier (Ann. sc. nat. Bruxelles 1898).

Pfeffer W., Pllanzenphysiologie. 2. Aufl. 2 Bd. Leipzig 1897-1904.

Prantl K., Exkursionsilora für das Königreich Bayern. Stuttgart 1884.

Probst J., Zur Kenntnis der in Oberschwaben wildwachsenden Rosen (Jahresh. Ver. Naturk. Württ. Stuttgart 1887).

Rau A., Enumeratio rosarum circa Wirceburgum et pagos adjacentes sponte nascontium. Norimbercae 1816.

Sagorski E., Die Rosen der Flora von Naumburg. Naumburg 1885.

Schimper W. F. und Schenk A., Paläophytologie. München 1890.

(Abt. Il von K. Zittel: Handbuch der Paläontologie.)

Schimper A. F. W., Pflanzengeographie auf physiologischer Grundlage. Jena 1898.

Schneider C. K., Illustriertes Handbuch der Laubholzkunde. Bd. I. ff. Jena 1906 ff.

Schnetz J., Die Rosenflora von Mïnnerstadt (Mitt. bayr. bot. Ges. 2. Bd. 1907 f. Nr. 3. 4. 7. 8) Mehrere neue Varietäten des Genus Rosa (Ebd. Nr. 6. 1908).

Schnizlein A. und Frickhinger A., Die Veffetationsverhibltnisse ler Jura- uni Kuperformation in den Flussgebieten der Wörnitz und Altmühl. Nördlingen 1818.

Schröter C., Das Yflanzenleben der Alpen. Zürich 1908.

Schultz E., Uber ontogenetische und phylogenetische Rückbildungen (Biol. Centralbl. 1908).

Schulze M., Jena's wilde Rosen. Mit Nachtrag (Mitt. geogr. Ges. Jena Bd. 5. Jena 1887).

Schwarz A., Flora von Nürnberg-Erlangen. 5 Tle. Nürnberg 1897-1901.

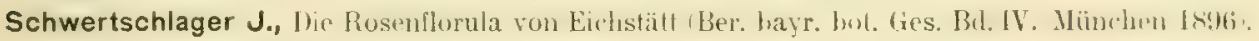
Über einige für Bayern neue Rosenarten und mehrere überhaupt neue Artbastarde von Rosen. (Ëbd. Bd. XI. 1907.)

Sendiner O., Die Vegetalionsverhältnisse des bayr. Waldes. Minchen 1860.

Solereder H., Systematische Anatomie der Vikotyledonen. 2 Bde. Stuttgart 1899 und 1908.

Solms-Laubach H. Graf zu, Dic leilonden fiesichtspunkte eincr allgemeinen Pflanzengeographie. Leipzig 190 ŏ.

Tischler G., Über die Entwickelung des Pollens und der Tapetenzellen bei Ribes-Hybriden (Jahrb. wiss. Bot. Bd. 42. 1906).

Tobler G., Uber Anthocyane (Sammelref. in "Naturw. Rundsch." 1907).

Trattinick L., Rosacearum monographia. \& Vol. Vindobonae 1823-1824.

Vries Hugo de, Die Mutationstheorie. 2 Bde. Leipzig 1901 und 1903.

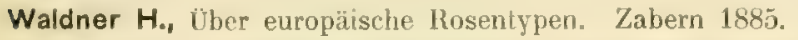

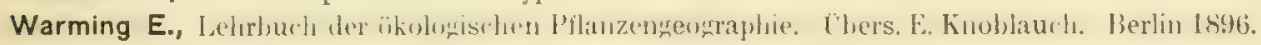

Wein K., IR. glauca Vill. usw. (Allg, bot. Zeitschr. Karlsruhe 1908).

Weinzierl T. von, Heranzüchtung von neuen Pflanzenformen unter dein Einfluss des Alpenklimas (79. Vers. d. Naturf. Dresden 1907).

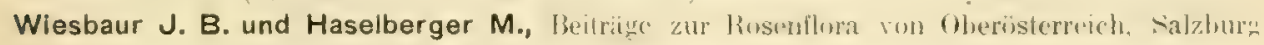
und Böhmen. Linz 1891.

Weitere Beiträge (bes. von J. B. v. Keller), herausgeg. vom Museum Franc. Carol. Linz 1893.

Woods J., A synopsis of the british species of Rosa. London 1816. 


\title{
Verzeichnis
}

\section{der in Teil II behandelten Rosen des Gebietes:}

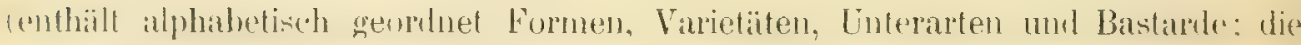
zugehörigen Arten sind in Klammer beigesetzt, die vom Verfassel neu aulgestellten Formen usw. Kursiv gedruckt)

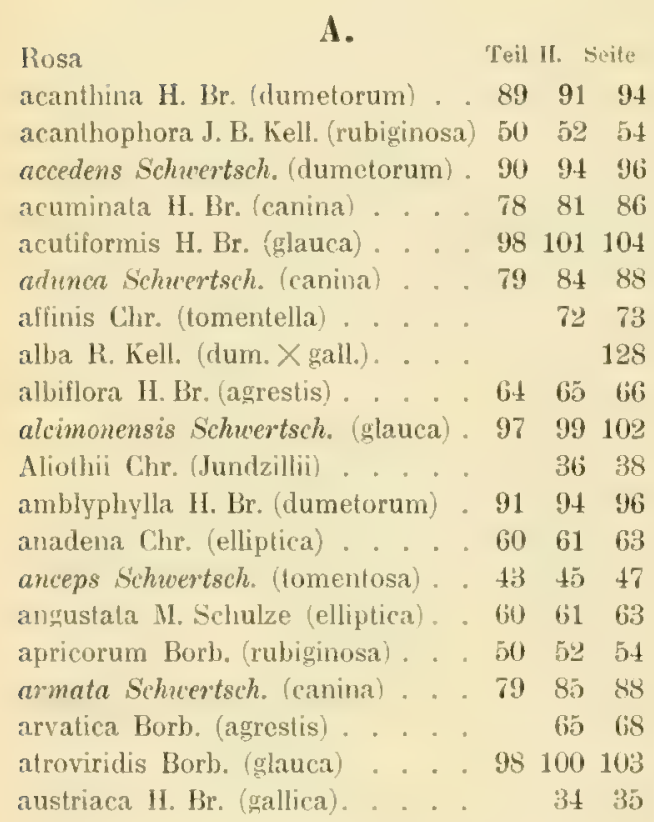

IB.

belnensis H. Br. (agrestis) . . . $6 \pm 6567$

libracteata Ser. (arvensis) . . . $31 \quad 32$

bihariensis Borb. (canina) . . . 78 83 87

Billietii Chr. (elliptica). . . . . . $59 \quad 6062$

Billotiana Crep. (tomentosa) . . . 434547

biserrata Bak. (canina) .. . . : . 798488

biserrata Crep. (arvensis) . . . $\quad 31 \quad 32$

bispinosa Schuertsch. (corilolia) . 105106

Blondaeana Crep. (canina). . . . $80 \quad 8589$

bohemica H. Br. (tomentella). . . $71 \quad 72 \quad 73$

Boreykiana R. Kell. (dum. X gall.) . 127128

briacensis H. Br. (elliptica). . . 606263
Rosa

(

caballicensis Chr. (glauca) . . .98100108 caesia R. Kell. (dumetorum) . . 91 9496 calcarea Chr. (elliptica) . . . . . $\quad 6062$ calcophila 11. Br. (rubiginosa). . . $50 \quad 5153$ calvescens Burn.\&Greml.(micrantha) $56 \quad 57 \quad 58$ Chaboissaei H. Br. (canina) . . . 79 8387 cheriensis Borb. (elliptica) . . . 6062 cinerascens Crep. (tomentosa) . . 4345 collina R. Kell. (dum.Xgall.). . . 127128 columnifera Schwertsch.

(subsp, v. rubig.) . . . . . 50

comata Schwertsch. (dumetorum) . $90 \quad 9295$ camaloides Schrertsch. (tlumetorum) 909396 communis Schwertsch. (tomentosa), 45 4648 comosa Dum. (rubiginosa). . . . 50 5153 comosella If. Br. (rubiginosa). . . $50 \quad 5254$ comosoides Schacertsch. (rubiginosa) 515355 complicata Chr. (ulauca). . . . 98 100103 composita Schwertsch. (canina) . . 78 8 8207 concomitans Schwertsch. (glauca) . 9799102 condensata K. Kell. (canina) . . 7780 conspicua Schwertsch. (canina) . . $79 \quad 8188$ corylicola H. Br. (canina) . . . . $77 \quad \begin{array}{lll}70 & 86\end{array}$ Crepiniana R. Kell. (glauca) . . . 9799102 cristata Chr. (tomentosa) . . . . $45 \quad 46 \quad 48$ cristata Duift (gall. X tomentosa) . 119120 conspidatoides Crep. (tomentosa) . $44 \quad 4647$

D.

(lecalvata Crep. (dumelorum) . . $90 \quad 9395$ decipiens Sag. (rubiginosa). . . $50 \quad 5254$ densa Borb. (rubiminosa). . . . . 50 50 50 denticulata R. Kell, (glauea) 。 : . 99101104 diacantha Schwertsch. (glauca) . .98 100103 
Rosa

Teil II. Seito

dilucida H. Br. (canina) . . . . $7780 \quad 86$

diminuta H. Br. (micrantha) . . . 54 $57 \quad 58$ dimorpha R. Kell. (tomentosa) • . $43 \quad 4547$ dimorphacantha Borb. (rubiginosa) $50 \quad 51 \quad 53$ dimorphocarpa Borb. \& H. Br. (coriifolia)

$105100^{\circ}$

diodus R. Kell. (glauca)

99101104

disparabilis H. Br. (canina) . . . 798188

dolomitica Schwertsch. (elliptica) . 606263 dolusa F. Kell. (anina) . . . . 77 s0 86

Ihrrii sichertsch. glauca!

Aryadea Kip. (can.X gall.).

(9) 111.2 10!

122123

\section{E.}

echinocarpa Borb. (rubiginosa) . . 505153 elata Chr. (gallica) . . . . . . $34 \quad 35$ ('minens Schuertsch. fontentella). $72 \quad 73$ ensfeldensis Schwertsch. (arv. $\times$ gall.) $\quad 116117$ Erineri R. Kell. (canina) . . . . $79 \quad 8388$ eriostyla Borb. (canina) . . . . $79 \quad 8488$ erinstyloides Schwertsch. (canina) . $80 \quad 85 \quad 89$ erubescens Schuertsch. (pimpinelli-

$$
\text { folia) . }
$$

111112 euoxyphylla Borb. (canina) . . $78 \quad 8287$

\section{F.}

falcata Borb. (glauca) . . . . . 9799102 fallar sicheretsch. Itomentosal . $4: 3$ 45 47 iallens Borb. (canina) . . . . 778086

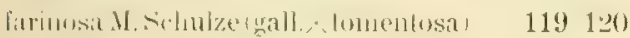
larinosa Ser. (tomentosa) . . . $44 \quad 46 \quad 47$ fertilis Schertsch. (dumetorum) 。 909396 fissideus Borb. (canina) . . . . . $78 \quad 8186$ flagellaris Chr. (rubiginosa) . . 50 52 55 foecundissima Koch (cinnamomea) 108109 Forsteri H. B. (dumetorum) . . . 90 9195 frondosa H. Br. (canina) . . . 788186 frutetorum H. Br. (corifolia) . . 105106

\section{G.}

greminata Boullu (arv. X gall.) . . yemuina S'chwertsch. (elliptica) . . nlabriuscula Pelerm. (rubiginosa). slandulifera R. Kell. (glauca) . . . Flandulosa A. Schw. (agrestis) . glandulosa Sag. (elliptica) . . . .

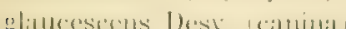
grandiceps S'chiertsch. (glauca) . .98 100103 grandiflora Scherertsch.(dum.Xgall.) 127128 Gravelii Borb. (glauca) . . . . 97 9!) 102 Gremlii Chr. (rubiginosa) . . . . 51 533 5ั5 gypsophila Sag. (elliptica) . . . 606063
11.

$\begin{array}{lll}\text { Rosa } & \text { I1. Teil II. Scite } \\ \text { Hadriana Schuertsch. (canina) . } & 78 \text { 81 } 86\end{array}$ haplodonta Borb. (gallica) . . . 3435 Hausmannii H. Br. (coriifolia) . . 105106 Heimerlii H. Br. (gall. X tomentosa) 119120 heliophila Schuertsch. (glauca) . . 100101 heteracantha Schwertsch. (micrantha) $56 \quad 57 \quad 58$ lirla H. Br. (dumetorum) . . . . $90 \quad 9195$ hirtifolia H. Br. (dumetorum) 。. 909396 Jispida M. Schulze (elliptica) . . $\quad 60 \quad 62$

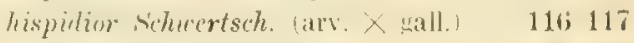
hispidula R. Kell. (canina) . . . $77 \quad \begin{array}{lll}70 & 80 & 86\end{array}$ hispiduloides Schwertsch. (canina) 。 $78 \quad 81 \quad 87$ horrida Lange (rubiginosa) . . . $50 \quad 51 \quad 58$ horrida Schwertsch. (arv. X gall.) . 116117 hybrita R. Kell. (arv. X gall.) . . 116117 hypsisepala Schwertsch. (canina) . $79 \quad 8589$

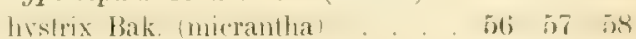

\section{I.}

jenensis M. Schulze (rubiginosa) , $50 \quad 52 \quad 54$

incana R. Kell. (coriifolia) . . . 105106

incanescens H. Br. (dumetorum) , $90 \quad 9396$

inodora Scheertsch.(subsp.v.elliptica) $\quad 60$

insignis Borb. (canina) . . . . . $79 \quad 8388$

intercedens $\mathrm{H} . \mathrm{Br}$. (canina) . . $78 \quad 8287$

interposita R. Kell.(dum.X gall.) . 128

moterpusila sichlimp. dumotorum!. $91 \quad 91 \quad 96$

irregularis Schwertsch. (dumetorum) $9094 \quad 96$ juncla II. Br. Alumetorum) . . . . . 90 99396 jurensis Schwertsch. (canina) . . $78 \quad 8287$

K.

Kosinsciana Bess. (can. $X$ gall.)

$122 \quad 123$

\section{L.}

laeta Schwertsch. (can. X gall.) . . 122 123124 lagenoides R. Kell. (pimpinellifolia) 111112 lagenoides Schwertsch. (canina) . . $78 \quad 8186$ lanuginea Schwertsch. (agrestis) . . 6567 lanigimosa Schwertsch. (elliptica) . $5960 \quad 62$ lasiostylis Borb. (canina) . . . $77 \begin{array}{lll}77 & 80 & 86\end{array}$ lalifolia Chr. (Jundzillii) . . . . . $36 \quad 37 \quad 38$ latifolia Schuertsch. (canina) . . $78 \quad 8187$

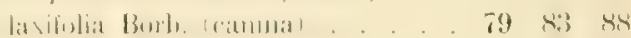
leuca Wiesb. (canina). . . . . . 798488 liostyla Chr. (rubiginosa) . . . 51 53 5.) Inngipedata Schwertsch. (elliptica) . 606063 lucida Bräuck. (coriifolia) . . . 105106 Iugdunensis Borb. (elliptica) . . . 59 6062 
Rosa

II.

macrantha R. Kell. (can, X salt.) .

Teil 11 s. site

12.2 1?3

macropetala Borb. (pimpinellitolia)

111112

macrophylla Favr. (glauca)

$98 \quad 100 \quad 103$

macrostyla Schuertsch. (rubiginosa) 51 52 50 mecocarpa schwertsch. (glauca) . 98 10110 t melanophylloides J. B. Kell. (glauca) 98101104 mentacea H. 13r. (canina) . . . 78 8: 87 microphylla IR. Kell. (rubiginosa) . $50 \quad 5254$ micropliylla R. Kell. (glauca) . . . 99 102 104 minuscula Crep. (rubiginosa) . . . $50 \quad 5255$ mollissima Schuertsch. (dumetorum) $90 \quad 92 \quad 95$ Mollardiana Mout. (canina) . . . $77 \begin{array}{lll}77 & 80 & 86\end{array}$ monticola Schwertsch. (canina) . . $78 \quad 81 \quad 86$ montivaga Borb. (canina) . . . . 78 84 87 moravica Borb. (can. X gall.) . . 122 123124 muscipula R. Kell. (gallica) . . . $34 \quad 35$ myriodonta Chr. (glauca)

98100103

N.

nummulifolia 12. Kell. (arv. $X$ gall.)

116117

0.

oblongala Opiz (canina) . obscura H. Br. (dumetorum) obtusifolia Crep. (tomentella) oenophora J. B. Kell. (canina) officinalis Thor. (Gallica) ololeia H. Br. (canina) omissa Parm. (subsp. v. pomifera) operta Borb. (micrantha) oreogiton $\mathrm{H}$. Br. (canina). ovata Desv. (arvensis)

\section{P.}

palatina Schwertsch. (dumetorum) parvifolia Rau (rubiginosa). paupercula Schwertsch. (rubiginosa) pegnesensis $\mathrm{H}$. Br. (tomentosa) . perciliata H. Br. (dumetorum) permixta Borb. (micrantha) piligera Schuertsch. (pimpinellifolia) pilosula Chr. (glauca)

pimpinelloides Chr. (rubiginosa) pinnatosepala A. Schw. (agrestis) platyphylla Chr. (dumetorum) percilacantharihwer/seh. tumentusa poleriffolia H. Br. (pimpinellifolia). pscudofalcata R. Kell. (glauca) pseudohystrix Chr. (rubiginosa) pubescens Chr. (agrestis)

$89 \quad 91 \quad 95$

$72 \quad 73 \quad 74$

788186

$34 \quad 35$

$77 \quad 80 \quad 86$
Risai

Teil II. Sutils

pubescens Koch (pendulina) .

110

P'ugetii Crep. (Jundzillii) . . . . . . 36 37 37

pumila H. Br, (gallica) $34 \quad 35$

\section{R.}

racemulosa H. Br. (canina) . . . . $79 \quad 79388$ ramosissima Rau (canina) . . . $78 \quad 8186$ recondita Chr. (pomifera) . . . ty reginae Schuertsch. (canina) . . $80 \begin{array}{ccc}80 & 85 & 89\end{array}$ repens Borb. (arvensis) . . . . . 31 ;2 reticulata Kern. (Jundzillii). . . . $36 \quad 38$ Reuteri H. Br. (glauca) _. . 9799 102 rigida H. Br. (glauca) . . . . 99 98101104 rotundifolia Rau (rubiminosa). . . 50 52

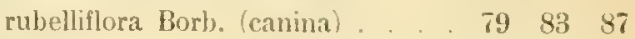

\section{S.}

Sabranskyi H. Br. (cauina) 。 . . . $79 \quad 83 \quad 87$ salicetorum H. Br. (canina) . . . $78 \quad \begin{array}{lll}7 & 83 & 87\end{array}$ Sandbergeri Chr. (glauca) . . . 98 100103 saxicola Schuertsch. (canina) . . . $78 \quad 82 \quad 87$ scabrata Crep. (canina) . . . . $80 \quad 8089$ scabriuscula M. Schulze (gall. $X$ tomentosa) .......

$1191 \div 0$ scabriuscula Schwertsch. (subsp. v. tomentosa) ....... 44

scaphusiensis Chr. (coriifolia)

105106

Schottiana Ser. (canina).

$\begin{array}{lll}7 y & 84 & 88\end{array}$

Schulzei R. Kell. (pomifera)

42

semibiserrata Borb. (canina) . . $82 \quad 87$

semiglabra J. B. Kell. (dumetorum) $8901 \quad 94$

separata Schucertsch. (glauca) . . . 97100102

sepioides R. Kell. (tomentella) . . 70 73

septicola Gren. (micrantha) _. . $56 \quad 57 \quad 58$

Seringeana Dum. (tomentosa) . $44 \quad 45 \quad 47$

serrata Schwertsch. (Jundzillii) . . $\quad 36 \quad 37 \quad 36$

sinuatidens Chr. (tomentella). . . $\quad 7273$

solstitialis H. Br. (dumetorum) . . $90 \quad 9295$

sphaerocarpa H. Br. (dumetorum). $\begin{array}{cccc}89 & 91 & 94\end{array}$

sphaeroidea Schwertsch.(dumetorum) $89 \quad 9195$

spinifera Schuertsch. (elliptica). $6061 \quad 63$

spinosissima Bräuck. (rubiginosa). $00 \quad 51 \quad 53$

spinosissima Koch (pimpinellifolia) - 111 112

spuria Borb. (canina) . . . . . $78 \quad 71 \quad 86$

squarrosa Borb. (canina) . . . . $79 \quad 84 \quad 88$

stephanocarpa R. Kell. (glauca). . 98101104

St. Halburgae Schucrtsch. (canina) $80 \quad 86 \quad 84$

subbibracteata H. Br. (arvensis). . $\quad 31 \quad 32$

subcanina Schuertsch. (subsp. ron glauca)

98

subcollina Schwertsch. (subsp. von coriifolia)

105 
Rosa

Teil II. Seito

subcuneata Burn. (rubiginosa) . . $50 \quad 5255$

subduplicata Borb. (tomentosa). . 434546

subglabra Borb. (dumetorum) 。 . $90 \quad 93 \quad 95$

subglobosa Car. (tomentosa) . . 434547

subhispida Schuertsch. (elliptica) . 606163

subuncinelloides Schwertsch. (dume-

torum) . . . . . 90 9396

subvillosa Chr. (tomentosa) . . $45 \quad 46 \quad 48$

surculosa Sm. (canina) . . . . . 778086

Swartzii Fr. (canina) . . . . . $78 \quad 8186$

syntrichostyla H. Br. (canina) 。 $.77 \quad 80 \quad 86$

\section{T.}

Theodori Schwertsch. (canina) . . $78 \quad 8387$ Thuillieri Chr. (dumetorum) . . 9 $90 \quad 91 \quad 95$ trachyphylla Crep. (Jundzillii) 。 $\quad \begin{array}{llll}36 & 37 & 38\end{array}$ trichuidea R. Kell. (dumetorum) • 90 92 95 trichomeura Chr. dumetorun) . . 90 92 95 turbinata Ait. tcinnam. $\times$ mall.) . . 135 typica Chr. (Jundzilliu). . . . . . $36 \quad 3738$ typica Chr. (tomentosa) . . . . 43 45 47 typica Chr. (micrantha) . . . . . $56 \quad 57$ typica Chr. (elliptica) ..... . 60 6\% typica Chr. (tomentella) . . . . 7273 typica Chr. (glauca)... . . . $979910 \mathrm{Z}$ typica Chr. (corifolia). . . . . 105106 typica Chr. (pimpinellifolia) . . . typica H. Br. (cinnamomea) . . . typica R. Kell. (arvensis) . . .

3132
$\operatorname{Ros} a$

Teil II. Seite

typica 1R. Kell. (agrestis) . . . . 65)

typica M.Schulze (gall.Xtomentosa) 119120

I.

umbellata Chr. (rubiginosa) . . $50 \quad 51 \quad 53$

umbellata God. (arvensis) . . . 3132

umbelliflora Crep. (tomentosa) . . $44 \quad 46 \quad 48$

umbrosa schuertsch. (dumetorum). 899195

uncinelloides H. Br. (dumetorum). $90 \quad 93 \quad 95$

uniserrata Schwertsch. (subsp. von tomentella) ....... 72

urbica Cir. (dumetorum) . . . . 8991

urbicoides H. Br. (dumetorum) 。 . $90 \quad 9195$

\section{V.}

vapiana R. Kell. focrifilolia!

105106

callis fagormm schuertsch. (rlanca) 99101101

erra riluertsch. tomentusa) . . $44 \quad 4647$

reridica siluertsch. (glauca) . . 98101104

villosiuscula Borb. (canina) . . . $79 \quad 8387$

vinealis R. Kell. (canina) . . . . $78 \quad \begin{array}{lll}78 & 83 & 87\end{array}$

vineticula H. Hir. (dum. X gall.) . . 127128

vinodora Borb. (agrestis) . . . $64 \quad 6566$

IV.

111112 | Wartmannii R. Kell. (glauca) . . 99102104

108 Wiegmannii M. Schulze (gall. X 


\section{Bestimmungsschlüssel.}

\section{A. Zum Erkennen der Gruppen (Sektionen und Untersektionen):}

1. Griffel zu einer Säule von der Lïnge der inneren Staubgefässe verwachsen:

1.* Griffel nicht verwachsen und viel kïrzer:

2. Kelchblätter nicht oder nur spurenhaft fiederteilig:

3. Blïten einzeln; dies an Fehlen der zungenförmigen Brakteen kenntlich:

3.* Blütenstand arm, abel melrbliitig; dies am Vorkommen der Brakteen mit rudimentärer Achselknospe kenntlich:

‘. Kronblätter dottergelb, innen zuweilen scharlachrot:

4. Kronblätter rosenrot:

5. Unter den Laubblättern kräftige hakige Stacheln gepaart:

5.* Stacheln gerade, schwach, ungleich, zerstreut, oft ganz fehlend:

2.* Kelchblätter deutlich bis stark fiederteilig:

3. Mittlere Laubblätter der Blütenzweige 3-5zählig:

3.* Nittlere Laubblätter der Blütenzweige 5̆-7 zählig:

4. Primärzähne der Blättchen langgestreckt, angedrückt flach; Blältchen beiderseits lilzig haarig:

..* Primärzähne \pm steil abstehend, zugespilzt; Blättchen haarig bis kahl:

5. Blättchen gross, lederig, mit unterseits stark hervortretendem Adernetz (Ahnlichkeit mit R. gallica):

5.* Blättchen mittelgross, derb, rundlich mit kurz auggesetztem Spitzchen; behaart:

5.** Blättchen klein bis mittelgross; behaart; unterseits stark driisig und am Rande mehriach drüsig gezahnt:

5.*** Blättchen mittelgross, eiförmig, mit nach vorn gestrecklen oft geschlängelten Zähnen; gewöhnlich drüsenarm. öftor behaart:
1. Sectio Syustylae I) (.

X. Subs. Pimpinellifolia $\mathbf{D C}$.

XI. Subs. Luteao Crep.

VIII. Subs.

Cinnamomeae rerae schwertsch.

LX. Subs. Alpina Dosegl.

II. Subs. Gallicanae verae Borb.

IV. Sectio Vestitae Chr.

III. Subs. Juudzillianae Crep.

VI. Subs. Tomentellae Crep.

V. Sectio Rubiginosa I) (.

VII. Subs, Eucanina Crop. 


\section{B. Zum Erkennen der Arten:}

\section{Sectio Synstyla DC.}

Stamm kriechend oder kletternd, Stacheln gleich; Bläten weiss auf sehr langem Stiel:

R. arzensis Huds. S. 31

\section{Subs, Gallicanate verae Borb.}

Achse unterirdisch verzweigt, oberirdische Äste kurz oder schlaff hingebreitet, Achsen reich drüsig heterakanth; Kronen gross, purpurn:

R. gallica Li. S. 33

\section{Subs. Jundzillianae Crep.}

Heterakanthie schwach; Blättchen tief mehrfach drüsig gezahnt; Kronen gross, lebhait rosa:

R. Jundzillii Bess. S. 36

\section{Sectio Vestitae Chr.}

1. Stacheln gerade; Blütenstiele kurz: (Stacheln krumm; Bliitenstiele kurz:

1.* Stacheln krumm; Blütenstiele lang: (Stacheln gerade; Blütenstiele lang:
R. pomifera Herrm. S. 11 subsp. omissa Parm. S. 42)

R. tomentosa Sm. S. 43 subsp. scabriuscula H. Br. S. 44)

\section{Sectio Rubiginosae DC.}

1. Blätlchen breit oval bis rundlich:

2. Blitenstiele kurz; Kelchzipfel subpersistent; Griffelköpfchen wollig:

R. Mubiginosa L. S. 49

(beim Fehlen eines oder zweier dieser Merkmale:

subsp. columnifera Schuertsch. S.50)

2* Blülenstiele lang; Kelchzipfel abfällig; Grillelsäulchen kahl:

R. micrantha Sm. S. 56

1.* Blättchen länglich elliptisch, Blattgrund keilig:

2. Blitenstiele kurz; Kelchziplel subpersistent; Griffelköpfchen wollig:

R. elliptica Tausch S. 59

(beim Fehlen eines oder zweier dieser Merkmale:

subsp. inodora Schwertsch. S. 60)

2.* Blütenstiele lang; Kelchzipfel abfällig; Griffelsäulchen kahl:

R. agrestis Savi S. 64

\section{Subs. Tonentellate Crep.}

Stacheln kurz, hakig gekrïmmt, seitlich zusammengedrückt. mit stark verdicktem breitem Grunde; 13lättchen mit kurzer breiter fast rechtwinkliger drüsig zusammengesetzter Zahnung:

R. tomentella Lem. S. 71

(Blattrand vorherrschend einfach gezahnt: subsp. uniserrata Schwertsch. S. 7\%) 


\section{Subs. Eucaninae Crep.}

1. Brakteen schwach, Blütenstiele lang; Kelchzipfel zurückgeschlagen; Griffelköpfchen verlängert:

2. Biätter kahl oder höchstens Stiele und Mittelnerv befläumelt:

R. canina L. S. 75

2.* Bläfter deutlich behaart:

R. dumetorum Thuill. S. 89

1* Brakleen kräftig, Blïtenstiele kurz; Kelchzipfel subpersistent; Griffelköpfchen kurz und wollig:

2. Blälter kahl oder höchstens Stiele und Mittelnerv befläumelt:

(wenn die Merkmale unter 1.* nicht alle vorhanden:

R. glauca Vill. S. 97

subsp. subcanina Scheertsch. S. 98)

2.* Blätter deutlich behaart:

(wenn die Merkmale unter 1.* nicht alle vorhanden:

R. coriifolia Fr. S. 105

subsp. subcollina Schucertsch. S. 105)

\section{Subs. Cinmamomeac veras Schvertsch.}

Aste mit braunroter Rinde: mittlere Laubblïlter der Blïtenzweige 5-7zählig, Blätlchen einfach gezahnt, unten weichhaarig; Griffelköpichen wollig; Kelchzipfel persistent: R. cinnamomea L. S. 107

\section{Subs. Alpinae Dosegl.}

1. Mittlere Laubblätter der Blütenzweige 5-7 zählig; Kronen weisslich bis rosa:

R. blanda Ait. S. 109

1.* Mittlere Laubblätter der Blütenzweige 7-11zählig; Kronen lebhaft rot:

R. pendulina L.S. 109

\section{Subs. Pimpinellifoliae D C.}

Zweige sehr dicht mit längeren derben geraden und kürzeren nadel- und borstenförmigen Stacheln besetzt; Blättchen klein, an Blütenzweigen 9-11 zåhlig; Blütenstiele lang; Kelchblätter persistent; Kronen weiss bis rötlich; Scheinfrïchte kuggelig (selten eiförmig); schwarz:

R. pimpinellifolia L. S. 111

\section{Xl. Subs. Luteace Crep.}

Stacheln gerade, zwischen den grossen am untern Teil des Stammes viele Stachelborsten; Laubblätter 5-7zählig, Blättchen ziemlich klein; Scheinfrüchte kugelig, rot: R. lutea 1rill. S. 113 
3.

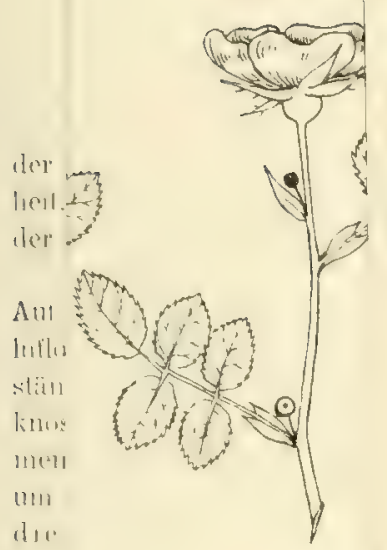

Blii

9.

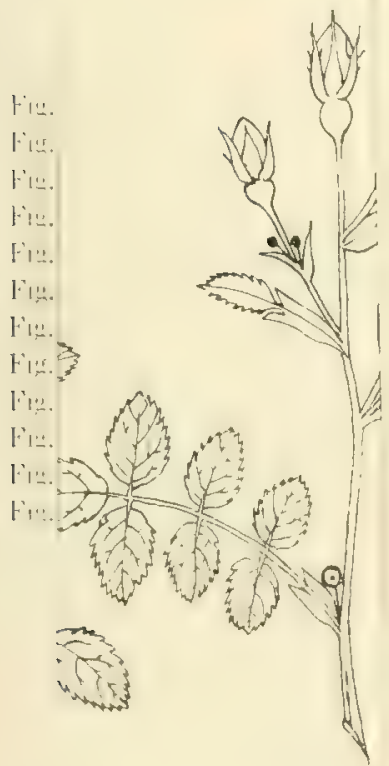


Tafel I.

\section{Erläuterung der Tafel l: Die Roseninflorescenz.}

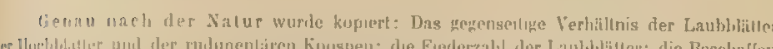

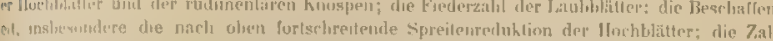

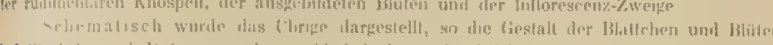

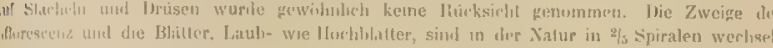

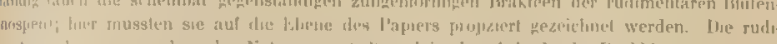

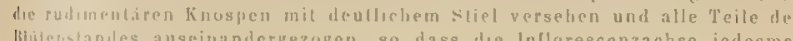

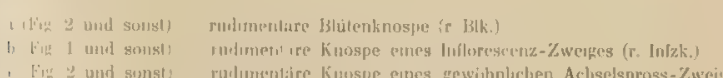

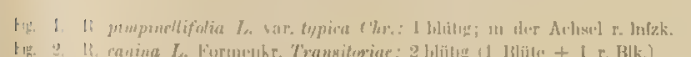

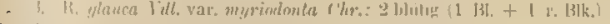

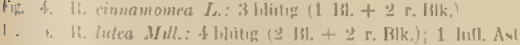

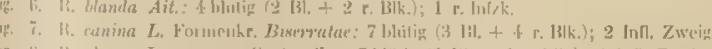

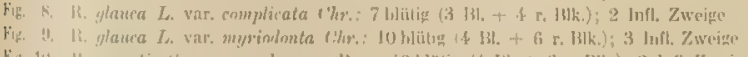

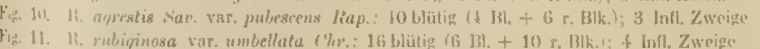

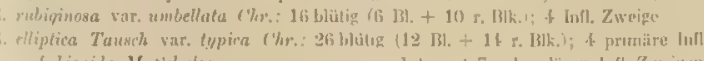

2.

9.

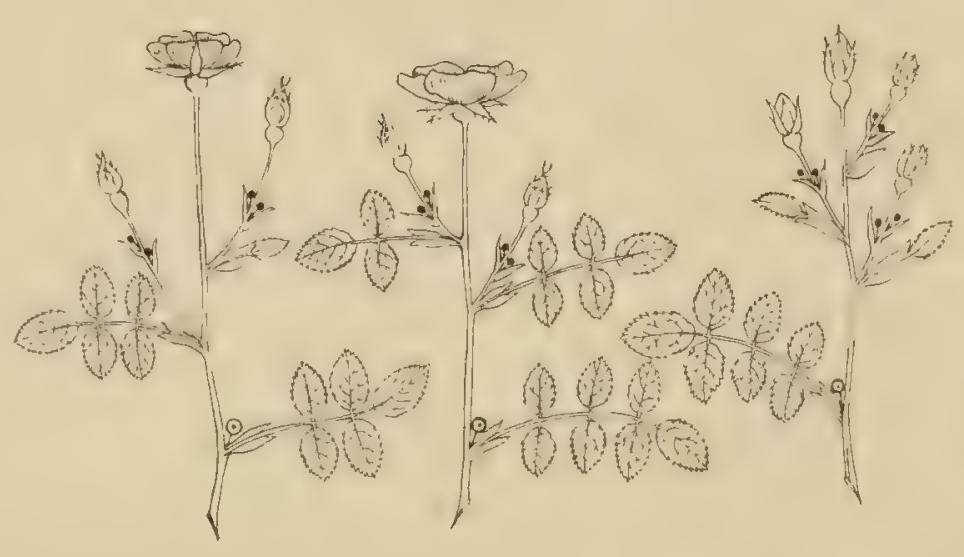

4.

5.

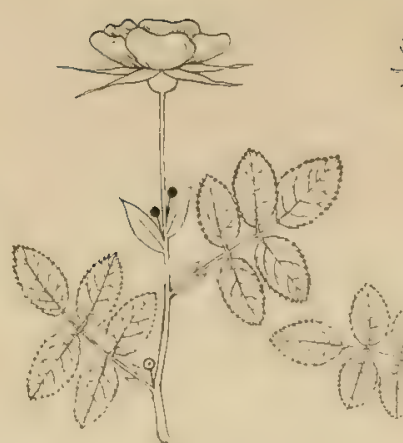

10

6.

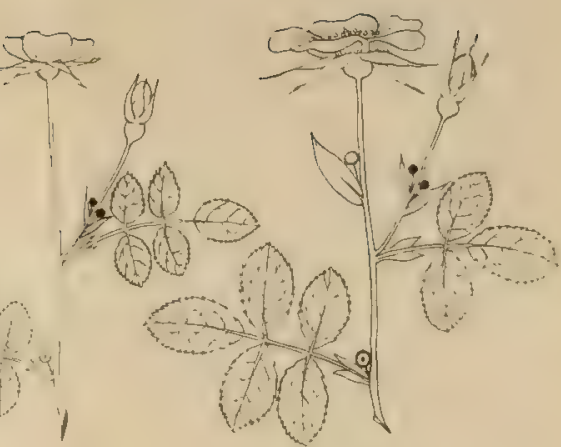

11.

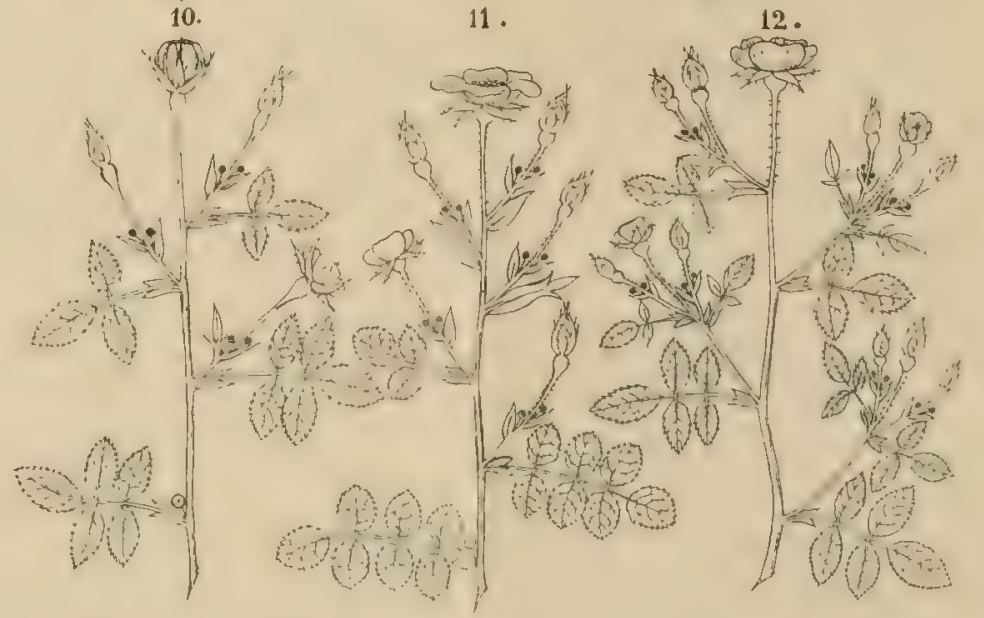



Erläuterung der Tafel II: Längsschnitte durch die Fruchtbecher der mitteleuropäischen Rosen.

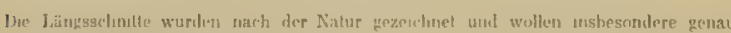

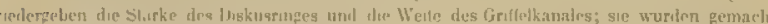

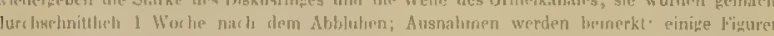

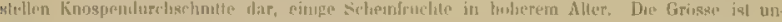

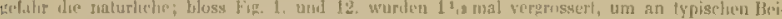

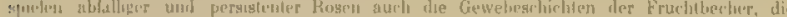

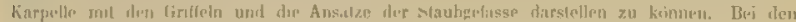

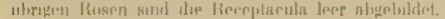

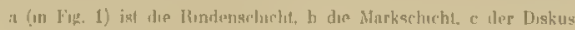

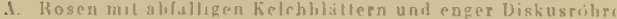

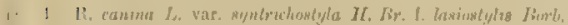

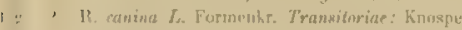

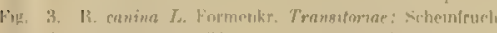

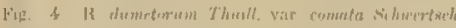

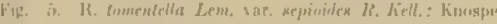

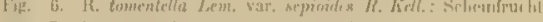

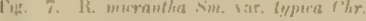

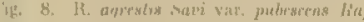

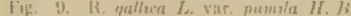

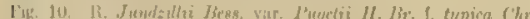

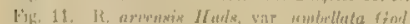

$$
\text { B. Rosin mat persisienten Kelchilatleren und weter Diskusribler }
$$

fin. 12. R. mimpentllofulia J. vir. typica Clir.

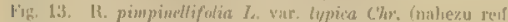

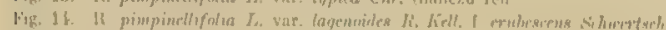

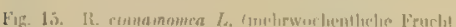

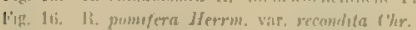

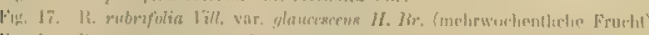

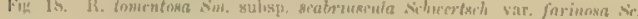

$$
\text { (2. Rosen mil subpersiklenten kelehblïleru }
$$

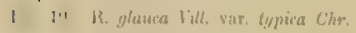

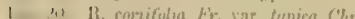

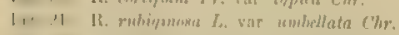

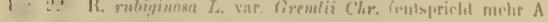

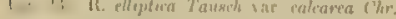

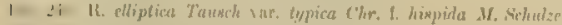

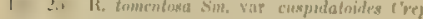

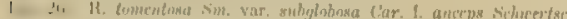

\section{Bastnride:}

Fis. 27. JR. canina $X$ galliva var. lacta Sharerfach

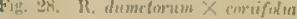

\section{Tafel II.}

$\therefore$

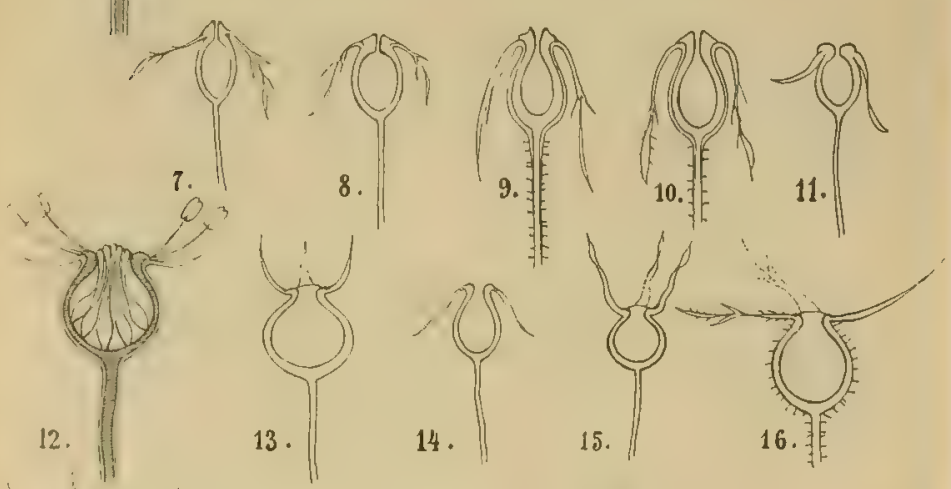

17.

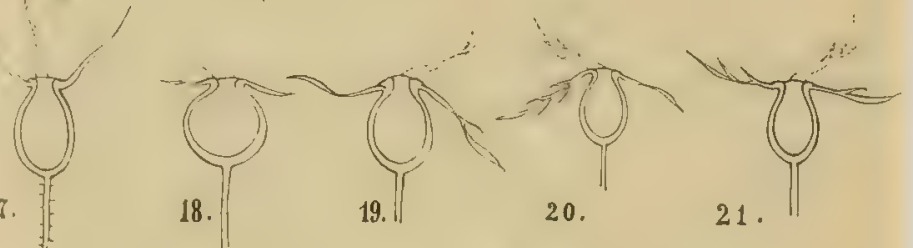

22 .
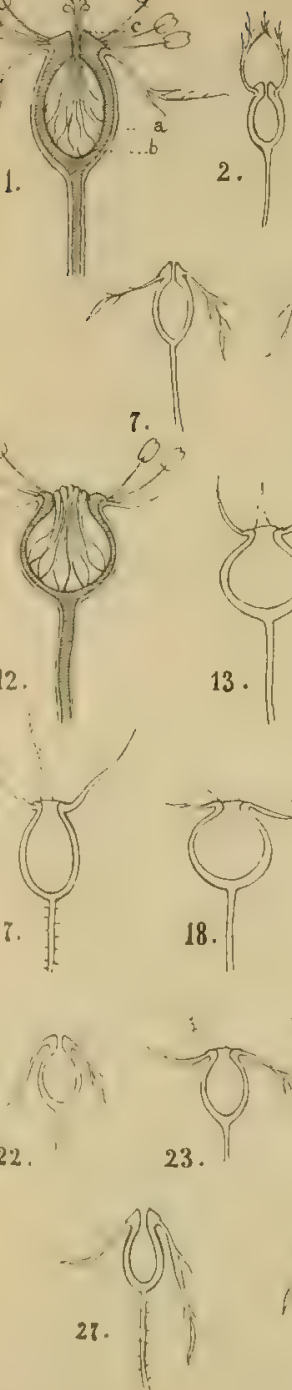<smiles>Ic1ccccc1</smiles>

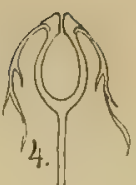

5.
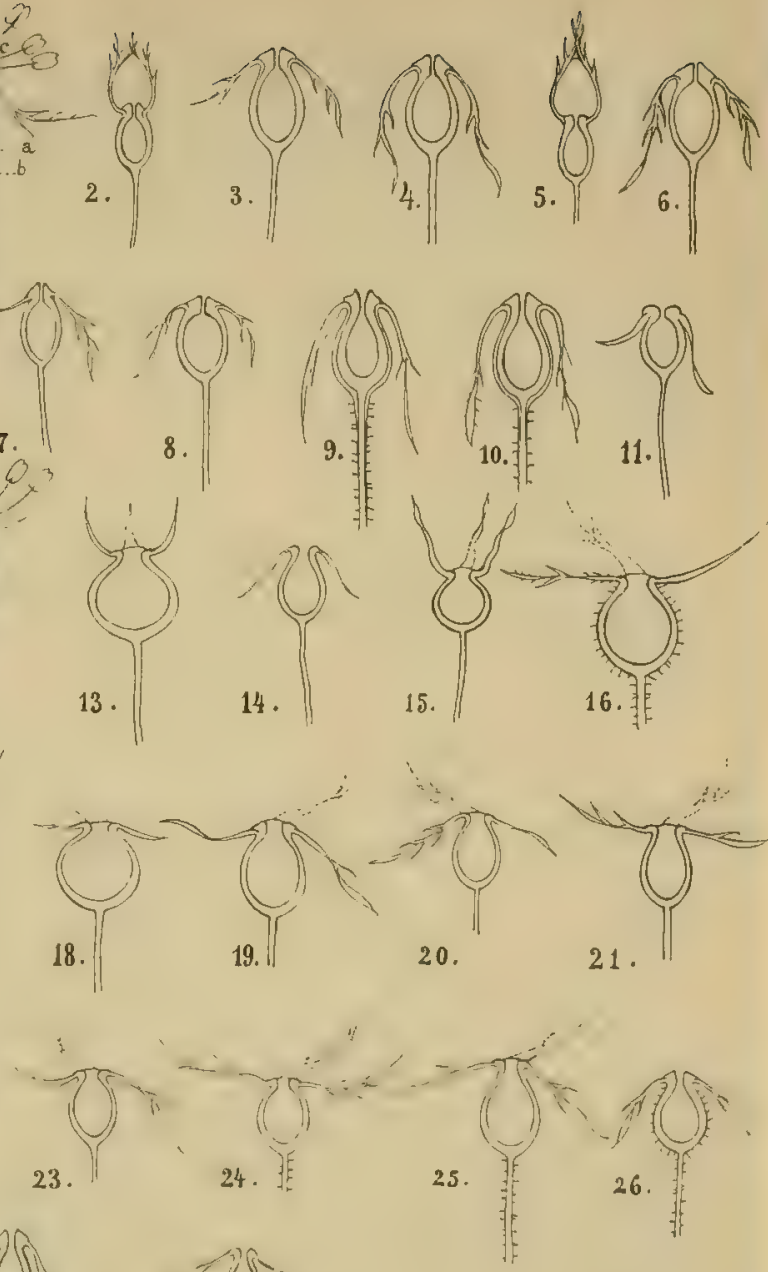





